\title{
SCHRIFT ALS BILD \\ IN DEN BILDERN WESTLICHER UND ARABISCHER KÜNSTLER IN DER ZWEITEN HÄLFTE DES 20. JAHRHUNDERTS
}

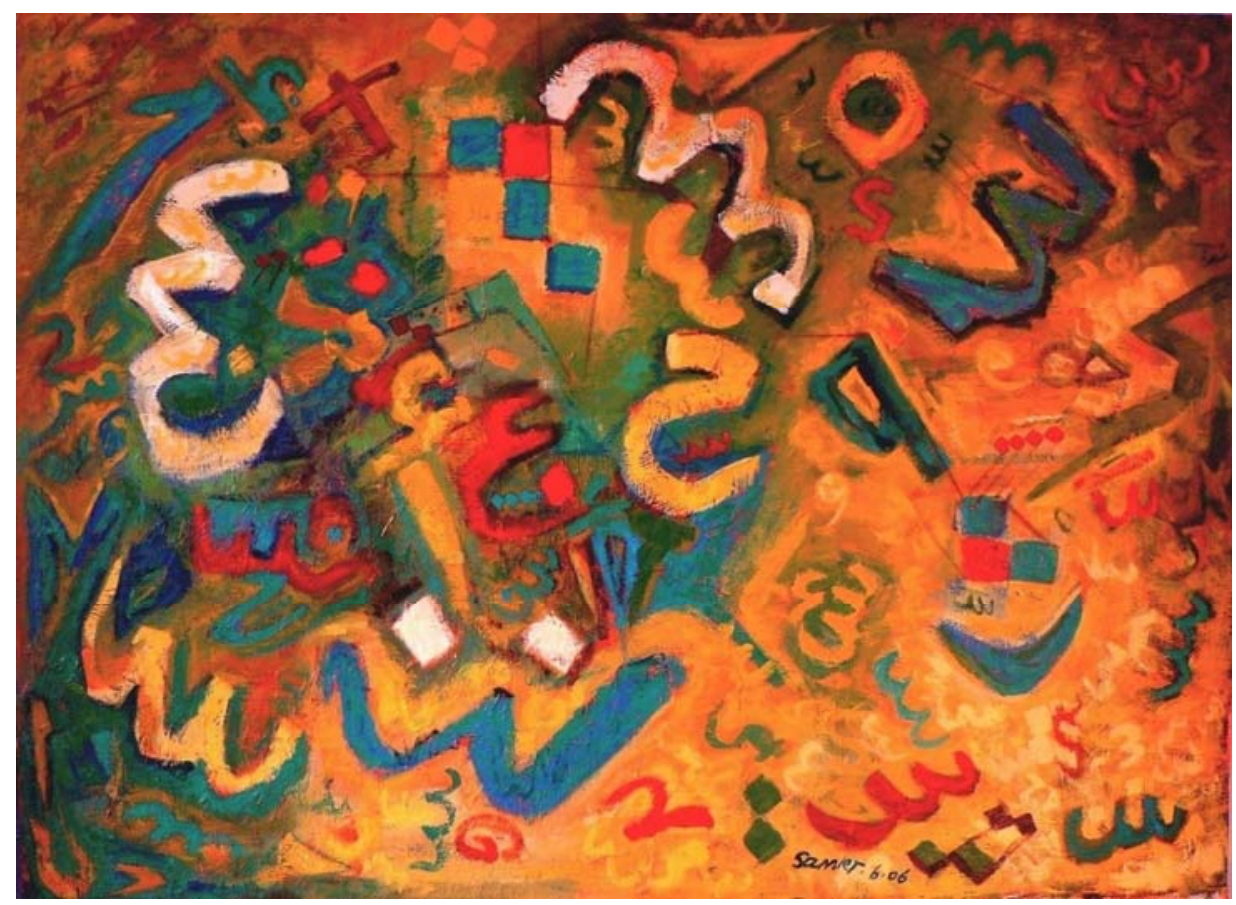

Dissertation
zur Erlangung des philosophischen Doktorgrades an der Philosophischen Fakultät
der Georg-August-Universität Göttingen

vorgelegt von

Samier Mahmoud Abdel-Fadeil Abdel-Kader

Aus Kairo

Göttingen 2006 


\section{DANKSAGUNG}

Vor allem möchte ich meinem Doktorvater Prof. Dr. Werner Schnell für seine Betreuung danken, und für seine Geduld mit meinen sprachlich bedingten Schwierigkeiten am Anfang meiner Dissertation.

Mein Dank geht auch an PD DR. Roman Loimeier; Prof. Dr. Carsten-Peter Warncke Prof. Dr. Hans Dieter Haller und PD. Dr. Ibrahim M. Adham, die sich dazu bereit erklärt haben, die Arbeit zu begutachten.

Das weiteren danke ich all meinen Kollegen und Kolleginnen, Freunden und Freundinnen, die Korrektur gelesen haben.

Der persönlichste Dank geht an meine Familie in Ägypten. 


\section{INHALT}

EINLEITUNG

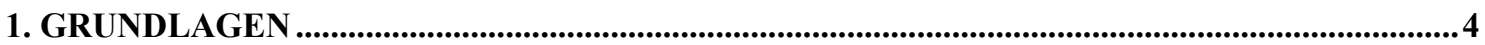

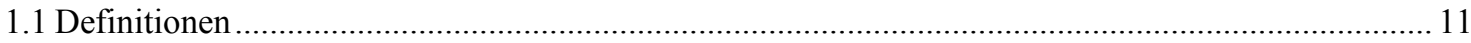

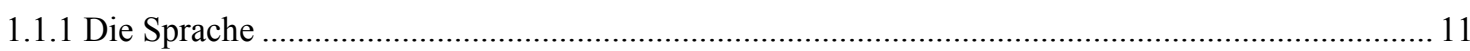

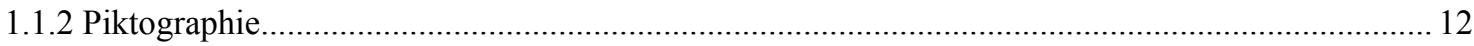

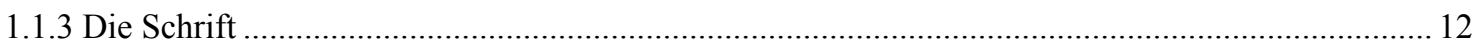

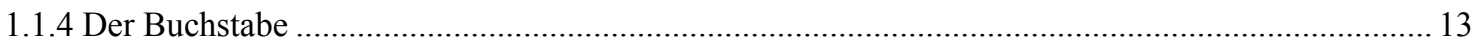

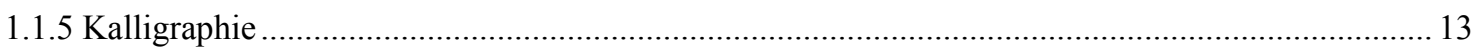

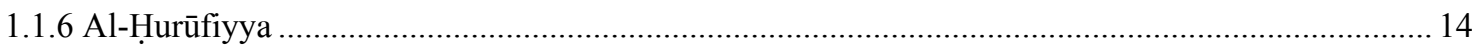

1.2 Die Zusammenfassung der Geschichte der Schriftentwicklung in Europa und im Mittleren Osten

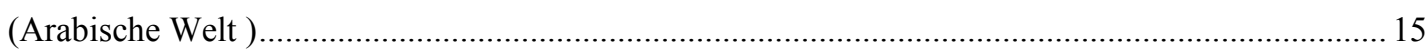

1.2.1 Die Geschichte der Entwicklung der europäischen Schrift ................................................. 18

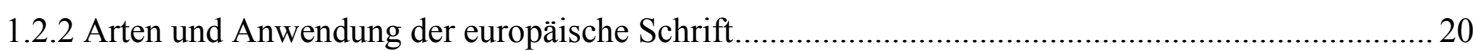

1.2.3 Die Geschichte der Entwicklung der arabischen Schrift ....................................................... 23

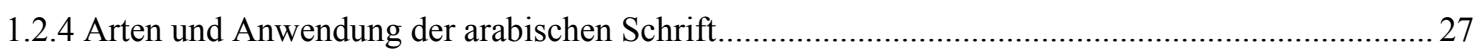

1.3 Das Verhältnis der monotheistischen Religionen zur bildenden Kunst........................................ 32

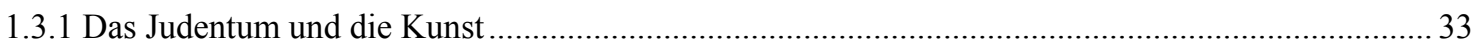

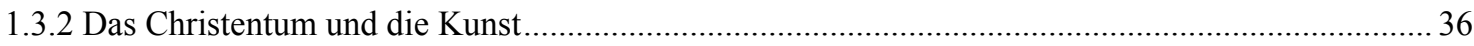

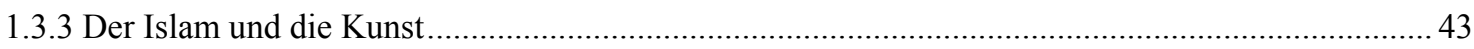

1.3.4 Die esoterische Bedeutung der arabischen Buchstaben......................................................... 48

2. Schriftelemente in Bildern westlicher Künstler in der zweiten Hälfte des 20. Jahrhunderts........49

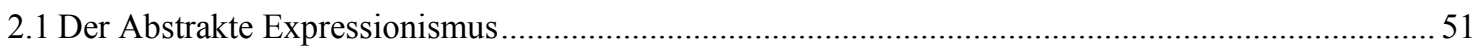

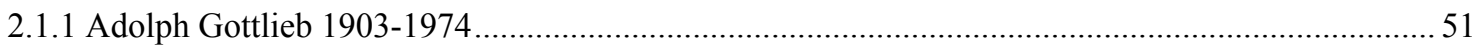

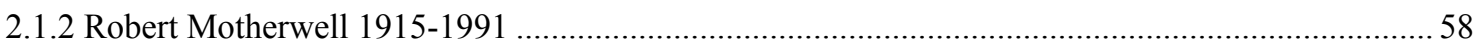

2.2 Die Inkarnation der ostasiatische Kalligraphie in den Bildern westlicher Künstler ........................ 64

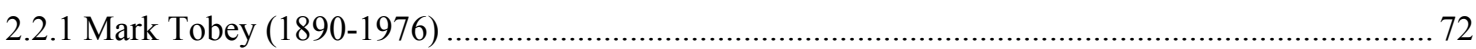

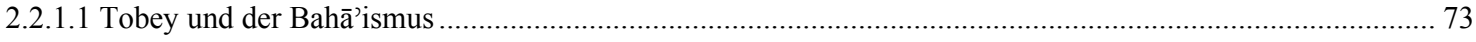

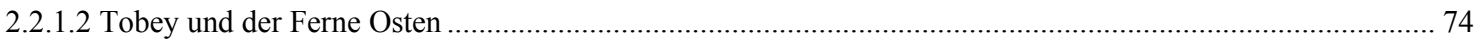

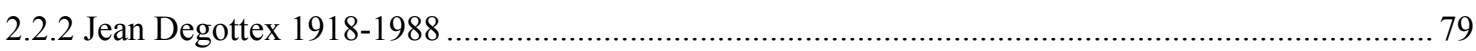

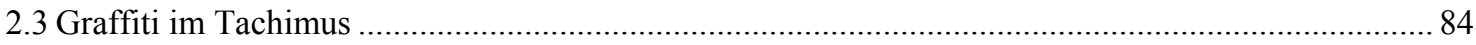

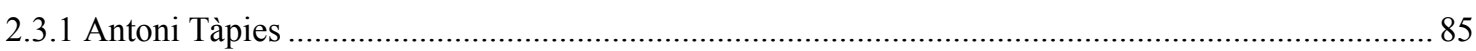




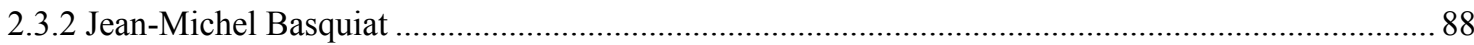

2.4 Die Einheit von Denken und Sprache in der Konzeptkunst................................................................ 92

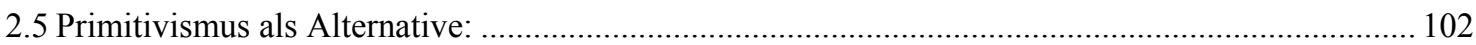

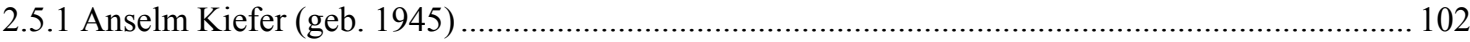

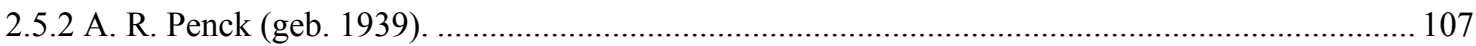

3. Schriftelemente in Bildern Arabischer Künstler in der zweiten Hälfte des 20. Jahrhunderts ....113

3.1 Der Gebrauch der arabischen Schrift in der zeitgenössischen Malerei: Klassifizierungsversuche.... 119

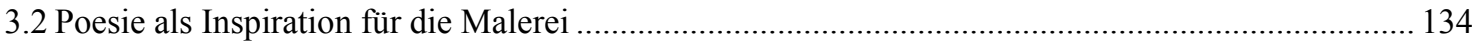

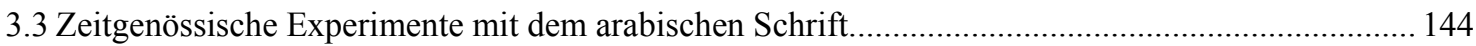

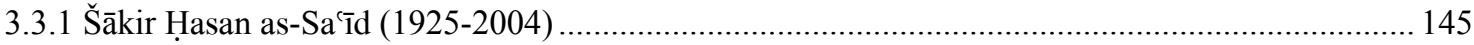

3.3.2 Diyā’' al-'Azzāwī

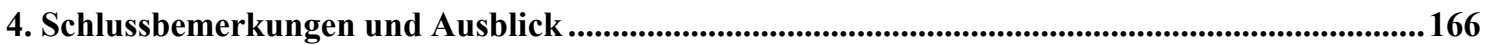

Literaturverzeichnis....................................................................................................................................... 175

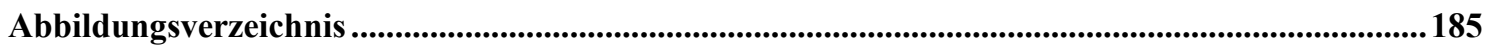

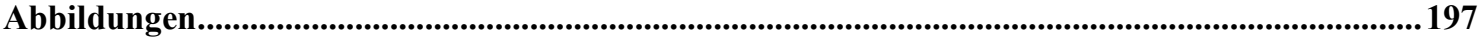




\section{Einleitung}

„Eines Tages - aber natürlich nicht von heute auf morgen - fing in 20. Jahrhundert die Malerei an, sich als eine Schreibkunst zu verstehen: die Maler malten ihre Bilder nicht, sie ,schrieben' sie. Wer sich an die vierziger und fünfziger Jahre zurückerinnert, der erinnert sich an die Faszination, die von dieser ,skripturalen' Wendung der Malerei ausging“ 1. Im Folgenden wird der Versuch unternommen, diese Entwicklung nachzuvollziehen und die Beziehung von Schrift und Malerei in Werken des 20. Jahrhunderts zu analysieren.

Im dritten und vierten Jahrzehnt des 20. Jahrhunderts zeigten viele abendländische Künstler und Kunstkritiker spürbar vermehrtes Interesse an der Übernahme der Schriftkunst verschiedener Kulturen - wie den ostasiatischen, islamischen, indianischen und europäischen - in die Malerei, um neue künstlerische Motive und Formen ausdrücken zu können. Dieses Interesse spitzte sich um die Mitte des 20. Jahrhunderts zu. Aus diesem Gesichtspunkt sind die fünfziger Jahre als eine wichtige Phase der modernen Kunstgeschichte $\mathrm{zu}$ erachten, in der in einer kurzen Zeitspanne viele Kunstrichtungen entstanden. In diesem Zusammenhang sollen nur der abstrakten Expressionismus, das Informel, der Tachismus usw. erwähnt werden. Vertreter dieser Richtungen hatten ihre eigenen Experimente mit dem Wort und dem Buchstaben im Bild gemacht. Die Kunst der Kalligraphie erfreute sich bei ihnen einer besonderen Aufmerksamkeit. Die Zahl der von ihnen angefertigten Werke legt Zeugnis davon ab. In dieser Arbeit werden bedeutende moderne Künstler der verschiedenen Stilrichtungen, die die Malerei der 2. Hälfte des 20. Jahrhunderts geprägt haben, soweit sie sich mit der Schrift als bildgestaltendem Element beschäftigt haben und in der Literatur gewürdigt sind, vorgestellt.

Am Anfang der zweiten Hälfte des 20. Jahrhunderts begannen auch in der arabischen modernen Kunst die ersten Experimente, die dem Buchstaben als einem wesentlichen Element des Bildes ein verstärktes Interesse widmeten. Die arabischen Avantgardisten entdeckten ihre traditionelle Kunst neu. Sie verbanden die Schrift im Bild mit einer modernen Formensprache, die sich von jener der früheren Generationen wie auch von

\footnotetext{
${ }^{1}$ Werner Schmalenbach: Zur Kunst von Mark Tobey, in: Bärmann, Matthias (Hrsg.): Mark Tobey. Between worlds. Werke 1935-1975, Mendrisio und Essen 1989. S. 43-45, hier S. 43.
} 
den islamischen traditionellen Schreibstilen unterschied. In diese Zeit fallen die Versuche, neue Maltechniken zu entwickeln und die Bemühungen, die Bildende Kunst mit der Literatur, der Philosophie, der Religion und der Gesellschaft in Verbindung zu bringen, ferner auch die Versuche, sich durch die Beschäftigung mit fremden Kulturen der eigenen kulturellen Identität zu vergewissern. Diese Faktoren beeinflussten die Bildproduktion, vor allem aber die Verwendung von Schrift im Bild. Spuren dieses Einflusses lassen sich bis heute in der Kunstmalerei verfolgen.

Die vorliegende Arbeit ist ein Versuch, diese künstlerische Erscheinung, nämlich die Verwendung von Schrift im Bild, die in dieser Zeit unverkennbar neue Formen hervorbrachte, in der abendländischen wie auch in der arabischen Welt zu erforschen. Motive wie auch Quellen, die diesen Künstlern, sowohl in der arabischen wie auch westlichen Welt dazu verhalfen, sich ihre charakteristischen Merkmale in dieser Kunst anzueignen, werden kunstgeschichtlich ermittelt und kommentiert, um Antwort auf folgende Fragen zu finden: Gab es eine Beziehung zwischen den Religionen und den Künstlern, die sich mit der Schrift als Bild beschäftigten? Gab es eine wechselseitige Beziehung zwischen der arabischen und der europäischen Bildenden Kunst?

Viele Werke mancher arabischer Künstler können verschiedenen Kategorien zugeordnet werden, ebenso kann ein einzelnes Werk eines Künstlers Merkmale mehrerer Stile aufweisen. Wie können die Werke dieser arabischen Künstler, die aus individuellen Versuchen entstanden und unterschiedliche Stilmerkmale zeigen, klassifiziert werden?

Die Arbeit besteht aus vier Kapiteln. Im ersten Kapitel wird der Versuch unternommen, Definitionen zu künstlerischen Begriffen zu geben, die für das Thema dieser Arbeit relevant sind, wie z. B. Sprache, Piktographie, Schrift, Buchstabe, Kalligraphie und AlHurūfiyya. Danach gibt das erste Kapitel die Hauptumrisse der Geschichte der Schriftentwicklung in Europa wie auch im Nahen Osten bzw. in der arabischen Welt wieder.

In einem zweiten Abschnitt wird die Beziehung der monotheistischen Religionen zur bildenden Kunst untersucht. Die Religion übte großen Einfluss auf die Künstler aus, die Schrift im Bild verwendeten, vor allem auf die arabischen Künstler. Es wird der Frage nachgegangen, ob bestimmte Religionen die Künstler stärker als andere motivierten, sich mit der Schrift als bildnerischem Element zu befassen. Haben gar einige Religionen 
die Beschäftigung mit bildender Kunst verboten? Im Rahmen dieser Arbeit werden unter „monotheistischen Religionen“ Judentum, Christentum und Islam verstanden. Andere monotheistische Religionen, wie etwa der Zoroastrismus und der Sikhismus werden nicht behandelt. Im Zusammenhang mit der Untersuchung über das Verhältnis des Islam zur bildenden Kunst wird auf die esoterische Bedeutung der arabischen Buchstaben eingegangen.

Das zweite Kapitel behandelt in fünf Abschnitten die Arbeiten westlicher Künstler anhand der künstlerischen Richtungen, die sie vertreten. $\mathrm{Zu}$ jeder Stilrichtung werden zwei oder mehr Künstler als Beispiel angeführt. Die für diese Arbeit ausgesuchten westlichen Künstler beschäftigten sich ausgiebig mit dem Thema „Schrift im Bild“. Sie schufen Werke, die für ihre Stilrichtungen kennzeichnend für die Beschäftigung mit diesem Thema waren. Für jeden dieser Künstler gibt es eigene Gründe, in dieser Arbeit behandelt zu werden. Für den abstrakten Expressionismus fiel die Wahl auf Adolph Gottlieb und Robert Motherwell, weil beide den Hauptanteil an der Verwendung von Schrift im Bild hatten, wobei sich Gottlieb von indianischen Piktogrammen, Motherwell von Schriftzeichen verschiedener Kulturen anregen ließ. Im Gegensatz zu Motherwell ließen sich Pierre Alechinsky, André Masson und Julius Bissier nur von einer Schrifttradition, der ostasiatischen, anregen. Sie beschäftigten sich außerdem mit dem gesamten ostasiatischen Kultursystem, insbesondere der Zen-Philosophie. Anders als diese, die sich durch Meditation auf ihr Kunstschaffen vorbereiteten, versuchte Henri Michaux durch Meskalin-Konsum in einen für seine Arbeit adäquaten Geisteszustand zu kommen. Mark Tobey beanspruchte dagegen, mit vollem Bewusstsein zu arbeiten und eine Synthese von östlicher und westlicher Kunst zu schaffen. Weil über ihn verhältnismäßig wenig Literatur erschienen ist, wurde Jean Degottex ein relativ großer Abschnitt gewidmet. Er machte Anleihen bei verschiedenen Schriftsystemen. Antoni Tàpies und Michel Basquiat ließen sich von Graffiti, also einer alltäglichen Verwendung der Schrift, inspirieren. In der Konzeptkunst kann man unterschiedliche Beweggründe bei der Verwendung von Schrift als bildgestaltendem Element erkennen. Joseph Kosuth ersetzte bildnerische Darstellungen durch Texte über die Kunst, Hans Haacke verband Bilder mit Texten, um die Betrachter zum Nachdenken über ihre soziale Umwelt zu bewegen, und Hanne Darboven versuchte, Zeit bildlich darzustellen. Anselm Kiefer malt dagegen realistisch anmutende Bilder, die durch Textbeigaben erklärt, teilweise aber auch ironisiert werden. Im Vergleich damit mutet A. R. Pencks Verwendung von Buchstaben wie Spielerei an. 
Das dritte Kapitel beschäftigt sich mit der Verwendung von Buchstaben in den Bildern der arabischen Künstler in der zweiten Hälfte des 20. Jahrhunderts. In drei Teilen werden die arabischen Künstler behandelt. Da die individuelle Natur die Versuche der arabischen Künstler beherrscht, beugen sie sich nicht der systematischen Klassifikation in Schulen oder Richtungen wie bei den westlichen Künstlern. Bei ihrer Darlegung wird der Versuch unternommen, sie in Gruppen $\mathrm{zu}$ klassifizieren. Nach den Klassifizierungsversuchen beschäftigt sich die Arbeit näher mit der visuellen Poesie in der arabischen Welt und schließlich mit zeitgenössischen Experimenten mit dem arabischen Alphabet. Die einzigartigen und wirkungsvollen Experimente zweier arabischer Künstler, Šākir Hasan as-Sa'̄̄è und Ḍiyā’ al-'Azzāwī, mit den arabischen Buchstaben werden ausführlich beschrieben.

Im vierten Kapitel erscheinen Schlussbemerkungen und ein Ausblick. Ein Abbildungsteil schließt sich ihm an.

\section{Grundlagen}

Es fällt auf, dass in der Kunstgeschichte bestimmter Zivilisationen, nämlich der altägyptischen und babylonischen wie auch der chinesischen und japanischen, Malerei und Kalligraphie gleichwertig nebeneinander bestanden haben. In der islamischen Welt haben Buchstaben und die ornamentale Kunst des Zeichens das Bild geprägt, während in der abendländischen Kunst Schrift und Bild lange Zeit getrennte Darstellungssysteme waren. Ausnahmen waren beispielsweise die Initialen mittelalterlicher Handschriften (Abb. 1). Eine Tradition der Kalligraphie vergleichbar mit der arabischen existiert dagegen in Europa nicht. Erst in der Malerei des 20. Jahrhunderts tritt der Buchstabe als kreatives Element von Form, Farbe und Zeichen in den Mittelpunkt ${ }^{2}$, während in früheren Perioden durch das Medium der Schrift Aussagen, die sich bildlich nicht darstellen ließen, ausgedrückt wurden, wie in den Spruchbändern auf dem Altenberger Altar (Abb. 2). Auf der linken Tafel wird der Gruß Gabriels an Maria (Lk 1,28) wörtlich wiedergegeben: AVE + MARIA + GRACIA + PLENA + DNS + TECV = Ave Maria gracia (richtig: gratia) plena Dominus tecum. Auf der rechten Tafel wird die Anrede Elisabeths an Maria (Lk 1, 44) sehr frei wiedergegeben: EXQo + FCA + E + SLACO + EXLTAV + IFAS + IUTO + MEO $=$ Exquo facta est salutatio exultavit infans in utero

\footnotetext{
${ }^{2}$ vgl. Khatibi, Adelkébir: Interférences, in : Métalsi, Mohamed (Hrsg.) : Croisement de Signes, Paris 1989, S.
} 10 (französischer Teil). 
meo (richtig: ecce enim ut factus est vox salutationis tuae in auribus meis exultavit in gaudio infans in utero meo).

Mit den künstlerischen Entwicklungen zu Beginn des 20. Jahrhunderts in Europa und den USA verringerte sich die Distanz zwischen der Welt der Schrift und der Welt des Zeichnens. In seinem Gedicht „Le Hasard“ (Ein Würfelwurf, 1897) (Abb. 3) strukturierte Stéphane Mallarmé (1842-1898) die Zeilen nach visuellen, nicht nach sprachlichen Gesichtspunkten. Ebenso verfuhr Guillaume Apollinaire (1880-1918) in seinem Gedicht „Calligrammes“ (1918). Apollinaire legte für sein Gedicht eine äußere Form fest, innerhalb derer er die Schrift als graphisches Element einsetzte. Dadurch kann die Absicht des Dichters nur verstanden werden, wenn das Gedicht in seiner geschriebenen Form betrachtet wird. Wird es dagegen nur gehört, verliert es seine besondere Form. So konnte Apollinaire sagen: „Ich bin ebenfalls ein Maler““3.

Auch in Italien existierte eine Gruppe von Dichtern, die sich auf ähnliche Weise mit dem Arrangement des Textes befasste. Führend unter ihnen war Filippo Tommaso Marinetti (1876-1944), der mit dem Manifest „Fondazione e manifesto del Futurismo“4 zu einer neuen Ästhetik der Bewegung und Geschwindigkeit aufforderte. Bekannt wurde seine Aussage, er halte ein Rennauto für schöner als die Nike von Samothrake. Im „Manifesto tecnico della letteratura futurista“ (1912), das für die moderne Literatur von großem Einfluss war, ,forderte er die Abschaffung der Syntax zugunsten der Darstellung von Geschwindigkeit oder subjektiver Erregung. Sein Verbot des Gebrauchs von Adjektiven und Adverbien unterbindet jegliche Form der Ausschmückung. Das Verb sei nur im Infinitiv zu verwenden, es müsse sich dem Substantiv anpassen, der aus Marinettis Sicht für die Dichtung zentralen Wortform“"5. Neben den französischen und italienischen Ansätzen gab es weitere, darunter die russischen Formalisten, die deutschen Expressionisten, die Dadaisten, die Surrealisten. Obwohl sich der Schwerpunkt der Gedichte vom sprachlichen zum visuellen Ausdruck verlagerte, wollten diese Dichter doch in erster Linie Texte, aber keine Bilder hervorbringen.

Dass nach der Jahrhundertwende auch erste abstrakte Formen in die Kunst eingeführt wurden führte $\mathrm{zu}$ einer neuen Wahrnehmung von Punkten, Buchstaben, Zahlen,

${ }^{3}$ vgl. Dāgiir, Širbil: al-Hurūfiyya al-'arabiya, al-fann wa-l-huwiyya, Beirut, 1990, S. 121.

${ }^{4}$ veröfentlicht am 20. 2. 1909 in Le Figaro, Paris.

${ }^{5}$ Bleicher, Joan (Hrsg.): F. T. Marinetti, Futuristische Dichtungen (1912), übersetzt von Else Hadwiger, Siegen 1985, S. 24. 
geometrischen Beziehungen und symbolischen Schriftzeichen als neue plastischästhetische Elemente ${ }^{6}$. Im Jahre 1911 hat Braque in das Porträt „Le Portugais“ (Abb. 4), das dem analytischen Kubismus zugerechnet wird, mit einer Schablone Buchstaben und Zahlen auf die linke und rechte Seite des oberen Drittels des Bildes geschrieben. Als Wort erkennbar sind die Buchstaben BAL (franz. Tanzveranstaltung). Das D vor diesem Wort könnte ein Überrest von grand (groß) sein. Dieses würde zusammen [GRAN]D BAL ergeben, als ob auf einem Plakat diese große Tanzveranstaltung angekündigt würde. Andere Kubisten haben Braque nachgeahmt, wie auch die italienischen und russischen Futuristen, die Dadaisten, die Surrealisten, die abstrakten Maler, die Gruppe Kobra, die so genannten Informellen. Alle haben aus dem Fundus der Schriftzeichen mit sehr unterschiedlichen Absichten geschöpft ${ }^{7}$. Asger Jorn behauptete in seinem theoretischen Text „Les harpes éoliennes“ (Die äolischen Windharfen) aus den vierziger Jahren, dass Schrift und Malerei in diesem ein und dieselbe Sache seien ${ }^{8}$. „L'image est écrite et l'écriture forme des images... On peut dire qu'il y a une écriture, une graphologie dans toute image, de même que dans toute écriture se trouve une image ${ }^{\text {‘9 }}$.

Das dachte auch Paul Klee: Zahlreiche seiner Kompositionen eröffnen Räume, in denen sich Malerei und Schrift begegnen, in denen Buchstaben, Zahlen, Formen und Farben spielerisch miteinander verbunden sind und völlig neue Zusammenhänge schaffen ${ }^{10}$.

Klee formulierte eine persönliche abstrakte Bildsprache. Sein Vokabular, das frei zwischen dem bildlichen und dem ungegenständlichen oszilliert, vermittelt sich durch eine einzigartige Symbolik, die eher ausdrucksvoll als beschreibend ist. Klee vermittelt Bedeutungen durch eine oft launenhafte Verschmelzung von Form und Text; oft schrieb er die Titel seiner Arbeiten auf die Unterlagen, auf denen sie angebracht sind und zeigte Worte innerhalb der Bilder. Ein Beispiel dafür ist „Der Bayrische Don Giovanni “, 1919 (Abb. 5). In diesem Bild dominieren warme Farben, vor allem gelb und rot. Das Bild ist in Drei- und Vierecke eingeteilt, die farbige Flächen darstellen. In der Mitte oben sind eine Mondsichel und ein sechszackiger Stern mit schwarzer Farbe auf ein gelbes Viereck gemalt. Am unteren Rand des Bildes ist ein Mann auf einer Leiter zu sehen. Er trägt bayerische Tracht (Kniehose, Wadenstutzen und Gamsbarthut), die bis auf die Schuhe grün-braun ist. Er macht einen fröhlichen Eindruck. Unverkennbar ist er der

\footnotetext{
${ }_{7}^{6}$ vgl. Dāgir ebd.

${ }^{7}$ Lambert, Jean-Clarence: L'écriture dans la peinture occidentale contemporaine, in : Métalsi, 1989, S. 19.

${ }^{8}$ zitiert in: Lambert, 1989, S. 21.

${ }^{9}$ ebd.

${ }^{10}$ ebd.
} 
„bayrische Don Giovanni“. Don Giovanni ist von Frauennamen umgeben. Die Flächen, auf denen die Frauennamen stehen, sind durch ein Kreuz als Fenster gekennzeichnet ${ }^{11}$. „Kathi“ (unten links) und „Cenzl““ (oben rechts) sind direkt mit Leitern verbunden, „Mari“ (mitte) und „Emma“ (oben links) indirekt. Lediglich zu „Theres“ (unten rechts) führt keine Leiter. Don Giovanni „,scheint aber noch unentschlossen zu sein, zu welcher Dame er zuerst einsteigen soll“"12. Der Künstler wandelte seine Experimente mit Tonwerten und Linien häufig in visuelle Anekdoten um.

Weitere westliche Künstler, die sich mit dem Thema „Schrift als Bild“ befassten, wie Mark Tobey (1890-1976) oder Henri Michaux (1899-1984) nahmen die künstlerischen Leistungen außerhalb des Westens, beispielsweise die arabische und chinesischjapanische Kalligraphie, die besonderen religiösen und künstlerischen Zusammenhänge zwischen Wort und Kunst sowie Wort und Materie wahr. Sie unternahmen in der ersten Hälfte des 20. Jahrhunderts Reisen nach Nordafrika, um die arabische Kalligraphie kennen zu lernen. Zu dieser Zeit hatten arabische Künstler längst die „Befreiung der Buchstaben“ und seine Loslösung von der traditionellen Kalligraphie gefordert. Traditionalisten kritisierten dieses Konzept, da nach ihrer Auffassung der Buchstabe als Träger der Offenbarung des Korans an eine bestimmte Form gebunden ist. Die modernen arabischen Künstler hielten trotzdem daran fest, dass die Buchstaben Träger einer Botschaft seien, im Gegensatz zu den westlichen Künstlern, die mit der Schrift und dem Buchstaben wie mit reiner, optischer Materie arbeiteten.

Seit „Le Portugais“ 1911 von Braque (Abb. 4) wurde die Schrift, wie jedes andere Mittel der Malerei, erforscht. Seitdem hat sie sich an jedes Material, an jede Komposition und jede Anordnung von Zeichen und Farben, die es auf der Leinwand gab, angepasst. In der Tat verfremdet die Linienführung des Malers und insbesondere sein individueller Schriftzug den Buchstaben. In einigen Werken springt die fehlende Unterscheidbarkeit von Schrift und Malerei so sehr ins Auge, dass man einer fortdauernd umkehrbaren Bewegung unterliegt: „Wer zeichnet was? Ist dies der Buchstabe? Ist es die Form? Oder die Farbe? In welcher Anordnung verwandelt sich der Buchstabe in Malerei? Außerdem schützt uns diese Unbestimmtheit nicht vor der Verwirrung zwischen den kalligraphischen Zügen und den gemalten Buchstaben. Dort sind die Erfahrungen noch mehrfach, unbeständig, ungemein offen oder bei der

\footnotetext{
${ }^{11}$ vgl. Paul Klee, Das Frühwerk 1883-1922, 12 Dezember 1979- 2. März 1980, Städtische Galerie im Lenbachhaus, München, S. 489.

12 ebd.
} 
Verbindung vom einen zum anderen getrennt ${ }^{613}$.

Nach dem Maler Pierre Alechinsky „écritures et dessins peuvent être considérés comme des cordes liées de façons diverses, comme des boucles que l'on fait, défait, refait. Ecritures et dessins seraient de même nature. Le dessin (dit il) vient de l'écriture dénouée et nouée autrement "14. Schrift und Malerei bilden einen visuellen Rhythmus. Deshalb ist es unmöglich, die Buchstaben frei von der sprachlichen Verbindung und dem Denken zu betrachten, vielmehr bilden sie die Brücke, die die visuelle Welt und den Bereich des Vorhandenen mit der Welt der Gedanken und der Vorstellungskraft verbindet. Der Buchstabe berücksichtigt das Phonetische, das heißt die Gestaltung des Lautes und seiner Zeitdauer, und er ist notwendigerweise von der Musik abgeleitet, wie der „es ist als ob er diese Eigenschaft von der Musik ableitete, denn er gleicht die verschiedenen Bewegungen in der Musik aus, und manchmal mischt sich das Schwere mit dem Leichten und manchmal entblößt sich das Leichte des Schweren, und manchmal erhebt sich eines von beiden vom anderen empor mit den Auslassungen und Hinzufügungen des Streites“ ${ }^{15}$. Und so wie die Ordnung der Buchstaben sich der einzigartigen gestalterischen Mechanik beugt, so verbergen sich Teile von den Buchstaben gemäß ihres Eindrucks von der Rede, und die Buchstaben treten heraus aus ihrer festen Prägung in die biegsame gestalterische Prägung, dies erschöpft das Extrem der Formen, die die Spielarten der arabischen oder der lateinischen Schrift hervorbringen.

Jean Clarence Lambert macht zwei Faktoren für das Interesse an der Schrift in der modernen westlichen Kunst des 20. Jahrhunderts aus. Erstens das Interesse an Linguistik und Sprache an sich. „Mallarmé et Lewis Carroll, les positivistes viennois et Freud, les formalistes russes, Valéry, Wittgenstein et, bien sûr, Saussure, qui enseignait dans cette même première décennie du siècle où tant de disjonctions furent accomplies, l'une d'elles étant le cubisme analytique du Portugais. Et Saussure a montré en toute rigueur que l'écriture a sa vie propre, parce que langue et écriture sont deux systèmes distincts. Le signe graphique est une image, ou une forme, à considérer en soi““16. Der zweite Faktor besteht darin, dass die Handschrift mit dem Wesen des Einzelmenschen verbunden.

\footnotetext{
${ }^{13}$ Khatibi, 1989, S. 10.

${ }^{14}$ Lascault, Gilbert: Remarques et petits récits autour de l'ecriture et des signes, in : Métalsi, 1989, S. 13.

15 al-Sibā̄̄i, Hālid: al-Hurūfiyya wa-l-huwiyya, http://www.altshkeely.com/2003/calligraphy2003/hrofia.html.

${ }^{16}$ Lambert, 1989, S. 19.
} 
In der arabischen Welt hat die Verbreitung der Druckerei, der Schreibmaschine und neuerdings des Computers zum Verfall der traditionellen Schreibkunst geführt. Auch wenn es mit dem Computer möglich geworden ist, viele Schriftformen zu kreieren, haben sie doch ihre „Seele“ verloren. Die Hinwendung gerade zeitgenössischer arabischer Künstler zum handgeschrieben Buchstaben ist ein Versuch, der Schrift wieder eine menschliche Seele zu geben. Die arabische Kunst und die arabischen Künstler des 20. Jahrhunderts haben sich nicht von der westlichen Kunst getrennt, dies gilt besonders für die zweite Hälfte. Die moderne westliche Kunst half den arabischen Künstlern, ihr Erbe darzustellen und inspirierte sie zu neuen Wegen. Obgleich in der westlichen Kunst bis zum Beginn des 20. Jahrhunderts die Künstler zumeist streng zwischen Buchstabe und Bild unterschieden ${ }^{17}$, wurde die Schrift später zu einem wichtigen Element in der modernen Kunst.

Nach Francine C. Legrand könnte man, vereinfacht gesagt, schlussfolgern, dass die Verwendung der Schrift in der Malerei in aufeinander folgenden Wellen stattfindet, hauptsächlich im Kubismus und seinen Nachfolgern, im Surrealismus und seinen Ableitungen, in der abstrakten Kunst und ihre späteren Entwicklungen, sowie der Aktionsmalerei $^{18}$, darüber hinaus in der Graffiti-Malerei seit den fünfziger Jahren.

Viele dieser westlichen Experimente mit der Schrift in der Kunst, beeinflussten später die Verwendung von Schrift in der modernen arabischen Kunst. So halfen diese modernen westlichen Experimente mit der Schrift, die Aufmerksamkeit der arabischen Künstler auf ihr reiches kalligraphisches Erbe zu richten, da dieses durch die arabischen Künstler, die im Westen studierten, nun berücksichtigt wurde.

In den Augen derjenigen westliche Künstler, die Buchstaben in ihren Bildern verwendeten, waren diese rein visuelle Zeichen. Asger Jorn definiert das „Signal““ als „absichtliches oder künstlerisches Zeichen, das bewusst von einem Sujet hervorgerufen wird ...eine Botschaft, die sich an die Sinne richtet“19. Der Sinn des Signals „,besteht vor allem darin, einem Objekt oder einem Sujet sinnliche Geltung zu geben. Bezeichnen heißt in der ursprünglichen Bedeutung des Wortes nicht nur ,Zeichen geben', sondern auch ,sich selbst ankündigen', sich Bedeutung beimessen, sich bemerkbar machen, sich

\footnotetext{
${ }^{17}$ Khatibi, 1989, S. 11.

${ }^{18}$ vgl. Legrand, Francine: Qadrum Nr. 13, Brüssel 1962, zitiert nach: Khatibi, 1989, S. 10.

${ }^{19}$ Jorn, Asger: Pour la forme, Ébauche d'une méthodologie des arts, Paris 1958, zitiert nach Claus, 1963, S. 58.
} 
aktualisieren““20. Ohne zugehöriges Objekt wird das Zeichen zum Symbol. Die Kunst des Zeichens existiert in der westlichen abstrakten Kunst, aber sie erscheint nur nach Schulen und Richtungen geordnet und folgt dabei genau deren stilistischen Vorgaben. Mit den verschiedenen arabischen Schriftarten harmonieren die Festlegungen der bekannten stilistischen Eigentümlichkeiten vollständig im Hinblick auf ihre charakteristische sprachliche Besonderheit ${ }^{21}$. Dennoch war die westliche Annäherung an die Schrift in der Kunst nicht ohne Nutzen für die arabischen Künstler.

Die Wahrnehmung der arabischen Buchstaben hat während der Entwicklung der islamischen Zivilisation und mehr noch in der Moderne viele Veränderungen durchlebt. Angesichts der politischen und soziokulturellen Änderungen des 19. und 20. Jahrhunderts verloren die arabischen Schriftzeichen jedoch zusehends ihren sakralen Charakter. Zwischen den zwanziger und vierziger Jahren des 20. Jahrhunderts eigneten sich arabische Künstler die Formensprache und die Stile der modernen westlichen Kunst an. In dieser Zeit waren die arabischen Schriftzeichen auf das Reich der traditionellen Fertigkeiten begrenzt, tauchten aber um die Mitte des 20. Jahrhunderts wieder in der arabischen Kunst auf, vor allem bei Madīha 'Umar (1908-2005) und Ğamīl Hammūdī (1924-?) im Irak.

Die arabischen Künstler beachteten das fruchtbare Reservoir ihres kulturellen Erbes. Sie schöpften aus dieser Quelle. Mit ihrer Kunst und der Erschaffung eines eigenen Stils versuchten sie, die Krise des nationalen Bewusstseins zu überwinden. Nicht die Überzeugung, dass die Schrift als Bestandteil der Kunst einen eigenen Wert hat, sondern das Streben nach etwas Neuem, auf der eigenen Kultur basierenden, war ihre wirkliche Motivation. Die Rückkehr der Schrift stand hauptsächlich im Zusammenhang mit nationalistischen Interessen. Es war die Zeit nach dem 2. Weltkrieg, in der die meisten arabischen Länder ihre Unabhängigkeit erlangten: Arabisch-nationalistische Gefühle waren weit verbreitet und beeinflussten auch arabische Künstler. Die arabische Sprache hatte einen hohen Stellenwert der mit der Zeit wuchs. Während des Zeitalters des Kolonialismus diente sie als Symbol der nationalen Identität, ${ }^{22}$ als einigendes Moment in einer Zeit, als viele arabische Künstler unter einer Identitätskrise litten. Eine große Anzahl von Künstlergruppen konzentrierte sich auf die Suche nach lokalen oder nationalen Kunststilen durch „,istilhām at-turät,"“(dt. ,inspiriert von der Tradition“), wie

${ }^{20}$ ebd.

${ }^{21}$ vgl. Dāgir, 1990, S. 132.

${ }^{22}$ Die moderne arabische Nationalbewegung sieht diejenigen Menschen als Araber an, deren Alltagssprache arabisch ist. 
zum Beispiel „Die moderne Kunstgruppe Baghdads“, die 1951 gegründet wurde.

Der arabische Buchstabe wurde zum Mittel der Verbindung ihrer Gegenwart und Vergangenheit durch einen Weg der Arabisierung oder Lokalisierung der westlichen modernen Kunst, als Schlüsselelement zur Neuerfindung ihrer eigenen Tradition.

Die Anfänge des modernen Gebrauches von arabischen Buchstaben in der Kunst lagen in der zweiten Hälfte des 20. Jahrhunderts, und sie resultieren aus unterschiedlichen Bemühungen. Es scheint aber eine Übereinstimmung unter arabischen Künstlern, Kunsthistorikern und Kritikern zu geben, dass die Arbeiten der zwei irakischen Künstler, Madīḥa 'Umar und Ğamīl Hammūdī die ersten Beispiele des modernen Gebrauches von Buchstaben in der Kunst $\operatorname{sind}^{23}$. Umstritten ist nur, wer von beiden zuerst angefangen hat. Die meisten Experten sprechen 'Umar die Priorität zu. Diesen folgten viele weitere Experimente.

\subsection{Definitionen}

\subsubsection{Die Sprache}

Die Sprache gilt als Grundlage des Denkens und der menschlichen Kultur und sie hat zusammengefasst - zwei charakteristischen Funktionen:

Formal ist sie ein funktionales Instrument der Kommunikation. Die Fähigkeit, Sprache $\mathrm{zu}$ benutzen ist es letztendlich, was den Menschen von allen anderen Lebewesen unterscheidet $^{24}$. Durch die Sprache kann der Mensch sowohl Sachinformationen vermitteln als auch seine Emotionen ausdrücken. Über den Vorgang der momentanen Verständigung hinausgehend ist die Sprache Vermittlerin von Kultur zur Wahrung des gemeinsamen intellektuellen und künstlerischen Erbes, das die Generationen miteinander verbindet ${ }^{25}$. Um diese Aufgabe erfüllen zu können, muss die Sprache vermittelt werden. Dies kann auf mündlichem oder schriftlichem Wege geschehen. Aristoteles fasst sein Verständnis des Verhältnisses von Sprache und Schrift am Anfang der „Hermeneutik“ folgendermaßen zusammen: „Die Sprache ist Zeichen und Gleichnis

\footnotetext{
${ }^{23}$ vgl. Dāgir, 1990, S. 20.

${ }^{24}$ vgl. Sampson, Geoffrey: Writing Systems, A linguistic introduction, Stanford 1985, S. 13.

${ }^{25}$ vgl. 'Umar, Hassan: al-Lisāniyyāt wa-t-tarğama in: Ğum`a, Ḥussein (Hrsg.): miğallat al-adab alağnabiyya, Nr. 115, Damaskus 2003, S. 10 - 14, hier S. 10.
} 
für die seelischen Vorgänge, die Schrift wieder für die Sprache ${ }^{626}$. Die gesprochene Sprache ist mit hoher Wahrscheinlichkeit älter als Schrift. Geoffrey Sampson zufolge könnten bereits seit einer Million Jahren gesprochene Sprachen existieren ${ }^{27}$, während die ältesten voll- ausgebildeten Schriftsysteme kaum älter als fünftausend Jahre alt sind.

\subsubsection{Piktographie}

Die Piktographie ist eine Form der bildlichen Darstellung. Ihre Besonderheit liegt darin, dass sie Informationen mitteilen soll, ihr ästhetischer Aspekt ist zweitrangig (Abb. 6). Deshalb können Piktogramme in hohem Maße konventionalisiert sein, wie etwa das Gefahrenzeichen für „giftig“, das aus einem menschlichen Schädel mit zwei gekreuzten Knochen besteht. An sich hat dieses Zeichen mit Gift nichts zu tun, in einem anderen Kontext kann es etwa als Piratenflagge auftreten (Abb. 7)

\subsubsection{Die Schrift}

Schrift ist „ein System grafischer Zeichen, die zum Zweck menschlicher Kommunikation verwendet und durch Zeichnen, Malen, Einkerben, Ritzen o. Ä. auf feste und dauerhafte Beschreibstoffe [Stein, Rinde, Leder, Holz-, Ton- und Wachstafeln, Papyrus, Pergament, Papier u. a.] hervorgebracht werden“" ${ }^{28}$. In einer Definition von Geoffrey Sampson heißt es: „Die Schrift ist ein System für die Darstellung von Äußerungen in gesprochener Sprache mittels dauerhaft sichtbarer Zeichen $^{29}$. Die meisten Arbeiten, die sich mit der Geschichte der Schrift und des Schreibens beschäftigen, betrachten diese hauptsächlich ,als Mittel zur Reproduktion von Sprache mit Hilfe graphischer Symbole ${ }^{630}$. Schrift dient der Kommunikation. Sie benutzt sichtbare Zeichen, die es uns möglich machen, Nachrichten an Menschen weiterzugeben und von ihnen zu empfangen, obwohl diese sich an einem anderen Ort zu einer anderen Zeit befinden.

Im Allgemeinen gehören alle Formen des Schreibens zu einer von zwei eindeutig getrennten Gruppen: Dem Niederschreiben von Begriffen oder von Lauten bzw. Silben.

\footnotetext{
${ }^{26}$ Aristoteles: Hermeneutik 1, in: Gohlke, Paul (Hrsg.): Die Lehrschriften des Aristoteles Bd. 2, Paderborn 1951, S. 86

${ }^{27}$ vgl. Sampson, 1996, S. 17.

${ }^{28}$ Art. „Schrift“ in: Brockhaus. Die Enzyklopädie, Leipzig/Mannheim 1996 ff., Bd. 19, S. 464.

${ }^{29}$ Sampson, 1996, S. 26.

${ }^{30}$ Gaur, 1984, S. 7.
} 
„Das Aufschreiben von Gedanken übermittelt eine Idee oder Vorstellung direkt: die Zeichnung eines Beines beispielsweise bedeutet ' Bein ' oder 'gehen', die Zeichnung eines Baumes Baum (sie könnte natürlich auch ' frisches Grün, das Leben ' etc. bedeuten). (...) Eine Vorstellung muss zuerst einmal in die Laute eines bestimmten Wortes oder Satzes einer entsprechenden Sprache übersetzt werden, dann müssen diese Töne in Form von gravierten, gemalten oder eingeritzten Zeichen auf der Oberfläche eines bestimmten Gegenstandes sichtbar gemacht werden. Dies sind meist Zeichen, die keine Verbindung zum Inhalt des ursprünglichen Gedankens tragen“‘31.

\subsubsection{Der Buchstabe}

Der Buchstabe ist in Alphabetschriften (im Unterschied zu Wort- und Silbenschriften) ein Grundelement der Schrift. Der Buchstabe ist durch Konvention festgelegtes Symbol für einen Laut. Hinzu können verschiedene extralinguistische Bedeutungen kommen wie in der Buchstabenmystik. So ist der Buchstabe Alif $\left({ }^{\prime}\right)$ des arabischen Alphabets nicht nur in den funktionellen Zusammenhang des Ausdrucks verschiedener Vokale und Konsonanten der arabischen Sprache eingebunden, sondern ist auch ein Zeichen für Allah.

Der Schreiber steht vor der Wahl, ob er die inhaltliche Bedeutung des Textes oder die formale Gestaltung der einzelnen Buchstaben hervorheben will ${ }^{32}$.

\subsubsection{Kalligraphie}

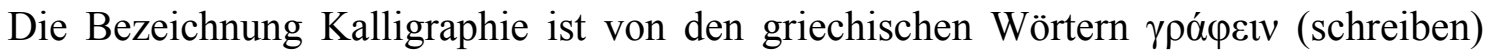
und $\kappa \alpha \lambda$ ó $\varsigma$ (schön) abgeleitet. Kalligraphie wurde 1596 vom französischen Humanisten Etienne definiert, als „, die Art Buchstaben gut anzuordnen“33. Entsprechend dem Gebrauch der Bezeichnung Kalligraphie während der Renaissance teilten alle Arbeiten von Kalligraphie ,eine Eigenschaft, nämlich, dass der spezifische Inhalt (von der Aussage unterschieden) des Textes entweder verwirrend und schwierig zu lesen wurde oder sogar unbrauchbar wurde ${ }^{634}$.

Somit wurde der Kalligraphie eine ästhetische Qualität zuteil, wodurch sie als

\footnotetext{
${ }^{31}$ Gaur, 1984, S. 14.

${ }^{32}$ vgl. Gray, Nicolette: A history of lettering, Oxford 1986, S. 9.

${ }^{33}$ Grabar, Oleg: The formation of Islamic art, New Haven 1987, S. 60.

${ }^{34}$ Grabar, 1987, S. 61.
} 
Kunstwerk betrachtet und bewertet werden konnte. Khatibi und Sijelmasi definieren sie als „Kunst der Linie; sie restrukturiert die Visualisierung ... einer Sprache ... So offenbart die Kalligraphie dem Text gleichsam einen plastischen Hintergrund: Es ist der eines bildhaften Buchstabens, gefangen von der Bewegung der Hand und der Linie, die der Rhythmus anschliessend verbindet und belebt ... Die kalligraphische Linie ist für die Sprache, die sie benutzt und dadurch verschönert, ein Zeichenlabor ${ }^{\star 35}$.

Nur drei Zivilisationen haben wirkliche Kalligraphie hervorgebracht: ,, die Araber (und die, die die arabischen Schriftzeichen benutzten), die Chinesen (bzw. die, die die chinesischen Schriftzeichen benutzten), sowie die westliche Zivilisation, ausgehend vom römischen Alphabet, den römischen Gesetzen und der christlichen Kirche ${ }^{\text {‘36 }}$.

Grabar erklärt, dass Beispiele aus den drei Traditionen mindestens zwei offensichtliche Eigenschaften teilen: „,die Umwandlung der einfachen Tätigkeit des Kommunizierens. Beim Schreiben geschieht dies durch eine Reihe von Hilfen, Vorrichtungen und Übereinkünften; manchmal endet diese Umwandlung allerdings indem sie die Kommunikation erschwert, unempfänglich oder sogar bedeutungslos macht und um eine ästhetische Reaktion, meist in Form von Vergnügen beim Betrachter auszulösen ${ }^{\text {‘37 }}$. Bis jetzt verursacht es Schwierigkeiten, wenn es um die Festlegung der künstlerischen oder ästhetischen Qualitäten aller unterschiedlichen Beispiele des Schreibens dieser drei Traditionen, ohne Unterscheidung in Kalligraphie, geht.

\subsubsection{Al-Ḥurūfiyya}

Im Gegensatz zur von der Tradition bestimmten Kunst der Kalligraphie hat Ḥurūfiyya einen experimentellen Charakter bei der künstlerischen Gestaltung arabischer Buchstaben in der arabischen Kunst. Die Bezeichnung Hurūfiyya wird zur Kennzeichnung der Verwendung arabischer Schriftzeichen in den Bildern moderner arabischer Künstler als eigenständiger Bildgegenstände, die nicht mehr nicht mehr textgebunden sind. Dāgigir definiert Ḥurūfiyya als einen Begriff, der „Kunstwerke bezeichnet, die sich mit arabischer Sprache, den Buchstaben oder Texten als sichtbares Element für die Komposition beschäftigten oder beschäftigen“38.

\footnotetext{
${ }^{35}$ Khatibi, Adelkebir u. Sijelmassi, Mohammed: The splendour of Islamic calligrapy, London 1976, S. 6.

${ }^{36}$ Gaur, 1984, S. 165.

${ }^{37}$ Grabar, 1987, S. 59.

${ }^{38}$ Dāäirir, 1990, S. 11.
} 


\subsection{Die Zusammenfassung der Geschichte der Schriftentwicklung in Europa und im Mittleren Osten (Arabische Welt)}

Bis heute weiß man nicht, wann die Geschichte des Schreibens begann. Als der französische Gelehrte Piette um 1900 in einer Höhle nahe der spanischen Grenze kleine Feuersteinstücke, datiert zwischen 12000 - 8000 vor Christus entdeckte, die mit in rot und schwarz gemalten Zeichen verziert wurden, reizte das äußere Erscheinungsbild einiger (obwohl auf keinen Fall aller) Zeichen eine Gruppe von Gelehrten, wenn auch nicht sehr überzeugend, zu Spekulationen. Und zwar über mögliche Verbindungen mit den Zeichen, gefunden in vollständig etablierten phonetischen Systemen des Schreibens wie die ägäischen Syllabarien, die semitischen Konsonantenmanuskripte und sogar das Alphabet ${ }^{39}$.

Die Entstehung der Schrift, so Albertine Gaur ${ }^{40}$, wurde initiiert durch das Bedürfnis nach Aufzeichnung. Die Schrift erlaubt es ihren Benutzern, Informationen über zeitliche und räumliche Entfernung genau zu übermitteln und so das kulturelle und intellektuelle Erbe der Gemeinschaft zu bewahren. Auch R. H. Robins sagt: „Jede Entwicklung eines Systems des Schreibens, das ermöglicht, eine Sprache visuell zu notieren, so wie sie gesprochen und verstanden worden ist, ist eine enorme, normalerweise über einige Generationen erbrachte Leistung, die in der linguistischen Analyse unmittelbar zu praktischen Zwecken besonders verwendet wird““41.

Jäger- und Sammler- sowie Bauernkulturen, die lediglich Subsistenzwirtschaft betreiben, haben keine Schriften hervorgebracht. Ihr oft reichhaltiges Traditionsgut wurde mündlich überliefert. Die ersten Schriftstücke waren Steuer- oder Warenlisten. Somit ist die Schrift eine Erfindung, deren Erscheinen mit der Gründung von Städten und Reichen zusammenfällt. Das bedeutete, dass durch die Einordnung einer riesigen Zahl von Individuen in einem hierarchischen politischen und religiösen System, wurde die Schrift zumindest in Ägypten und China erfunden ${ }^{42}$. Die Schrift durchlief zahlreiche Entwicklungsstufen, bevor sie den Grad der Einfachheit von Alphabetschriften erlangte, und zwar:

\footnotetext{
${ }^{39}$ vgl. Jensen, Hans: Signs, symbols and script, London 1970, S. 23.

${ }^{40}$ vgl. Gaur, 1984, S. 15.

${ }^{41}$ Robins, 1990, S. 11.

${ }^{42}$ vgl. Șafwān, Muṣṭafā: al-Kitāba wa-s-sulța, Kairo 2002., S. 33.
} 
1- Die Phase der Bilder, in der die Bilder als Zeichen die Bedeutung erzeugen. Dabei können zwei Formen unterschieden werden, erstens wenn der sichtbare Eindruck abgebildet wird, wie wenn man eine Mondsichel malt, um den Mond darzustellen. Die zweite Möglichkeit besteht darin, den Gedanken im Bild auszudrücken, dies ist zum Beispiel der Fall, wenn man ein Kind mit einem Buch mahlt, um das Konzept eines Schülers zu vermitteln.

2- Die symbolische Phase: Das ist die Phase, in der die Menschen aus den symbolischen Bildern auf die Bedeutung schlussfolgerten, und das ist eine Form der Schrift, in der gemalte Symbole benutzt werden, um Gedanken oder bestimmte Laute zu bilden, zum Beispiel die hieroglyphische Schrift. Und sie wurde auch benutzt von den alten Zivilisationen, zum Beispiel von den Hethitern, die in der Türkei lebten oder vom Stamm der Maya, die in Mittelamerika lebten. Und diese Symbole waren wie eine genaue Darstellung der Gedanken, zum Beispiel wenn die Menschen Licht darstellen wollten und die Sonne als Ausdruck des Lichts zeichneten.

3- Die syllabische Phase: Hier besteht keine Verbindung zwischen Schriftzeichen und Begriff mehr. Zum Beispiel, wenn jemand das Wort yadaheru (sparen) schreiben will, dann beginnt er mit der Silbe yad, die zugleich die Bedeutung Hand hat, und er zeichnet das Bild einer Hand und betrachtet sie als Silbe aus Buchstaben, mit denen er nicht die Hand selbst meint.

4- Die phonetische Phase, in der der Schreiber zur Nutzung des Bildes als Ausdruck für den ersten Buchstaben greift und wie ein Symbol für den ersten Buchstaben den Namen des Bildes nahm, zum Beispiel das Bild eines Hundes, das den Buchstaben $\mathrm{H}$ symbolisiert und das Bild einer Gazelle, das den Buchstaben G symbolisiert, so wie die Kinder im Leseunterricht lernen.

5- Die Phase des vollständigen Alphabets, in der neben den Konsonanten auch die Vokale mit eigenen Zeichen ausgedrückt wurden. Kleinasien, die sumerische Schrift in Mesopotamien sowie die chinesische Schrift.

Die älteste und berühmteste Art eines solchen Alphabetes sind die ägyptische und hethitische Hieroglyphenschrift in Ägypten und In Ägypten wurden im Laufe der Zeit die Wort-Bild-Zeichen auch als Wort-Laut-Zeichen gelesen. So konnte etwa das 
Zeichen „Laute“ auch als „schön“ gelesen werden, da beide Worte denselben Konsonantenstand (n-f-r) aufwiesen. Schließlich konnten die Zeichen als (zwei-, drei und vierkonsonantische) Silbenzeichen gelesen werden. Das System wurde dadurch kompliziert, dass alle diese Lesarten in ein und demselben Text möglich waren, so dass Deutezeichen (Determinative) nötig wurden, um anzuzeigen, wie ein Zeichen gelesen werden sollte. Die ägyptische Schrift tritt in der Form der Hieroglyphenschrift seit etwa 3215 v. Chr. auf. Das früheste erhaltene Schreibmaterial sind Steininschriften, daneben wurde auf Papyrus geschrieben. Seit etwa 1600 v. Chr. entwickelte sich aus der Hieroglyphen- die hieratische Schrift, die im wesentlichen eine Kursive der Hieroglyphenschrift darstellte und ausschließlich auf Papyrus geschrieben wurde. Um 800 v. Chr. kam die demotische Schrift auf. Sie war neben der Hieroglyphenschrift völlig selbständig, indem sie auf Wort-Bild- und Wort-Laut-Zeichen bis auf wenige Ausnahmen verzichtete und nur auf Silben- und Konsonantenzeichen basierte. Sie kam dadurch mit erheblich weniger Zeichen als die Hieroglyphenschrift aus. Die Entzifferung der beiden ägyptischen Schriftsysteme, des hieroglyphischen und des demotischen gelang 1822 Jean François Champollion aufgrund des 1799 entdeckten „Steins von Rosetta“, der eine Gedenkinschrift für Ptolemäus V. (205-181 v. Chr.) aus dem Jahre 198 v. Chr. in ägyptischer (hieroglyphisch und demotisch geschrieben) und griechischer Sprache trug (Abb. 8).

Im Süden Mesopotamiens entstand seit ca. 3200 v. Chr. die sumerische Kultur. Ähnlich den Ägyptern benutzten die Sumerer eine Bildschrift. Da die sumerische Sprache zahlreiche einsilbige Worte aufwies, flossen Wort-Bild- und Wort-Laut-Schrift ineinander. Die sumerische Schrift auf Tontafeln geschrieben, indem die Zeichen mit einem Rohrgriffel eingedrückt wurden. Als nach 2300 v. Chr. die semitischen Akkader die Schrift der (nichtsemitischen) Sumerer übernahmen, wurden die Zeichen, abgesehen von wenigen Wort-Bild-Zeichen, die jedoch teilweise als (stumme) Determinative gelesen wurden, als reine Silbenzeichen verwendet. Im Laufen der Zeit verloren die Zeichen ihren bildhaften Charakter und bildeten ein Ensemble von Keilen, dem Grundelement der Schrift. Ihren Höhepunkt erreichte die Entwicklung des klassischen akkadischen Schriftduktus um 700 v. Chr. Da die akkadische Schrift als (fast) reine Silbenschrift nicht an eine bestimmte Sprache gebunden war, konnte mit ihr auch andere Sprachen geschrieben werden. So übernahmen etwa die Hethiter die Keilschrift neben ihrer Hieroglyphenschrift. Die äußere Form der Keilschrift wurde nach 700 v. Chr. von den Medern und Persern übernommen, die aber die Anzahl der Zeichen 
drastisch reduzierten.

Eine dritte sehr alte Wort-Bild-Schrift ist die chinesische Schrift (Abb. 9), eine Silbenschrift die japanische (Abb. 9a).

Unter den vielen Theorien hinsichtlich des Ursprungs der semitischen Konsonantenschriften galt lange die, die ägyptischen Verbindungen unterstützte, als populärste, trotz der Tatsache, dass der wirkliche (archäologische) Beweis ${ }^{43}$, auf dem diese Theorie ruht, eindeutig zu kurz greift ${ }^{44}$. Die angenommene Brücke, die Gaur zur Stützung dieser Theorie erwähnt, ist die Sinaischrift, die der britische Archäologe Flinders Petrie im Winter 1904/05 in antiken Malachitminen des Sinai, vor allem um und in den Ruinen des Tempels der ägyptischen Göttin Hathor in Serabit al- Hadim, fand. In dieser Schrift wurde eine Anzahl von kurzen Inschriften, die er auf 1500 v. Chr. datierte, geschrieben. Flinders Petrie leitete zweiunddreißig unterschiedliche Buchstabenzeichen von diesen etwas unachtsam geschriebenen Hieroglyphen $\mathrm{ab}^{45}$. Die Inschriften ergaben in ägyptischer Sprache keinen Sinn. Der britische Ägyptologe Gardiner erklärte 1916, er habe, indem er die Wortbedeutungen der Hieroglyphen ins Nordwestsemitische übertragen und die Zeichen nach dem akrophonischen Prinzip (von den eigentlich mehrkonsonantischen Zeichen wird nur der erste genommen) gelesen, das Wort lb lt (le ba 'alat) „der Herrin“ als Name für Hathor gelesen.

Geht man von der Gültigkeit der Theorie Gardiners aus, ist die Sinaischrift die Mutter der Alphabetschriften, die von den Phöniziern übernommen und von ihnen über die Griechen an die Römer, Ostslawen, Armenier und Georgier einerseits, die Aramäer, Araber, Perser, Mongolen und Inder andererseits weitergereicht wurde. Trotz des großen Unterschieds, der in der äußeren Form zwischen dem lateinischen und arabischen Alphabet besteht, sind sie im Grunde nur Varianten einer Grundform.

\subsubsection{Die Geschichte der Entwicklung der europäischen Schrift}

Die Griechen übernahmen von den Phöniziern die Alphabetschrift. Um Vokale auszudrücken, die für die indoeuropäischen Sprachen im Gegensatz zu den semitischen ebenso wichtig wie die Konsonanten sind, wurden die Konsonantenzeichen Aleph, He,

\footnotetext{
${ }^{43}$ vgl. Gaur, 1984, S. 89.

${ }^{44}$ vgl. ebd.

${ }^{45}$ vgl. ebd.
} 
Cheth, Waw, Yodh und Ayin als Vokalzeichen Alpha (a), Epsilon (kurzes e), Eta (langes e), Ypsilon (u) und Omikron (kurzes o) übernommen (Abb. 10). Die frühesten bis heute entdeckten Beschreibungen einer alphabetischen Natur stammen aus dem 8. Jahrhundert vor Christus ${ }^{46}$. „Es kann angenommen werden, dass die Griechen mit der phönizischen Form des Schreibens in einer oder mehreren phönizischen Handelsstätten, entweder in Kleinasien, in Syrien oder möglicherweise auf einer der griechischen Inseln in Kontakt kamen. Die Zeit der Übertragung kann um 1000 vor Christus herum, früher oder später, nach Ansicht verschiedener Gelehrten, gewesen sein““47. Wenn wir an attische Schrift denken, so denken wir in erster Linie an die Steininschriften, die zahlreich nach den Perserkriegen erschienen. Aber diese Inschriften geben ein deutlich einseitiges, wenn nicht sogar verzerrtes Bild der Kunst des Schreibens wieder, denn sie mussten auf Papyrus und Wachsbrettern geübt worden sein, wie es sich in gemalten und gekratzten Inschriften auf verschiedenen Materialien von Anbeginn der Einführung des Alphabetes wiederspiegelt ${ }^{48}$.

Irgendwann im 8. Jahrhundert vor Christus scheinen griechische Siedler ihr Alphabet nach Italien gebracht $\mathrm{zu}$ haben, wo es nach einigen mehr oder weniger kleinen Änderungen und sehr vielen lokalen Veränderungen, durch die Etrusker angenommen wurde. Bis heute sind fast 10.000 Inschriften entdeckt worden, die zwar entzifferbar, aber nicht lesbar sind, da - abgesehen von Eigennamen - die etruskische Sprache völlig unbekannt ist. Das frühe etruskische Alphabet (Abb. 11) bestand aus sechsundzwanzig Buchstaben und wurde, wie die frühe griechische Schrift, von rechts nach links geschrieben. In einigen Beschriftungen werden die Wörter durch Punkte getrennt, was in gewissem Sinne an eine syllabische Form des Schreibens erinnert ${ }^{49}$.

Unter den verschiedenen Abzweigungen des etruskischen Alphabetes, das für kurze Zeitabschnitte in den unterschiedlichen Teilen Italiens florierte ${ }^{50}$, entwickelte sich als wichtigste das römische (oder lateinische) Alphabet, dokumentiert vom 7. oder 6. Jahrhundert vor Christus an. Es verdrängte allmählich alle weiteren italienischen Schriften und wurde im entsprechenden Verlauf zu der Schrift der westlichen Hälfte des römischen Reiches. Durch die Einrichtungen der römisch-katholischen Kirche und (später) westlichen Kolonialexpansion, verbreitete es seinen Einfluss über Europa, nach

\footnotetext{
${ }^{46}$ vgl.Gaur, 1984, S. 118.

${ }^{47}$ Gaur, 1984, S. 119.

${ }^{48}$ Immerwahr, Henry R.: Attic script. A survey, Oxford 1999, S. 1.

${ }^{49}$ vgl. Gaur, 1984, S. 126.

${ }^{50}$ vgl. Jensen, 1970 , S. $507 \mathrm{ff}$.
} 
Amerika, Asien und Afrika hinaus ${ }^{51}$.

Die primitiven Formen der griechischen, etruskischen und römischen Buchstaben sind ähnlich. Die Römer übernahmen einundzwanzig der sechsundzwanzig etruskischen Buchstaben; sie fügten den Buchstaben $\mathrm{G}$ und im ersten Jahrhundert vor Christus die Buchstaben Y und Z für den Gebrauch der griechischen Wörter hinzu. Latein behielt F und $\mathrm{Q}$ von frühen griechischen und etruskischen Buchstaben, die im klassischen Griechischen aufgegeben wurden $^{52}$. Die Römer verbreiteten mit der lateinische Sprache das römische Alphabet in den europäischen Ländern, nachdem das römische Imperium Europa beherrschte. Dieses Alphabet ist mit einigen Veränderungen bis heute in Gebrauch.

\subsubsection{Arten und Anwendung der europäische Schrift}

Bereits am Anfang der christlichen Ära hatten die Römer eine große Vielzahl von Schriftarten entwickelt, um sie verschiedenen Aspekten des täglichen Lebens anzupassen. Neben denen, die für Steininschriften taugten, gab es noch formale Bücherschriften, sowie mehrere kursive Handschriftarten, geeignet für Anmerkungen persönlicher, administrativer oder kommerzieller Natur. Die wesentlichen Bücherschriften der späten römischen Periode, Unziale (Abb. 12) und Halbunziale, favorisierten eine Verringerung der Größe der einzelnen Buchstaben und eine Tendenz in Richtung größerer Neigung der Buchstaben war zu erkennen. Sie haben auch das Vier-Linien-System (anstatt des alten Zwei-Linien-Systems) eingeführt, um die Anordnung der einzelnen Steigungen und Gefälle anzupassen. Nach dem Zerfall des römischen Reiches und mit der Verbreitung des Christentums wurde die Unziale zur bevorzugten Schrift der christlichen Literatur ${ }^{53}$. Im 6. Jahrhundert wurde die Halbunziale in Irland eingeführt. Von dort aus wurde, als Resultat der Klostergründungen der irischen Mönche, die neue irische Schrift zu den Rheinfranken (Fulda), Alemannen (St. Gallen), nach Aquitanien (Tours) und Italien (Bobbio) gebracht. Auf den britischen Inseln, wo das Christentum von irischen und römischen Missionaren eingeführt worden war, führte die resultierende Kombination von Schriftarten im 8. Jahrhundert zur Entwicklung der angelsächsischen Handschrift ${ }^{54}$,

\footnotetext{
${ }^{51}$ vgl. Gaur, 1984, S. 127.

52 vgl. Gray, 1986, S. 12.

53 vgl. Gaur, 1984, S. 165.

${ }^{54}$ vgl. Gaur, 1984, S. 171.
} 
einer Schrift, die bis weit nach der Eroberung durch die Normannen vorherrschte. Wegen ihrer geographischen Isolation waren die britischen Inseln und Irland in der Lage, eine gewisse Gleichförmigkeit beizubehalten, soweit es mehrere formale Buchschriften betraf. Dagegen entwickelten sich auf dem europäischen Kontinent viele lokale Schriftarten, wie zum Beispiel das süditalienische Beneventinisch (Abb. 13), das fränkische Merowingisch (Abb. 14), das Westgotische in Spanien und viele andere Schriften. Dieser Prozess des Auseinanderfallens wurde schließlich durch Karl den Großen (742-814) zum Erliegen gebracht, dessen neu gewonnenes Imperium eine neue Einheit nach Westeuropa brachte ${ }^{55}$. Dort entstand eine Schrift, die Karolingische Minuskel (Abb. 15), die in den höfischen und Klostereinrichtungen dienen sollte. Die Karolingische Minuskel war eine Schrift der großen Klarheit und Harmonie, die das Vier-Linien-System mit wenig Ligaturen und Abkürzungen verwendete und häufig künstlerisch die großen oder Unzialbuchstaben für Initialen und Überschriften verschönerte. Diese Klarheit des graphischen Schriftbildes ging später teilweise verloren mit der Entwicklung der anderen Hauptschrift, der gotischen Minuskel (und ihren verschiedenen Unterformen und späteren Entwicklungen), die ihren Platz in den 12. und 13. Jahrhunderten eroberte. (Abb. 16). Diese Schrift ,zerbrach“ die gebogenen Elemente der Buchstaben in eckige Kombinationen der Striche, fügte dekorative kleine Füße und Köpfe hinzu und führte feine Haarlinien ein, um einzelne Schriftzeichen zu verbinden.

Das 14. Jahrhundert, die Blütezeit der gotischen Schrift, war für viele Teile Europas eine Zeit der großen Verwüstung. Die Pest, die von 1348 bis 1350 wütete, endlose dynastische Streitigkeiten, plündernde Söldner und ein rivalisierender Papst in Avignon (1378-1415) untergruben den Glauben und das Vertrauen der Menschen an die errichtete Ordnung sehr. In Norditalien entstand unter dem Einfluss der reichen Handelsstädte wie Florenz und Venedig eine Sehnsucht nach der Vergangenheit, die den Weg für die Renaissance ebnete. Künstler, Schreiber, Gelehrte und ihre Gönner wandten ihre Aufmerksamkeit dem Studium der römischen Antike zu. Die römische Kapitale erschien jetzt als Norm für eine schöne Schrift.

Die frühen Humanisten, wie Coluccio Salutati (1330-1406), Nicola Niccoli (1363-1437) und Poggio Bracciolini (1380-1459), forderten einen klaren Schriftindex (Manuskript), der sich vom Gotischen unterscheiden sollte. Die Handschrift der Humanisten, die

\footnotetext{
${ }^{55}$ vgl. ebd.
} 
insbesondere von Poggio entwickelt wurde, basiert auf Handschriften der karolingischen und besonders den romanischen Schriften der Manuskripte, von denen die klassischen Texte abgeschrieben wurden ${ }^{56}$. Es ist die Handschrift, die in sehr vielen schönen Manuskripten der Renaissance benutzt wurde und ist das Modell, auf dem die französische und italienische Schrift basieren. Diese neue Schrift, die Antiqua (Abb. 17), wurde besonders von professionellen Kopisten benutzt. Der kursive italische Schriftstil (Abb. 18), der ungefähr zur gleichen Zeit entstand, wurde als Buchhandschrift verwendet, aber auch als schnellere, weniger formale Handschrift. Als solche wurde sie zum Modell für zeitgenössische Handschrift und für die Wiederbelebung der kursiven Kalligraphie im zwanzigsten Jahrhundert ${ }^{57}$. Mit den neuen handgeschriebenen Büchern der Humanisten wurden neue Großbuchstaben eingeführt. Die frühen Buchstaben, die zum Beispiel von Poggio benutzt wurden, sind im Wesentlichen mit der Feder geschrieben; sie ähneln weder den karolingischen Großbuchstaben noch stehen sie in einer Beziehung zu den gemeißelten römischen Buchstaben. Tatsächlich, wie man erwarten würde, sind sie der romanischen Rustica näher, die in den Manuskripten gefunden wird, die sie kopierten ${ }^{58}$.

Wie bei jeder Schrift wurde eine Vielzahl an Variationen verwendet. Die auffälligste Eigenschaft der formlosen Handschrift dieser Zeit waren die Schräge und das Verengen der ovalen und runden Buchstaben, alle Buchstaben wurden dicht zusammen geschrieben, häufig aneinander angeschlossen, und die aufsteigenden Linien waren sehr hoch.

Die italienische Schreibschrift wurde zuerst als ein Schriftbild von den damaligen kursiven Handschriften entwickelt, die sehr populär geworden waren. Ludovico Arrighis italienisches Design war ein besseres als die meisten, wurde jedoch von allen Druckern vernachlässigt. Es ist dieses Design (welches er beim Arbeiten als Schrift in der Kanzlei im Vatikan verwendete), das wir heutzutage als die italienische Schrift kennen.

Um 1600 begann die nächste Entwicklung in der Geschichte der Schrift, dies lag am wachsenden Einfluss der spitzen Feder und des Stiches. Diese Änderung von der quadratischen Spitze zu der spitzen und flexiblen Feder, führte zu einem Schriftstil der

\footnotetext{
${ }^{56}$ vgl. Gray, 1986, S. 122.

${ }^{57}$ vgl. ebd.

${ }^{58}$ vgl. ebd.
} 
extremen Kontraste, von haarfeinen bis zu kräftigen breiten Strichen.

Diese Änderung verlief etappenweise, da im 16. Jahrhundert Federn die einzigen Schreibgeräte waren, die verwendet wurden. Diese konnten nur bis zu einem bestimmten Grad angespitzt und geschärft werden, da sie von Natur aus sehr weich waren. Während des ersten Viertels des 19. Jahrhunderts war der Gebrauch von Stahlspitzen aufgekommen, die zu einer sehr feinen Spitze geschliffen werden konnten und auch Kupferfedern, die eine Ableitung von der Gravur waren und im 17. Jahrhundert weit verbreitet waren. Hierfür wird eine gespaltene, spitze Feder benötigt, anstatt einer kantigen Feder, wie sie für alle anderen Schriftarten benutzt wird.

\subsubsection{Die Geschichte der Entwicklung der arabischen Schrift}

Nach einigen islamischen Überlieferungen wurde die arabische Schrift von Allah selbst oder doch von Adam „erfunden“59. Diese Überlieferungen können in der modernen Wissenschaft jedoch nur im theologischen, nicht im historischen Sinne Wahrheit beanspruchen. Die unterschiedlichen Meinungen über den Ursprung der arabischen Schrift stimmen in dem Punkt überein, dass ihr Ursprung nicht im Hiğaz (Gegend auf der arabischen Halbinsel, um Mekka gelegen) liegt, sondern dass die arabische Schrift Ergebnis der Verbindung der Einwohner des Hiğaz mit anderen in der Nähe gelegenen städtischen Kulturen im Yemen, im mittleren Euphrattal, in Syrien, in Nabațīya (heutiges Jordanien) und im Hauran (Gebirge im Nordosten Palästinas) gewesen ist ${ }^{60}$. Der Kontakt zwischen den Wüstenarabern und den sesshaften Kulturen wurde hauptsächlich durch den Handel geprägt. Ein Teil der arabischen Stämme gab seine beduinische Lebensweise auf, wurde sesshaft und hat sich an ein neues Leben angepasst $^{61}$.

Auf der arabischen Halbinsel wurde aus der Sinai-Schrift (s. o.) eine Schrift entwickelt, die zuerst von den Sabäern im heutigen Yemen (ab 700 v. Chr.) ${ }^{62}$, ab dem 6. Jahrhundert v. Chr. bei den Lihyaniten und Thamuditen in Nord- und seit dem 2. Jahrhundert n. Chr. bei den Safaiten in Zentralarabien verwendet wurde. Diese Schrift, von den arabischen Grammatikern „Musnad“ genannt, wurde mit der Islamisierung

${ }^{59}$ vgl. Khatibi, 1989, S. 21 f.

${ }^{60}$ vgl. Šištīi, 'Abdal-Muhsin: al-Wazị̂a az-zuhrufìyya lī- 1-ḥarf al-'arabī, Kairo 2000, S. 19.

${ }^{61}$ vgl. Ğum'a, Ibrāhīm: Qiș̣sat al-kitāba al-'arabīya, Kairo 1979, S. 15f.

${ }^{62}$ Schriftbeispiele bei Driver, Godfrey: Semitic Writing, Oxford 1948, S. 145; Datierung bei Gese, Hartmut: Die Religionen Altsyriens, Altarabiens und der Mandäer, Stuttgart 1970, S. 393. 
verdrängt. Ein Abkömmling dieser Schrift wird bis heute in Äthiopien verwendet.

Seit dem 8. Jahrhundert v. Chr. war Aramäisch die Sprache der Fernhändler im Nahen Osten, im Perserreich (539-330 v. Chr.) war es auch die erste Amtssprache. In Tema (heute al-Ula in Saudi-Arabien) wurden aramäische Inschriften aus dieser Zeit gefunden. Seit dem 4. Jahrhundert v. Chr. begann die aramäisch Schrift, quadratische Formen anzunehmen, aus der einerseits die moderne hebräische Schrift, andererseits die palmyrenische und nabatäische Schrift hervorgingen. Nach den Eigennamen in den Inschriften zu schließen, waren die Nabatäer und Palmyrener Araber, auch wenn sie in aramäischer Sprache schrieben. Den quadratischen Charakter verlor die aramäische Schrift im Gebiet von Edessa (heute Urfa / Türkei). Edessa war seit dem 2. Jahrhundert n. Chr. das Zentrum des Christentums in den Euphratländern. Aus der edessinischen Schriftentwickelte sich im 4. / 5. Jahrhundert die Estrangelo-Schrift (von syrisch angela $=$ Evangelium), seit dem 6. Jahrhundert aus dieser die runde, die Buchstaben miteinander verbindende Serto-Schrift. Die Ähnlichkeit zwischen Serto und der arabischen Schrift ist auffallend ${ }^{63}$. Die Namen der Buchstaben in der kanaanitischen, aramäischen und syrischen Schrift sind nahezu identisch, allerdings folgen die Buchstaben einer unterschiedlichen Reihenfolge ${ }^{64}$.

Der erste westliche Wissenschaftler, der diesen Zusammenhang beschrieb, war 1724 der Numismatiker Georg Jakob Kehr. Diese Beobachtung wurde 1865 von Theodor Nöldeke (1836-1930) bestätigt und ist seit Rudolf Euting (1869-1913) und Mark Lidzbarski (1868-1928) allgemein anerkannt ${ }^{65}$. Die arabischen Arabisten Nāmī Halīl Yahyā ${ }^{66}$, und Nabia Abbot ${ }^{67}$ kamen ebenso zu dem Schluss, dass dieser Konsens nicht zu bezweifeln sei. .

Aus der vorislamischen Zeit sind vier arabische Steininschriften erhalten geblieben. Die erste Inschrift wurde in Zabad (Abb. 19), südöstlich von Halab, gefunden ${ }^{68}$ und befindet sich heute im Kunstgeschichtlichen Museum in Brüssel ${ }^{69}$. Die Inschrift, die sich an einer Kirche befand, (Mar Sirkis) ${ }^{70}$ befand, ist in griechischer, syrischer und arabischer

\footnotetext{
${ }^{63}$ vgl. Diringer, David: The Alphabet, $3^{\text {rd }}$ revised edition, Bd. 2, London 1968, S. 218.

${ }^{64}$ vgl. Bahnas̄ì, 'Afîfĩ: Šamāl wa- ğanūb, Hiiwār al-fann al-islāmī, Arabische Emirate, aš-Šāriqa 2001, S. 14.

${ }^{65}$ vgl. Grohmann, Adolf: Arabische Paläographie, Wien 1971, S. 11.

${ }^{66}$ vgl. Nāmī, Halīl Yahyā: Aṣl al-ḩatṭ al-'arabī wa-tārīh taṭauwwurihi ilā mā qabla al-islām, Kairo, 1935., S. 6.

${ }^{67}$ vgl. Abbot, Nabia: The rise of the North Arabic script and its Qur'ānic development with a full description of the Qur'ān Manuscripts in the Oriental Institute, Chicago 1938, S. 5.

${ }^{68}$ vgl. Yūsuf, Aḥmad: al-ḩațt al-kūfî, Kairo 1934, S. 31.

${ }^{69}$ vgl. Grohmann, 1971, S. 14.

70 vgl. al-Hुāzin, Wahīb: min as-Sāmīyyīn al-`arab, Beirut 1962, S. 170 f.
} 
Sprache verfasst ${ }^{71}$. In der Inschrift werden die Namen von Personen erwähnt, bei denen es sich vielleicht um diejenigen handelt, die den Bau der Kirche durchgeführt oder befohlen haben. Der arabische Text lautet: بنص) رالأله شرحو بر أمع منفو وهليا بر مر القيس) ) وسرحو بر سعدو وسترو وشريحو (وسريحو) mer al-Qais wa-saraḥu bar sa đū wa sitrū wa-šarīhū ${ }^{72}$. Dass die Inschrift mit dem Jahr 512 christlicher Zeitrechnung datiert ist, ergibt der griechische Text ${ }^{73}$. Das Original wird in der Abteilung Naher Osten der Musées Royaux d'Art et d'Histoire (Inv.-Nr. A. 1308) aufbewahrt ${ }^{74}$.

Die zweite ist die Inschrift von Ises (Usais, Ses; Abb. 19 a), 105 Kilometer südöstlich von Damaskus gelegen ${ }^{75}$. Sie wurde im September 1955 entdeckt $^{76}$. Die Inschrift enthält einen arabischen Text von vier Zeilen, der lautet (إبر اهيم بن مغيرة الأوسي أرسلني الحرث الملاك (Mich, Ībrāhīm bn Mugīira al-Ausī, schickt mir der König von Al-Hुart ${ }^{77}$ gegen Sulaiman Masallaḥa im Jahr 423).

Die dritte ist die Inschrift von Ḥurran, einer Stadt südlich von Damaskus, im ḤurranGebirge (Abb. 19 b), die in den Ruinen einer Kirche auf einem Stein oberhalb der Tür gefunden wurde ${ }^{78}$. Sie ist im Jahre 568 in zwei Sprachen verfasst worden, Griechisch und Arabisch ${ }^{79}$. Der Text lautet أنا شرحبيل بر ظلمو بنيت ذا المرطول سنت 463 بعد مفسد خيير. (Ich bin Šarḥabīl bar Zalamū, ich habe dieses Gebäude im Jahr 463 nach der Zerstörung von Haībar errichtet).

Die vierte Inschrift ist die von Umm al-Ǧimmal bekannt (Abb. 19 c). Sie wurde von einer archäologischen Expedition der Princeton-Universität nach Syrien im Jahre 1904/05 ${ }^{80}$ im nördlichen Schiff einer Doppelkirche (zwei unmittelbar nebeneinander gebaute Kirchen) gefunden. Littmann vertritt die Auffassung, dass einige christliche Araber diese Inschrift angefertigt haben ${ }^{81}$. Diese Inschrift ist als einzige nicht datiert.

\footnotetext{
${ }^{71}$ vgl. an-Naqšabandī, Nāṣir As-Sayyid Mạ̣mūd: manšā' al-ḩaṭ̣ al-'arabī wa-taṭawwuruhu ḥattā 'ahd alhulafā' ar-rāšidīn, Bagdad 1947, S. 132.

${ }^{72}$ vgl. Yūsuf, 1934, S. $31 \mathrm{f}$.

73 vgl. Littmann, Enno: Arabic inscriptions, Leiden 1949, S. 14.

${ }^{74}$ vgl. Grohmann, 1971, S. 14.

${ }^{75}$ vgl. Hatūm, Nūr ad-Dīn: Qaṣr ğabal sīs al-ummawī, Damaskus 1963, S. 243 u. Hasan, Zakī Muhammad: funūn al-islam, Kairo 1944, S. 44.

${ }^{76}$ vgl. Hațūm, 1963, S. 16.

${ }^{77}$ al-Harīî ibn Ğubla siegte 528 über al-Mundhir al-Lahmī III.

${ }^{78}$ vgl. Wēlfenson, Isrā̄îl: tārīh al-lugààt as-sāmīya, Kairo 1929, S. 192.

${ }^{79}$ vgl. Yūsuf, 1934, S. 32.

${ }^{80}$ vgl. Littmann, 1949, S.1.

${ }^{81}$ ebd.
} 
Die Mehrheit der Experten verbindet sie mit dem sechsten Jahrhundert nach Christus ${ }^{82}$.

In diesen Inschriften kommen alle arabischen Buchstaben außer den Buchstaben zīn (j) und șad (ص) vor.

Wenn man die arabischen und nabatäischen Buchstaben vergleicht, fällt die Ähnlichkeit zwischen ihnen, besonders bei den Buchstaben bā', (ب) ğīm hā' (०), lām (ل), nūn (ن), tā' (ت), und lām Alif (ل), auf.

Obwohl es eine arabische Schrift schon Ende des 4. bis Anfang des 5. Jahrhunderts nach Christus gab, wurde sie nach den archäologischen Befunden nur für kurze Inschriften benutzt, eine Literatur gab es nicht ${ }^{83}$. Der Grund dafür dürfte die Hochschätzung des gesprochenen Wortes auch bei den sesshaft gewordenen Arabern sein, für die die rein mündliche Kultur der Beduinen immer noch Vorbild war. Im vorislamischen Arabien war besonders die Dichtung populär. Die Dichter trugen ihre Werke öffentlich auf einer Art Bühne vor.

In der vorislamischen Zeit waren die Araber sehr stolz auf ihre Sprache, aber sie war nicht heilig. Als Muhammad den neuen Glauben predigte, gehörte $\mathrm{zu}$ seinen Grundsätzen, dass Gott sein Wort in Büchern überliefert wissen wollte und dass den Arabern nun auch ein solches Buch in ihrer Sprache anvertraut werden sollte. Gleichwohl lag der Koran zu Lebzeiten Muḥammad s noch nicht als Buch vor, wenngleich die Suren zumindest seit der medinensischen Zeit aufgeschrieben wurden. Diese Aufzeichnungen trugen jedoch in erster Linie privaten Charakter, wichtiger war die Rezitation Suren. Nachdem 633 viele ḥuffāz (Männer, die den Koran verinnerlichen und rezitieren) in den Schlachten, die nach dem Tod des Propheten folgten, gefallen waren, ließ der Kalif Abu Bakr (632-634) die Offenbarungen Muhammad s schriftlich sammeln, um sie zuverlässig zu bewahren. Unter dem Kalifen 'Uțmān ibn- 'Affān (644656) wurde ein für authentisch erklärter Text des Korans vorgelegt. Mit der Verbreitung des Korans und der islamischen Mission in allen Ländern fand die arabische Schrift weite Verbreitung und wurde in unterschiedlichen, nichtarabischen Sprachen benutzt, darunter ins Persische und Türkische.

Hundert Jahre später, nachdem das Abbasidenkalifat (742-1258 n. Chr.) in Bagdad

\footnotetext{
${ }^{82}$ ebd. u. Grohmann, 1971, S. 14.

${ }^{83}$ vgl. Gaur, 1984, S. 97.
} 
errichtet worden war, war die arabische Schrift nicht nur effektiv verbessert worden, sondern man begann Kalligraphie zur Kunstform $\mathrm{zu}$ entwickeln und sie in der arabischen Welt zu etablieren. Mehrere Elemente trugen zu dieser Entwicklung bei: Es gab zu allererst das geheiligte Wesen des Korans selbst. Da der Text eine direkte Offenbarung Gottes war, musste er nicht nur korrekt übertragen werden, sondern in einer Art und Weise, die seinem göttlichen Ursprung im Erscheinungsbild Rechnung tragen sollte, also so schön und tadellos, wie es nur menschenmöglich war $^{84}$. „In diesem Kontext war der Schriftgelehrte, besonders der Schreibkünstler, kein bloßer Bediensteter oder Handwerker mehr, sondern eine Person, die mit dem Willen und den Absichten Gottes in Einklang stand“" ${ }^{\text {85 }}$.

Grabar beobachtet, dass alle unterschiedlichen Entwicklungen der Schriftzeichen, im frühen Stadium der islamischen Zivilisation, tatsächlich eher typologischer als ästhetischer Natur waren. Zwischen dem mittleren 7. und frühen 10. Jahrhundert wurde eine große Anzahl von Schreibschriften entwickelt, die Klarheit durch Standardisierung der Schrifttypen anstrebten ${ }^{86}$, damit beschäftige ich mich ausführlicher im folgenden Abschnitt.

\subsubsection{Arten und Anwendung der arabischen Schrift}

Die Auffassung vom Ideal der vollkommenen Schrift wandelte sich im Laufe der Zeiten. In dieser Entwicklung spiegelte sich auch die Konkurrenz wieder, die zwischen den einzelnen Städten und den Dynastien bestand. In erster Linie regten die Kalifen und Herrscher als Mäzene von Kalligraphen die Entwicklung neuer Schriftarten an, weil es als eine Angelegenheit von hohem Prestige galt, für diese Entwicklung zu sorgen.

Alle arabischen Schriftarten lassen sich hauptsächlich in zwei Grundkategorien unterteilen: Zum einen muqawwar wa-mudawwar (kurvig und rund) das kursiv und einfach zu schreiben war. Zum anderen mabsūt wa-mustaqīm (verlängert und gerade gezeichnet) das eckig und steif war, und aus starken geraden Anschlägen bestand, die meistens rechteckige Buchstaben bilden. Beide Kategorien „entsprechen den zwei Arten der geometrischen Motive, die in abstrakter Dekoration verwendet werden, die eine ist geradlinig (Polygone), die andere kurvenförmig (Spirale und Arabeske)“, sie sind „der

\footnotetext{
${ }^{84}$ vgl. Gaur, 1984, SS. 97 u. 165.

${ }^{85}$ Gaur, 1984, S. 155.

${ }^{86}$ vgl. Grabar: The mediation of ornament, Princeton 1992, S. 66ff.
} 
konkrete Beweis einer unaufhörlichen Suche nach geometrischer Struktur" ${ }^{87}$. Jede Schriftart hatte ihre einzigartigen Eigenschaften und wurde für bestimmte Anwendungen genutzt. Da mit der Zeit jede Schriftart dekorative Variationen entwickelte, wurde der Gebrauch nicht auf das Schreiben des Korans oder amtlicher Urkunden beschränkt, sondern auch für dekorative Zwecke benutzt.

Kalligraphie wurde in der Architektur, besonders im Innenausbau und als Außendekoration von Moscheen und anderen religiösen Gebäuden verwendet. Sie war die Kunstform für dekorative Motive, die unabhängig von der Funktion des Gebäudes verwendet wurden. Sie wurde auf unterschiedlichen Materialien genutzt: Auf Wänden von Gebäuden oder, darin eingearbeitet, auf Keramikplatten und vielen weiteren Gegenstände. Im Islam ist die perfekte Kalligraphie eine Äußerung von Spiritualität, einer inneren Vervollkommnung, die von vollkommener Harmonie mit dem Willen und den Absichten Gottes zeugt. Es hat immer starke Verbindungen zwischen Mystik/Mystizismus und Kalligraphie gegeben, da die Kalligraphen und die Sufis ihre Traditionslinien auf den Vetter Muḥammads, 'Alī ibn Abī Ṭālib, zurückführten ${ }^{88}$.

Ibn Nadīm und Ibn Haldūn konstatieren, dass die frühen Arten der Kalligraphie hauptsächlich mit den Namen bestimmter Städte wie Mekka, Medina, Basra und Kufa verbunden waren ${ }^{89}$. Im Laufe der Zeit beeinflussten sich diese Schreibstile gegenseitig und bildeten eine Vielzahl neuer Formen, die ihrerseits zahlreiche Varianten aufwiesen. Jede dieser Schriften entwickelte ihre Eigenarten, wobei innerhalb einer Schrift eine Vielzahl von Zeichen sich kristallisierte. Diese Vielfalt bildet die Grundlage einer Kunst, die von großen Kalligraphen geschaffen wurde, wie beispielsweise die kufische Schrift. Es handelt sich hierbei um eine breite eckige Schriftform mit horizontal ausgedehnten Linien, die die breiteste Zustimmung als Schrift für das Schreiben des Korans fand.

Unter vielen verschiedenen Schriftarten sind die im Folgenden aufgeführten die am häufigsten verwendeten. Die älteste überlieferte Schrift ist die kufische (Abb. 20). Sie war eine Kombination aus quadratischen und eckigen Linien einerseits und kompakten, fetten und kreisförmigen Formen andererseits. Die vertikalen Linien waren kurz, während die horizontalen lang und ausgedehnt waren. Als das Kufische in der zweiten

\footnotetext{
${ }^{87}$ Papadopulo, Alexandre: Islam and Muslim art, New York 1979, S. 176.

${ }^{88}$ vgl. Gaur, 1984, S. 165.

${ }^{89}$ Khatibi/ Sijelmassi: Die Kunst der islamischen Kalligrafie, Köln 1995, S. 97.
} 
Hälfte des 8. Jahrhunderts seine Vervollkommnung erreichte, ersetzte es andere frühe Versuche der Verbesserung der arabischen Kalligraphie und wurde zur einzigen Schrift, die für die Kopie des heiligen Koran in den folgenden drei Jahrhunderten eingesetzt wurde. Als die kursiven Arten im 10. Jahrhundert populär und verfeinert wurden, zeigte sich dies am Kufischen, indem es viele Qualitäten der kursiven Schriftarten in einer geometrischen Art, „Ostkufisch“ genannt, überbetonte, wobei schlanke vertikale und schräge Striche das früher steifere Kufische beleben. Diese Art war hauptsächlich eine Kalligraphie für Bücher statt einer architektonisch genutzten Kalligraphieart, aber sie war auch auf Keramik sehr beliebt. Auf Baudenkmälern wurden seit dem 8. Jahrhundert der einfachen frühen kufischen Schrift Serifen hinzugefügt und Verzierungen, die der Maserung von Blättern ähnelten, erschienen schon 866 an den Enden der vertikalen Linien $^{90}$. Diesen Verzierungen wurden später runden Strichen hinzugefügt, und dieses dekorierte Kufisch wurde die populärste Form für architektonische Beschriftungen seit dem 10. Jahrhundert.

Seit dem 11. Jahrhundert wurden die Buchstaben verändert und wurden selbst als Verzierungen eingesetzt. Es kamen neue geometrische Elemente in geflochtener Form, wie Knoten und Zöpfe auf. Der übertriebene Gebrauch solcher Verzierungen verursachte komplizierte Zusammensetzungen, die manchmal sehr schwer zu entziffern waren.

Während des 13. und 14. Jahrhunderts entwickelte sich das quadratische Kufische aus dem Gebrauch der Kalligraphie in Gebäuden. Seine einfachen Formen stehen im Gegensatz zur Tendenz, einen komplizierten kalligraphischen Aufbau zu entwickeln. Es war die einzige Art der Kalligraphie, die verwendet wurde, um komplette Gebäude zu bedecken, eine einzigartige Praxis der islamischen Architektur. Viele Schriftarten wurden aus der kufischen Schrift geschaffen, darunter Kufi Basīt (einfaches kufisch), Kufi Murabba' (quadratisches K.), Kufi Handas̄ (geometrisches K.), Kufi Mūṣať (Mossul-K.), Kufi Muḍaffar (geflochtenes K.), Kufi Mutašābik (zusammenklebendes K.) und Kufi al-Mu warraq (Blätter-K.) ${ }^{91}$. Der Kalligraph Kāmil al-Baba sagt über das Mu warraq: Die arabische Schrift verleiht den Buchstaben Leben und macht aus einem leblosen Ding eine Pflanze und aus ihr entspringen Zweige, Blätter und Blüten ${ }^{92}$.

\footnotetext{
${ }^{90}$ vgl. al-'Afîfī, Fawzī Sālim: naš’at wa tạ̦awwur al-kitāba al-ḩaț̣yya al-'arabiyya, Kuwait 1980, S. 139.

$91 \mathrm{ebd}$.

${ }^{92}$ vgl. Zuraiq, Ma'rūf: Kaifa nata'allam al-hatṭ al-'arabī, Damaskus 1999, S. 52.
} 
Die kursiven Stile: Neben der kufischen Schrift, die vor allem für die Niederschrift des Korans und Beschriftungen repräsentativen Charakters verwendet wurden, gab es eine Kursivschrift für informelle Zwecke. Nach Khatibi und Sijelmasi, die hier Ibn Hualdūn folgen ${ }^{93}$ wurde die Kursivschrift nach der Gründung Bagdads (762) besonders in der Kanzlei der Kalifen verwendet. Nach dem arabischen Wort für Kopie, Nash, wurde sie Nashī genannt. Im 10. Jahrhundert stellte Ibn Muqla (886-940) (siehe Abb. 21) Regeln für die Gestaltung der Nash̄̄ auf, die auf dem rhombischen Punkt, dem „Standard“- Alif (') und dem „Standard“-Kreis basierten ${ }^{94}$. Der rhombische Punkt wird gebildet, indem man die Feder diagonal auf dem Papier führt, so dass die Länge der gleichen Seiten des Punktes dieselbe ist wie die Breite der Feder. Das „Standard“-Alif $\left({ }^{\prime}\right)$ ist eine gerade vertikale Linie, der eine bestimmte Anzahl an gesetzten rhombischen Punkten zugehörig ist, die von Scheitelpunkt zu Scheitelpunkt plaziert werden (fünf oder sieben entsprechend der Art) Der „Standard“-Kreis hat einen Durchmesser, der der Länge des „Standard“- Alif $\left({ }^{\prime}\right)$ entspricht. Das ,Standard“- Alif $\left({ }^{\prime}\right)$ und der „Standard“-Kreis liefern auch die grundlegenden geometrischen Formen für die Formgebung der einzelnen Buchstaben $^{95}$. Diese Schrift wurde durch Ibn al-Bawwāb (gest. 1022) zur hatt almansūb al-fầiq (vollkommenes Maß) weiterentwickelt, einem proportionierten Schriftindex, um ein rationales System der Anordnung und Schaffung von Buchstaben zu kreieren. Die Nash̆̄ wurde als eine Kunstform in der Türkei im 16. Jahrhundert verfeinert. Seit damals wurde es im Allgemeinen für das Schreiben des Koran angenommen. Nashī ist klar lesbar und wurde als die bevorzugte Art für das Schriftsetzen und den Druck angepasst. Es ist eine kleine Schriftart, deren Linien dünn und Buchstabenformen rund sind ${ }^{96}$ (Abb. 22).

Die Tulut Schrift (Abb. 22) ist eine eindrucksvollere, prächtige Art der Kalligraphie, die häufig für Titel oder Epigramme anstatt langer Texte verwendet wurde. Seine Formen entwickelten sich über Jahrhunderte und viele Varianten sind auf architektonischen Denkmälern, sowie auf Glas, Metallarbeiten, Gewebe und Holz zu finden. Mamlūk Tulut des 14. Jahrhunderts war wuchtig und groß, während die Osmanen die einfachere, verfeinerte Version bevorzugten, die noch heute praktiziert wird ${ }^{97}$.

Die traditionelle Klassifikation der Hauptarten umfasst weiter Muhaqqiq, das weniger

\footnotetext{
${ }^{93}$ Zuraiq, 1999, S. 97.

${ }^{94}$ vgl. Gaur, 1984, S. 166.

95 ebd., Abb.16.

${ }^{96}$ vgl. al-'Afïfì, 1980, S. 147.

${ }^{97}$ vgl. al-'Afífí, 1980, S. 149.
} 
rund als Tulut ist; Rayhani, das einem kleinen Muhaqqaq ähnlich ist, sowie Tawqī viele Ligaturen hat. Alle diese Schriften werden heutzutage nur noch selten verwendet.

Die Riq'a-Schrift: die einfachere Art des alltäglichen Schriftgebrauchs, ist sehr zweckmäßig und einfach zu schreiben ${ }^{98}$. Sie ist heute die gebräuchlichste Schriftform, um arabisch zu schreiben (Abb 22).

Die Nasta Tiq-Schrift: entwickelte sich im Iran während des 14. und 15 Jahrhunderts. Es ist von den hier behandelten Schriftarten die flüssigste und ausdrucksvollste ${ }^{99}$ und wird weitgehend verwendet, um die romantischen und mystischen persischen Epen zu kopieren. Nasta \iq hat sehr kurze vertikale Linien ohne Serifen und tief gebogene Horizontalen. Es liegt, im Gegensatz zu allen anderen Arten, die schräg nach links liegen, eher rechts (Abb. 22).

Die Dīwāni-Schrift (von persischem Diwan „Hof“ trat nach dem Jahr 857 der Higra (1453) auf und wurde von Ibrāhīm Munīf kodifiziert (Abb. 23, obere Zeile) ${ }^{100}$. Dìwānn̄ wurde vor allem zum Niederschreiben offizieller Dokumente benutzt.

Die Dīwānn̄ Gallī -Schrift: Sie entwickelte sich aus der Dīwānī und wird zwischen zwei parallelen Linien geschrieben, wobei kein Buchstabe die Höhe von Alif (') übersteigt. Sie wird mit zwei Federn geschrieben, die eine ist breit, die andere misst ein Viertel der Breite die ersten. Die Lücke zwischen den Buchstaben wird durch Vokalisierung, Punkte und Verzierung gefüllt. Sie ist eine ungebräuchliche Schrift (Abb. 23, untere Zeile).

Eine Sonderform der Schrift bildete die Tugrää, (siehe Abb. 24) die als Unterschriften der politischen Machthaber verwendet wurde. Theoretisch sollte es unmöglich sein, sie nachzuahmen. Sie tauchte erstmals nach der Eroberung Konstantinopels durch den Osmanen Moḥammed al-Fātạ̣ (807/1453) auf ${ }^{101}$.

${ }^{98}$ vgl. al-'Afífì, 1980, S. 153.

${ }^{99}$ vgl. al-'Afífî, 1980, S. 161.

${ }^{100}$ vgl. Khatibi/Sijelmasi, 1976, S. 164.

${ }^{101}$ vgl. Khatibi/Sijelmasi, 1995, S. 81 u. Abb. 19. 


\subsection{Das Verhältnis der monotheistischen Religionen zur bildenden Kunst}

Jede Religion gebraucht die Künste als Ausdrucksmittel, wobei sie unterschiedliche Affinitäten zu den verschiedenen Künsten haben. Der Katholizismus der Barockzeit etwa stellte Malerei, Plastik, Musik, Architektur und Dichtung gleichermaßen in seinen Dienst. Seit dem 19. Jahrhundert besteht demgegenüber in der europäischen Kunst die Tendenz, sich von der Rolle als Dienerin der Religion zu emanzipieren. Dagegen sah Richard Pousette-Dart (1916-1992), ein Vertreter der „New York School“, Kunst und Religion als ein und dasselbe an. „My definition of religion amounts to art and my definition of art amounts to religion. I don't believe you can have one significantly without the other. Art and religion are the inseparable structure and living adventure of the creative" 102 .

Die monotheistischen Religionen (die nachislamischen monotheistischen Religionen bleiben wie die zoroastrische Religion in diesem Zusammenhang unberücksichtigt) haben den Anspruch, auf eine Botschaft Gottes an die Menschen zurückzugehen. Dieses ursprünglich gesprochene Wort wurde in einem heiligen Buch oder mehreren heiligen Büchern aufgeschrieben. So verwundert es nicht, dass Sprache und Schrift als Träger des göttlichen Wortes Gegenstand besonderer Pflege sind. Demgegenüber ist das Verhältnis der monotheistischen Religionen zur bildenden Kunst spannungsgeladen.

Der folgende Abschnitt vergleicht die Haltung der drei monotheistischen Religionen Judentum, Christentum und Islam zur bildenden Kunst. Es sollen die Gründe des Verbots von Bildern im Alten Testament und die Auffassung des Christentums diesbezüglich erläutert werden. Ferner soll der Haltung des Islam nachgegangen werden. Hier werde ich auf die Schriftkunst und die Wandbilddekoration in den islamischen Gebetshäusern eingehen und die religiöse Begründung hierfür vorstellen. Schließlich werde ich mich mit der Frage auseinandersetzen, warum später in islamischen Gebäuden doch Wandbilder zum Vorschein kamen.

${ }^{102}$ Pousette-Dart, Richard: What is the relationship between Religion and Art?, Vortrag im Union Theological Seminary am 2. Dezember 1952, zitiert nach: Tuchman, Maurice (Hrsg.): New York School. The first generation. Paintings of the 1940s and 1950s, Los Angeles 1965, S. 26 f. 


\subsubsection{Das Judentum und die Kunst}

Die kritische Religionsgeschichte Israels seit dem 19. Jahrhundert, insbesondere die Arbeiten Julius Wellhausens (1844-1918), haben ergeben, dass diese Geschichte anders verlaufen ist, als sie in den geschichtlichen Büchern des Alten Testaments (1. Mose bis Nehemia) dargestellt wird. Nach dem Bericht der Bibel habe Gott (JHWH) Abraham erwählt (1. Mose 12, 1-3) und einen Bund mit ihm geschlossen (1. Mose 15, 18). Diesen Bund habe er später mit dem Volk Israel am Sinai erneuert (2. Mose 24, 3-8) und die Israeliten damit auf den Monotheismus und einen bilderlosen Kult verpflichtet. Nachdem sie Kanaan erobert hatten, seien die Israeliten immer wieder periodisch in Fremdgötter- und Bilderdienst verfallen (Richter 2, 11-13 und öfter). Den Monotheismus und den bilderlosen Kult habe erst König Josia (639-609 v. Chr.) durchgesetzt und erst seit der Zeit Nehemias (445-433 v. Chr.) und Esras (458 oder 398 v. Chr.) sei die Befolgung der Thora gesichert.

Die historisch-kritische Forschung kam demgegenüber zu dem Ergebnis, dass in der Frühzeit Israels bis in die Zeit des babylonischen Exils (587-539 v. Chr.) neben der Verehrung JHWHs der Kult anderer Götter völlig selbstverständlich war und Bilder auch zum JHWH-Kult gehörten. Explizit wird die Existenz eines Kultbildes im JHWHKult in der vorstaatlichen Zeit (vor ca. 1000 v. Chr.) erwähnt, wo die Mutter eines Ephraimiten namens Micha 1.100 Silberstücke für JHWH weiht: „Ich weihe nun das Geld dem HERRN; es kommt aus meiner Hand für meinen Sohn, damit man ein geschnitztes und gegossenes Bild davon machen soll“" (Richter 17,3).

Nach König Salomos Tod (926 v. Chr.) zerfiel das Reich Davids in die zwei Teile Juda mit der Hauptstadt Jerusalem und der davidischen Dynastie im Süden und Israel mit wechselnden Hauptstädten und Dynastien im Norden. Jerobeam I. (926-907 v. Chr.), der erste König Israels errichtete zwei Staatsheiligtümer an den Grenzorten seines Landes, Bethel und Dan. „Und der König hielt einen Rat und machte zwei goldene Kälber und sprach zum Volk: Es ist zuviel für euch, dass ihr hinauf nach Jerusalem geht; siehe, da ist dein Gott, Israel, der dich aus Ägyptenland geführt hat" (1. Könige 12,29). Mit der Weiheformel ,siehe, das ist dein Gott, Israel, der dich aus Ägyptenland geführt hat", ist offensichtlich, dass die Stierfiguren JHWH nicht ersetzen sollten. Eher muss man sich vorstellen, dass sie als Podest oder Thron für JHWH dienten, also dieselbe Funktion erfüllten wie die Cherubim (siehe unten) im Tempel von Jerusalem. 
Der Priesterschaft in Jerusalem erschien später die Errichtung der konkurrierenden Staatsheiligtümer als der religiöse Frevel schlechthin.

Während der unruhigen Zeit der assyrischen Expansion nach Syrien und Palästina in der zweiten Hälfte des 8. Jahrhunderts v. Chr. wirkte der Prophet Hosea. Er formulierte den frühesten literarisch bezeugten Exklusivitätsanspruch JHWHs: „Ich aber bin der HERR, dein Gott, von Ägyptenland her, und du solltest keinen andern Gott kennen als mich und keinen Heiland als allein mich“ $(13,4)$. Hosea vergleicht das Verhältnis JHWHs und Israels mit einer Ehe. JHWH ist der Mann, Israel die Frau und die Baal-Gottheiten Liebhaber, mit denen Israel Ehebruch begeht (1,2.7-15). Zur verwerflichen Kultpraxis wurde von Hosea auch das Opfer auf Bergen, die „Höhen“ in den Geschichtsbüchern gezählt, unabhängig davon, wem sie dargebracht wurden $(4,13)$, zugleich ist Hosea der erste, der explizit Kultbilder verwirft: „Aus ihrem Silber und Gold machen sie Götzen, (...)Ein Goldschmied hat das Kalb gemacht, und es kann doch kein Gott sein; darum soll das Kalb Samarias zerpulvert werden“ (8,6 f.). Das Schicksal des „goldenen Kalbes“ (2. Mose 32) nimmt offenkundig das Schicksal der übrigen Götterbilder vorweg.

Den Juden soll das Geschick der Nordstämme, die wegen ihres Götzendienstes aus der Geschichte verschwanden, als Warnung vor Augen stehen. Deshalb werden Bilder so eindringlich verboten: "Du sollst dir kein Bildnis noch irgendein Gleichnis machen, weder von dem, was oben im Himmel, noch von dem, was unten auf Erden, noch von dem, was im Wasser unter der Erde ist: Bete sie nicht an und diene ihnen nicht! Denn ich, der HERR, dein Gott, bin ein eifernder Gott, der die Missetat der Väter heimsucht bis ins dritte und vierte Glied an den Kindern derer, die mich hassen, “ (2. Mose 20, 35). Weitere Stellen im Alten Testament verbieten die Anbetung von Statuen (hebräisch päsäl) ausdrücklich, beispielsweise 5. Mose 27,15.

Es lässt sich feststellen, dass die Verbote in zwei Richtungen ausgesprochen werden. Erstens gegen die Herstellung von Statuen, die Gott darstellen, zweitens gegen das Anbeten jeglicher Darstellung, weil sie für das Dargestellte genommen wird. So wird darauf hingewiesen, dass es bei der Ausführung ritueller Gebete keiner bildlichen Darstellung Gottes bedarf. Der Grund des Verbots ist die Natur Gottes, die nicht materiell darstellbar ist, und was materiell dargestellt werden kann, ist nicht göttlich. Dem Propheten Jeremia zufolge sind Götterbilder „nichts als Vogelscheuchen im 
Gurkenfeld. Sie können nicht reden; auch muss man sie tragen, denn sie können nicht gehen“(Jeremia, 10, 5).

Wir sehen hier deutlich, dass Gott offensichtlich die Verehrung von Götzen verabscheut, jedoch kann man trotzdem feststellen, dass Bild und Statue eine religiöse Rolle einnehmen. So befiehlt Gott Mose am Sinai im Zusammenhang mit der Bundeslade, zwei goldene Cherubim herzustellen: „Und du sollst zwei Cherubim machen aus getriebenem Golde an beiden Enden des Gnadenthrones, so dass ein Cherub sei an diesem Ende, der andere an jenem, dass also zwei Cherubim seien an den Enden des Gnadenthrones. Und die Cherubim sollen ihre Flügel nach oben ausbreiten, dass sie mit ihren Flügeln den Gnadenthron bedecken und eines jeden Antlitz gegen das des andern stehe; und ihr Antlitz soll zum Gnadenthron gerichtet sein“(2. Mose 25, 18 -20). Die Cherubim stellen geflügelte Mischwesen dar, zwischen deren Flügeln Gott thronend gedacht wird.

Neben der Verfertigung der Cherubim wird noch ein anderes Bild mit Mose in Verbindung gebracht: „Da sprach der Herr zu Mose: Mache dir eine eherne Schlange und richte sie zum Zeichen auf; wer gebissen ist und siehet sie an, der soll leben. Da machte Mose eine eherne Schlange und richtete sie auf zum Zeichen; und wenn jemanden eine Schlange biss, so sah er die eherne Schlange an und blieb leben“"(4. Mose 21, 8 f). Wie aus 2. Könige 18, 4 hervorgeht, wurde diese Schlange im Tempel von Jerusalem durch Rauchopfer verehrt, bis König Hiskia (725 - 697 v. Chr.) sie zerstören ließ.

Der jüdische Geschichtsschreiber Josef Ben Matitjahu (d. i. Flavius Josephus, 37- nach 93) legt in seinen „Jüdischen Altertümern“ das Bilderverbot dahin aus, „dass man keines Tieres Bild anbeten darf“ (Ant III 5,5). Josephus, der für ein griechisches Publikum schrieb, scheint in die griechische Polemik gegen die ägyptische Sitte, die Götter in Tiergestalt zu verehren, einzustimmen. In einem anderen Werk „Über das hohe Alter gegen das jüdische Volk gegen Apion“ spottet er über die Götter, „die bei den Ägyptern als solche galten, der Stier, der Bock, Krokodile und Hundsaffen“ (Ap I, 28). In den „Altertümern“ erwähnt Josephus mehrmals, wie religiös-politsche Unruhen ausbrachen, wenn sich Juden durch die Verletzung des Bilderverbotes provoziert 
fühlten ${ }^{103}$.

Ausführlich behandelt der Traktat Avoda Zara des Talmud den Götzendienst und die Aspekte, die mit ihm zusammenhängen. „Alle Götzenbilder sind verboten, weil sie einmal im Jahr verehrt werden - Worte von Rabbi Me'ir. Und die Weisen sagten: es ist nur jedes verboten, in dessen Hand ein Stab, ein Vogel oder eine Kugel ist. Rabban Shim'on-ben-Gamli'el sagte: jedes, in dessen Hand irgendeine Sache ist" (Avoda Zara 3,1). Rabbi Me'ir verbietet also den Gebrauch von Bildern, insofern sie wenigstens einmal jährlich kultisch verehrt werden. Rabbinischer Konsens ist dagegen, dass nur Statuen der römischen Kaiser, die durch Zepter (Stab), Adler (Vogel) oder (Welt-) Kugel in der Hand als solche ausgewiesen sind, verboten sind, während Rabban Gamli'el das Verbot noch verschärft. Dass die Rabbinen das Bilderverbot nur auf Plastiken bezogen, zeigen bildliche Darstellungen in antiken Synagogen. In Dura Europos am Euphrat wurde eine Synagoge aus dem 3. Jahrhundert ausgegraben, in der die die Thora-Nische umgebende Wand mit biblischen Szenen bemalt war. Aus dem 6. Jahrhundert stammen Reste einer Synagoge in Beth-Alfa (Israel), deren Fußboden mit einem Mosaik geschmückt war, das im unteren Teil die Opferung Isaaks und im oberen Teil die Sonne von den zwölf Tierkreiszeichen und den vier Jahreszeiten umgeben zeigte. Dabei wurde die Sonne als Helios, der den Sonnenwagen lenkt, dargestellt. Offenbar wurde es nicht als problematisch empfunden, eine griechische Gottheit abzubilden, wenn sie lediglich als allegorischer Schmuck angesehen wurde. Für das Judentum im Mittelalter war charakteristisch, dass die Juden im muslimischen Machtbereich das islamische Bilderverständnis übernahmen und - abgesehen von Buchillustrationen - auf die Darstellung von Tieren und Menschen verzichteten. Im christlichen Machtbereich verzichteten die Juden auf Bilder, weil sie die christliche Bilderverehrung als Götzendienst ansahen. Mit der jüdischen Reformbewegung im 19. Jahrhundert entspannte sich das Verhältnis des Judentums zur bildenden Kunst wieder. Der bekannteste jüdische Maler des 20. Jahrhunderts, der religiöse Themen in seinem Werk aufgriff, war Marc Chagall (1887-1985).

\subsubsection{Das Christentum und die Kunst}

Die Auffassung über die Legitimität bildlicher Darstellungen in Kirchen differiert

${ }^{103}$ Um 4 v. Chr. unter Herodes I. (Ant XVII,6,2), um 26 n. Chr. unter Pontius Pilatus (Ant XVIII,3,1) und ca. 38 unter Caligula (Ant XVIII,8). 
zwischen den Kirchen östlicher und westlicher Tradition. Innerhalb der Ostkirchen lässt sich weiterhin ein Unterschied zwischen den so genannten altorientalischen Nationalkirchen (Ost- und Westsyrer, Kopten, Armenier und Äthiopier) und den Kirchen byzantinischer Tradition feststellen. Innerhalb der westlichen Kirchen bestehen Unterschiede zwischen der katholischen Kirche und den verschiedenen protestantischen Kirchen. Darüber hinaus unterscheiden sich im Protestantismus die Bilderfeindlichkeit zwinglischer und die wohlwollende Neutralität lutherischer Tradition.

Der Gebrauch von Gemälden im Katholizismus und der Orthodoxie wird von den Protestanten als Verstoß gegen biblische Aussagen gesehen. Insbesondere die Praxis der Verehrung von Heiligenbildern stößt dort auf Ablehnung. Für die Protestanten stellt dies eine Vergötterung sowohl der Bilder als auch der abgebildeten Personen dar, die von Gott in der Heiligen Schrift verurteilt wird, speziell durch das zweite Gebot. Die katholische Kirche betont auf der anderen Seite, dass solche Bilder ein Teil einer neuen Haltung sind, die jetzt von Gott angesichts der Wahrheit der Inkarnation Christi erlaubt wird.

Das Christentum hat die heidnischen Götter als Dämonen abgelehnt. Daraus folgte die Ablehnung des heidnischen Kultus. „Aber wir ehren auch nicht mit vielerlei Opfern und Blumengewinden die, welche Menschen gebildet, in Tempeln aufgestellt und Götter genannt haben - wir glauben nämlich, dass die Gottheit nicht die Gestalt hat, in der man sie zum Zwecke der Verehrung abgebildet hat -, dass sie vielmehr Namen und Formen jener sichtbar erschienenen bösen Dämonen haben“" ${ }^{104}$. Bischof Theophilus von Antiochia schreibt um 180 an Autolykos: „Das göttliche Gesetz also verbietet nicht bloß, die Götzenbilder, sondern auch die Himmelskörper, Sonne, Mond und die übrigen Gestirne, anzubeten, ebenso dem Himmel, der Erde, dem Meere oder den Quellen oder Flüssen göttliche Ehre zu erweisen, sondern nur dem wahren Gott und Schöpfer des Alls darf man göttliche Ehre erweisen in Heiligkeit des Herzens und aufrichtiger Gesinnung“6105.

Die Anfänge einer christlichen bildenden Kunst lassen sich seit ca. 200 in den Wandmalereien der Katakomben nachweisen. Die ältesten Darstellungen sind Oranten

\footnotetext{
${ }^{104}$ Justinus, Erste Apologie 9, ebd.

1053 Bücher an Autolykos II, 35, in: Theophilus von Antiochia, übersetzt von J. Leitl und Andreas Freiherrn di Pauli. Frühchristliche Apologeten und Märtyrerakten Bd. II, Bibliothek der Kirchenväter Bd. 14, München 1913, S. 12-106.
} 
und Philosophen als Sinnbild für Frömmigkeit und Weisheit, die auch Porträtzüge der Verstorbenen aufweisen können, der Hirte als Symbol für Christus, Szenen aus dem Alten Testament, vornehmlich die Rettung Noahs aus der Sintflut, die Opferung Isaaks sowie Jona und der Fisch; hinzu kommen Szenen aus dem Neuen Testament, besonders Darstellungen von Jesu Speisungs-, Heilungs- und Auferweckungswundern, außerdem Propheten, Apostel, Heilige und Bischöfe ${ }^{106}$. Allen szenischen Bildern ist gemeinsam, dass sie sich auf die Auferstehungshoffnung beziehen ${ }^{107}$. Eine Verehrung von Bildern wird zuerst gnostischen Häretikern zugeschrieben. Gegen die kultische Verehrung der Bilder sprach sich 306 der Kanon 36 der Synode (Bischofsversammlung) von Elvira in Spanien aus: „Placuit picturas in ecclesia non esse debere, ne quod colitur et adoratur in parietibus depingatur (Man befindet für gut, dass Gemälde in Kirchen nicht sein dürfen, damit nicht das, was auf den Wänden gemalt ist, verehrt oder angebetet wird)“(108. Papst Gregor I. (590-604) bezeichnete die Bilder als Bücher für Analphabeten, die aus ihnen den Inhalt der biblischen Geschichten lernen konnten. „Uns war ... berichtet worden, Du habest ... Heiligenbilder mit der vorgeblichen Entschuldigung, sie dürften nicht angebetet werden, zerbrochen. Und zwar heißen Wir durchaus für gut, dass Du verboten hast, dass sie angebetet werden; dass Du sie aber zerbrochen hast, tadeln Wir. ... Es ist nämlich etwas anderes, ein Bild anzubeten, als durch das, was das Bild erzählt, zu lernen, was anzubeten ist. Denn was für die, die lesen können, Schrift ist, das leistet für die Ungebildeten das Bild, weil in ihm Unkundige sehen, wonach sie trachten sollen, in ihm lesen, die die Buchstaben nicht kennen; daher steht auch vornehmlich für die Völker anstelle des Lesens das Bild. ... Wenn einer Bilder herstellen will, untersage es keinesfalls; Bilder anzubeten aber vermeide in jeder Weise ${ }^{\text {(109. }}$.

Zwischen dem 5. und 7. Jahrhundert entstand im christlichen Osten ein neuer Bildertyp, die Ikone, d.h. ein Tafelbild, welches das Porträt Christi oder eines Heiligen zeigt, der im Bild als anwesend gedacht wird. Diese Bilder wurden verehrt, indem man sie küsste, vor ihnen niederfiel oder vor ihnen Kerzen und Weihrauch anzündete. Theologisch reflektiert wird die Bilderverehrung zunächst in der polemischen Literatur gegen das Judentum: Auch die Juden kennen bildliche Darstellungen, wie die Cherubim auf der

${ }^{106}$ vgl. Thümmel, 1980, S. 530.

${ }^{107}$ vgl. Thümmel, Hans-Georg: Art. Bilder IV. Alte Kirche, in: Theologische Realenzyklopädie (TRE) Bd. VI, Berlin 1980, S. 525-531, hier S. 527.

${ }^{108}$ Kanones der Synode von Elvira, in: Migne, Jaques-Paul: Patrologiae cursus completus. Series latina Bd. 84, Paris 1862, S. 302-310, hier S. 306.

${ }^{109}$ Gregor I.: Brief an Serenus v. Marseille, in: Denzinger, Heinrich: Kompendium der Glaubensbekenntnisse und kirchlichen Lehrentscheidungen. Verbessert, erweitert, ins Deutsche übertragen und unter Mitarbeit von Helmut Hoping herausgegeben von Peter Hünermann, 39. Aufl. Freiburg, 1991, S. 216 f. 
Bundeslade, und verehren materielle Dinge, wie die Thora-Rolle. Die Christen dagegen haben den Anspruch, nicht den materiellen Gegenstand, sondern die durch ihn dargestellte geistige Wirklichkeit verehren ${ }^{110}$.

Im 8. und 9. Jahrhundert wurden die griechische und die lateinische Kirche vom Bilderstreit (Ikonoklasmus) erschüttert, wodurch sich die Kirche genötigt sah, den Gebrauch der Bilder theologisch zu überdenken ${ }^{111} .726$ verbot Kaiser Leon III. (717741) die Bilderverehrung. Auf seiner Seite standen die Bischöfe und das Heer, während das Kirchenvolk unter Führung der Mönche den bisherigen Brauch der Bilderverehrung verteidigte. Es ist interessant, dass das Bilderverbot in den Patriarchaten von Alexandria, Antiochia und Jerusalem, die unter muslimischer Herrschaft standen, nicht ausgesprochen wurde. Auch die Häupter des westlichen (lateinischen) Patriarchats, die Päpste Gregor II. (715-731) und Gregor III. (731-741) widersetzten sich dem Bilderverbot. Kaiser Konstantin V. (741-755) ließ 754 auf einer Synode in Konstantinopel die Bilderverehrung erneut verurteilen. Kaiserin Irene (780-802) ließ im Einvernehmen mit Papst Hadrian I. (772-795) durch das siebte ökumenische Konzil (787) die Bilderverehrung wieder zulassen. Das Konzil unterschied zwischen der erlaubten Verehrung (douleia) und der verbotenen Anbetung (latreia) der Bilder. Bezüglich der Christusdarstellungen lehrte das Konzil, dass Gott selbst über allen möglichen Beschreibungen oder Darstellungen steht, aber da das göttliche Wort die menschliche Natur nach sich zog, wurde es durch die göttliche Schönheit in seine ursprüngliche Form zurückgeführt. Gott kann und muss durch das menschliche Bild Christi verehrt werden ${ }^{112}$. Die Darstellbarkeit Christi ist also die Folge seiner Inkarnation.

Die Ikonoklasten wurden vom biblischen Bilderverbot beeinflusst. Sie leiteten ihre Abneigung von den Gefahren, die sie in der Bildverehrung sahen, ab. Mit der Abschaffung der Bilder konnten sie zugleich dem Vorwurf der Muslime, Götzendienst zu betreiben, entgehen. Daher haben sie ihre Sicht vorgetragen, welche besagte, dass Christus nicht bildlich dargestellt werden sollte. Das Zeichen des Kreuzes würde ausreichen ${ }^{113}$. 843 endete der Bilderstreit mit dem endgültigen Sieg der Ikonenbefürworter über die Ikonolasten. Die Ikonophilen sahen in der Ikonenverehrung

\footnotetext{
${ }^{110}$ vgl. Thümmel: Art. Bilder V/1. Mittelalter, Byzanz, in: TRE VI, S. 532-540, hier S. 534.

${ }^{111}$ vgl. Heussi, Karl: Kompendium der Kirchengeschichte, 5. Aufl. Tübingen 1922, S. 132.

112 vgl. Burckhardt, Titus: Art of Islam, London 1976, S. 29.

113 vgl. Bahnasī, 2001, S. 62.
} 
einen Ausdruck christlicher Freiheit ${ }^{114}$. In der Orthodoxie werden die Ikonen nicht als Kunstwerke gesehen, in denen die schöpferische Freiheit des Künstlers zum Ausdruck kommt, sondern als „Fenster zum Himmel“, die die unsichtbare göttliche Realität sichtbar machen. Deshalb müssen sich die Ikonenmaler an einen von der kirchlichen Tradition vorgeschriebenen Formenkodex halten und sich mit Gebet und Fasten auf die Verfertigung der Ikonen vorbereiten. Die Ikonen sind erst dann „fertig“, wenn sie geweiht werden, wodurch gewissermaßen das himmlische Urbild in das irdische Abbild einzieht.

Die westliche (lateinische) Kirche war während des ikonoklastischen Streites gespalten. Befürworteten die Päpste, wie oben gezeigt, die Bilderverehrung, stand der Frankenkönig Karl (768-814) auf Seiten der Bildergegner. Auf dem siebten ökumenischen Konzil waren die fränkischen Bischöfe nicht vertreten. In einer Denkschrift, die wahrscheinlich am Hofe Karls entstand, den ,libri carolini“, wurde die Bilderverehrung verurteilt, (,Wir haben die Bilder als Schmuck in den Kirchen und zum Gedächtnis an die Geschichten; wir beten Gott allein an und zollen seinen Heiligen die passende Verehrung; so sind wir weder mit jenen Bilderzerstörer noch mit diesen Bilderanbeter“) ${ }^{115}$, ebenso 794 auf einer fränkischen Reichssynode in Frankfurt am Main. Im Westen verstummte der Widerspruch gegen die Bilderverehrung im 11. Jahrhundert $^{116}$. Das erneute Aufkommen der Bilderverehrung im Westen seit dem 12. Jahrhundert hatte den Wunderglauben zur Voraussetzung. Christus-, Marien- und Heiligenbilder wurden verehrt, weil sie als wundertätig galten und die Gläubigen sich weitere Wunder, meistens Krankenheilungen, erhofften ${ }^{117}$. In der Zeit der Gotik, deren Beginn mit dem Bau der Abteikirche von St. Denis bei Paris (1140-1144) zusammenfiel, traten Maler und Bildhauer erstmals in der christlichen Kunst als schöpferische Einzelpersönlichkeiten auf, wie die Bildhauer Niccolo Pisano (gest. ca. 1280) und sein Sohn Giovanni Pisano (gest. nach 1320) und der Maler Giotto di Bondone (gest. 1336). In der französischen und deutschen Kirchenbaukunst führte die Auflösung der Wände als tragende Bauelemente zur Verdrängung der Wand- durch die Fenstermalerei ${ }^{118}$. Seit dem 14. Jahrhundert verdrängte in Italien ein neues Lebensgefühl des Genusses der Schönheit der Welt den mittelalterlichen Geist der

\footnotetext{
${ }^{114}$ vgl. Ipsiroglu: M.S: Masterpieces from the Topkapi museum, painting and miniatures, London 1980, S. 81.

${ }^{115}$ Loewenich, Walther von: Art. Bilder V/2, in : TRE VI; S. 540-546, hier S. 542.

${ }^{116}$ vgl. Heussi, 1922, S. 137.

117 vgl. Heussi, 1922, S. 184.

118 vgl. Heussi, 1922, S. 194.
} 
Weltverneinung. In der Plastik wurde auf die Formen der griechisch-römischen Antike zurückgegriffen. Donatello (gest. 1466) schuf erstmals seit Jahrhunderten Statuen völlig nackter Menschen (z. B. David). In der Malerei repräsentieren Masaccio (1401-1428), Fra Angelico (gest. 1455) Sandro Botticelli und andere den neuen Kunststil ${ }^{119}$.

Theologisch überschritt die römische Kirche nicht die 787 gezogenen Grenzen. Das Zweite Vatikanische Konzil bestimmte über die Bilder in Abschnitt 125 der Konstitution „Sacrosanctum Concilium“vom 4. 12. 1963: „Firma maneat praxis, in ecclesiis sacras imagines fidelium venerationi proponendi; attamen moderato numero et congruo ordine exponantur, ne populo christiano admirationem inficiant, neve indulgeant devotioni minus rectae (Die Praxis, in den Kirchen geweihte Bilder für die Verehrung der Gläubigen aufzustellen, bleibe fest; trotzdem sollen sie in mässiger Zahl und in harmonischer Ordnung aufgestellt werden, damit sie nicht die Bewunderung des christlichen Volkes verderben, noch sollen sie weniger richtige Verehrung gestatten) $)^{6120}$.

Die lutherischen Kirchen stehen Bildern in den Kirchen, sofern sie nicht verehrt werden, indifferent gegenüber. Martin Luther (1483-1546) behandelte in seiner Vorlesung über den Römerbrief (1515/16) das Bilderverbot. In der Auslegung von Röm 14,1 erklärte er: „In Noua Lege omnia sunt Libera et nulla necessaria ii, qui credunt in Christo (Im neuen Gesetz sind denen, die an Christus glauben, alle Dinge freigestellt und keine notwendig)“121. Daher seien Bilder, obwohl die bisherige Praxis missbräuchlich sei, weder heilsnotwendig noch verboten. Am 6. Februar 1522 wurden die Kirchen in Wittenberg durch eine Volksmenge gestürmt. Altäre, Bilder, Statuen, Fenster und Orgeln, wurden dabei zerstört oder beschädigt. Nach seiner Rückkehr von der Wartburg am 6. März 1522 nahm Luther in seinen Predigten vom Dienstag und Mittwoch nach Invocavit (11. und 12. März) zum Bildersturm Stellung. Die Bilder seien „unnötig“. Dennoch sei es „frey gelassen sie zu haben oder nicht zu haben“, um der bisherigen Missbräuche wegen, die mit der Bilderverehrung verbunden seien, wäre es jedoch besser, „wir hetten derselbigen Bilder gar keines“"122. Abschließend setzte sich Luther in der Schrift „Wider die himmlischen Propheten, von den Bildern und Sakrament“ vom

\footnotetext{
${ }^{119}$ vgl. Heussi, 1922, S. 220 ff.

${ }^{120}$ Acta Apostolicae Sedis Bd. 56, Rom 1964, S. 126.

${ }^{121}$ Luther, Martin: Vorlesung zum Römerbrief, in: Luthers Werke in kritischer Gesamtausgabe (WA) Bd. 56, Weimar 1938, S. $493 \mathrm{f}$.

${ }^{122}$ Luther: Predigt am Dienstag nach Invocavit (11. März), in: Predigten des Jahres 1522, WA Bd. 10, Abt.III, Weimar 1905, S. 21-30, hier S. 26.
} 
26. Februar 1525 mit den Bilderstürmern auseinander. Durch die Predigt des Wortes Gottes sollten zunächst die Gläubigen das Bedürfnis nach Bildern verlieren, anschließend könne man sie als unschädlich beibehalten oder aber als unnütz durch die Obrigkeit entfernen lassen. Es sei wichtiger, die Götzen aus dem Herzen, als aus den Kirchengebäuden zu entfernen ${ }^{123}$. Die Bilder seien „nicht alleine zu dulden“, sondern „löblich und ehrlich“"124, wenn sie an das Heilswerk Christi und an den Glauben der Heiligen erinnerten. Insbesondere sollten solche Bilder verbreitet werden, die die biblische Geschichte illustrierten ${ }^{125}$. Die Bekenntnisschriften der evangelischlutherischen Kirchen erwähnen die Bilderverehrung beiläufig in Artikel 21 der Apologie der Augsburgischen Konfession (1531), der sich eigentlich mit der Heiligenverehrung befasst. Die Missbräuche und Auswüchse der Bilderverehrung seien nur ein Spiegelbild einer verkehrten Auffassung von den Heiligen gewesen. „Und ob solcher Greuel, solch Abgötterei, Wallfahrten und Betrug mit den Bildern unzählig und unsäglich nicht gewesen, so sind doch noch gräulicher und hässlicher gewesen die vielen Fabeln und Lügen der Legenden von Heiligen, welche man öffentlich geprediget ${ }^{\star 126}$.

Im Gegensatz zur lutherischen Kirche lehnt die reformierte Kirche bildliche Darstellungen in den Kirchengebäuden ab. Huldrych Zwingli (1484-1531), der Reformator Zürichs, war der Auffassung, dass das Verbot der Bilderverehrung in der Bibel so aufzufassen sei, dass in Kirchenräumen überhaupt keine bildlichen Darstellungen zulässig seien. Im August und September 1523 kam es in der Umgebung Zürichs zu einem Bildersturm. Auf Veranlassung des großen Rates von Zürich fand vom 26. bis 28. Oktober eine Disputation über Bilder und die Messe statt. Das Ergebnis der Disputation war die Empfehlung, die Bilder aus den Kirchen zu entfernen ohne Aufsehen zu erregen ${ }^{127}$. Nach weiteren Unruhen (Dezember 1523 in Zürich, Pfingsten 1524 in Zollikon) beschloss der Rat in der zweiten Maihälfte 1524, Privatpersonen, die Bilder gestiftet hatten, acht Tage Zeit zu geben, sie aus den Kirchen zu entfernen. Danach sollten gestiftete Bilder von den Sigristen (Küstern) entfernt und verwahrt werden. Aus dem Gemeindevermögen beschaffte Bilder sollten nach Mehrheitsbeschluss der Gemeinden entfernt werden, die Neuaufstellung von Bildern

${ }^{123}$ vgl. Luther: Wider die himmlischen Propheten, von den Bildern und Sakrament, in: WA Bd. 18, Weimar 1908, S. 37-214, hier S. 72 f..

${ }^{124}$ Luther, 1908, S. 74.

${ }^{125}$ vgl. Luther, 1908, S. 83.

${ }^{126}$ Die Bekenntnisschriften der evangelisch-lutherischen Kirche, 5. Aufl. Göttingen 1982, S. 324.

${ }^{127}$ vgl. Zwingli: Die Akten der zweiten Disputation vom 26.-28. Oktober 1523, in: Zwingli, Werke Bd. 2 , Berlin, S. 730. 
wurde verboten. Eventuell in den Kirchen belassene Bilder sollten weder durch Kerzen, Weihrauch oder auf eine andere Weise verehrt werden ${ }^{128}$. Am 15. Juni ordnete der Rat die Entfernung aller Bilder aus den Kirchen an, die im „Götzenkrieg“ vom 20. Juni bis 2. Juli im Stadtgebiet Zürichs, später auch in den Landgemeinden stattfand. Später wurde der Verzicht auf Bilder in den Kirchen von den Mennoniten, Baptisten, Methodisten und anderen Konfessionen übernommen. Davon unabhängig war der Gebrauch von Illustrationen in Bibeln und Lehrbüchern.

\subsubsection{Der Islam und die Kunst}

Im vorislamischen Mekka gab es in der Kaaba Götterbilder, darunter der Göttinnen alLāt, al- Uzza und Manat, aber auch Darstellungen Abrahams, Ismaels und eine Darstellung Mariä mit dem Kind ${ }^{129}$. Burckardt beschreibt, dass die Abgrenzung des Haram mit 360 Götterbildern geschmückt war. Nach seinem Einzug in Mekka (630) stürzte Muhammad die Götterbilder beim Umritt um die Kaaba mit seinem Stock um. Die Wandgemälde in der Kaaba ließ er übertünchen, wobei er die Mariendarstellung mit beiden Händen schützte. Sie ist jedoch nicht mehr erhalten, da sie später durch ein Feuer zerstört wurde ${ }^{130}$. Dies belegt Burckardt zufolge, dass der Islam irrtümlich als „ikonoklastisch“ (bilderzerstörend) bezeichnet wird, angemessener sei der Terminus „anikonisch“ (bildlos), das heißt, dass nicht jedes Bild um jeden Preis zerstört werden muss.

Nach Hofmann gibt es im Koran kein explizites Bilderverbot, jedoch wird Sura 4,48: „Gewiss, ALLAH vergibt nie, dass Ihm gegenüber Širk betrieben wird! Doch ER vergibt (was an Verfehlungen) geringer ist als dies, wem ER will“, im Sinne des Bilderverbots ausgelegt. Jedoch bedeutet Širk (Beigesellung) im strengen Sinne die Verehrung anderer Götter neben Allah; ob die Verwendung von Bildern im Kult verboten ist, bleibt damit Auslegungssache. Weiter wird Sura 5,90 „O ihr, die ihr glaubt! Berauschendes, Glücksspiel, Opfersteine und Lospfeile sind ein Gräuel, das Werk des Satans. So meidet sie, auf dass ihr erfolgreich seid.“, von den islamischen Juristen ( fuqahā’) im Sinne des Bilderverbots gedeutet. Keinem Zweifel unterliegt das Verbot von Rauschmitteln, Glücksspielen und Losorakeln. Die ebenfalls verbotenen

\footnotetext{
${ }^{128}$ vgl. Zwingli: Vorschlag wegen der Bilder und der Messe, in: Zwingli, Werke Bd. 3, S. 114-131, hier S. 116.

${ }^{129}$ Hofmann, Murad: Der Islam als Alternative, München 1992, S. 137.

${ }^{130}$ Burkhardt, a.a.O., S. $10 \mathrm{ff}$.
} 
Opfersteine waren Steine, denen geopfert wurde, weil man in ihnen den Sitz einer Gottheit sah, so war etwa der al-Lāt ein weißer Stein in Tă̄if geweiht. Diese Steine konnten, mussten aber nicht, von Bildhauern bearbeitet worden sein. Die strikt wörtliche Auslegung verbietet also nur, den Steinen zu opfern, wahrscheinlich weil die Kaaba und al-Hağar al-'Aswad (der schwarze Stein) die einzigen Kultobjekte sein sollten. Näher ausgeführt wird das Bilderverbot in der Sunna. Danach ist „die Herstellung und Nutzung von Bildern und Statuen unerwünscht (..), wenn sie

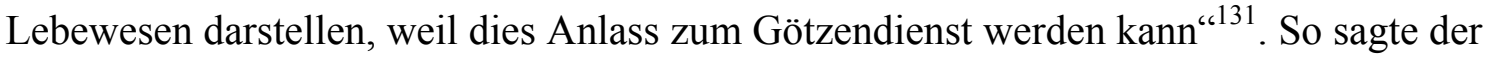
Prophet Muhammad „Diejenigen Menschen, die am Tag der Auferstehung am härtesten bestraft werden, sind solche, die Bilder (vom Menschen oder vom Tier) machen““132.

Meiner Meinung nach verbietet der Islam diese Art Kunst. Jedoch beschränkt sich dieses Verbot auf die Nachbildung Gottes oder die Herstellung von Statuen, die angebetet werden, um die Götzenanbetung unter den Arabern seiner Zeit aufzuheben. Und die Intention der Strafe für die Bildhauer, die der Prophet betonte, begrenzt sich auf diejenigen, die Gott abzubilden meinen, denn „Der Ratio des Verbots - Magie und Götzendienst vorzubeugen - entspricht die differenzierte Ausgestaltung des islamischen Bilderverbots: Als erlaubt gelten Kinderspielzeug, zumal 'Á 'iša noch als blutjunge Frau des Propheten mit Puppen gespielt hatte; ferner [in der Gegenwart, S. 'Abdelkader] Passfotos, anatomische Darstellungen sowie wirklichkeitsferne, relativ abstrakte Abbildungen, zumal wenn sie, wie auf Kissen und Teppichen, zum despektierlichen Darauf Sitzen bzw. -treten bestimmt sind. Als absolut verboten gelten jedoch

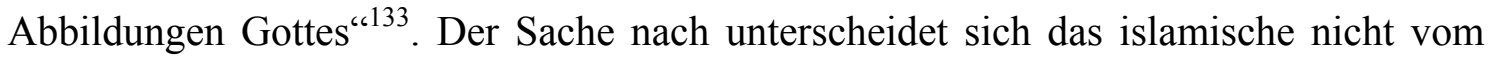
jüdischen Bilderverbot.

Die islamischen Gelehrten haben weder in der Vergangenheit noch in der Gegenwart einen Kunststil für verbindlich erklärt, weil unter ihnen keine Übereinstimmung, was Kunst und die Haltung des Islam dazu angeht, vorhanden ist. Insbesondere bezüglich der Photographie scheinen einige Probleme bei manchen Gelehrten aufzutauchen. Hier ist besonders von Bedeutung, dass der Islam keine zentral organisierte Kirche kennt, was die Macht der Theologen einschränkt. Dort wo wir Übereinstimmung der Interessen der Religion mit der Kunst beobachten, ist dies zufällig ohne Weisung der Theologen entstanden. Es handelte sich um einen Ausdruck der Schöpfung des

${ }^{131}$ vgl. Hofmann, a.a.O., S. 137.

${ }^{132}$ Ibn-Hağar al- 'Asqalānī : Fatḥ al-bārī bi-šarh ṣaḥīh al-Buhāāī, Nr. 5494, Ba. 9, Kairo 1987.

${ }^{133}$ vgl. Hofmann, a.a.O., S. 137. 
Künstlers und der künstlerischen Freiheit, die jedoch mit seinen religiösen Gefühlen verbunden sind. So entstand eine vielfältige muslimische Kunst, die Architektur, Malerei, Kalligraphie und abstrakte Kunst beinhaltete.

Im Islam stellt das Wort Gottes das Zentrum der Andacht dar. Deshalb brauchte er nicht die Hilfe der Kunst, um die Gottesdienste auszuführen, seine Inhalte zu vermitteln oder seine Ideen den Menschen näher zu bringen. Die islamische Kunst entstand somit nicht, um der Religion zu dienen. Der Islam benutzte also die Kunst nicht, um sich oder seine Lehre darzustellen. Schmuck in Moscheen besteht daher aus einer Synthese von Schrift, graphischen Mustern und Ornamenten.

Der Koran spricht von scheinbar anthropomorphen Bildern Gottes, so spricht er von Händen $(48,10)$, Antlitz $(2,272)$ und Thronsitz $(7,54)$ Allahs, jedoch handelt es sich hierbei um metaphorische und symbolische Beschreibungen von Objekten des Unsichtbaren ${ }^{134}$. Somit entwurzelt die Ablehnung von Bildern jegliche visuelle Kunst, die eine Behandlung heiliger Dinge anzustreben versucht.

Vielmehr beschäftigt sich die heilige islamische Kunst mit „menschlichen Umgebungen“, dies in stiller, kontemplativer Weise, daher die dominante Rolle der Architektur $^{135}$.

Der Verzicht auf Bilder im Islam betrifft zwei Aspekte. Einerseits soll er die ursprüngliche Würde des Menschen schützen, dessen Gestalt als Abbild Gottes geschaffen wurde und nicht nachgeahmt werden darf, da ein von Menschen geschaffenes Kunstwerk notwendigerweise begrenzt und einseitig ist. Zweitens kann nach islamischer Vorstellung nichts die Vollkommenheit Gottes darstellen. Außerdem darf nichts, das möglicherweise ein „Götze“ werden könnte, zwischen Mensch und Gott gestellt werden. Was alles andere überwiegt, ist das Zeugnis ,es gibt keinen Gott außer dem einen Gott“. Dies verhindert jede Verobjektivierung Gottes, schon bevor sie auftauchen könnte.

Der Mangel von bildlichen künstlerischen Arbeiten in den Moscheen kommt mit den islamischen Vorstellungen von der Kunst überein. Diese Vorstellungen verfolgten unterschiedliche Methoden und Ansätze, gelangen jedoch zu einer übereinstimmenden

\footnotetext{
${ }^{134}$ vgl. Burckhardt, 1976, S. 27.

${ }^{135}$ vgl. Burckhardt, 1976, S. 28.
} 
Meinung, welche betont, dass dies mit der islamischen Rechtssprechung zusammenhängt.

Die islamische Vorstellung toleriert nicht, wie viele Traditionen im Christentum die Hochschätzung der Bilder, die Christus dinghaft verkörpern oder die die Trinität zum Thema haben. Das führte in der christlichen Tradition, islamisch gesehen, zur Ikonodulie, was im Islam nicht zu akzeptieren ist. Aus diesem Grunde werden Personendarstellungen in der Malerei nicht empfohlen, solange die ikonodulischen Bedenken noch vorhanden sind. Daraufhin benutzte man in der islamischen Architektur, d. h. in der inneren Architektur der Moscheen keine Personendarstellungen, um erstens Bilderverehrung zu vermeiden und zweitens damit die Bilder nicht die Hingabe der Betenden stören. Man benutzte in der Innerarchitektur der islamischen Gebäude nur symbolische Bilder und zwar zur Unterstreichung bestimmter Koranverse und haditete des Propheten.

Im Islam wird die Darstellung jedes lebenden Wesens aus Respekt vor dem göttlichen Geheimnis, das in jedem Geschöpf enthalten ist, abgelehnt. Auch wenn man bei einigen „Konfessionen“, wie etwa den Schiiten, kein absolutes Bilderverbot findet, so kann man feststellen, dass überall die abbildhafte Kunst vom Gottesdienst ausgeschlossen wurde. Die Ablehnung bildlicher Darstellungen ist eines der Fundamente, wenn nicht sogar das Hauptfundament der sakralen Kunst im Islam ${ }^{136}$.

Außerdem wird im Koran eine Geschichte von Jesus erzählt, in der Bildwerke verfertigte und dazu sagte: „Seht, ich erschaffe für euch aus Ton die Gestalt eines Vogels und werde in sie hauchen, und sie soll mit Allahs Erlaubnis ein Vogel werden“"(Sura 3,49). Er ist ein Prophet, den Gott als Vorbild für die Menschen sandte, so kann dieser nichts tun, was eigentlich verboten sein soll. Im Zusammenhang mit diesem Koranvers wird folgender hadit (Ausspruch Moḥammads außerhalb des Korans) überliefert: „Ibn Umar, Allahs Wohlgefallen auf beiden, berichtete: Der Gesandte Allahs, Allahs Segen und Heil auf ihm, sagte: Diejenigen, die Bilder machen, werden am Tag der Auferstehung bestraft. Zu ihnen wird gesagt werden: Macht das lebendig,

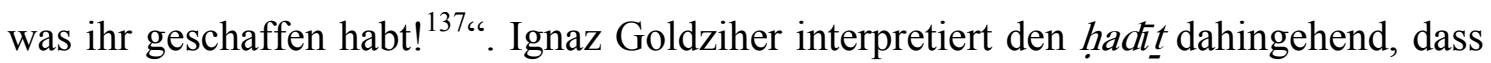
ein Mensch nur dann Lebewesen nachbilden darf, wenn er wie Jesus die Kraft besäße,

\footnotetext{
${ }^{136}$ vgl. Burckhardt, 1976, S. 27.

${ }^{137}$ Sahih Muslim Nr. 3942.
} 
diesem Bild Leben einzuhauchen ${ }^{138}$. Daraus folgt nach einer wörtlichen Interpretation, dass Malerei und Plastik verboten sind, nicht nur in religiösen, sondern auch in weltlichen Gebäuden. Jedoch sieht man trotz des Konsensus unter den muslimischen Juristen (fuqahā) Abbildungen von Vögeln und anderen Tieren auf den Wänden einiger Moscheen und auch illustrative bildliche Wandbilddekorationen auf den Wänden von vielen schiitischen Schreinen in Š̆ rāz und anderen Städten des Irans.

Diese Praxis lässt sich damit legitimieren, dass Salomo von den Dämonen mit Bildwerken verzierte Bauwerke errichten ließ, was der Koran wie folgt erwähnt: „Sie machten für ihn, was er begehrte: Paläste und Bildwerke, Becken wie Teiche und feststehende Kochbottiche. Wirkt ihr vom Hause Davids in Dankbarkeit. Und nur wenige von Meinen Dienern sind dankbar“ (Sura 34,13). Da Salomo ein Prophet war und es nicht möglich ist, dass Propheten, die von Gott als Vorbild gesandt worden sind, etwas tun, was den Gesetzen Gottes zuwider ist, folgt daraus, dass die Herstellung von Bildern und Statuen freigestellt ist, sofern sie nicht angebetet werden.

Die islamische Abstraktkunst entstand als Folge des Verlangens des Künstlers danach, das Wesentliche darzustellen, was ihn dazu führte, die vorübergehende Aktualität zu überschreiten. Da die islamischen Lehren die Darstellung von Personen weder als Bilder noch als Statuen toleriert, wurde der Muslim zu zweierlei verpflichtet: erstens, die Realität zu modifizieren, das heißt, ihre besonderen Merkmale, Proportionen und Dimensionen nach der Betrachtungsweise des Künstlers zu modifizieren, zweitens die Gestalt und die Realität abstrakt darzustellen und soweit wie möglich die Sache nicht in ihren Details nachzuahmen. Aus dem Gefühl der Vergänglichkeit des Irdischen und der dauerhaften Beschäftigung mit dem unvergänglichen Jenseits greift er zur Modifikation zurück. Große Aufmerksamkeit schenkt der Künstler der Existenz und den Gestalten in seiner Malereikunst nicht. Er geht auf sie mit großer Vereinfachung und Abstraktion ein, ohne sie ihrer Realität gleich erscheinen zu lassen.

Der Grund für die Strategie der Umbildung basiert auf dem Gefühl der Unwichtigkeit der realen Existenz und die stete Beschäftigung mit dem ewigen Sein. Der Künstler teilt bei seinen Arbeiten den Formen und ihrer Existenz keine besondere Rolle zu. Er bildet sie vereinfacht und primitiv ab, ohne den Versuch, Mittel zu verwenden, welche sie der Realität näher bringen würden.

${ }^{138}$ vgl. Goldziher, Ignaz: Zum islamischen Bilderverbot, in: Zeitschrift der Deutschen Morgenländischen Gesellschaft LXXIV (1920), S. 288. 
Das Verbot, Darstellungen von Menschen und Tieren herzustellen bedeutet nicht, dass der Islam der bildenden Kunst an sich feindlich ist. Die islamischen Künstler sind frei, Pflanzen, geometrische Muster oder abstrakte Darstellungen zu schaffen. Der Reichtum der islamischen Architektur an Arabesken wäre meines Erachtens, ebenso wie die arabische Kalligraphie, ohne das Bilderverbot nicht möglich gewesen.

Zusammenfassend lässt sich sagen, dass die monotheistischen Religionen bildliche Darstellungen ablehnten, wenn sie die Gefahr der Anbetung boten. Das Bilderverbot ist insofern eine Notwendigkeit für den Monotheismus, als dass aus der Existenz einer Vielzahl von bildlichen Darstellungen Gottes leicht irrtümlicherweise auf eine Vielzahl von Göttern geschlossen werden könnte. Obwohl der Vergleich ein wenig hinkt, könnte man auf den Sprachgebrauch in der Marienverehrung in der römisch-katholischen und der orthodoxen Kirche verweisen, wo unbefangen von der Gottesmutter von Guadalupe, Tschenstochau, Kasan etc. die Rede ist, obwohl natürlich immer nur die eine Maria gemeint ist. Sofern ihre Werke nicht angebetet werden, ist die bildende Kunst erlaubt. Eine gewisse Ausnahme bildet das Christentum, das mit einer fundamentalen Ablehnung der bildenden Kunst begann, diese aber später in den Gottesdienst integrierte und die religiöse Bedeutung der Kunst anerkannte. Ich denke dabei besonders an die Verehrung der Ikonen und geweihten Bilder in den orthodoxen und der römisch-katholischen Kirche.

\subsubsection{Die esoterische Bedeutung der arabischen Buchstaben}

Im Jahre 788/89 AH (1386/87 AD) trat bei Iṣfahan im Iran Faḍl Āllah al-Ḥūrūfĩ auf. Er war (wahrscheinlich) unter dem Namen 'Abd-ar-Rahmān im Jahre 740 AH (1340 AD) als Sohn eines Richters geboren. 1394 wurde er in Alandjak in Nachitschewan als Apostat vom Islam hingerichtet, weil er sich als Manifestation Allahs verstand. FaḍlAllah gilt als Begründer des Ilm al-ḥuñ f(Wissenschaft der Buchstaben), wobei hier nicht an die Grammatik, sondern an jenen Bereich des Wissens gedacht ist, der als 'uh̄m Ġā̄bā (seltsame Wissenschaften) oder 'uh̄m Hafiyya (geheimnisvolle Wissenschaften) genannt wird. In dieser Wissenschaft werden den Buchstaben Zahlenwerte, die vier Elemente und ähnliches zugeordnet. Weil Allah sich durch die arabischen Buchstaben mitteilte, haben sie an seiner Schöpferkraft Anteil. Deshalb glaubte man, man könne bestimmte Buchstabenkombinationen $\mathrm{zu}$ magischen Manipulationen verwenden. 
In der Buchstabenmystik haben die Buchstaben eine doppelte Bedeutung, „ein unverkennbares Ziel, also das reine philologische Ziel, und das esoterische Ziel, womit das geistige Ziel gemeint ist ${ }^{\text {“139 }}$. So werden beispielsweise viele arabische Buchstaben in Zauberformeln, die Krankheiten oder böse Geister fernhalten sollen, eingebaut. Diese Formeln soll der Betroffene mit sich tragen.

Gerade die Mehrdeutigkeit machte die arabischen Buchstaben für die moderne Kunst interessant. Der Künstler kann mit seinem ganzen künstlerischen Gefühl all das verstehen, was die Buchstaben an geheimer Bedeutung enthalten, die ihren philologischen Sinn übersteigen, ihnen ähnelt oder mitunter ihrem philologischen Inhalt entsprechen. Hierbei liegt die Besonderheit in den festen Stellungen der arabischen Buchstaben, in ihrem geometrischen Bau und ihrer Kraft zur Anpassung an jeder gegebenen Form. Wenn ein heiliger Text niedergeschrieben wurde, dann achtete der Schreiber auf eine sorgfältig ausgewählte, künstlerisch anspruchsvolle Schrift. Auch ein profaner Text konnte in seiner Würde hervorgehoben werden, wenn man ihn in einer Schrift niederschrieb, die sonst heiligen Texten vorbehalten war.

\section{Schriftelemente in Bildern westlicher Künstler in der zweiten Hälfte des 20. Jahrhunderts}

Die Verwendung von Schrift im Bild ist keine Neuentdeckung des 20. Jahrhunderts. Trotzdem kann man feststellen, dass erst im 20. Jahrhundert ein bewusstes Einsetzen der Schrift in der Kunst im Rahmen von Kunstbewegungen stattgefunden hat.

Im Unterschied zum Fernen Osten und dem islamischen Kulturkreis hatte der Westen keine Tradition der Verwendung von Schriftzeichen als Bildelemente, an die er anknüpfen konnte. Wassilij Kandinsky, Paul Klee, Joan Miró, Mark Tobey, André Masson, Willi Baumeister, Hans Hartung u. a. benutzten Schriftzeichen, seien es lateinische oder solche anderer Schriften, oder an Schriftzeichen erinnernde Formen als Bildelemente. Es war jedoch nicht ihre Absicht, wie man es bei mittelalterlichen Malern findet, in ihren Bildern verbale Botschaften auszudrücken. Diese Formen können nur im Zusammenhang des Bildes interpretiert werden. Schrift im Bild ist eine Form der Gestaltung, die in den Bewegungen des Dadaismus, des Futurismus und des analytischen Kubismus verwendet wurde. Die Grenzen zwischen Literatur und

\footnotetext{
${ }^{139}$ Qadīh, ‘Adel: at-ta' șîl wa-t-taḥdīt fi-l-funūn at-taškīlīyya, in: al-Waḥda, Nr. 70 u. 71, Paris 1990, S. 56.
} 
Bildender Kunst verwischen sich dadurch. Das Bild erhält mit den dargestellten Schriftzeichen eine zweite Bedeutungsdimension. Diese Tatsache können wir im Abstrakten Expressionismus, in der art informel, im Tachismus und auch in der concept-art der sechziger und siebziger Jahre, bei Robert Barry, Carl André, Sol Le Witt und anderen feststellen. Das Schriftzeichen wird in der westlichen Moderne zum wesentlichen Bestandteil der Bildenden Kunst. So stellte Michel Tapié 1952 fest: "The Occidental world is finally discovering the Sign“"140.

Ein Zeichen dafür, dass sich westliche Künstler mit fremden Kulturen auseinandersetzen, ist, dass in ihren Werken Formen auftauchen, die an fremde Schriftzeichen erinnern, oder dass sie direkt Schriftzeichen verwenden, wobei dahingestellt bleibt, ob sie auch ihre Bedeutung verstehen. Jede Kultur hat ihre besondere Schrift, so sind die abendländische Kultur durch die lateinische Schrift, die islamische Kultur durch die arabische, die fernöstlichen Kulturen besonders durch die chinesische Schrift geprägt. Durch die gewonnene Mobilität, die zunehmend Reisen auch in ferne Kontinente erlaubt, wird es im 20. Jahrhundert für sehr viele Künstler möglich, fremde Kulturen und Schriften vor Ort kennen zu lernen, dazu kommt der Kulturtransfer durch Einwanderung etwa aus Ostasien oder den islamischen Ländern nach Europa und Nordamerika. Viele moderne Künstler sammelten außereuropäische Kunstwerke. Tobey, Michaux und Alechinsky besaßen etwa ostasiatische Kalligraphien, Gottlieb Kunstwerke mittelamerikanischer Indianer ${ }^{141}$. Fremde, nicht mehr gebräuchliche oder neu erfundene Schriftzeichen fanden parallel mit dem Interesse an außereuropäischen Kulturen Eingang in die moderne Malerei. Seit Anfang der achtziger Jahre wurden auch Elemente des Graffiti in die Kunst übernommen. In die Reihe jener Künstler gehört Jean-Michel Basquiat, aber auch Antoni Tàpies hatte sich schon in den fünfziger Jahren von Graffiti anregen lassen. In der Konzeptkunst schließlich wurden Buchstaben, Ziffern, ja ganze Wörter und Texte ohne weitere bildliche Elemente zum Kunstwerk erhoben. Als Gegenbewegung dazu lässt sich der Primitivismus verstehen, vertreten durch Kiefer und Penck, deren Bilder erstens eine konkrete Botschaft vermitteln und zweitens allgemein verständlich sein wollen.

\footnotetext{
${ }^{140}$ Zitiert nach Cueff, Alain: The actual and the discontinuous: present space, in: Parent, Béatrice (Hrsg.): La peinture après l'abstraction, Paris 1999, S. 21-43, hier S. 28.

141 vgl. Linsmann, Maria: Schriftähnliche Zeichen und Strukturen in der Kunst des 20. Jahrhunderts, Bonn 1991, S. 151.
} 


\subsection{Der Abstrakte Expressionismus}

Vom Ende der 30er Jahre an erlebte New York nicht nur einen politischen und wirtschaftlichen, sondern auch kulturellen Aufbruch. Binnen kurzer Zeit löste New York Paris als Zentrum der modernen Kunst ab, vor allem bedingt durch Auswanderungen führender europäischer Künstler während des Zweiten Weltkriegs aufgrund der beklemmenden Situation der modernen Kunst im nationalsozialistisch beherrschten Europa. In den USA und insbesondere in New York konnten sie ihre Arbeit wiederaufnehmen. Unter ihnen waren auch bekannte Vertreter des Surrealismus wie Dali und Masson. Der Surrealismus war bis weit in die vierziger Jahre der tonangebende Stil unter den modernen Malern Amerikas. Anfang der fünfziger Jahre brachte eine junge Künstlergeneration, deren Vertreter wie Adolph Gottlieb oder Jackson Pollock und Robert Motherwell zwischen 1900 und 1915 geboren waren, den Abstrakten Expressionismus hervor. Ausgehend vom Dadaismus und der Bauhausbewegung verstand sich der Abstrakte Expressionismus als interdisziplinäre künstlerische Bewegung. Unter dem Einfluss der Sprachphilosophie Ludwig Wittgensteins und der Dichtungen Charles Olsons öffnete er sich für die Synthese von Sprache und Malerei in dem Sinne, dass die gemalten Symbole keine Bedeutungsträger in irgendeiner bekannten Sprache sein und deswegen nicht von jedermann „gelesen“ werden sollten, wie Adolph Gottlieb sagte: „I have no desire to communicate with everyone, only with those whose thoughts and feelings are related to my own “142. Da Adolph Gottlieb und Robert Motherwell die einzigen Vertreter des Abstrakten Expressionismus waren, die Schrift- oder schriftähnliche Zeichen in ihren Bildern verwendeten, soll anhand ihrer Werke untersucht werden, wie Beziehung von Schrift und Bild im Abstrakten Expressionismus gesehen wurde.

\subsubsection{Adolph Gottlieb 1903-1974}

Adolph Gottlieb wurde am 14. März 1903 in New York geboren. Von 1919 bis 1921 und von 1923 bis 1924 studierte er an der Arts Students League in New York. Zwischenzeitlich hielt er sich in Paris auf, wo er an der Académie de la Grande Chaumière studierte, sowie in Berlin, München, Prag und Wien. In Paris begann er, sich

\footnotetext{
${ }^{142}$ Zitiert nach Jonas-Edel, in: Buhlmann, 1998, S. 134.
} 
mit dem Surrealismus zu beschäftigen ${ }^{143}$.

In den zwanziger Jahren traf Gottlieb mit dem russischen Emigranten John Graham, einem Maler und Kunsttheoretiker zusammen, dessen Sammlung primitiver Kunst großen Eindruck auf ihn machte ${ }^{144}$. Unter Grahams Einfluss begann Gottlieb ab 1935 ebenfalls, Werke primitiver Kunst zu sammeln.

Von Anfang bis Mitte der dreißiger Jahre malte Gottlieb in einem expressionistischen oder fauvistischen Stil, der an Avery erinnerte. Seine Bilder spiegelten die düstere Stimmung der Depressionsjahre wieder ${ }^{145}$.

Gesundheitliche Probleme seiner Frau veranlassten Gottlieb, den Winter 1937/38 in der Wüste Arizonas zu verbringen. Er studierte Indianerkulturen vor Ort und erwarb verschiedene Stücke für seine Sammlung ${ }^{146}$. Unter dem Eindruck indianischer Bildsprache schuf Gottlieb in den vierziger Jahren seine Pictographs, mit denen er seinen künstlerischen Durchbruch erlebte ${ }^{147}$. Gottlieb sagte über seine Pictographs selbst: „My Pictographs have been linked with totem-poles, Indian writing, psychoanalysis, neoprimitivism, private symbolism, etc., the implication being that my work is not quite what painting should be" 148 .

„Archaisierende Themen und Mythen bieten ihm die gewünschte Distanz. Aus ihnen erwachsen imaginäre Räume, in die er sich zurückziehen kann, um Verbindungen herzustellen und persönlichen Entdeckungen nachzuspüren. In der Verknüpfung archaischer Symbolformen mit modernen Mythen sieht er eine Möglichkeit, komplexen Gedanken einfache Formen zu verleihen. Handschrift und Pinselduktus bringen die Persönlichkeit des Künstlers auf mehr oder weniger gelenkte Weise ins Bild“،149.

„In der frühen, klassischen Phase seiner Pictographs zeigten diese hauptsächlich menschliche Körperteile, phallische Formen sowie Brustformen, Hände und Köpfe, aber auch und vornehmlich Augen (...). Stufenweise erweiterte der Künstler das

${ }^{143}$ vgl. Buhlmann: Jackson Pollock, Robert Motherwell, Adolph Gottlieb, Richard Pousette-Dart, in: Dies., 1998, S. 71.

${ }^{144}$ vgl. Linsmann: 1991, S. 78.

145 vgl. Wheeler, 1991, S. 54.

146 Zbikowski, 1996, S. 343.

${ }^{147}$ vgl. Wheeler, 1991, S. 55.

${ }^{148}$ Gottlieb, Adolph, zitiert nach: Batt, J.I.H. (Hrsg.): the new decade, New York 1955, S. 36, zitiert nach: Zbikowski, 1996, S. 349.

${ }^{149}$ Buhlmann, 1998, S. 72. 
Repertoire, um solche Formen wie die Schlange, den Vogel, den Fisch, den Punkt und den Pfeil einzuschließen, Symbole, die aus indianischer Tradition und der primitiven Kunst entstammen“"150. Ein Beispiel dafür ist „Man looking at Woman“, 1949 (Abb. 25). Gottlieb unterteilte einen grau-braunen Hintergrund mit braunen Linien in einzelne, unterschiedlich große Kästchen. In einem Raum, der in der Höhe die oberen zwei Drittel und in der Breite das mittlere Drittel einnimmt, hat Gottlieb die Titel gebenden Gestalten gemalt. Die Frau wirkt dominierend. Sie besteht nur aus dem Kopf und den zwei Brüsten. Der Kopf ist als von einer weißen Linie begrenztes, horizontal ausgerichtetes Oval gemalt. Zwei kleine, schmale Augen zeigen an, dass der Betrachter sie frontal anblickt. Ihre Nase wird durch ein auf der Spitze stehendes Dreieck mit zwei von der Basis aufwärts führende, schräge Linien mit einem Kringel am oberen Ende gebildet. Ihr Mund wird durch eine gestrichelte Linie dargestellt. Im Vergleich mit den Gesichtskonturen wirkt ihr Kopf überproportioniert. Die Brüste der Frau werden durch zwei, von weißen Linien begrenzte, horizontale Ovale dargestellt, die jede etwa die Größe des Kopfes haben. Kopf und Brust der Frau werden durch ein Dreieck, die Brüste durch eine linsenförmige Figur miteinander verbunden. Links neben der Frau ist der Mann abgebildet. Er ist ebenso hoch wie die Frau, aber nur etwa halb so breit. Der Betrachter sieht den Mann im Profil, so dass er die Frau anblickt, wobei das Auge auf die Seite des Kopfes gerückt wurde, so dass es frontal gesehen wird. Vom Gesicht des Mannes sind nur ein geöffneter Mund, eine „Adlernase“ und das Auge mit einer schwarzen Augenbraue zu sehen. Im Verhältnis zur Größe des Kopfes sind sie viel zu groß. Mit einer sich selbst im Zick-Zack überschneidenden weißen Linie wird der Körper des Mannes dargestellt. Links vom Mann ist das Bildfeld mit Bildzeichen bedeckt. Von oben sind dies ein schlüsselförmiges Zeichen, eine Raute und ein gefurchtes Oval. Sie sind in schwarzer Farbe gemalt. Darunter folgt eine weiße Kurve, rechts daneben von oben nach unten ein schwarzes Dreieck mit nach oben gerichteter Spitze, eine schwarze Zick-Zack-Linie und zwei schwarze Punkte. Unterhalb der weißen Kurve malte Gottlieb eine schwarze Schlangenlinie. Rechts von der Frau befindet sich ein Auge, darunter ein umgedrehtes Herz und rechts daneben ein Oval, darunter ein Punkt. Alle diese Zeichen wurden mit schwarzen Umrisslinien gemalt. Im unteren Drittel des Bildes erscheinen von links nach rechts ein weißes Quadrat mit einem schwarzen Punkt in der Mitte, daneben ein Bogen, ein Kreis, eine unregelmäßige Struktur und ein nach oben gerichteter Pfeil. Keine dieser Figuren ist als Fläche gemalt und bis auf das Quadrat sind alle schwarz. Oberhalb des Kreises hat Gottlieb einen 
schwarzen und einen orangefarbenen quer verlaufenden Strich gemalt. Die Farben sind insgesamt in einem warmen, erdigen Ton gehalten. Es gibt keine Tiefenperspektive.

Man darf „bei dem Vergleich nicht übersehen, dass die Bildwelten der Pictographs simultan gelesen werden wollen. Sie unterscheiden sich in diesem wesentlichen Punkt von der chronologischen Folge der christlichen Vorbilder. Abstraktionen des Augenmotivs, wie sie in Pictographic Symbol zu sehen sind, können laut Zbikowski als Verweis auf prophetische Visionen, aber auch auf Erblindung gelesen werden. Die Durchdringung der inneren und äußeren Welt wird gleichermaßen durch das Augenpaar symbolisiert. Andere Zeichen stehen für Kopf, Bauch und Rumpf, oder sind rein abstrakter Natur. Der Betrachter sollte wissen, dass zahlreiche Motive auf unterschiedliche Weise decodiert werden können - andere entziehen sich einer schlüssigen Deutung. In diesem Zusammenhang legt Gottlieb Wert darauf, dass seine Bildsprache ungeeignet sei für einen Transfer in geläufige Sprachkategorien, er betont daher: ,It was an ambiguos message that had to do with my subconscious " ${ }^{151}$.

Gottlieb verneint ausdrücklich, dass seine Pictographs Schriftzeichen in einer Geheimsprache seien. “[My Pictographs] couldn't really be read, in that [literary] sense (...). I didn't consider it a private language" ${ }^{\Perp 152}$. Der Vergleich seiner Pictographs mit einer Schrift seitens der Kritiker erschien Gottlieb willkürlich. Er benutzte die Schrift und die Symbole vielmehr zur Komposition des Bildes. Die Schrift ist somit visuelle Form ohne Bedeutung. Auf die Frage, was diese Bilder bedeuteten, gab Gottlieb die Antwort: "This is simply the wrong question (...). A better question would be 'Do these images convey any emotional truth'?",153.

Die einzelnen Zeichen in einem Pictograph, ganz gleich ob sie dem Betrachter lesbar oder unlesbar erscheinen, sind keine „Elemente“ eines „Textes“. Die Zusammenstellung der einzelnen Zeichen erfolgte nach Gottlieb zufällig ${ }^{154}$.

Über den Gebrauch von Symbolen sagte Gottlieb 1947, die bevorzugt verwendeten

\footnotetext{
${ }^{151}$ Buhlmann, 1998, S. 73.

${ }^{152}$ Gottlieb in einem Interview mit Martin Friedman, August 1962, Transkription S. 3, Adolph \& Esther Foundation Archives, New York, zitiert nach: Zbikowski, 1996, S. 339.

${ }^{153}$ Gottlieb: zitiert nach: Batt, a.a.O., S. 36, zitiert nach: Zbikowski, 1996, S. 356.

${ }^{154}$ vgl. Zbikowski. 1996, S. 339.
} 
Symbole in seinen Bildern seien diejenigen, die ihm selbst „,am unverständlichsten““155 wären. Damit drückte er sein Misstrauen gegen den Anspruch von Kritikern und Kunsthistorikern aus, sich seiner Bilder mittels Sprache zu bemächtigen, zudem war ihm die Bedeutung der Symbole, seinen eigenen Worten nach, selber nicht bewusst ${ }^{156}$.

Zusammen mit den übrigen Künstlern der New York School lehnte es Gottlieb ab, einfach die europäische avantgardistische Malerei zu kopieren. Als amerikanischer Künstler müsse er seine Gedanken und Erfahrungen in einer besonderen amerikanischen Formensprache ausdrücken ${ }^{157}$. Die Maler der New York School griffen in ihren Werken archaische Bildmotive und mythologische Themen auf, mit denen sie sich ebenso beschäftigten, wie sie ihre eigene und die gesellschaftliche Befindlichkeit hinterfragten. Voraussetzung für gute Malerei war ihrer Meinung nach die Wahl eines adäquaten Sujets $^{158}$. Besonders die primitive Kunst hielt Gottlieb zufolge ein großes Repertoire an Themen für einen modernen Maler bereit. 1943 sagte er: „Obwohl moderne Kunst durch die Entdeckung primitiver Kunstformen erste Impulse erhielt, meinen wir, dass die wahre Bedeutung primitiver Kunst nicht vorrangig im formalen Bereich zu suchen ist, sondern in dem geistigen Gehalt, der allen archaischen Werken zugrunde liegt ${ }^{\text {159 }}$. $\mathrm{Zu}$ diesen archaischen Werken gehörten auch Schrift- und schriftähnliche Zeichen alter Kulturen, umso mehr, als Gottlieb in diesen Zeichen eine Verbindung zu tieferen Schichten des menschlichen Geistes zu erkennen meinte ${ }^{160}$

Gottlieb suchte fortwährend nach Zeichen und Symbolen fremder Kulturen, ohne sich jedoch um ihre Aussagekraft zu kümmern. "'I felt that some primitive man could think up images that were eggs or fertility symbols or so on, I could think up things myself.' Einschränkend fügt Gottlieb hinzu: 'Now, maybe I didn't; I may have just seen these things and to a certain extent I felt free to use anything whether I had seen it or not seen it""161. Wenn Gottlieb sich auf eine primitivistische Bilderwelt bezog, schloss das nicht aus, dass er sich moderner Maltechniken bediente. So nahm er den surrealistischen Automatismus als Mittel auf, um sein Unterbewusstsein nach neuen, frei assoziierten

${ }^{155}$ Gottlieb, zitiert nach Maurer, Evan M.: Adolph Gottlieb: Pictographs and Primitivism, in: Katalog The Pictographs of Adoph Gottlieb, S. 35, hier: Jonas-Edel, Justus, in: Buhlmann, 1998, S. 137.

${ }^{156}$ vgl. vorige Seite.

157 vgl. Buhlmann, 1998, S. 71.

${ }^{158}$ vgl. ebd.

${ }^{159}$ Gottlieb, Adolph, in: The Portrait and the Modern Artist, Rundfunkmanuskript über „Art in New York“, WNYC, 13.10.1943, in: Mac Naughton, M.D.: Adolph Gottlieb: His life and art, in: Adolph Gottlieb, A Retrospective, New York 1981, S. 42, zitiert nach: Linsmann, 1991, S. 77.

${ }^{160}$ vgl. Linsmann, 1991, S. 77.

${ }^{161}$ Friedman, M.: Interview mit Adolph Gottlieb, August 1962, in: Zbikowski, 1996, S. 352. 
biomorphen Bildern zu durchsuchen, die persönlich genug waren, ihm authentisch zu erscheinen, aber dennoch genügend vieldeutig, um sich mit dem kollektiven Unterbewusstsein zu verbinden ${ }^{162}$. Diese Arbeitsweise beschrieb er folgendermaßen: „(...) I was using a method of the Surrealists, which was to use a kind of automatic writing which represented to stemmed from the subconscious. In that sense it was irrational, so that any attempt to get a rational reading of the pictograph - like a written language - wouldn't make sense" 163 .

Anfang der fünfziger Jahre änderte sich die Form der Schrift und der Zeichen in Gottliebs Werken. An die Stelle indianisch anmutender traten abstrakte Formen. Lateinische Buchstaben und die Zahlen erschienen in seinen Werken, so zum Beispiel in Monolith (Female) 1956, (Abb. 26), eines der letzten Unstill Lives, aus dem Jahre 1956. Auf einem beigefarbenen Grund ist eine braune, rechteckige Form, wahrscheinlich der Namen gebende Monolith, zu sehen, die sich vom oberen und unteren Ende her zur Mitte verjüngt. Sollte die Form der Monolith sein, könnte sich das „Female“ im Titel dadurch erklären, dass hier an die Taille einer Frau gedacht ist. Die schmalen Streifen an den Ecken, der Formen, die sich bis zum Bildrand fortsetzen, ließen sich dann als Arme und Beine erklären. Der „weibliche Monolith“ würde dann etwas breitbeinig und mit erhobenen Armen dastehen. Ein Kopf fehlt auf dem Gemälde. Falls Gottlieb den Monolithen allerdings nicht als Menschen gedacht hat, verwundert das Fehlen eines Kopfes nicht weiter. Auf dem „Rumpf“ sind von oben nach unten vier Zeichen gemalt, wobei sich das oberste so scharf vom Untergrund abhebt, als sei es mit einer Schablone gemalt. Dieses Zeichen, das in schwarzer Farbe gemalt ist, besteht aus zwei zusammenhängenden Bögen. Es erinnert an ein m, könnte aber auch eine liegende 3 oder - in Schreibschrift- ein liegendes E sein. Zbikowskis Vermutung zufolge ${ }^{164}$ hat sich Gottlieb möglicherweise an indianischen Schriften orientiert. In der ChippewaSchrift würde es das Silbenzeichen „tci“ und in der Dene-Schrift das Silbenzeichen „go“ darstellen. Darüber hinaus erinnert dieses Zeichen an einen der bemalten Kiesel von Mas d'Azil ${ }^{165}$. Darunter ist ein weißes Zeichen zu sehen, das wie ein T aussieht, wobei Zbikowski auch hier Assoziationen an indianische Schriftzeichen hat, in diesem Fall an die Cherokee-Schrift. Darunter befindet sich ein gelbes Zeichen, das an ein X erinnert. Man könnte natürlich auch an ein auf die Seite gekipptes phönizisches Taw

${ }^{162}$ vgl. Wheeler, 1991, S. 55.

${ }^{163}$ Gottlieb, Interview mit Stewart Kranz im Whitney Museum, 1968, in: Zbikowski, 1996, S. 347.

${ }^{164}$ Vgl. Zbikowski, 1996, S. 359.

${ }^{165}$ Vgl. Schauer, Lucie (Hrsg.): Elementarzeichen, Berlin 1985, S. 28, linke Abbildung. 
denken, Zbikowski sieht auch hier Anklänge an ein Cherokee-Zeichen. Zuunterst befindet sich schließlich ein roter Kringel, der als auf dem Kopf stehendes e oder auch als auf dem Kopf stehendes arabisches ba-waw (بو) gelesen werden kann, wobei diese Deutungen natürlich auch immer beim Betrachter liegen.

Obwohl die Zeichen in „Monolith Female“ also Assoziationen an verschiedene Schriftsysteme hervorrufen, bilden sie keine deutbaren Schriftzeichen. Anklänge an indianische Zeichen sind eher Gottliebs Werkgeschichte geschuldet. „Die Symbole wurden so verändert, dass sie keine verbindlichen Angaben über ihre Referenzen mehr zulassen“"166.

Gottlieb beschäftigte sich mit primitiven Kunstformen, ohne sie jedoch lediglich zu kopieren. Im Gegensatz zu modernen europäischen Malern interessierten ihn weniger die Formen, als mehr der Geist, der sich in ihnen ausdrückte bzw. den er in sie hineininterpretierte ${ }^{167}$.

Neben indianischen verwendet Gottlieb ostasiatische Motive. Er benutzt keine eindeutigen Schriftzeichen, jedoch ahmt er die japanische Schrift nach, wie beispielsweise in "Sign" 1962; (Abb. 27). Dörte Zbikowski meint dazu, dass „Gottliebs Windungen (...) wie freie Interpretationen der japanischen Silbenschrift [wirken]; sie befinden sich in formaler Nähe zu kalligraphischen Zeichen wie den in (Abb. 28) zusammengestellten. Sie lassen sich mit dem Hiragana, der kursiven Silbenschrift Japans, in Verbindung bringen, ohne dass der spezifische Duktus fernöstlicher Kalligraphie imitiert wäre. Da es sich bei Gottlieb stets um einfache lineare Schwünge handelt, können auch arabische Buchstaben zum Vergleich herangezogen werden. So erinnert die Zeichenkombination aus e und Punkt in "Sign" an den Buchstaben - ف

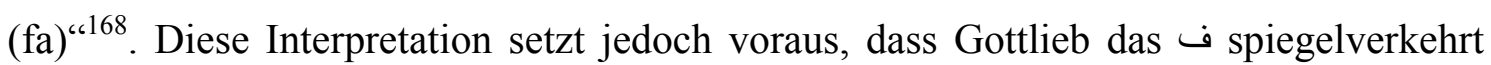
geschrieben hat.

1960 entstand das Werk Dialogue Number 1 (Abb. 29). Der Hintergrund des Bildes ist in unterschiedlichen Grautönen gestuft. In der oberen rechten Hälfte sieht man zwei Scheiben, die rechte schwarz, die linke rot. Im unteren Teil des Bildes befinden sich schwarze, geschwungene Linien, die Hiragana-Zeichen ähneln und ineinander

\footnotetext{
${ }^{166}$ Zbikowski, 1996, S. 361.

${ }^{167}$ vgl. Linsmann: 1991, S. 77.

${ }^{168}$ Zbikowski, 1996, S. 365.
} 
verschlungen sind. Sie sind über ähnlich geformte schwarze Linien gemalt, die allerdings blasser sind, als ob sie übermalt oder weggewischt worden sind. Die schwarze Scheibe könnte die Nacht symbolisieren, während die rote den Tag darstellt, da die rote Scheibe ein traditionelles japanisches Sonnensymbol ist. Dörte Zbikowski kommentiert das Bild folgendermaßen: „Die beiden Scheiben scheinen durch die Energie des kalligraphischen Feldes bewegt zu werden. Bereits in die rechte Bildhälfte platziert, halten sie die vorgegebene Richtung ein. Ruhe und Statik der Kreisformen sind zumindest in Frage gestellt" ${ }^{\text {“ }}$.

Gottlieb verweigert sich dem Prinzip, seine Zeichen - wie es in einer Schrift zwangsläufig der Fall sein muss -, konventionellen Regeln zu unterwerfen. Jeder Betrachter kann seine Zeichen anders interpretieren. Er will keine Fakten auflisten oder Geschichten erzählen, sondern Gefühle erwecken ${ }^{170}$.

\subsubsection{Robert Motherwell 1915-1991}

Robert Motherwell wurde am 24. Januar 1915 in Aberdeen, Washington, geboren. Von 1932 bis 1937 studierte er Malerei an der California School of Fine Art in San Francisco sowie Philosophie und französische Literatur an der Stanford University, von 1937 bis 1939 Philosophie an der Harvard University. Während seines Studiums beschäftigte er sich mit der Psychoanalyse Sigmund Freuds und der Tiefenpsychologie Carl Gustav Jungs. Großen Einfluss auf sein kunsttheoretisches Verständnis übte John Deweys Schrift „Art as Experience“ (1934) aus. Kunst sei nach Dewey Reaktion auf gelebte Erfahrung und die expressive Idee eines Kunstwerkes sei stärker auf formale Interaktion als auf die Formulierung gegenständlicher Themen zurückzuführen. Im Rückblick erinnerte sich Motherwell 1979: „Dewey verdanke ich einen Teil meines Gefühls für den Arbeitsprozess. (...) Er bewies philosophisch, dass unmittelbar gefühlte abstrakte Rhythmen ein Ausdruck des verborgenen Ichs sein können“171. 1938/39 unternahm Motherwell eine ausgedehnte Europareise, während der er von Oktober 1938 bis Juli 1939 in Paris arbeitete. Nachdem er für kurze Zeit an der Universität von Oregon unterrichtet hatte, wandte sich Motherwell, nachdem er ein Jahr vorher in New York durch den Kunsthistoriker Meyer Shapiro mit den aus Europa geflohenen Surrealisten bekannt gemacht worden war, 1941 ausschließlich der Malerei zu. Gemeinsam mit dem

\footnotetext{
${ }^{169}$ Zbikowski, 1996, S. 367.

${ }^{170}$ vgl. Zbikowski, 1996, S. 368.

${ }^{171}$ Buhlmann, 1998, S. 49.
} 
chilenischen surrealistischen Maler Roberto Matta reiste Motherwell 1941 nach Mexiko, wo erste ,automatische“ Zeichnungen, die vom Hell-Dunkel-Kontrast geprägt wurden, entstanden. Trotz seines jungen Alters entwickelte er sich zum Bindeglied zwischen der europäischen Avantgarde und den progressiven amerikanischen Künstlern ${ }^{172}$. 1945 wurde Motherwell Herausgeber der Documents of Modern Arts. Von 1950 bis 1959 unterrichtete er am Hunter College und am Black Mountain College. Am 17. Juli 1991 starb er.

An seine Begegnung mit dem Surrealimus erinnerte sich Motherwell mit den Worten: "I had had a firm intuition, (...) that the New York painting scene was filled with technical talent, but lacked an original creative principle, so that its work appeared one-step removed in origin" ${ }^{173}$ Die freie Assoziation, im psychoanalytischen Jargon der Surrealisten „psychic automatism“, leitete sein Handeln und bestimmte den Rahmen seines Wirkens. Dabei entwickelte er gewissermaßen einen Automatismus der in vielerlei Hinsicht starke Eigenschaften besitzt.

Motherwells Theorie orientiert sich stark an der Terminologie von Freud. So beschreibt er die freie Assoziation gemäß der Freudschen Terminologie von Unbewusstem, Vorbewusstem und Bewusstem. Jedoch scheint ,the resistance to the word 'automatism'... to come from interpreting its meaning as 'unconscious' in the sense of being stone-drunk or asleep, not knowing what one is doing." (...) Das Vertrauen im Unbewussten steht im Widerspruch zum Willen, denn "that which is reached is the fluid and free "fringes of the mind" called the pre-conscious." ${ }^{174}$ Das Bewusstsein greift immer in den Prozess ein. Anders als bei anderen Künstlern, bei denen die Schrift eine wichtige Rolle spielt, spielt bei Motherwell die Farbe eine zentrale Rolle neben der Schrift. Nur durch die Farbe ergibt sich hier die Bedeutung der Schrift.

An dieser Stelle weicht Motherwell von den Farbtheorien früherer abstrakter Künstler ab. Kandinsky etwa war, beeinflusst durch die Theosophen, von einer universellen Bedeutung von Farben und Formen ausgegangen. Kandinsky setzte Atheismus, Positivismus in den Wissenschaften und Naturalismus in der Kunst gleich ${ }^{175}$. Die Theosophie sah er als eine Bewegung, die den Materialismus überwinden und den

${ }^{172}$ vgl. Wheeler, 1991, S. 56.

173 ebd.

${ }^{174}$ Motherwell, Robert: The Significance of Miró, in: Terenzino, Stephanie (Hrsg.): The collected writings of Robert Motherwell, New York 1992, S. 114-120, hier S. 119 f.

175 vgl. Kandinsky, Wassily: Über das Geistige in der Kunst, 4. Aufl., Basel 1952, S. 36 f. 
Menschen dazu bringen könnte, sich wieder auf sein eigenes Wesen zu besinnen ${ }^{176}$. Kunst sollte nicht die Natur abbilden, sondern die innere Welt des Künstlers ausdrücken $^{177}$. Die Malerei hat es nach Kandinsky mit Farben und Formen zu tun. Während eine Form von der Farbe unabhängig ist - ein Dreieck bleibt ein Dreieck unabhängig von seiner Farbe - ist es unmöglich, eine Farbe auf dem Untergrund zu platzieren ohne dass sie eine Form annimmt. Ebenso wie reine Formen lassen sich auch reine Farben, etwa rot, denken, jedoch nur denken, da in der visuellen Praxis nur bestimmte Rottöne existieren ${ }^{178}$. Motherwell hielt diesen Gedankengang für überflüssig: „The 'pure' red of which certain abstractionists speak does not exist, no matter how one shifts its physical contexts. Any red is rooted in blood, glass, wine, hunters' caps, and thousand other concrete phenomena. Otherwise we should have no feeling to red or its relations, and it would be useless as an artistic element" ${ }^{\text {"179 }}$. Während Kandinsky die „psychische Wirkung“ ${ }^{180}$ von Farben durch Abstraktion hervorhob, da er meinte, Assoziationen mit materiellen Gegenständen seien zur Betrachtung der Kunst schädlich, hob Motherwell eben diese Verbindungen hervor aufgrund der Überzeugung, dass dieses die Ursache für die emotionale Stärke einer Farbe sei. Motherwells Sinn für Mystizismus und für die Wahl der Farbe kann man auf sein Interesse an prähistorischen Höhlenmalereien zurückführen. Er schrieb: „So lange ich mich erinnern kann, bin an Höhlenmalereien interessiert. Vergessen Sie nicht, ich bin ein Buchleser und habe eifrig Anthropologie, Soziologie, Psychoanalyse, Philosophie sowie die Dinge, die direkt auf die Kunst bezogen sind, gelesen. So kann ich Höhlenmalereien in jedem von hundert unterschiedlichen Zusammenhängen gesehen haben“"181. Mit seinem Interesse an H.öhlenmalerei hing seine Wahl der Farbe zusammen. "Primitive" Kunst verwendet die Konzepte der Primärfarbe anders als die der westlichen Kultur, die in der Wissenschaft der Farbentheorie gegründet ist. Die prähistorischen Malereien verwenden Farben, die aus den verfügbaren Pigmenten entwickelt werden, die schwarz, weiß, rot oder gelb einschließen, gelegentlich unter Hinzufügung von blau. Dieses beschreibt Motherwells persönliche Palette.

„Motherwell sucht seine Malerei zu verdichten, scheinbar einfache Beziehungen von Farbe und Form mit dem größtmöglichen Gehalt an Gefühl und Bedeutung aufzuladen.

\footnotetext{
176 vgl. Kandinsky, 1952, S. 42 f.

177 vgl. Kandinsky, 1952, S. 54 f.

178 vgl. Kandinsky, 1952, S. 66 f.

${ }^{179}$ Mattison, Robert Saltonstall: Robert Motherwell: The Formative Years, Ann Arbor 1986, S. 57.

${ }^{180}$ Kandinsky, 1952, S. 61.

${ }^{181}$ Mattison, 1986, S. 176.
} 
Geleitet wird er dabei von einem tief verinnerlichten Wissen um den Kampf einander widersprechender Elemente; Ambivalenzen, die es in der Kunst wie im alltäglichen Leben ständig in ein Gleichgewicht $\mathrm{zu}$ bringen gilt. Erst die solcherart erreichte Authentizität verleihen Werk und Persönlichkeit ihre spezifische Ausstrahlung. Bewusstsein und Unbewusstes, Struktur und Spontaneität, Zwang und Freiheit gehen ein in eine variantenreiche Bildsprache, die sich geometrischer, organischer, biomorpher, geradliniger, spontaner, präziser und von Zufall geprägter Elemente zu bedienen weiß“. ${ }^{182}$

Motherwell war durch sein Studium der französischen Literatur, seinen Aufenthalt in Paris und seine Bekanntschaft mit französischen Surrealisten im amerikanischen Exil enger mit der französischen Kultur verbunden als die übrigen Vertreter des abstrakten Expressionalismus ${ }^{183}$. Phasenweise verwendete er französische Wörter als Bildelemente. Ab 1955 malte Motherwell eine Serie von Bildern, die er Je t'aime betitelte. Allen Bildern gemeinsam ist, dass diese Botschaft darin als Schrift auftaucht.

Je t'aime II, 1955 (Abb. 30) ist in fünf vertikale Bildzonen aufgeteilt. Der zentrale Bildstreifen nimmt den größten Teil der Fläche ein. Sie ist zunächst mit weißer Farbe grundiert und dann mit orangefarbener und schwarzer Farbe bemalt. Die Farben wurden nass in nass direkt auf die Leinwand aufgetragen, so dass sie ineinander übergingen. Dadurch entstanden unterschiedliche Brauntöne. Auf der linken Seite schließt sich ein monochrom hellroter Streifen und ein etwas schmalerer orangefarbener Streifen an, rechts folgen ebenso ein roter und ein orangefarbener Streifen. Im Mittelteil lassen sich zwei ovale Figuren ausmachen, von denen die eine hellbraun, die zweite schwarz-weiß ist. Diese Figuren werden jeweils einzeln mit einer orangefarbenen Linie eingerahmt. Unter den Figuren zieht sich eine orangefarbene Linie zwischen den roten Streifen, die das Mittelfeld begrenzen, quer über das Feld. Unter dieser Linie befindet sich ein dunkelgraues Feld. Es ist teilweise mit weißen, hellbraunen und orangefarbenen Farbspuren bedeckt. Dieses Feld wird durch drei vollständige und ein auf der linken Seite angedeutetes Dreieck in Segmente gegliedert. Das Dreieck auf der rechten Seite ist schwarz, die übrigen sind hellgrau. Am unteren Rand des dunkelgrauen Feldes zieht sich eine dunkelbraune Farbspur entlang. Der Satz „Je t'aime“ wurde in schwarzer Schrift oberhalb der eiförmigen Formen geschrieben und spannt sich vom zweiten in

\footnotetext{
${ }^{182}$ Buhlmann, 1998, S. 51.

${ }^{183}$ vgl. Edel, in: Buhlmann, 1998, S. 133.
} 
den dritten Vertikalstreifen. Die schwarze Schrift vor dem hellen Hintergrund des Mittelstreifens erhöht ihre Lesbarkeit. Die Farbwahl (rot-orange-weiß-rot-orange) lässt den Satz deutlich hervortreten. Ein statischer Aufbau ist mit der malereispezifischen Verwendung der Ölfarben verbunden. Eine Redewendung wird verwendet, von der der Betrachter annehmen kann, dass sie dem Künstler persönlich wichtig sei, obgleich die Einzelheiten nicht im Kontext des Gemäldes erkannt werden können. Und schließlich werden diese individualistischen Aspekte, wie die assoziative Bedeutung und Spontaneität, gegen einen konventionellen Zugang zum Aufbau und zur Wahl der Grundfarben ausgespielt.

Allerdings beurteilt Motherwell die Verwendung des Französischen im Nachhinein als ungünstig: „Ich bedauere, dass ich mich so oft in meinem Leben auf das Französische bezogen habe, weil es den Eindruck gibt, ein bisschen geziert und überkultiviert zu sein. Tatsächlich könnte ich in den meisten meiner Aspekte kaum amerikanischer sein, und ich spreche Französisch, wie ein orientalischer Hausdiener Englisch spricht. Andererseits bin ich nicht besonders an Frankreich interessiert. Mein Interesse besteht an bestimmten Ideen der modernen Kunst ${ }^{\text {"184 }}$. Dass er dennoch eine Fremdsprache verwendete, kann teilweise als Motherwells Versuch gedeutet werden, seine Arbeit mit der Bewegung der Modernen Kunst zu verbinden, die er in Paris während der dreißiger Jahre kennen lernte.

Manche Kritiker schätzen Motherwells Werke als Protest gegen eine Tendenz in der modernen Malerei Amerikas Mitte der fünfziger Jahre, in oberflächliche Dekoration abzugleiten $^{185}$.

In den sechziger Jahren begann Motherwell eine neue Serie zu malen, die er mit Open betitelte. Britta Buhlmann gibt eine Anekdote wieder, wonach Motherwell eines Tages eine Leinwand habe zur Hand nehmen wollen. Dabei habe er bemerkt, dass auf ihr noch eine kleinere Leinwand lag. Anstatt diese nun einfach wegzulegen, habe er ihren Umriss mit Kohle nachgezeichnet, so dass schließlich auf der größeren Leinwand der Umriss der kleineren zu sehen war. Motherwell habe ursprünglich vorgehabt, diesen Umriss für die Gestaltung eines Bildes zu nutzen. „Ich überlegte zu diesem Zeitpunkt, das Bild entweder außerhalb oder innerhalb der kleineren Fläche zu malen. Und eines Tages

\footnotetext{
${ }^{184}$ Motherwell: Letter from Robert Motherwell to Frank O’Hara, in: Terenzino, 1992, S. 147-155, hier S. 154.

${ }^{185}$ vgl. Pleynet, Marcelin: Robert Motherwell, Paris 1990, S. 45, zitiert nach: Buhlmann, 1998, S. 52.
} 
entdeckte ich, dass das Bild keinen Strich mehr brauchte, dass es in sich bereits ein Bild war, eine schöne, ebene Fläche, schön, denn minimal durch das geteilt, was eine Zeichnung ist. Die Bildassoziation war eine, Öffnung', und da ich mehrere davon machte, wurde schließlich die Serie aus zweiundachtzig Gründen Open genannt ${ }^{\star 186}$.

Motherwell las auch Zen- Philosophie, die die Leere seiner „Open“-Serie direkt beeinflussen sollte. Sein Interesse an ,action painting“, kalligraphischen Pinselarbeiten, und Schwarz-Weiß-Malerei führte ihn zu japanischem Zenga (jap. Zen-Bild) ${ }^{187}$. Obgleich die Spontaneität von Zenga bedeutet, das Bewusstsein des Künstlers und nicht notwendigerweise seine Individualität $\mathrm{zu}$ entwickeln und $\mathrm{zu}$ reflektieren, passt Motherwell sie seinem eigenen Zweck an. Es ist eine erfolgreiche Kombination, die Motherwells späte Lithographien und Schwarz-Weiß-Malereien in ihrer Freiheit, Einfachheit und Energie auszeichnet. Die Lithographie "Hollow Men Suite, No. 2" 1985-1986 (Abb. 31) und die Radierung „Telemachia - Odyssey - Nostos“, 1985-1988 (Abb. 32) ähneln in ihrer Verwendung von Kreis, Dreieck und Quadrat Sengai Gibons (1750-1837) ${ }^{188}$ Tuschezeichnung „Symbole des Universums“ (Abb. 34). In der japanischen Shingon-Mystik ist das Quadrat ein Symbol für die Erde auf makro- und den Körper auf mikrokosmischer Ebene, das Dreieck Feuer und Sprache und der Kreis für Wasser und Geist. Die Zusammenfügung der drei geometrischen Figuren symbolisiert als im Makrokosmos die Gesamtheit des Universums und im Mikrokosmos die Gesamtheit des Menschen ${ }^{189}$.

Sengai hat Quadrat, Dreieck und Kreis von links nach rechts angeordnet. Links neben die Formen hat er 扶桑客初禅墨 ( fú sāng kè chū chán mò, chin.: japanischer Anfänger der Zen-Malerei) geschrieben, was wohl eine bescheidene Selbstbezeichnung sein sollte. . Es fällt auf, dass die Tuschestriche des Quadrates heller sind als die der anderen Formen und der Schriftzeichen. Das Dreieck muss nach dem Quadrat gezeichnet worden sein, da seine untere linke Ecke die rechte Seitenlinie des Quadrats teilweise

\footnotetext{
${ }^{186}$ Pleynet, 1990, S. 52, zitiert nach: Buhlmann, 1998, S. 55.

${ }^{187}$ Nach dem hundertjährigen Bürgerkrieg der Sengoku-Zeit (1478-1577) erlebte Japan eine neue kulturelle Blüte, die wirtschaftlich hauptsächlich durch die städtischen Kaufleute getragen wurde. In dieser Zeit versuchten die Zen-Meister, eine vereinfachte Form des Zen auch unter Nicht-Mönchen populär zu machen. Neben einer vereinfachten Sprache und der gegenüber der chinesischen leichter lesbaren Hiragana-Schrift stellten sie auch das Bild in den Dienst der Verbreitung des Zen. Einer der ersten Vertreter dieser Richtung war Takuan Sôhô (1573-1645). Theoretisch durchgebildet wurde die ZenMalerei von Hakuin (1685-1768), der als eigentlicher Begründer des Zenga im engeren Sinne gilt, vgl. Brasch, Kurt: Zenga (Zen-Malerei), Tokyo 1961, S. 49 ff. u. S. 115.

${ }^{188}$ Die von Sengai ,gemalten Bilder weisen viel Witz und Humor auf (...) Sein sarkastischer Witz führt ihn in manchen seiner Malereien zu Gestalten, deren geniale Deformierung an moderne europäische Kunst erinnern. Manche Bilder Sengais gemahnen an expressionistische Karikaturen“ (Brasch 1961, S. 120 ff.).

${ }^{189}$ vgl. Brasch, 1961, S. 184.
} 
schneidet. Der Kreis wurde zuletzt gezeichnet, da er die Basis- und die rechte Seitenlinie des Dreiecks schneidet. Motherwell hat zwar die geometrischen Formen, die auch Sengai benutzte, verwendet, sie jedoch nicht mit einer Beischrift versehen. In der „Hollow Men Suite, No. 2“ ordnete er die Formen von links nach rechts in der Reihenfolge Quadrat, Kreis und Dreieck an. Verglichen mit den genauen Formen bei Sengai machen bei Motherwell jedoch zumindest Kreis und Dreieck den Eindruck, sehr flüchtig gezeichnet zu sein. Das Dreieck - eher ein Keil - ist außerdem mit der Spitze nach unten gestellt. In „Telemachia - Odyssey - Nostos“ ordnete Motherwell die Formen in derselben Reihenfolge wie Sengai (Quadrat, Dreieck, Kreis) an, stellte jedoch auch hier das Dreieck auf den Kopf. Ober und unterhalb der Formen zeichnete Motherwell jeweils eine horizontale Linie. Auch hier erwecken die Linien den Eindruck, vergleicht man sie mit der Genauigkeit, mit der Sengai gearbeitet hat, sehr flüchtig gezeichnet zu sein.

„Es überrascht nicht, dass (...) der großzügig gesinnte Motherwell eine Kunst geschaffen hat, die durch keinen geringeren Dualismus als die Gottliebs bestimmt ist, einen Dualismus des monumentalen Gedankens und des momentanen Gefühls, der eiförmigen und eckigen Formen, die in Arbeiten kombiniert werden, die von kleinen, spontanen, zen-gleichen Kalligraphien zu großformatigen, durchdacht orchestrierten, fugenähnlichen Kompositionen reichen“ ${ }^{190}$.

\subsection{Die Inkarnation der ostasiatische Kalligraphie in den Bildern westlicher Künstler}

Die Zen-Philosophie und die ostasiatische Kalligraphie haben einen unverkennbaren Einfluss auf viele Künstler des Informel. Den Begriff Informel prägte 1950 der Kritiker Michel Tapié, um den neuen spontaneistischen Trend in der französischen Malerei von der geometrischen oder „formellen“, intellektuell abgeleiteten abstrakten Malerei abzugrenzen. Letztere war ein Erbe der dreißiger Jahre und blühte auch noch im Paris der Nachkriegszeit. Populär machte Tapié den Begriff informel mit seinem Buch Un art autre aus dem Jahre 1951. Darin stellt er einen deutlichen Bruch fest, den die spezielle Kombination der Qualitäten des Informel mit den vorangegangenen Richtungen gemacht hat. ${ }^{191}$

\footnotetext{
${ }^{190}$ Wheeler, 1991, S. $55 \mathrm{ff}$.

${ }^{191}$ vgl. Wheeler, 1991, S. 70.
} 
Im Laufe der fünfziger Jahre wurde der Informel der Pariser Schule zum internationalen Stil, dessen Einflussbereich sich über nahezu alle Länder in Europa erstreckte und viele lokale Schulen von zahllosen Variationen in der Form und im Prozess durchzog ${ }^{192}$. Neben dem Begriff art informel wurden auch die Begriffe tachisme und matiére sowie ihre Derivate in anderen Sprachen verwendet, um diese neue Kunstrichtung zu bezeichnen $^{193}$.

Ihren Durchbruch erlebte die art informel 1959 auf der ersten Biennale von Paris. Obwohl dort die etablierten Vertreter der abstrakten Malerei wie Hans Hartung nicht vertreten waren, zeigte sie, „dass die abstrakte Malerei, sei sie lyrisch oder tachistisch, von der kommenden Generation ebenso weitläufig angewandt wurde. Diese Anschauung stimmt mit dem herrschenden Diskurs der europäischen und amerikanischen kritischen Avantgarde überein, demzufolge die lyrische Abstraktion nun die ,Universalsprache’ der zeitgenössischen Kunst darstellte“194.

Die Universalität der abstrakten Malerei lässt sich etwa bei Alcopley studieren. Alcopleys „abstrakte Kalligraphien“ sind als „moderne Chinoiserien“ bezeichnet worden. „Modern“ in dem Sinne, dass schon im 17. und 18. Jahrhundert europäische Maler unter dem Einfluss chinesischer Vorbilder „Chinoiserien“ malten ${ }^{195}$. Die „Kalligraphie“ bei Alcopley ist insoweit „abstrakt“, als dass die Bildelemente in seinen Werken eben keine lesbaren Schriftzeichen sind.

War Alcopley von chinesischen Vorbildern beeinflusst, so Tobey von japanischen. Tobey sah sogar eine Wechselwirkung zwischen abendländischer und japanischer Kunst, als er beobachtete, dass japanische Maler in kunsttheoretischen Abhandlungen die Zen-Malerei mit dem eigentlich europäischen Ausdruck ,abstrakt“ beschrieben. Allerdings wies Tobey darauf hin, dass die Kunstideale des Zen-Buddhismus, wie Einfachheit, Unmittelbarkeit und Tiefe, nicht nur für alle Bereiche der Kunst, sondern auch für die Gestaltung des täglichen Lebens Gültigkeit hatten. Da auch die japanische Volksreligion, der Schintoismus, ähnliche Ideale vertrat, konnte Tobey sagen: „es ist ein

\footnotetext{
192 vgl. Wheeler, 1991, S. 79.

193 vgl. Wheeler, 1991, S. 61.

${ }^{194}$ Fleck, Robert: Five Artists, the same historical rupture, in: Parent, 1999, S. 129-198, hier S. 132.

195 vgl. Müller-Yao, Marguerite Hui: Der Einfluss der Kunst der chinesischen Kalligraphie auf die westliche informelle Malerei, Bonn 1985, S. 107.
} 
Ausdruck des Geistes“ ${ }^{196}$, des japanischen nämlich.

Umbro Apollonio stellt fest, dass neben Tobey Michaux seit 1933 von ostasiatischer Kalligraphie beeinflusst wurde. Dagegen habe Klee mit seinen Pflanzenideogrammen von 1930 die arabische Schrift zum Vorbild genommen. ${ }^{197}$.

Tobey bringt den Unterschied in der Malereiauffassung zwischen der abendländischen Kultur seit der Renaissance und den östlichen Kulturen so auf den Punkt: „Vergleicht man allgemein östliche und westliche Kunst, so könnte man sagen, dass die Künstler im Osten mehr an der Linie interessiert waren, im Westen mehr an der Körperlichkeit. Die östlichen Künstler waren sicher weit von der Renaissance-Vorstellung entfernt, auf die ein chinesischer Freund anspielte: ,Die Bilder westlicher Maler sind gerahmte Löcher'،198.

Den Zusammenhang von Schrift und Malerei im Fernen Osten erklärt Shiryu Morita damit, dass „beide (...) gemeinsame Elemente und in jedem Fall eine gemeinsame Grundlage [haben]. Vom Standpunkt der Formen aus sind es zwei Künste, bei denen es um die Linie und den Raum geht. Vom metaphysischen Standpunkt aus sind es zwei Ausdrucksformen, die den vitalen Schwung im Innern des Menschen erfassen und ihn dank eines entsprechenden physischen Elans nach außen projizieren“ “199. Darum war es möglich, zugleich Maler und Kalligraph zu sein ${ }^{200}$. Als die fernöstlichen Völker die europäische realistische Malerei kennen lernten, gaben einige Maler jeden Bezug zur Kalligraphie auf, während die Kalligraphen die Möglichkeit einer Weiterentwicklung ihrer Kunst ablehnten und der Formenkanon der Kalligraphie erstarrte ${ }^{201}$.

Unter den westlichen Künstlern, die sich in der 2. Hälfte des 20. Jahrhunderts mit fernöstlicher Kalligraphie beschäftigten, ragt Pierre Alechinsky (geb. 1927) mit seinen Werken hervor. Alechinsky lernte 1954 den chinesischen Maler Wallasse Ting kennen, der zwar selbst ein Vertreter des Informel war, dessen Kunst aber von traditioneller chinesischer Malerei und Kalligraphie ausging. 1955 hielt er sich auf Einladung des

\footnotetext{
196 Tobey, Mark: Aus dem Ausstellungskatalog der Whitechapel Gallery, London 1962, zitiert nach: Claus, 1963, S. 88-90, hier S. 89.

${ }^{197}$ vgl. Apollonio, Umbro: Schriftwerte im sogenannten Tachismus, in: Mahlow, 1963, S. XLV-LVIII, hier S. L.

${ }^{198}$ Tobey in: Claus, 1963, S. 89.

${ }^{199}$ Morita, Shiryu, in: Claus, 1963, S.104.

200 vgl. ebd.

${ }^{201}$ vgl. Morita, in: Claus, 1963, S. 105.
} 
informellen Kalligraphen Shiryu Morita in Japan auf, wo er Radierungen veröffentlichte und einen Film über japanische Kalligraphie drehte ${ }^{202}$.

Müller-Yao ist der Ansicht, dass Alechinsky zwar theoretisches Verständnis für die Prinzipien der fernöstlichen Kalligraphie gehabt, aber die Technik der Kalligraphie kaum beherrscht habe ${ }^{203}$. Als Beispiel dafür, wie Alechinsky von der ostasiatischen Kalligraphie inspiriert wurde, führt sie unter anderem „Variationen nach Sengai“ (Abb. 33) an ${ }^{204}$. Alechinsky nahm Sengais Tuschezeichnung „Symbole des Universums“ (Abb. 34) zum Vorbild. In den „Variationen nach Sengai“ setzt er die von Sengai verwendeten Figuren Kreis, Dreieck und Rechteck, die in der Symbolik des Zen für die Einheit der Welt stehen, ${ }^{205}$ in die Mitte. Hat jedoch Sengai die Figuren in der Reihenfolge Rechteck, Dreieck und Kreis (von links nach rechts) angeordnet, so bevorzugt Alechinsky die Reihenfolge Rechteck, Kreis und Dreieck. Bei Sengai berühren sich die Umrisslinien aller Figuren, das Dreieck schneidet sogar den Kreis. Alechinsky setzt dagegen die Figuren voneinander ab, wenngleich von der Umrisslinie des Rechtecks Farbschlieren bis zur Umrisslinie des Kreises reichen. Es fällt auf, dass Sengai die Umrisslinien der Figuren zwar mit einem dicken Pinselstrich, aber doch einigermaßen scharf konturiert ausgeführt hat, während sie bei Alechinsky stärker verwischt erscheinen. Im Gegensatz zu Sengai verzichtet Alechinsky auf eine Beischrift, dafür zeichnet er um die drei Figuren einen Rahmen aus kleineren Feldern, die mit abstrakten Figuren gefüllt sind.

Alechinsky hatte nicht die Absicht, die Technik und die Formensprache der ZenMalerei zu übernehmen. Die Gemeinsamkeit sah er eher in der Haltung, dass sich der Künstler in sich selbst versenken müsse, um seine Werke hervorbringen zu können ${ }^{206}$.

Gilt Alechinskys Interesse eher den theoretischen Überlegungen, schenkt André Masson (1896 - 1987) mehr der praktischen Umsetzung Beachtung. Schon in jungen Jahren beschäftigte sich Masson mit chinesischer Philosophie, seit 1925 setzte er sich in theoretischen Schriften und eigenen Bildern mit ostasiatischer Tuschemalerei

\footnotetext{
${ }^{202}$ vgl. Müller-Yao, Marguerite Hu: Der Einfluss der Kunst der chinesischen Kalligraphie auf die westliche informelle Malerei, Bonn 1985, S. 107.

203 vgl. Müller-Yao, 1985, S. 108.

${ }^{204}$ vgl. Müller-Yao, 1985, S. 109.

205 vgl. Linsmann, 1991, S. 118.

206 vgl. ebd.
} 
auseinander ${ }^{207}$. Für Masson, der zunächst das Stilmittel der ,écriture automatique" benutzte, bedeutete es keine große Schwierigkeit, ostasiatische Elemente der ostasiatischen Formsprache zu übernehmen, da die spontan, schnell und präzise gezeichnete Linie und spontane, nicht vom Verstand kontrollierte Niederschrift Merkmale beider Techniken sind ${ }^{208}$. Im Gegensatz zu den meisten Vertretern des kalligraphischen Informel, die dunkle Linien auf hellem Grund, aber auch zu Graves und Tobey, die helle Linien auf dunklem Grund bevorzugen, malt Masson seine graphischen Elemente farbig ${ }^{209}$. Masson grenzte sich vom Prinzip des reinen Automatismus ab, wie er in Zeichnungen von Kleinkindern oder Geisteskranken zum Ausdruck kam. Stattdessen überzeugte ihn das chinesische Prinzip des bewußten Automatismus. Dies ist insofern bewusst, als dass der Künstler oft mühsam eine Technik erlernen muß, die er dann, wenn sie ihm in Fleisch und Blut übergegangen ist, anwendet, ohne darüber nachzudenken - wie ein geübter Radfahrer auch nicht daran denkt, das Gleichgewicht halten zu müssen, sondern einfach losfährt ${ }^{210}$. Bevor der Maler mit seiner Arbeit anfange, so Masson, müsse der Maler seinen Geist von allen äußeren Dingen befreien, um in einem tranceartigen Zustand zu malen ${ }^{211}$. Wie Masson vom Geist der chinesischen Kalligraphie inspiriert arbeitete, kann man an der Tuschezeichnung „Multiplikation“ von 1943 (Abb. 35) und auch an der Farblithographie „Wirbel“ von 1956 (Abb. 36) beobachten. In „Multiplikation“ wird die Mitte des Blattes von einem Gewirr aus geschwungenen Linien eingenommen. Es ist auf den ersten Blick fast unmöglich zu erkennen, ob diese Linien in einem Zug gezeichnet sind oder ob Masson mehrfach ansetzte. Am unteren Ende des Bildes lassen sich zwei lose Enden erkennen. Den Rand des Bildes bedeckte Masson mit Tuscheschraffuren, die das Liniengewirr einrahmen. Die Räume zwischen den Linien sind teils freigelassen, teils mit Strichen unterschiedlicher Stärke gefüllt. Müller-Yao verweist auf die Ähnlichkeit der Linien mit der Ts'ao-Shu-Schrift, wie sie Huai Ssu in seiner Autobiographie verwendet hat (Abb. 37). Sie stellt aber auch insofern einen Unterschied fest, als dass Masson mit seinen Linien beinahe die gesamte Fläche des Blattes bedeckt, ohne dass man erkennen könnte, wo sie anfangen und wo sie aufhören. Dagegen folgen die Zeichen bei Huai Ssu der regelmäßigen Anordnung der chinesischen Schrift. Auch ist bei einem lesbaren Text das einzelne Zeichen wichtig,

\footnotetext{
207 vgl. Linsmann, 1991, S. 112.

208 vgl. ebd.

${ }^{209}$ vgl. Müller-Yao, 1985, S. 129.

${ }^{210}$ zum bewussten und unbewussten Handeln in der chinesischen Kalligraphie vgl. Müller-Yao, 1985, S. 246.

${ }^{211}$ vgl. Müller-Yao, 1985, S. 247 f.
} 
während bei Masson „figurative Elemente beziehungsweise Zeichenhaftigkeit“ ${ }^{212}$ keine Rolle spielen. Im Gegensatz zu „Multiplikation“ besteht „Wirbel“ aus einem einzelnen „Zeichen“. Das linke Drittel des Blattes ist mit einer dunklen Fläche bedeckt, das „Zeichen“ füllt in etwa die Bildmitte aus. Es ist aus einzelnen, gut abgrenzbaren, schwungvollen Strichen aufgebaut. Die Striche sind von einer feinen Schattierung umgeben, die insgesamt den Eindruck einer spiralförmigen Bewegung machen. MüllerYao weist auf die Ähnlichkeit zum Anfangszeichen der Autobiographie von Huai Ssu (Abb. 38) hin, wobei im Schriftzeichen spiralartige Bögen links neben, in „Wirbel“ auf einer Achse verlaufen, die durch einen langen, abwärts führenden Strich gebildet wird $^{213}$.

Massons Werke stellen in diesem Zusammenhang nicht einen einmaligen Fall dar. Zu den Künstlern, die von der chinesischen Weltanschauung und Kunst, insbesondere der Kalligraphie inspiriert wurden, zählt auch Julius Bissier (1893-1965). Seine Beschäftigung mit der Gedankenwelt Ostasiens begann nach dem Ersten Weltkrieg, als er 1919 den Freiburger Sinologen Ernst Grosse kennenlernte, der bis zu seinem Tod 1927 auch sein wichtigster Förderer war. Unter dem Einfluss Willi Baumeisters wandte sich Bissier 1929 von der Neuen Sachlichkeit ab und der abstrakten Malerei zu. Die Verwendung von Tusche und Pinsel, die Zeichenhaftigkeit der Bildelemente und die Pinselführung waren von der chinesischen Kalligraphie beeinflusst ${ }^{214}$.

Zwischen 1933 und 1945 konnte er nicht ausstellen, 1934 verlor er seine Stelle als Leiter einer Malklasse an der Universität Freiburg. Ohne je offiziell des Landes verwiesen $\mathrm{zu}$ sein, lebte Bissier bis 1945 in der ,inneren Emigration“. Seinen internationalen Durchbruch erlebte Bissier in den fünfziger Jahren.

Ein Beispiel für Bissiers Adaption chinesischer Kalligraphie ist eine Tuschekomposition aus dem Jahre 1955 (Abb. 39). Vor einem hellen Hintergrund sind vier kalligraphische Bildelemente zu sehen, von denen die beiden Zeichen in der Mitte deutlich größer sind als die am rechten und linken Rand. Das rechte Zeichen entstand offenbar durch Aufsetzen und anschließendes Drehen des Pinsels. Die übrigen Zeichen bestehen aus mehreren Strichen. Die mittleren Zeichen sind nach Müller-Yao lesbare Schriftzeichen,

\footnotetext{
${ }^{212}$ Müller-Yao, 1985, S. 264.

${ }^{213}$ vgl. Müller-Yao, 1985, S. 270.

${ }^{214}$ vgl. Müller-Yao, 1985, S. 111.
} 
links pai (Hundert) und rechts $h s i$ (Westen) ${ }^{215}$. Vergleicht man allerdings die Zeichen bei Bissier mit Müller-Yaos eigener Schreibung der chinesischen Ideogramme, fällt auf, dass pai bei Bissier einen sehr viel runderen Duktus hat und mit einem, höchstens zwei Strichen geschrieben ist, während pai bei Müller-Yao etwa sieben Striche benötigt. Beim $h s i$ verkürzt Bissier die beiden mittleren senkrechten Striche, die nur bis zum zweiten waagerechten Strich von oben reichen. Dazu verwendet Bissier einen senkrechten Strich in der Mitte, der bei Müller-Yao nicht vorkommt, ebenso die kleinen Querstriche, die bei Bissier im unteren Viereck auftauchen. Bissier hat die Zeichen nicht untereinander, wie es der traditionellen chinesischen Schreibrichtung entspräche, sondern nebeneinander gesetzt. Müller-Yao unterstellt Bissier, trotz seiner Annäherung an die chinesische Kalligraphie die spezielle Technik nicht zu beherrschen und „einen lebendigen raumplastischen Duktus“ vermissen zu lassen. Bissier sagte selbst über den Stellenwert der Tuschezeichnungen in seinem Werk: „Die Tuschen halte ich für das einzig wirklich originelle geistige Zeugnis in meinem wirren Malerleben““216. Seinen Platz innerhalb der weltweiten Malerei schätzt Bissier eher marginal ein: „Ich bin für die westliche Kunst ein für alle mal verloren und sitze demgemäß auf einem äußersten Ästchen, das nach dem äußersten Osten mehr tendiert als dem Westen“217. Bissier hat sich durch seine Hinwendung zur fernöstlichen Kunst von der westlichen Kunst getrennt. Wir bemerken, dass sich sein Werk größtenteils auf die ostasiatische Kalligraphie bezieht. Auch seine Technik und die von ihm verwendeten Materialien, Tinte, Wasserfarbe und Papier sind ostasiatisch.

Ein weiterer Künstler, der von ostasiatischer Kalligraphie beeinflusst wurde, war Henri Michaux. Er wurde am 24. Mai 1899 in Namur (Belgien) als Sohn eines Rechtsanwaltes geboren. Seine Schulzeit verbrachte er in Brüssel. Wegen der deutschen Besetzung Belgiens im Ersten Weltkrieg konnte er nach der Beendigung der Schule keine Universität besuchen. 1919 studierte er für kurze Zeit Medizin, 1920 bis 1921 fuhr er zur See. Danach betätigte er sich als Schriftsteller, wobei er einen Hang zur Mystik offenbarte. 1925 reiste er nach Paris, wo er die moderne Kunst kennenlernte. Er interessierte sich für die Arbeiten von Paul Klee, Max Ernst, Giorgio Chirico und Salvador Dali. "Das surrealistische Übernatürliche ist ein wenig vorhersagbar", sagte er, „aber ich würde nicht zögern, wenn ich die Wahl zwischen dem Übernatürlichen und

${ }^{215}$ vgl. Müller-Yao, 1985, S. 110.

${ }^{216}$ Vietta, Egon: Julius Bissier, in: Das Kunstwerk, 8-9/1950, S. 52 ff., zitiert nach: Müller-Yao, 1985, S. 111.

${ }^{217}$ Rose, Barbara: Miro aus amerikanischer Sicht, in: Katalog zur Ausstellung „Joan Miro“, Düsseldorf 1986, S. 103-141, hier S. 117, zitiert nach: Linsmann, 1991, S. 115. 
etwas anderem hätte. Lang lebe das Übernatürliche!“"218 1927 ließ sich Michaux endgültig in Paris nieder.

Im gleichen Jahr an zeichnete Michaux fiktive Alphabete deren Zeichen an Hieroglyphen und orientalischen Buchstaben orientiert waren ${ }^{219} .1930 / 31$ reiste er durch Indien, Indonesien, China und Japan, 1963/64 noch einmal nach Indien. 1937 hatte er in Paris seine erste Ausstellung. „Es ist zwar davon auszugehen, dass Michaux die Texte und Ideen der Surrealisten kannte, jedoch meint H. Schneider, Michaux sei den surrealistischen Experimenten mit psychischen Automatismen mit Skepsis begegnet. (...) Hier wird offensichtlich, dass es Michaux wie den Surrealisten darum ging, die inneren Schwingungen, die Regungen des Unterbewussten seismografisch auf das Papier zu bringen. Während sich die Surrealisten zugunsten des Bildes zunehmend vom Zeichen entfernten, erprobte Michaux Ausdruck und Dynamik des Zeichens. ‘220

Nach dem Tod seiner Frau 1948 konzentrierte sich Michaux auf seine Malerei und darauf, Berichte über seine Experimente mit Drogen zu schreiben. Das erste Buch über seine Drogenerfahrungen, „Turbulenz im Unendlichen“ erschien 1957. In einem weiteren Buch, „Unseliges Wunder, Das Meskalin“ von 1972 präsentierte er Zeichnungen und niedergeschriebene Gedanken in Verbindung mit genauen Angaben, wie viel Meskalin er eingenommen hatte ${ }^{221}$. Michaux nutzte den Meskalinrausch, um beim Malen die Kontrolle durch den Verstand auszuschalten ${ }^{222}$. An sich war dieses Verfahren nicht neu. „Auch die Surrealisten hatten mit Drogen experimentiert, aber keiner hatte vor ihm die Funktionsweise und die Auswirkung von Rauschgiften auf die Inspiration so systematisch erforscht ${ }^{223 ، 6}$.

Michaux war sehr schnell und produktiv. Wenn er mittels der Drogen die Bewusstseinskontrolle ausschaltete, unterdrückte er somit potenzielle Sinnzusammenhänge in der Schrift in seinen Bildern. Er zeichnete nur die Form und folgte ganz dem Rhythmus der Schreibbewegung. "Ich war besessen von Bewegungen, ganz angespannt durch die Formen, die mir äußerst schnell und rhythmisch zugeströmt

\footnotetext{
${ }^{218} \mathrm{http} / / / \mathrm{www}$. kirjasto.sci.fi/hmichaux.htm.

${ }^{219}$ vgl. Frémon, Jean : Degottex, Paris 1986, S.32.

${ }^{220}$ Linsmann, 1991, S. 95.

${ }^{221}$ vgl. Linsmann, 1991, S. 97.

${ }^{222}$ vgl. Mahlow, 1963, S.110.

${ }^{223}$ Linsmann, 1991, S. 96 f.
} 
sind ${ }^{\text {‘224 }}$, beschrieb er seine Arbeitsweise.

Die Zeichen in seinen Werken ähneln ostasiatischen Schriftzeichen. Man kann sie nicht lesen, aber manchmal als tanzende und manchmal als sich unregelmäßig bewegende Figuren erkennen. Meiner Meinung nach gibt es eine Beziehung zwischen dem Regelmaß der Bewegung und der Quantität der Drogen, die der Künstler einnahm, da ein von Drogen betäubtes Gehirn die Hand nicht kontrollieren kann.

In seiner Tuschezeichnung Dessin, 1962, (Abb. 40) sind Figuren in zeilenförmiger Anordnung zu erkennen, die an die Grundlinien auf altägyptischen Gemälden erinnern. Allerdings verwendet Michaux in dieser Arbeit Tiefenperspektive, im Gegensatz zu den altägyptischen Künstlern, deren Bilder perspektivlos waren. Bei längerem Hinsehen gewinnt man den Eindruck, dass die Zeichen keine üblichen Schriftzeichen sind, sondern allmählich menschliche Gestalt annehmen. Diese reihen sich in Linien, als führten sie eine tänzerische bzw. sportliche Schau vor. Die Figuren sind mit einer Art Schatten oder Nebel unterlegt. In der untersten Reihe erscheinen die Figuren am deutlichsten, in den oberen Reihen weniger deutlich. In diesem Werk erfüllt die Schrift nicht mehr die übliche Funktion, nämlich Sinn zu vermitteln, sondern wird zu Figuren und Bewegungen. Michaux schreibt Figuren und zeichnet Schrift.

Maria Linsmann schreibt: „Hier wird deutlich, dass Michaux in seinen Arbeiten den freien, ungehemmten, unmittelbaren Ausdruck einer einzigen, momentanen Regung des Unbewussten sah. Während in der konventionellen, der lesbaren Schrift ein Gedanke meist anders, über- und ausgeformter wird, wenn man ihn zu Papier bringt, so wird hier jede Regung, jede Schwingung des Geistes spontan und unmittelbar niedergeschrieben; seine Arbeiten sind, wie H. Schneider sagt "Reinschriften psychischer Protokolle"225.

\subsubsection{Mark Tobey (1890-1976)}

Mark Tobey wurde in Centerville / Wisconsin geboren. 1906 begann er, am Art Institute von Chicago Wochenendkurse zu belegen. Von 1908 bis 1911 war er Angestellter in einem Studio für Modedesign, seit 1911 arbeitete er als selbständiger Modezeichner in New York. 1917 wurden seine Werke erstmals ausgestellt. Von 1922 bis 1925 war er Kunsterzieher in Seattle. Dort beschäftigte er sich erstmals mit chinesischer

\footnotetext{
${ }^{224}$ Massin, Buchstabenbilder und Bildalphabete, Paris 1970, S. 262, zitiert nach: Linsmann, 1991, S. 96.

${ }^{225}$ Schneider, Helmut: Henri Michaux, in: Die Zeit Nr. 53/1987, S. 39, zitiert nach: Linsmann, S. 96.
} 
Kalligraphie. 1925 und 1926 reiste Tobey nach Europa und Persien, wo er begann, sich mit arabischer Kalligraphie zu beschäftigen. Von 1930 bis 1937 war er als Kunstlehrer an der Dartington Hall School in Devonshire / England tätig. Häufig unternahm er in dieser Zeit Reisen, so in die USA, Mexiko und 1934 nach China und Japan. Von 1938 bis 1960 lebte Tobey in Seattle. 1944 wurden seine Werke erstmals auf einer Einzelausstellung in der Willard Gallery in New York präsentiert, wo auch seine „White Writings“ zum ersten Mal gezeigt wurden. Mit einer Wanderausstellung 1951, die in San Francisco, Seattle, Santa Barbara und New York gezeigt wurde, gelang ihm der internationale Durchbruch. 1959 und 1964 stellte Tobey auf der documenta in Kassel aus. Von 1960 an lebte er bis zu seinem Tod in Basel. 1974 zeigte die Smithsonian Institution in Washington D.C. eine große Retrospektive Tobeys.

Tobey wurde durch unterschiedliche Quellen beeinflusst. Auf Reisen lernte er die islamische und die ostasiatische Kultur auf Reisen aus erster Hand kennen. Besonders wurde er dabei von der arabischen und chinesischen Kalligraphie angeregt. Auf die Frage nach der Herkunft der Quellen seiner Malerei antwortete Tobey: "Mine are the Orient, the Occident, science, religion, cities, space, and writing a picture instead of building it up in the Renaisance tradition" ${ }^{226}$. Tobey sagt damit aus, dass er aus der abendländischen Maltradition kommt. Wie er an anderer Stelle sagte, wurde er sich bewusst, „dass ich nie etwas anderes sein würde als der westliche Mensch, der ich bin““227. Orientalisch war nach Tobeys eigener Auffassung der Aufbau seiner Bilder aus Linien statt aus Flächen ${ }^{228}$. Wissenschaft und Religion ,are the two great powers which must be balanced if man is to become mature" ${ }^{, 29}$. Städte waren seit 1935 immer wieder Themen seiner Bilder ${ }^{230}$.

\subsubsection{Tobey und der Bahā'ismus}

Tobey, der von Hause aus Kongregationalist ${ }^{231}$ war, trat 1918 zum Bahā'ismus über ${ }^{232}$.

${ }^{226}$ Kuh, Katharina: The Artist's Voice, New York 1962, S. 236.

${ }^{227}$ Aus dem Ausstellungskatalog der Galerie Beyeler, Basel 1961, zitiert in: Claus, 1963, S. 91

${ }^{228}$ vgl. Kuh, 1962, S. 240.

229 ebd.

${ }^{230}$ Bildbeispiele in: Kuh, 1962, S. $241 \mathrm{ff}$.

${ }^{231}$ Der Kongregationalismus ist eine protestantische Glaubensrichtung, die an der Wende vom 16. zum 17. Jahrhundert in England entstand. Die Kongregationalisten lehnten die Gottesdienstordnung und die bischöfliche Verfassung der Kirche von England ab. Sie verlangten nach einem reinen Predigtgottesdienst nach der Ordnung Calvins und die völlige Unabhängigkeit der Gemeinden vom Staat oder übergeordneten kirchlichen Instanzen.

232 Tobey wurde häufig als Anhänger des Zen-Buddhismus angesehen. Zen ist allerdings im strengen Sinn des Wortes keine Religion, sondern eine Meditationstechnik. Darüber hinaus leugnet der Buddhismus die 
Diese Religion hatte sich seit 1844 aus dem schiitischen Islam entwickelt. Damals beanspruchte Mirza 'Alī Muḥammad (1819-1844), als „Bab“ (arab. Tür) Vorläufer des wiederkehrenden 12. Imams zu sein. Einer seiner Anhänger, Mirza Ḥussein 'Alī (18171892), beanspruchte die Prophetenwürde für das gegenwärtige Zeitalter. Er nannte sich Bahā'ullāh (Herrlichkeit Gottes). Kern seiner Botschaft war, dass alle Religionen in der Vergangenheit Manifestationen des Weltgeistes waren, die nun in einem einzigen Weltglauben aufgehen würden. Die Einheit der Religion zöge automatisch die Einheit der Menschheit nach sich. Nach Bahā'ullāhs Tod übernahm sein ältester Sohn Abbas Effendi (1844-1921) unter dem Titel 'Abd al-Bahā' (Diener der Herrlichkeit) als berufener Ausleger der Schriften Bahā'ullāhs die Leitung der Gemeinschaft. Von 1910 bis 1913 unternahm 'Abd al-Bahā' Missionsreisen nach Europa und die USA, wo er 1912 seinen Glauben verbreitete. Vielleicht motiviert durch die Erfahrungen des Ersten Weltkriegs trat Tobey dieser Glaubensrichtung bei ${ }^{233}$. Die „meditative Suche“ des Bahā̄̄-Glaubens ,nach der Einheit innerhalb der sichtbaren Vielfältigkeit des Lebens [schien] einen Schutz vor dem entmenschlichenden Effekt der amerikanischen Industrialisierung und ihres materialistischen Geistes anzubieten“234. Tobey glaubte, dass der Bahaismus das letztbegründende Prinzip für die Einheit aller menschlichen Kultur sei: Naturwissenschaft, Kunst, Religion, persönliche Lebensführung etc. ${ }^{235}$. Zeitlebens interessierte sich Tobey für Naturwissenschaften und Philosophie ${ }^{236}$.

\subsubsection{Tobey und der Ferne Osten}

Tobey lernte die ostasiatische Kunst durch Ernest F. Fenollosa (1853-1908), den Autor des Buches Epochs of Chinese and Japanese Art, kennen, der sich ihrer mit solchem Eifer angenommen hatte, „dass ihm die Wiederherstellung des Stolzes der Japaners an ihrem Erbe gutgeschrieben wird, zu einer Zeit, als Japan zum Westen schaute und seiner eigenen Vergangenheit den Rücken zugekehrt hatte ${ }^{237}$.

„M. Müller - Yao weist (...) in einer detaillierten Untersuchung nach, dass Tobey nicht nur von ostasiatischen Weltanschauungen und Kunstvorstellungen beeinflusst war,

Realität und den Wert des Seins, das er als Täuschung und Leid ansieht. Für den Bahaismus dagegen ist die Welt eine Emanation Gottes und der Mensch ist dazu ausersehen, die Welt zu gestalten, vgl. Seltz, 1984, S. 16.

${ }^{233}$ Rathbone, Eliza: Mark Tobey. City Paintings, Washington D.C. 1984, S. 20.

${ }^{234}$ Wheeler, 1991, S. 45.

${ }^{235}$ vgl. Seitz, William C.: Tobey’s world view, in: Dahl, Arthur L. (Hrsg.): Mark Tobey : art and belief, Oxford 1984, S. 13-21, hier S. 15.

${ }^{236}$ vgl. Rathbone, 1984, S. 56.

${ }^{237}$ Rathbone, 1984, S. 22. 
sondern dass er auch formale Mittel und Prinzipien der Kalligraphie, wie beispielsweise die chinesische Zellenform, die Verwendung lebendiger, raumplastischer Linien als bildnerisches Medium und die spezifische Technik des 'Hebens und Senkens' und des 'Drehens und Wendens' des Pinsels adaptiert hat. Er hat Technik und Methodik ostasiatischer Kalligraphie intensiv geübt, erlernt und schließlich verinnerlicht‘ ${ }^{\star 238}$.

1923 traf Tobey in Seattle Teng Kuei, einen chinesischen Kunststudenten an der Universität von Washington, welcher Tobey die philosophischen Grundlagen und die Technik der chinesischen Kalligraphie beibrachte. Dennoch dauerte es noch ungefähr zehn Jahre, bis Tobey Elemente der ostasiatischen Kalligraphie in seinen Werken verwendete. Auf seiner Reise nach China und Japan 1934 besuchte Tobey Teng in Shanghai und verbrachte in Kyoto einen Monat in einem Zen-Kloster. In den auf dieser Reise entstandenen Bildern setzte Tobey erstmals chinesische und japanische Schriftzeichen oder aus ihnen entlehnte Formen ein.

Seinem Reisebegleiter Bernard Leach zufolge war Tobey von den Hinweistafeln an chinesischen Geschäften fasziniert ${ }^{239}$. In China, 1934, (Abb. 41) erscheinen vor dem dunklen Hintergrund drei relativ helle Tafeln, die schräg hintereinander hängen. Rechts neben den Tafeln ist ein runder Bogen, vielleicht ein Fenster oder ein Gewölbe, zu erkennen. Die Tafeln sind mit Zeichen bedeckt. Die Zeichen auf der Tafel vorne rechts sehen wie ein schlangenlinienförmiges Muster aus. Die mittlere Tafel ist von der vorderen fast ganz verdeckt, so dass die Zeichen kaum zu sehen sind. Auf der Tafel hinten links sind in hellem Farbton einige miteinander verbundene Zeichen zu erkennen, die Zbikowski als authentischen Wortzeichen erstaunlich nahe kommend, wenn auch nicht als lesbar bezeichnet ${ }^{240}$. Tobey füllt, auch wenn er an sich wenig darstellt, doch fast die gesamte Oberfläche des Blattes mit Gegenständen aus. Für den Hintergrund, der zudem kaum deutbar ist, bleibt wenig Raum.

Wie China ist auch Shop Front, Hong Kong, 1934, (Abb. 42) mit Tusche schnell auf nassem Papier gemalt. In beiden Bildern benutzte Tobey chinesische Schriftzeichen oder Zeichen, die ihnen ähneln. In Shop Front, Hong Kong ist eine geöffnete Tür in einer Wand zu sehen, durch die der Blick in einen Raum fällt. Man kann zwei schemenhaft gezeichnete Menschen erkennen, die sich gegenüberstehen. Die vordere

\footnotetext{
${ }^{238}$ Linsmann, 1991, S. 111, vgl. Müller-Yao, S. 321-386.

${ }^{239}$ Vgl. Zbikowski, 1996, S. 393.

${ }^{240}$ vgl. ebd.
} 
Person, deren Körper bis auf den Kopf hell gehalten ist, geht anscheinend auf die zweite Person, die in einer Art Nische steht und deren Körper dunkel ist, zu. Zu Füßen der vorderen Person befinden sich zwei Gefäße. Der Raum macht durch die Innenstrukturen den Eindruck, ziemlich ausgefüllt zu sein. Am rechten Türpfosten des Raumes hängt eine Tafel, die den Anschein erweckt, von oben nach unten zuerst mit drei vertikalen und dann mit drei horizontalen Zeilen beschrieben zu sein. Darunter befindet sich quasi als Unterschrift ein Viereck, dessen Grundlinie von einem Strich gekreuzt ist. Über der Nische, in der die verschattete Person steht, hängt eine Laterne, auf welcher ein stilisiertes Schriftzeichen erscheint.

Nach der Rückkehr von seiner Asienreise malte er 1935 Broadway Norm, (Abb. 43) seine erste Arbeit in der „White Writing“-Technik. Auf einem braunen Hintergrund malte er überwiegend weißliche, zu einem kleinen Teil dunkle Linien, die in teils runden, teils eckigen Bahnen fast über die gesamte Bildfläche verlaufen. Die dunkleren Linien und der Hintergrund verursachen eine Bewegung in die Raumtiefe, der durch die sich überschneidenden Netze aus blassem Grau und Weiß umfasst und begrenzt und, so weit das Auge reicht, ununterbrochen geformt wird. Man kann bei der eingedrückten rundlichen Form in der Bildmitte noch erkennen, dass Tobey sie als Einzelfigur gemalt hat, ansonsten aber gehen die Linien unentwirrbar ineinander über. Tobey bemerkte, dass er den spontanen Bewegungsimpuls, wie er in der Zenmalerei gefordert wurde, angewandt hatte, das Bild aber mit der Formensprache der Zenmalerei oder mit ostasiatischer Kalligraphie nichts zu tun hatte. Weil er in diesem Bild die Energie New Yorks eingefangen glaubte, nannte er es Broadway Norm. Der Titel erst, der zudem erst im Nachhinein gegeben wurde ${ }^{241}$, funktioniert sinnstiftend. Neu an diesem Bild ist die absolute und ununterbrochene lineare Spontaneität, mit der es ausgeführt wurde, und, charakteristisch, die Entscheidung des Künstlers, weiße Farbe für die Linien zu verwenden. Der spontane Malimpuls ist der Zenkalligraphie und dem ,automatischen Schreiben“ des Surrealismus gemeinsam. Über diesen spontanen Impuls schrieb Tobey 1954 an Ulfert Wilke: „I have no system - I never know when I can paint; I just have to arouse myself -get into a state and forget all things if possible to make a union with what I am doing and the less I think of it -the paintings and myself, the better the result “ ${ }^{242}$. Obgleich durch orientalische Kalligraphie inspiriert, stellt Broadway Norm einen Fall in der Arbeit Tobeys dar, die nah an automatischem Schreiben ist, eine

\footnotetext{
241 vgl. ebd.

${ }^{242}$ Rathbone, 1984, S. 61.
} 
surrealistische Technik, in der der Künstler frei oder ,,automatisch“ zeichnet und dann seine Bilder in dem, was er gezeichnet hat, findet. Tobey war zweifellos mit dem Surrealismus vertraut. In Broadway Norm stellte Tobey erstmals abstrahierte Bewegungen dar, eine Technik, die er zunächst nicht mehr anwandte. Erst nach seiner Rückkehr nach Seattle 1938 wandte er das Stilmittel, kalligraphieähnliche Bilder zu malen wieder häufiger an. Mit komplexen abstrakten Mustern drückte Tobey seine „tiefe religiöse Überzeugung“ aus, „dass Raum, weit davon entfernt, ein Vakuum zu sein, ebenso durch geistige und körperliche Energie lebendig sei, wie feste Materie ${ }^{\text {2 } 243}$.

In den fünfziger Jahren erreichte Tobeys Stil seine Reife. Seine Bilder haben kein Zentrum, keinen perspektivischen Raum. Sie sind voller Zeichen und Buchstaben, die sich in einer solchen Dynamik über die Bildfläche verteilen, dass der Blick des Betrachters kaum an einer Stelle zu ruhen kann. Im Gegensatz zu den Malern der New York School war Tobey an Tiefenpsychologie nicht interessiert. Auch in seiner kleinteiligen Malweise unterschied er sich vom abstrakten Expressionismus. Einige Quellen, die bedeutenden Einfluss auf Tobeys Arbeit hatten, unterschieden ihn von seinen New Yorker Zeitgenossen: der Orient, seine Religion und sein fortwährendes Interesse an der sichtbaren Wirklichkeiten der körperlichen Welt. Vom Orient leitete er den „kalligraphischen Impuls“ ab, wie er ihn nannte, der der wesentliche Bestandteil seiner Art wurde; von seiner Religion leitete er Persönlichkeit, Stärke und Vision sowie einen Rahmen für sein Leben und seine Kunst ab; und von der sichtbaren Welt leitete er Ideen und Anregungen für das Denken und Malen während seiner Karriere ab. Anders als die abstrakten Expressionisten gab er nie den Bezug zur äußeren Welt auf, selbst wenn dieser sich nur im Titel manifestierte.

1954 begann Tobey die Meditative Series zu malen, in der er ebenfalls „White Writing“ verwendete. Ein Vorspiel zu dieser Serie war 1953 Edge of August (Abb. 44). Bis auf ein hellbraunes Feld in der unteren linken Ecke und einen dunkelbraunen Streifen im oberen Teil des rechten Randes ist das Bild sehr dicht mit kleinen weißen Strichen ausgefüllt, die so aneinandergesetzt sind, dass sie wie ein Gewebe wirken. Der Eindruck eines Gewebes wird noch dadurch verstärkt, dass auf dem dunkelbraunen Streifen weiße Striche in geringerer Dichte erscheinen, so als ob sie ausfaserten. Das weiße Gewebe ist mit hellbeigen Streifen durchzogen, die leicht gewellt von links oben nach rechts unten verlaufen. Diese Streifen setzen sich auch auf dem hellbraunen Feld 
unten links fort, erscheinen dort aber rötlich. Tobey selbst formuliert den Anspruch, mit diesem Gemälde ,to express the thing that lies between two conditions of nature, summer and fall. It's trying to capture that transition and make it tangible. Make it sing ${ }^{6244}$.

Authentische Zeichen der japanischen Silbenschrift Hiragana sind in Tobeys Bildern der 50er Jahre nachweisbar. Die Rezeption manifestiert sich in einzelnen Werken seiner Sumi-Tusche-Bilder ${ }^{245}$.

Da Tobey nicht versuchte, das asiatische Zeichen, die Kalligraphie des Ostens zu usurpieren, sondern, was wir eben als den ,kalligraphischen Impuls' bestimmten, in das westliche Bild einzubeziehen, wurden seine Zeichen nie zur Ideologie. Sie waren das subtile und bewegliche Instrument seiner bildnerischen und geistigen Intentionen.

In seinem Werk Sumi Still life, 1957, (Abb. 45), gezeichnet mit Tinte auf Papier, sind zwei Bildteile unterscheidbar. Von einem dunkleren Hintergrund hebt sich eine hellere Fläche ab, die wie ein Blatt Papier erscheint. Eine breite dunkle Linie markiert seinen Abschluss zum Hintergrund nach oben hin. Auf den helleren Bildgrund sind zwei Schriftzeichen in schwarzer Tinte angebracht. Das rechte Zeichen, das einem arabischen g (wau) ähnlich sieht, wurde in einem Zug, das linke in drei Zügen geschrieben. Es ähnelt dadurch einem japanischen Schriftzeichen. Der Künstler füllte sein Werk mit kleinen Zeichen (Punkten, Strichen, Haken, X-förmigen Kreuzen), die dem Werk eine gewisse Dynamik verleihen und dem Betrachter den Verlauf seiner Blicke vorgeben. Sollten beide Zeichen japanischen Schriftzeichen nachempfunden sein, so entspräche das rechte Zeichen dem Genitivpartikel „no“246. Das linke Zeichen scheint keinem realen japanischen Schriftzeichen zu ähneln. Müller-Yao stellt fest, dass man das „no“Zeichen in Tobeys Bildern häufiger finden kann. „Es ist eine lineare Form und Bewegung, die durch ihren zentrierenden Schwung wahrscheinlich das besondere Interesse Tobeys erregt hatte، ${ }^{\text {(247. }}$

Neben lesbaren verwendete Tobey auch verfremdete Zeichen. In der Aquatinta Trio von 1970 (Abb. 46) setzt er drei Gruppen von Zeichen nebeneinander. Die Zeichen, die sich

\footnotetext{
${ }^{244}$ Selz, Peter: Art in our times. A pictural history 1890-1980, London 1982, S. 426.

${ }^{245}$ Zbikowski, 1996, S. 404.

${ }^{246}$ vgl. Müller-Yao, 1985, S. 325.

247 ebd.
} 
in ihrer Helligkeit deutlich vom dunklen Hintergrund abheben, haben unregelmäßige Fortsätze, die sich in der Farbabstufung zwischen dem Hintergrund und den Zeichen zu befinden scheinen. Diese Zeichen ähneln chinesischen Schriftzeichen. Das Zeichen in der Mitte ist länger als die anderen. Diese Anordnung ist laut Zbikowski ein Zeichen dafür, dass keine reale Schrift vorliege, da in der chinesischen Schrift die Zeilen gleich lang, bzw., da die chinesische Schrift von oben nach unten und von rechts nach links verläuft, gleich hoch sein müssen. Nur die Schlusszeile, die sich am linken Rand eines Textes befindet, kann kürzer $\operatorname{sein}^{248}$. In Ostasien ist eine weiße Schrift auf dunklem Grund aus Musterschriften und Abreibungen bekannt. Tobey habe jedoch aus den Linien der Schriftzeichen Flächen gemacht ${ }^{249}$.

Obwohl Tobey von der östlichen Kalligraphie beeinflusst worden war, basierten seine Werke doch auf westlichen Wurzeln. Tobey wurde oft von einigen Kritikern vorgeworfen, ein Orientalist zu sein und östliche Modelle zu benutzen. Er selbst äußert sich gegenteilig: „,...) als ich mich in Japan und China mit ihrer Sumi- Tusche und dem Pinsel herumschlug in dem Bemühen, ihre Kalligraphie zu verstehen, wurde mir bewusst, dass ich nie etwas anderes sein würde als der westliche Mensch, der ich bin. Aber ich erhielt von dort das, was ich den kalligraphischen Impuls nenne“ ${ }^{250}$.

\subsubsection{Jean Degottex 1918-1988}

Degottex wurde am 25. Februar 1918 in Sathonay an der Rhône geboren. Von 1938 bis 1941 hielt er sich in Tunesien auf, anschließend ließ er sich als Maler in Paris nieder. Als Autodidakt malte er zunächst Landschaften im Stil der Fauves, bis er 1949 zur abstrakten Malerei fand ${ }^{251}$. 1951 gewann er den Prix Kandinsky. Bald danach wurde er von André Breton gefördert, „der ihn als einen Erforscher des psychischen Automatismus, der für die Surrealisten so wichtig war, ansah““252.

„Breton, whose constant preoccupation was to apply the notion of psychic automatism to all domains of human thought and activity, had, until then, encountered some practical resistance from painting. The time necessary for the development and

\footnotetext{
${ }^{248}$ vgl. Zbikowski, 1996, S. 410.

249 vgl. ebd.

${ }^{250}$ Aus dem Ausstellungskatalog der Galerie Beyeler, Basel 1961, zitiert nach: Claus, 1963, S. 91.

${ }^{251}$ Vgl. Art. „Degottex“ in: Lexikon der Kunst Bd. 4, Freiburg 1988, S. 5 und Durozoi, G.: Art. „Degottex“ in: Saur. Allgemeines Künstlerlexikon Bd. 25, München 2000, S. 236 f.

${ }^{252}$ Fleck, 1999, S. 134.
} 
realization of a painting would run counter to automatism, said painters in his entourage then. Upon discovering Degottex, he perceives a pathway for automatism in painting: a rapid movement of the brush which, as it also expresses the painter's inner soul, reveals not the things he observes but their spirit“" 253 .

1955 wandte sich Degottex der Lyrischen Abstraktion zu. Im gleichen Jahr fand eine Degottex-Ausstellung in der Galerie l'Etoile Scellee in Paris statt, deren Katalog von Breton und Charles Estienne verfasst wurde. Durch das Vorwort Bretons angeregt, befasste sich Degottex mit der Zen-Philosophie.

1957 begann Degottex, schriftähnliche Zeichen in seinen Arbeiten zu verwenden, die denen ostasiatischer Kalligraphien ähnelten. Dazu bemerkt Rolf Wedewer: „Diese Zeichensetzung äußert sich vielfach in gestischen Verläufen, deren formale Verwandtschaft mit asiatischen Schriftzeichen offensichtlich ist. In der chinesischen Schrift beispielsweise ist die Möglichkeit gegeben, das Bild des einzelnen Bedeutungszeichens gemäß den persönlichen Empfindungen des Schreibers umzuformen, (...) Von hier aus erklärt sich die formale Analogie der Gestik zur asiatischen Schrift, geht es doch auch in der Gestik darum, einen Inhalt durch den Duktus der Hand zu gestalten. Diese Zusammenhänge treten besonders deutlich (...) nicht nur auf der Ebene der formalen Analogie, sondern auch in Hinblick auf die zugrunde liegende Bedeutung [hervor]. Degottex beschäftigte sich im Jahre 1957 unter dem Einfluss der Philosophie des Zen mit ausgedehnten Studien zur Geschichte der Kalligraphie. Es ging ihm dabei vornehmlich um das Problem, von der Kalligraphie ausgehend eine europäische Kunst des Zeichens (un art de signe) zu entwickeln, ...Wir haben bei Degottex den Fall, dass die formale Analogie zur asiatischen Schrift sich nicht im Nachhinein von der Gestik ergibt, sondern auf der Ebene verwandten Denkens bewusst gesucht wird. ... Es ist bezeichnend, wenn Degottex kürzlich [1961] in einem Gespräch mit Julien Alvard äußert: 'Das Abendland ist, glaube ich, zu sehr auf Gegensätze festgelegt. Das, was sich in dem asiatischen Gedanken des Yin und des Yang ausdrückt, kennzeichnet weniger einen Unterschied, als eine Reihenfolge, vom Yin zum Yang'، ${ }^{254}$. Neben der ostasiatischen Kalligraphie wurde Degottex vom Surrealismus und Lettrismus, einer 1945/46 in Paris begründeten Kunstrichtung, in der ,ähnlich dem Dadaismus, Buchstaben zu sinnfreien Lautgebilden zusammengesetzt wurden,

\footnotetext{
${ }^{253}$ Frémon, 1986, S. 10.

${ }^{254}$ Wedewer, Rolf: Jean Degottex, in: blätter + bilder, 14/1961, S. 57 f.
} 
inspiriert $^{255}$.

Degottex beschrieb seine Herangehensweise an die Schrift folgendermaßen: „Suche nach einer neuen Sprache, gehe von der spontanen gestischen Schrift aus, die aus dem Unbewussten (dem Metaphysischen) entsteht Studiere zugleich den symbolischen und konkreten Wert der Geste in alten Schriften (der chinesischen besonders)“ ${ }^{256}$. Damit wollte er ausdrücken, dass seine Schriftbilder keine realen Schriften darstellen, sondern nur den Eindruck, den sie auf sein Unterbewusstsein gemacht hatten, wiedergeben sollten. Nach Müller-Yao weisen Degottex' Bilder Ähnlichkeiten mit Ts'ao-ShuKalligraphien auf, die „dynamische Bewegungsspuren in der Art chinesischer Fei-PaiTechnik (Überflogenes Weiß)،257 enthielten.

„Während viele westliche Maler der fünfziger Jahre nur eine oberflächliche Verbindung mit der fernöstlichen kalligraphischen Kunst haben, von der sie nur den Stil nachahmen, handelt es sich bei Degottex weder um Referenz, noch um Zitat, sondern um Intelligenz und um heimliches Einverständnis, sogar um eine vollständige Identifikation“‘258.

In seiner Hagakure BIII, 1957 (Abb. 47) schreibt Degottex Zeichen, die japanischer Schrift ähneln, mit schwarzer Farbe auf eine breite Fläche. Das Bild ist durch zwei weiße Linien in drei Felder unterteilt. Von links aus gesehen befindet sich das erste Zeichen größtenteils im linken Feld, sein Querstrich ragt etwas ins mittlere Feld hinein. Es ist so platziert, das der Querstrich zusammen mit dem Querstrich des zweiten Zeichens in etwa die Mittelachse des Bildes darstellt. Das erste Zeichen nimmt etwa ein Drittel der Höhe des Bildes ein, und zwar so, dass die Mittelachse des Bildes zugleich die Mitte des Zeichens ist. In der Breite nimmt das Zeichen in etwa den Raum der rechten zwei Drittel des Feldes ein. Das zweite Zeichen befindet sich größtenteils im mittleren Feld, sein Querstrich ragt etwas ins rechte Feld hinein. Bis auf einige Striche, die den Querstrich kreuzen, besteht das Zeichen fast nur aus diesem. Der längste dieser Striche ragt nach unten fast bis zum unteren Drittel des Bildes. Das zweite Zeichen nimmt in der Breite die rechten zwei Drittel des mittleren Feldes ein. Das dritte Zeichen befindet sich auf der rechten Tafel, wo es die in der Höhe die untere Hälfte fast bis zum Ende und in der breite einen vn der Hälfte etwas nach rechts verschobenen Raum

\footnotetext{
255 vgl. Fleck, 1999, S. 134.

${ }^{256}$ Degottex, Jean: Leitfaden, in: blätter + bilder, 14/1961, S. 56.

${ }^{257}$ Müller-Yao, 1985, S. 112.

${ }^{258}$ Breerette, Geneviève: La traversée des signes, in: Métalsi, 1989, S. 40-45, hier S. 41.
} 
einnimmt. Das erste Zeichen ist das komplexeste, das dritte Zeichen das einfachste. Der Hintergrund ist dunkelbraun, die Textur der Leinwand ist deutlich sichtbar. Die beiden Farben harmonisieren, so dass der Betrachter denkt, dass die schwarze Farbe eine dunkle Abstufung der braunen ist.

„,,Sho-do', wörtlich: ,der Pfad der Auserwählten', ist der Titel einiger Gemälde von 1960 (Abb. 48) und die gewöhnliche Bezeichnung für Kalligraphie in Japan. Es ist amüsant, wahrzunehmen, dass ein anderes Wort ohne semantische Anschlüsse die gleiche Transkription hat und ,Antrieb' bedeutet. Die Transkription in lateinische Buchstaben klärt nicht, welches Wort Degottex verwenden wollte, doch die Mehrdeutigkeit steht für sich. Während dieser Jahre verwendete Degottex häufig

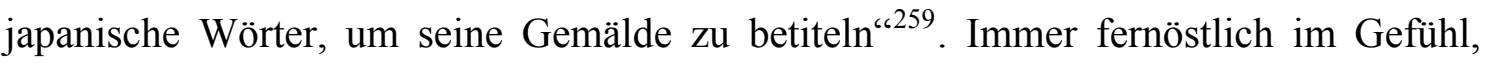
bewegt Degottex' Kunst sich zwischen Gesten und Zeichen, Zeichen und Schrift, sowie Lesbarkeit und Unlesbarkeit.

Müller-Yao meint über Degottex’ Bilder in ostasiatischem Stil: „Dennoch fehlt auch in seinen Werken die Beherrschung der kalligraphischen Technik und des raumplastischen Duktus, welche nur nach langer Übung zu erreichen sind, so dass hier auch die weiteren Bemerkungen Degottex' nicht weiter als im Sinne einer Inspiration wirksam gewesen sind“ ${ }^{260}$.

Degottex ,versuchte, die Hand soweit wie möglich zurückzuhalten, um so eine minimale Geste zu produzieren, eine vertikale Spur oder gekritzelte Kalligraphie, eine, inexpressive' Autonomie unbelastet durch Verstellung, psychologische oder subjektive Bezüge. Folglich ,desensibilisierte' der Gebrauch begrenzter Farben, wie der Künstler sie nannte (Schwarz, Grau, Weiß, Braun) damit ,die Dinge' von selbst ,liefen"، ${ }^{\text {‘261. }}$.

Degottex sagte: „Meine Malerei ist eine leichte, erregbare Sprache, die sich allem widersetzt, was in der konventionellen Sprache festgelegt ist (...) Allein diese Sprache bietet einen Zugang zum Unbewussten“،262.

\footnotetext{
${ }^{259}$ Frémon, 1986, S.15.

${ }^{260}$ Müller-Yao Müller-Yao, 1985, S. 112.

${ }^{261}$ Dupuy, Jean-Paul: Les Gestes uniques, 1997, zitiert nach: Parent, Beatrice: Painting « reinvented », in: Dies., 1999, S. 43-101, hier S. 49.

${ }^{262}$ Degottex im Gespräch mit Julien Alvard, in: Quadrum Nr. 10, 1961, zitiert nach: Breerette, 1989, S. 43.
} 
Ein Gemälde von Degottex entspringt nicht ausgeklügeltem Aufbau, sondern einem lebendigen, klaren gesturalen Antrieb, der in langer Meditation gründet. Er wird in Suite Serto 19-3-1957 (Abb. 49), in Schrift übersetzt, die der syrischen Serto-Schrift ähnelt. Eine große einheitliche Oberfläche, grau schattiert, ohne Perspektive, Tiefe oder materielle Effekte. Auf der waagerechten Mittelachse des Papiers hat Degottex ein „Wort“ geschrieben, jedenfalls erscheint auf der rechten Seite ein Zeichen, welches dem syrischen Aleph ähnelt. Dieses Zeichen erstreckt sich vom oberen Bildrand bis etwa zur Bildmitte. Man kann an einigen Stellen erkennen, dass Degottex den Pinsel nur leicht aufsetzte, da die sich die Tinte nicht gleichmäßig über die Schrieblinie verteilt und teilweise noch das Papier sichtbar ist. Jede einzelne Bewegung des Pinsels ist deutlich an den Strichen zu erkennen.

Sein Werk Suite Écriture (x) 12-1962 (Abb. 50) ist ein Ölgemälde. Man kann hier die einzelnen Arbeitsschritte ebenfalls erkennen. Der Hintergrund ist dunkel. In die getrocknete Farbe der Leinwand zeichnet der Künstler mit dem Pinselstiel, den er zwischen Daumen und Zeigefinger hält, eine Kalligraphie. Die zeichnende Bewegung enthüllt mehr oder weniger das Anfangsweiße der Leinwand. Neun aufeinander folgende Linien (der Schriften) erzeugen „eine Seite“. Man nimmt links den Beginn wahr, der Impuls reserviert einen Spielraum, während sich die Kalligraphie auf dem geraden Rand verliert. Für jede von ihnen ist die Schreibbewegung merklich verschieden: Anstiege, darauf folgende Abstiege, kürzere Ankündigungen, um in der Paraphe, der Unterschrift zu enden. Die Amplitude der Schreibbewegung ist erkennbar sowie die Geschwindigkeit ihrer Ausführung. Die verstohlenen Zeichen durchqueren die Leinwand. Die Füllungen und die Unverbundenheiten dieser unleserlichen, unbedeutenden Schrift sind die graphische Erfassung einer schöpferischen Handlung.

„Die Auf- und Abstriche der Handschrift sind ein Atem, ich möchte, dass meine Malerei der eine große Atem ist“, erklärte Degottex Julien Alvard 1961 ${ }^{263}$. „, Degottex sei es vornehmlich um das Problem gegangen, von der Kalligraphie ausgehend eine europäische Kunst des Zeichens zu entwickeln“،264.

Jean Fremont schreibt: „Mehrmals bereits haben wir die Gelegenheit gehabt, die Bedeutung der Schrift für Degottex' Werk zu erwähnen. Eine Schrift, die nichts

\footnotetext{
${ }^{263}$ Frémon, 1986, S.32.

${ }^{264}$ Wedewer, 1961, S. 58.
} 
bedeutet, oder eine, die nichts anderes bedeutet als die Stimmung und Bewegung des schreibenden Körpers, ein bloßer schriftlicher Antrieb“ ${ }^{265}$.

Maria Linsmann schreibt: „Der Künstler selber betont in Anlehnung an ostasiatische Geisteshaltungen die Bedeutung von Absichtslosigkeit, Leere und gestischer Trance beim künstlerischen Schaffen“‘266.

„So ist es nicht, genau genommen, die Entdeckung des Orients, die Degottex zu solchen Formen in der Malerei führt, sondern eher seine natürliche Anlage, die zu dieser Begegnung führt. ,Ich habe zu viel Norden in mir', sagt Breton; offenbar hat Degottex etwas Osten abbekommen“" 267.

Jean Degottex macht aus dem Zeichen eine Bewegung, vergleichbar wie viele europäische und amerikanische Künstler der Nachkriegszeit. Jedoch ist das Zeichen als Geste der wesentliche Bestandteil seiner bildlichen Sprache, die er offensichtlich benutzt, um die Geschwindigkeit seiner Bewegung abzubilden ${ }^{268}$. Trotz seiner Leidenschaft, Geschwindigkeit und der Kraft seiner Bewegung sowie der Genauigkeit seiner Pinselführung, ist die Malerei von Degottex nicht mit der Gewalt der einfachen Aktionsmalerei vergleichbar. Degottex ließ seine Untersuchung von Schrift, Farbe, Raum und Materie in einem außerordentlich mannigfaltigen Oeuvre nicht enden.

\subsection{Graffiti im Tachimus}

Der Name Tachimus wird vom französischen tache, „Klecks“ oder „Fleck“ abgeleitet und bezeichnet eine Anfang der 1940er Jahre erstmals in Paris aufgetretene Variante der abstrakten Malerei. Es ist nicht eindeutig, ob zuerst der französische Kritiker Charles Estienne 1950 mit Bezug auf in der Galerie Drouin ausgestellter Werke den abwertenden Begriff „tachisme“ geprägt hat, oder der Kunstkritiker Michel Seuphor anlässlich der Ausstellung „L'imaginaire“6269 . Estienne bezog sich dabei auf die losen, organischen und oft stark ertastbaren „Kleckse“ oder „Flecken“ der Farbe, mit denen die informalistischen oder tachistischen Künstler ihre gemalten Flächen in Netze von komplexer, interaktiver Emotion verwandelten. Wo die Oberflächenstruktur selbst der

\footnotetext{
${ }^{265}$ Frémon, 1986, S.31.

${ }^{266}$ Linsmann: 1991, S. 118.

${ }^{267}$ Frémon, 1986, S.11.

${ }^{268} \mathrm{vgl}$. Breerette, S. 40.

${ }^{269} \mathrm{http}: / /$ www.beyars.com/kunstlexikon/lexikon_8863.html
} 
hauptsächliche Träger für Gefühle wurde, besonders wenn das Impasto dicht und reich nuanciert ist oder in einer haute-pâte, wie man es in Fautriers otages sehen kann, aufgebaut ist, oder gerade durch solche körnigen, nicht in der Kunst verwendeten Materialien wie Sand, Zement, Eisenfeilspäne oder Sackleinwand gebildet wird, wird die Kunst häufig als matière oder „Materie“ - Malerei bezeichnet, deren Oberfläche emphatisch und konkret genug ist, um ein abstraktes Bild als paradoxe, existentiale Verkörperung sowohl von An- wie auch Abwesenheit erscheinen zu lassen ${ }^{270}$.

\subsubsection{Antoni Tàpies}

Antoni Tàpies wurde 1923 in Barcelona geboren. Er wurde vom Spanischen Bürgerkrieg (1936-1939) und einer katholischen Erziehung ebenso geprägt, wie vom intensiven Studium Nietzsches, Dostojewskys, Ibsens, Schopenhauers und der ostasiatischen Philosophien. Nach dem Bürgerkrieg begann er ein Jurastudium, das er aber 1943 abbrach und sich ganz der Malerei widmete. Tàpies hatte durch den katalanischen Philosophen Arnaldo Puig den Existentialismus kennen gelernt. Zwischenzeitlich hatte er mit dem Dichter Ioan Brossa zusammengearbeitet und ging 1950-51 nach Paris, wo er Picasso und Miró traf und sowohl den Kubismus wie den Surrrealismus studierte. Während der Surrealismus ihn befähigte, seine Phantasie zu beflügeln, „um bildlichen Reichtum in den ärmlichsten, wahllos vorhandenen Materialien zu sehen“, lehrte ihn der Kubismus, „seinen intuitiven, spontanen Ansatz durch die Disziplin solider, geometrischer Organisation zu zügeln.“271.

Im Rückblick auf seine frühe Schaffensphase schrieb Tàpies im Jahre 1969: „Meine ersten Arbeiten von 1945 hatten bereits etwas von Straßen-Graffiti und einer ganzen Welt von Protest - unterdrückt, heimlich, aber voller Leben - ein Leben, das man ebenso auf den Mauern meines Landes finden konnte“" ${ }^{272}$. Bis heute sind die Werke von Antoni Tàpies von der Beschäftigung mit populären Graffiti und prähistorischen Höhlenmalereien gekennzeichnet.

Ab 1954 experimentierte Tàpies mit einer neuen Maltechnik. Er mischte die Farbe mit Sand, Gips, Marmorpuder und Leim. Dieses mörtelartige Gemisch trug er auf die Leinwand auf, um es anschließend an einigen Stellen wieder wegzukratzen oder Figuren

\footnotetext{
${ }^{270}$ vgl. Wheeler, 1991, S. 70.

271 vgl. Wheeler, 1991, S. 79.

272 Wheeler, 1991, S. 79.
} 
hineinzuritzen ${ }^{273}$.

In „Kreuz aus Zeitungspapier“, 1946-47 (Abb. 51) taucht erstmals in Tàpies Werk lesbare Schrift auf. Bis heute verwendet er in seinen Bildern Ziffern, Buchstaben, Symbole, archaische Schriften, lesbare Worte, Satzfragmente und Zeichen, die teilweise deutlich vom Hintergrund abgesetzt werden.

Tàpies Verhältnis zur Schrift ,,is tied to his absorption in the complexities that underlie reality, the transformations that constantly occur in what we perceive as reality, and the relationship of that reality to spirituality“愺4 . Die „Worte“ bei Tàpies sind häufig nicht entzifferbar, so als würde er gedankenlos herumkritzeln. Hin und wieder tauchen aber auch lesbare Wörter auf, die einem oberflächlichen Betrachter vielleicht entgehen.

Für sein Werk Cruz y tierra, 1975 (Abb. 52), trägt er bis auf einen schmalen Streifen am oberen Rand einen rauputzähnlichen ockerfarbenen Untergrund auf eine Holzplatte auf, bei dem noch einzelne Sandkörner zu erkennen sind. Auf diesen Streifen schrieb Tàpies am rechten Rand mit blutroter Farbe den Buchstaben H. In der Mitte wurde ein scharf abgesetztes gleichschenkliges, flächiges Kreuz aus dem Putz herausgekratzt. Die Querbalken des Kreuzes in der Mitte werden teilweise von Stoffstreifen überlappt, die die Längsstriche des Buchstabens H bilden. Der Querstrich des H, der sich oberhalb des Kreuzes befindet, besteht ebenfalls aus einem Stoffstreifen, der nach rechts ein wenig, nach links deutlich über den Längsstrich hinausragt. Die Stoffstreifen waren ursprünglich weiß und wurden mit derselben Ockerfarbe bemalt, die auch der Untergrund hat. Die Stoffstreifen der Längsstriche wurden am oberen Ende nach links verdreht. Rechts unterhalb des Kreuzes kratzte der Künstler ein R heraus, dessen Bogen von einem weiteren gleichschenkligen Kreuz, das aber nur aus heraus gekratzten Strichen besteht, geschnitten wird. Links oberhalb des flächigen Kreuzes kratzte der Künstler die Buchstabenfolge $\mathrm{G}, \mathrm{a}, \mathrm{t}$ (?) heraus. Diese Buchstabenfolge wird vom linken Längsstrich des $\mathrm{H}$ abgeschlossen. Links neben das $\mathrm{H}$ setzte der Künstler ein $\mathrm{x}$ in einer Farbe, die an getrocknetes Blut erinnert. Mit derselben Farbe schrieb der Künstler ein R in den Zwischenraum zwischen dem Quer- und den Längsstrichen des H. Der obere Rand des Putzes ist mit blutroter Farbe bedeckt.

Häufig verwendet Tàpies vereinzelte Buchstaben, die er gleichzeitig als bildliche

\footnotetext{
${ }^{273}$ vgl. Linsmann: 1991, S. 120.

${ }^{274}$ Wye, Deborah: Antoni Tapies in Print, New York 1991, S. 24.
} 
Elemente und Träger codierter Botschaften verwendet ${ }^{275}$. In seiner 1974 entstandenen Lithographie (Galfetti Nr. 482; Abb. 53) hat er vor einem beigen Hintergrund in der Mitte ein schwarzes T gezeichnet. Das T wird teilweise von einem M verdeckt, das sich mit seinen Seitenstrichen über die ganze Breite und fast die gesamte Höhe des Bildes erstreckt. Die Mittelstriche des M treffen sich auf dem senkrechten Strich des T etwa in halber Höhe. Das M ist in weißer Farbe mit schwarzen Schlieren gehalten. Das Beige des Hintergrundes ist innerhalb des Raumes, der vom $M$ begrenzt wird, teilweise mit weiß aufgehellt. Rechts neben dem senkrechten Strich des T hat Tàpies in Schreibschrift mit schwarzer Farbe in zwei Zeilen drei Worte geschrieben (...ars ill B...ka?). Diese Worte hat er durch Einkästelung und Einkreisung hervorgehoben. Der rechte senkrechte Strich des Kästchens geht direkt in den Strich eines R über, hinter dem ein c (?) steht. Links neben dem $\mathrm{T}$ hat er auf dem aufgehellten Hintergrund zwei weiße Zeichen angebracht, ein Zeichen, das einem \& ähnelt und eine geschwungene Linie. Rechts neben dem T steht auf dem aufgehellten Hintergrund ein Buchstaben o oder die Ziffer 0. Rechts oben an das M schließt sich mit aufgehelltem beige ein Kringel, der mit keinem Schriftzeichen sicher zu identifizieren ist.

Tàpies verwendet das $\mathrm{T}$ auffallend oft in seinen Werken, das häufig als Initial seines Nachnamens oder als Initial des Vornamens seiner Frau, Teresa, gedeutet wird ${ }^{276}$. Das M wird häufig ,als Anspielung auf Tod (mort) gedeutet, als Drapierung, die um die Christusfigur in der Kreuzabnahme wabert, als die Linien in der Handfläche oder als die gespreizten Beinen einer Frau“6277. Man kann sich jedoch nie sicher sein, ob Tàpies wirklich eine Botschaft übermitteln oder nur einen spielerischen Umgang mit den Buchstaben demonstrieren will.

Als in den sechziger Jahren die demokratische Opposition gegen das Franco-Regime in Katalonien erstarkte, tauchten in Tàpies Werken häufiger deutliche politische Anspielungen auf $^{278}$, in Werken, die sich mit der Geschichte und der politischen Situation Kataloniens befassen, manchmal sogar ganze Wörter ${ }^{279}$, wie etwa auf Tafel 1 seiner Suite Catalana von 1972 (Abb. 54). Hier bilden vier blutrote, senkrechte Streifen einen Kontrast zum gelben Hintergrund. Dieses Form- und Farbgebung, die der der katalanischen Flagge entspricht, verwendet Tàpies häufig. Auf die Leinwand hat Tàpies

\footnotetext{
${ }^{275}$ vgl. Wye, 1991, S. 25.

${ }^{276}$ vgl. Augustî, Anna (Hrsg.): Tapies: the Complete Works Volume 2: 1961-1968, Barcelona 1990, S. 13.

277 vgl. Wye, 1991, S. 23.

${ }^{278}$ vgl. Augustî, 1990, S.16.

${ }^{279}$ vgl. Linsmann, 1991, S. 120.
} 
Namen und Begriffe aus der katalanischen Geschichte geschrieben, so etwa die Namen der aragonesischen Könige Jaime I. und Jaime II., des republikanischen Politikers Companys oder des mittelalterlichen Gelehrten Raimundus Lullus (katalanisch Ramon Llull). Über das Bild ist weiterhin der Slogan „Visca Catalunya“ („Lang lebe Katalonien“) verteilt, der während der Franco-Zeit häufig auf oppositionellen Demonstrationen zu hören war. Tàpies sagte dazu: "Ich möchte auf meinen Gemälden alle Mühen meines Landes einschreiben, selbst wenn ich missfallen muss: Das Leiden, die schmerzlichen Erfahrungen, die Gefangenschaft, eine Haltung der Revolte"280.

Carl Vogel bemerkt zum Werk Tàpies jedoch, dass es nicht direkt politischer Natur sei. Tàpies sei jedoch ein politischer Mensch. Die Suite Catalana transportiere dagegen eine unmittelbar politische Botschaft ,auf die einfachste Weise, die freilich nur der Eingeweihte versteht: sie zeigt das Panier, für das gestritten wird, vier rote Streifen auf gelbem Grund, die katalanische Flagge. Kennt man das Zeichen, so erkennt man es immer wieder ${ }^{\text {(281 }}$.

\subsubsection{Jean-Michel Basquiat}

Jean-Michel Basquiat (1960-1988) wurde als Sohn einer haitianisch-spanischen Familie in Brooklyn geboren. Nachdem er wegen Aufsässigkeit von einer Privatschule verwiesen wurde, begann er mit siebzehn Jahren, Graffiti zu malen. Dabei arbeitete er mit Al Diaz zusammen; ihre Graffiti signierten sie mit SAMO. Basquiat und Diaz achteten darauf, ihre Graffiti dort anzubringen, wo sie von Liebhabern der neuesten Kunst gesehen werden konnten. „Basquiats frühe ,Samo'-Graffiti kann eher als eine Art ,Anti-Graffiti' zu der bestehenden New Yorker Graffiti beschrieben werden. Er schrieb in einem bewusst ,ungekünstelten’ Duktus ${ }^{6282}$, der sich ,durch eine ironische, gebildete und raffinierte Beobachtung der Realität auszeichnete. Dabei beinhalten sie [die Graffiti] neben Resonanzen von afrikanischer Kunst, Jazz, Rap und Reggae auch die Gewalt als Ausdrucksform‘283.

„Basquiats spätere Integration von Schrift ins Bild übernimmt dieses ,understatement’

\footnotetext{
${ }^{280}$ Tàpies, Antoni, in: Le Pratique de l'art, Paris 1974, S. 85ff. zitiert nach: Antoni Tàpies (Amsterdam: Stedelijk Museum, 1980), S. 10. zitiert nach: Wye, 1991, S. 31.

${ }^{281}$ Vogel, Carl: Einführung, in: Galfetti, Mariucca (Hrsg.): Tàpies. Das graphische Werk, Bd. 1, Sankt Gallen 1975, S. XI.

${ }^{282}$ Reichling, Susanne: Jean-Michel Basquiat, Hamburg 1998, S. 37.

${ }^{283}$ Selzer, 2001, S. 216.
} 
des Geschriebenen und seine sozialkritischen Aussagen. Die Schnelligkeit und Spontaneität seines Schreibens sowie sein gesellschaftskritisches Anliegen haben mit dem Stil der Graffiti-Künstler New Yorks wenig zu tun“284. Im Sommer 1980 traten Basquiat und Diaz auf der „Times Square Show“ auf. Anfang 1981 machte sich Basquiat selbständig, als er auf der „New York/New Wave“ - Ausstellung im P.S.1 einen Satz ungestrichener Leinwände präsentierte, die spärlich mit kindlich anmutenden Kritzeleien in Kreide und Farbe bedeckt waren ${ }^{285}$.

In Hollywood Africans, 1983 (Abb. 55), ist die ganze Fläche des Bildes mit lesbaren Worten in roten, schwarzen und grünen Buchstaben auf gelbem Hintergrund gefüllt. Mehrmals wird die Phrase Hollywood Africans oben und unten auf dem Bild wiederholt, einige Male wird sie durchgestrichen. Weiterhin hat er schwarze, weiße und rote Kästchen gemalt, in die er Worte hineingeschrieben hat. Die schwarzen Kästchen sind in ihrer Fläche ausgemalt. Anschließend kratzte er Buchstaben hinein, die die Wörter TOBACCO und 200 YEN bilden. Links neben letzterer Aufschrift sind zwei schwarze Schuhabdrücke unterschiedlicher Größe sichtbar. Links neben das schwarze Kästchen mit TOBACCO hat er mit roter Farbe „Popcorn“ und darunter mit brauner Farbe SUGAR geschrieben. Auf der rechten Seite des Bildes hat Basquiat drei Köpfe gezeichnet. Unter dem äußert rechten Kopf erscheint eine Hand, auf der zweimal die Buchstabenfolge $P A W$ geschrieben ist, einmal grün und einmal rot. Links neben den Köpfen sind sechs fünfzackige Sterne gemalt, über ihnen die Worte SEVEN STARS. Auf der unteren linken Seite erscheint eine schwarze Fläche, als ob der Untergrund angebrannt sei. Darauf ist in weiß das Wort GANGSTERISM geschrieben. Links davon erscheinen Buchstaben, die mit roter Farbe geschrieben sind. Der schwarzen Fläche gegenüber befindet sich eine helltürkisfarbene Fläche.

Basquiat beschreibt das Leben auf der Straße, das er mit eigenen Augen sieht. Neben den äußeren Eindrücken schlagen sich auch seine Gefühle in seinen Bildern nieder. Obwohl er auf Leinwand malt, sehen seine Bilder wie Wandkritzeleien aus. Der Künstler benutzt die einfache und die automatische Schrift in seiner Zeichnung. Er interessiert sich für Details. Seine Zeichnung ähnelt Kinderzeichnungen und seine Werke schöpfen aus seiner Umwelt und ihrer volkstümlichen Kultur.

\footnotetext{
${ }^{284}$ Reichling, 1998, S. 37.

${ }^{285}$ vgl. Wheeler, 1991, S. 319.
} 
1984 entwickelte Basquiat die Technik, seine Zeichnungen mit einem Farbkopierer zu kopieren und sie anschließend auf Leinwand zu collagieren. Die Farbkopien bewahrte er in einem Bild/Textarchiv auf ${ }^{286}$.

„In seiner Kunst umarmte“ Jean-Michel Basquiat „die Zeichen der Konsumkultur, wobei er immer solche mit soziopolitischem Kontext wählte. In den populären Cartoons sah er eine tiefere Reflexion auf die Institutionalisierung von Rassismus und Diskriminierung sowie eine ironische Repräsentation von Gut und Böse in der Gesellschaft“، 287 .

Schriftzeichen spielen im Werk Basquiats eine ganz zentrale Rolle. Die Elemente Farbe, Figuration und Schrift existieren in seinen Bildern immer wieder gleichwertig nebeneinander. Dabei taucht immer wieder ein bestimmter Kanon von Zeichen und Formen auf, der immer wieder zu finden ist. So experimentierte er beispielsweise gerne mit Probe- und Arbeitstiteln oder setzte das Trademark- ( ${ }^{\mathrm{TM}}$ ) bzw. Copyright (C)Zeichen neben ausgestrichene Wörter. ${ }^{288}$

Mit seiner Integration von Schrift ins Bild knüpft Basquiat an die Tradition des Dadaismus, Futurismus und analytischem Kubismus an. Das Besondere bei ihm ist jedoch, dass er Hip-Hop-Texte in seine Bilder integriert, die durchaus laut gelesen werden sollen. Wie es jedoch beim HipHop nicht selten ist, haben die Wortkaskaden keinen syntaktischen Zusammenhang ${ }^{289}$. Ähnlich wie Anselm Kiefer, der Schrift in seine Gemälde einfügt, „um diese mit geschichtlichen, mythologischen oder literarischen Kontexten zu verbinden“, benutzt auch Basquiat die Schrift, um ,auf Dinge, Ereignisse und Zustände innerhalb und außerhalb des Bildraums“ zu verweisen“،290.

In Basquiats Bildtexten wird der Fluss der Wörter „durch das linkische Durchstreichen einzelner Buchstaben oder ganzer Wörter unterbrochen, im , Originaltext' der Farbkopie einstmals zusammenhängende Textstücke werden mitten im (unter Umständen sinnvollen) Text abgerissen, um keinen eindeutigen linearen Text mit einer diskursiven

\footnotetext{
${ }^{286}$ vgl. Reichling, 1998, S. 33.

${ }^{287}$ Selzer, 2001, S. 221.

${ }^{288}$ Selzer, 2001, S. 218.

${ }^{289}$ vgl. Reichling, 1998, S.36.

$290 \mathrm{ebd}$
} 
Aussage entstehen zu lassen“291.

Basquiat benutzte in seinen Arbeiten vorgefundene Worte, Zeichen und Piktogramme, die er „facts“ nannte. „Meine facts hole ich mir aus Büchern. Sachen über Zerstäuber, den Blues, Methylalkohol, Gänse im ägyptischen Stil. Ich beziehe meine Anregungen aus Büchern. Was mir gefällt, erscheint in meinen Bildern. Ich übernehme nicht die Verantwortung für meine facts. Sie existieren ohne mich. Eine Speisekarte in einem Restaurant ist ein Bild. Vielleicht esse ich den Schweinebraten nicht, aber sein Bild lebt weiter. Das Menü, die Schrift, sie existieren weiter ohne mich"292.

Neben Graffitikünstlern wie Keith Haring beeinflussten Basquiat Jean Dubuffet, Robert Rauschenberg, Willem de Kooning, Antoni Tàpies, Henri Michaux und Cy Twombly ${ }^{293}$; dennoch muss man Basquiat vor allem im Kontext der Afroamerikanischen Kunst sehen ${ }^{294}$.

Seine Bilder erinnern teilweise an schwarzafrikanische Volkskunst, teilweise an ein Sammelsurium der Straßen- und Gebrauchskultur nordamerikanischer Großstädte. Ähnlich mannigfaltig sind die Materialien und Techniken, die er verwendete. Er konnte alles zur Produktion von Bildern verwenden ${ }^{295}$.

„Fred Braithwaite bezeichnet Basquiats Schreibweise als die eines "linkischen Krüppels"296. Auch die Schriftart Twomblys ist linkisch, verweist ihn, wie es Roland Barthes formuliert, "in den Kreis der Ausgeschlossenen" ${ }^{297}$ Doch während Twomblys Schrift trotzdem selbstverständlich erscheint, suggeriert sie bei Basquiat immer ein mühsam erlerntes Schreiben. Basquiats Dysgraphie, seine Barbarismen, seine nicht beendeten, durchgestrichenen und neu geschriebenen Worte lassen den Betrachter den Prozess des Schreibenlernens nachvollziehen. Das durch Basquiats Schriftart konnotierte mühsam erlernte Schreiben weist auf dessen Bedeutung als "Menschheitszertifikat" hin. Laut Henry Louis Gates sind schriftliche Texte seit der

\footnotetext{
${ }^{291}$ Reichling, 1998, S. 40.

${ }^{292}$ Basquiat, in: Haenlein, Carl (Hrsg.): Jean-Michel Basquiat, Ausstellungskatalog, Hannover 1987, S. 23, zitiert nach: Selzer, 2001, S. 218.

${ }^{293}$ vgl. Selzer, 2001, S. 216.

${ }^{294}$ vgl. Reichling, 1998, S. 4.

295 vgl. ebd.

${ }^{296}$ Sischy, Ingrid. "Jean-Michel Basquiat as told by Fred Braithwaite a.k.a. Fab 5 Freddy." Interview. Oktober 1992, 119-123, zitiert nach: Reichling, 1998, S. 59.

${ }^{297}$ Barthes, Roland: Der entgegenkommende und der stumpfe Sinn. Kritische Essays III. Frankfurt 1990 (Orginalausgabe: L` obvie et l` obtus. Essais critiques III. 1982), zitiert nach: ebd.
} 
Aufklärung sichtbares Zeichen von Vernunft, von Zivilisation, von ,Menschsein'“. ${ }^{298}$

\subsection{Die Einheit von Denken und Sprache in der Konzeptkunst}

Die Konzeptkunst basiert auf der Überlegung, dass die „Idee“, die ein Kunstwerk verkörpert, wichtiger ist als das fertige „Produkt“. Das „Produkt“ hat eher den Charakter einer Dokumentation des schöpferischen Vorgangs als den eines „Kunstwerkes“. Diese Dokumentation kann auf vielerlei Arten erfolgen, etwa durch Fotos, Ton- und Videokassetten, Texte, Karten oder Diagramme ${ }^{299}$. Es sollen in dieser Arbeit nur jene Konzeptkünstler berücksichtigt werden, die in ihren Werken mit sprachlichen Mitteln umgegangen sind.

Man zählt die Konzeptkunst zu jener Kunstrichtung, in der die Verbindung zwischen Kunst und Denken manifest ist. Philosophie und Logik spielten dabei eine wichtige Rolle. Das half ihnen dabei, eine eigene Sprache vielfältiger Verständnis- und Interpretationsebenen $\mathrm{zu}$ entwickeln. Da die Interpretation notwendigerweise die Sprache voraussetzt, begreift man die unerlässliche Beziehung zwischen dem Denken und der Sprache, denn sie beide sind die bedeutendsten Themen der Konzeptkunst.

Daher lässt sich festhalten, dass die Sprache der Konzeptkunst einen einzigartigen Charakter verliehen hat. Sie erlaubte, neue und breite Möglichkeiten künstlerischer Techniken zu nutzen, die manchmal an Stelle von Bildern oder Plastiken treten. Zeitungen, Zeitschriften, Plakate, Postkarten, Telegramme, Bücher und Kataloge - als entsprechende Sprachdokumente - sind neue Mittel, denen sich die Konzeptkünstler zuwandten und als komplementäre Arten zur Vermittlung der Idee oder des Konzepts bedienten. Sie ermöglichten dem Konzeptkünstler, auf verschiedene Weise seine Kunst dem Rezipienten zu vermitteln. Hier taucht die entscheidende Rolle der Sprache in der künstlerischen Formulierung der Form auf.

1968 wurde in Coventry, England die Gruppe Art \& Language gegründet, die ein Jahr später das erste Heft der gleichnamigen Zeitschrift veröffentlichte. Seit ihrem Anfang verband sich die Bewegung mit renommierten Namen wie Michael Baldwin, Mel Ramsden und Charles Harrison. Die Bewegung verbreitete sich in England und in New

298 ebd.

${ }^{299}$ vgl. Art. "Conceptual art”, in: Chilvers, Ian (Hrsg.). The Oxford Dictionary of Art, 3. Aufl. Oxford 2004, S. 164 
York, im Jahre 1976 hatte sie 35 Mitglieder. Joseph Kosuth (geb. 1945), Terry Atkinson, David Bainbridge, Ian Burn, Harold Hurrell, Philip Pikington, David Rushton u. a. sind einige ihrer herausragenden Mitglieder. Alle diese Künstler widmeten sich Untersuchung der Sprache in der Kunst und veröffentlichten dazu eine Reihe von Aufsätzen. Sie stellten Karten, Akten, Urkunden und Dokumente aus, deren Titel Kunst als Form von Wissenschaft auswiesen. Ihre Aufmerksamkeit schenkten sie seit Bestehen der Gruppe der Aufgabe, eine Definition der Kunst zu finden. Neuartig war ihr Anspruch, dass nicht Bilder, sondern Texte betrachtet werden sollten. Dabei war es ihnen unwichtig, ob sich die Betrachter an literarischen Texten erfreuten oder aus Gebrauchstexten Nutzen zogen. Die Texte sollten angeschaut, nicht gelesen werden. Als Beispiel dient hier ein Werk von Mel Ramsden "100\% abstract", 1968 (Abb. 56), wo ein Etikett mit der Zusammensetzung von Farbe zum Kunstwerk erklärt wurde. Diese Wendung zur Analyse und Dekonstruktion der Sprache geht auf die Einflüsse der Strukturalisten wie Ferdinand de Saussure zurück, der sich der Analyse und Dekonstruktion der Sprache gewidmet hatte. Gerade strukturelle Linguisten wie Ferdinand de Saussure objektivierten die Sprache durch das Analysieren und Zergliedern $^{300}$.

Die Mitglieder der Gruppe Art \& Language interessierten sich für die Konzepte des Modernismus, vor allem für die Richtung „Art for Art's sake“, und den sie begleitenden Begriff von Individualismus und Originalität. Deshalb sahen sie in Dialog, Diskussion und Konzeptualismus ein Mittel, Kunst zu schaffen. Dies hielten sie für eins der wirksamsten Mittel, den verfälschten Vorstellungen, die die traditionelle Kunst unterstützten und verteidigten, entgegenzutreten ${ }^{301}$.

Die Konzeptkünstler gebrauchten die Sprache auf verschiedene Art und Weise und nicht nur als Mittel für rein künstlerische Zwecke, sondern auch zur Untersuchung gesellschaftlicher Fragen. Douglas Heubler (geb. 1924) und Hans Haacke (siehe dort) benutzten die Sprache zur Sammlung von Informationen, um einige Fragen mittelbar oder symbolisch zu behandeln. Diese Fragen sind meistens ihrem Wesen nach politisch oder sozial.

Die Bedeutung der Sprache als wesentliches Mittel in der Konzeptkunst erscheint auch

\footnotetext{
${ }^{300}$ Wheeler, 1991, S. 250.

301 vgl. ebd.
} 
greifbar, insofern sie den Konzeptkünstlern eine charakteristische Prägung verliehen hat. Ferner hat sie auch vielfältige Ausdrucksmöglichkeiten. In diesem Zusammenhang soll erwähnt werden, dass es bei Weiner und Heubler nicht bloß darum ging, sich von der Last und Fessel des Materials zu lösen, sondern auch darum, dass das hörbare und geschriebene Wort den Konzeptkünstlern ein neues und ausgedehntes Feld der künstlerischen Tätigkeit bot. Es gibt eine Beziehung zwischen dem Denken und der Sprache. Die Sprache ist das Rohmaterial des Denkens und ohne sie ist die Formulierung der Gedanken undenkbar. Sprache steht nicht vor dem Denken und ebenso ist die Vermittlung des Denkens ohne die Sprache undenkbar. Obwohl die Sprache manchmal ausweichend erscheint, kann man sie definitiv und entschieden zur Formulierung von Gedanken verwenden.

Emile Benveniste betont die Einheitlichkeit zwischen Denken und Sprache. „Dieser Inhalt [des Denkens] erhält Form, wenn er ausgesagt wird und nur so. Er erhält Form von der Sprache und in der Sprache, die die Form für jeden möglichen Ausdruck ist; er kann von ihr nicht getrennt werden und kann sie nicht transzendieren“"302. Diese Äußerung unterstreicht die Bedeutung der Sprache dem Denken gegenüber. In der Tat spiegelt diese Meinung präzise die Bedeutung der sprachlichen Formulierung als eine Voraussetzung zur Vermittlung des Denkens wieder. Es gibt viele sprachliche Möglichkeiten, die man zur Vermittlung der Gedanken und Begriffe benutzen kann. Performance, Tanz, Bewegung und auch Mimik sind Mittel, die man als besondere Sprachen zur Vermittlung von Gedanken benutzen kann, die durch die verbale sprachliche Form schwer auszudrücken bzw. zu vermitteln sind.

Viele Werke der Konzeptkunst zeigen, dass die Sprache für den Künstler ein wesentliches Mittel ist, seine Gedanken darzustellen. Als Beispiel kann John Baldessaris Werk angeführt werden, der darin die Sprache als wirksames Mittel zur Vermittlung des Gedanken erscheinen ließ. Nachdem er seine Werke aus dreizehn Jahren Arbeit zerstört hatte, schuf er sein erstes Konzeptkunstwerk, indem er immer wieder die Phrase „I will not make anymore boring art“ (Abb. 57) schrieb, ähnlich einem Jungen, der gezwungen wurde, nach Schulschluss hunderte Mal sein Versprechen an die Tafel zu schreiben, dass er nie wieder einen Regelverstoß begehen werde. Baldessari kommentiert dieses Werk mit den Worten: „I really care about meaning in art, (...) I want things to look simple, but to raise issues, and to have more

\footnotetext{
${ }^{302}$ Benveniste, Émile : Probleme der allgemeinen Sprachwissenschaft, München 1974, S. 77 f.
} 
than one level of comprehension“303.

Einige Beiträge der Konzeptkünstler waren in Form von Aufsätzen über die Konzeptkunst veröffentlicht worden. Darin hoben sie den Wert der Sprache als wesentliche Ausdrucksweise von Konzepten und Gedanken hervor. Erwähnenswert in diesem Zusammenhang ist Sol Le Witts Aufsatz „Paragraphs on Conceptual Art 1967“, in denen er relevante Themen behandelte, wie den Versuch, der Falle der formalen Perspektive und auch der Rolle der mentalen Teilnahme des Zuschauers bzw. Empfängers auszuweichen. Solche Beiträge hatten beträchtlichen Einfluss auf die Entwicklung der Konzeptkunst. Trotz der Übereinstimmung der Konzeptkünstler über die Bedeutung der Sprache, erhoben sich auch andere Stimmen mit anderen Meinungen, wie etwa Joseph Kosuth mit seinem Artikel „Art after Philosophy“, 1969, und seiner Vorlesung ,Art“.

Sol Le Witt unterscheidet sich von Joseph Kosuth in der Klassifikation der geschriebenen Sprache, die sich mit der Kunst auseinandersetzt. Sol Le Witt besteht darauf, dass seine Schriften über die Kunst bloß künstlerische Kommentare und nicht Kunst sind. Joseph Kosuth nimmt das Gegenteil an. Ende der sechziger Jahre geht er davon aus, dass über Kunst zu schreiben, genauso wichtig sei, wie die Kunst selbst. Bei ihm zielen die Gedanken auf Untersuchung der Natur der Kunst, was bei einem echten Künstler der Mühe wert sei ${ }^{304}$. Diese Überlegung war ihm Anlass für seinen bekannten Aufsatz „Art after Philosophy“, in dem er die Kunst vor Duchamp von der danach unterschied. Er argumentierte, Kunst sei eine Art Logik und Kunstwerke seien somit analytische Vorstellungen und Vorschläge, die sich mit der Definition von Kunst beschäftigten. ${ }^{305}$

Joseph Kosuths Werke, besonders sein Werk „Art as Idea as Idea 1966“ (Abb. 58) weisen deutlich auf diese Konzeption hin. Das Werk ist ein mit weißen Buchstaben auf dunklen Hintergrund geschriebener Auszug aus einem englischen etymologischen Wörterbuch, im Falle oben genannter Abbildung über das Wort „subject“. Die Fähigkeit der Sprache, etwas auszudrücken und neue Bedeutungen in den artikulierten bzw. geschriebenen Wörtern zu schaffen, zeigt sich in diesen Werken, die Sprache, die sich

\footnotetext{
303 zitiert nach: Wheeler, 1991, S. 251.

${ }^{304}$ vgl. Wheeler, 1991, S.247.

305 Joseph Kosuth: 'Art after Philosophy, 1', in: Guercio, Gabriele (Hrsg.): Joseph Kosuth. Collected writings 1966-1990, London 1991, S. 134-137.
} 
durch Entfremdung und Rätselhaftigkeit der darin enthaltenen Wörter, charakterisieren. Diese Wörter nehmen die Form von Symbolen an und weisen auf Bedeutungen und Gedanken hin.

Durch einige Verwendungen der Sprache werden manche Fragen über die Funktion von Wörtern, Syntax und Bedeutungsassoziationen der Sätze aufgeworfen. Die Sprache ist in der Konzeptkunst ein Gebilde von bestimmten Regeln, das Abstraktion anstrebt, die Beziehung der Sprache zur Wirklichkeit reduziert und ihr die Natur einer Kunstsprache verleiht.

Der Künstler Lawrence Weiner unterstreicht die Bedeutung der Sprache als Ausdruckmittel. Er ist der Meinung, dass es ohne Sprache keine Kunst gäbe ${ }^{306}$. Um diese Auffassung zu bestätigen, gab er die Malerei auf, um ein Heft mit Vorschlägen herauszubringen, von welchen er 196824 unter dem Titel „Statements“ veröffentlichte. Er sah die umfangreiche und vielfältige Ausdrucksfähigkeit der Sprache ein und beschloss, sie als wesentliches Mittel zu verwenden. Er sah auch, dass sie stark genug dazu sei, eine visuelle Figur, die Bedeutung enthalte, herzustellen ${ }^{307}$. In seinem Werk With Relation to the Various Manners of Use for / of Various Things, 1974 (Abb.59), zeigt er eine Satzgruppe, die mit Schablone auf die Wand des Ausstellungsraumes geschrieben auf ist. Sie lautet:

\section{WITH RELATION TO THE VARIOUS MANNERS OF USE}

FOR/OF VARIOUS THINGS:

HAVING HAD LEVERAGE FOR/OF

(WITH OR WITHOUT DIRECTION)

HAVING HAD ADVANCEMENT FOR/OF

(WITH OR WITHOUT DIRECTION)

HAVING HAD DIRECTION

(WITH OR WITHOUT ....)

Das Werk erzeugt eine Art Verfremdung und Verwunderung, als Folge der inkonsequenten Beziehung zwischen den traditionellen sprachlichen Begriffen und den sprachlichen Assoziationen im Verstand, die nach Mel Bochner von bestimmten Regeln beherrscht werden. Mel Bochner unterstreicht den engen Zusammenhang zwischen der

\footnotetext{
${ }^{306}$ vgl. Wheeler, 1991, S. 249.

307 vgl. ebd.
} 
Konzeptkunst und den feinen sprachlichen Assoziation ${ }^{308}$.

Obwohl das gedruckte Wort in den meisten konzeptkünstlerischen Werken, angefangen von Büchern bis zu Plakaten wiederholt vorkommt oder mit Photographien verknüpft wird, unterscheidet sich seine Natur von einem Werk zum anderen. Darüber hinaus unterscheidet es sich nach den Verwendungsweisen der Sprache oder der Malerei.

Die Konzeptkünstler beabsichtigten, aus der Funktion der Sprache in den künstlerischen Werken eine Art der mentalen Zusammenarbeit zwischen dem Werk und den Rezipienten herzustellen, wie Ibrāhīm Zakarīyā betont. Er schreibt: „Viele Werke der Konzeptkunst deuten darauf hin, dass die Verwendung der Sprache in unterschiedlichen Graden erfolgte. Man benutzte sie als Mittel, das viele Aspekte des Lebens zutage bringt. Bedeutungen und Begriffe variieren je nach der Verwendungsweise der Sprache. Das heißt, dass die Bedeutung der Sprache von der Art und Weise ihrer Verwendung abhängt ${ }^{\text {*309 }}$. Man benutzte die Sprache als Mittel, durch die Informationen über Themen oder Ereignisse dargeboten werden, um sie, obwohl sie kompliziert oder rätselhaft sind, leicht verständlich zu machen. Oft sind diese Themen oder Ereignisse politischer, sozialer oder ideologischer Natur und werfen Fragen nach der Notwendigkeit von Kunst in Politik, Gesellschaft und Ideologie auf. In dieser Hinsicht wird auf die Stellungnahme der Konzeptkünstler zu politischen Fragen oder Ereignissen hingewiesen, indem sie Sprache, teils allein, teils begleitet von einer Photographie, als Mittel benutzten. So hat die Sprache als eins der verbreitetsten Mittel der Konzeptkunst eine große Rolle gespielt.

Im Folgenden werden die wichtigsten Konzeptkünstler, die durch die Sprache Gedanken in ihren Werken ausgedrückt haben, vorgestellt.

Hans Haacke wurde am 12. September 1936 in Köln geboren. Er studierte von 1956 bis 1960 in Kassel, danach bis 1962 in Paris und Philadelphia und lebt seitdem in New York. Seit den siebziger Jahren versucht er, die Beziehungen zwischen der Kunst und der Gesellschaft künstlerisch darzustellen und zu kritisieren. Diese Arbeiten nennt er real time systems. Ein Beispiel dafür ist „Real Time Social System“, 1970, (Abb. 60). Diese Installation bestand aus zwei verschlossenen Plexiglasboxen und einer darüber aufgehängten Tafel. Auf dieser Tafel fragte er die Besucher des Museum of Modern Art

\footnotetext{
${ }^{308}$ vgl. Stangos, 1983, S. 259.

${ }^{309}$ vgl. Zakarīyā, Ibrāhīm: Falsafat al-fann fī-l-fikr al-mu'āṣir, dār miṣr li-'ṭ-ṭibā'a, Kairo.1987, S. 257.
} 
in New York, ob die Tatsache, dass Gouverneur Rockefeller ${ }^{310}$ die Indochinapolitik Präsident Nixons nicht verurteilte, ein Grund sei, ihn nicht zu wählen. Ja-Stimmen sollten in die linke, Nein-Stimmen in die rechte Box eingeworfen werden. Die Antworten wurden tabellenförmig aufgezeichnet und täglich per Post verschickt ${ }^{311}$.

Hans Haacke erkannte die Gefahr, die entsteht, wenn Kunst vom privaten Sektor, insbesondere industriellen Großspendern, finanziell abhängig ist. Es besteht die Gefahr, dass ein solcher Spender nur solche Projekte unterstützt, die ihm gelegen kommen und so der künstlerische Inhalt einer Zensur unterworfen wird, indem nicht dem Massengeschmack entsprechende oder kritische Kunst kaum noch an die Öffentlichkeit gelangt. Daher versuchte er, diese Probleme offen zu legen, ihre Aufdeckung zu fordern und Lösungen für sie zu finden. Dies geschieht in seinem charakteristischen Stil, der den in seinen Werken implizierten Inhalt untermauert und die konzeptkünstlerische Struktur deutlich zutage bringt. Haacke läßt in seinen konzeptkünstlerischen Werken eine Beziehung des Nebeneinanders zwischen Wort, Symbol und Photographie in einem einzigen Werk entstehen. So erhob er Protest gegen die despotische Interessenpolitik des Aluminiumkonzerns Alcan in der Republik Südafrika. „Voici Alcan“, 1983 (Abb. 61), besteht aus drei Firmenschildern Alcans unter denen sich jeweils eine Photographie in einem Aluminiumrahmen befindet. Die Photographie links zeigt ein Plakat mit der Aufschrift „Norma, produit par l'Opéra de Montréal avec des fonds Alcan“. Unten auf dem Plakat steht: „La filiale d'Alcan en Afrique du Sud a été désignée comme, industrie de pointe' stratégique par le gouvernement sud-africain. Les ouvriers noirs de la compagnie se sont mis en grève en 1981“. Auf dem zweiten Plakat steht oben „Lucia di Lammermoor, produit par l'Opéra de Montréal avec des fonds d'Alcan“, unten steht „La filiale d'Alcan en Afrique du Sud est le plus important producteur d'aluminium et le seul fabricant de tôle d'aluminium laminée en Afrique du Sud. Sur une main d'oeuvre de 2300 ouvriers de couleur la compagnie forme huit ouvriers spécialises“. Auf dem dritten Plakat ist der Leichnam des 1977 von der südafrikanischen Polizei ermordeten Schwarzenführers Steve Biko zu sehen. Oben auf dem Plakat steht geschrieben: „Stephen Biko. Leader noir. A succombé à des blessures à la tête reçues lors de sa détention par la police sud-africaine“, unten: „La filiale d'Alcan en Afrique du Sud vend au gouvernement sud-africaine des produits semi-finis pouvant être utilisés dans

\footnotetext{
${ }^{310}$ Nelson A. Rockefeller,1959-1973 Gouverneur von New York, war 1968 und 1972 Bewerber als Präsidentschaftskandidat der Republikaner.

${ }^{311}$ vgl. Arnason, H. H.: History of Modern Art: Painting, Sculpture, Architecture, Photography. 3. Aufl. New York 1986, S. 575.
} 
l'équipement policier et militaire. La compagnie ne reconnaît pas le syndicat de ses travailleurs noirs“. Die zwei Plakate links scheinen tatsächlich Plakate der Oper von Montréal zu sein, auch der Hinweis auf die Unterstützung der Oper durch Alcan könnte authentisch sein. Haacke verfremdete die Plakate durch die Hinweise auf Alcans Geschäftsgebaren in Südafrika. Mit dem dritten Plakat machte er indirekt Alcan für den Tod Bikos verantwortlich. Dieselbe Firma, die den Kanadiern einen schönen Opernabend ermöglichte, ermöglichte die Tötung Bikos. Haacke zielt mehr auf den soziologischen als den ästhetischen Gesichtspunkt der Kunst $a b^{312}$.

Joseph Kosuth wies darauf hin, dass es ein anderes Mittel als bildliche Darstellungen gäbe, Gedanken auszudrücken. Damit meinte er wohl die Sprache als Mittel zur Erforschung des künstlerischen Motivs. Das stimmt zum größten Teil mit seinen Überlegungen in den sechziger Jahren überein, die sich der Erforschung der Kunst an sich hingaben. Er glaubte, Erforschung der Natur der Kunst sei in sich Kunstschaffen. Das sei das einzige Anliegen, das der Mühe des echten Künstlers würdig sei ${ }^{313}$. Im Gegensatz zu Joseph Kosuths Verwendungsweise der Sprache als Forschungsmittel, neigte Lawrence Weiner zur „Reinigung seiner Kunst von allen visuellen Zeichen“. Er verwendete die Sprache, weil er sie als das einzige Vehikel seiner Gedanken ansah. Während Joseph Kosuth darauf bestand, die Sachen darzustellen, neigte Weiner im Jahre 1967 zum Verzicht auf die materialistische Existenz ${ }^{314}$.

Kosuth bildete in seinen Werken Artikel aus Lexika und Wörterbüchern ab. In seiner Serie Art as Idea as Idea, 1966 (Abb. 62), gibt er Einträge in einem etymologischen Wörterbuch als bildende Kunst aus. Eigentlich sollen sie „ein Projekt dualer Bedeutung repräsentieren, das durch das Sehen den Begriff der Kunst demonstriert“‘315. Dieses Werk demonstriert Kosuths Beschäftigung mit einer Idee und deren Begriffen, die er anhand einer Gruppe sprachlicher Quellen untersucht und in einem Kunstwerk darstellt. Das Werk stellt den etymologischen Ursprung des Worts „Idee“ dar. Das „Bild“ besteht aus dem Eintrag „Idee“ in einem englischen Wörterbuch, das zugleich die über das Lateinische entlehnte griechische Herkunft und die synonymen französischen Formen des Wortes Idee und seiner Derivate angibt. Das englische Wort „idea“ und das französische „idée“ werden über das lateinische „idea“ vom griechischen

\footnotetext{
312 vgl. Morgan, Robert C.: Art into Ideas: Essays on Conceptual Art, London 1996, S. 124.

313 vgl. Wheeler, 1991, S. 247.

314 vgl. Joachimides, Christos M. (Hrsg.): American Art in the 20th Century, Painting and Sculpture 19131993, München, 1993, S. 123.

${ }^{315}$ Walker, John A.: Art Since Pop, London 1975, S. 54.
} 


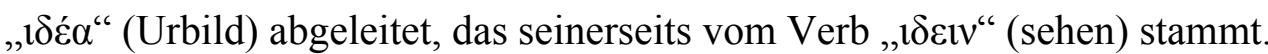

Zero and Not, 1986 (Abb. 63), ist die Vergrößerung einer Seite aus Sigmund Freuds Buch Psychologie des Alltags, die Kosuth 31 mal wiederholte, so dass die Schrift die Wände der Caselli Galerie vom Boden bis zur Decke bedeckte. Dann strich der Künstler die Zeilen absichtlich mit fetten schwarzen Linien so durch, dass man den Text trotzdem noch lesen konnte. Dieses Werk, wie Daniel Wheeler sagt, ein Wortspiel, in dem der Titel Zero \& Not (null und nicht) als überflüssiges Zero \& Naught (null und null) gehört warden kann. Es "reflects a way of thinking about how and what arts signifies, since for Kosuth, ,art is a definition of art' and ,exists for its own sake ${ }^{\text {}}{ }^{\text {(3) }}$.

Passend genug kam der Abschnitt von einem Kapitel, das mit „Federstriche“ überschrieben war, in dem Freud ein Telegramm seines Verlegers besprach, das „Versorgung erhalten, Einladung X dringend“ lautete, obwohl es den Erhalt eines Vorworts bestätigen und um eine versprochene Einleitung bitten sollte. „Wir können annehmen“, schrieb Freud, dass es einer Überprüfung durch einen hungrigen Telegrafisten zum Opfer fiel, in deren Verlauf die beiden Satzhälften enger verbunden wurden als vom Absender beabsichtigt." Wenn man sich diesen speziellen Text - Buchstabierfehler, die durch unbewusste Sehnsüchte ausgelöst wurden - in der Welt der Kunst vergegenwärtigt und dann auslöscht, scheint es, dass Kosuth die Transaktion, die zwischen dem Künstler und seiner Arbeit, der Arbeit und ihrem Betrachter auftaucht, verdeutlicht. Zur selben Zeit, in der das fertige Kunstwerk als nichts mehr als ein Echo seiner eigenen Schöpfung aufzutauchen scheint, erscheint es niemals mehr als die Totale der vorher existierenden, unbewussten Wünsche zu sein, die von den Betrachtern projiziert werden. Weil es nur solche Ausrutscher oder fälschliche Verbindungen sind, die der Künstler für immer aufzulösen versucht, ließ Kosuth die Phrasen nicht nur fallen, sondern wiederholte sie endlos, Seite an Seite, auf Deutsch und dann auf Englisch, wobei er weiterhin die normale Erfahrung des Lesens unterbrach. Also macht er eine Arbeit so vom Ort abhängig, dass, während Zero \& Not das Auge ebenso wie den Verstand belohnen könnte, es den Hunger des Marktes nach einem konsumierbaren, verkäuflichen Gegenstand verneint. Es muss darauf hingewiesen werden, dass einige Werke der Konzeptkunst, der Bedeutung nach, sich nicht selbst transzendieren.

${ }^{316}$ Wheeler, 1991, S. 248. 
Die intellektuelle Teilnahme des Zuschauers in der Konzeptkunst besteht darin, dass der Betrachter zum Versuch angetrieben wird, die Werke zu lesen, zu interpretieren und ihre Rätsel zu dechiffrieren. Oft zielte man darauf ab, den Zuschauer in eine Reaktion auf und den Umgang mit dem Kunstwerk zu ziehen. Augenfällig ist dies bei Hans Haacke, wo er versuchte, die Dinge bloßzulegen und Fragen beim Zuschauer auszulösen, um ihn zu Erschließung der Fakten anzutreiben. Demgegenüber treiben Robert Berrys und Lawrence Weiners Werke mit einer Art Rätselhaftigkeit und Verwirrung den Zuschauer dazu, die Gleichnisse ihrer sprachlichen Modelle zu dechiffrieren. So war der Betrachter nicht mehr der passive Empfänger, sondern der aktive Mitarbeiter, der über das Werk nachdenkt und versucht, es zu interpretieren.

Stellt Kosuth die Etymologie von Begriffen dar, so Hanne Darboven (geb. 1941) die Zeit. Sie benutzt reduzierte und wiederholende Formen. Das heißt, sie stützt sich in ihrer Darstellung des Zeitverlaufs auf die Reduktion der Ausdrucksmittel, die bei ihr zu bloßen Buchstaben und Zahlen werden. In diesem Zusammenhang meint Peter Selz, dass sie Zahlen zum Bau ihrer Werke benutze. Ihren Werken fehle jedoch eine symbolische Bedeutung. Die Zahlen seien eine bloße Widerspieglung des mentalen Zustandes der Künstlerin. Die Wiederholung verweise zwar auf bestimmte Entwicklung der Zeit wie auch auf die Erfahrung der Künstlerin ${ }^{317}$, beschränke sich aber auf die Ordnung der Zahlen in einer kalenderähnlichen Weise.

Die ersten Anfänge von Hanne Darboven zeigen ihre Neigung, eine Seite nach der anderen mit abstrakter Schrift und vielen Zahlen, die höchstwahrscheinlich einem Kalender entstammen, zu füllen. So erzeugt sie ein Gemisch von Zeichen und Zahlen, die sie so wiederholte, dass sie auf den unaufhörlichen Zeitlauf hinweisen ${ }^{318}$ (Abb. 64 und 65). Darbovens Verwendung der Ausdrucksmittel unterscheidet sich von der ihrer Zeitgenossen wie Roman Opalka (siehe Abb. 66) darin, dass sie großes Interesse daran hat, ihre Zeitrechnung durch ein den Werken beigelegtes Verzeichnis zu erläutern.

Die künstlerische Erfahrung Roman Opalkas half Darboven zur Entwicklung ihres Stils, den Raum der Galerie für ihre Werke umzufunktionieren und aus Gedanken und Begriffen ein einziges Gewebe zu machen. „In exhibition, Darboven covers entire walls with these pages of rhythmic, incessant scrawl and the effect of is of acumulative,

\footnotetext{
317 Selz, 1982, S. 47.

${ }^{318}$ vgl. Wheeler, 1991, S. 253.
} 
mesmerizing marking of time ${ }^{6319}$. Man kann dieses Werk (Abb. 65) als Dokumentation der unaufhörlichen Wiederholung mathematischer Zeichen von visueller Wirkung im Raum der Galerie verstehen ${ }^{320}$.

\subsection{Primitivismus als Alternative}

\subsubsection{Anselm Kiefer (geb. 1945)}

Anselm Kiefer wurde am 8. März 1945 in Donaueschingen geboren. 1966 begann er nach einem abgebrochenen Jura- und Romanistikstudium das Studium der Malerei in Freiburg. Kurz nach Beginn seines neuen Studiums besuchte er das Kloster La Tourette und lebte drei Wochen bei den Mönchen, um zu erfahren, wie „abstrakte fromme Ideen ein konkretes materielles Aussehen“ ${ }^{321}$ erhielten. Das war für ihn eine geistig wirkungsvolle Erfahrung. 1969 setzte er sein Studium an der Akademie der bildenden Künste in Karlsruhe fort. Von 1970 bis 1972 studierte Kiefer bei Josef Beuys in Düsseldorf, den er „,seinen Lehrer im weitesten Sinne des Wortes“3322 nannte.

Für Beuys war die Kunst der Gipfel der menschlichen Kultur im weitesten Sinne. Er konnte Mythen und Symbole aus verschiedenen Kulturen verarbeiten, aus denen er zusammen mit seinen Erfahrungen als Kampfflieger im Zweiten Weltkrieg neue Metaphern schuf. Ebenso unbegrenzt wie seine Offenheit gegenüber künstlerischen Themen war die für Techniken und Materialien. Vor allem schulte Kiefer bei Beuys seinen Ehrgeiz und sein Sendungsbewusstsein, „das heißt, den Wunsch, große Bereiche der menschlichen Geschichte innerhalb der Grenzen seiner Kunst zu erfassen“3323.

Im Gegensatz zu Beuys hat Kiefer keine eigene Weltanschauung, aus deren Warte er die Gesellschaft herausfordert, sich und ihre Probleme zu verstehen. Kiefers Bilder leben aus ihrer Mehrdeutigkeit. In Kiefers Werk bewirken „erst die Metaphern und Beschriftungen, die meist als Fremdkörper beispielsweise auf Landschaften aufgebracht sind, die Individualität und Deutbarkeit der einzelnen Bilder“ ${ }^{324}$. Beuys regte Kiefer an, die Auseinadersetzung mit der deutschen Geschichte und Mythologie zum Zentrum

\footnotetext{
${ }^{319}$ vgl. Stangos, 1983, S. 267.

${ }^{320}$ vgl. Wheeler, 1991, S. 253.

${ }^{321}$ Rosenthal, 1987, S. 10.

${ }^{322}$ Rosenthal, 1987, S. 12.

${ }^{323}$ Rosenthal, 1987, S. 13.

${ }^{324}$ Selzer, 2001, S. 201.
} 
seiner Arbeit zu machen.

Obwohl Kiefer häufig Themen aus der deutschen Geschichte und Mythologie aufgreift, ist er kein „,moderner Historienmaler (...), denn er hat wenig Interesse an der wörtlichen Aufzeichnung einer Erzählung،6325.

Vielen seiner Bilder schreibt Kiefer den Titel ein oder gibt ihnen Beischriften, die auf ihren Inhalt Bezug nehmen. Die Themen von Kiefers Bildern regen zu kulturellen Debatten an. Seine Beschäftigung mit den deutschen Sagen, Richard Wagners Opern oder mit einer dem heroischen Realismus nationalsozialistischer Künstler wurde von vielen Kritikern abgelehnt. Kiefer wäre allerdings missverstanden, würde man ihm Sympathien für den Nationalsozialismus unterstellen. Eher geht er davon aus, dass man das, was man bekämpfen will, erst einmal an sich heranlassen muss. „In einem System gesehen versucht Kiefers Kunst, uns mit Hilfe des Mythos durch den Vorhof jüngster Geschichte zu führen, hin zu Fragen des Seins. Mit anderen Worten: Der einzige Weg zu einer geistigen Vision führt durch die Welt ${ }^{326}$."

Trotz der Fülle an gedanklich-künstlerischen Motiven und Einzelheiten ist ein roter Faden in seinen Werken nicht schwer zu verfolgen. In seiner Arbeit Märkische Heide ,1974 (Abb. 67), malt Kiefer eine Landschaft. Das Geländeprofil ist leicht wellig. Durch die Landschaft hindurch führt ein Weg. Dieser beginnt am unteren Ende des Bildes und geht auf einem Fluchtpunkt am Horizont zu. Es ist als ob sich der Weg in den Himmel hineinbohre, so dass die Schnittstelle zwischen Weg und Himmel hellblau ist. Der Weg wurde in unterschiedlichen Farbintensitäten in den Farben weiß, blau und grün gemalt. Beiderseits des Weges kann man Vegetation vermuten, auch wenn sie bis auf einige Strukturen an den Wegrändern, die Gräser oder Sträucher darstellen könnten, wenig differenziert dargestellt ist. Bis auf drei kahle Birken im Vordergrund am rechten Wegesrand erscheint die ganze Vegetation überwiegend als grün-braune Masse. Die Landschaft erweckt dadurch den Eindruck, verbrannt und ohne Leben zu sein. Der Künstler benutzt dafür dunkle Farbtöne (schwarz, grün und gelb). Der Himmel nimmt ein Fünftel des Bildes ein. Er macht einen wolkenverhangenen Eindruck. Die kalten Farben, die am Boden benutzt worden sind, werden am Himmel wiederholt. Durch diese ausschließliche Verwendung kalter Farben, die miteinander harmonieren, wird der Eindruck, den die tote Landschaft auf den Betrachter macht, verstärkt. Wie bei vielen

\footnotetext{
${ }^{325}$ Rosenthal, 1987, S. 10.

${ }^{326}$ Hutchinson, John, Kiefers Welt, in: Anselm Kiefer. Ausst.kat. Stuttgart 1980, o. S., zitiert nach: Selzer, S. 200.
} 
Bildern Kiefers wird auch hier durch die Farbwahl eine düstere Stimmung erzeugt. Auf dem unteren Drittel des Weges schrieb Kiefer mit schwarzer Farbe „Märkische Heide“. Der Titel weckt Assoziationen an das gleichnamige $\operatorname{Lied}^{327}$ :

1.

Märkische Heide,

Märkischer Sand

Sind des Märkers Freude,

Sind sein Heimatland.

Sind des Märkers Freude,

Sind sein Heimatland.

Steige hoch, du deutscher Adler,

Hoch über Sumpf und Sand,

Hoch über dunkle Kiefernwälder,

Heil dir mein Brandenburger Land.

Hoch über dunkle Kiefernwälder,

Heil dir mein Brandenburger Land.

2.

Uralte Eichen,

Dunkler Buchenhain,

Grünende Birken

Stehen am Wiesenrain.

Grünende Birken

Stehen am Wiesenrain.

Steige hoch.......

Dieses Lied war ein beliebtes Soldatenlied und ruft damit auch Erinnerungen an viele blutige Schlachten in Brandenburg, zuletzt am Ende des Zweiten Weltkrieges, hervor. Kiefer stellt seine Landschaften keineswegs romantisch-verklärend dar, Sehnsucht ist ihm fremd. In seinem unerbittlichen Realismus nimmt er eine „kalte, sogar distanzierte Haltung“328 gegenüber einer deutschen Landschaft ein. Das Motiv der Birken taucht auch in Kiefers Gemälde auf, wenngleich sie bei ihm gerade nicht grünend sind.

Kiefer konfrontiert seine Betrachter, die nach jahrzehntelanger Vorherrschaft der

\footnotetext{
${ }^{327}$ Text und Melodie (1923): Gustav Büchsenschütz (1902-1996), in: Frisch gesungen! Singbuch A für die unteren und mittleren Klassen der höheren Knabenschulen, für Knabenmittelschulen und verwandte Lehranstalten Bd. 1, 80. Aufl., Hannover 1938, S. 116.

${ }^{328}$ vgl. Rosenthal, 1987, S. 35.
} 
Abstraktion, bei der ,the medium the message“ ist, mit einer Bildsprache, die nur deuten kann, wer über die entsprechenden kulturellen Hintergrundinformationen verfügt. Indem Kiefer Schrift in seine Bilder einschreibt, lässt er die Betrachter jedoch nicht ganz allein. „Um die Bedeutung von Kiefers Bildern zu enträtseln, ist es erforderlich, die Aussagen des Künstlers und die Muster der Bilder mit einer Analyse des Charakters seines Werkes und den Worten, die auf die Oberfläche geschrieben sind, zusammenzubringen. Dieser Zugang ist besonders für die Kunst angebracht, die vom Anfang seiner Karriere bis 1980 datiert, als sein Ehrgeiz größtenteils auf den Inhalt konzentriert zu sein schien“6329.

„Kiefer bietet Kunst als theoretisches Gegengift für den Terror der menschlichen Geschichte und des Scheiterns der mythischen Gestalten an. Sie diente Beuys in einer ähnlichen Funktion, der sich vorstellte, dass sie enorme stärkende Energie habe: ,Nur Kunst ist fähig, die repressiven Effekte eines vergreisten Gesellschaftssystems zu zerstören, das fortfährt, entlang dem Abgrund zu taumeln’ . Früher im Jahrhundert hatte auch Wassily Kandinsky vorausgesagt, dass Kunst tatsächlich Menschen von einer verdorbenen Gesellschaft wegführen würde. Die idealistische Auffassung ist, dass, während Kunst dem Reich der Männer und Frauen angehört, sie auf einer höheren Ebene als die bloße Geschichte zu existieren scheint und die erhabensten und positivsten Bestrebungen der Menschheit darstellt ${ }^{\text {‘330. }}$

In Die Ordnung der Engel, 1983-84 (Abb. 68), malt Kiefer eine Felsenlandschaft in verschiedenen Schwarz- und Brauntönen, die fast bis an den oberen Bildrand reicht. Über der Landschaft erstreckt sich ein grauer Himmel, in dessen Mitte eine helle Fläche erscheint. An dieser Stelle stößt eine Bergspitze, auf die die Felsenlandschaft zuläuft, in den Himmel. Auf die linke Seite des Himmels hat Kiefer mit dunkelgrauer Farbe „Dionysius Aeropagita“ geschrieben, auf die rechte „die Ordnung der Engel““. Dionysius, ,einer aus dem Rat“, wie Luther das griechische A $\rho \varepsilon о \pi \alpha \gamma \imath \tau \eta \varsigma$ übersetzt, war einer der wenigen Männer, die nach der Predigt des Paulus in Athen den christlichen Glauben annahmen (Apg 17,34). In der kirchlichen Tradition wurde er der erste Bischof von Athen. Wahrscheinlich im 5. Jahrhundert in Syrien entstand eine Schrift „Über die himmlische Hierarchie“, die diesem Dionysius zugeschrieben wurde. Ausgehend vom Bibelvers Gen 1,1 „Am Anfang schuf Gott Himmel und Erde“, wird in dieser Schrift

\footnotetext{
${ }^{329}$ Rosenthal, 1987, S. 10.

${ }^{330}$ Rosenthal, 1987, S. 56.
} 
ausgesagt, dass mit „Erde“ das natürliche Universum, mit „Himmel“ die Welt der Engel gemeint sei. Die öde Felsenlandschaft könnte sich dann auf den Zustand der Erde beim Beginn der Schöpfung beziehen, von der ausgesagt wird, dass sie „wüst und leer“ gewesen sei (Gen 1,2). Da nach dem Schöpfungsbericht von Gen 1 die Erde am Anfang von einer Chaosflut bedeckt war, spielt die Felsenlandschaft eher auf Gen 2,5 an, wonach am Beginn der Schöpfung der Erdboden eine trockene Wüste war. Die helle Fläche am Himmel, an den die Bergspitze stößt, erinnert an die Gotteserscheinung auf dem Berg Sinai, von der es heißt, dass sich „ein Donnern und Blitzen und eine dichte Wolke auf dem Berge“" erhoben (Ex 19,16). Das Bild beschriebt den Augenblick, in dem „Gott eine himmlische Hierarchie anordnete ${ }^{\text {‘331 }}$. Durch hellgraue Linien, die vom Himmel ausgehen, sind neun einzelne Felsen, die das Wesen der Engel symbolisieren, da der Fels ,in vielen Traditionen als heilig betrachtet wird“3332 mit ihm verbunden, entsprechend den Ordnungen in der himmlischen Hierarchie. In absteigender Ordnung von Gott sind es: Seraphim, Cherubim, Throne, Herrschaften, Mächte, Gewalten, Fürstentümer, Erzengel und Engel. Am Ende der Linien, wo sie den Himmel berühren, steht der Name der Ordnung auf einem Schild, bei den Felsen im Vordergrund ihre Ordnungszahl in römischen Ziffern. Dabei ändert Kiefer die traditionelle Rangordnung der Engel. Mit I. bezeichnet er die Throne, mit II. die Cherubim, mit III. die Seraphim, mit IV. die Mächte, mit V. die Herrschaften, mit VI. die Gewalten, mit VII. die Fürstentümer, mit VIII. die Erzengel und mit IX. die Engel. Es fällt im Bild auf, dass die erste Ordnung ganz rechts beginnt und nach links hin absteigen. Allerdings hat Kiefer nicht den Engeln, also der neunten Ordnung, den Platz ganz links gegeben, sondern den Erzengeln, also der achten Ordnung. Die Engel haben ihren Platz an der zweiten Stelle links. Weiter fällt auf, dass die Felsen, welche jeweils eine Engelsordnung symbolisieren, im halbrund im Vordergrund angeordnet sind. Lediglich die Felsen für die sechste und siebente Ordnung befinden sich tiefer im Raum. Wie üblich in den Bildern Kiefers, sind Zahlen wichtig; in diesem Fall zählen sie die himmlischen Kategorien auf und ordnen sie. Die Seraphim und Cherubim werden außerdem durch Schlangen dargestellt. Das hat vermutlich damit zu tun, dass die Cherubim nach Gen 3,24 den Weg zum Baum des Lebens bewachen, während im Gilgamesch-Epos der Baum des Lebens durch eine Schlange bewacht wird. Weiterhin sind die geflügelten Seraphim (hebr. Sing. saraph) in Jes 6,2 semantisch von Schlangenarten abgeleitet, wie dem „feurigen fliegenden Drachen“ in Jes 14,29 (hebr.

\footnotetext{
${ }^{331}$ Rosenthal, 1987, S. 137.

332 ebd.
} 
saraph me'opheph) oder den „feurigen Schlangen“ in Num 21,6 (hebr. ha-seraphim hanaḩaš). Auch die eherne Schlange die Mose in Num 21,8 anfertigen soll, wird als saraph bezeichnet.

Beim genauen Lesen fällt auf, dass Kiefer den Namen Dionysius Areopagita in Aeropagita umgewandelt hat. „In diesem Fall ist es die ausdrückliche Absicht des Spiels, eines der [vier] Elemente hervorzuheben (...). Erstens leben Engel in der Luft. Zweitens ist „Aero“ ein Spiel mit den französischen Worten aérer, was „die Luft bewegen“ oder „,üften“ bedeutet, und aérien, „luftartig“, „himmlisch“ oder ,in der Luft lebend“; ebenso erinnert es an Worte, die mit aéro- anfangen und sich auf Flugzeuge beziehen“6333.

Durch seine Kunst fordert Kiefer den Betrachter auf, sich mit seiner Kultur und Geschichte auseinanderzusetzen. Mit Hilfe der Kunst soll der Schmerz über die Entzauberung der Welt abgemildert werden. Auch den schlimmsten Themen kann man sich durch die Kunst annähern, ohne abgeschreckt zu werden. Letztlich illustriert sie die Frage: „Kann sie oder kann sie nicht die Probleme des Lebens lösen?“ ${ }^{334}$. Es stellt sich allerdings die Frage, ob Rosenthal das Werk Kiefers nicht metaphysisch überfrachtet. In einem ZEIT-Interview anlässlich seines 60. Geburtstages antwortete Kiefer auf die Frage nach dem Sinn des Lebens - die beantwortet werden muß, bevor man nach den Problemen des Lebens fragt -: „Den gibt es für mich nicht. Ich halte das Leben aus, indem ich in einem kleinen Bereich eine Ordnung herstelle. Ordnung ist nicht der richtige Begriff. Indem ich in meiner künstlerischen Tätigkeit einen Zusammenhang herstelle. Sonst würde ich nicht leben“" ${ }^{335}$. Kiefer selbst misst seiner Arbeit also erheblich weniger Gewicht bei, als Rosenthal dies tut.

\subsubsection{A. R. Penck (geb. 1939).}

A. R. Penck, eigentlich Ralf Winkler, wurde am 5. Oktober 1939 in Dresden geboren. Mit zehn Jahren begann Winkler nach eigenen Angaben, Landschaften und Porträts zu malen ${ }^{336}$. Nach dem Ende seiner Grundschulzeit 1953 belegte er einen Mal- und Zeichenkurs an der Volkshochschule Dresden. Bei seinem Lehrer Jürgen Böttcher traf

\footnotetext{
333 ebd.

${ }^{334}$ Rosenthal, 1987, S. 60.

${ }^{335}$ DIE ZEIT 03.03.2005 Nr.10, S. 45.

${ }^{336}$ vgl. Grisebach, Lucius u. a., in: Kirchner, Thomas (Hrsg.): a.r. penck, München 1988, S. 11.
} 
sich privat ein Schülerzirkel, der sich nicht nur mit Malerei, sondern auch mit Jazz befasste $^{337}$. Daneben ,hatte er schon immer eine große Affinität zur Literatur ${ }^{\text {‘338 }} 1955$ brach Winkler die Schule ab und begann eine Lehre als Werbezeichner. 1956 erhielt er für einige Holzschnitte einen Preis des Wettbewerbs der Lehrlinge und Berufsschüler des Bezirks Dresden, ebenso für ein Gedicht. Einige Gemälde, die er ebenfalls eingereicht hatte, wurden als bürgerlich-dekadent zurückgewiesen ${ }^{339}$. Nach dem Abbruch seiner Lehre bemühte sich Winkler vergeblich darum, einen Studienplatz für Bildende Künste zu erhalten. Im Herbst 1957 richtete Winkler gemeinsam mit seinem Freund Peter Makolies ein privates Atelier in einem Gartenschuppen ein ${ }^{340}$. Im Herbst 1961 konnte Winkler an der Ausstellung „Junge Künstler. Malerei“, der Deutschen Akademie der Künste (später Akademie der Künste der DDR) teilnehmen. In einer Kritik der von der FDJ herausgegebenen Zeitschrift „Junge Kunst““ wurde Winklers Arbeit als „Dilettantismus“ bezeichnet. Wichtiger als künstlerische Mängel für diese Beurteilung dürfte die Tatsache gewesen sein, dass Winkler nicht „... Auf dem Weg, den die Partei den Künstlern gewiesen hat ${ }^{\text {(341 }}$, wandelte.

Seit dem Mauerbau 1961 war Winkler ,für die folgenden neunzehn Jahre innerhalb der kulturellen und politischen ,Eiszeit' eingeschlossen, die ein totalitäres Regime seinen unglücklichen Bürgern auferlegte. Als Untergrund-Progressiver vom Kunststudium und jedem anderen Aspekt des institutionellen Lebens ausgeschlossen, entwickelte Penck ein System der Malerei, die sehr seiner eigenen freien Form der Jazzmusik entsprach. Wie der Jazz selbst, entwickelte sich der Prozess als Mittel, die dynamische Wechselwirkung von Individuum und Kollektiv auszudrücken, eine Dynamik, die im kommunistischen Lager durch ihre monolithische Kollektivierung aller Dinge grausam blockiert wurde““342. Um seinen Lebensunterhalt zu verdienen arbeitete Winkler in dieser Zeit u. a. als Heizer, Nachtwächter, Briefträger und in einer Margarinefabrik ${ }^{343}$. Anfang der sechziger Jahre entwickelte Winkler, der bis dahin vor allem in einem naivimpressionistischen und kubistischen Stil gemalt hatte, eigene Stilrichtungen, so seine „Systembilder“ mit Menschendarstellungen im Stil steinzeitlicher Höhlenmalereien und erste Standart-Arbeiten. Er bezeichnete sie als „eine Form von Concept-Art. Diesen

\footnotetext{
${ }^{337}$ vgl. Grisebach, 1988, S. 12.

${ }^{338}$ Selzer, 2001, S. 205.

339 vgl. Grisebach, 1988, S. 13.

340 vgl. Grisebach, 1988, S. 15.

${ }^{341}$ Bartke, Eberhard in: Junge Kunst. Organ des Zentralrats der Freien Deutschen Jugend, 5, 1961, Heft 11, S. 34-40 zitiert nach: Grisebach, 1988, S. 20 f.

${ }^{342}$ Wheeler, 1991, S. 313.

${ }^{343}$ vgl. Grisebach, 1988, S. 24.
} 
Begriff kannte ich damals nicht. Standart $=$ Konzept, Plan, Idee, Strategie ${ }^{\text {(3444 }}$. Eine Ausstellung, in der Werke von Winkler und seinen Freunden gezeigt wurden, im Puschkinhaus in Dresden musste vorzeitig abgebrochen werden, weil „in den Räumen noch alle möglichen anderen Veranstaltungen stattfanden, was dann auch als Kultur bezeichnet wurde. Tanzveranstaltungen oder sozialistische Hochzeiten unterm Leninbild und so. Der ganze Laden platzte, als sich eine Braut weigerte, unter so einem Bild - es war, glaube ich, das Anti-Kälte-Bild von Ralf - zu heiraten“3345.

1966 versuchte Winkler erneut, einen „offiziellen“ Status als Bildender Künstler in der DDR zu erreichen, indem er sich um die Mitgliedschaft im Verband Bildender Künstler bewarb. Er wurde zwar als Kandidat aufgenommen, jedoch nach Ablauf der Kandidatenzeit 1969 nicht als Vollmitglied bestätigt.

Ende 1968 zeigte die Galerie Hake in Köln die erste Einzelausstellung mit Werken

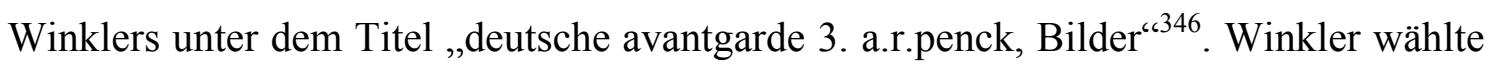
sein Pseudonym nach dem Geologen Albrecht R. Penck (1858-1945). So wie der Geologe die Erdgeschichte, so habe Winkler die Kunstgeschichte erforscht ${ }^{347}$. Außerdem ermöglichte ihm das Pseudonym, im Westen auszustellen, ohne dass die Behörden der DDR ihn, den nonkonformistischen Künstler, der seine Bilder regelrecht in den Westen schmuggeln musste, belästigten. Während A. R. Penck in der Bundesrepublik von Galerien und Museen entdeckt wurde, konnte Ralf Winkler in der DDR nur privat, halb versteckt ausstellen. Nachdem in der DDR 1979 mit einer Änderung des Strafgesetzbuches die ungenehmigte Mitwirkung an ausländischen Publikationen - wozu auch Ausstellungskataloge gehören konnten - als ,illegale Nachrichtenübermittlung“ unter Strafe gestellt wurde, stellte Penck 1980 einen Antrag auf „ständige Ausreise und Entlassung aus der Staatsbürgerschaft der DDR“, dem noch im selben Jahr stattgegeben wurde. Nachdem Penck in die Bundesrepublik gekommen war, ließ er sich bei Köln nieder. 1983 übersiedelte er nach einem längeren Aufenthalt in Israel nach London. 1989 erhielt er eine Professur an der Kunstakademie Düsseldorf.

Charakteristisch für die Arbeiten Pencks der sechziger Jahre waren die Welt- und Systembilder. Penck verstand diesen Stil als Realismus, obwohl die Menschen aufs

\footnotetext{
${ }^{344}$ Penck im Interview mit Johannes Gachnang, 1975, S. 148, zitiert nach: Grisebach, 1988, S. 30.

345 Peter Herrmann im Gespräch mit Jürgen Schweinebraden am 9. Februar 1988, zitiert nach: Grisebach, 1988, S. 31.

${ }^{346}$ vgl. Grisebach, 1988, S. 33.

${ }^{347}$ vgl. Grisebach, 1988, S. 32.
} 
äußerste reduziert wurden. „Für ihn lag der wirkliche Realismus eben nicht in einer naturalistischen, äußerliches Wohlbefinden vorspiegelnden Malerei, wie sie in den fünfziger Jahren in der DDR gefordert wurde“ ${ }^{348}$. Grisebach deutet den Titel „Weltbild“, 1961 (Abb. 70), in dem Penck das erste Mal Buchstaben verwendete, wörtlich als Beschreibung des Zustandes der Welt im Kalten Krieg ${ }^{349}$. In der Mitte sind eindeutig Szenen des Konflikts zu erkennen. Zwei kleine Strichmännchen stehen sich gegenüber und zeigen mit ausgestrecktem Arm aufeinander. Das linke Strichmännchen hat den Mund weit geöffnet, als würde es laut rufen. Hinter ihnen stehen größere Strichmännchen, die Waffen in den Händen tragen, das auf der linken Seite zwei Schwerter, das auf der rechten eine Pistole. Auf beiden Seiten sind Strukturen zu erkennen, die man als Radarantennen und Raketenabschussvorrichtungen deuten kann. Weiter gibt es auf beiden Seiten dreiarmige Strichmännchen, die etwas zu erklären scheinen, auf der linken Seite ein kleineres, das eine Tafel mit der Aufschrift ,,$\Lambda=$ $\Lambda$ “ hält, auf der rechten ein großes, das eine Tafel mit der Aufschrift , $\Lambda=A+\sim A$ “ hält. Der „Lehrer“ auf der linken Seite steht auf einer Konstruktion, die Kirchner als Fließband deutet. Während es mit einem Arm die Tafel hält, stützt es mit den beiden anderen die Raketenbasis. Der „Lehrer“ auf der rechten Seite stützt zwar auch mit einem Arm die Raketenbasis auf seiner Seite, streckt aber den zweiten Arm einem Strichmännchen mit zwei Köpfen entgegen, das eine Art Handkurbel betätigt. Sein dritter Arm setzt sich über die Tafel hinaus in Form eines Pfeils fort, der auf das Männchen an der Kurbel zuläuft, als ob ein Informationsfluss angedeutet werden soll. Der „Lehrer“ auf der linken Seite ist demgegenüber völlig isoliert. Das Männchen an der Handkurbel hat sein Pendant auf der linken Seite in einem ebenfalls zweiköpfigen Männchen am Fließband. Auf diesem Fließband steht außer dem „Lehrer“ ein zweites Männchen, dass mit einer Pistole zwei Männchen bedroht, die die Arme heben. Ganz links kehrt ein Männchen der Szene den Rücken zu. Zeigt sich auf der linken Seite ein eher bedrohliches Szenario, so auf der rechten ein idyllisches: Neben einem sich umarmenden Paar spielt ein Kind mit einem Ball. In diesem Bild drückt sich nach Meinung Kirchners die zu diesem Zeitpunkt noch gegebene positive Einstellung Pencks zur DDR wieder: Die bedrohlichen Szenen spielen sich links, kartographisch für Westen, die friedlichen rechts, kartographisch für Osten ab. Bei der Betrachtung der Systembilder fällt auf, dass Penck Buchstaben nur selten zu kompletten Wörtern

${ }^{348}$ Grisebach: Ich sehe meine Arbeit nach wie vor als Bildforschung, in: Grisebach, 1988, S. 70-88, hier S. 75.

${ }^{349}$ vgl. Kirchner, Thomas: A.R. Penck - Kann Kunst noch Wissenschaft sein?, in: Grisebach, 1988, S. 89-93, hier S. 90. 
zusammensetzt, sondern sie in einer Art algebraischer oder logischer Gleichung benutzt. Seine von Logik und Mathematik geprägte Sprache zeigt sich auch an der Verwendung von Ziffern und mathematischen Zeichen.

Anstatt die Strichmännchen als Doppelgänger des Betrachters zu zeichnen, zu dem er Zuneigung empfinden kann, sind Pencks Strichmännchen weit entwickelte Formen einer verschlüsselten Schrift. In anderen Bildern stellt Penck Personen als Schattenrisse dar. Die dargestellten Personen interagieren mit anderen Piktographien. Während die Piktographien in diesen Gemälden an jungpaläolithische Höhlenmalereien erinnern, unterstreichen die schematischen und diagrammatischen Zusammensetzungen das Gemälde als eine Karte, die der Künstler an die Wand gehängt hat. In dieser Hinsicht sind Pencks Standardgemälde - seine Fahnen und Banner - als Herausforderungen der Institutionen und der institutionellen Denkweise gedacht.

1967/68 malte Penck die ersten „Standarts“, Bilder, deren „Struktur so einfach ist, dass jeder es perzipieren und imitieren kann ... Verkehrszeichen, Warenzeichen, Schilder gehören zu Standarts، ${ }^{\text {350. }}$. Die Strichmännchen aus den Systembildern behielt er bei, ließ sie aber nicht mehr untereinander agieren, sondern sich dem Betrachter mit erhobenen Händen zuwenden.

„1970/71 entstanden die ersten großen Standart- Leinwände. Sie beinhalteten skripturale Äußerungen in Form von Graffiti, Kritzeleien, Mitteilungen, Hinweisen, Kürzeln, geheimnisvollen Botschaften als Knotenpunkte des Informationsaustauschs in der Stadt oder Spuren des Denkens und der Auseinandersetzung von Menschen mit Hilfe von Signalen. In dadaistisch anmutender Riesenschrift finden sich verschiedene Schriftarten eingebettet zwischen zahlreichen Zeichnungen und Symbolen“351.

In größerem Umfang scheint Penck erst 1973 Worte in den Standarts verwendet zu haben, als er mit der Serie „Standart Ende“ sein Experiment mit den Standarts abbrechen wollte. Die Entwicklung endete mit dem letzten Bild dieser Serie „Standart Endart“ (Abb. 71), wo sich im linken Drittel des Bildes an die Aussage „Final space is an maximum of the complexity of the system an an maximum of the monotony of the parts of the system“ eine Reihe hingekritzelter Kreuze, die Vokalreihe UOAIE, die Buchstabenfolge

\footnotetext{
${ }^{350}$ Penck, A.R.: Was ist Standart, 1970, zitiert nach: Grisebach, 1988, S. 35.

${ }^{351}$ Selzer, 2001, S. 206.
} 
AAAAAAAAAAA

ABABABABABAB

AABAABAABAAB

AABBABAABBAB

AAABBAABAAA,

einige unleserliche Krakel und schließlich auf einem gepunkteten Untergrund ein großer Farbspritzer anschließen. Die restlichen zwei Drittel werden von einem Fensterkreuz in grau-brauner Farbe eingenommen, durch das eine Art Laubwerk sichtbar wird. Seine schwarze Farbe kontrastiert mit dem weißen Hintergrund, wie sich Laubwerk vom durchscheinenden Tageslicht abhebt. Das Bild wird mit einer schwachen Spur aus roter Farbe umgeben.

Penck benutzt in seinen Systembildern und Standarts die primitivste Form der Menschendarstellung, das Strichmännchen, dennoch kann man sie nicht ,wie die Werke eines Expressionisten noch eines Primitivsten ${ }^{\text {352 }}$ sehen, weil ihre Strukturen komplex sind.

Pencks Kunst fordert den Betrachter auf, sein Netzwerk der Zeichen, Symbole und Bilder zu entziffern. Seine Symbole ähneln denen, die in der Logik, Mathematik und Kybernetik verwendet werden. „Dennoch bleibt die Arbeit unveränderlich eher kryptisch und persönlich als linguistisch übersetzbar،6353.

Pencks Zeichensystem, das unterschiedlichen Kulturen entstammt, von der Steinzeit bis zum Computerzeitalter, wirkt verwirrend und faszinierend zugleich. Obwohl einige seiner Symbole entziffert werden können, ergeben sie doch im Kontext der Bilder keinen sein. „Analog hierzu verlieren auch die wörtlich lesbaren eingeflochtenen Begriffe, Schlagworte und Sätze im Beziehungsgeflecht völlig an eindeutiger Bedeutung" 354.

\footnotetext{
${ }^{352}$ Yau, John in: Peltason, 1993, S. 15.

${ }^{353}$ Wheeler, 1991, S. 313.

${ }^{354}$ Selzer, 2001, S. 207.
} 


\section{Schriftelemente in Bildern Arabischer Künstler in der zweiten Hälfte des 20. Jahrhunderts}

Bevor die Kalligraphie von der modernen arabischen Malerei um die Mitte des 20. Jahrhunderts rezipiert wurde, hatte sie schon eine jahrhundertealte Geschichte. Die Schrift diente nicht nur dazu, Texte niederzuschreiben und Bauwerke mit Inschriften zu versehen, sondern stellte selbst ein Schmuckelement dar. Da nach islamischem Verständnis die arabische Schrift würdig war, das Wort Allahs festzuhalten, stellte sie auch das Höchstmaß an menschlicher Weisheit und Kreativität dar. Die Beschäftigung mit der Schriftkunst war begleitet von einer Art religiösem Ritual. Der Schriftkünstler pflegte, bevor er zur Schreibfeder griff, sich zum Gebet zu waschen und einige Koranverse zu rezitieren.

Im Laufe der Zeit kultivierte eine große Zahl von Künstlern eine Schriftkunst, die ausgefeilten Regeln unterlag. Das Kunstverständnis beruhte auf religiösen Empfindungen, da der größte Teil der sprachlichen Formulierungen oder Phrasen, die kalligraphisch verarbeitet wurden, religiöser Natur waren, wie Koranverse oder Aussagen über die Eigenschaften Allahs. Die Schrift, also das geschriebene Wort, hat sowohl eine inhaltliche Bedeutung als auch ästhetische Aussagekraft. Ihre besondere Gestaltung spiegelte die Schönheit ihrer Bedeutungen wider. Schrift und Arabeske wie auch die florale oder geometrische Ornamentik mischten sich oft und formten Verzierungen, ungeachtet der Größe oder Bedeutung der so verzierten Fläche ${ }^{355}$.

„Es gibt zwischen Wort und Bild ein sichtbares Verhältnis und eine wahrnehmbare geistige Verbindung ${ }^{6356}$, so schrieb der arabisch-muslimische Sufist Muhīy ad-Dīn ibn 'Arabi (1165-1240). Für Araber war und ist die Kalligraphie das wirkungsvollste Mittel für das Erwecken von Phantasie. Deshalb ist die arabische Schrift bis in die moderne arabische Kunst immer ein bedeutendes Element im künstlerischen Schaffensprozess gewesen.

Wie bereits erwähnt, übernahmen in den vierziger Jahren des 20. Jahrhunderts Madīḥa 'Umar und Ğamīl Ḥammūdī den Gebrauch arabischer Schriftzeichen in der modernen

\footnotetext{
${ }^{355}$ vgl. Lambert, 1989, S. 25.

${ }^{356}$ Nashashibi, Salwa Mikdadi (Hrsg.): Rhythm and form, visual reflection on Arabic poetry, ohne Ort, 1997, S. 6.
} 
Malerei. Madīha 'Umar entdeckte die graphischen Möglichkeiten der arabischen Schrift und ihre Abstraktheit als Form, als sie 1944/45 während ihrer frühen Jahre in den Vereinigten Staaten - ihr Mann war seit 1939 an der irakischen Botschaft in Washington beschäftigt - auf ein Buch über Kalligraphie von Nabia Abbot stieß. Auf Anregung des Kunsthistorikers Richard Ettinghausen, der sich mit islamischer Kunst beschäftigte und von der Originalität ihrer ersten Experimente beeindruckt war, stellte Madīha 'Umar 1949 zweiundzwanzig Gemälde in der Georgetown Public Library in Washington D.C. aus $^{357}$. Der Ausstellungskatalog enthielt 'Umars erste Abhandlung über Kunst, den Aufsatz Arabic Calligraphy: An Element of Inspiration in Abstract Art, in dem sie ihren Zugang zur Schrift und deren Verhältnis zur westlichen abstrakten Kunst erklärte und die Entwicklung der arabischen Schriftzeichen über die Zeit hin $\mathrm{zu}$ ihrer augenblicklichen Form darlegte. Das arabische Schriftzeichen, „das nur abstrakte Bedeutung ist, in seinem Wesen symbolisch, sollte nicht als bloße geometrische Formen und Dimensionen angesehen werden... Jeder Buchstaben erfüllt als abstraktes Bild eine spezifische Bedeutung, und diese Buchstaben werden mit ihren unterschiedlichen Ausdrücken eine Quelle der Inspiration: der Buchstabe,$\left(y a^{3}=y\right)$ hat eine kraftvolle Persönlichkeit, die viele Bedeutungen ausdrückt; der Buchstabe $\varepsilon$ ('ayn), der kein Äquivalent im Englischen hat, ist ein starker vitaler Buchstabe, der auf Arabisch zwei unterschiedliche Bedeutungen hat; er ist eine Quelle des Wassers sowie das Auge, mit dem die Menschen $\operatorname{sehen}^{358}$; der Buchstabe J (lam = l) zeigt geschmeidige und musikalische Bewegungen“6359.

ihren abstrakten Arbeiten versucht 'Umar, die einfachen Formen der arabischen Buchstaben in ausdrucksvolle Gedankenbilder $\mathrm{zu}$ verwandeln, wie in einem ihrer früheren Experimente, einer Studie über den Buchstaben Alif $\left({ }^{(}\right)$, in einem unbetitelten, undatierten Bild (Abb. 71). Den Vordergrund nimmt eine blaue Fläche ein, wahrscheinlich durch leichte Wellen gekräuseltes Wasser. In dieses Wasser sind unterschiedlich große 'Alif-Zeichen unterschiedlich tief eingetaucht. Besonders die Zeichen in den ersten beiden Reihen scheinen das Wasser umzurühren, jedenfalls lassen sich die Strudel an ihrem Schaft so deuten. Die Buchstaben, die ihrem Wesen nach reine Gedankenkonstrukte sind, werden hier als körperliche Wesen behandelt. In dieser Arbeit versucht die Künstlerin, durch die wiederholte Abbildung des 'Alif, des ersten

${ }^{357}$ vgl. 'Alī, Wijdan: Contemporary art from the Islamic world, Ammann und London, 1989, S. 152.

358 cayn ist nicht nur Name für einen Buchstaben, sondern auch ein Wort. Es bedeutet sowohl „Quelle“ als auch „Auge“".

${ }^{359}$ Madīḥa 'Umar: al-ḥarf 'unșur istilhām fi-1-fann at-tağrīdī, zitiert nach: Dāg̀ir, 1990, S. 139-141, hier S. 141. 
Buchstabens im arabischen Alphabet, in einer konstanten Bewegung einen Rhythmus zu finden. Im Hintergrund, etwa einem Zehntel der Bildfläche, ist ein dunkler Sternenhimmel dargestellt.

In At the Concert, 1948 (Abb. 72), befreit Madīha 'Umar die Buchstaben von ihren geometrischen und formalen Elementen. Sie benutzt nur vier Buchstaben - $\varepsilon\left({ }^{\prime}\right.$ ayn $)$, ? (mim), ي ( $\left(\mathrm{y}^{\prime}\right)$ und $(\mathrm{lam})$ - und erlaubt ihnen, in einer neuen Form aufzutauchen. Sie unterstreicht ihre Elastizität durch Abstraktion und schafft eine moderne Sprache, die die innewohnenden Qualitäten der arabischen Schrift verändert ${ }^{360}$. Madīha 'Umar war die erste moderne arabische Künstlerin, die ihre Arbeit völlig dem arabischen Buchstaben widmete.

Hammūdī, der sich anfänglich durch Selbststudium zum Künstler ausbildete und 1945 an der Akademie der Künste in Bagdad graduierte, begann seine Karriere als Surrealist. Als er sich jedoch 1947 in Paris aufhielt, um seine Studien fortzusetzen, gab er den Surrealismus auf, nachdem er die Künstler um André Breton kennen gelernt hatte. Er sagte: „Ich sah in ihren Bildern eine krankhafte schwermütige Seite. Über ihre Werke herrschen dunkle teuflische Stimmungen, die von Verlust und Verzweiflung sprechen.

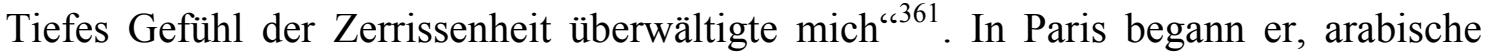
Buchstaben in seine Arbeit $\mathrm{zu}$ integrieren, die seiner surrealistischen Phase von kubistischen Kompositionen beeinflusst wurde, was in An-nās sa wāsīyā ka-'asnān almušt (Die Menschen gleichen den Zähnen eines Kammes), 1976, (Abb. 73), erkennbar ist. Das Gemälde ist in unterschiedlichen Brauntönen gehalten, die untereinander harmonieren. Das Bild ist in kubistischer Weise in verschiedene kleine Flächen aufgeteilt, die bis auf zwei runde Strukturen in der linken Bildhälfte eckig sind. In der Mitte des Bildes schrieb Hammūdī mit geometrischer kufischer Schrift die Worte الناس سو/سية (An-nās sa wāsīyā = Die Menschen sind gleich). Das sin erscheint als Zeichen nur einmal und wird sowohl für das Wort na Die Oberlängen von Alif $\left({ }^{\prime}\right)$ und lam (ل) in An-nās sind sehr ausgeprägt, dagegen ist die Oberlänge des Alif in sāwasiya nur etwa halb so hoch. Die diakritischen Punkte von

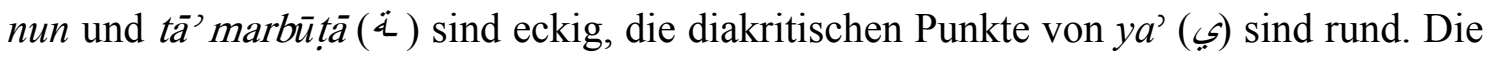
Punkte des tā' sind nicht neben-, sondern übereinander geschrieben. Die

\footnotetext{
${ }^{360} \mathrm{vgl}$. http://www.metmuseum.org/toah/hd/trmd/hd_trmd.htm.

${ }^{361}$ Hamoudi in einer Rede anlässlich seiner Ausstellung im UNESCO_Gebäude in Paris 1987, zitiert in: Dāgigir, 1990, S. 22.
} 
Zwischenräume zwischen den Buchstaben sind mit dunkelbrauner Farbe aufgefüllt. Der Titel des Bildes, dessen erste Worte auch als Bildelemente erscheinen, ist einem hadīt des Propheten Muhammad entnommen ${ }^{362}$, in dem dieser die Gleichheit aller Menschen feststellt.

Während der fünfziger Jahre fand eine Reihe anderer Experimente mit der arabischen Schrift statt. Der libanesische Künstler Wağīh Naḥla (geb. 1932) war von der klassischen Kalligraphie, besonders der iranischen ${ }^{363}$ Tradition beeinflusst, wie er in Der Krieger, 1954 (Abb. 74), zeigt. In dieser Arbeit zeichnet der Künstler den Oberkörper eines Kriegers, indem er eine Mischung aus arabischer Kaligraphie und Ornamentik anwendet. Es fällt auf, dass das Gesicht nur teilweise ausgeführt ist. In der linken Gesichtshälfte ist nur eine Augenbraue zu sehen, dagegen in der rechten das Auge und ein Teil der Nase. Der Nasenflügel wird von einem sin gebildet. An der Stirn kann man einen lockigen Haaransatz erkennen. Der Kopf scheint von einem Helm bedeckt zu sein, auf den der Künstler das Wort Henna geschrieben hat. Unter dem Helm trägt der Krieger ein Tuch, das um den Kopf gewickelt ist und die Hals- und Mundpartie bedeckt. Das Tuch ist mit Ornamenten geschmückt. Mit Ornamenten und Schriftzeichen ist auch der Rumpf bedeckt, der dadurch den Eindruck erweckt, der Krieger trage einen reliefierten Brustpanzer. Es fallen dort zwei figürliche Darstellungen auf, einmal ein Vogel und eine Getreideähre auf der rechten Seite unterhalb einer ausgestreckten Struktur, die vielleicht eine Hand darstellt, und ein Gesicht unten in der Mitte. Auf der linken Schulter ist eine „Hand Faṭimas“ (yad Fātima), ein apotropäisches Symbol, dargestellt. Auf dem Rücken scheint der Krieger ein Gewehr zu tragen, dessen Ende des Laufes mit dem Korn über der rechten Schulter gerade noch sichtbar ist. Auf einer schwarzen Fläche in der Mitte des Rumpfes sind mehrere Vokalzeichen abgebildet, z. B. ('̌̌adda) und '(sukūn). Auf dem Rumpf unten links erscheint die Buchstabenkombination mim, mim, 'alif, bā', tā'.

Die sudanesischen Künstler der madraset al-ḩartūm al-qadìma (alte Schule von Khartum, seit ca. 1962) haben einen traditionellen Zugang zur Kalligraphie. Ein Beispiel dafür ist Aḥmad Muhammad Šibrīns (1931-?) reliefierte, gefärbte

\footnotetext{
${ }^{362}$ „Die Menschen gleichen den Zähnen eines Kammes. Ein Araber ist nicht besser als ein Fremder und ein Fremder ist nicht besser als ein Araber, und ein Hellhäutiger ist nicht besser ein Schwarzer und ein Schwarzer ist nicht besser ein Hellhäutiger, es sei denn wegen der Gottesfurcht“", zitiert nach: Ibn-Hanbal Aḥmad: Musnad al-Imām Aḥmad Ibn-Ḥanbal : wa-bi-'l-hāmiš muntahab kanz al-'ummāl fī sunan alaqwāl wa-l-af́āl, al-muğallad., Bd. 5, Kairo 1978, S. 411.

${ }^{363}$ vgl. Khatibi/Sijelmassi, 1976, S. 132 f.
} 
Mahagoniplatte Ohne Titel, undatiert (Abb. 75), ein Werk aus seiner Frühzeit, aus der er in kufischer Schrift la ilāha illā 'llāh (Es gibt keinen Gott außer Allah) geschnitzt hat. Die Schrift erscheint in den oberen zwei Dritteln der Platte, die Buchstaben sind im Halbkreis geschrieben. Das $h a$ am Ende von Allah ist mit einem überlangen Schlussstrich versehen, der alle Worte unterstreicht.

Ein anderes Beispiel für seine Verwendung von Schrift im Bild findet sich in Calligraphy, 1997, (Abb. 76). Bei der Komposition des Bildes spielen arabische Buchstaben und Wörter eine zentrale Rolle. Am unteren Ende schrieb der Künstler mit grüner Farbe kufische Buchstaben, die so übermalt wurden, dass nicht zu erkennen ist, was dort ursprünglich stand. Jetzt machen sie den Eindruck, als ob sie ein Dickicht bildeten, durch das ein beladenes Kamel schreitet, das in dunkelblauer, fast schwarzer, Farbe gehalten ist. Es entsteht der Eindruck, dass sie an roten Linien, die sich vertikal durch das Bild ziehen, aufgehängt wurden. In der oberen Hälfte schrieb Šibrīn in kufischer Schrift mit blau-violetter Farbe تحملن (Tahmmīlanna, dt. ihr tragt). Diese Phrase nimmt offenbar Bezug zu dem Kamel. Darunter schrieb er in derselben Farbe einzelne Buchstaben, die zusammen kein Wort ergeben. Offenbar im selben Farbton wurden vorher die Buchstaben im Hintergrund geschrieben, die dann weiß übermalt wurden und jetzt blass hindurchschimmern.

Was als isolierte Experimente während der Mitte der vierziger und fünfziger Jahre begonnen hatte, wandelte sich während der sechziger Jahre zu einem Trend, der eine wachsende Zahl von arabischen Künstlern aus verschiedenen Ländern anzog. Die Künstler dieser zweiten Generation entdeckten oder entwickelten ihr Interesse am Buchstaben meistens entweder während ihrer Studien im Westen, wo ihre einzige Verbindung mit ihrer Kultur und Tradition „das arabische Wort" war, oder durch den Einfluss moderner westlicher Experimente mit Schriftzeichen ${ }^{364}$. Dieser Trend kam während der siebziger Jahre und der achtziger Jahre immer mehr in Schwung, und wurde zu einem Phänomen, in dem fast jeder arabische Künstler zu irgendeinem Zeitpunkt mit Buchstaben experimentierte. Dennoch entstand, trotz einiger Bemühungen, nie eine einheitliche Bewegung oder eine Stilschule.

1971 sammelte der irakische Künstler Šākir Hasan as-Sa`̄̄id die Gruppe Ǧamā‘at al-bū ‘d al-wāḥid(Eine Dimension). Sie bestand aus erfahrenen Künstlern, deren Arbeit sich der 
Verwendung von Schriftelementen widmete. Ihr gehörten auch Madīha 'Umar und Ğamīl Ḥammūdī an ${ }^{365}$. Die Gruppe bildete jedoch keine Schule im strengen Sinne, da die Mitglieder nicht darauf beschränkt waren, as-Saīds Stil zu folgen. Stattdessen regte er jedes Mitglied an, seinen eigenen persönlichen Stil zu entwickeln. Im Katalog ihrer ersten Ausstellung, die im gleichen Jahr in Bagdad stattfand, erklärte as-Sacīd seinen Einsatz von Buchstaben in Beziehung zum Konzept von al-bū'd al-wāhìd (Eine Dimension).

Der Buchstabe wurde einmal mehr ein Symbol mit Dimensionen, die von einem Ausdruck zum anderen variieren. Der arabische Buchstabe in der modernen arabischen Kunst ist nicht nur ein Mittel, um Gott und seiner Offenbarung zu dienen und sie zu verherrlichen, sondern vielmehr eine Wesenheit (res) mit tiefen symbolischen Ausdrucksmöglichkeiten. Zum ersten Mal wurde Individualismus ein Aspekt der arabischen Kunst. Die Künstler scheuten sich einerseits nicht vor der Freiheit, andererseits wurden sie nicht mehr durch festgelegte Regeln eingeschränkt, abgesehen von selbst gewählten ästhetischen Überlegungen. Es gibt eine wahrnehmbare Änderung in der Musik und im Rhythmus, hervorgerufen durch den Dialog zwischen den Buchstaben, in ihrem Verhältnis und in der Weise, in der sie sich verflechten.

Der Vergleich von Malerei mit Musik kommt nicht von ungefähr, Ḍiyā' al-'Azzāwī etwa bezeichnete eine Phase seines Schaffens als „Taqāsı̄m"(Solo-Improvisation eines Melodieinstruments) $)^{366}$.

Weiterhin ist eine der wichtigsten Veränderungen, die der Buchstabe in der arabischen Kunst durchgemacht hat, der Verlust seiner Einzigartigkeit und Bedeutsamkeit als Element der schriftlichen Sprache. In seinem modernen Gebrauch in der Kunst wurde der Buchstabe von seiner Rolle in der geschriebenen Schrift befreit. Der Buchstabe musste nicht länger nur sprachlichen Sinn vermitteln, sondern gewann als ästhetische Form einen Wert in sich selbst. Dennoch hinterfragen einige Kritiker die Möglichkeit der Ablösung des arabischen Buchstabens von seinem linguistischen Wert auf der Grundlage, dass der Betrachter, wenn er mit Buchstaben konfrontiert wird, versuchen wird, die Schrift zu lesen. Weiterhin meint Wijdan Ali, dass "jeder Buchstabe des arabischen Alphabets, abgesehen von seiner visuellen und graphischen Wirkung, selbst

\footnotetext{
365 'Alī, Wijadan: Modern Islamic art, development and continuity, Gainesville 1997, S. 168.

${ }^{366}$ vgl. Joch, Peter: Broken Letters, Darmstadt 2003, S. 10.
} 
wenn man ihn für sich betrachtet, eine bestimmte Bedeutung hat... Er überträgt Konnotationen auf mehr als einer Ebene ${ }^{6367}$.

\subsection{Der Gebrauch der arabischen Schrift in der zeitgenössischen Malerei: Klassifizierungsversuche}

Im Zusammenhang mit „Ḥurūfiyya“, der nicht-kalligraphischen bildlichen Verwendung der arabischen Schrift, werden mehrere Probleme angesprochen, die in der arabischen Welt mit der Kunst zusammenhängen: die Frage der Identität der arabischen Kunst, ihrer Stellung, ihre lokale Gebundenheit und Universalität.

Wijdan 'Alī betrachtet in ihrem 1997 erschienenen Buch „Modern Islamic art“ die arabische Welt als Teil der islamischen und schließt folglich auch Experimente mit Buchstaben aus Ländern wie dem Iran, Malaysia und der Türkei in ihre Betrachtung der arabischen Kalligraphie mit ein. Sie macht insofern einen Unterschied in der Betrachtung der arabischen Kalligraphie, die in arabischen und nicht-arabischen Ländern hervorgebracht wird, als die Beziehung der außerarabischen islamischen Länder zur arabischen Sprache auf ihre Beziehung zur Religion, insbesondere zum Koran, begrenzt ist, da in diesen Ländern nicht arabisch gesprochen wird. Durch die Benutzung der arabischen Schrift bekennen sie ihre islamische Identität. In den arabischen Ländern andererseits ist die arabische Sprache ein Teil der täglichen Erfahrung, der politischen, sozialen und kulturellen Wirklichkeiten der Araber.

Wenn jedenfalls für Wijdan 'Alī Kalligraphie, oder spezifischer, der moderne Gebrauch von Schrift in der Kunst, als eine Fortsetzung der Kunst der islamischen Kalligraphie gilt, dann verwendet sie den Begriff „Kalligraphie“ anders als üblich. Der Begriff bezeichnet normalerweise eine bestimmte Art des Schreibens und wird mit Ordnung und Stetigkeit konnotiert. Kalligraphie, so erklären Khatibi und Sijelmassi, ist „eine Kunst, die bewusst geübt wird und sich auf einen Kodex geometrischer und dekorativer Regeln gründet; als eine Kunst, die in den Formen, die sie hervorbringt auch eine Theorie der Sprache und des Schreibens enthält (...) Das Wesen der Kalligrafie ist in ihrer Beziehung zur Sprache beschlossen. Wohl können sich Malerei und Kalligrafie zuweilen berühren, doch unterscheiden sie sich darin, dass letztere dem geschriebenen Buchstaben Bedeutung und Leben verleiht (...) Der Kalligraf ist ein Künstler, der 
kopiert, und der Text, den er zu kopieren hat, ist ihm vorgegeben. ${ }^{\text {368 }}$.

Somit verwischt Wijdans Alis Begriffswahl, bei Betrachtung der Werke, die dadurch zusammengefasst und betitelt werden, die Unterscheidung zwischen Malerei und Kalligraphie, eine Unterscheidung, die in der islamischen Kunst bis zum Anfang des 20. Jahrhunderts beachtet wurde.

Wijdan 'Alī unterteilt die Themen der Kalligraphie in zwei Hauptkategorien: Religiöse Motive auf der einen und weltliche Motive auf der anderen Seite. Letztere werden wiederum als soziopolitisch, literarisch, oder dekorativ klassifiziert. Bei den Stilen der Kalligraphie unterscheidet sie zwischen vier Kategorien, der reinen Kalligraphie, der abstrakten Kalligraphie, den kalligraphischen Kombinationen und der unbewussten Kalligraphie.

Als reine Kalligraphie definiert sie Arbeiten, in denen Thema und Aufbau ausschließlich durch die arabischen Schriftzeichen gebildet werden. Der Hinter- und Vordergrund besteht aus einem oder mehreren Buchstaben, einem oder mehreren Wörtern, einem Text oder einer Kombination dieser Elemente. Das Schriftzeichen behält in dieser Kategorie seine linguistische Bedeutung bei, auch wenn es vollkommen isoliert vorliegt.

Innerhalb der reinen Kalligraphie gibt es vier Kategorien: Die erste ist der neoklassische $\underline{\text { Stil, }}$ der die Arbeiten der traditionellen arabischen Schriftzeichen einschließt, ausgeführt basierend auf den Regeln der traditionellen islamischen Kalligraphie. Diese Arbeiten sind im Allgemeinen Wiederbelebungen und Wiederholungen ihrer islamischen Vorgänger, mit einigen wenigen Änderungen in den Zeichen und Motiven. Wijdan 'Alī zufolge sind die Arbeiten dieser Sparte "trotz ihrer Ausführung mit neuen Mitteln und modernen Techniken, die authentischen modernen Nachkommen der klassischen osmanischen und persischen kalligraphischen Einzelstücke sind“369.

Unter dem modernen klassischen Stil wird im Allgemeinen eine Kombination von traditionellen Schriftzeichen mit modernem Aufbau verstanden, wie in der Arbeit des ägyptischen Handwerkskünstlers Aḥmad Muștafā (geb. 1943) ${ }^{370}$ - im Still Life of

\footnotetext{
${ }^{368}$ vgl. Khatibi u. Sijelmasi, 1995, S. 14.

369 'Alī, 1997, S. 160.

${ }^{370}$ vgl. 'Alī, 1997, S. 167.
} 
Qur'anic Solids, von 1987 (Abb. 77), in dem die durch Perspektive und Schattenwurf dreidimensional erscheinenden Formen mit kursiver, geschwungener Tulut-Schrift beschrieben sind. Auf der Figur rechts erscheint als einzig lesbarer Schriftzug der Koranvers: „Wir haben ein jegliches Ding nach Maß geschaffen“ $(54,49)$.

Bei den Kalligraffiti arbeitet der Künstler Buchstaben in seiner gewöhnlichen Handschrift in eine moderne Komposition ein. Wijdan 'Alī wählte die Bezeichnung „Kalligraffiti”, „weil, obgleich die Schrift selbst durch Kalligraphie inspiriert wird, sie ebenso dem Kritzeln von Graffiti nahe ist“371.

Innerhalb dieses Stils ordnet sie die Arbeit des irakischen Künstlers Šākir Ḥasan asSa ${ }^{\top} \overline{1}$ ein, der in seinen Werken auf die Aufspaltung und Zerstörung der Bedeutung abzielte, die durch das Zeichen als Teil der Sprache dargestellt wurde.

In Objektive Betrachtungen, 1984 (Abb. 78), stellte as-Sa'̄id Spuren der Zeit durch verwitterte Farbe oder Sprünge in der Wand dar. Die Oberfläche wurde ein Maß für sichtbare Betrachtung, indem abstrakte Formen einschließlich des arabischen Alphabetes, Zahlen und andere Zeichen, wie der rote Pfeil auf der linken Bildseite, verwendet werden. In diesen elementaren Linien sah as-Sa'̄id die Einheit des Menschen mit Gott. Dem arabischen Buchstaben ب(bā) geht die Ziffer $\wedge$ (8) voran, die das numerische Äquivalent für den Buchstaben $\rightarrow\left(h \bar{a}^{\prime}\right)$ ist, so dass $h u b b$ (Liebe) gelesen werden kann, indem die Zusammenstellung ^ ( 1 ( 8 b) gleich (h), also habb ist. Dem arabischen Betrachter fällt eine Ähnlichkeit zu Chiffres inversé, 1976 (Abb.79), von Antoni Tapies auf, indem er das Zeichen unter dem Bruchstrich als $\wedge$ (8) und das Zeichen darüber als ع('ayn) liest. Wie Tàpies trug er die Farbe sehr dick auf und kratzte anschließend Linien hinein. Er gab seinem Bild die Struktur einer Wand, die mit Zeichen bedeckt wird. Khatibi und Sijelmassi behaupten zutreffend, dass al-Sa'̄îd den Buchstaben vollständig losgelöst und nur auf sich selbst zurückweisend verwendet hat und man „im Falle von Šākir Hasan keinerlei Verlust spürt: wo Kalligraphie endet, beginnt die Malerei “ ${ }^{372}$. as-Sa ${ }^{\top} \overline{1} d$ benutzte unterschiedliche folkloristische Motive gleichzeitig in seiner Arbeit. So schuf er eine Phantasiewelt aus dem alltäglichen Leben durch Wandgraffitis. Die eingearbeiteten Schriften erscheinen wie aus einer vergangenen Zeit. Die Bildoberfläche ähnelt einer alten Mauer, von der der Putz bröckelt und die mit Graffiti beschrieben ist. Seine Schriften sind vergleichbar mit der

\footnotetext{
371 'Alī, 1997, S. 168.

${ }^{372}$ Khatibi u. Sijelmasi, 1995, S. 228.
} 
Handschrift von Kindern. as-Sa'̄d variierte seinen Gebrauch von Buchstaben. Mal verwendete er vereinzelte Buchstaben mit Bedeutung, ein anderes Mal ohne Bedeutung, jedoch nahmen sie eine ästhetische Rolle ein. Auch wurden Buchstaben zu Wörtern zusammengefügt.

Die letzte Ausprägung ist die Freeform Calligraphy, eine Schriftform, die zwischen der klassischen Form und dem Kalligraffiti einzuordnen ist ${ }^{373}$. Sie folgt nicht dem Formenkanon der klassischen Kalligraphie, ist aber im Vergleich mit Graffiti strengeren Regeln unterworfen. Ein Beispiel für diesen Stil ist das Werk des libyschen Künstlers 'Alī 'Umar Irmaṣ (geb. 1945). Irmaṣ' Schrift ist, wenn auch manche Arbeiten bestimmten Traditionellen ähneln, immer frei von den klaren Regeln der Kalligraphie.

Seine Arbeiten können in zwei Gruppen unterteilt werden: Der ersten Gruppe lassen sich Bilder zuordnen, die sich auf einen einzigen Buchstaben als zentrales Motiv des Gemäldes konzentrieren. Ein Beispiel dafür ist ḥarf al-kāf(Buchstabe Kaf), 1991 (Abb. 80), wo der Buchstabe Kaf (S) an der linken Serife seiner Grundlinie von einem Gedicht des Kalifen al-Mansur (754-775) umgeben ist. Eine zweite Gruppe bilden die Arbeiten mit Wiederholungen eines einzelnen Buchstaben oder mehrerer Buchstaben, die den gesamten Raum des Gemäldes füllen, wie in ألف، باء، تاء ('Alif, bā', tā') (Abb. $81)$.

Man könnte ebenso einige von Wijdans eigenen Arbeiten in diese Gruppen einstufen wie zum Beispiel Karbalā, von 1992 (Abb. 82). Verwirklicht wurde dieses Bild im Kontext des ersten Golfkrieges und mit Rückgriff auf die Aufstände im Süden des Iraks nach Beendigung der Kampfhandlungen. Der Buchstabe $\tau$ ( $\left.h \bar{a}^{\prime}\right)$ beherrscht gegen einen purpurnen, in der rechten oberen Ecke grünen Hintergrund den Raum. Auf das nasse Papier schrieb 'Alī mit schwarzer Aquarellfarbe den Buchstaben hăa', so dass seine Konturen verliefen. Außerdem tröpfelte grüne Farbe auf die purpurne. In Verbindung mit dem Titel erinnert das ḥầ, der Anfangsbuchstabe Husaīs, des Enkels Muhammad s und Sohn seines Vetters und 4. Kalifen Ali, an die Schlacht von Karbalā'im Jahre 680, in er den Tod fand.

Die zweite Hauptrichtung der Kalligraphie neben der reinen Kalligraphie ist die abstrakte Kalligraphie, in der „der Aspekt der visuellen Ästhetik der arabischen 
Schriftzeichen als strukturelles Element der Komposition“" ${ }^{374}$ genutzt wird, eine autonome graphische Form. In dieser Kategorie gibt es zwei Gruppen ${ }^{375}$. Die erste ist eine „lesbare Schriftform“, bei der Buchstaben geschrieben werden, die als solche zu erkennen sind, aber keine Worte bilden. Dafür bildet das Werk des syrischen Künstlers Mạ̣mūd Hammād (1923-1988) ein Beispiel. Arabische Schrift, 1970 (Abb. 83), und Kalligraphie, 1985 (Abb. 84), sind abstrakte kreative Kompositionsstudien der geometrischen Formen und des räumlichen Erscheinens der Buchstaben als für sich stehende Einheiten. Hammād verwendet ein Geflecht aus Buchstaben, um eine Masse von Formen entstehen zu lassen, mit dem Ziel, vertraute Formen zu benutzen, die eher seiner Kultur entstammen, als die lediglich abstrakten Formen, wie sie in der westlichen Kunst Verwendung finden ${ }^{376}$.

Die zweite ist die „Pseudoschrift“, bei der die Form der Buchstaben nicht mehr zu erkennen ist. Eine Arbeit, die diese Schriftform verwendet, „trägt keine Aussageabsicht in ihren Buchstaben, also wird diese Form der Kalligraphie ein ruhiges bauliches Muster, das der Arabeske ähnlich ist ${ }^{\text {‘377 }}$. Ein Beispiel dieses Stils ist die Arbeit des Tunesiers Nja Mahdaoui (geb. 1937): In seinem Bild takw̄̄n ḥun̄fi (kalligraphische Komposition) (Abb. 85) teilt er die Bildfläche in drei horizontale Streifen, die je etwa ein Drittel der Fläche einnehmen. Der obere und untere Streifen sind schwarz, der mittlere ist orangefarben. Der mittlere Streifen ist eng mit kleinen ockerfarbenen Schriftzeichen bedeckt, die sich vom Hintergrund abheben. Der Rand des mittleren Streifens ist jedoch frei von Buchstaben, so dass zwei schmale Linien in einem gelbbraunen Ton den ockerfarbenen Streifen von den beiden schwarzen abgrenzen. Über den mittleren Streifen zieht sich eine Kalligraphie aus kufischen Buchstaben in demselben gelb-braunen Ockerton. Die Kalligraphie verbindet die drei Streifen miteinander. Die einzelnen Buchstaben der Kalligraphie sind so aneinander gefügt, dass sie an die Striche eines chinesischen Schriftzeichens erinnern, dass auf die Seite gekippt wurde.

Das Werk Ohne Titel, 1991, der palästinensischen Künstlerin Ğumana al-Ḥusaīn̄̄ (geb. 1932) kann ebenfalls in diese Kategorie eingeordnet werden (Abb. 86). In dieser Arbeit ist arabische Schrift durch aufgetragene Acrylschichten absichtlich unleserlich gemacht

\footnotetext{
374 'Alī, 1997, S. 170.

${ }^{375}$ vgl. 'Alī, 1997, S. 170-173.

${ }^{376}$ vgl. Al-Haidari, Buland: The effect of the letter in the contemporary Arabic art, in: Funūn 'arabīya, Nr. 4, London 1981, S. 15-24, hier S. 21.

${ }^{377}$ vgl. 'Alī, 1997, S. 171.
} 
worden. Im unteren Viertel ist die Schriftrichtung um $90^{\circ}$ nach links gedreht, wie sie im frühen Mittelalter geläufig war. Am linken und am unteren Rand tauchen weiterhin wellenförmige Zeichen auf, die keine Buchstaben sind, aber in ihrem Gesamtduktus einer formlosen arabischen Schrift ähneln, die normalerweise zum Briefe schreiben verwendet werden.

Kalligraphische Kombinationen ist die dritte Hauptkategorie, die von Wijdan 'Alī aufgestellt wurde. Die arabische Schriftzeichen stehen nicht im Zentrum des Bildes, sie sind nur ein Element unter anderen, die auch aus den bildlichen oder nicht-bildlichen Formen und anderen symbolischen Motiven, Buchstaben, Wörtern oder Teilen von lesbaren Texten bestehen, die in hohem Grade bedeutend sein können, um eine Aussage zu übermitteln ${ }^{378}$. Dieser Kategorie kann auf Grund der Freiheit und der Vielzahl von Arten, die sie erlaubt, eine große und unterschiedliche Anzahl von Arbeiten vieler arabischer Künstler zugeordnet werden. Aus dieser Kategorie gehen zwei Sparten hervor, die „zentrale Kalligraphie“ und die „begrenzte Kalligraphie“.

In der „zentralen Kalligraphie“ ist die Schrift, unabhängig von ihrer Größe, ein dominierender visueller Bestandteil des gesamten Aufbaus. Ein Hauptbeispiel dieses Stils ist die Arbeit des Algeriers Rašīd Qoraīšy (geb. 1947), Tell az-za tar ${ }^{379}, 1979$ (Abb. 87). Im oberen Drittel des Vordergrundes erscheinen drei nach rechts blickende, schreiende Köpfe, deren Haar nach links geweht wird. Von den Gesichtern sind nur Augenhöhlen und Mundöffnungen zu erkennen, wodurch sie an Totenschädel erinnern. Die Köpfe gehen in Körper über, die nur aus dem Rumpf bestehen und aus Strichen gebildet werden, die lang gezogenen Schriftzeichen ähneln. Während die Köpfe noch deutlich voneinander getrennt sind, gehen die Körper ineinander über. Unterhalb der Körper erscheint der Schriftzug Tell az-za'tar. Der Hintergrund wird durch eine fortlaufende Reihe Zeichen gebildet, die an eine Schrift erinnern, aber nicht lesbar sind. In der Wahrnehmung des Schriftzuges Tell az-za'tar macht sich macht sich eine unterschiedliche Rezeptionsweise zwischen einem Betrachter, der der arabischen Sprache mächtig ist, und einem, der es nicht ist, bemerkbar. Wer den Schriftzug nicht lesen kann und wem das Massaker von Tell az-za'tar nicht im Gedächtnis präsent ist,

${ }^{378}$ vgl. 'Alī, 1997, S. 173-182.

379 Tell az-za'tar. war ein Lager für palästinensische Flüchtlinge und Bürgerkriegsflüchtlinge aus dem Südlibanon in einer nördlichen Vorstadt von Beirut. Vom 12. März bis zum 22. Juni 1976 wurde das Lager von der maronitischen Kataib-Miliz belagert und mit Artillerie beschossen. Dabei wurden etwa 1.500 Bewohner getötet. Am 12. August 1976 wurde das Lager unter der Aufsicht des Internationalen Komitees des Roten Kreuzes evakuiert. Dabei wurden bei einem Überfall weitere 1.500 Menschen getötet. 
nimmt sowohl die Schrift als auch den Titel erst bei näherer Erklärung war. Für ihn „dominiert“ die Schrift nicht. Im arabischen Betrachter weckt er dagegen heftige Emotionen.

Ein anderes Beispiel ist die Arbeit des Ägypters Ṭahā Ḥusaīn (geb. 1929). In Fruchtbarkeit, 1983 (Abb. 88), tauchen die Worte Allah und die Formel bi-smi llāhi arraḥmāni ar-raḥ̄m auf. Für den Untergrund hat Ṭahā Husaīn verschiedene Stoffstücke aus grobem Gewebe aneinander geklebt und anschließend in verschiedenen Brauntönen eingefärbt. In der Mitte des oberen Drittels erscheint der Name Allah, wobei die Buchstaben nicht neben- sondern ineinander geschrieben sind. Im unteren Drittel erscheinen, von einem fast schwarzen Rahmen umgeben, die Formeln bi-smi llăhi arraḥmāni ar-raḥ̂̄m und lā ilāha illā llāh. Das geometrische Gefüge des Bildes besteht aus Strukturmusterfeldern und monochromen Farbflächen. „Die verwendeten Farben beschränken sich dabei im Wesentlichen auf die Kombinationen Weiß und Schwarz, sowie Weiß, Schwarz und Braun oder Blau. Tahā Husaīn benutzt in dieser Werkphase die Farben als Ausdrucksgrundlage, weshalb er die Werkgruppe selbst als ,Farbigen Sufismus' bezeichnet ${ }^{6380}$.

In der „begrenzten Kalligraphie“ wird die Schrift im gesamten Aufbau anderen Komponenten untergeordnet oder mit ihnen vermischt. Ein Beispiel von Werken, die diesem Stil zugeordnet werden, ist šağarat al-ḥubb (Baum der Liebe), 1977 (Abb. 89), der jordanischen Künstlerin Munā Sa'ūd̄̄ (geb. 1945). Zwei horizontal verlaufende Schriftbänder im Hintergrund treten hinter eine gemalte Form im Vordergrund zurück, welche die gesamte Höhe des Bildes einnimmt und an altorientalische Standarten erinnert. Ihre Basis bildet ein Sockel aus drei übereinander liegenden Säulentrommeln. Darauf sitzt ein stilisiertes, sich umarmendes Paar. Über den beiden Personen befindet sich ein liegender Halbmond, in dessen Mitte eine viereckige Figur aufragt. Auf dieser Figur liegen zwei weitere Trommeln. Den Hintergrund des Bildes bildet eine rotbraune Fläche, die durch zwei Schriftbänder in Segmente unterteilt wird. Von oben nach unten folgen eine freie Fläche, ein Schriftband, eine weitere freie Fläche, das zweite Schriftband und wiederum eine freie Fläche aufeinander. Das obere Schriftband ist 16 Zeilen breit, das untere 20. Die Schrift ist lesbar, es sind einzelne Wörter, aber kein zusammenhängender Text zu identifizieren.

\footnotetext{
${ }^{380}$ Thesing, Dagmar: Mohammed Taha Hussein: ein künstlerischer Dialog zwischen Orient und Okzident,
} Hamburg 2003, S. $101 \mathrm{f}$. 
Ähnlich verfährt der ägyptische Maler Hạid Nadā in seinem Werk Masīrat at-ta'mī̄r (Prozess des Aufbauens), 1976 (Abb. 90). Auf der linken Bildseite steht eine im altägyptischen Profil gemalte Figur. Neben ihren Füßen steht in roter Farbe Masīrat at$t^{\prime} m \bar{n} r$ geschrieben. Die Schrift hat eine eckige Form. Über der Schrift sind in gelber Farbe geometrische Figuren dargestellt. Die rote Farbe des Schriftzuges taucht auch in anderen Teilen des Bildes auf, besonders auf dem Oberkörper und dem rechten Arm der Figur. Die Schrift fügt sich harmonisch in die geometrischen Figuren ein.

Auf dem Bild șìnā` wa-nizāe (Kampf und Konflikt), Öl auf Leinwand, 1985, des Palästinensers Sāmīa Zarus (Abb. 91) erscheint in einem hellen Feld in der Bildmitte insgesamt sechsmal das Wort al-Quds (Jerusalem), wobei das Wort in der oberen Zeile von rechts nach links einmal richtig herum, einmal spiegelverkehrt und noch einmal richtig herum geschrieben ist. In der unteren Zeile erscheint die obere Zeile um 180 Grad gespiegelt. An drei Seiten um dieses Schriftfeld herum sind drei gemusterte Felder zu sehen, deren Muster an traditionelle Teppichmuster erinnern.

Im Gegensatz zu den vorigen Werken steht in ya-ğārat al-wādı taribtu (Oh Nachbar des Tales, ich genieße), 1994 (Abb. 92), des Ägypters Moḥammed 'Abdal Min'im Ibrāhīm (geb.1965) die arabische Schrift im Vordergrund. Die Worte ya-ǧārat sind in der oberen, das Wort al-wādi ist der unteren waagerechten Zeile geschrieben. Das Wort taribtu ist links von diesen beiden Zeilen senkrecht von oben nach unten geschrieben. In die Buchstaben sind mit Bleistift weitere Buchstaben geschrieben. Den Hintergrund des Bildes nimmt überwiegend eine rotbraune Fläche ein. Sie hat in etwa dieselbe Farbe wie die aus Nilschlamm bestehenden Häuser in den ägyptischen Dörfern. Die Fläche wird von grün-blauen Flächen durchbrochen, in denen nackte Frauen zu sehen sind. Man kann die rotbraune Fläche im Hintergrund als Häuser interpretieren, die grün-blauen Flächen als Türen und Fenster. Im oberen Teil besteht der Hintergrund aus einem dunkelblauen Sternenhimmel.

Auf dem Bild Arabian Motif, Acryl auf Holz, 1984 (Abb. 93), des Irakers Dịā' al'Azzāwī (geb. 1939) bildet das Wort لو (law ,wenn“) den Blickfang. Am linken und oberen Rand des Bildes wird mit hellgrauer Farbe die Wand eines Hauses angedeutet. Den größten Teil des Bildes nimmt eine dunkle Fläche ein, die durch die Andeutung eines Gitters als Fenster charakterisiert wird. Vor dem dunklen Hintergrund erscheint grob konturiert eine Figur, die im unteren Teil grün, ansonsten in verschiedenen 
Blautönen wiedergegeben ist, in die gelbe und rote Flächen eingesprengt sind. Auf dem oberen Teil der Figur erscheint der erwähnte Schriftzug.

Als vierte Hauptkategorie bezeichnet Wijdan 'Alī die unbewusste Kalligraphie, in der nicht- kalligraphische Arbeiten „unbewusst kalligraphische Formen enthalten verkleidet als menschliche, tierische und abstrakte Gestalten“6381. Ob eine Arbeit als Kalligraphie bezeichnet werden kann, hängt davon ab, ob der Künstler die nīya (dt. Absicht) hatte, eine Kalligraphie zu schaffen. Auch wenn beim absichtslosen Zeichnen kalligraphische Formen herauskommen können, so sind sie doch im strengen Sinn keine Kalligraphien, da der Künstler eben nicht die Absicht hatte, sie zu schaffen. Ein Beispiel für unbewusste Kalligraphie kann in dem Werk bațal aš-ša $b$ al-'arabī (Held des arabischen Volkes), ohne Datum, von Yūsuf Sīda (1922-1994) gesehen werden (Abb. 94). Die Arbeit besteht aus Buchstaben, Buchstabengruppen und der Wortfolge batal ašša $b$ al- $a r a b \bar{l}$. Der Hintergrund besteht aus einer dunkelblauen Fläche, vor der in weißer, roter, hellblauer und oranger Farbe einzelne Buchstaben gemalt sind, die sich ineinander verschlingen, wodurch sie den Eindruck von Dynamik hervorrufen. Obwohl die Buchstaben miteinander verbunden sind, bilden sie keine Worte. Darüber ist mit dünnerem Strich die Wortfolge batal $a \check{s}$-ša $b$ al- ${ }^{\prime} a r a b \bar{l}$ geschrieben, die jedoch auf den ersten Blick nur schwer zu entziffern ist, da das Gewirr der Buchstaben im Hintergrund den Blick verwirrt.

Dāgiir versucht in al-Hunūfiyya al-arabīya, al-fann wa al-huwiyya (Arabische Buchstaben: Kunst und Identität), 1990, eine andere Art der Klassifikation in Übereinstimmung mit seiner Analyse der im Folgenden aufgeführten Arbeiten, die darauf basiert, Kunstwerke als Texte zu lesen ${ }^{382}$. Huñ̄fiyya ist die Verwendung der arabischen Schrift als Bildelement. Dazu gehört allerdings nicht die ,plastische Kalligraphie ${ }^{6383}$. Dies sind Arbeiten, die sich hauptsächlich mit der arabischen Schrift im traditionellen Sinne beschäftigen. Ihre Schriftform bewegt sich im Allgemeinen zwischen einem islamisch-sakralen und einem alläglichen Typ; ihre Textbasis reicht von Koranversen bis hin zu Sprichwörtern und Slogans. Die Schriftzüge sind gut lesbar und stimmen mit einem der klassischen Schrifttypen überein. Dāgir bezeichnet diese Gruppe mit Recht als moderne Schreibkünstler und nicht als Maler, weil sie ähnlichen

\footnotetext{
381 'Alī, 1997, S. 183.

${ }^{382}$ Dāgirirs Lesung von Kunstwerken als Text basiert auf Louis Martins Etudes Sémiologiques (Paris, 1971): ein Gemälde ist ein Text weil es ein Zeichenträger ist. Ein Gemälde "Lesen" bedeutet es als "graphisches System" wahrzunehmen und sein Vokabular zu entziffern vgl. Dāgiir, 1990, S. 53 f.

383 vgl. Dāgìir, 1990, S. 67-72.
} 
Betrachtungen folgen wie die traditionellen Schriftkünstler: ihr Hauptinteresse gilt den Schriftzeichen.

Der moderne Aspekt der Arbeit dieser „reinen Kalligraphen“ besteht im Gebrauch von modernen Kunstwerkzeugen und -techniken, dem höheren Freiheitsgrad im Aufbau und dem Gebrauch von Farbe, wie z.B. in der Arbeit des irakischen Schreibkünstlers Moḥammed Sacid As-Saqqar, Tawtid al-hatț (Entstehung der Schrift), 1985 (Abb. 95). Er schreibt ein Gedicht von $A b \bar{u}$ Șahr al-Hudať in traditioneller Nashīi-Schrift nieder, kreiert jedoch für die Anfangszeile einen neuen Schrifttyp. Die Anfangszeile ist wesentlich größer als der Rest des Gedichtes geschrieben und erstreckt sich schräg von rechts oben diagonal über das Blatt. Das übrige Gedicht ist in zwei Spalten geschrieben, die auf halber Höhe der Seite beginnen. As-Saqqar versuchte insgesamt, die traditionelle Kalligraphie weiter zu entwickeln, indem er neue Schrifttypen, die auf älteren Formen basierten, erfand. Damit bewegte er sich auch in der Tradition der arabischen Kalligraphie.

Nach Dāgirs Definition basiert Hurūfiyya auf zwei Grundregeln: Erstens auf dem kompletten Bruch mit den traditionellen arabischen Schreibstilen, stattdessen werden die Buchstaben als künstlerische Elemente verwendet. Und zweitens auf der Erschaffung eines modernen Kunstwerkes, das fähig ist, eine kulturelle Besonderheit zum Ausdruck zu bringen. Weiterhin stuft er Huñ fiyya - Arbeiten in vier weit gefasste Kategorien $\operatorname{ein}^{384}$.

Die erste Kategorie ist das Gemälde aus Buchstaben, ,wobei der Buchstabe das Material der Arbeit ist- als Ausgangspunkt und Endprodukt ${ }^{\star 385}$. In solchen Arbeiten experimentiert der Künstler mit den plastischen Möglichkeiten des einzelnen Buchstaben zu unterschiedlichen Zwecken: Diese können kreativer, dekorativer, dekonstruktiver oder meditativer Art sein. In diese Kategorie können die Bilder ohne Titel, ohne Datum (Abb. 71), und At the concert, 1948 (Abb. 72), von Madịha 'Umar und Objektive Betrachtungen von as-Sā̄i 1984 (Abb. 78) eingeordnet werden.

Die zweite Kategorie ist das Gemälde aus Wortgruppen, wobei die linguistische

\footnotetext{
${ }^{384}$ Dāgir beschreibt noch zwei weitere Klassifikationsversuche, den des irakischen Künstlers al-Qayssi von 1980, und den des tunesischen Autoren Mohammed Azizah von 1977. Er findet beide unzureichend und verwirrend vgl. Dāgigir, 1990, S. 48ff.

${ }^{385}$ Dāgir, 1990, S. 59.
} 
Bedeutung ein Teil des Ausdruckes ist. Durch das Einfügen religiöser Aussprüche mit traditionellen Schriftzeichen benutzen die Künstler die klassischen oder modernen arabischen literarischen Texte als Material ihrer Arbeit. In diesem Fall ist die Struktur der Arbeit sichtbar und sprachlich relevant: Farben und Text wirken in einem Dialog zusammen. Werke, die dieser Kategorie zugeordnet werden können, sind etwa ilā Ummī (An meine Mutter), 1985 (Abb. 96), von Rašīd Qoraīšy. Mit dem Titel des Bildes spielt er auf das gleichnamige Gedicht des Palästinensers Mạ̣mūd Darwī̌s an. Ebenso bahä’ al-hazimma (Herrlichkeit der Niederlage), 1994 (Abb. 97), von Ethel Adnan, auf dem ein Ausschnitt aus dem gleichnamigen Gedicht der saudi-arabischen Dichterin Fawzīya $A b \bar{u}$ Halid zu sehen ist ${ }^{386}$. Auf der linken Seite des Gemäldes befindet sich ein gelber Streifen, auf dem die Andeutungen einzelner Buchstaben erscheinen. Den Raum rechts daneben nimmt eine weiße Fläche ein, die mit gelben, blauen, grünen, violetten und roten Kringeln sowie mit einzelnen, kaum leserlichen Worten bedeckt ist. Das Gemälde besteht zum größten Teil aus einer hellroten Fläche, die den rechten Bildteil einnimmt. Diese Fläche ist mit weißen, gelben und schwarzen Pflanzenmotiven bedeckt. Links auf dieser Fläche befindet sich ein weißer Streifen, auf dem in vertikaler Richtung in zwei Zeilen folgende Worte geschrieben stehen: Zeile 1: Fawzīya Abū Halid nīya 1994 (Fawż̀ya Abū Halid Absicht 1994). Zeile 2: bahā’ al-haz̄ma İ̃̄l 'adnān (Herrlichkeit der Niederlage - Ethel Adnan).

Der ägyptische Künstler 'Abd al-Hādī al-Ğazzar (1925-1966) integrierte in seine Tuschezeichnung ibn al-Kilāb (Hundesohn), 1953 (Abb. 98) folgendes Gedicht:

Damned son of a bitch

Child of deviled slaves

Mean and lowly

A rogue typical of his time

Lives for himself alone

Wets his appetite with a goat

Puts his ass on a throne

Across the streams and fields

A perpetual blasphemer

Women and wine

Seven black heads

Like a morbid crow

${ }^{386}$ Englische Übersetzung des Gedichts von Ethel Adnan in: Nashashibi, 1997, S. 20 f. 


\section{Wail the news on shore}

\section{The one with the sincere palm}

\section{Has made me vow}

\section{To fold the times of injustice. ${ }^{387}$}

In dem Gedicht beschreibt al-Ğazzar die Tyrannei Nassers, der jeden verhaften ließ, der Kritik an seiner Amtsausübung übte. Sein Werk beschreibt somit den psychischen Druck, dem der Künstler jener Zeit ausgesetzt war. Im Zentrum der Zeichnung steht ein Baum, der fast die gesamte Höhe des Bildes einnimmt, rechts neben ihm unterhalb seiner Zweige das erwähnte Gedicht. Das Gedicht ist in normaler Schrift geschrieben. Auf dem Stamm des Baumes sind ein geknebeltes Gesicht und darüber eine Eule dargestellt. Links an den Stamm angelehnt sitzt zusammengekauert eine Frau mit langen, strähnigen Haaren. Hinter ihr sitzt ein Mann, der seine Knie zum Mund gezogen hat. Im Hintergrund erscheinen einige Gebäude. Auf der rechten Seite liegt ausgestreckt ein Mann auf dem Boden. Über ihn beugt sich eine Frau mit langen offenen Haaren und ringt die Hände. Hinter der Frau steht ein Gestell, an dem ein Krug aufgehängt ist. Von diesem Gestell wendet sich eine weitere Person ab. Auf dem Querbalken des Gestells sitzt ein Rabe, auf den drei weitere Raben zufliegen.

Eine Variante dieser Kategorie stellt as-Samā' gàa'ima wa-rūḥ̂̉ muballala bi-l-matar(Der Himmel ist bewölkt und meine Seele ist nass durch den Regen) des Irakers Rašād Salīm, 1986 (Abb. 99) dar. Salim gibt den Worten as-Samā’ gà̃ima (Der Himmel ist bewölkt) die Form von Wolken. Die Worte wa-rūḥ̂ muballala bi-1-mațar (und meine Seele ist nass) werden in fließender Bewegung abwärts geschrieben, so dass sie fallenden Regen symbolisieren. Die Wort bi-1-matar (durch den Regen) werden durch einen Halbmond auf der Spitze eines Dreiecks wie von einer Schale aufgefangen.

Die dritte Kategorie ist das Gemälde aus Schrift, wo die Arbeiten zwar an die Form der geschriebenen Sprache angelehnt sind, nicht jedoch an ihre Bedeutung. Es ist eine Zusammensetzung von unleserlicher Schrift ohne sprachlichen Inhalt. Ein Beispiel für die Künstler dieser Kategorie ist Yūsuf Aḥmad aus Qaṭar. In takw̄̄n haț̣̄ (Kalligraphische Komposition), 1983 (Abb. 100), setzte er auf einem schwarzen Hintergrund in grauer Farbe Buchstaben aneinander. Die Schreibrichtung verläuft von

${ }^{387}$ Roussillon, Alain \& Christine: 'Abd al-Hādī al-Ǧazzar, The best avilable monography of the outstanding Egyptian pioneer artist Abel Hadi Al-Gazzar. With texts in Arabic, English and French; Cairo, 1990, S.194. 
rechts unten nach links oben. Außer in den ersten beiden langen Zeilen erscheinen in jeder Zeile dieselben Buchstaben nebeneinander, so in der dritten Zeile yā und in der vierten wāw. In der zweiten Zeile stehen zwar verschiedene Buchstaben, aber sie bilden kein Wort. In der ersten Zeile steht bi-sm. Davon nach oben abgesetzt erscheinen in erscheinen in zwei kurzen Zeilen die Worte allah ar-raḥmāni ar-raḥ̄m, so dass allah unten zu stehen kommt, ar-rahīm darüber. Man muß also die bi-smi llāha nicht von oben nach unten, sondern von unten nach oben lesen.

Die letzte Kategorie ist „das Gemälde als Text". Diese Kategorie unterscheidet sich nach Dāgir von den drei ersten dadurch, dass hier vom Buchstaben als einem Element des Aufbaues unter anderen Abschied genommen wird. Der Buchstabe wird nicht auf seine konventionelle Form beschränkt, sondern abgewandelt oder verzerrt. Es werden Ornamente gezeichnet, die arabischen Buchstaben ähnlich sehen. Ein Beispiel für diese Kategorie ist simfüniyat al-hutụt (Symphonie der Linien), 1997 (Abb. 101). Hussayn alĞībālī (geb. 1934) teilt sein Gemälde in fünf ungleichmäßige horizontale Streifen. Die Buchstaben und Wörter sind eins der fragmentierten Elemente, die die gesamte Komposition bilden. Im zweiten und vierten Streifen von oben schreibt er Buchstaben, in den übrigen Streifen erscheinen buchstabenähnliche Linien. Im zweiten Streifen von oben sind die Buchstaben spiegelverkehrt und auf den Kopf gestellt. Im vierten Streifen von oben kann man das Wort ğamāl (Schönheit) neben funktionslosen Buchstaben erkennen. Die tatsächlichen Buchstaben wurden formlos hingeschrieben, ohne Rücksicht auf konventionelle Schreibstile.

Außerhalb dieser Kategorien stuft Dāgir die Arbeit des Palästinensers Kamal Boullata ein $^{388}$. Er nennt dessen Stil geometrische Huñufiyya. Die Buchstaben werden als Elemente streng symmetrischer Figuren verwendet. In seinen Drucken verwendet Boullata die eckigen Buchstaben des alten kufischen Alphabets und ordnet sie als visuelle Elemente an: der Aufbau entspricht sowohl traditionellen geometrischen islamischen Designs als auch modernen Computergraphiken. Dies kann man in Ohne Titel, 1985 (Abb. 102), sehen. „Seine Arbeit basiert auf dem Kufi-Stil; er hat dessen Reinheit der Linie und die für ihn charakteristische Strenge ohne jede Verzierung umgesetzt, so als wünsche er, durch dieses fast durchsichtig anmutende Liniensystem, das Geheimnis des arabischen Buchstabens, das Rätsel seiner Schriftspuren dem verzauberten Auge aufzudecken. Seine Arbeit ist insgesamt von der klassischen 
Kalligrafie inspiriert. Boullata ist es gelungen, ihr eine neue Stellung in der zeitgenössischen Kunst zu verleihen“389. Möglicherweise bleibt Boullata ein wenig traditionell, denn, obgleich er moderne Mittel in seiner Arbeit einsetzt, bewahrt er auch die Integrität des Buchstabens als Teil der Sprache.

Ungeachtet dieser Klassifikationen ist Huñ fiyya weitgehend akzeptiert, bis hin zu festlichen Anlässen in arabischen Gesellschaften und bei Beamten. Seit seinen Ursprüngen ist es von den westlichen Kritikern ähnlich begrüßt worden. Midyyin, der meint, dass es nicht einfach sei, über Huñ̄fiyya zu diskutieren, argumentiert, dass durch die Experimente mit den Zeichen „die Angelegenheiten innerhalb eines neuen Konstruierens, in dem das Zeichen, wie aus seinem ursprünglichen religiösen Kontext entrissen" scheint, und eine bemerkenswerte und weltliche Öffnung für Zeichen sei ${ }^{390}$. Wegen seiner Affinität zur religiösen Empfindsamkeit der Araber kam es jedoch zu einer Massenproduktion von „kommerziellen Huñfiyya “391. Diese populären kommerziellen Arbeiten, die lediglich dekorativ sind, werden von den Kritikern in der arabischen Presse als Hurūfiyya eingestuft. Die Vorbehalte und der Unmut unter vielen etablierten Huñ fiyya -Künstlern führten nach und nach dazu, dass einige Künstler den Gebrauch von Buchstaben in ihrer Arbeit komplett aufgaben. Nach al-'Azzāwī „,wurde der Buchstabe eine Art Wundermittel, welches die Wünsche des Künstlers erfüllt“, der nicht so sehr auf die Qualität der Arbeit, sondern eher auf deren Akzeptanz konzentriert $\operatorname{war}^{392}$.

Dennoch muss sich Hurūfiyya anderen substantiellen Kritiken stellen, die ihren Verdienst und Erfolg, ihr Ziel zu erreichen, in Frage stellen. Der syrische Kunstkritiker Maurice Sankary schreibt, dass die arabische Welt den arabischen Buchstaben jetzt für eine Weile im Namen „der Authentizität und der Erneuerung“ in der plastischen Kunst „einem barbarischen Angriff, der ihre Grundlage erschütterte und ihre Form verzerrte“, unterworfen habe ${ }^{393}$. Er meint, dass die Experimente der Huñ fiyya im Allgemeinen nur erfolgreich entweder die Unterlegenheit einiger Künstler in ihrer Bemühung, ihre

\footnotetext{
${ }^{389}$ Khatibi und Sijelmassi, 1976, S. 23 f.

${ }^{390}$ vgl. Midyyin, Bin'mar: Iškāliytāt al-Muqaddas wa al-Dunyawī fi fann ar-Rasm al-'arabī al-Mu'aṣr wa al-Magaribī, in: at-T’aṣil wa-t-tahdīt fî-l-Funūn al-taškīlya, in: al-Wạ̣da, Heft 70/71, Paris 1990, S. 3846, hier S. 46.

${ }^{391}$ Insbesonere für Arbeiten, die für den Markt in Saudi-Arabien und den Golfstaaten bestimmt sind.

${ }^{392}$ vgl. Farh, Basim: The plastic artist Diyā' al-'Azzāwī; the seven solden odes: a beautiful past like a desert mirage, in: Al-Majalla (Baghdad), no. 16 (June 1980), S. 57.

393 vgl. Sankary, Maurice: Lawḥat al-Ḥurūfiyya al-`arabīya wa Șarab al-Bāḥit̄in 'an al-huwiyya, in: al-Wạ̣da, Heft 70/71, S. 99-111, hier S. 109.
} 
künstlerische Identität zu behaupten, oder den Fehlschlag der anderen, kreative Arbeiten hervorzubringen demonstriert hätten. Huñfiyya, so fügt er hinzu, versuchte nur, „a șala“, (dt. Originalität), in „Modernität in traditionellem Sinn umzuwandeln“: sie sei aber nichts anderes als eine oberflächliche Vereinbarung zwischen moderner Abstraktion und traditioneller Abstraktion; ein hybrides Produkt ${ }^{394}$.

Tatsächlich sieht Sankary im Gebrauch des Buchstaben, losgelöst von seiner linguistischen Bedeutung, eine Verunstaltung des Buchstaben, welche im Gegenzug den Verlust „der einzigartigen Sozial- und vereinigten künstlerischen Identität von traditioneller islamischem Kalligraphie“ zur Folge habe ${ }^{395}$. Während ihm viele der Arbeiten gefallen, findet er keinen humanistischen Wert in ihnen: Sie drückten keinerlei Wissen aus, verzerrten jedoch eine vertraute und geliebte Form, die mit Wissen verbunden sei $^{396}$. Sankarys Kritik entspringt seiner Ansicht, dass Hurūfiyya nicht das Selbst, die arabische Wirklichkeit oder Befindlichkeit ausdrücke. Sie drücke eher den Versuch des arabischen Künstlers aus, sich mit dem Anderen, dem Westen zu verbinden, indem die exakte Feder des Kalligraphen durch den freien Pinsel des westlichen Malers ersetzt werde.

Ich vertrete eine gegensätzliche Ansicht. Obwohl viele arabische Künstler von den arabischen Buchstaben Gebrauch machten, haben sie sie missbraucht, darüber hinaus entstellt, ohne eine greifbare künstlerische Darstellungsweise zu erreichen. Andere aber haben durch ihre Benutzung der Buchstaben Gemälde produziert, die über alle Merkmale des erfolgreichen künstlerischen Werkes verfügen. Somit haben sie die Vergangenheit mit der Gegenwart durch eine moderne Betrachtungsweise vereinigt. Meines Erachtens spricht sich Sankary gegen die Huñ fiyya aus, weil er einmal selber ein traditioneller Kalligraph ist, der in der Huñfiyya eine Entweihung der arabischen Buchstaben sieht. Zum anderen wurde er durch diejenigen Künstler beeinflusst, die mit Hurūfiyya experimentiert hatten, aber erfolglos blieben und nun ihre erfolgreichen Kollegen verleumdeten.

Eine andere Meinung vertritt der Kunsthistoriker Samīr aṣ-Ṣaīyg. Während er prinzipiell das Ziel der Hurūfiyya, die Lücke zwischen islamischer Kunst und moderner Kunst in Gegenwart und Vergangenheit zu schließen, anerkennt, hinterfragt er die 
Anwendungen. Er argumentiert, dass „der Anspruch des Umwandelns von Schriftzeichen in formale Elemente, obgleich es logisch klingt, in Ästhetik ausgedrückt, mehrdeutig ist: um die traditionelle Schrift als Element der Plastik wahrzunehmen, muss ihr eine autonome Ästhetik gegeben werden“397. In der modernen Malerei jedoch, die die Schrift dekonstruiert, um nur einige ihrer Komponenten als plastische Elemente zu benutzen, hat die Ästhetik der Schrift ihren Ursprung weniger in der traditionellen Kunst, als vielmehr im Dialog mit der modernen Kunst. In der modernen Kunst werden die arabischen Schriftzeichen in ihrer alltäglichen Gebrauchsform verwendet, nicht in einer ,gemalten“ oder ausgeschmückten Form wie in der islamischen Kalligraphie. So entsprechen sie nicht mehr ihrer autonomen Ästhetik. Stattdessen werden sie ein bloßes Element der modernen Kunst, die alle Elemente unterschiedlicher Materialien gleich behandelt, ohne zwischen ,einer künstlerischen Sache und einer nicht-künstlerischen Sache oder ästhetischem Element bzw. einem nicht-ästhetischen Element“ “398 . zu unterscheiden. Das Schriftzeichen, so aṣ-Ṣaīyg ist nicht materiell. Es sei ein Symbol, eine Form und ein System. Die Ästhetik der traditionellen Schriftzeichen sei nicht in ihren Buchstaben, sondern im Ausdruck, in der Bedeutung, im System und in der Logik, durch die die Buchstaben gebildet werden, zu finden. Infolgedessen glaubt er nicht, dass Hurūfiyya die zwischen traditioneller und moderner Kunst klaffende Lücke schließen könne, weil sie die traditionelle Ästhetik aufgegeben und durch moderne ersetzt habe ${ }^{399}$.

Stark vereinfacht lässt sich sagen, dass es zwei große Gruppen von Ḥuñfiyya gibt. Die eine nutzt den Buchstaben als Zugang zum Werk, er ist aber nur Mittel, um einen Zugang zu anderen Themen zu schaffen. Für die zweite ist der Buchstabe selbst das Werk, in diesen Bereich fällt auch die rein dekorative kommerzielle Huñ fiyya.

\subsection{Poesie als Inspiration für die Malerei}

Die arabische Poesie mit ihrer reichen Symbolik und Bildersprache hat die Araber seit vorislamischer Zeit fasziniert. Als Botschafter für seinen Stamm nahm der Dichter einen wichtigen Platz in der arabischen Gesellschaft ein und schuf Bilder, die verwendet wurden, um Nachrichten, Politik, Liebe, Lob und Verherrlichung seiner Auftraggeber zu vermitteln. Die arabische Sprache bietet einen Wortschatz, der fähig ist, Harmonien

\footnotetext{
${ }^{397}$ vgl. aṣ-Ṣaīyg , Samīr: al-fann al-islāmī: qirā’a ta’ammuliyya fî-l-falsafa wa-l-ḩuṣūṣīyya al-ğamālīyya, Beirut, 1988, S. 377.

${ }^{398}$ vgl. aș-Ṣaīyg், 1988, S. 378.

399 vgl. ebd.
} 
von Reim und Rhythmus zu erzeugen, die sowohl den Zuhörern gefallen, als auch sicherstellen, dass das Gedicht von einer Generation zu nächsten weitergegeben wir ${ }^{400}$. Wegen seiner nuancenreichen Ausdrucksmöglichkeiten ist Arabisch eine der am schwersten übersetzbaren Sprachen. Ebenso wie in der Kunst der Kalligraphie ein ästhetischer Kanon die Kreativität der Künstler in traditionellen Normen eingrenzte, so neigten auch Rhetorik und Improvisation in der traditionellen arabischen Dichtung dazu, gesetzten Richtlinien und Regelungen zu folgen. In den letzten fünfzig Jahren sind die traditionellen Grenzen der modernen arabischen Dichtung und der Kunst durch den freien Vers und individualistischere Kunststile ersetzt worden. Bis heute bleibt die Dichtung eine populäre Kunstform in der arabischen Welt; Tageszeitungen und Zeitschriften mit breiten Leserschichten widmen Kolumnen und ganze Seiten der Dichtung. Der arabische Historiker Phillip Hitti meinte hierzu: „No people in the world, perhaps, manifest such enthusiastic admiration for literary expression and are so moved by the word spoken or written, as the Arabs"401.

Diyā’ al-'Azzāwī (geb. 1939), ,erhielt früh eine archäologische Ausbildung, was sich in seiner Arbeit widerspiegelt. Er fügte in seine Zeichnungen babylonische Figuren ein, die an die Fresken des alten Irak erinnern und setzt das gesamte Bild mit Dichtung neu zusammen. Das Lesen der sieben großen vorislamischen Oden, die als Múallaqā $t^{402}$ bekannt sind, inspirierte ihn dazu, Bilder von Stammesstolz, Loyalität und Liebe zu ergründen, mit dem Ergebnis, dass die Bilder und die Wörter in seinen realistischen Zeichnungen die Zeit transzendieren. Seine großen gemalten Manuskripte der Oden haben beachtliche Resonanz in der arabischen Welt erfahren“" 403 . Mit dem Transzendieren der Zeit ist gemeint, dass 'Azzāwī die älteste arabische Dichtung mit moderner bildender Kunst verbindet.

Die Sammlung al-Mu'allaqāt as-sab`a (1978) besteht aus acht Bildern auf Seidengewebe, die durch die oben genannten Oden inspiriert waren und als einzelne

${ }^{400}$ vgl. Nashashibi, 1997, S. 8.

401 zitiert nach: Nashashibi, 1997, S. 8.

402 al-Mu'allaqāt (arab. die Hängenden) sind so benannt weil sie früher die Tücher schmückten, die die Kaaba in Mekka bedeckten, also von ihr herabhingen. Die Mehrzahl der Oden wurden 50 bis 150 Jahre vor der Geburt des Propheten [420-470 n. Chr.] verfasst. Sie wurden öffentlich bei den Festen, die jährlich nahe Mekka am Markt Suq Ukaz stattfanden, rezitiert oder gesungen, wobei das Publikum sein Urteil über den Wert der Gedichte abgab. Die sieben Oden haben einen festen Aufbau, und sind in drei thematische Bereiche gegliedert: die Liebes-Prelude, das Reisethema, das Lob für Pferd und Kamel des Dichters einschließt, und das Hauptthema des Gedichtes, das der Dichter entweder dem Preisen seiner eigenen Tugend oder dem Glorifizieren seines Stammes und dem Herabwürdigen seiner Feinde widmen konnte. vgl. Nashashibi, 1997, S. 30.

${ }^{403}$ Nashashibi, 1997, S. 9. 
Einheiten, nämlich Einleitung zu den sieben goldenen Oden (Abb. 103) und Die sieben goldenen Oden: Umr'u 1-Qais (Abb. 104) ausgestellt werden konnten. Der geschriebene Text der Dichtung wurde als Bild arrangiert. 'Azzāwī ordnet die Oden in wechselnden Schreibrichtungen so an, dass sie um einen Mittelpunkt herum geschrieben sind. Die Namen der Dichter, einer je Ode, sind mit roter Farbe hervorgehoben.

Al-'Azzāwīs Absicht war, ein Verhältnis zwischen Buchstaben und anderen visuellen Formen zu schaffen, einen Dialog zwischen Schrift und den visuellen Künsten. Es ist unwichtig, ob der Betrachter den Text lesen kann oder nicht. Stattdessen, so schreibt Lu'ībī, ,al-'Azzāwī erfasst, was der Akt des Schreibens selbst erfassen könnte, durch den Aufstieg und Abfall seiner Buchstaben, durch ihr Ineinandergreifen, Zusammenspiel und ihre Biegungen kultureller Hinterlassenschaft, die, von einem visuellen Standpunkt aus, den Múallaqāt eine neue Dimension zusätzlich zum ihrem Status als literarisches Meisterwerk verleiht ${ }^{\text {‘404. }}$

Al-'Azzāwī selbst deutete die Grundlage seiner neuen Erfahrung in einem Text, mit dem er die Arbeit einleitete:

„Weder die Wörter noch die alte Zeit, die diese Gedichte umhüllen, sondern die Ansammlung der Buchstaben und der Fluss der Symbole auf einer einzigen Linie der Vorstellung zeigen sich hier (...)Die gezeichneten Formen als solche sind nicht in den Versen oder in der Gesamtheit des Gedichtes definiert. (...) Daher kommt der Widerspruch zwischen al-Mu'allaqāt als Bild und al-Mu'allaqāt als Dichtungen, trotz der Abhängigkeit des Ersteren vom Letzteren. Das gemalte Mu'allaqah [Singular] ist ein Vermittler zwischen den visuellen Wahrnehmungsfähigkeiten des Betrachters und dem sprachlichen Gedächtnis (...) So genommen, können die al-Mu'allaqāt ihre gegenwärtige äußere Form aus der Vergangenheit des Gedichtes und ihren sprachlichen Details erschaffen, um ein zeitgenössisches visuelles Zeichen zu werden“‘405.

Bevor sich 'Azzāwī mit den ältesten überlieferten arabischen Gedichten beschäftigte, ließ er sich von der zeitgenössischen Poesie inspirieren. Der Bürgerkrieg im Libanon und die Erfahrungen während seiner eigenen Dienstzeit in der irakischen Armee inspirierten ihn in den siebziger Jahren zu einer Reihe von Poesie-Bildern, in denen er sich besonders mit politischer Dichtung beschäftigte. In diesen Bildern versuchte al-

\footnotetext{
${ }^{404}$ vgl. Lư̄ìīi, Šākir: Baḥt 'an Ru’yya ğadīda, in: Mawakif Nr. 67, London 1992, S. 161-175, hier S. 170.

405 Al-'Azzāwī, Ḍiyā' : Poetry, a visual text, in: Mawakif Nr. 72, London 1992, S. 134 ff.
} 
'Azzāwī nicht, die menschliche Tragödie und die blutige Situation in eine ästhetische Erfahrung umzusetzen, sondern behielt in seiner Beschreibung eher Objektivität bei.

1972 malte er $a \check{s}$-šahìd min waqtunnā (Der Zeuge aus unserer Zeit), in dem er visuell

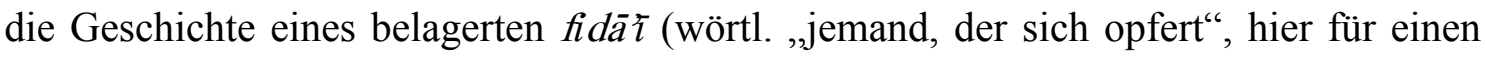
palästinensischen Freiheitskämpfer) nach dem Blutbad vom „Schwarze September“ 1970 erzählt ${ }^{406}$. Al-'Azzāwīs ,,nackte, brutale und oft gespenstisch wirkende Bilder dienen dazu, die Grausamkeit und das Unverständnis festzuhalten, die im Tagebuch eines unbekannten Soldaten - später vermisst, vermutlich gefallen - zum Ausdruck kommen“407.

Unmittelbar nach dem Blutbad von Tell az-za'tar 1976 im Libanon ließ sich al-`Azzāwī durch drei Gedichte von Mạ̣mūd Darwī̌s, Taher Ben Jalloun und Yūsuf aṣ-Ṣaīyg zu dem Bildband an-našd al-ğasadĭ (Hymne des Körpers) ${ }^{408}$ inspirieren. Al-`Azzāwī illustierte diese Gedichte und gab sie als Buch heraus. In diesem Buch versammelt er 42 Bilder, von denen ich zwei (Abb. 105 und 106) als Beispiele für schwarz-weiße und mehrfarbige Bilder ausgewählt habe. Außerdem sind es die meiner Meinung nach ausdrucksstärksten Bilder

In diesen Arbeiten greifen Figuren und Wörter dramatisch als dunkle und gewalttätige Formen ineinander. Der Aufbau von „Hymne des Körpers“ wird unmittelbar von der dramatischen Realität geleitet und ist eine Stellungnahme gegen den blutigen Fall des Lagers Tell az-za'tar. Alle Strukturen der „Hymne des Körpers“ dekonstruieren den menschlichen Körper und rekonstruieren ihn wieder, um die Qual darzustellen. Die Dekonstruktion wird dargestellt, indem einzelne Körperteile abgebildet werden, vornehmlich Hände und Augen. Die im Buch enthaltenen Werke sind eindringliche Personendarstellungen. Sie sind aber keine realistischen Darstellungen. Sie rekonstruieren die menschlichen und tierischen Elemente auf eine Weise, die den Zuschauer verstehen lässt, dass der Künstler einen dröhnenden Schrei ausstoßen will. Spannung manifestiert sich in der Erscheinung der Hände, die sich nach den leeren Stellen der Werke um Hilfe strecken, wie auch in der Darstellung der Augen, die so in

\footnotetext{
${ }^{406}$ Nachdem Israel 1967 das Westjordanland besetzt hatte, verlegte die Fatah-Miliz ihre Basen nach Jordanien. Dort entwickelte sie sich zur Bedrohung für die Herrschaft König Husseins. Im September 1970 ließ der König durch die jordanische Armee die Fatah aufreiben. Ihre Reste flohen anschließend in den Libanon.

${ }^{407}$ vgl. 'Alī, Maureen: Painting Poetry, in: Gilgamesh, a journal of modern Iraqi arts Nr. 4, Bagdad 1988, S. 15-17, hier S. 15.

${ }^{408}$ Al-'Azzāwī: The body's anthem, Beirut 1980.
} 
den Strukturen gestreut sind, als wären sie erschrockene Zeugen der Gräueltat. Ein Pferd, das an das in Guernica von Picasso dargestellte erinnert, taucht hier auf. Ähnlich wie in Guernica stößt das Pferd einen Entsetzensschrei aus (Abb. 106). Die Gestaltung stützt sich auf die Schaffung eines deutlichen Kontrasts zwischen den schwarzen und den weißen Flächen. Die Linien aber erscheinen verwirrt und schnell gezogen, was in al-'Azzāwīs Öl- und Grafikwerken kaum zu finden ist. Die meisten ornamentalen Motive verschwinden in „Hymne des Körpers“ vollständig, als sei das Werk selbst ein physischer Schmerz, der aus Qualen entsteht, und nichts mit Dekorativität zu tun hat. Die relative Marginalisierung der Schrift lässt das Werk an übertriebenen, formalistischen, spielerischen und ästhetischen Elementen verlieren, was dabei hilft, den angestrebten traurigen und protestierenden Eindruck im Werk zu unterstreichen. Für die farbigen Arbeiten in „Hymne des Körpers“ nutzte al-'Azzāwī nicht seine gewöhnliche Palette. Das in dem Druck benutzte Violett wie auch Hellgrün erscheinen nur selten in den anderen Werken al-'Azzāwīs. Dies macht eine Gegenüberstellung von al-'Azzāwīs Druckwerken aus der „Hymne des Körpers“ mit seinen anderen Werken deutlich.

Nach seinem Umzug nach London 1977 widmete sich al-'Azzāwī seit Ende der achtziger Jahre der Herstellung bemalter Manuskripte zeitgenössischer arabischer Dichtung. Dazu regte ihn die Sammlung islamischer Manuskripte in der British Library $\mathrm{an}^{409}$. Seine Ansicht, dass die Herstellung von Büchern die wahre Quelle islamischer Kunst sei, wurde bestätigt und erweckt und deshalb entschied er, dass das Konzept eines „Buches“ als wesentliches Material weiterentwickelt werden sollte. al-'Azzāwī glaubte, dass ,einen literarischen Hintergrund für Malerei zu haben eine geistige Atmosphäre schaffen könnte, welche dem Betrachter, sogar einem Westlichen ermöglichen würde, das Werk zu hinterfragen. Vielleicht akzeptiert er es nicht, gänzlich ablehnen oder zurückweisen jedoch kann er es nicht", weil es sich mit lebendigen Größen, dem Konzept und der Sprache beschäftigt. Andererseits meint er: "Experimente mit der arabischen Folklore können nur als Teil der Folklore verstanden werden, also als Teil toter Museen“" ${ }^{410}$.

In al-'Azzāwīs entwickelter Manuskriptform werden Wörter mit Zeichnungen und Farbe in kompletter Mühelosigkeit und Freiheit vermischt, wie etwa in qabla an yantahīa alginā'(Bevor das Lied endet), 1998/99 (Abb. 107), nach einem Gedicht von Adonis. Der

\footnotetext{
${ }^{409}$ Al-'Azzāwī, Gespräch mit dem Verfasser vom 10. November 2003.

${ }^{410}$ Al-'Azzāwī, 10. November 2003.
} 
Text und die bildliche Darstellung stehen gleichberechtigt nebeneinander. Weder illustriert das Bild den Text, noch werden aus den Buchstaben Bilder aufgebaut. Der Text des Buches soll eigentlich nicht gelesen werden. Tatsächlich meint al-'Azzāwī, „um diese bemalten Bücher zu lesen, benötigt man die Fähigkeit, gleichzeitig die Wirklichkeit des Textes, ebenso wie die der gemalten Bilder zu erfassen. Mit anderen Worten, Kenntnis des Alphabets alleine genügt dem Leser/Betrachter nicht, denn er muss das Verhältnis zwischen Farbe und Wort aufrechterhalten, die Formen, das Arrangement und den Textfluss ergründen“411. Im Grunde entfernt sich der Text des Gedichtes vom Konzept „des Buches“. Stattdessen verkörpern diese bemalten Bücher einen Dialog zwischen "Text-Gedächtnis und Gemälde-Betrachtung. Sie sind ,visuelle poetische Bücher, im Gegensatz zu dem, was wir von den besten gedruckten Gedichtsammlungen kennen, die nur Schachteln gefüllt mit Worten und ein paar Abbildungen sind“4 ${ }^{412}$.

Oft benutzt al-'Azzāwī die Farben Schwarz und Rot als Hintergrund seiner Bilder. Darauf malt er seine Figuren sowie seine Schriften. Somit vermittelt er bei dem Betrachter ein Gefühl der Tiefe. Auch fühlt man die Figuren sehr nah. In den alĞawāhin̄-Verses, 1989 (Abb. 108), bildet das Zentrum des Bildes bildet ein leicht diagonal gelegtes schwarzes Rechteck auf rotem Hintergrund. Auf dem schwarzen Rechteck ist oben eine Mondsichel in grüner Farbe mit gelbem und rotem Rand gemalt. Darunter befindet sich eine in weiß, gelb, grün und schwarz gemalte, stilisierte Palme. Auf die Palme fliegt von links ein Vogel zu. Am Fuß der Palme ist mit roten Strichen eine Figur gemalt, die man für ein tanzendes Männchen halten könnte. Ganz unten erscheint ein weißer Streifen, auf den arabische Worte geschrieben sind. Die Figuren im Bild leiten die Blicke des Betrachters in alle Richtungen, bis man die Schrift liest. Sie führen erneut die Blicke nach oben, was damit erklärt wird, dass sich die rote Farbe in den weißen Bereich ausdehnt. Weiße, gelbe und grüne Kästchen, die sich auf der roten Farbe dynamisch nach oben bewegen, reißen den Betrachter mit.

In Adonis: Ein Grab um New Yorks willen, 1990 (Abb. 109), wird der Text teilweise von Schwarz und hellem Rot, auf dem er erscheint, sowie von den Bildmotiven

\footnotetext{
${ }^{411}$ Nūrī, Šākir: Ḥiwār ma'a al-fanān Ḍiyā’ al-'Azzāwī (Gespräch mit dem Künstler Ḍiyā’ al-'Azzāwī) in: alQūds al-'arabī, Nr. 3876, London 29. 10. 2001, S. 121.
}

${ }^{412}$ Al-'Azzāwī , 1992, S. 137. 
verdeckt ${ }^{413}$. Er taucht an einigen Stellen deutlich auf, während er an anderen verblasst. Er ist einer kursiven Freihandschrift geschrieben, die keinen bekannten Regeln folgt, sondern eher in Form eilig hingeworfener Notizen erscheint. Die Schriftrichtung variiert; manchmal verläuft sie in horizontalen Linien, ein anderes Mal um die Ecke oder sogar rückwärts. Von oben gesehen verläuft der Text auf der linken Hälfte in fünf Zeilen waagerecht von rechts nach links. Daran schließen sich vier Zeilen an, die schräg von rechts unten nach links oben verlaufen, daran wiederum acht Zeilen waagerecht von rechts nach links. Die oberen vier dieser Zeilen bedecken etwa ein Achtel des gesamten Bildes, die fünfte und sechste ein Viertel, die siebte und achte die Hälfte. Auf der rechten Seite ist auf im oberen Teil des schwarzen Hintergrundes eine waagerechte Zeile aus violetten Buchstaben spiegelverkehrt von links nach rechts geschrieben.

In an-Niffar̄ (Abb. 110), das durch das gleichnamige Gedicht von Mohammed alFaytūrī (geb. 1930) inspiriert wurde, benutzt al-'Azzāwī erneut die beiden Farben Rot und Schwarz als Hintergrund. Das Bild wird in zwei Dreiecke unterteilt. Oben rechts dominiert die Farbe Schwarz, während Rot den Rest des Bildes dominiert. In der Mitte des Bildes wurde eine Person gemalt, die sich von rechts nach links bewegt. Diese Bewegung wird durch sechs Beine verdeutlicht. Der Oberkörper der Person wurde von einem Rahmen umrandet. Auf der roten Fläche ist eine Schrift erkennbar. Diese wurde in schwarz und willkürlich angebracht. Weil die Farben ineinander übergehen, wird es für den Betrachter schwierig, das Geschriebene zu lesen. al-'Azzāwī versucht, ein arabisches Modell zu schaffen: Er ist der Araber, der in seiner weitläufigen Heimat nach einem Raum sucht, wo er frei sein kann. Im Grunde emigriert er ständig, geographisch und historisch.

An-Niffarī, (gestorben 965) der Sufi-Dichter, der zwischen Babylon und Basra lebte, ist die Geschichte, die 'Abdullah [das ist an-Niffarī] an seine Heimat erinnert, und an das Verhältnis zu ihr. Er spricht mit ihm [an-Niffañ] durch die kufische Schrift, zählt mit ihm die Niederlagen, die zerstreuten Familien und die Märtyrer, die mit ihren Träumen

${ }^{413}$ Adonis ('Alī Ahmad Sa'īe) wurde 1930 in einem Dorf nahe Latakia, Syrien, geboren. Er studierte Literatur und Philosophie an der Universität von Damaskus. Wegen seiner Gedichte musste er 1956 nach Beirut fliehen, wo er seit dem als eingebürgerter Libanese lebt. In seiner Dichtung, in kritischen Schriften und Anthologien fordert Adonis radikale Veränderungen in allen Aspekten des arabischen Lebens, um Anschluss an die moderne Welt zu finden und zu ihr beizutragen. Seine symbolistische Dichtung, die überaus subtil und manchmal von einzigartiger Reinheit ist, drückt gleichzeitig seine politischen und sozialen sowie seine mystischen und metaphysischen Interessen aus. Er hat viele Bände mit metrischer und Prosadichtung veröffentlicht, den ersten 1945, sowie viele Bücher zur Literaturkritik. Er veröffentlichte auch eine Anthologie klassischer arabischer Dichtung. vgl. Nashashibi, 1997, S.59, Anhang A. 
im Sand begraben liegen. Dennoch buchstabieren die zerstreuten Buchstaben kein erkennbares Wort ${ }^{414}$. Der hohe Farbkontrast zwischen der Abbildung und dem Hintergrund verstärkt den Eindruck der Trennung, der durch das Gedicht übermittelt wird.

Rašīd Qoraīšy (geb.1947) ist ein weiterer Künstler, der mit visuellen Kreationen von Dichtung experimentiert hat. Im Gegensatz zu al-'Azzāwīs Ansatz sind Text oder Fragmente des Textes des Gedichtes in den Kreationen Qorā̄šys zentral, obwohl nicht notwendigerweise lesbar. In umma fi '1-manfā (eine Nation im Exil) produzierte Qoraīšy 20 Drucke nach Motiven der Gedichte des Palästinensers Mạ̣mūd Darwīšs ${ }^{415}$. Diese Drucke wurden später Teil eines größeren Projektes, eines Buches mit demselben Titel. Dies war die Gemeinschaftsarbeit eines Dichters, eines Malers und eines Kalligraphen. In diesem Buch werden Drucke Qorā̄šys neben dem Text der Gedichte Darwīš’ gezeigt, die vom irakischen Kalligraphen Hasan Mas'udī in kufischer Schrift wiedergegeben werden. Laut Abdelkebir Khatibi stellen „diese Kompositionen von Formen und Zeichen, diese Metamorphosen des Sichtbaren“ dem Betrachter die grundlegende Frage über die Möglichkeit „die poetischen und künstlerischen Grundlagen für eine Nation im Exil zu legen“‘116.

Qoraīšys gesamte Serie ist durch ein Monogramm verbunden, das einem chinesischen oder japanischen Ideogramm ähnelt, wie in Druck 4, 1985 (Abb. 111) ${ }^{417}$. Er setzt Kalligraphie in einer abstrakten symbolischen Weise ein, so dass seine Alphabete zu Symbolen für Revolution und Protest werden. Er vermeidet Farbe, besonders in seinen Graphiken, und schafft stattdessen drastische Schwarz-Weiß-Kontraste.

Qoraīšys Arbeit ist „ein Dialog zwischen arabischer Schrift und den visuellen Künsten

${ }^{414}$ vgl. Dāg̀ir, 1994, S. 53.

${ }^{415}$ Maḥmūd Darwīš wurde 1942 im Dorf Al-Barweh in Palästina geboren. Nach einem israelischen Angriff auf das Dorf 1948 floh die Familie Darwīš für mehr als ein Jahr in den Libanon, bis Darwīš von seinem Onkel zurück über die Grenze in ein Dorf in Galiläa gebracht wurde. Da er jedoch bei der ersten israelischen Volkszählung nicht erfasst war, die während seiner Zeit im Libanon stattfand, wurde er als „Eindringling“ eingestuft und hatte kein Anrecht auf einen Personalausweis. So lebte Mahmūd Darwīš illegal in seinem eigenen Land und versteckte sich vor der Polizei, bis eine andere Regelung getroffen wurde. Seine Dichtung brachte ihm Schwierigkeiten mit den israelischen Beh.örden, aber auch den Titel des „Dichters des palästinensischen Kampfes“ (vgl. Nashashibi, 1997, S.60).

${ }^{416}$ Bei einem Gespräch mit Al-'Azzāwī am 10. November 2003 wurde dem Verfasser ein Videoband vorgeführt, auf dem ein Interview mit Khatibi aufgezeichnet war, in welchem er diese Worte äußerte.

${ }^{417}$ Qoraīšy schreibt die Ähnlichkeit zwischen seinen Monogrammen und chinesischen oder japanischen Ideogrammen der Vertikalität seiner Symbole zu. Tatsächlich sind seine Monogramme eine kreative Variation alter Zeichen, die man in algerischen Höhlen findet, vgl. 'Abdul-Hamīd- Shoman-Stiftung, Dar al-Funūn, Ammann (Hrsg.): Interview mit Rašīid Qoraīšy, Ammann, 3. Dezember 1998 (Video). 
sowohl des Westens und des Fernen Ostens. (...) jeder der Drucke Qoraīšys stellt ein interkulturelles Aufeinandertreffen dar, oder genauer ein intersemiotisches Aufeinandertreffen“ “418. Dieses Monogramm ist eine Art Piktogramm, durch das Qoraīšy die Palästinafrage „,in eine gestenhafte Bewegung“ „verwandelt“; eine Methode die palästinensische Tragödie durch einen modernen Universalwortschatz auszudrücken $^{419}$. Es ist ein Zeichen, das Bilder des Leidens, Überlebens und des Todes wachruft. Farbe ist im Allgemeinen kein Element in der Arbeit Qoraīšys, stattdessen baut er auf den dramatischen Kontrast von Schwarz und Weiß. Das Wahrnehmung der gestenhaften Bewegung wird weiter durch die Dichte der Buchstaben, der Energie der Schrift und ihrer Verarbeitung $\mathrm{zu}$ verschiedenen abstrakten folkloristischen und mythologischen Formen mit alten oder modernen Wurzeln erweitert: magische Geometrie, Talismane, Tätowierungen, wie in Druck 6, 1985 (Abb. 112). Darin besteht der Hintergrund aus arabischer Schrift, die aber zu klein ist, um sie lesen zu können. Die Verwendung der Schrift auf diesem Blatt ähnelt nordafrikanischen Zaubertexten. Die Buchstaben sind teilweise $\mathrm{zu}$ geometrischen Formen, wie Dreiecke und Kreise angeordnet. Auf die rechte Seite schrieb Qoraīšy eine Zeichengruppe, deren einzelne Teile teils wie arabische, teils wie chinesische Schriftzeichen aussehen. Die Zeichengruppe wurde von oben nach unten geschrieben, wobei sich „arabische“ und „chinesische“ Zeichen harmonisch miteinander mischten. Dies zeichnet die Arbeiten Qoraīšys aus. Die Schrift in dieser Arbeit nimmt unterschiedliche Richtungen ein. So wurde auf der linken Seite von unten nach oben geschrieben. Darauf folgen Schriftzeichen, die von rechts nach links verlaufen. Im oberen Drittel der linken Seite kann man eine Unterteilung in sieben gleichmäßige Teile feststellen. Im ersten unten wurde die Schrift von unten nach oben angebracht, während im zweiten eine Tabelle darstellt wurde, in der Buchstaben und Zahlen angebracht worden sind. Im dritten Teil wurde die Schrift von rechts nach links geschrieben. Im vierten sind Zauberzeichen und im fünften sind Dreiecke erkennbar. Im sechsten Teil sind einfache Schriftzeichen lesbar, die von Linien umrahmt werden, während der siebte Teil in gleich große Vierecke unterteilt worden ist. Die Schrift darin nimmt die Form von Kreisen und Vierecken an. Diese Arbeit zeichnet sich durch die ununterbrochene Bewegung von Zeichen aus.

Ein anderes Werk der Ägypterin Liliane Karnouk, Buch von Adonis, 1985 (Abb. 113),

\footnotetext{
${ }^{418}$ vgl. Shoman-Stiftung, 1998, Interview mit Qoraǐšy.

419 ebd.
} 
präsentiert noch eine weitere Darstellungsform. In der Arbeit Karnouks verkörpert das Buch selbst (in seiner Beschaffenheit, Form und Farbe) das Wesentliche des gewählten Gedichtes Die Gegenwart und der Donnerstein:

Ich öffne eine Tür zur Erde, ich entzünde das Feuer der Gegenwart

In den Wolken, die widerspiegeln oder folgen

Im Ozean und seinen leidenschaftlichen Wellen

In den Bergen und ihren Wäldern

In den Felsen

Schaffend für die schwangeren Nächte

Ein Land aus der Asche der Wurzeln

Von den Feldern der Lieder und vom Donner

Und dem Blitz

Brennend die Mumie der Zeiten

\section{Der Donnerstein}

Ich bin der Donnerstein

Der Gott, der den verlorenen Schnittpunkt trifft

Ich bin die Flagge

Die am Augenlid der wandernden Wolken hängt

Und der quälende Schmerz

Ich bin der Verlorene, der wie Sturzbäche und Feuer vorwärts kommt

Mischend den Staub und den Himmel

Ich bin die Betonung von Blitz und Donnerstag

Ich möchte knien und beten

Für die Eule mit dem gebrochenen Flügel

Zur Glut, zum Wind

Ich möchte beten

Zu dem erstaunten Planeten am Himmel

Zum Tod, zur Pest

Ich möchte meine weißen Tage und meine Lieder verbrennen

In meinem Weihrauch

Ich möchte mein Buch, meine Tinte und das Tintenfass verbrennen

Ich möchte beten 


\section{Zu allem, das dem Gebet unbekannt ist ${ }^{420}$.}

Das Bild bringt dieselbe Bildersprache zum Ausdruck, die durch bestimmte Wörter im Gedicht - Feuer, Wolken, Asche, Staub, Schmerz - benutzt wird, und vollendet letztgültig Adonis' Absicht: „Ich möchte mein Buch, meine Tinte und das Tintenfass verbrennen.“ Das Gedicht ist lesbar von Hand auf Arabisch um die Ränder der Seiten herum geschrieben.

Die Libanesin Ethel Adnan (geb. 1925) ist eine weitere Künstlerin, deren Arbeit um das Buch kreist. Als mehrsprachige Dichterin und Künstlerin, die erst während der siebziger Jahre die arabische Sprache erlernte, war sie sowohl mit der literarischen Welt als auch mit der visuellen Kunst verbunden. Ihr erstes Experiment mit der Konzeptkunst fand während der frühen sechziger Jahre statt.

Nach dem Sechs-Tage-Krieg 1967 wurde „den Buchstaben zu malen“ ihr einziges Mittel, Selbstvertrauen wiederzugewinnen und ihre Identität zu bestätigen. In ihren Büchern ist der Text zentral. Er ist klar und deutlich auf Hintergründen aus Wasserfarben geschrieben, mit der Absicht gelesen $\mathrm{zu}$ werden. Adnan, die keine Ausbildung in Kalligraphie hatte, schreibt den Text sorgfältig mit Tinte in einer freien Handschrift auf ein Leporello, wie in Ein Lindenbaum, dann ein anderer, 1985 (Abb. 114), mit dem ihr eigenes, gleichnamiges Gedicht visualisiert.

\subsection{Zeitgenössische Experimente mit dem arabischen Schrift}

Innerhalb der verschiedenen Experimente mit arabischen Buchstaben gibt es einige Herangehensweisen, die anderen arabischen Künstlern als Präzedenzfälle dienten und eine Anzahl von Nachfolgern anzogen. In diesem Teil werden die Arbeiten zweier Pioniere behandelt, die von as-Sa ${ }^{c} \overline{1} d$ und al-'Azzāwī. Beide Künstler haben einen bedeutenden Teil ihrer künstlerischen Arbeit einem neuen Zugang der bildlichen Darstellung des arabischen Buchstabens gewidmet. Jeder zeigt bei der Darstellung des Buchstabens ein reifes Verständnis für die Harmonie zwischen seinem künstlerischen Erbe und modernen Stilen. Beide haben sehr produktiv mit unterschiedlichen Mitteln und Techniken experimentiert. Durch Deutung, Innovation und Experimente hat jeder

\footnotetext{
${ }^{420}$ Übersetzt vom Verfasser nach: Nashashibi, 1997, S. 43.
} 
erfolgreich einen eigenen Stil geschaffen, der den Ausdruck einer individuellen künstlerischen sowie einer kulturellen Identität ermöglicht.

\subsection{1 Šākir Ḥasan as-Sa ${ }^{c} \bar{d} \mathbf{d}(\mathbf{1 9 2 5 - 2 0 0 4 )}$}

Šākir Hasan as-Sa⿳̄īd besuchte nach seinem Abschluss in Sozialwissenschaften 1948 bis 1954 Abendkurse an der Fakultät der Schönen Künste in Bagdad. Dort wurde er von Jawad Salim, der Kunstgeschichte an der Fakultät unterrichtete, in die moderne westliche Kunst eingeführt. An den Arbeiten von Picasso, Braque und Klee, studierte er den europäischen Gebrauch der Linie in der Malerei. ${ }^{421}$ Dies kennzeichnete den Anfang eines Interesses an der Linie, die ihn bis zu seinem Tode beschäftigte. In seinen Bildern aus den fünfziger Jahren war sein Interesse an der Linie in seinem linearen Zugang offensichtlich, der sich in seinem Gebrauch des Cloisonismus zeigte.

Vom Beginn seiner künstlerischen Karriere an entwickelte sich as-Sa ${ }^{c} \overline{1} d$ zu einem der Künstler, die den Weg für die Entwicklung der modernen Kunst im Irak ebneten. Er teilte ähnliche Ideen und Gedanken mit Jawad Salim und war 1951 ein Gründungmitglied der Baghdad Modern Art Group ${ }^{422}$.

Nachdem er 1954 sein Diplom an der Fakultät der Schönen Künste erhalten hatte, studierte as-Sa ${ }^{\complement} \overline{1} d$ von 1955 bis 1959 in Paris. Dort machte er einerseits im Museé du Louvre Bekanntschaft mit mesopotamischer, insbesondere sumerischer Kunst, andererseits mit der Art Informel, besonders den Werken Jean Fautriers (1898-1964) und Jean Dubuffets (1901-1985) ${ }^{423}$.

As-Sa'̄ids Arbeit während der 50-er und 60-er Jahre brachte die Ideale der Baghdad Modern Art Group in ihrer Suche nach einer andersartigen lokalen Kunst, die gleichzeitig einheimische und internationale Tendenzen enthielt, getreu zum Ausdruck. Es war das Ziel der Gruppe, durch moderne Stile eine kulturelle Vision zu erreichen. Als Ausgangspunkt nahmen sie „istilhām at-turāt (Suche nach Inspiration aus der Tradition) ${ }^{، 424}$.

\footnotetext{
${ }^{421} \mathrm{http}: / /$ www.iraqiartist.com/Archive/Shakir_Hassan/Shakir_Hassan_ALSaid.htm.

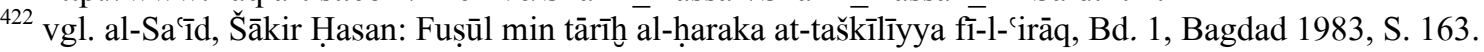

${ }^{423}$ Arnason, H. H., 1986, S. 417.

${ }^{424}$ vgl. Dāgir, 1990, S. 75.
} 
Wie viele Künstler seiner Zeit, experimentierte as-Sa ${ }^{c} \overline{1} d$ mit arabischen Buchstaben und der arabischen Sprache. Aber er gebrauchte die Schrift in einem ausgedehnteren Sinne, indem er auf die Elastizität der Sprache zurückgriff - ihre besondere Fähigkeit, äußere Einflüsse aufzusaugen und $\mathrm{zu}$ synthetisieren -, um ihre Form und Bedeutung $\mathrm{zu}$ zerstören. "Seine Theorie war, dass die Kunst normalerweise eine bestimmte Art der Annäherung an Gott war. Da Gott den Menschen nach seinem Bild erschuf, war die gesamte Entwicklung der westlichen Kunst von der Frage geleitet, wie man die menschliche Natur malen könne, um die göttliche zu malen. Dieser Mann wollte eine ähnliche Idee finden“" ${ }^{425}$.

As-Sa'̄ìd hatte einen klaren Blick für die soziale Wirklichkeit seiner Umgebung. Aus ihr schöpfte er in hohem Maße Anregungen für sein künstlerisches Schaffen. Er betrieb seine eigene Forschung zur irakischen und islamischen Geschichte und zeigte ein großes Interesse an Volkskunst und Legenden. Er entwickelte ein besonderes Interesse für Geschichten aus Tausend und eine Nacht, von denen er einen Teil er visuell in Strichzeichnungen uminterpretierte, welche zusätzlich geschriebenen Text enthielten (Abb. 115). In Eine Geschichte aus tausend und einer Nacht, 1962 (Tinte auf Papier) ${ }^{426}$, zeichnete der Künstler Budur, die Frau von Qahrmān, eine der Heldinnen der Geschichte, die sich auf ein Sofa lehnt und einen Fächer in der Hand hält, während sie sich eine Geschichte von einer ihrer Dienerinnen erzählen lässt. Diese sitzt auf der linken Seite im unteren Teil des Bildes. Eine Katze liegt nahe am Bett. Im Hintergrund sehen wir alte arabische Häuser. Auf einem Dach sitz ein krähender Hahn, der einen neuen Morgen ankündigt. Darüber steht „dīk aṣ-șabāḥ (Hahn des Morgens) geschrieben. Dies symbolisiert gemäß der Tradition von Tausend und einer Nacht das Ende der Geschichte. Auf der linken Seite des Bildes sehen wir einen Spiegel und eine Vase. Darüber wurde al-Qamar (Der Mond) geschrieben. Dies symbolisiert in der arabischen Kultur die Schönheit. Unter dieser Szene wurde mit einer einfachen Schrift der Satz assayyida Badūr ma šūqat Qamar az-Zamān wa qahramānatihā (Die Dame Budur ist der Liebling von Qamar az-zamān und seiner Dienerin) angebracht. Damit schlägt der Künstler eine einfache Interpretation des Werkes vor, das unmittelbar in Verbindung mit den Geschichten von Tausend und eine Nacht steht. In dem Bild kann man insgesamt feststellen, dass der Künstler hinsichtlich Kleidung und Ästhetik von der arabischen Tradition beeinflusst worden ist.

\footnotetext{
${ }^{425}$ Wilson-Goldie Kaelen: Paying tribute to an Iraqi master before his legacy disappears. http://www.dailystar.com.lb/article.asp?edition_id=10\&categ_id=4\&article_id=13579.

${ }^{426}$ vgl. 'Alī, 1989, S. 159-168.
} 
„As-Sa‘̄id kämpfte, um Nachahmung zu widerstehen, um zu vermeiden, Impressionismus auf lokale Dorflandschaften zu verpflanzen oder Picasso dutzendweise nachzuahmen. In einer Zeit der nach-kolonialen Unabhängigkeitsbewegungen und nationalistischer Projekte im Irak wie in der Region und der Welt, kämpfte er für einen Weg, seinen eigenen Sinn für Identität, Tradition und die Moderne auszudrücken. Zu einer Zeit, als die meisten seinen Kollegen mit dem Kommunismus und Sozialismus liebäugelten, rang er, sehr ungewöhnlich für die Zeit, mit der Hingabe zum Islam“427.

Al-Sa'̄ids intellektuelle und künstlerische Kreativität erreichte neue Höhen nach einem persönlichen Wendepunkt Mitte der sechziger Jahre, welcher seine künstlerische, geistige und kulturelle Entwicklung beeinflusste. Die bedrückende Atmosphäre, die aus der politischen Situation im Irak entstand, - am 15. Juli 1958 wurde mit einem blutigen Militärputsch die Monarchie gestürzt, am 8. Februar 1963 Präsident 'Abd al-Karim Qassim ermordet, am 17. Juli 1968 übernahm die Baath-Partei nach einem weiteren blutigen Putsch die Macht, wobei jeder Machtwechsel mit brutalen Säuberungsaktionen begleitet war - stürzte ihn in eine klinische Depression und einen Zustand der selbst verordneten Zurückgezogenheit ${ }^{428}$. Seinem Interesse an religiösen Studien folgend, das er früher während seines Aufenthalts in Paris entwickelt hatte, fand er eine seelische Rettung in Sufismus und insbesondere in der Arbeit des mystischen Philosophen alHallāğ ${ }^{429}$.

Der Einfluss des Sufismus auf al-Sa $\overline{1} \mathrm{~d}$, der den Anfang seiner Karriere als Kunsttheoretiker kennzeichnete, beeinflusste seinen künstlerischen Ausdruck tiefgreifend. Seine Arbeit wandelte sich zu einer Suche nach Abstraktion. Er verließ allmählich bildliche Ausdrücke und nahm den arabischen Buchstaben als zentrales Thema seiner Kompositionen an. Zwischen 1958 und 1965 diente der Buchstabe asSa⿳亠̄⿵ als eine Übergangsform vom Bildlichen zum Abstrakten, wobei Buchstaben oder Wörter in die Komposition eingewoben werden ${ }^{430}$.

Im Sufismus fand as-Sa ${ }^{c} \bar{i} d$ eine Motivation, zu malen und in seinen Bildern einen Weg, religiösen Wahrheit auszudrücken. Der Vorgang des Malens stellte für ihn einen Weg

\footnotetext{
${ }^{427}$ Kaelen Wilson-Goldie: in http://peacecorpsonline.org/messages/messages/2629/2030285.html.

${ }^{428}$ vgl. 'Alī, 1996, S. $190 \mathrm{f}$.

${ }^{429}$ Die Anfänge einer Hinwendung zur Religion entwickelten sich während seiner Jahre als Student in Paris, als Reaktion auf die Umwälzung, die er angesichts einer anderen westlichen Kultur empfand. Es war seine Art eine Verbindung mit seiner Kultur zu erhalten und geistigen Frieden zu erlangen.

${ }^{430}$ vgl. Dāgìir, 1990, S. 77.
} 
dar, über den Ruhm Gottes nachzusinnen. Das Nachdenken über Gott sei auch ein Weg, das vergängliche Selbst des Menschen in das unvergängliche Selbst Gottes aufzulösen. al-Sa'̄ìd erklärte das Konzept der „Kunst als Betrachtung" in seinem 1966 veröffentlichten al-fann ka-ta'ammulät (Kunst als Betrachtung), das er in Nr. 880 der irakischen Zeitung al- ğumhūrn̄yya veröffentlichte. Als Ergänzung veröffentlichte in Nr. 887 der gleichen Zeitung einen Artikel „Zusatz gegen künstlerischen Luxus“.

Kontemplation, schrieb er, sei des Künstlers wahrer Standpunkt; kontemplative Kunst sehe die Welt lediglich als ein geschaffenes Wesen und die Rolle des Menschen, einschließlich die des Künstlers, als größeren Ausdruck einer Idee. Entsprechend dieser Ansicht werde die Kunst, die durch die unbefangene Freiheit eines Menschen produziert werde, eine abstrakte Beschreibung der Existenz, eine positive Kraft, die die Menschheit mit dem Universum vereinige. Diese Beschreibung sei nur durch den Aufstieg vom Selbst zur Universalität und durch ein Herabsteigen von der menschlichen Natur zum Ursprung möglich. Wir können eine geistige Nähe zwischen as-Sa'̄ì und Mark Tobey (s. Kapitel II) feststellen. Diese Nähe äußert sich darin, dass beider Werk religiös verwurzelt ist und sie die Kunst als Ausdruck von Meditation nutzen.

Er gab die figurale Abbildung in seinen Gemälden auf und wendete sich der arabischen Kalligraphie zu, wobei die geistige Bedeutung und die graphische Erscheinung der Buchstaben das zentrale Thema seiner Kompositionen wurde. 1971 gründete er die Gruppe „Eine Dimension“ in Bagdad, welche die moderne Kalligraphieschule in der arabischen Kunst förderte. Im gleichen Jahr hielt die Gruppe ihre einzige Ausstellung ab. Seine Hauptbeschäftigung mit dem geistigen Element in der Kunst setzte sich in seinem Konzept der „Eindimensionalität““ (arab. Al-bū'd al-wāḥid) fort. Er versuchte, die Spannung zwischen dem gedachten Buchstaben als ,idealer“ Linie (eindimensional) und dem geschriebenen Buchstaben als „realer“ Fläche (zweidimensional) zu überwinden. Die „Eindimensionalität““ ist eine Philosophie, eine Technik und ein Stil; ein Verhältnis zwischen Zeit und Raum, zwischen Sichtbarem und Unsichtbarem ${ }^{431}$. al-Sā̄id behauptete, dass „es möglich [ist], sich vorzustellen, dass die Eindimensionalität zwischen dem Sichtbaren und Unsichtbaren stattfindet ${ }^{\star 432}$.

Die Suche nach der Eindimensionalität war das Resultat seiner künstlerischen und geistigen Experimente über die Jahre hinweg, jedoch hatte sie ihren Anfang in seiner

${ }^{431}$ Ein Verhältnis ähnlich von Körper und des Geist. vgl. al-Sa ‘̄id Šākir Ḥasan: Ḥiwār al-fann at-taškīlī, Ammann 1995, S. 127.

${ }^{432}$ Al-Sa'̄̄ō: Hiwār al-fann ... S. 129. 
Erfahrung als Student in Paris. Dies lässt sich an seinen Arbeiten verfolgen, die aufgrund seiner Erfahrung mit der französischen Moderne entstanden.

Seit seiner Rückkehr nach Bagdad 1959 suchte as-Sa ${ }^{c} \overline{1} d$ bewusst nach einer Kunstrichtung, die auf seinen Pariser Entdeckungen basierte, und durch die er kreativ tätig sein konnte ${ }^{433}$. Er studierte die Entwicklung der Geschichte der Kunst als Ganzes, angefangen vom akademischen Realismus bis zum Post-Impressionismus einschließlich der Abstrakten Kunst.

Die erste technische Problematik, auf die er traf, war der Versuch, eine Linie auf einer Bildoberfläche ohne einen zweidimensionalen Bereich zu zeichnen oder zu malen, weil dies physikalisch unmöglich ist. Da die einzige wahre Existenz der Bildfläche ihre Zweidimensionalität ist, ist die Farbe die einzige Ergänzung, die ihrer Existenz treu bleibt. al-Sa ${ }^{\top} \overline{1} d$ begann, mit Farbabstufung und Dichte zu experimentieren, um eine Linie auszudrücken, ohne sie wirklich zu malen. Dies war eine Idee, die er in den siebziger Jahren weiterentwickelte, nachdem er entdeckt hatte, dass Risse in Wänden ungezeichnete Linien schufen. Ein Riss, wie er beobachtete, ist leer, frei von Dimensionen und erscheint dem Beobachter nur wegen der angrenzenden Oberflächen, wie in fi ta’ammulāt al-mawḍ̂̀ 'iyya (Objektive Betrachtungen), 1984 (Abb. 78).

Der Kern der Arbeit as-Sa`̄îds war, seine „Problematiken“, wie er sie nannte, zu durchleben. Die Problematiken, so schrieb er, bestünden immer aus der Gegenwart ohne eine Vergangenheit oder Zukunft, als etwas, was erfahren, aber nicht gelöst werden kann. Das Bestehen des Kunstwerks hinge von einer Handlung ab, die in der Gegenwart stattfinde. Jede Tat jedoch sei an die Bedeutung der „Gegenwart“" gebunden, folglich gehe ihr eine Vergangenheit voraus und eine Zukunft folge ihr.

As-Sa'̄id schrieb, dass sein künstlerischer Ausdruck drei Stadien durchlaufen habe, die drei Niveaus entsprächen, aus denen ein Kunstwerk bestehe: die Ebene des Künstlers, dann die des Beobachters und schließlich die des Kunstwerks als Objekt. Während der frühen fünfziger Jahre habe er sich selbst ausgedrückt. Im Rest des Jahrzehnts habe er den Anderen (den Betrachter) durch den Stil des Anderen ausgedrückt. In der Gegenwart sei wichtig, was die Dinge über sich selbst aussagten, während er sie

\footnotetext{
${ }^{433}$ vgl.Al-Sa'̄id: Hiwār al-fann ... S. 132 f.
} 
male ${ }^{434}$. Während dieses letzten Stadiums sei sein Ziel, die Realisierung seiner Problematik zu sein und dadurch Möglichkeit und dann Wahrscheinlichkeit, durch Zufall (Spontaneität und Intuition), lebendigen Ausdruck und die Spur. Das Element seiner Arbeit werde die „Spur" der Sache, nicht ihre Form oder Kontur.

Das Konzept der Eindimensionalität erkennt die Formentwicklung vom alten Nahen Osten zum Mittelalter bis hin zu modernem Methoden. Für as-Sa ${ }^{\top} \overline{1} d$ wurde es auch synonym zum istilhām al-ḥarf (Suche nach Inspiration aus dem Buchstaben) ${ }^{435}$. „Den Buchstaben oder die Zahl als Ausgangspunkt zu nehmen, um zur Bedeutung der Linie zu kommen: als reiner plastischer Wert ${ }^{4436}$. as-Sa ${ }^{\star \top} \overline{1} d$ fand in der Suche nach Wahrheit durch den Buchstaben als Form und Bedeutung einen Weg, die Freiheit des zeitgenössischen humanistischen Gedankens auszuüben, um sowohl an materialistische als auch an geistige Sicherheit durch einen Wert zu gelangen, der gleichzeitig persönlich und universell sei ${ }^{437}$. al-Sa'̄īd zufolge sei es auch ein Projekt, das Legitimation historisch (in der Geschichte der modernen Kunst) und kulturell (im Rahmen der islamischen Zivilisation) erziele. as-Sa ${ }^{\top} \overline{1} \mathrm{~d}$ glaubte, dass die arabische Schrift in ihren unterschiedlichen Formen und Schulen die Geschichte der arabischen individuellen und sozialen Wirklichkeit, die im intellektuellen Unbewusstsein der Kultur und Gesellschaft gespeichert geblieben sei, reflektiere ${ }^{438}$. Gleichzeitig sei sie ein Produkt der Umgebung, in der sie sich entwickele. al-Sa ${ }^{c} \overline{1} d$ fand eine unbewusste Kontinuität der älteren Traditionen in der arabischen Schrift: sie habe das mythologische Bewusstsein der mesopotamischen Gesellschaften und aller anderen, die ihnen folgten, enthalten. So sei die Sprache und ihre schriftliche Form Mittel des Aufdeckens des Versteckten.

Außerdem ging as-Sā̄id davon aus, dass von Anfang der Geschichte an ein dialektisches Verhältnis zwischen der Schrift und den bildenden Künsten bestanden habe $^{439}$. So könne die Schrift ornamental verwendet werden. Ornamentierung basiert auf Einheiten, die in bestimmten Formen wiederholt und organisiert werden können. Buchstaben, die Einheiten, aus denen sich Schrift zusammensetzt, symbolisieren Laute.

\footnotetext{
${ }^{434}$ vgl.Al-Sā̄ìd: Hiwār al-fann ... S. 254.

435 Telefongespräch des Verfassers mit al-Sā̄id, 22.03.2002.

${ }^{436}$ vgl. Al-'Azzāwī: Zu einer neuen Vision, in: al-Sa'̄īd, Šākir Ḥasan: Ḥiwār al-fann at-taškīlı̄, Bagdad 1973, S. 25-39, hier S.39.

${ }^{437}$ Al-Sa'īd: Légitimité d'une recherché de l'undimensionel, in: Métalsi, 1989, S. 55-59, hier S. 56.

${ }^{438}$ vgl. Al-Sa'̄id: The unconscious structure of the Arabic letter, in: Funūn 'arabīya Nr. 1, London 1981, S. 64-68.

${ }^{439}$ Al-Sa'īd,Telefongespräch mit dem Verfasser 2002.
} 
Wenn sie kombiniert werden, um Bedeutung zu bezeichnen, wird jedoch diese Bedeutung nicht durch diese Zeichen an sich gebildet, sondern aus der Bedeutung, die ihnen durch Konvention gegeben sind. So verliert innerhalb des Konzeptes der „Eindimensionalität“ der Buchstabe seine linguistische Bedeutung und wird ein beliebiges Bildzeichen (Abb. 116): „Ich versuchte, zu dieser Zeit die Welt zu malen. Nicht wie ich sie nur durch meine Augen sehe, sondern wie ich sie fühle in meiner Hinwendung zum Absoluten. Ich fing folglich an, den Buchstaben als bloßes nichtformales Wesen ohne Identität oder eine linguistische Bedeutung zu behandeln“ ${ }^{\text {440 }}$. Er verzichtete folglich auf die Referenz des Buchstaben um des Zeichens willen, besonders in seiner Betrachtung des Buchstaben durch die Farbabstufung. In sufischer Tradition sah as-Saīd das menschliche Ego, das nicht von Gottes Geist erfüllte Bewusstsein, als negative Kraft. In der Malerei sah er dieses Ego durch die leere Leinwand dargestellt ${ }^{441}$.

Die Form des Buchstaben, nicht seine Bedeutung, wurde $\mathrm{zu}$ einem geistigen und sinnlichen Vermittler in as-Sa⿳̄1ds Arbeit: „Der Buchstabe ist nicht bloß ein linguistisches Symbol. Es ist der einzige Isthmus, um aus der Welt der Existenz zur Welt des Gedankens durchzudringen “442.

Buchstaben als Linien haben Richtungen, die nach as-Sa'̄ìd die Grundlage ihres Ausdruckes wurden, wo die Form des Buchstaben auf senkrechte und horizontale Linien reduziert wurde, wie in Ruhm für Mandily, 1983 (Abb. 117). In dieser Arbeit malte er die Spalten einer Wand, sowie abgeschälte Wandteile, wo die Farbe fehlt. Betrachtet man die Wahl der Farben, so wird deutlich, dass er dadurch die Auswirkungen der Zeit und Wetters implizieren wollte. Hier kann man erneut erkennen, dass Pfeile ein Merkmal seiner Werke sind. Damit will er die Blicke des Betrachters auf bestimmte Stellen seines Werkes führen. Die Schrift und die Kratzer sind auf das gesamte Werk verteilt. Die meisten Schriftstücke sind in weißer Farbe. Es handelt sich um arabische Buchstaben, die teilweise unlesbare oder sinnlose Wörter ergeben. Eine Ausnahme ist oben rechts. Hier kann man eine orangefarbene Schrift erkennen, die Allah bedeutet. Unten im Bild kann man das Wort Allah in weißer Schrift erneut lesen. Er benutzt im Allgemeinen blasse Hintergründe, gegen den die Bewegung des Buchstaben dominierend ist. as-Sa ${ }^{\top} \overline{1} d$ betrachtet die Wand als Untergrund, auf dem Menschen während langer Zeit durch Graffiti ihre Gedanken und Gefühle ausgedrückt

\footnotetext{
${ }^{440}$ vgl. Dāgir, 1990, S. 77.

441 vgl. 'Alī, 1997, S. 169.

442 vgl. Dāgir, 1990, S. 81.
} 
haben. As-Sa'īds Interesse für Graffiti entspringt ihrer Einfachheit und Spontaneität. „Ich ziehe es vor, den Buchstaben in meinen Bildern eher so zu schreiben, wie es Kinder, Schüler und der Halbintellektuelle tun, anstatt im Stil von Druckmaschinen und Schreibkünstlern“ ${ }^{\star 443}$, das bedeutet, er war an einer künstlerisch ausgefeilten Gestalt der Buchstaben nicht interessiert.

In den meisten Werken as-Sa`̄̄īs bemerken wir, dass die Zeichen in den Grund hineingeritzt sind, hineingekerbt wie in eine alte Mauer. Der Untergrund ist an manchen Stellen weggeschabt, ähnlich wie bei alten Mauern Stücke abbröckeln und der Putz abblättert. Auch der Farbklang des Bildes, ocker und braun, grau und schwarz verstärkt die Assoziation an alte Gemäuer. Diese Art der Betrachtung nennt er ,realistische Betrachtung“, wobei der Künstler dem Beobachter das zufällig entstandene Werk in der Umgebung vorstellt. Das Bild bleibt folglich ein Teil der gegenwärtigen Realität und nicht einer idealen Sufi-Welt: sein Buchstabe ist der Buchstabe der Straße „und des weltlichen Lebens.“ In diesem Sinne wird der Buchstabe zum Fluss des nachdenklichen menschlichen Geistes auf seiner unbewussten Ebene.

Dieses Stadium wiederum führte as-Sa'īd zu einem neuen Trend, der seine Arbeit seit den achtziger Jahren beschäftigte, „die Erfahrung der Umgebungswahrheit in der Kunst", wobei der Künstler anstrebte, die ästhetischen und realistischen Elemente durch das Wesen der Umwelt zu entdecken, wie in Linien auf einer Wand, 1975 (Abb. 118) ${ }^{444}$. as-Sa'̄̄id nutzte die Erinnerung an ein reales Wandgemälde, um ein Thema für sein Bild zu finden. Die Technik, die al-Sa'̄id verwendete, um die Oberfläche des Bildes zu gestalten, bestand darin, dass er die Farbe mit feinem Sand oder ähnlichen Materialien vermischte und diese dickflüssige Masse reliefartig auftrug. In Linien auf einer Wand wird eine alte Mauer in Bagdad dargestellt. Das Bild ist in zwei Teile unterteilt. Das untere Drittel ist dunkelbraun, wobei in der Mitte die Farbe teilweise weggekratzt ist. Der obere Teil ist ocker und hellbraun. Die Farben des Hintergrundes harmonisieren miteinander. Sie wurden so dick aufgetragen, dass die Farbe beim Trocknen teilweise riss. Darauf wurde ziemlich unsystematisch in schwarz eine Schrift gesprüht. Der Betrachter kann auf der linken Seite das Wort Allah lesen. Im Zentrum des Bildes sieht man ein wau (و). Die restliche Schrift ist unlesbar.

\footnotetext{
${ }^{443}$ Dāgiir, 1990, S. 79.

${ }^{444}$ Al-Sa'̄id: The environment in Iraqi art. Ungedrucktes Manuskript.
} 
As-Sā̄òd experimentierte auch mit al-ğafr. Al-ğafr entstand im 8. oder 9. Jahrhundert christlicher Zeitrechnung und basiert darauf, dass jedem arabischen Buchstaben ein numerischer Wert zukommt. Dadurch ist es zum Beispiel möglich, ein Wort durch ein anderes $\mathrm{zu}$ ersetzen, wenn es denselben numerischen Wert hat. So hat etwa das islamische Glaubensbekenntnis den Wert 619, ebenso aber auch das Wort Kalligraph (hatt). Eine andere Technik in al-ğaff ist, die Buchstaben eines Wortes zu vertauschen, den ersten mit dem letzten, den zweiten mit dem vorletzten usw. Ein anderer Gebrauch der esoterischen Verwendung der Buchstaben ist hisāa al-Ğummal, bei der die Buchstaben mit den Elementen, Sternen und ähnlichem in Beziehung gesetzt werden. So werden den vier Elementen je sieben Buchstaben zugeordnet, indem von einem Initialbuchstaben an der erste, fünfte, neunte etc. Buchstabe gezählt werden. Bei Feuer beginnt die Reihe mit 'alif, bei Luft mit waw, bei Wasser mit lām und bei Erde mit $d \bar{a} l^{445}$.

In Objektive Betrachtungen, 1984 (Abb. 78), verwendete as-Sa'īd das Verfahren, Buchstaben durch Ziffern zu ersetzen. Er drückte das Wort „Liebe“ (hubb), das aus zwei Buchstaben: $\rightarrow$ ( $(H)$ und) $(B)$ besteht, so aus, dass er das h, als achter Buchstabe des Alphabets, durch die Ziffer ^ (8) ersetzt.

An al-ğafr interessierte al-Sa ${ }^{\top} \overline{1} d$ das esoterische Verhältnis von Buchstaben und Zahlen sowie ihrer doppelten Bedeutung: az-z̧āhir (das Äußere oder Sichtbare) und al-bātin (das Innere oder Unsichtbare). In al-fă $w$, einem Werk, geschaffen um der Befreiung seiner südirakischen Stadt al-fă $w$ zu gedenken ${ }^{446}$, ersetzte er die Buchstaben des Wortes FAW durch ihre numerischen Werten $(\mathrm{F}=80, \mathrm{~A}=1, \mathrm{~W}=6)$. Er summierte die numerischen Werte der Buchstaben $(80+1+6=87)$, die er dann manipulierte, um zu neuen Formen zu kommen (Abb 119). So stellte er sie durch ihre semiologische Bedeutung und wie in den islamischen Miniaturen dar; nur die Eingeweihten waren in der Lage, ihre esoterische Bedeutung zu dechiffrieren.

as-Sa $\mathrm{i}$ īds Erfahrung mit der Kunst war spirituell und intellektuell. Seine kontemplative sufische Kunst grenzt im breiten Sinne an islamische Ästhetik. Er kann jedoch kaum als ein Modern- oder Neo-Islamischer Künstler angesehen werden. Seine geistige Ästhetik

\footnotetext{
${ }^{445}$ vgl. Schimmel, Annemarie: Calligraphy and Islamic culture, London 1990, S. 92.

${ }^{446}$ Die Stadt liegt auf einer gleichnamigen Halbinsel an der Mündung des Schatt el-Arab in den Persischen Golf. Während des iranisch-irakischen Krieges war die Stadt heftig umkämpft und zeitweise in iranischer Hand.
} 
ist das Produkt seiner modernen Neuinterpretation der islamischen Ästhetik sowie des modernen westlichen Denkens: Seine Betrachtung Gottes war im weltlichen Sinne nicht die des „Ideals“. Sein Gebrauch des Buchstaben war sehr stark an seine zeitgenössische Wirklichkeit gebunden. al-Sā̄ō verzichtete in der Kunst auf den Gebrauch des Buchstaben als Design oder Verzierung sowie auf statische traditionelle Stile wie Kalligraphie.

\subsection{2 Ḍiyā' al-'Azzāwī}

Das Werk Diyā̄' al-'Azzāwīs (geb. 1939), stellt einen weiteren Zugang zum Gebrauch arabischer Buchstaben in der modernen arabischen Kunst vor. Von ihren Anfängen an war Al-'Azzāwīs Wahrnehmung der Kunst durch sein Interesse an der Archäologie vorgeprägt. Von 1959 bis 1962 studierte er Archäologie an der philosophischen Fakultät der Universität Bagdad. Während seines ersten Studienjahres schrieb er sich in Abendkurse für Schöne Künste ein, um moderne künstlerische Design und Techniken zu studieren. 1964 erhielt er das Diplom für Schöne Künste.

Al-'Azzāwīs Künstlergeneration war durch die Experimente der irakischen Pioniere genährt, die ihnen vorangegangen war, und wurde besonders von den Idealen der von as-Sa'īd mitbegründeten Baghdad Modern Art Group beeinflusst. Während al-'Azzāwī am Institut der Schönen Künste studierte, traf er den Künstler Hậfiz ad-Dūrubī (geb. 1914), der dort sowie an der Hochschule der Wissenschaft an der Universität von Bagdad Kunst unterrichtete, und schloss sich der irakischen Impressionistengruppe an, die ad-Dūrubī 1953 gegründet hatte. Die Gruppe hatte sich im Wesentlichen aus adDūrubī Interesse an der Kunstausbildung und der Notwendigkeit gebildet, nach einer Technik zu suchen, die wirklich das Verhältnis zwischen dem Künstler und seiner Wirklichkeit ausdrücken würde ${ }^{447}$.

Ad-Dūrubī wählte für die Gruppe einen gemeinsamen pädagogischen Ausgangspunkt anstelle eines künstlerischen und erlaubte komplette Freiheit bei der Entwicklung persönlicher Ansichten und Stile, die in den meisten Fällen ohne Bezug zum Stil des

${ }^{447}$ Al-Dūrubī sagte 1956 in einem Interview mit der libanesischen literarischen Zeitschrift al-migallah aladabia: "heute spüren wir stark und schmerzlich unseren Abstand von der lokalen Wirklichkeit und dem nationalen Stil [...] und Ich persönlich, obwohl ich fortwährend versuche, irakische Themen mit Blick auf meine Jugend in einer rein irakischen Umgebung zu malen, wenn ich Pinsel und Farben in die Hand nehme, ich denke dennoch an die Arbeit europäischer Künstler. Deswegen sehe ich mich immer noch im Rahmen der Versuche, die moderne irakische Schule zu finden. Und obwohl ich dem traditionellen irakischen Stil gefolgt bin, war es nichts als eine Imitation“, in: Al-Sa`̄̄id, 1983, S. 181. 
Impressionismus waren. Die Gruppe teilte dennoch das gemeinsame Interesse aller irakischen Künstler der Zeit, das in ihrer Erforschung der Tradition und der Suche nach Inspiration in dieser Tradition anschaulich wird. Der Name der Gruppe wurde schließlich eher zur Beschränkung, besonders nach der Entwicklung verschiedener Einzelstile. Deshalb trennte sich die Gruppe, nachdem sie 1968 ihre letzte Ausstellung veranstaltet hatte.

Die Frühgeschichte und das Erbe seines Landes wurden eine seiner ersten und beständigsten Quellen der Inspiration: „Das Altertum war ein Anreiz. Anstatt einem europäischen Beispiel zu folgen, suche ich Inspiration in der Tradition““448. Al-`Azzāwī erklärt weiter: „Ich begann meine Versuche, mich auf das Erbe zu verlassen und meine Versuche, historische Formen, insbesondere sumerische Kunst zu verwenden, wegen meines Archäologiestudiums “449. So begann er seine künstlerische Karriere mit einem klaren Blick, der einen Entwicklungsprozess durchlief, und nach Ansicht des irakischen Kunsthistorikers und Kritikers 'Ādil Kāmil, seinen Arbeiten erlaubt, Bewusstsein und Konventionen zur Kreativität hin zu überschreiten ${ }^{450}$.

Al-'Azzāwī stand vom Anfang seiner Karriere an der Herausforderung gegenüber, zwei Welten zu verbinden: die antike Kultur seines Landes, die er durch seine Beschäftigung mit der Archäologie entdeckte und seine moderne Welt. Beide Welten waren für al'Azzāwī neu: „Es war eine große Offenbarung für mich. Es gab tief in mir eine enorme Reaktion. Ich fühlte mich besonders den sumerischen Ideen nahe. Ich liebte die einfachen Linien, die riesigen Augen. Es war für mich und alle neu. Wir alle waren uns dieses Aspekts unserer kulturellen Vergangenheit fast nicht bewusst “451. Al-'Azzāwī verließ sich nicht auf seine intuitive Fähigkeit und Kreativität, sondern widmete sich dem Verstehen der intellektuellen Seite des kreativen Prozesses als bewusste Erfahrung, die direkt mit menschlichem Fortschritt verbunden ist. Kāmil schreibt, dass Malerei für al-'Azzāwī ,eine Komposition [ist], eine Konstruktion, eine Umsetzung einer gut durchdachten Idee. Sie ist das Produkt von mentaler, wissenschaftlicher oder logischer Bemühung. Eine Bemühung, die Intuitivität der Idee oder der Situation auszudrücken“452. „Ein Gemälde“, erklärte Al-`Azzāwī, ,,ist ein Aufbruch in Zeit, Raum

\footnotetext{
${ }^{448}$ vgl. Al-'Azzāwī, 1992, S. 156 f.

449 vgl. Yūsuf, Farūq: Diyā') Al-'Azzāwīs “Total Dedication to Painting”, in: Gilgamesh. A journal of modern Iraqi arts Nr. 4, Bagdad, 1988, S. 7-14, hier S. 12.

${ }^{450}$ vgl. Kāmil, 'Adil: al-Fann at-taškīlī al-mu'āṣir fī-l-'Irāq: marḥalat as-sittīnāt, Bagdad 1986, S. 82.

451 'Alī, Maureen, 1988, S. 15.

${ }^{452}$ Kamil, 1986, S. 95.
} 
und Erinnerung; ein Erreichen des sufischen Stadiums, Sufismus dessen, was greifbar

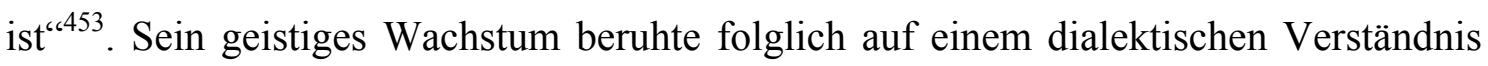
der Wirklichkeit, das mit einem Ausdruck des nationalen und persönlichen Selbst begann und in einem Ausdruck der Menschheit endete. In seinem Streben nach internationaler Kunst sah al-'Azzāwī sein kulturelles Erbe als das Erbe der Menschheit an, ohne durch einen geographischen Ort begrenzt $\mathrm{zu} \operatorname{sein}^{454}$.

Solange er mit der irakischen Impressionistengruppe ausstellte, zeigte al-'Azzāwī in seiner Arbeit Interesse an folkloristischen Themen. In seiner ersten Einzelausstellung 1965 ergründete al-'Azzāwī lokale Tragödien aus unterschiedenen Kapiteln der irakischen Geschichte, sowohl der des Altertums wie der islamischen. Tatsächlich hingen alle Gemälde, in der Ausstellung ,entweder mit folkloristischen Themen, Formen und Symbolen oder Geschichten zusammen, besonders der Tragödie von Karbalä $^{\natural 4455}$. Ein Beispiel dafür ist Karbalä’, 1964 (Abb. 120). Das Bild wurde mit schwarzer Tinte und blauer Farbe gemalt. Der größte Teil der Fläche ist frei, die bildlichen Elemente konzentrieren sich auf den unteren linken Teil. Der Künstler hat sein Bild durch eine Linie, ähnlich einer Zeitlinie, in zwei Teilen aufgeteilt. Auf der linken Seite hat er einen Rahmen gezeichnet. Darin hat er eine Kuh platziert. Der Körper der Kuh ist mit Ornamenten bedeckt. Einige Teile der Kuh wurden blau ausgemalt. Aus dem linken Bein steigt ein Strich auf, teilt die Schrift oberhalb der Kuh, durchschneidet den Rahmen und endet in einer Standarte. Die Form der Standarte erscheint auch auf dem Körper der Kuh und ist mit dem Wort al-mawğ (Welle). Ein wellenförmiges Muster erscheint auch unterhalb dieser Form. Die Kuh hebt das rechte Vorderbein und öffnet vor Schmerz über die Ermordung des Enkelkindes des Propheten schreiend das Maul. Darüber steht der Satz: „Die Ermordung von Ḥusaīn , Gottes Frieden über ihn“. Auf der rechten Seite wurden zwei betrachtende Augen angebracht, die der Ermordung beiwohnten, denn sie befinden sich innerhalb der Umrahmung. Ein Auge befindet sich auf der teilenden Linie. Davor wurde ein Ornament platziert, das eine Palme symbolisiert. Der überwiegende Teil des Bildes ist leer, wie ein Zeichen für die Leere und Stille, die durch die Ermordung geschaffen wurde. Der Künstler zeichnet eine Linie zum Geschehen im Alten Testament, als Moses vom Berg mit dem Gesetz zurückkam, um festzustellen, dass sein Volk einen jungen Stier anbetete und damit in

\footnotetext{
${ }^{453}$ Descendre, Nadine (Regie): Baghdad Memory: Diyā' al-Azzawi, artist. Video, 49 Minuten, Paris ohne Jahr. Sufismus wird hier im allgemeinen Sinne des Erlangens von Spiritualität verstanden.

${ }^{454}$ Al-'Azzāwī, Gespräch mit dem Verfasser, 10.11.2003.

${ }^{455}$ Al-'Azzāwī, E-Mail vom 30.1. 2004.
} 
den Unglauben zurückgefallen war. Hier wird darauf Bezug genommen, in dem der Künstler darauf hinweist, dass die Muslime mit der Ermordung des Enkelkindes ihres Propheten, der eine hohe Stellung bei seinem Großvater besaß, in die vorislamische Zeit zurückfielen. Die Schrift „die Ermordung von Husaīn ..." trennt und verbindet zugleich. Sie trennt das Unrechte vom Rechten. Sie befindet sich jedoch auf der Zeitlinie und verbindet uns heute mit den Ereignissen von damals. Das wird durch das Auge auf der Zeitlinie unterstrichen.

Jedoch entschied sich al-'Azzāwī bald, die Früchte seiner lokalen irakischen Tradition zu übertreffen: „Von Anfang an war meine Neigung der Tradition zugewandt. Also wählte ich eine arabische Strömung und las in den folkloristischen und legendären Traditionen. Ich erkannte, dass ich in dieser kulturellen Situation nicht nur ein irakischer Maler sein kann, sondern ein arabischer sein musste ${ }^{\text {“456. }}$

Aus seinen frühen Arbeiten ist offensichtlich, dass al-'Azzāwī ein intuitives Gespür für Farbe besaß, das in der Intensität seiner Farben zutage tritt, die der der Fauves ähnlich ist.

1969 gründete al-'Azzāwī gemeinsam mit Hāšim Samarši, Moḥammed Māhr ad-Din, Rāfi an-Nāṣirī, Ṣālih al- Ğumai'ā und Ismā'̄̄l Fattāḥ die Gruppe ar-ru’ya al-ğadîda (Neue Vision). Die Gruppe Neue Vision verband die Künstler auf einer intellektuellen und kulturellen Ebene anstatt einer stilistischen: „Es war eine Bewegung, um einen Dialog zwischen Künstlern mit gemeinsamen Interessen herzustellen, um zusammen zu arbeiten. Möglicherweise würde durch diese Arbeit das Konzept in ein Kunstwerk verwandelt werden, das klare künstlerische Ideen hat ${ }^{\star 457}$. Die Bildung der Gruppe erfolgte in einer Stimmung des Trotzes und der Verleugnung der Niederlage der arabischen Staaten im Sechs-Tage-Krieg von 1967 gegen Israel, die damals in der Bevölkerung der arabischen Länder herrschte und bis zum Oktober-/ Yaum al- Ubūr Krieg 1973 andauerte. Sie wurde ebenso vom Fieber des Pan-Arabismus beeinflusst und dem Wunsch nach arabischer Einheit, der in Al-'Azzāwī's Ziel, eine Kunst zu schaffen, die in der arabischen Kultur wurzelt, offenkundig ist. Dieses war in der Sprache offensichtlich, die al-'Azzāwī benutzte, als er das Manifest der Gruppe schrieb, das im Oktober des gleichen Jahres unter dem Titel „Hin zu einer neuen Vision“ veröffentlicht wurde.

\footnotetext{
${ }^{456}$ Al-'Azzāwī, 1992, S. 156 f.

${ }^{457}$ Al-'Azzāwī, Gespräch mit dem Verfasser, 11.11. 2003.
} 
Der Kunstkritiker Farūq Yūsuf behauptete 1986, dass das Manifest der Gruppe die Grundlagen enthalte, auf denen die Unterschiede zwischen den Künstlern der sechziger Jahre und denen, die ihnen vorangingen, beruhen ${ }^{458}$. Die arabische Künstlergeneration der 60er Jahre wusste nicht nur um die turbulente politische Situation, sondern auch um ihre Verantwortung, bei der Gestaltung ihrer Kulturkreise und Gesellschaften eine aktivere Rolle zu übernehmen. Man glaubte, dass „keine Generation mit einer solchen Heimatliebe, Menschlichkeit und Ausdauer ausgestattet ist, wie die unserige. Wir müssen ständig alle Gefahren herausfordern die unser Vaterland bedrohen, und uns ihnen stellen. Wir leben inmitten des Strudels eines neuen Nazi-Militärmarsches ${ }^{459}$, den wir immer durch unsere Existenz bedrohen. Wir arbeiten um der Konzentration und um einer avantgardistischen Kunst willen, die in ihre menschlichen Zielen eine neue künstlerische Vision integriert ${ }^{\text {‘460 }}$.

Sie lehnten die Arbeit ihrer Vorgänger nicht ab; sie beabsichtigten die Bedeutung des Kunstwerks und dessen kreativer Rolle sowie das Konzept von Kunstgruppen wieder aufzuwerten $^{461}$. In einer Einleitung zu einer Ausstellung der New Vision Gruppe im Jahre 1970 schrieb al-'Azzāwī: „Während die Arbeiten, die wir in unserer (gemeinsamen) Ausstellung vorstellen verschiedene Visionen und Experimente darstellen, bestätigt sie [die Ausstellung] auch die Platzierung unserer Bilder an einer Wand, die die Ablehnung jeder möglichen Annahme einer neuen Kunstsammlung [ in Bezug auf die Einheit des Stils ] ist, denn wir glauben nicht länger an den Nutzen [der Art und Weise] wie die Kunstgruppen in unserer Heimat sich selbst innerhalb früherer Deutungen einordnen, die geholfen haben, sie $\mathrm{zu}$ bilden. (...) Wir sehen uns verpflichtet, dass jeder seine Wahrheit ohne jegliche Formeln und abstrakte Zahlen, die uns einschränken, ausdrückt ${ }^{\text {‘462 }}$.

Der „lokale Stil“, der von der Bagdad Modern Art Group befürwortet wurde, wurde folglich durch al-'Azzāwīs neue Ideen ${ }^{463}$, die er „epische Zeitgenössigkeit“ nannte, ersetzt. Sowohl Stil als auch Inhalt, sollten „durch ein plastisches Maß eine an unsere psychologische und intellektuelle Wirklichkeit gebundene Gegenwart erzielen“" 464 .

\footnotetext{
${ }^{458}$ vgl. Yūsuf, Farūq: Modern Painting in Iraq: Three Experiments, in: Fikrun wa Fann Nr. 43, Bonn 1986., S. 60-64, hier S. 61.

459 Al-'Azzāwī bedient sich hier der arabischen ,,antizionistisch-antiimperialistischen“ Propagandasprache.

${ }^{460}$ Al-'Azzāwī, 1973, S. 39.

${ }^{461}$ vgl. Yūsuf, 1986, S. 61.

462 Al-'Azzāwī: Introduction to the Exhibition of the New Vision Group, Bagdad.1970. o. S.

${ }^{463}$ vgl. Lu'īìì, 1992, S. 166.

464 ebd. vgl. Al-Sa'̄id, 1988, S.85.
} 
Vorliebe für die Tradition als Quelle für die Entwicklung ,unserer Form des Aufbaus und des Inhalts“, sowie das objektive Verständnis dieser Vorliebe wird teilweise zum Mittel für die Entwicklung eines neuen Stils ,,indem sie [ die Tradition ] durch die Gegenwart mit Blick auf die Zukunft wiedererschaffen wird, die gleichsam sowohl ihre Übersteigung als auch ihre Weiterentwicklung ist ${ }^{\star 465}$.

Einem solchen Konzept folgend sammelte al-'Azzāwī alle Elemente, die für ihn durch seine breite Definition der Tradition als Symbole, einschließlich des geschriebenen Wortes, zugänglich waren, um einen reichhaltigen zeitgenössischen visuellen Wortschatz zu schaffen.

Die symbolische Dimension, die sich in seinen früheren Arbeiten fand, war mit Geschichte, Tradition und Legende verbunden, fand jedoch mehr und mehr Verbindung zur Wirklichkeit. Er leitete seine Zeichen und Symbole vom täglichen Leben ab. Gleichsam änderten sich seine Formen, besonders Abbildungen, die den Betrachter früher auf ein altes Epos oder eine Geschichte verwiesen, zu einer Realisierung der zeitgenössischen menschlichen Verfassung der Araber. Sein Interesse am Konzept der Tragödie beibehaltend, konzentrierte sich al-'Azzāwī auf die Schilderung eines zeitgenössischen arabischen Themas, die palästinensische Tragödie. Sich realistisch mit dem Thema der palästinensischen Märtyrer zu beschäftigen hatte einen Einfluss auf seinen Stil. 'Adil Kāmil schreibt, dass al-'Azzāwīs intellektuelle Auseinandersetzung mit einem zeitgenössischen Thema und dem Geist desselben, nämlich Schmerz und Tod, auszudrücken ,ihn zu einer neuen Methode des Ausdruckes führte: Verringerung der Farbe, Schärfung des Ausdrucks, der Kahlheit der Linien, Spontaneität der Komposition und weitgehende Aufgabe von Verzierungen “466.

Al-'Azzāwī bemühte sich, in seiner Arbeit den „kulturelle[n] Kontrast zwischen Vergangenheit und Zukunft، ${ }^{\star 467} \mathrm{zu}$ artikulieren. Nach dem gleichen Konzept führte al'Azzāwī eine Reihe von 45 Zeichnungen aus, die von den Geschichten aus Tausend und eine Nacht inspiriert sind. Als Beispiel kann das im Jahre 1986 verfertigte „Tausend und eine Nacht" genommen werden (Abb. 121). An der rechten Seite des Bildes ist König Šahrayār abgebildet. Seine Gestalt ist in groben Umrissen gezeichnet, deren Vorlagen assyrische Personendarstellungen waren. Šahrayār scheint mit seinen Händen

\footnotetext{
${ }^{465}$ vgl. Lưīììi, 1992, S. 166.

${ }^{466}$ vgl. Kamil, 1986, S. 99.

${ }^{467}$ Descendre, ohne Jahr.
} 
Schriftzüge aufzufangen, die von der linken Seite aus allen Richtungen auf ihn zukommen. Die Schrift ist spiegelverkehrt und verläuft von links nach rechts, also entgegen der arabischen Schreibrichtung. Einige Buchstaben und Wörter erscheinen auf einem Streifen in der Mitte des Bildes. Diese sind in der richtigen Richtung geschrieben, aber dennoch unlesbar. Das Bild ist in dunklen Farben, Schwarz und schwarz untermischtes Rot, Grün und Gelb gehalten.

Der arabische Buchstabe tauchte von Anfang an intuitiv in al-'Azzāwīs Arbeiten auf; jedoch sah er ihn jetzt in einer anderen Dimension, was unter anderem bedeutete, dass die einzelnen Buchstaben einen verhältnismäßig größeren Raumanteil im Bild einnahmen. Als Šākir Ḥasan as-Sā̄id Ende 1970 den ersten Versuch unternahm, die One-Dimension Group zu bilden, war al-'Azzāwī einer der Künstler, die die erste Sitzung besuchten. Er schloss sich der One-Dimension Group an, während er seine Beziehungen zur New Vision Group bis 1972 aufrechterhielt, als diese ihre letzte Ausstellung in Beirut hatte. Dennoch teilte al-'Azzāwī as-Sa'̄̄ids introspektive SufiPhilosophie nicht und trat schon nach kurzem wieder aus der Gruppe aus ${ }^{468}$.

Buchstaben waren für al-'Azzāwī ein Element seines breiten Verständnisses der Tradition: „,von Anfang an, war der Buchstabe nicht das zentrale Material meiner Gemälde. Ich bevorzugte ihn immer als einen Teil der Gruppe der Elemente, aus denen das Bild komponiert war; der Buchstabe als Zeichen und Form. So werden seine Eigenschaften die Energie haben, die Welt zu erreichen“" ${ }^{469}$. Schließlich wollte al'Azzāwī den Buchstaben zu einem Teil der visuellen Sprache machen, die dann eine „visuelle Kultur“ konstituieren würde, die seiner Ansicht nach in der arabischen Welt fehlt, wo „Zeichen und visuelle Formen das schriftliche Wort ersetzen“ würden ${ }^{470}$.

In seiner Arbeit Homage to Baghdad, London, 1982; (Abb. 122), die mit der Technik der Serigrafie verwirklicht wurde, vereinigt sich der arabische Buchstabe mit der

${ }^{468}$ Für die Sufi-Philosophie al-Sa‘̄ìds, die zur Formation der Gruppe führte und in ihren Theorien „des lebenswichtigen Ausdruckes“ und „der räumlichen Verkleinerung“ als Methode der Betrachtung ausgedrückt wurde, war die Aufnahme des Buchstabens als künstlerisches Element, mit der Al-'Azzāwī sich beschäftigte, nicht von Belang; man nahm aber den Buchstaben als Mittel in der Suche nach der „Eindimensionalität“ und des Begreifens der Bedeutung der Existenz in der Kunst wahr. Sufismus ist für al-Sa'̄̄id eine allumfassende Lebensweise, während es für al-'Azzāwī nur eine Dimension von Spiritualität ist.

${ }^{469}$ Al-'Azzāwī, Gespräch mit dem Verfasser, 10.11.2003.

${ }^{470}$ „Visuelle Kultur ist für uns fast nicht existent. Wenn wir irgendeinen Flughafen der Welt betreten, finden wir genügende Zeichen und visuelle Formen, die geschriebene Worte ersetzt haben, an die sich das europäische Individuum gewöhnt hat", vgl. Nūrī, 2001, S. 119. 
Klarheit der Farben, die durch den Siebdruck hervorgerufen werden. Die Farben leuchten und das Schwarze erscheint noch tiefer. Die dargestellte Gesamtheit kleiner Formate, denn es handelt sich um gedruckte Arbeiten und nicht um Wandmalerei, hebt eine große Meisterschaft hervor.

Poesie ist für al-'Azzāwī eine der Hauptverbindungen zwischen geschriebenem Wort und Gemälden ${ }^{471}$. Dennoch ist das Verhältnis zwischen Poesie und Bildern für al'Azzāwī kein direktes: das Eine ist literarisch und das Andere visuell. Auf dieser Unterscheidung basieren die Bedürfnisse und die Interessen des Dichters und Malers: „Narrative [repräsentierende] Bilder bedeuten in der Malerei nicht viel, dementsprechend erscheint beschreibende Poesie, ob klassisch oder modern als Material, das zu Arbeiten dekorativer Werte führt und als solches die literarische Bedeutung eines Kunstwerks reflektiert [...] Der einzigartige Wert jeder visuellen Arbeit soll von dem Thema, das ihn inspirierte, völlig unabhängig sein. Es ist die Befreiung von Bildern, von Darstellungen, die von Malern befürwortet wurde, in deren Interesse es lag, die Wahrheit des Lesens und nicht die des Sehens auszudrücken ${ }^{472}$.

Tatsächlich erhob al-'Azzāwī gegen das in der Kunstkritik verwendete Konzept, ein Gemälde „zu lesen“, Einwände, weil der Vorgang des „Lesens“ Literatur und nicht visuelle Kunst betreffe ${ }^{473}$. „Jeder Versuch, ein Kunstwerk in der Art eines literarischen Dokuments zu beschreiben konnte uns nicht zur entscheidenden Erfahrung führen, die im Wesentlichen eine visuelle ist, weil die ästhetische Form im Allgemeinen eine visuelle ist ${ }^{\text {“474 }}$. Daraus folgt, dass Poesie für al-`Azzāwī ,als ein Mittel des Ausdrucks die Kraft dazu hat, Phantasie anzuregen. Die abschließende Formel liegt nicht notwendigerweise in den Worten, sondern in der Methode eines anderen vom Dichter geschaffenen Verständnisses““475. Der Text, den al-'Azzāwī malt, „hat die materielle Form eines schriftlichen Bilds. Es ist der Weggang von Worten von ihrer linguistischen

\footnotetext{
${ }^{471}$ Neben persönlichen Beweggründen, so argumentiert der irakische Kritiker May Mudhaffar, ist die ursprüngliche Erfahrung Kunst und Poesie zu verbinden, wie 1971 von al-'Azzāwī, Rafa, Al-Nasiri und Hashim Samarchi beim ersten al-Marbid Poesiefestival in Basra angeregt: „eine allgemeine Aussage, welche die tiefgründigen Beziehungen zwischen Künstlern und Dichtern in einem neuen Zeitalter erklärt.“ May Mudhaffar, moderne irakische Künstler und Poesie, in vgl. Mudhaffar, 1986, S. 15-16.

${ }^{472}$ vgl. Al-'Azzāwī, 1992, S. 135.

${ }^{473}$ Im Gegensatz dazu wandte Farūq Yūsuf sich gegen den ,archaischen“ Ausdruck des „Gemäldes mit Worten", der im Zusammenhang mit Dichtung verwendet wurde, der nahelegt, dass die Beziehung zwischen Poesie und Malerei auf „Gefühlen und begrifflicher Kraft“ beruht, da „Wörter das Material des Schreibens sind, während Farben das Medium der Malerei sind“, in: Yūsuf, Farūq: Aqna'at ar-Rasm (dt. Masken der Zeichnung), Ammann 1996, S. 31.

${ }^{474}$ vgl. Yūsuf, 1988, S. 11 .

475 vgl. Yūsuf, 1988, S. 9.
} 
Wirklichkeit hin zu einer visuellen Struktur, in welcher Farbe eine grundlegende Rolle spielt. Farbe ist hier die Methode für die Schaffung des Raumes, in dem sich der Text erhebt, es ist eine ununterbrochene Suche nach dem Verhältnis des Wortes zu seiner umgebenden Leere ${ }^{476}$.“

Al-'Azzāwīs Experimente mit dem Buchstaben beschränken sich jedoch nicht auf literarische Themen ${ }^{477}$. Während der 1980er Jahre schuf er eine beträchtliche Zahl von abstrakten Kompositionen, die eine kraftvolle visuelle Wirkung hatten und in denen der Buchstabe ein Element war. Die Malerei war für al-'Azzāwī immer eine Lebensart, „eine tägliche Notwendigkeit“ gewesen, durch welche sich seine „Existenz verwirklicht“ und seine „Einheit mit dieser Welt“ erreicht wurde ${ }^{478}$. Jedes Bild war folglich eine Seite seiner Autobiographie ,psychologische und kulturelle Erfahrungen“ reflektierend ,und niedergelegt im menschlichen Unterbewusstsein “479.

Die Gemälde von 'Azzāwī, deren Zusammensetzung auf den Buchstaben basiert, bieten eine doppelte Interpretation an: sie führen gleichzeitig durch die Kunst der Kalligraphie - basierend auf der Ruhe, der Festigkeit und der Flexibilität -, und durch die manuelle Schrift, deren innere Natur die Persönlichkeit des Künstlers und seine Verwirrung zu dem Zeitpunkt enthüllt, an dem er sein Werk vollendet. Dennoch könnten diese Gemälde, möglicherweise wegen seiner neuen Erfahrung in einem fremden Land, als einige seiner persönlichsten Kreationen betrachtet werden. Fragmente der Architektur, der Landschaft, der Abbildungen und Zeichen, in reinen Farben, werden in den harmonischen Verhältnissen vereinigt. Al-'Azzāwīs kraftvolle und leuchtende Farben sind, laut Farūq Yūsuf, „durch ihre Natur, Bewegung und Struktur, den Farben im Irak populärer Textilien nahe“ ${ }^{480}$.

Das lässt sich anhand von Internal Notes No. 3, 1978 (Abb. 123), nachweisen. Das Bild wird durch eine weiße Linie in zwei ungleich große Flächen geteilt. Auf der größeren oberen Fläche ist vor einem dunkelbraunen Hintergrund, zur rechten Seite hin verschoben, eine rosafarbene Fläche gemalt. Sie ist durch weiße und rote Linien gitterförmig unterteilt. In der unteren rechten Ecke sind drei konzentrische Viertelkreise

\footnotetext{
${ }^{476}$ Bin Rağab, Mohamed: "Diyā' Al-'Azzāwī wa Nagib Belkhoja: aš-šic r huwa at-tașwīr al-mar’aī wa attașwīr huwa aš- ši '́r al-ğaīr mar’aī, in: al-ğarīda at-tūnusiyya, Tunis 17.11.1997, S. 7.

477 Sein Werk ist auch nicht auf ein Material beschränkt, Al-'Azzāwī hat mit verschiedenen Materialien experimentiert, unter anderem Lehmreliefs und Skulpturen.

${ }^{478}$ vgl. Al-'Azzāwī: Al-Fannan Amam al-Tağrūba fi hụud al-Lawha (dt. Der Künstler vor dem Experiment innerhalb der Grenzen des Gemäldes), in: Al-Mutaqqaf al-'arabī Nr. 4, Bagdad 1971, S. 53 -58.

${ }^{479}$ vgl. Al-'Azzāwī, 1971, S. 57.

480 vgl. Yūsuf, 1986, S. 63.
} 
in roter und brauner Farbe $\mathrm{zu}$ sehen. Ferner ist die Fläche zum größten Teil mit Schriftzügen in kleinem Format bedeckt, die sich in mehreren Richtungen über sie erstrecken. Innerhalb des Schriftzuges unten ist die Zahl 1978 lesbar. Darüber schrieb 'Azzāwī mit größeren Buchstaben kalligraphische Schriftzüge nach Art einer Ṭugrāà in roter, brauner, und, am linken Rand, türkiser Farbe. Insgesamt macht die beschriebene rosafarbene Fläche den Eindruck eines mehrfach beschriebenen Papierfetzens. Im unteren Teil ist vor demselben dunkelbraunen Hintergrund eine etwas hellere braune Fläche gemalt, die an ihrem linken Rand vier senkrechte Streifen in roter, olivfarbener, violetter und rot-brauner Farbe trägt. Darüber sind zwei Buchstaben, 'ayn (ع) und waw (9), und zwei rhombische Punkte gemalt. Die Buchstaben sind spiegelverkehrt.

Der Buchstabe verliert in diesen Arbeiten jede linguistische Bedeutung und jeden lautlichen Wert und ist stattdessen eine reine und abstrakte Form ästhetischen Wertes. Für al-'Azzāwī wird die Verwendung von Buchstaben ,ein Versuch, formale Kreationen zu finden [...], selbst wenn dies zur Übertretung der grundlegenden Richtlinien von Kalligraphie [der Schrift] führte. Manchmal mag ich es, einen bestimmten Buchstaben in seiner klassischen Form zu malen, ein anderes Mal versuche ich, den Buchstaben zu zerstören““481. Schließlich möchte al-'Azzāwī kein „Schreibkünstler sein, der Farbe verwendet, sondern ein Maler, der Schrift in der Komposition eines Gemäldes einsetzt ${ }^{\text {“482. }}$.

In al-'Azzāwīs Arbeiten erscheint der Buchstabe auch in Verbindung mit anderen Motiven. In 'Abdullah leaving his city, no 2, 1983 (Abb. 124) aus der Reihe „Abdullah“ erscheinen Buchstabenfragmente, welche die Gedanken des Sufi-Dichters "Abdullah al-Niffarī, der im 10. Jahrhundert lebte, symbolisieren, auf dem massiven Abbild von 'Abdullah, das an monumentale sumerische Formen erinnert. Die Schrift erscheint in Form von Buchstaben bzw. Teilen von Buchstaben auf dem rechten Arm von 'Abdullah. Der Hintergrund des Bildes ist schwarz. Die Farben der Figur sind braun, gelb, rot und weiß. So wie die meisten Figuren, die 'Azzāwī malte, bewegt sich diese Figur auch von links nach rechts. Dass einer sumerisch anmutenden Gestalt der typisch arabisch-islamische Name 'Abdullah gegeben wurde, drückt durch die wiederholte Verwendung der Abbildung 'Abdullahs in anderen Arbeiten die Suche nach Identität und Freiheit aus. 'Azzāwī drückt in der 'Abdullah-Serie seine Identität als

\footnotetext{
${ }^{481}$ vgl. Nūrī, 2001, S. 121.

${ }^{482}$ ebd.
} 
Iraker aus, indem er Motive der antiken mesopotamischen Kulturen mit solchen der arabisch-islamischen vermischt. Indem 'Abdullah ständig in Bewegung dargestellt wird, spielt 'Azzāwī auf seine Flucht aus dem Irak und die im Exil gewonnene Freiheit an.

Al-'Azzāwīs Gemälde sind mehr als Bilder, sie sind Objekte mit berührbaren Oberflächen. Formen bewegen sich frei auf der Oberfläche, schneiden sie, greifen ineinander und treffen sich und überragen manchmal die Ränder der Arbeit. Die Fortsetzung der Formen im Raum wird durch die unregelmäßige Form einiger der Gemälde oder der Reliefs und durch die Ausweitung der Farben an den Seiten der Leinwand oder des Brettes hervorgehoben ${ }^{483}$.

Durch seine Farben schafft al-`Azzāwī bestimmte psychologische Atmosphären: „Farbe enthält einen psychologischen Aspekt. Im Reichtum seiner Verwendung, gibt Farbe dem Betrachter eine Art Assoziation““484. Zum Beispiel betrachtet er die Farbe Schwarz, die in vielen von al-'Azzāwīs Arbeit vorkommt, als "Eine der grundlegenden Farben in der irakischen Kultur, in der tragische Tradition einen großen Platz einnimmt ${ }^{\text {“485. Die }}$ Spannung, die durch seine Verwendung von gegensätzlichen Farben wie schwarz und rot entsteht, formt die Dynamik seiner Arbeit, genauso wie die Intensität und Kraft von Gefühlen.

Seine Palette leuchtender Farben und seine besondere Aufmerksamkeit für den ästhetischen Wert der visuellen Erfahrung führte jedoch eine Reihe von Kunstkritikern dazu, seine Arbeit als ornamental zu beurteilen. Ein solches Urteil beleidigt al-`Azzāwī nicht, der sagte, „so lange ich einzigartige ästhetische Formen schaffen kann, die ihre eigenen Terminologien haben und mich zu der nationalen Tradition zurückführen, zu der ich gehöre, halte ich dies für eine Art Erfolg. Letztendlich liegt der ästhetische Wert dieser Formen in dem Versuch, Formen zu schaffen, die zu unserer Wirklichkeit gehören“" ${ }^{*} 46$.

Dennoch wird diese instinktive und leidenschaftliche Empfindlichkeit intellektuell immer ein wenig von Idee und Aufbau gesteuert. Fortschritt in der Arbeit al-'Azzāwīs

\footnotetext{
${ }^{483}$ vgl. Dallul, Zīyad: ḥurūf 'ala Alwān, in: Mawakif Nr. 67, London 1992, S. 151 ff. 1992, S. 151.

${ }^{484}$ Nūrī, 2001, S. 119.

${ }^{485}$ Bin Boushta, Zubair: Diyā' Al-'Azzāwī , collective memory in contemporary guise, in: Al-Hayat Nr. 10890 (3. 12.), London 1992, S. 20.

${ }^{486}$ zitiert nach: Nūrī, 2001, S. 119.
} 
war überwiegend intellektuell; er beruht auf dem Versuch, Wirklichkeit durch Kunst zu verstehen, indem man die Vergangenheit und die Gegenwart wieder entdeckt und sie zur Zukunft hin überschreitet. 'Adil Kāmil schreibt, „,seine [al-'Azzāwīs] Arbeit deutet diesen Fortschritt nicht auf der Ebene des Stils und der Ausführung an, sondern auf der Ebene intellektueller und ideologischer Absichten“4 ${ }^{487}$.

Trotz Al-`Azzāwīs lang andauernder Beziehung zum arabischen Buchstaben, zum Wort und zum Text, stand er der populären Hunū fiyya Strömung so kritisch gegenüber, dass er es ablehnte mit ihren Vertretern zusammenzuarbeiten. Er erklärte, dass das Experiment istilhām al-ḥarf, Inspiration in Buchstaben zu suchen, in der arabischen Kunst, ,auf eine Art Untersuchung der Elemente und der Zeichen einer alten kulturellen Beschaffenheit hindeutet“ “488. Huñ fiyya, behauptet er, „,ist eine positive Strömung, wurde aber durch eine direkte oberflächliche Natur dominiert, zu der die Literatur beitrug. Literaturkritiker regten diese Strömung an, bis sich der Ausdruck von Identität mit der Einbeziehung des arabischen Buchstabens in Gemälde verband. Dies erlaubte vielen mittelmäßigen Malern, Teil dieser Strömung zu werden“489. Der Kunstmarkt war ein weiterer Faktor: ,der [ Kunst- ] Markt, besonders nach der Mitte der 1960er und in den frühen 1970er Jahren, wurde durch die Golfstaaten beherrscht. Sie bevorzugten die abstrakte, nicht bildliche Kunst. Huñ fiyya wurde Teil der abstrakten Tendenz, mit der sie sich identifizieren können. So trugen verschiedene Faktoren, außerhalb der Logik des Gemäldes, zur Popularität der Hurū fiyya bei“‘490.

Al-'Azzāwī gibt Huñ̄fiyya die Schuld für die Entstehung einer Vermischung von Malerei und Kalligraphie. Die meisten zeitgenössischen Kalligraphen zögen es vor, als Maler bezeichnet zu werden, obgleich, wie al-'Azzāwī betont, „die historische arabische Kalligraphie ihren eigenen einzigartigen Status und Erfahrung innehatte und nicht Malerei genannt werden musste“ ${ }^{491}$. Außerdem glaubte er, dass die Identität einer Arbeit, ihr Arabisch-Sein, nicht mit dem Vorkommen des arabischen Buchstaben in der Arbeit zusammenhänge. Was die Rolle der Verzierungen betrifft, ,glaube ich, muss man visuelle Elemente finden, die in einem Gemälde als Primärmaterial benutzt werden können; die arabische Schrift kann Teil, aber nicht Grundlage der Struktur des Bildes sein. Ich finde nicht, dass ein Gemälde durch den Gebrauch arabischer Schrift arabisch

\footnotetext{
${ }^{487}$ Kamil, 1986, S. 92.

${ }^{488}$ Nūrī, 2001, S. 120.

${ }^{489}$ Al- 'Azzāwī, Gespräch mit dem Verfasser, 10.11.2003.

${ }^{490}$ ebd.

${ }^{491}$ ebd.
} 
wird. Das Werk muss eine bestimmte Identität repräsentieren, die von einer Gruppe von Elementen, nicht von Schrift oder Verzierungen allein, hergestellt wird“492.

Er fügte hinzu, dass die Identität eines Bildes ,,von seinem internen geistigen Fluss, von seiner psychologischen Struktur und von seiner inspirierenden Bauweise und seinen Plänen ausgeht, die frei von allen früheren Formulierungen sind. Ein Gemälde ist keine Form und kein Buchstabe, sondern vielmehr ein affektiver und provozierender visueller Satz, der auf Andeutungen beruht ${ }^{\star 493}$.

\section{Schlussbemerkungen und Ausblick}

Die moderne arabische Kunst ist von der westlichen Moderne unverkennbar beeinflusst. Diese ist ihrerseits von verschiedenen fremden Künsten und Kulturen beeinflusst worden. $\mathrm{Zu}$ erwähnen ist hier die islamische Kunst, die schon vor Jahrhunderten die abstrakte Kunst entwickelt hatte, und ihre Wirkung auf die moderne westliche Kunst.

Peter Joch schreibt: „...die Entwicklung der europäischen Moderne [ist] ohne die Einflüsse fremder Kulturen, insbesondere des islamischen Orients, überhaupt nicht denkbar. (...) Andererseits ist die Entwicklung der Moderne in islamischen Ländern ohne die vielfältigen Einflüsse durch die westliche Welt ebenso undenkbar،‘494.

Es war keine neue Erscheinung, als am Beginn des 20. Jahrhunderts in der westlichen Malerei Buchstaben in den Bildern auftauchten. Buchstaben und Worte waren auch vorher, besonders im Mittelalter, bedeutungstragende Motive der Malerei. Allerdings waren sie vor dem 20. Jahrhundert bloß auslegende und ergänzende Elemente im Bild. Erst am Anfang des zweiten Jahrzehnts des 20. Jahrhunderts erhielten Buchstaben eine vom Wortsinn unabhängige Bedeutung als Bildelement, wie man bei Braque sehen kann (Abb. 4). Seitdem wird der Schrift eine neue Funktion im Kunstwerk zugewiesen, die sie vorher weder in der religiösen noch in der profanen Kunst hatte. Die neue Rolle der Schrift im Bild war nicht mehr ein ergänzendes, sondern ein wesentliches Element. In einigen Kunstwerken der zweiten Hälfte des 20. Jahrhunderts wurden Buchstaben, Wörter und Sätze sogar die einzigen Bildelemente. Zur gleichen Zeit entdeckten arabische Künstler erneut die bildliche Verwendung der Schrift, aber mit moderner

${ }^{492}$ Al-'Azzāwī, 1992, S. 160.

${ }^{493}$ Al-'Azzāwī, Gespräch mit dem Verfasser vom 10.11.2003.

${ }^{494}$ Joch, Peter (Hrsg.): Broken Letters. Zeitgenössische Kunst aus arabischen Ländern, Darmstadt 2003, S. 36. 
Auffassung, die sich völlig von der Auffassung ihrer Vorfahren über die traditionelle islamische Schriftkunst unterschied.

Bereits im neunzehnten Jahrhundert und verstärkt Anfang der dreißiger Jahre des 20. Jahrhunderts fingen viele westliche Künstler an, sich mit den verschiedenen außereuropäischen Kulturen zu beschäftigen. Um ihr geistiges Inventar mit fremden Kulturelementen zu bereichern, reisten sie in fremde Länder. Zwar waren sie darauf bedacht, die charakteristischen Muster ihrer westlichen künstlerischen Identität in ihren Werken zu behalten, dennoch sind die Einflüsse dieser außereuropäischen Kulturen sind allerdings in ihren Werken unverkennbar. So haben sie sich mit diesen fremden Kulturen befasst, um neues im Bereich der Kunst zu entdecken.

Einige studierten die mittelamerikanischen indianischen Kulturen und Künste wie z. B. der amerikanische Künstler Adolph Gottlieb. Andere, wie Mark Tobey und Henri Michaux, reisten in „die arabischen Länder, um die arabische Schrift in ihrem Milieu kennenzulernen“ ${ }^{495}$. An diese Reisen schlossen sich weitere nach Ostasien an. Auf diesen Reisen lernten die genannten Künstler die Grundsätze der islamischen und ostasiatischen Kulturen kennen, die sie dann im Westen vermittelten.

Die Spuren der ostasiatischen Kalligraphie in den Werken dieser Künstler waren deutlicher als jene der arabischen Kalligraphie, denn sie suchten die Spontaneität, die ihren Händen beim Malen mehr Freiheit gibt. Diese Spontaneität bzw. Freiheit fanden sie nicht in der arabischen, sondern in der ostasiatischen Kaligraphie. Somit begann die fruchtbare West-Ost-Beziehung durch die Verwendung orientalischer Schriften im Bild, welche die Künstler mit Hilfe von westlichen Stilen und Techniken modifizierten.

Viele dieser Künstler, welche die Schrift im Bild verwendeten, waren vom Surrealismus und seiner Methode des ,automatischen Schreibens“, wodurch das Bild ohne die Kontrolle des Verstandes gemalt wurde, beeinflusst, auch wenn sie zu nichtsurrealistischen Schulen und Richtungen gehörten, wie beispielsweise Robert Motherwell und Gottlieb, die zum abstrakten Expressionismus gerechnet werden.

Bei allen in unserer Arbeit vorgestellten europäischen und nordamerikanischen Künstlern finden wir, dass die Schrift und die Sprache wesentliche Motive und 
Ausdrucksmittel in ihren Werken waren. Ihr Beitrag zur Verwendung von Schrift im Bild in der zweiten Hälfte des 20. Jahrhunderts bleibt bis heute fühlbar.

Verglichen mit den europäischen und nordamerikanischen Künstlern begannen arabische Künstler verhältnismäßig spät, unabhängig von der Tradition mit der Schrift im Bild zu experimentieren. Sehen wir von Madīha 'Umar ab, die Ende der dreißiger Jahre damit begann, datieren alle diese Experimente vom Beginn der fünfziger Jahre. Inspiriert worden sind sie von ihrer heimischen Kultur, durch individuelle Versuche und von den westlichen Schulen und Techniken. Sie waren bei ihren Versuchen darauf bedacht, ihre arabische Identität durch Benutzung der arabischen Schrift zu bewahren. Dennoch konnten sie wegen der starken Einwirkung der modernen westlichen Kunstrichtungen und -stile auf sie, die Muster ihrer Identität nicht bewahren. Aus diesem Grund büßte die arabische Schrift ihren heiligen Status und ihre bekannten Formen und Gestaltungsweisen in den Werken der modernen arabischen Künstler ein. Von westlichen Sichtweisen beeinflusst, begannen sie, arabische Buchstaben auf eine neue Art zu verwenden. Viele arabische Künstler und Kunstkritiker vertreten die Meinung, dass die Werke der irakischen Künstler Madīḥa 'Umar und Ğamīl Hammūdī die ersten Beispiele dieser Richtung sind, in denen die arabischen Buchstaben unabhängig von den alten Traditionen im Kunstwerk benutzt wird. Beide haben ihre Werke während ihres Aufenthalts im Westen angefertigt. Madīḥa 'Umar ist die erste arabische Künstlerin, die ihr ganzes Schaffen dem arabischen Buchstaben gewidmet hat.

In den fünfziger Jahren begannen einige andere Experimente mit dem arabischen Buchstaben. Zu erwähnen seien z. B. jene von Wağhh Naḥla, Sa'id 'Aql und die sudanesischen Künstler der alten Khartum-Schule mit ihrem traditionellen Schriftstil, wie Aḥmad Moḥammed Šibrīn. Was in der Mitte der vierziger und fünfziger Jahre Experiment war, wurde in den Sechzigern zur Kunstrichtung und zog mehrere arabische Künstler an. Die Künstler dieser zweiten Welle haben das Interesse am Buchstaben im Bild weiter entwickelt fortgetrieben, entweder durch ihr Studium in westlichen Ländern, wo die einzige Beziehung zu ihrer Kultur und Tradition „,das arabische Wort und der arabische Buchstabe“ war, oder durch die Wirkung der modernen westlichen Experimente mit dem Buchstaben auf sie. All dieses Interesse wurde zum Phänomen in den Siebzigern und Achtzigern, aber nicht zur festumrissenen Kunstbewegung bzw. Kunstschule, trotz der zahlreichen Versuche. Der irakische Künstler Šākir Ḥasan asSa`̄id gründete im Jahre 1971die Gruppe „Eine Dimension“ mit einer Reihe von 
Künstlern, die den Buchstaben als wesentliches oder sekundäres Element im Bild, wie z. B. Madīḥa 'Umar und Ğamīl Hammūdī, benutzten. Die Gruppe war nicht eine Kunstschule im eigentlichen Sinne, da ihre Mitglieder dem Stil as-Saīids nicht folgten. Jeder Künstler hatte seinen eigenen individuellen Stil. Seitdem ist der Buchstabe nicht mehr wie früher bloß ein Schreibelement, sondern wurde auch ein wesentliches Bauelement im Bild.

Es gibt verschiedene Ansichten, wie die Verwendung von Schrift in der modernen arabischen Malerei eingeordnet werden soll.

Wijdan 'Alī hat vier Kategorien aufgestellt.

I. Die reine Kalligraphie, die sich in vier Zweige gliedert:

1. der neoklassische Stil ist in einigen Werken des libanesischen Künstlers Wağih Nahla vertreten.

2. der moderne klassische Stil ist in den Werken des ägyptischen Handwerkskünstlers Aḥmad Muṣtafā vertreten.

3. Kalligraffiti. Vertreter dieser Richtung ist der irakische Künstler Šākir Hasan as$\mathrm{Sa} \overline{1} \overline{\mathrm{d}}$.

4. Kalligraphie der freien Form. Das ist eine Schriftform, die irgendwo zwischen der klassischen Form und dem Kalligraffiti einzuordnen ist. Vertreter dieser Art ist der libyschen Künstlers 'Alī 'Umar Ermaṣ.

II. Die abstrakte Kalligraphie, die sich in zwei Arten gliedert:

1. die lesbare Schriftform ist in den Werken des syrischen Künstlers Mạmūud Hammād vertreten.

2. die Pseudoschrift ist in den Werken von Nja Mahdaoui vertreten.

III. Die Kalligraphischen Kombinationen, die sich in zwei Zweige teilt:

1. Die zentrale Kalligraphie. Ein Hauptbeispiel dieses Stils ist die Arbeit des Algeriers Rašīd Qoraīšy.

2. Die begrenzte Kalligraphie. Vertreter dieser Art ist die jordanische Künstlerin Munā Sa`ūdī.

IV. Die unbewusste Kalligraphie. In dieser Art, die nicht- kalligraphisch erscheint, sind „unbewusst kalligraphische Formen enthalten - verkleidet als menschliche, tierische und abstrakte Gestalten“496. Diese Richtung vertritt der ägyptische Kunstmaler Yūsuf Sīda.

496 'Alī, 1997, S. 183. 
Širbil Dāgir unterscheidet zwischen Huñ fiyya und „plastischer Kalligraphie““497. An letzterer, die in etwa Alis „reiner Kalligraphie“ entspricht, ist Dāgir nicht weiter interessiert, weil sie seiner Ansicht nach zu konventionell ist und der künstlerischen Originalität entbehrt. Huñ̄fiyya stuft er in vier Kategorien ein ${ }^{498}$.

Die erste Kategorie ist das Gemälde aus Buchstaben, ,wobei der Buchstabe das Material der Arbeit ist- als Ausgangspunkt und Endprodukt ${ }^{\star 499}$. In solchen Arbeiten experimentiert der Künstler mit den plastischen Möglichkeiten des einzelnen Buchstaben zu unterschiedlichen Zwecken: Diese können kreativer, dekorativer, dekonstruktiver oder nachdenklicher Art sein.

Die zweite Kategorie ist das Gemälde aus Wortgruppen, wobei die linguistische Bedeutung ein Teil des Ausdruckes ist. Durch das Einfügen religiöser Aussprüche mit traditionellen Schriftzeichen benutzen die Künstler die klassischen oder modernen arabischen literarischen Texte als Material ihrer Arbeit. Diese Richtung vertreten Rašīd Qoraīšy und Ethel Adnan.

Die dritte Kategorie ist das Gemälde aus Schrift, wo die Arbeiten zwar an die Form der geschriebenen Sprache angelehnt sind, nicht jedoch an ihre Bedeutung. Es ist eine Zusammensetzung von unleserlicher Schrift ohne sprachlichen Inhalt. Ein Beispiel für die Künstler dieser Zweig ist Yūsuf Aḥmad aus Qaṭar

Die letzte Kategorie ist „das Gemälde als Text”. Diese Kategorie unterscheidet sich nach Dāgirir von den drei ersten dadurch, dass hier vom Buchstaben als einem Element des Aufbaues unter anderen Abschied genommen wird. Der Buchstabe wird nicht auf seine konventionelle Form beschränkt, sondern abgewandelt oder abstrahiert. Es werden Ornamente gezeichnet, die arabischen Buchstaben ähnlich sehen. Ein Beispiel für diese Kategorie ist Ḥussayn al-Ğ̄îālī aus Ägypten.

Man merkt, dass Wijdan 'Alis Klassifikation, indem sie von der calligraphic school, ausgeht, verglichen mit Dāgirs Klassifikation umfassender und reichlicher ist. Dāgir beschränkt sich in seiner Klassifikation auf die Künstler, die die Schrift in ihren Bildern nicht in der Art traditioneller Kalligraphie verwendet haben. Diese schließt er

\footnotetext{
${ }^{497}$ vgl. Dāgìir, 1990, S. 67-72.

498 vgl. Dāġir, 1990, S. 48ff.

${ }^{499}$ Dāgìir, 1990, S. 59.
} 
„plastische Kalligraphie“ von der Huñ fiyya aus. Wijdan 'Alī schließt die Verwendung der Schrift im traditionellen Sinne als „reine Kalligraphen“ in ihr Klassifikationssystem ein.

\section{Schlußfolgerungen:}

Erstens: Trotz der Wirkungen der fremden Kulturen auf die Werke westlicher Künstler, bleibt die „Schrift im Bild“ in der westlichen Kunst doch weiterhin durch die westlichen Kunstschulen und -richtungen geprägt. Ebenso folgt auch die arabische Hurū fiyya ihren eigenen Stilen und geht nicht in den westlichen Stilrichtungen auf. Beide verwenden Buchstaben als Bildelemente, haben aber unterschiedliche, in der jeweils eigenen künstlerischen Tradition liegende Herangehensweisen. Die westliche Kunst bleibt westlich, die arabische arabisch.

Dennoch ist die westliche Einwirkung auf die Formung der modernen arabischen Kultur ist unverkennbar. Die Araber haben die Grundsätze und Hauptgedanken der westlichen Kultur assimiliert. Die West-Ost-Beziehung ist nicht einseitig, sondern wechselseitig. Der Einwirkung der westlichen Kultur auf die arabische seit dem 19. Jahrhundert ging eine Einwirkung der arabischen auf die westliche Kultur vom 8. bis 13. Jahrhundert voraus.

Trotz der unaufhörlichen westlichen Wirkung auf die moderne arabische Kunst versucht die arabische Kunst eine neue Identität auszubilden, die ihr eine besondere Stellung unter den Künsten der Welt gibt. Nach Peter Joch sei sie dazu in der Lage, weil zum einen „die arabischen Künstler traditionell Kosmopoliten [sind], die eine Fülle von Anregungen aus vielen Ländern aufgreifen und in ihre individuellen Bildsysteme verwandeln. Zum anderen schaffen sie eine Kunst, die weder der ,orientalischen' Historie folgt noch sie zugunsten internationaler Trends einebnet ${ }^{\star 6500}$.

Aber bestimmte Hindernisse stehen diesen Versuchen im Wege. Zuerst ist hier die Abwesenheit der arabischen Kunst von der internationalen Bühne trotz der modernen fortgeschrittenen Kommunikationsmittel zu erwähnen. In der Tat ist diese Abwesenheit nicht nur auf der internationalen, sondern auch auf der gesamtarabischen Ebene zu bemerken. In der arabischen Welt sind einige Künste, wie Musik und Schauspiel, von

\footnotetext{
${ }^{500}$ Joch, Peter, 2003, S. 9.
} 
den Medien auf Kosten anderer, vor allem der bildenden Künste, begünstigt. Auch die in den meisten arabischen Ländern herrschende Armut spielt dabei eine Rolle. Wegen der Armut nehmen die Alltagsprobleme die Interessen der Menschen in Anspruch. Deswegen findet die bildende Kunst kaum Interesse. Weiterhin ist die moderne arabische Kunst im Westen unbekannt, taucht kaum in den Medien oder in den Veranstaltungen und Museen auf, trotz der vermehrten Beschäftigung mit anderen Aspekten der arabischen Kultur im Westen. Für Werke der bildenden Kunst, die die Schrift ins Bild integrieren, auch für die Moderne, bilden immer noch die Golfstaaten den wichtigsten Absatzmarkt. Die moderne bildende Kunst steht jedoch im Schatten der schon bekannten islamischen Kunst, insbesondere der Kalligraphie ${ }^{501}$.

Obwohl viele arabische Künstler ihre Inspiration zu modernen Kunstwerken, die viele Formen und Symbole enthalten, aus der islamischen Kunst beziehen, unterscheiden sich ihre Werke von der bekannten islamischen Kalligraphie. Aber man findet ohne Mühe darin unverkennbare arabische Züge. Deswegen ist das Schaffen der modernen arabischen Künstler nicht für bloß islamisch zu halten. Die Bezeichnung „,moderne oder zeitgenössische arabische Kunst“ trifft hier mehr als „moderne islamische Kunst“ zu.

Man muss bedenken, dass der Gebrauch des arabischen Buchstabens in der modernen arabischen Kunst, die in der Mode der Huñ fiyya gipfelte, nur ein Werkzeug war, das die arabischen Künstler zu einer bestimmten Zeit benutzten, um ein bestimmtes Problem zu lösen. Es erlaubte ihnen nicht nur, die westliche mit der islamischen Abstraktion zu vereinen, sondern diente ebenso als ein direktes Symbol ihrer arabischen Identität. Es gab ihrer modernen abstrakten Malerei eine Identität. Nichtsdestoweniger haben die meisten vollendeten arabischen Künstler solche künstlichen Bedürfnisse hinter sich gelassen. Sie haben bemerkt, dass ihre Identität von ihrem Bewusstsein nicht $\mathrm{zu}$ trennen ist und daher kein Etikett braucht. Sie haben ebenso wahrgenommen, dass ein arabischer Buchstabe, der einem Gemälde aufgesetzt wird, es noch nicht zu einem arabischen Gemälde macht.

Ein gelungenes Beispiel, die Isolation der arabischen zeitgenössischen bildenden Kunst zu durchbrechen, war die 1989 von der Abteilung für zeitgenössische Kunst des Institute du Monde Arabe, Paris, veranstaltete Ausstellung „Croisement de Signes“. Es wurden nicht einfach Kunstwerke aus verschiedenen Kulturen nebeneinander

\footnotetext{
${ }^{501}$ vgl. Joch, 2003, S. 7.
} 
ausgestellt, sondern beabsichtigt war auch ein Dialog zwischen Ost und West durch das Werk von fünf Künstlern aus verschiedenen Ländern (Algerien, Frankreich, USA, Irak, Südkorea).

Brāhīm T/w̄i, der Leiter der genannten Abteilung, führte folgendermaßen in die Ausstellung ein: Unter anderem seien die Schnittpunkte der Kulturen solche des Mediums und der Technik. Während der Westen die realistische Malerei entwickelt habe, sei der Beitrag des Ostens die Kalligraphie. Die in der Ausstellung vertretenen Künstler hätten, indem sie die europäische Maltradition und die arabische und ostasiatische Kalligraphie vermischt hätten, mehr als eine hybride Ästhetik erreicht. Jeder Künstler sei immer noch unverkennbar ein Vertreter seines eigenen Kulturkreises. Gerade weil sie in ihren jeweiligen Kulturen verhaftet seien, seien sie in der Lage, sich anderen Kulturen zu öffnen ${ }^{502}$.

Zweitens: Viele Künstler, die das Wort und den Buchstaben im Bild benutzten, waren religiöse Menschen. Auffällig ist, dass sich die Schrift in den Werken der stark religiös gestimmten Künstler durch bestimmte Eigenschaften auszeichnet, die nicht bei anderen Künstlern erscheinen. Bei Mark Tobey und Hasan as-Sa ${ }^{c} \overline{1} d$ schlägt sich ihre nach innen gekehrte Religiosität in leeren Räumen in ihren Bildern nieder. Dennoch hatten sie einen unterschiedlichen religiösen Hintergrund: Tobey gehörte als Bahā̄̄ einer Religionsgemeinschaft an, die sich zu seiner Zeit noch in der Formationsphase befand und, zumindest bei ihren westlichen Anhängern, eher durch ihre sozialreformerischen Bemühungen als durch ihre Lehre Anklang fand. As-Sa ${ }^{\top} \overline{1} d$ dagegen stand in einer jahrhundertealten Tradition des Sufismus. Die geistige Nähe zwischen Tobey und as$\mathrm{Sa}^{\top} \overline{1} \mathrm{~d}$ lässt sich anhand der Methode und Art des Betrachtens erkennen. Ist es schwierig, bei Tobey eine Form von religiöser Orthodoxie festzustellen, gibt es bei as-Sa ${ }^{\overline{1}} \overline{1} d$ immerhin den Hinweis, dass er seit den sechziger Jahren bis zu seinem Tod 2004 auf die Darstellung von Menschen verzichtete, womit er sich der Bildlosigkeit der traditionellen islamischen Kunst einfügte.

Eine andere Formensprache finden wir bei Anselm Kiefer. Er spielt in seinen Werken immer wieder auf die traditionelle realistische europäische Malerei an. Wenn er sich mit religiösen Themen beschäftigt, so sind ihm diese durch den römisch-katholischen Bilderkanon vorgegeben. Die Schrift hat bei ihm eine dienende Funktion, sie hilft, das 
Bild zu deuten. Darin zeigt sich aber auch der Unterschied des modernen Europäers zu seinen mittelalterlichen Ahnen: Konnten diese ein Bild „lesen“, auch wenn sie Analphabeten waren, steht jener häufig Bildern mit ungewöhnlichen religiösen Themen ahnungslos gegenüber.

Zum Schluss scheint dem Forscher, dass die arabischen Länder, verglichen mit anderen Gegenden der Welt, Europa ziemlich nahe liegen. So sind diese dank ihrer Lage dazu fähig, die europäische Kultur zu rezipieren und zu assimilieren. Daher kann ein kultureller Dialog entstehen, der ein größeres Interesse an der Erforschung der arabischen bildenden Kunst hervorruft und die Ergebnisse dieser Forschungen in der westlichen Welt verbreitet. Im Rahmen dieses Kulturdialogs sollte man den arabischen Künstler optimale Gelegenheiten bieten, Ausstellungen für ihre Werke zu organisieren, ihnen also auch genügend Räume für ihre Werke in den Museen und Ausstellungshallen geben, damit der westliche Zuschauer die Kunst und Kultur dieser Völker kennen lernt, in einer Zeit, in der die aktuellen Ereignisse der Welt besonders nach dem 11. September 2001 ein nicht präzises Bild von diesem Gebiet assoziieren lassen. 


\section{Literaturverzeichnis}

\section{Lexika}

Brockhaus. Die Enzyklopädie, Leipzig/Mannheim 1996 ff., Bd. 19.

Lexikon der Kunst Bd. 4, Freiburg 1988.

Saur. Allgemeines Künstlerlexikon Bd. 25, München 2000.

The Oxford Companion to Twentieth Century Art, Oxford 1981.

The Oxford Dictionary of Art, 3. Aufl. Oxford 2004.

Theologische Realenzyklopädie (TRE) Bd. VI, Berlin 1980.

\section{Quellentexte}

\section{- Heilige Schriften}

Die Bibel nach der Übersetzung Martin Luthers. Bibeltext in der revidierten Fassung von 1984. Herausgegeben von der Evangelischen Kirche in Deutschland und vom Bund der Evangelischen Kirchen in der DDR, Stuttgart 1985.

Der Koran, übersetzt und eingeleitet von Hans Zirker. Darmstadt 2003

\section{- hellenistisches und rabbinisches Judentum}

Flavius Josephus: Jüdische Altertümer. Übersetzt und mit Einleitung und Anmerkungen versehen von Heinrich Clemntz, Halle o. J.

Flavius Josephus: Gegen Apion, in: Des Flavius Josephus kleinere Schriften. Übersetzt und mit Anmerkungen versehen von Heinrich Clementz, Köln 1960.

Der Babylonische Talmud neu übertragen durch Lazarus Goldschmidt, Berlin 1929-1936. 


\section{- Frühchristentum und katholische Kirche}

Denzinger, Heinrich: Kompendium der Glaubensbekenntnisse und kirchlichen Lehrentscheidungen. Verbessert, erweitert, ins Deutsche übertragen und unter Mitarbeit von Helmut Hoping herausgegeben von Peter Hünermann, 39. Aufl. Freiburg, 1991.

Leitl, J. u. di Pauli, Andreas Freiherr von (Hrsg.): Theophilus von Antiochia. Frühchristliche Apologeten und Märtyrerakten Bd. II, Bibliothek der Kirchenväter Bd. 14, München 1913.

Migne, Jaques-Paul: Patrologiae cursus completus. Series latina Bd. 84, Paris 1862.

Rauschen, Gerhard (Hrsg.): Die Werke Justin des Märtyrers. Frühchristliche Apologeten und Märtyrerakten Bd. I, Bibliothek der Kirchenväter Bd. 12, München 1913.

\section{- Reformation}

Die Bekenntnisschriften der evangelisch-lutherischen Kirche, 5. Aufl. Göttingen 1982.

Egli, Emil (Hrsg.): Huldreich Zwingli. Sämtliche Werke Bd. 2, Berlin 1905.

Egli (Hrsg.): Huldreich Zwingli. Sämtliche Werke Bd. 3, Berlin 1914.

Luther, Martin: Luthers Werke in kritischer Gesamtausgabe (WA) Bd. 56, Weimar 1938.

Luther: WA Bd. 10, Abt. III, Weimar 1905.

Luther: WA Bd. 18, Weimar 1908.

\section{- Islām}

Ibn-Ḥağar al- ‘Asqalānī : Fatḥ al-bārī bi-šarḥ Șaḥị̣ al-Buhārī 9, Kairo 1987. 
Ibn-Ḥanbal Aḥmad: Musnad al-Imām Aḥmad Ibn-Ḥanbal : wa-bi-'l-hāmiš muntaḩab kanz al-`ummāl fĩ sunan al-aqwāl wa-l-af'āl, al-muğallad. 5, Kairo 1978.

\section{Monographien}

Abbot, Nabia: The rise of the North Arabic script and its Kur'anic development with a full description of the Kur'an Manuscripts in the Oriental Institute, Chicago 1938.

Agustí, Anna (Hrsg.): Tapies: the Complete Works Volume 2: 1961-1968, Barcelona 1990.

Al-Hูāzin, Wahīb: min as-Sāmīyyīn al-carab, Beirut 1962.

Al-Kurdī, Ṭahir Muhammad: Tārīh al-ḩatṭ al-`arabī wa-adābuhu, 2. Aufl. Riyad 1982.

Al-Sa‘̄ī Šākir Hasan: Hiwār al-fann at-taškīlī, Amman 1995, S. 127.

As-Sa'̄id, Šākir Ḥasan: Fuṣūl min tārīh al-ḥaraka at-taškīlīyya fì-l-irāq, Bd. 1, Bagdad 1983, S. 163.

Al-‘Afīfi, Fawzī Sālim: naš’at wa tatawwur al-kitāba al-hațīyya al-`arabiyya, Kuwait 1980.

Al-'Azzāwī: Introduction to the Exhibition of the New Vision Group, Bagdad.1970.

Al-‘Azzāwī: The body’s anthem, Beirut 1980.

An-Naqšabandī, Nāṣir As-Sayyid Maḥmūd: manšāà' al-ḩaț al-'arabī wa-taṭawwuruhu ḥattā 'ahd al-hulafā' ar-rāšidīn, die Zeitschrift Somer, Band III, Teil I, Bagdad,1947.

Aṣ-Ṣaīyg , Samīr: Al-Fann al-islāmī: qirā’a ta'ammuliyya fī-l-falsafa wa-l-huș̣ūṣīyya al-ğamālīyya, Beirut 1988.

Arnason, H. H.: History of Modern Art: Painting, Sculpture, Architecture, Photography. 3. Aufl. New York 1986.

Bahnasī, ‘Afîfĩ: al-fann wa-l-qawmīyya, Das Kultusministerium, Damaskus, 1963.

Bahnasī, 'Afífi: Ğamālīyyāt al-fann al-'arabī, ‘ālam al-ma'rafa, Kuwait, 1979. 
Bahnasī, 'Afífĩ: Šamāl wa- ğanūb, Ḥiwār al-fann al-islāmī, Arabische Emirate, aš-Šāriqa 2001.

Benveniste, Émile : Probleme der allgemeinen Sprachwissenschaft, München 1974.

Bleicher, Joan (Hrsg.): F. T. Marinetti, Futuristische Dichtungen (1912), übersetzt von Else Hadwiger, Siegen 1985.

Brasch, Kurt: Zenga (Zen-Malerei), Tokyo 1961.

Breasted, James Henry.: The conquest of civilization, New York 1926.

Burckhardt, Titus: Art of Islam, London 1976.

Claus, Jürgen: Theorien zeitgenössischer Malerei in Selbstzeugnissen, Reinbeck 1963.

Dāgigir, Širbil: al-Ḥurūfiyya al-'arabīya , al-fann wa al-huwiyya, Beirut, 1990.

Diringer, David: The Alphabet, $3^{\text {rd }}$ revised edition, Bd. 2, London 1968.

Driver, Godfrey: Semitic Writing, Oxford 1948.

Ğum‘a, Ibrāhīm: Qiṣṣat al-kitāba al-‘arabīya, Kairo 1979.

Frémon, Jean: Degottex, Paris 1986.

Gaur, Albertine: A history of writing, London 1984.

Gese, Hartmut: Die Religionen Altsyriens, Altarabiens und der Mandäer, Stuttgart 1970.

Gohlke, Paul (Hrsg.): Die Lehrschriften des Aristoteles Bd. 2, Paderborn 1951.

Grabar, Oleg: The formation of Islamic art, New Haven 1987.

Grabar: The mediation of ornament, Princeton 1992.

Gray, Nicolette: A history of lettering, Oxford 1986.

Grohmann, Adolf: Arabische Paläographie, Wien 1971.

Guercio, Gabriele (Hrsg.): Joseph Kosuth. Collected writings 1966-1990, London 1991. 
Heussi, Karl: Kompendium der Kirchengeschichte, 5. Aufl. Tübingen 1922.

Hofmann, Murad: Der Islam als Alternative, München 1992.

Ḥaṭūm, Nūr ad-Dīn: Qaṣr ğabal sīs al-ummawī, Damaskus 1963.

Ḥasan, Zakī Muḥammad : funūn al-islām, Kairo 1944.

Immerwahr, Henry R.: Attic script. A survey, Oxford 1999.

Ipsiroglu: M.S: Masterpieces from the Topkapi museum, painting and miniatures, London 1980.

Jensen, Hans: Signs, symbols and script, London 1970.

Kāmil, 'Adil: al-Fann at-taškīlī al-mu'āṣir fì-1-'Irāq: marḥalat as-sittīnāt, Bagdad 1986.

Kandinsky, Wassily: Concerning the Spiritual in Art, übers. M. T. H. Sadler, New York 1977.

Khatibi, Adelkebir u. Sijelmassi, Mohammed.: The splendour of Islamic calligrapy, London 1976.

Khatibi/ Sijelmassi: Die Kunst der islamischen Kalligrafie, Köln 1995.

Linsmann, Maria: Schriftähnliche Zeichen und Strukturen in der Kunst des 20. Jahrhunderts, Bonn 1991.

Littmann, Enno: Arabic inscriptions, Leiden 1949.

Mattison, Robert Saltonstall: Robert Motherwell: The Formative Years, Ann Arbor 1986.

Morgan, Robert C.: Art into Ideas: Essays on Conceptual Art, London 1996.

Muğāhid, Ḥamīd: al-Abğadīyya al-hīrūgilīfiyya aṣl abğadīyyāt al-cālam, Vereinigte Arabische Emirate, 2000.

Müller-Yao, Marguerite Hui: Der Einfluss der Kunst der chinesischen Kalligraphie auf die westliche informelle Malerei, Bonn 1985.

Șafwān, Muștafā: al-Kitāba wa-as-sulța, Kairo 2002. 
Safwat, Nabil F.: The Art of the Pen, Calligraphy of the $14^{\text {th }}$ to $20^{\text {th }}$ Centuries, London 1996.

Nāmī, Halīl Yahyā: Aṣl al-ḩaț̣ al-'arabī wa-tārīh tațauwwurihi ila mā qabla al-islām, Kairo, 1935.

Papadopulo, Alexandre: Islam and Muslim art, New York 1979.

Rathbone, Eliza E.: Mark Tobey. City Painting, Washington D.C. 1984.

Reichling, Susanne: Jean-Michel Basquiat, Hamburg, 1998.

Robins, R. H.: A Short History of Linguistics, London/New York 1990.

Rosenthal, Mark: Anselm Kiefer, München u. New York 1987.

Roussillon, Alain \& Christine: 'Abdal Hadi Al-Gazzar, The best avilable monography of the outstanding Egyptian pioneer artist Abel Hadi Al-Gazzar. With texts in Arabic, English and French; Cairo, 1990

Sampson, Geoffrey: Writing Systems, A linguistic introduction, Stanford 1985.

Schimmel, Annemarie: Calligraphy and Islamic culture, London 1990.

Šīštīr, ‘Abdil-Muḥsin: al-Wazịifa az-zuhrufīyya lī- 1-ḥarf al-'arabī, Kairo 2000.

Selz, Peter: Art in our times. A pictural history 1890-1980, London 1982.

Selzer, Dominique Saskia Ariane: Lesbare Schriftzeichen in der Malerei des 20 Jahrhunderts, Heidelberg, 2001.

Stangos, Nikos: Concepts of modern art, London 1983.

Terenzino, Stephanie (Hrsg.): The collected writings of Robert Motherwell, New York 1992.

Thesing, Dagmar: Mohammed Taha Hussein: ein künstlerischer Dialog zwischen Orient und Okzident, Hamburg 2003.

Walker, John A.: Art since Pop, London 1975.

Welfenson, Isrā̄īl: tārīh al-lugàat as-sāmīya, Kairo 1929. 
Wheeler, Daniel: Art since Mid-Century. 1945 To the Present, New York 1991.

Wye, Deborah: Antoni Tàpies in Print, New York 1991.

'Alī, Ğawād: Tārīh al-'arab qabla al-islām, Bagdad 1957.

'Alī, Wijdan: Contemporary art from the Islamic world, Amman und London, 1989.

'Alī, Wijdan: Contemporary Art from the Islamic World, London 1989.

'Alī, Wijdan: Modern Islamic art, development and continuity, Gainesville, 1997.

Yūsuf, Aḥmad: al-ḩaṭt al-kūfī, Kairo 1934.

Yūsuf, Fārūq: Aqnicāt ar-rasm, Amman 1996.

Zakarīyā, Ibrāhīm: Falsafat al-fann fī-l-fikr al-mu'āṣir, dār miṣr li-’t-ṭibāca, Kairo.1987.

Zbikowski, Dörte: Geheimnisvolle Zeichen : fremde Schriften in der Malerei des 20. Jahrhunderts ; Paul Gauguin, Wassily Kandinsky, Paul Klee, Willi Baumeister, Julius Bissier, Joaquín Torres-García, Adolph Gottlieb, Mark Tobey, Göttingen 1996.

Zuraiq, Ma'rūf: Kaifa nata'allam al-ḩatṭ al-`arabī, Damaskus 1999.

\section{Sammelwerke und Kataloge}

as-Sa'̄ìd (Hrsg.): al-bayānāt al-fannīya fī-l-` Irāq, Bagdad 1973.

Bärmann, Matthias (Hrsg.): Mark Tobey. Between worlds. Werke 1935-1975, Mendrisio und Essen 1989.

Barnes, Rachel (Hrsg.): The 20 ${ }^{\text {th }}$ Century Art Book, Hong Kong 1996.

Buhlmann, Britta E. (Hrsg.): Malerei des amerikanischen abstrakten Expressionismus, Kaiserslautern, 1998.

Dahl, Arthur L. (Hrsg.): Mark Tobey : art and belief, Oxford 1984.

Galfetti, Mariucca (Hrsg.): Tàpies. Das graphische Werk, Bd. 1, Sankt Gallen 1975, 
Germain, Marie-Claude (Hrsg.) : Dia azzawi. Exposition organisée par l'Institut du monde arabe avec la collaboration du Arab Museum of Modern Art, Doha, Qatar, du 30 octobre 2001 au 13 janvier 2002.

Joachimides, Christos M. (Hrsg.): American Art in the $20^{\text {th }}$ Century, Painting and Sculpture 1913-1993, München, 1993.

Joch, Peter (Hrsg.): Broken Letters. Zeitgenössische Kunst aus arabischen Ländern, Darmstadt 2003

Kirchner, Thomas (Hrsg.): a.r. penck, München 1988.

Mahlow, Dietrich (Hrsg.): Schrift und Bild. Katalogbuch zur Ausstellung Schrift und Bild, Baden Baden 1963, Frankfurt am Main, 1963.

Métalsi, Moḥammed (Hrsg.) : Croisement de Signes, Paris 1989.

Nashashibi, Salwa Mikdadi (Hrsg.): Rhythm and form, visual reflection on Arabic poetry, ohne Ort, 1997.

Parent, Béatrice (Hrsg.): La peinture apres l'abstraction, Paris 1999.

Tuchman, Maurice (Hrsg.): New York School. The first generation. Paintings of the 1940s and 1950s, Los Angeles 1965.

Zweite, Armin (Hrsg.): Paul Klee, Das Frühwerk 1883-1922, 12 Dezember 1979- 2. März 1980, Städtische Galerie im Lenbachhaus, München, 1979.

\section{Zeitungen und Zeitschriften}

Acta Apostolicae Sedis Bd. 56, Rom 1964.

Al-Mutaqqaf al-'arabī Nr. 4, Bagdad 1971.

Al-Qūds al-'arabī, Jahrgang 13 - Nr. 3876, London 29. 10. 2001.

al-waḥda, Nr. 70 u. 71, Paris 1990. 
Arab perspectives, No. 4, London 1984.

blätter + bilder. Zeitschrift für Musik, Dichtung und Malerei, Nr. 14, Würzburg 1961.

Fikrun wa Fann Nr. 43, Bonn 1986.

Funūn `arabīya Nr. 1, London 1981.

Funūn ‘arabīya Nr. 4, London 1981.

Gilgamesh, a journal of modern Iraqi arts Nr. 4, Bagdad 1988.

Life vol. 5, Nr. 228, September 1953.

Mawāqif Nr. 67, London 1992.

Mawāqif Nr. 72, London 1992.

Mağallat al-adab al-ağnabīyya, Nr.115, Damaskus 2003.

Newsweek, 29. 7. 1974.

Al-Mağalla (Baghdad), no. 16 (June 1980).

Al-ğarīda at-tūnusiyya, Tunis 17.11.1997.

Al-Ḥayāt Nr. 10890 (3. 12.), London 1992.

\section{$\underline{\text { Internetseiten }}$}

Al-Qawāry, Sucād: al-qaṣīda ağ-ğadīda. aw aṭṭ̣āîr al-mutamarīd, in: http://www.ofouq.com.

Al-Sibāī̄, Hoālid: al-Ḥurūfiyya wa-l- huwiyya, http://www.altshkeely.com/2003/calligraphy2003/hrofia.html 
http://www.beyars.com/kunstlexikon/lexikon_8863.html

http://www.borghi.org/european/jean.html

http://www.iraqiartist.com/Archive/ Shakir_Hassan/Shakir_Hassan_ALSa id.htm

http://www.kirjasto.sci.fi/hmichaux.htm.

http://www.littlebluelight.com/lblphp/intro.php?ikey=19.

http://www.metmuseum.org/toah/hd/trmd/hd_trmd.htm

Wilson-Goldie, Kaelen: Paying tribute to an Iraqi master before his legacy disappears. http://www.dailystar.com.lb/article.asp?edition_id=10\&categ_id=4\&article_id= 13579.

Kaelen Wilson-Goldie:

http://peacecorpsonline.org/messages/messages/2629/2030285.html

$\underline{\text { Varia }}$

as-Sa'īd: The environment in Iraqi art. Ungedrucktes Manuskript.

Descendre, Nadine (Regie): Baghdad Memory: Ḍiyā' al-'Azzāwī, artist. Video, 49 Minuten, Paris ohne Jahr.

'Abdul-Ḥamīd-Shoman-Stiftung, Dar al-Funūn, Amman (Hrsg.): Interview mit Rašīd Qorā̄šy, Amman, 3. Dezember 1998 (Video). 


\section{Abbildungsverzeichnis}

Abb. 1: Initiale: links Initialenseite „Initiu(m) Evangelii, Beginn des Markusevangeliums; irische Handschrift um 750; rechts Initiale T aus dem „Canon Missae“, 1458 von Johann Fust und Peter Schöffer in drei Farben gedruckt, in: Brockhaus, Bd. 10, S. 540.

Abb. 2: Rheinischer Meister um 1330, Altenberger Altar, linker Flügel, obere Hälfte, in: Brinkmann, Bodo und Kemperdick, Stephan, Deutsche Gemälde im Städel 1300-1500, Mainz 2002, S.

Abb. 3: Stéphane Mallarmé, Le Hasard, 1897, ohne Maßangabe, in: Mahlow, Dietrich (Hrsg.): Schrift und Bild. Katalogbuch zur Ausstellung Schrift und Bild, Baden Baden 1963, Frankfurt am Main, 1963 S. XVII

Abb. 4: Georges Braque, Le Portugais, 1911, Öl auf Leinwand, 117 x 81cm, Kunstmuseum Basel.

Abb. 5: Paul Klee, Der Bayrische Don Giovanni, 1919/116, Aquarell auf Zeichenpapier 27 x 22,5 cm R. Guggenheim Museum. New York, in: Paul Klee, Das Frühwerk 1883-1922, 12 Dezember 1979- 2. März 1980, Städtische Galerie im Lenbachhaus, München.

Abb. 6: Rauch- und Sprechverbotszeichen in Lourdes, http://de.wikipedia.org/wiki/Piktogramm

Abb. 7: Bild:Gefahrensymbol T.png, http://de.wikipedia.org/wiki/Bild:Gefahrensymbol_T.png

Abb. 8: Der Rosetta-Stein. British Museum, London; Department of Ancient Egypt and Sudan, in: Gaur, 1988, S. 137.

Abb. 9: Moderne chinesische Schriftzeichen, in: Diringer, David: The Alphabet. A Key to the History of Mankind Vol. 2, 3rd revised edition, London 1968, S. 93. 
Abb. 9 a: Japanische Silbenzeichen, in: Diringer, 1968, S. 129.

Abb. 10: Vergleich von phönizischer und griechischer Schrift, Gaur, 1984, S.262.

Abb. 11: Frühitalische Schriften, Gaur, 1984, S. 298.

Abb. 12: Details der Moutier-Grandval -Bibel (Ex 1,1-2,16), geschrieben in Tours 83443. Überschrift in Kapitalien, Vers 1 in Unziale, Rest in karolingischen Minuskeln. British Library, London; Abteilung für Manuskripte; 10546, f.26, in: Gaur, 1984, S. 169.

Abb. 13: Evangelienlektionar (Lk 2,52-3,4) aus Dalmatien (Zadar), beneventanische Schrift, spätes 11. Jahrhundert. Bodleian Library, Oxford; Ms Canon Bibl Lat 61, f 7v, in: Gaur, 1984, S. 170.

Abb. 14: Sacramentum Gelasianum, merowingisch, 8. Jahrhundert. Bodleian Library, Oxford; Ms Douce f. 1, f I V, in: Gaur, 1984, S.171.

Abb. 15: Beda Venerabilis, Expositio in Lucam. Unter- und Überschrift in Rustica, erste Zeile in Unziale, Rest in karolingischen Minuskeln; Tours, um 820, mit späteren Hinzufügungen aus dem 10. Jahrhundert. Bodleian Library, Oxford; Ms Bodl. 218, f 62r, in: Gaur, 1984, S. 172.

Abb. 16: Stundenbuch des Herzogs von Bedford (Ps 80 LXX), gotisch, zwischen 1420-1422. British Library, London; Abteilung für Manuskripte; 4213 1, f 152, in: Gaur, 1984, S. 173.

Abb. 17: Episteln (2 Kor 11,21-12,3), Frankreich um I500; Text in Antiqua, Kommentar in Italic. Victoria and Albert Museum, London; K.R.P.C. 30, f 76v, in: Gaur, 1984, S. 174.

Abb. 18: Italic-Handschrift, datiert von 1517. Die Beispiele, die in den Büchern der Kalligraphen gegeben werden, sind durch Holzschnitte vervielfältigt, so dass Spontaneität verloren geht.

Abb. 19: Zabad-Inschrift in zwei Sprachen (Griechisch, Arabisch), 512 n. Chr., in: 
Khatibi, Adelkebir u. Sijelmasi, Moḥammed: Die Kunst der islamischen Kalligraphie, Köln 1995, S. 36.

Abb. 19 a: Ises-Inschrift In Arabische Sprache 528 n. Chr., in: Adolf Grohmann: Arabische Paläographie, Bd. II, Wien 1971, S. 16.

Abb. 19 b: Harran-Inschrift in drei Sprachen (Griechisch, Syrisch und Arabisch). Vermutlich 568 n. Chr., in: Grohmann, 1971, S. 17.

Abb. 19 c: Umm al-Ğimmal-Inschrift Zwischen 250 und 271 n. Chr., in: Grohmann, 1971, S. 16.

Abb. 20: Koran (Sura 46,20 f.) geschrieben in kufischer Schrift; vermutlich aus Nordafrika; 9./10. Jahrhundert. British Library, London; Abteilung für orientalische Handschriften und Drucke; Or. 1397, f 13r, in: Gaur, 1984, S. 98.

Abb. 21: Das Maßsystem von Ibn Muqlah, in: Al-Kurdī, Ṭahir Muḥammad: Tārīhn alhatṭ al-'arabī wa-adābuhu, 2. Aufl. Riyad 1982, S. 65

Abb. 22: Proben von kursiven Arten der arabischen Kalligraphie. Von oben nach unten: Nash̄ī, Tulut, Muḥaqqiq, Nasta'liq und Riq'a, in: Al-Kurdī, 1982, S. 80.

Abb. 23: Die Dīwānī-Schrift (oben) und das sog. königliche Dīwānī (unten), in: AlKurdy, 1982, S. 80.

Abb. 24: Ṭugrā̄' von Sultan 'Abdul-Hamīd II (1876-1909), in: Khatibi/Sijelmasi, 1995, S. $76 \mathrm{f}$.

Abb. 25: Adolph Gottlieb, Man looking at Woman, 1949, Öl auf Leinwand, ohne Maßangabe, The Museum of Modern Art-MoMA, New York.

Abb. 26: Adolph Gottlieb, Monolith Female, 1956, in: Schauer, Lucie (Hrsg.): Elementarzeichen, Berlin 1985, S. 81.

Abb. 27: Adolph Gottlieb, Sign, 1952, Öl auf Leinwand ; 228,5 x 213,5 cm; David Mirvish Gallery, Toronto, Ontario, Kanada, in: Zbikowski, 1996, S. 365. 
Abb. 28: Japanische Silbenschrift Hiragana; Zusammenstellung einiger Schriftzeichen, in: Zbikowski, 1996, S. 365.

Abb. 29: Adolph Gottlieb, Dialogue Number 1, 1960, Öl auf Leinwand, 167,6 x 335 cm; Albright - Knox Art Gallery, Buffalo, New York.

Abb. 30: Robert Motherwell, Je t'aime II, 1955, Öl auf Leinwand., ohne Maßangabe, in: Terenzino, Stephanie (Hrsg.): The collected writings of Robert Motherwell, New York 1992, Farbtafeln S.194 ff.

Abb. 31: Robert Motherwell, Hollow Men Suite Nr. 2, 1985/86, etching and aquatint, 11,25 x 13 Zoll, in: Terenzino, 1992, Farbtafeln S.194 ff..

Abb. 32: Robert Motherwell, Telemachia - Odyssey - Nostos, ohne Maßangabe, in: Terenzino, 1992, Farbtafeln S.194 ff.

Abb. 33: Pierre Alechinsky, Variationen zu Sengais Symbolen des Universums, 1960, Lithographie und Tusche auf Papier, 55 x 76 cm; Galerie van der Loo, München, in: Müller-Yao, 1985, S. 10, Abb 13.

Abb. 34 Gibon Sengai, Symbole des Universums, Edo-Zeit, 1603-1867, Tusche auf Papier, 57 x 109 cm, Idemitsu-Museum, Toki,. in: Müller-Yao, 1985, S. 10, Abb.14.

Abb. 35: Andrè Masson, „Multiplikation“, 1943, Tuschezeichnung in: Müller-Yao, 1985, S. 62, Abb. 65.1

Abb. 36 André Masson, Wirbel, 1956, Farblithographie, 66 x 50,5 cm, Galerie Louise Leiris, Paris, in: Müller-Yao, 1985, S. 87, Abb.92.

Abb. 37: Ausschnitt aus der Autobiographie des Huai Ssu (725 n. Chr.), in: MüllerYao, 1985, S. 63, Abb.66.

Abb. 38: Ausschnitt aus der Autobiographie des Huasi Ssu, National Palace Museum Taipei, in: Müller-Yao, 1985, S. 87, Abb.90. 
Abb. 39: Julius Bissier, Tuschekomposition, 1955, ohne Maßangabe, in: Mahlow, 1963, S.154.

Abb. 40 Henri Michaux, dessin a la sepia, 1962, ohne Maßangabe, Galerie Cordier, Paris, in: Mahlow, 1963, S. 32.

Abb. 41: Mark Tobey, China, 1934, ohne Maßangabe, Privatbesitz, in: Rathbone, Eliza E.: Mark Tobey. City Painting, Washington D.C. 1984, S. 24.

Abb.42: Mark Tobey, Shop Front, Hong Kong, 1934, ohne Maßangabe, Dr. Solomon Katz, White Gallery, Seattle, in: Rathbone, 1984, S. 24.

Abb. 43: Mark Tobey, Broadway Norm, 1935, ohne Maßangabe, Sammlung Carol Ely Harper, in: Rathbone, 1984, S. 27.

Abb. 44: Mark Tobey, Edge of August, 1953, Tempera, 48 x $28 \mathrm{~cm}$, the Museum of Modern Art, New York, in: Dahl, Arthur L. (Hrsg.):Mark Tobey: art and belief, Oxford 1984, S. 23.

Abb. 45: Mark Tobey, Sumi Still life, 1957, ohne Maßangabe, in: Mahlow. 1963, S. 143.

Abb. 46: Mark Tobey, Trio, 1970, Aquatinta, 31,5 x 24 cm, Editions der Beauclair, Frankfurt, in: Müller-Yao, 1985, S. 122, Abb. 130.

Abb. 47: Jean Degottex, Hagakure BIII, 1957, Öl auf Leinwand, 106 x 240 cm, ehem. Besitz des Künstlers, in: Parent, 1999, S. 70.

Abb. 48: Jean Degottex, Sho do (1) 7-1960, Öl auf Leinwand, 106 x 80 cm, im Besitz des Künstlers, in: Frémon Jean: Degottex, Paris, 1986, S. 104.

Abb. 49: Jean Degottex, Suite Serto 19-3-1957, Chinesische Tinte auf Papier, 65 x 60 cm, Privatbesitz, in: Frémon, 1986, S. 172.

Abb. 50 : Jean Degottex, Suite Écriture (x) 12-1962, Öl auf Leinwand, 120 x 80 cm, Privatbesitz, in: Frémon, 1986, S. 127. 
Abb. 51: Antoni Tàpies, Kreuz auf Zeitungspapier, 1945/46, Collage und Wasserfarben auf Papier, 40 x $31 \mathrm{~cm}$, Privatbesitz, in: Agustì, Anna: Tàpies: the complete work, Bd.1, 1943-1960, Barcelona 1983, S. 80.

Abb. 52: Antoni Tàpies, Cruz y tierra, 1975, 162 x 162 cm, Mischtechnik, im Besitz des Künstlers, in: http://cv.uoc.es/ 991_04_005_01_web/fitxer/perc128.html

Abb. 53: Antoni Tàpies, Berlin-Suite, Tafel 7, 1974, Lithographie, 55,2 x 76,1 cm, Galfetti Nr. 482, Schleswig-Holsteinisches Landesmuseum Schloß Gottorf, Schleswig, in: Museum Moderner Kunst - Stiftung Wörlen, Passau (Hrsg.): Antoni Tàpies. Radierungen, Lithographien und vier Einzelwerke aus der Sammlung Großhaus, Passau 2002.

Abb. 54: Antoni Tàpies, Ohne Titel, Suite Catalana, Tafel 1, 1972, Tiefdruck, 75,8 x 100,9 cm, David Anderson Gallery, Buffalo, in: Wye, 1991, S. 82.

Abb. 55: Jean-Michel Basquiat, Hollywood Africans, 1983, Acryl und Ölstift auf Leinwand, 213,4 x 213,4 cm, in: Reichling, Susanne: Jean-Michel Basquiat, Hamburg, 1998, Abb. 1.3.

Abb. 56: Mel Ramsden, 100\% abstract, 1968, ohne Maßangabe, Fotokopie, Lisson Gallery, London, in: Wheeler, Daniel: Art since Mid-Century 1945 to the Present, London 1991, S. 250.

Abb. 57: John Baldessari, I will not make anymore boring art, 1971, 22,75 x 29 Zoll, Lithographie, Museum of Modern Art, New York, in: Wheeler, 1991, S. 244

Abb. 58: Joseph Kosuth, Art as Idea as Idea 1966, ohne Maßangabe, montierte Fotokopie, Leo Castelli Gallery, New York, in: Wheeler, 1991, S. 247.

Abb. 59: Lawrence Weiner, With Relation to the Various Manners of Use for / of Various Things, ca. 1974, Leo Castelli Gallery, New York in: Wheeler, 1991, S. 249.

Abb. 60: Hans Haacke, A Real time Social System, 1970, Installation, in: Arnason, H. H.: A History of Modern Art, London 1977, S. 576 
Abb. 61: Hans Haacke, Voici Alcan, 1983, in: Morgan, Robert C.: Art into Ideas. Essays on Conceptual Art, Cambridge 1996, S. 122 f.

Abb. 62: Joseph Kosuth, Art as Idea as Idea, 1967, Schwarz-Weiß-Fotografie, in: Barnes, Rachel (Hrsg.): The 20 ${ }^{\text {th }}$ Century Art Book, Hong Kong, 1996, S. 251.

Abb. 63: Joseph Kosuth, Zero and Not (französische Version), 1986, Offsetdruck auf Papier, in: Wheeler, 1991, S. 248.

Abb. 64: Hanne Darboven, Ausschnitt von Ohne Titel, 1972/73, in: Stangos, Nikos: Concepts of Modern Art, London, 1983, S. 294.

Abb. 65: Hanne Darboven, und Gesamtansicht von Ohne Titel, 1972/73, in: Stangos, Nikos: Concepts of Modern Art, London, 1983, S. 294.

Abb. 66: Roman Opalka, Description of the World 1965/1 -..., Detail 1-35327, 1965; Ö1 auf Leinwand, Kunstmuseum Łodz, in: www.poland.gov.pl/ ?document=489.

Abb. 67: Anselm Kiefer, Märkische Heide,1974, 118 x 254 cm, Öl, Acryl, und Schellack auf Sackleinen, Van Abbe Museum, Eindhoven, in: Rosenthal, Mark: Anselm Kiefer, München u. New York 1987, S. 34.

Abb. 68: Anselm Kiefer, Die Ordnung der Engel, 1983-84, 330 x 555 cm, Öl, Acryl, Emulsion, Schellack und Stroh auf Leinwand mit Karton und Blei, with cardboard und lead, 330 x $555 \mathrm{~cm}$, The Art Institute of Chicago, in: Rosenthal, 1987, S. 126.

Abb. 69: A.R. Penck, Weltbild, 1961, Öl auf Hartfaser, 122 x 160 cm, Privatbesitz, in: Grisebach, Lucius (Hrsg.): a.r. penck, München 1988, S. 138.

Abb. 70: A.R. Penck, Standart-Endart, 1973, Dispersion auf Leinwand, 278,5 x 280,5 cm, Privatbesitz, Grisebach, 1988, S. 167.

Abb. 71: Madīha 'Umar, Ohne Titel, ohne Datum, Maßangaben nicht verfügbar, in: Dāgir, Ś̉irbil: al-Ḥurūfiyya al-'arabīya , al-fann wa al-huwiyya, Beirut, 1990, S. 158.

Abb. 72: Madīḥa 'Umar, At the Concert, 1948, Tinte auf weißem Kratzbrett, 23.75 x 
$32.5 \mathrm{~cm}$ in: http://www.metmuseum.org/toah/hd/trmd/hd_trmd.htm

Abb. 73: Ğamīl Ḥammūdī , An-nās sawāsīyā ka-'asnān al-mušț,1976, Öl auf Leinwand, 145 x $100 \mathrm{~cm}$, Jordanische Nationalgalerie, Amman, in: Ali, Wijdan: Modern Islamic Art, Gainesville, 1997, Farbtafeln S. 84 ff.

Abb. 74: Wağǐh Naḥla, Der Krieger, 1954, Tinte auf Papier, 35 x 25 cm, im Besitz des Künstlers, in: Ali, 1997, S. 154.

Abb. 75: Aḥmad Muḥammad Šibrīn , Ohne Titel, gefärbtes Mahagoniholz, Durchmesser 55 cm, Privatbesitz, Ali,1997, S. 156.

Abb. 76: Aḥmad Moḥammed Šibrīn , Kalligraphie, 1997, Öl auf Leinwand, 80 x 80 cm, in: http://www.shibrain.com/artists/shibrain/call1.htm

Abb.77: Aḥmad Muṣtafā, Still Life of Qur'anic Solids, 1987. Öl und Wasserfarbe auf Büttenpapier, 125 x 76 cm, im Besitz des Künstlers, in: Ali, 1997, S. Farbtafeln S. $84 \mathrm{ff}$.

Abb. 78: Šākir Ḥasan as-Sa`̄̄d, Objektive Betrachtungen, 1984, Öl auf Holz, 120 x 120 cm, Privatbesitz, in: Ali, 1997, S. 169 (schwarz-weiß-Abbildung). http://www.metmuseum.org/toah/hd/trmd/hd_trmd.htm

Abb. 79: Antoni Tàpies, Chiffres inversé, 1976, Farbdruck auf Vélin d'Arches -Papier, 63 x 90,5 cm, Galeria Maeght, Barcelona, in: http://scolarfineart.com/pages/single/10098.html

Abb. 80: 'Alī 'Umar Ermaș, Kaf, 1991, verschiedene Materialien auf Papier, 153 x 123 $\mathrm{cm}$, British Museum, London.

Abb. 81: 'Alī 'Umar Ermaș, 'Alif, bā', tā', 1990. Acryl und Tinte auf Papier, ca. 80 x 65 cm, im Besitz des Künstlers, in: http://www.aliomarermes.co.uk/gallery/view_series.cfm?series_id=1

Abb. 82: Wijdan 'Alī, Karbalā', 1992, verschiedene Materialien auf Büttenpapier, 62 x 98 cm, Privatsammlung, 'Alī, 1997, Farbtafeln S. 84 ff. 
Abb. 83: Mạ̣mūd Hammād, Arabische Schrift, 1970, Öl auf Leinwand, ohne Maßangaben, in: http://www.syriatourism.org.

Abb. 84: Mạ̣mūd Hammād, Kalligraphie, 1985, Öl auf Leinwand, 60 x 75 cm, Jordanische Nationalgalerie, Amman, in: 'Alī, 1997, Farbtafeln S. 84 ff.

Abb. 85: Nja Mahdaoui, Kalligraphische Komposition, undatiert, Seidendruck, 27 x 39 cm, Privatbesitz, in: 'Alī, 1997, Farbtafeln S. 84 ff.

Abb. 86: Ğumana al-Husaīn̄̄, Ohne Titel, 1991, Mischtechnik auf Leinwand, 77 x 57 cm, Metropolitan Museum, New York, in: http://www.metmuseum.org.

Abb. 87: Qoraīšy, Tell az-za'tar, 1979, Radierung, 48 x 35 cm, Jordanische Nationalgalerie, Amman.

Abb. 88: Ṭahā Ḥusaīn , bi-smi llāhi ar-raḥmāni ar-raḥimm in Fruchtbarkeit, 1983, Acryl auf Leinwand, 200 x 200 cm, Museum of Modern Egyptian Art, Kairo, in Thesing, Dagmar: Moḥammed Ṭahā Ḥusaīn : ein künstlerischer Dialog zwischen Orient und Okzident, Hamburg 2003, S. XXXIX.

Abb. 89: Munā $\mathrm{Sa}^{\top} \bar{u} d \overline{1}$, šağarat al-ḥubb (Baum der Liebe), 1977, Radierung, 73 x 39 cm, Jordanische Nationalgalerie, Amman, in: 'Alī, 1997, S. 176 (schwarz-weißAbbildung).

Abb. 90: Hamid Nadā, Masīrat at-ta'mīr (Prozess des Aufbauens), 1976, Acryl und Ölfarbe auf Karton, 100 x 70 cm, Museum of Modern Egyptian Art, in: 'Alī, Fatma: Hamid Nada, Kairo 1984, ohne Paginierung.

Abb. 91: Sāmīa Zaru, șīā̄ wa-nizāec (Kampf und Konflikt), 1985, Öl und Collage auf Leinwand, 40 x 35,75 cm, Jordanischen Nationalgalerie Amman.

Abb. 92: Mohammed 'Abdal Min'im Ibrāhīm, ya-ğārat al-wādī taribtu (Oh Nachbar des Tales, ich genieße), 1994, Mischtechnik auf Leinwand 210 x 154 cm, im Besitz des Künstlers.

Abb. 93: Diyā̄' al-‘Azzāwī, Arabian Motif, Acryl auf Holz, 198493 x 70 cm, im Besitz 
des Künstlers, in: Germain, Marie-Claude (Hrsg.): Dia Azzawi, Paris 2001, S. 44.

Abb. 94: Yūsuf Sīda, Held des arabischen Volkes, ohne Datum , Öl auf Leinwand, 132 x $86 \mathrm{~cm}$, Museum of Modern Egyptian Art.

Abb. 95: Sa id al-Saqqar, Aus einem Gedicht von Abū Șaḩr al-Hudalīi, ohne Datum Kalligraphie, Gold und Gouache auf Karton, 50 x 70 cm, Privatbesitz, in: State of Kuwait, National Council for Culture Arts and Letters (Hrsg.): Saggar. Arabic Calligraphy and Illumination, Kuwait 1985.

Abb. 96: Rašīd Qoraīšy, ilā Ummī, 1985, Lithographie, 32-1/2 x 24-3/4 Zoll, in: Nashashibi, Salwa Mikdadi, Rhythm and Form, 1997, ohne Ort, S. 51.

Abb. 97: Ethel Adnan: bahä’ al-hazīma, 1994, Wasserfarben und Tinte auf japanischem Papier, 6 1⁄4 x 69 1/5 Zoll (in geöffnetem Zustand), in: Nashashibi, 1997, S. 19.

Abb. 98: 'Abd al-Hādī al-Ğazzar ibn al-Kilāb, 1953, Tusche auf Papier, 30 x 48 cm, Museum of Modern Egyptian Art, Kairo.

Abb. 99: Rašād Salīm, as-samā' gāàima wa-rūḥ̄ muballala bi-l-maṭar (Der Himmel ist bewölkt, und meine Seele ist vom Regen naß), 1986, Tinte auf Papier, ohne Maßangabe, im Besitz des Künstlers.

Abb. 100: Yūsuf Aḥmad, Kalligraphische Komposition,1983, Siebdruck, 40 x 30 cm, Jordanischen Nationalgalerie, Amman.

Abb. 101: Ḥussayn al-Ǧībālī, simfūniyat al-ḩuṭūṭ (Symphonie der Linien), 1997, Holzschnitt, 80 x 69,5 cm, Museum of Modern Egyptian Art, Kairo.

Abb. 102: Kamal Boullata, ohne Titel, 1985, Siebdruck, ohne Maßangabe, in: Khatibi, Abdelkebir/ Sijelmassi, Mohamed: Die Kunst der islamischen Kalligrafie, Köln 1995, S. 232.

Abb. 103: Ḍiyā' al-'Azzāwī, Einleitung zu den sieben goldenen Oden, 1978, Siebdruck, 43-1/8 x 31-1/8 Zoll, im Besitz des Künstlers, in: Nashashibi, 1997, S. 29 
Abb. 104: Ḍiyā' al-'Azzāwī, Die sieben goldenen Oden, Mu'allaqa 'Antara b. Šaddad, 1978. Siebdruck, 90 x 64 cm, im Besitz des Künstlers, in: Germain, MarieClaude (Hrsg.): Dia Azzawi, Paris 2001, S. 44.

Abb. 105: Ḍiyā' al-'Azzāwī, Hymne des Körpers, Illustrationen zu drei Gedichten von Maḥmūd Darwīš , Taher Ben Jalloun und Yūsuf Aṣ-Ṣaīyg , 1979, Siebdruck, $65 \times 65 \mathrm{~cm}$, in: Germain, 2001, S. 45.

Abb. 106: Diyā’’ al-'Azzāwī, Illustration zu „Westwärts ... zum Ölberg“'von Yūsuf AÒÑaīyÈ , 1979, Siebdruck, 65 x 65 cm, in: Diyā’ al-‘Azzāwī: The Body’s Anthem. Illustrated Poems for Tel el-Zaatar. Poems by Mạ̣mūd Darweesh, Tahar Ben Jalloun, Yusef Aṣ-Ṣaīyğ, Beirut 1980.

Abb. 107: Ḍiyā' al-'Azzāwī, qabla an yantahīa al-ġinā', (Bevor das Lied verklingt) 1998/99, Gouache und Acryl auf Papier, 37,5 x 30,2 cm, Germain, 2001, S. 55.

Abb. 108: Ḍiyā’ al-`Azzāwī, al-Ǧawāhin̄-Verses, 1989, Lithographie auf Büttenpapier, 50 x 66 cm, in: Germain, 2001, S. 14.

Abb. 109: Dịā̄’ al-‘Azzāwī, Adonis: Ein Grab um New York willen, 1990, Farblithographie, 38 x $110 \mathrm{~cm}$, im Besitz des Künstlers.

Abb. 110: Diyā’’ al-‘Azzāwī, Mohammed al-Fayturī, 1989, Farblithographie, 50 x 66 cm, im Besitz des Künstlers.

Abb. 111: Rašīi Qoraīšy, umma fī 'l-manfā, Druck 4, 1985, Lithographie, 32,5 x 24, 75 Zoll, in: Khatibi, Abdelkebir (Hrsg.): Umma fī '1-manfā, Amman 1997, S. 302.

Abb. 112: Rašīd Qoraīšy, Umma fī 'l-manfā , Druck 6, 1985. Lithographie, 32- ō x 24Z Zoll, in: Khatibi, 1997, S. 303.

Abb. 113: Liliane Karnouk, Buch von Adonis, 1985, Mischtechnik, 226 x 38 Zoll, in: Nashashibi, 1997, S. 43.

Abb. 114: Ethel Adnan, Ein Lindenbaum, dann ein anderer, 1985, Originalbuch, Wasserfarben und Tinte auf japanischem Papier, 9-5/8 x 217 Zoll (in geöffnetem 
Zustand), in: Nashashibi, 1997, S. 35.

Abb. 115: Šākir Ḥasan as-Sạ̄îd, Eine Geschichte aus tausend und einer Nacht, 1962, Tinte auf Papier, ohne Maßangabe, in: Jabra, Ibrāhīm Jabra: Iraqi Art Today, Bagdad 1972, S. 184.

Abb. 116: Šākir Ḥasan as-Sac̄îd, ohne Titel, ohne Datum (sechziger Jahre), ohne Maßangabe, verschiedene Materialien auf Holz, in: Dāgir, 1990, S. 174.

Abb. 117: Šākir Haasan as-Sa`̄id, Ruhm für Mandily, 1983, Öl auf Holz. 200 x 180 cm, in: Dāgir, 1990, S. 173.

Abb. 118: Šākir Hasan as-Sa $1 \overline{1}$, Linien auf einer Wand. 1978. Öl auf Leinwand, $120 \mathrm{x}$ 120 cm, in: Finoon Arabiyah Nr. 7, London 1982, S. 74.

Abb. 119: Šākir Ḥasan as-Sa'̄id, erläuternde Konzeptskizze von al-Faw, 1997.Tinte auf Papier, im Besitz des Künstlers.

Abb. 120: Ḍiyā' al-'Azzāwī, Tragödie von Karbala', c.1964. Tinte auf Papier, ohne Maßangaben, im Besitz des Künstlers.

Abb. 121: Ḍiyā' al-'Azzāwī, Tausend und eine Nacht, 1986, Lithographie und Gravur, 65 x $50 \mathrm{~cm}$, Institut du monde arabe, Paris, in: Germain, 2001, S. 68.

Abb. 122: Ḍiyā' al-'Azzāwī, Homage to Baghdad, 1982, Siebdruck, 50x $50 \mathrm{~cm}$, Privatbesitz, in: Germain, 2001, S. 68.

Abb. 123: Ḍiyā' al-'Azzāwī, Internal Notes No. 3, 1978, Gouache auf Papier, 100x 70 cm, Privatbesitz, in: Germain, 2001, S. 59.

Abb. 124: Ḍiyā' al-'Azzāwī, 'Abdullah Leaving his city, no 2, 1983, Öl auf Leinwand, 102 x 70 cm, Privatbesitz, in: Germain, 2001, S. 63. 
Abbildungen 

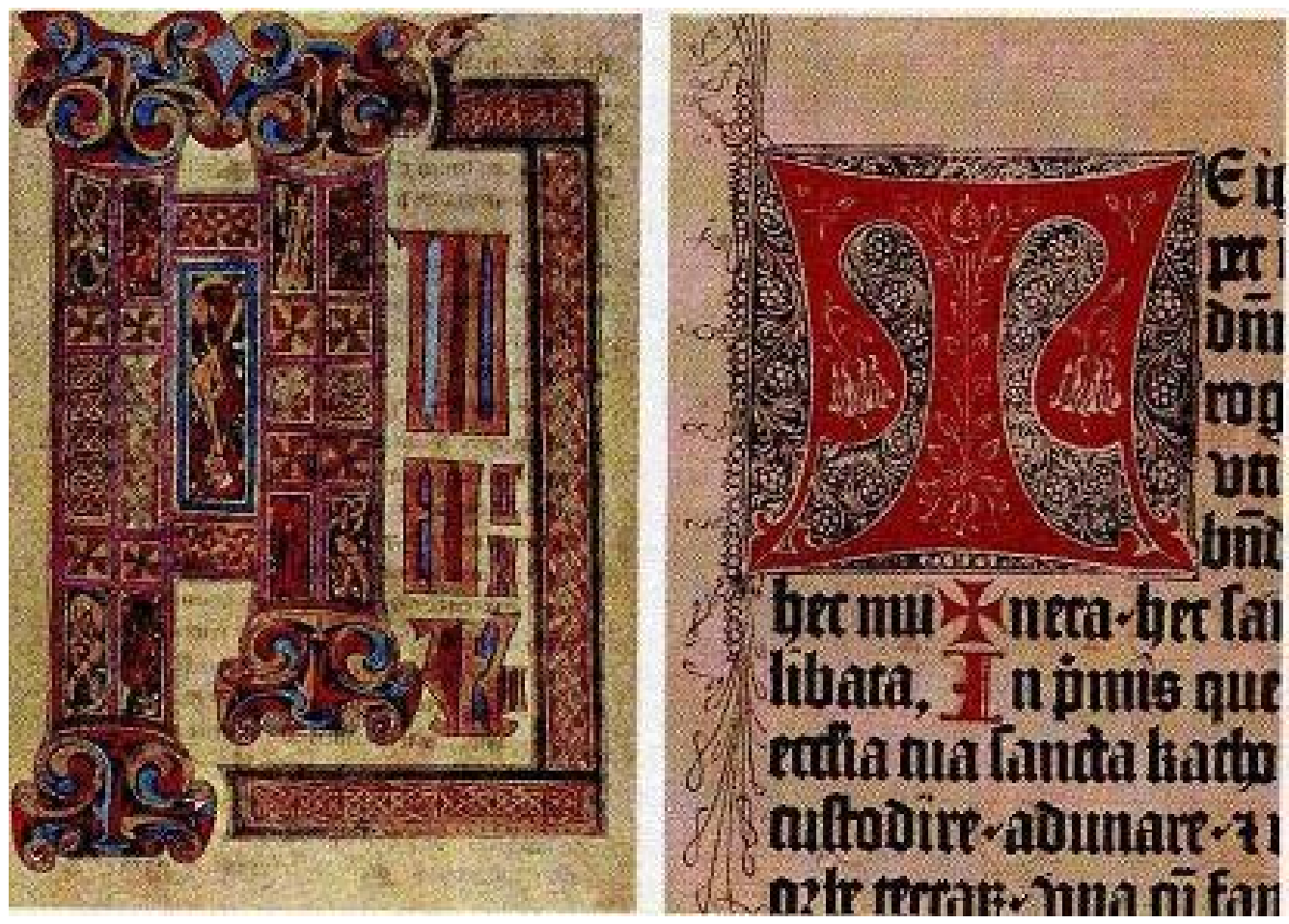

Abb. 1

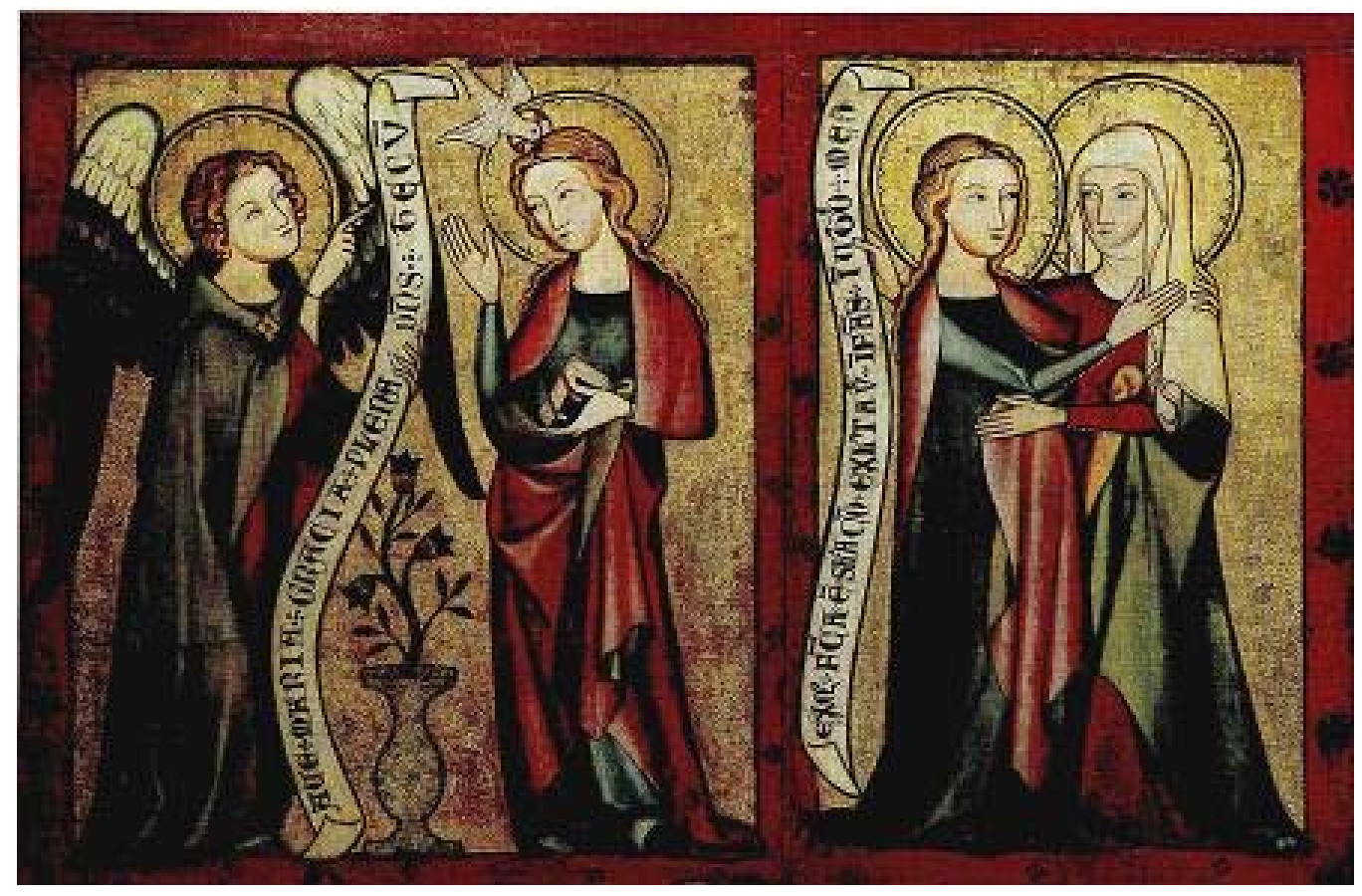

Abb. 2 


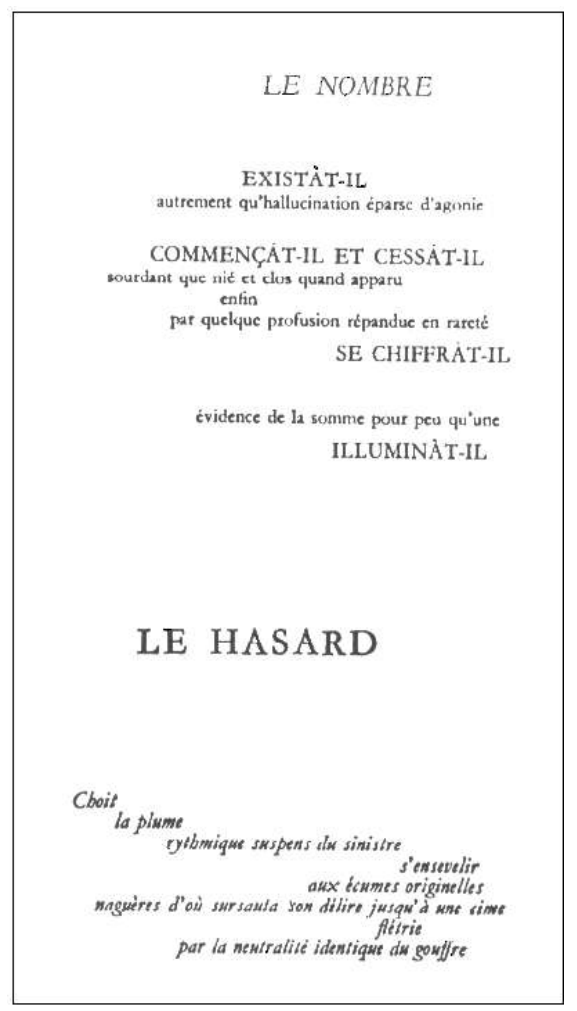

Abb. 3

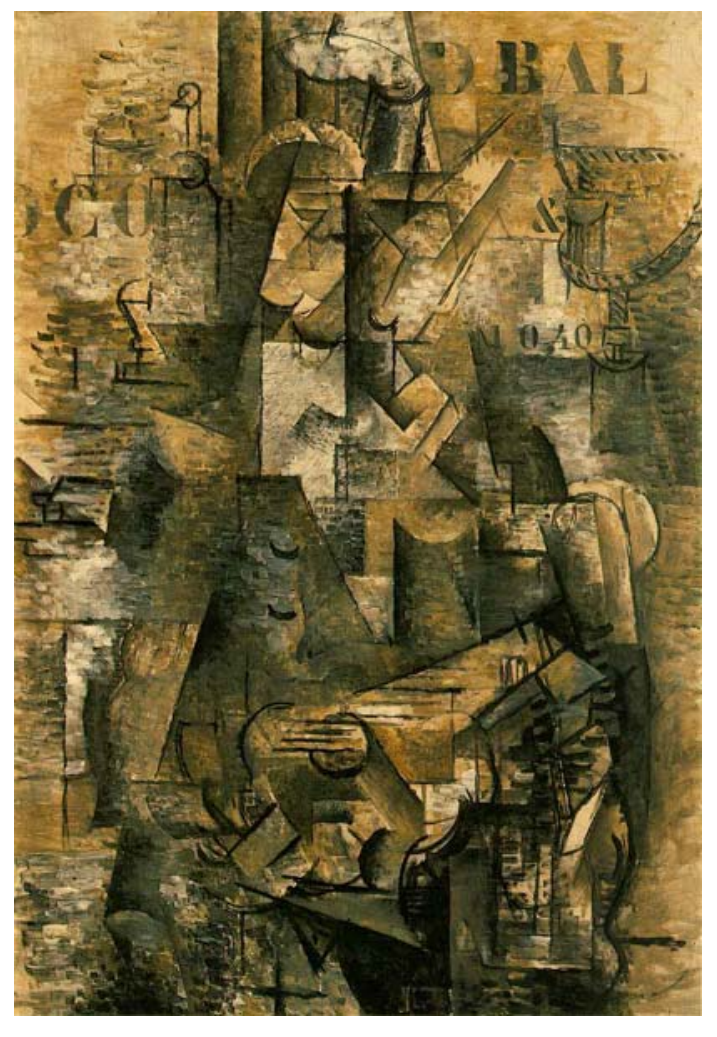

Abb. 4 


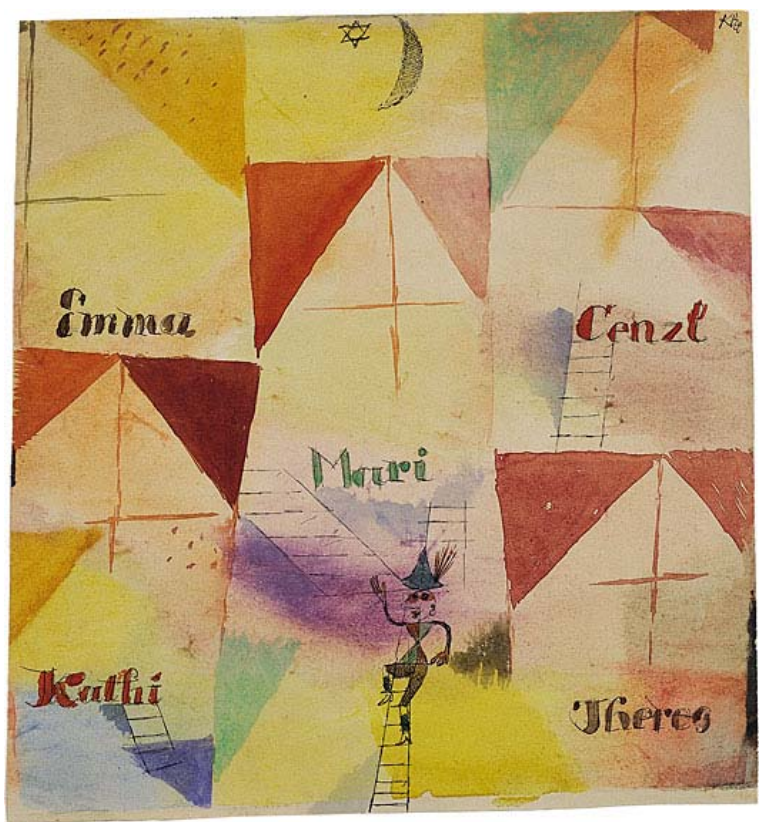

Abb. 5

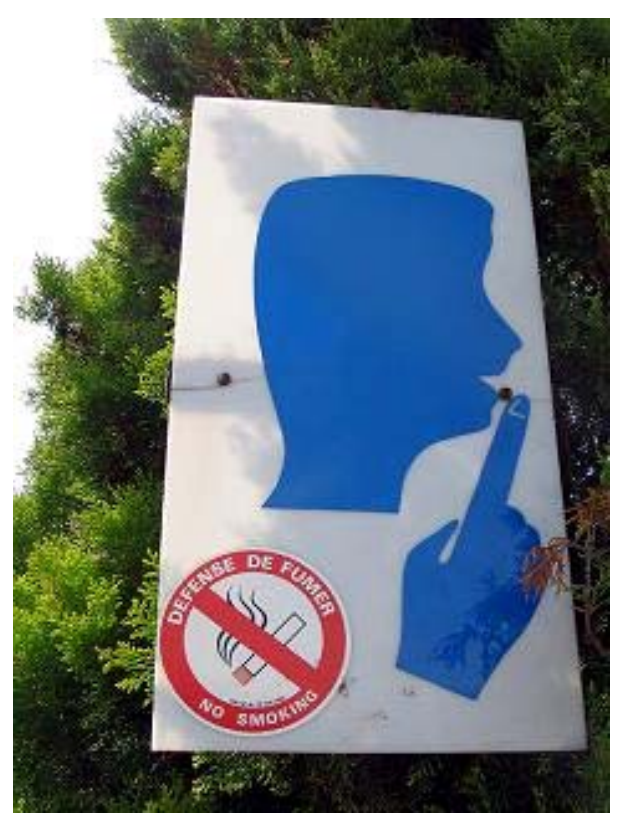

Abb. 6

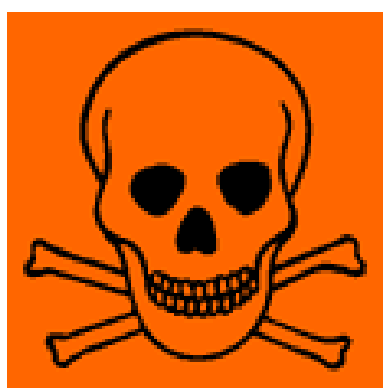

Abb. 7 


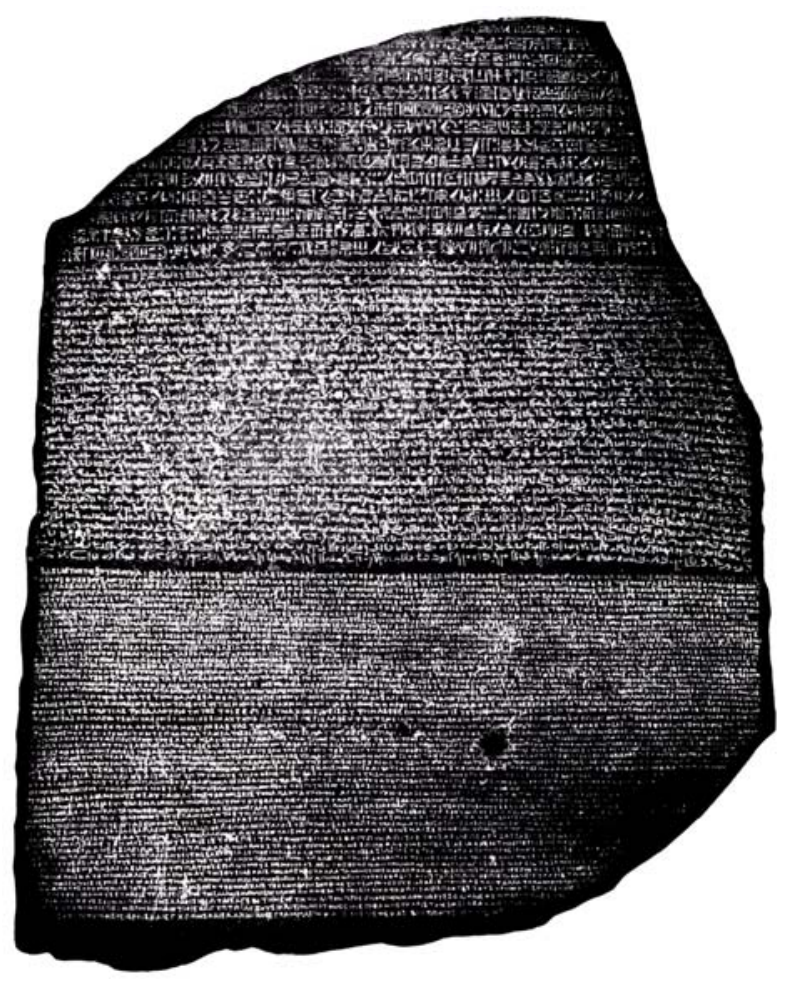

Abb. 8

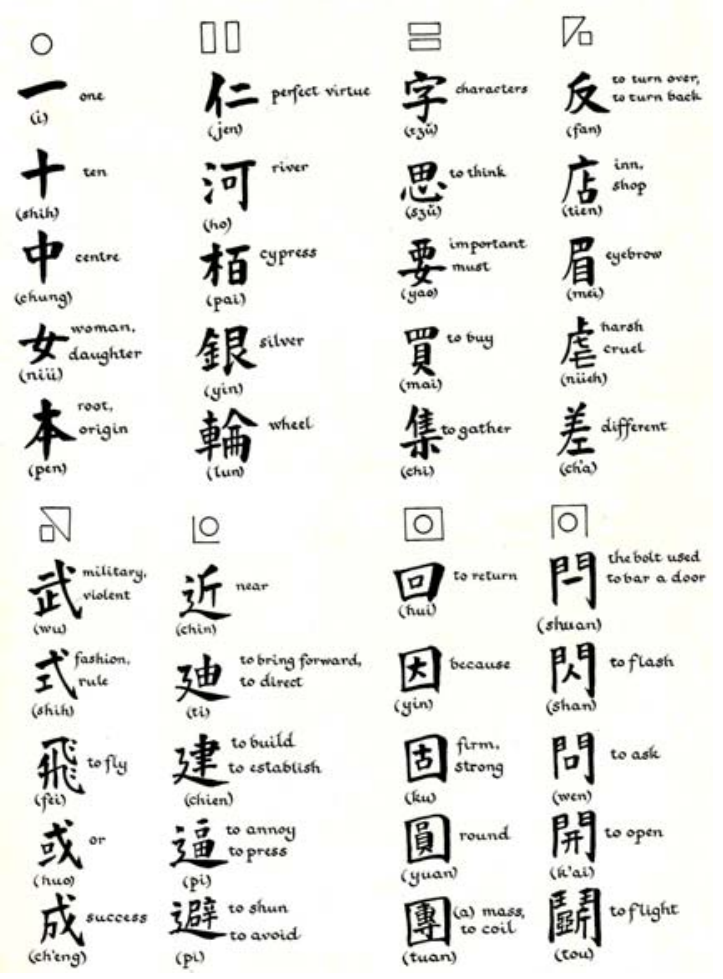

Abb. 9 


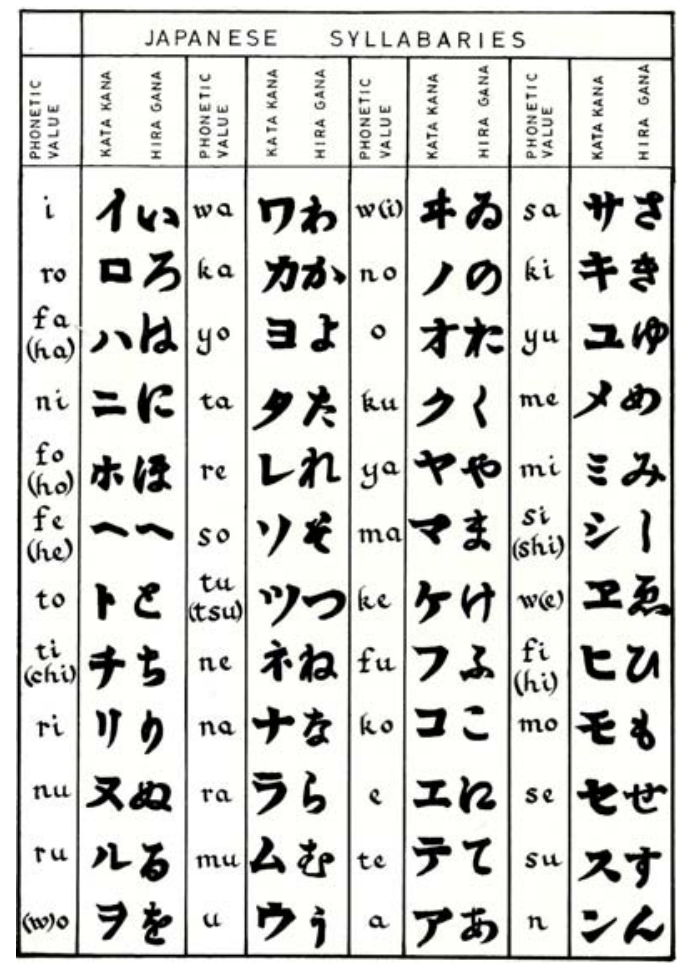

Abb. 9a

TABLE 2I.I: Comparison of the Phoenician Consonantal Signs and the Letters of the Greek Alphabet

\begin{tabular}{|c|c|c|c|c|}
\hline \multicolumn{2}{|c|}{ PHOENICIAN } & \multicolumn{3}{|c|}{ GREEK } \\
\hline \multirow{2}{*}{$\begin{array}{l}\text { Name } \\
\text { ālef }\end{array}$} & \multirow{2}{*}{$\begin{array}{c}\text { ca. } 900 \text { B.C.E. } \\
\text { KKX }\end{array}$} & \multicolumn{2}{|c|}{$800-600$ Attic (400) } & \multirow{2}{*}{$\begin{array}{l}\text { Name } \\
\text { alpha }\end{array}$} \\
\hline & & $\triangle A A$ & A & \\
\hline bẽt & 29 & S B B & B & bẽ̃ta \\
\hline gìmel & $r 1$ & rrc & $r$ & gamma \\
\hline dālet & $\Delta \Delta \Delta$ & $\triangleright \Delta D$ & $\Delta$ & delta \\
\hline hē & $\exists \exists$ & EEE & $E$ & e psilon \\
\hline wāw & YYY & FF ᄃ & & (digamma) \\
\hline zajin & $I \simeq I$ & $I \geq I$ & $I$ & zēta \\
\hline ḥēt & 日月日 & 由日н & $\mathrm{H}$ & ēta \\
\hline țēt & $\otimes \oplus$ & $\otimes \oplus \odot$ & $\odot$ & thēta \\
\hline yōd & $z Z z$ & 々 < । & 1 & iôta \\
\hline kaf & שvy & KKK & K & kappa \\
\hline lāmed & $\angle L C$ & レトヘ & $\wedge$ & labda \\
\hline mēm & $\xi \xi y$ & $\mu \mu M$ & M & $\mathrm{mu}$ \\
\hline nūn & SSy & $N N N$ & $N$ & nu \\
\hline sāmek & $\mp$ & ま王三 & 王 & $\mathrm{ksi}$ \\
\hline 'ayin & 0 & 0 & o & o mikron \\
\hline $\mathrm{pe \overline {e }}$ & $>1$ & $r \Gamma$ & $\Gamma$ & $\mathrm{pi}$ \\
\hline șādē & hz & M & & (san) \\
\hline qōf & $Q \varphi \phi$ & $\varphi \varphi$ & & (qoppa) \\
\hline rēšs & 94 & PDR & $\mathbf{P}$ & rhō \\
\hline $\sin /$ sin & $w$ & $\xi \zeta \xi$ & $\xi$ & sigma \\
\hline \multirow[t]{6}{*}{ tāw } & $+x$ & $\mathrm{~T}$ & $\mathbf{T}$ & tau \\
\hline & & rYV & $Y$ & u psilon \\
\hline & & $\phi \oplus \phi$ & $\Phi$ & phi \\
\hline & & $x+$ & $x$ & chi \\
\hline & & $\psi v$ & $\psi$ & psi \\
\hline & & $\Omega \Omega \Omega$ & $\Omega$ & ō mega \\
\hline
\end{tabular}

Abb. 10 
PART V: EUROPEAN WRITING SYSTEMS

\begin{tabular}{|c|c|c|c|c|c|}
\hline & \multicolumn{2}{|c|}{ Etruscan } & \multirow[b]{2}{*}{ FAlLSCAN } & \multirow[b]{2}{*}{ Latin } & \\
\hline & Marsiliana & Archaic \& Recen & & & \\
\hline $\bar{a}$ & $A$ & $A$ & $\Delta 9$ & $A$ & a \\
\hline b & 8 & & & & b \\
\hline c/g & 1 & $>$ & $c$ & $c$ & $c / g$ \\
\hline d & $a$ & & $D$ & $D$ & d \\
\hline e & $\nexists$ & $\lambda$ & $E$ & $E$ & e \\
\hline $\mathrm{v}$ & 7 & 1 & & & $\mathrm{v}$ \\
\hline $\mathrm{z}[\mathrm{ts}]$ & $I$ & 1 & IL & & $z[t s]$ \\
\hline h & 目 & $B O$ & व日 & 日 & h \\
\hline th & $\otimes$ & $\otimes \odot$ & $\odot$ & & th \\
\hline i & 1 & 1 & 1 & 1 & $\mathrm{i}$ \\
\hline k & त्र & x & $k$ & K & k \\
\hline 1 & $\checkmark$ & $\checkmark$ & $l$ & $b$ & 1 \\
\hline $\mathrm{m}$ & $m$ & $m m \wedge$ & $\mu m$ & m & $\mathrm{m}$ \\
\hline $\mathrm{n}$ & 1 & $4 \mathrm{H}$ & $\mathrm{NH}$ & $N$ & $\mathrm{n}$ \\
\hline$\S$ & 田 & & & & ร \\
\hline o & 0 & & 0 & 0 & o \\
\hline p & 1 & 1 & $\Gamma$ & $r$ & $\mathrm{p}$ \\
\hline$\$$ & M & $M \bowtie$ & & & s \\
\hline$q$ & Q & Q & $\Phi$ & 9 & $q$ \\
\hline$r$ & 4 & 90 & P & P & $r$ \\
\hline s & $s$ & 23 & $s \leqslant \xi$ & $s$ & s \\
\hline t & $T$ & $T$ & $T$ & $T$ & t \\
\hline u & $Y$ & YV & V & $Y V$ & u \\
\hline $\mathrm{s}, \mathrm{x}$ & $x$ & $x$ & $x$ & $x$ & s. $x$ \\
\hline ph & $\Phi$ & $\Phi \oplus$ & & & ph \\
\hline ch & $\psi$ & $\Psi V$ & & & ch \\
\hline f & & f日, 8 & $\uparrow$ & F & $f$ \\
\hline
\end{tabular}

Abb. 11

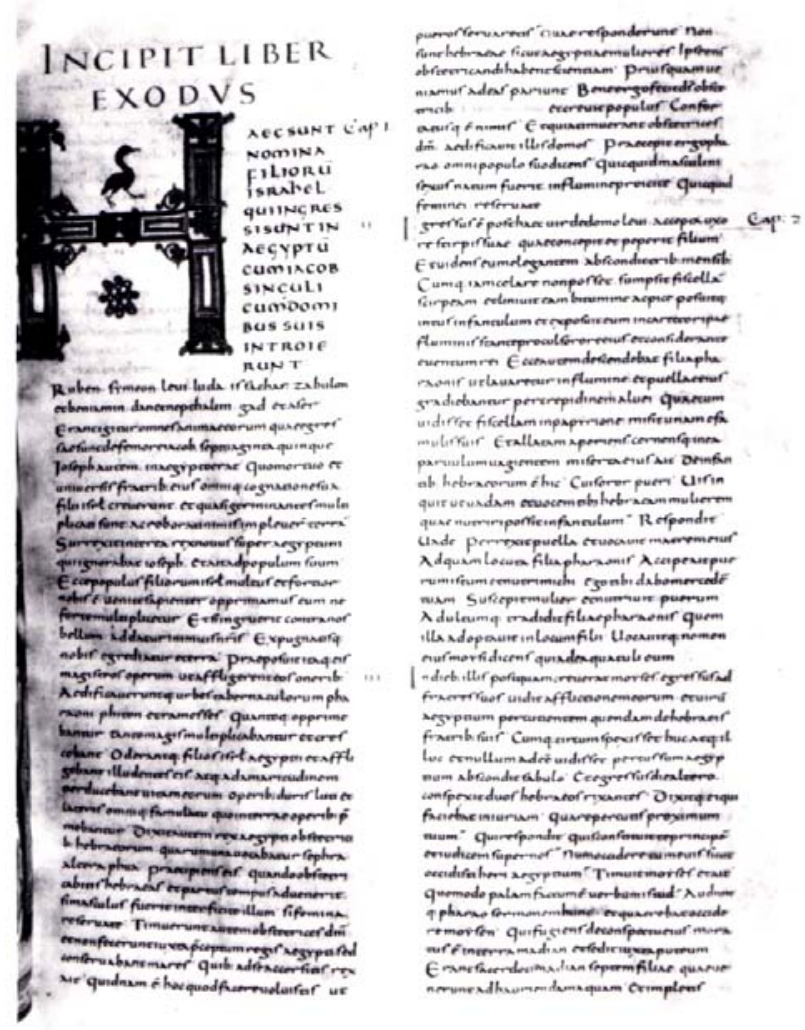

Abb. 12 


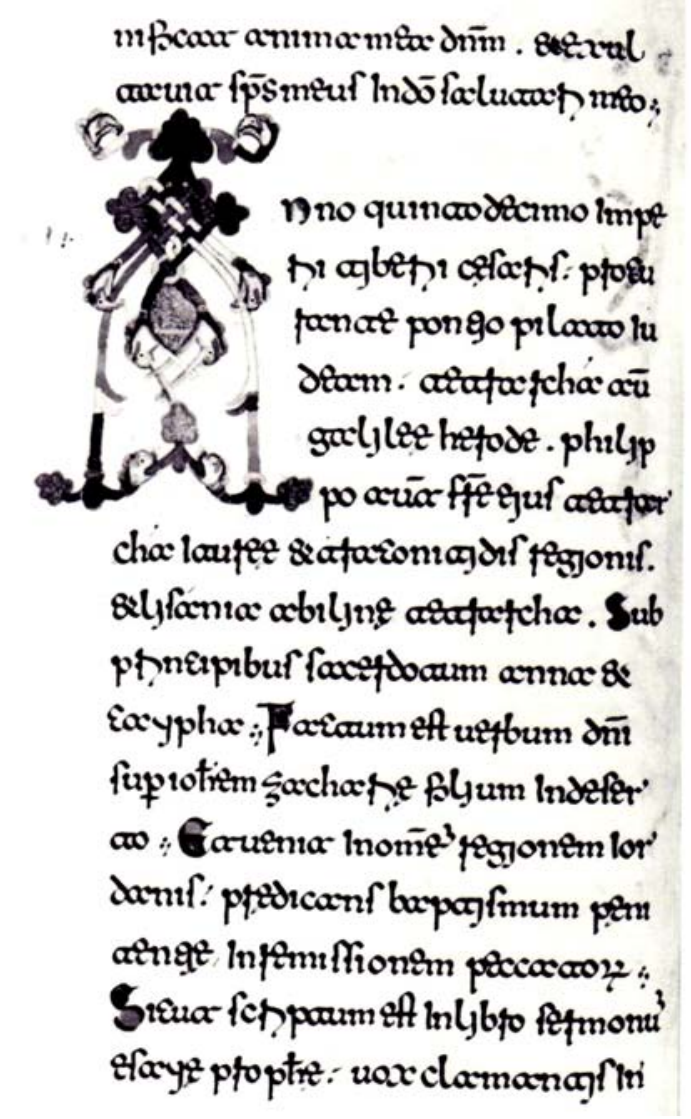

Abb. 13

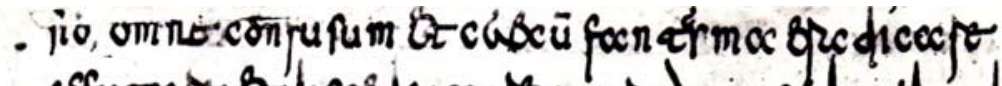

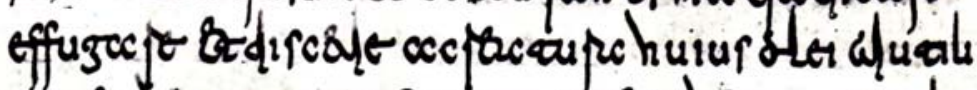

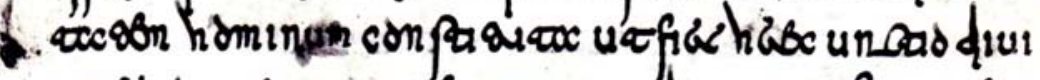

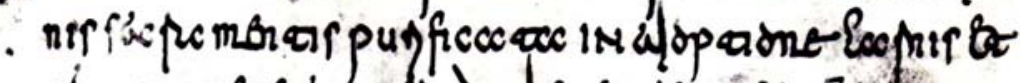
pirerguibetrungofe-hoctor in fonisfisne dnintum

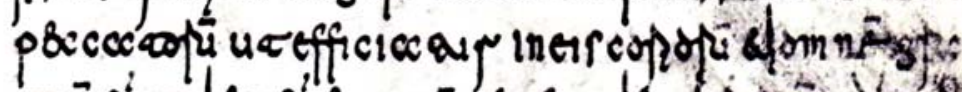

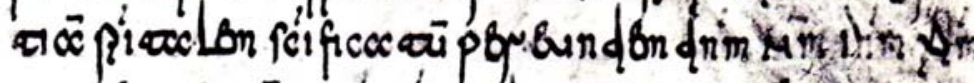

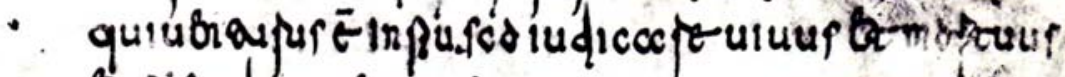

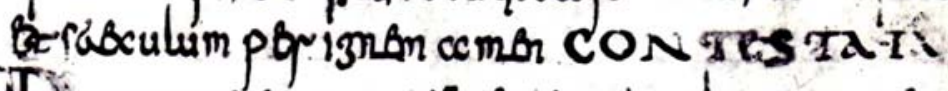

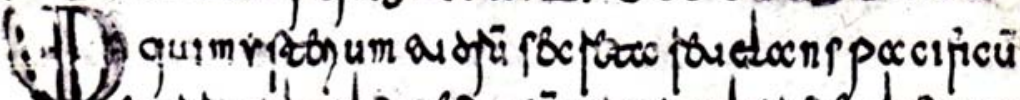

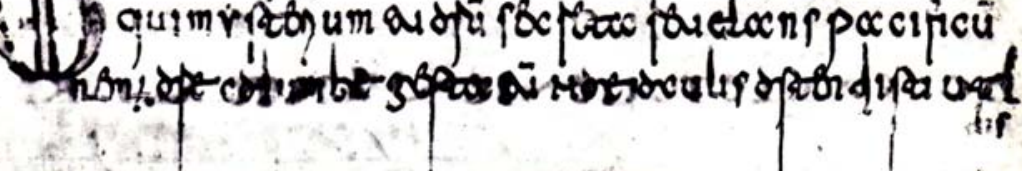

Abb. 14 


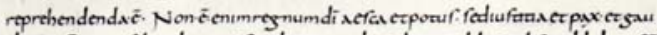

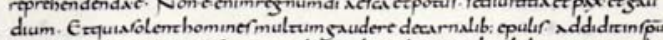

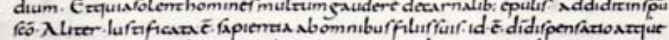

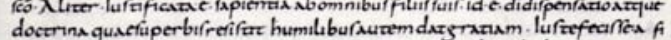

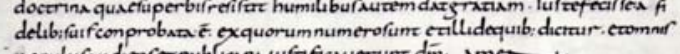
populufaudienfezpublicant-tufaficuerume dóm amen

$f \times[L \perp C 1 T$

LIBER SECVNDVS

INCIIII L I ER TERTIVS

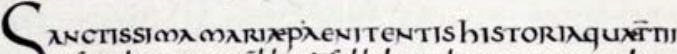

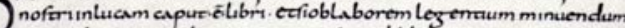

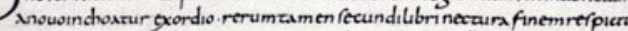

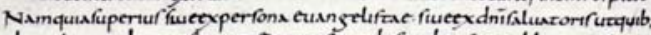
damplacurr diezum fuerax . Cromnir populufaudien rezpublicant tufafia

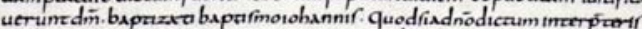
audienfiobannem populufimzelligrzurefiederignazur: fiabeuanselifa

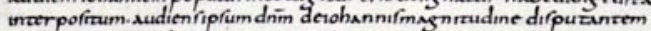

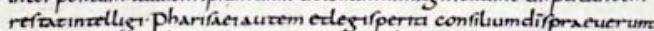

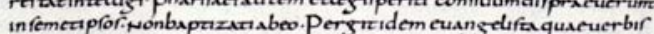

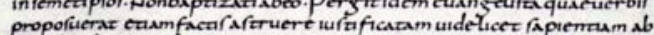

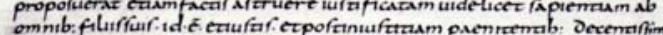

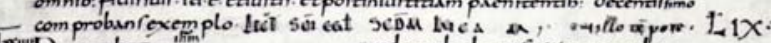
is $\mathrm{R}$ Sabar - guidam dephartialtiturmanduca recumillo, ezing renturdomum pharifaet difaburz, ezecce

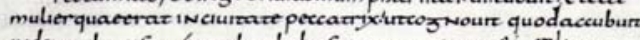

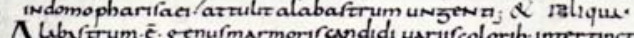

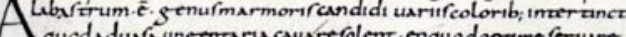
quodaduata ungentaria causerefoleme coquodopame feruare

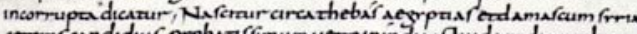
ceorif candidiur probazifimum ueroinin dix quidum dicume hane andem noneflemulierem quatenminemer domimea puffione a a purpederg

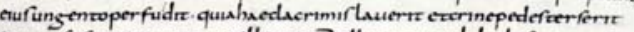

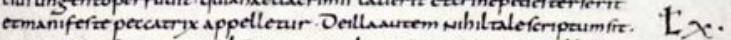

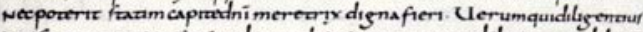
tnuefagane tnuenutite endem mulierem marism uidelices mapeduleñ

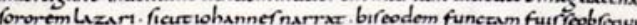

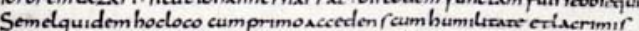
remiffion em merurz pecaxorum. Nameziohanner hocquamuifnomur

Abb. 15

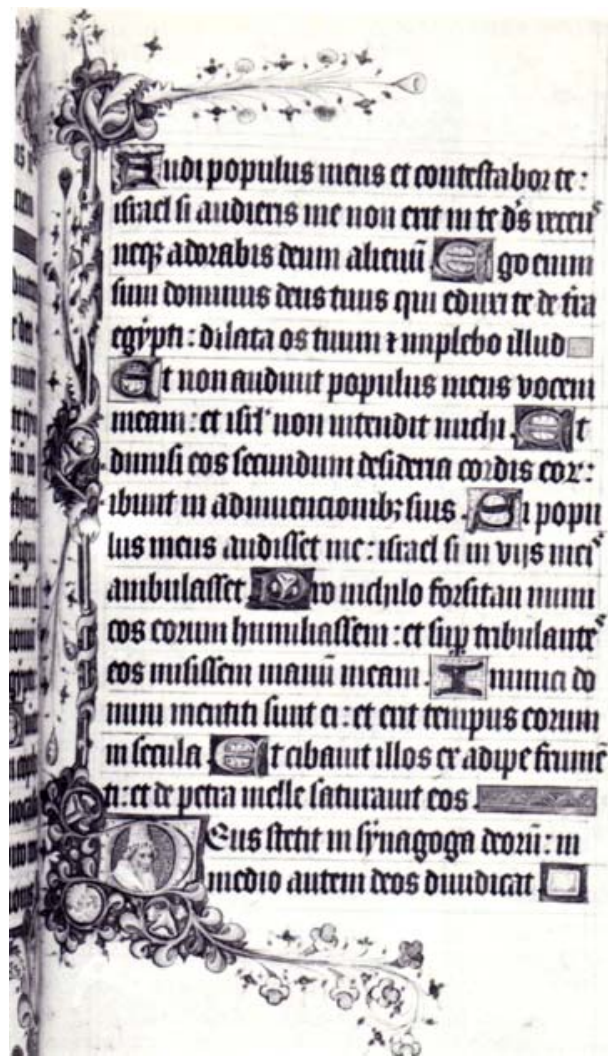

Abb. 16 


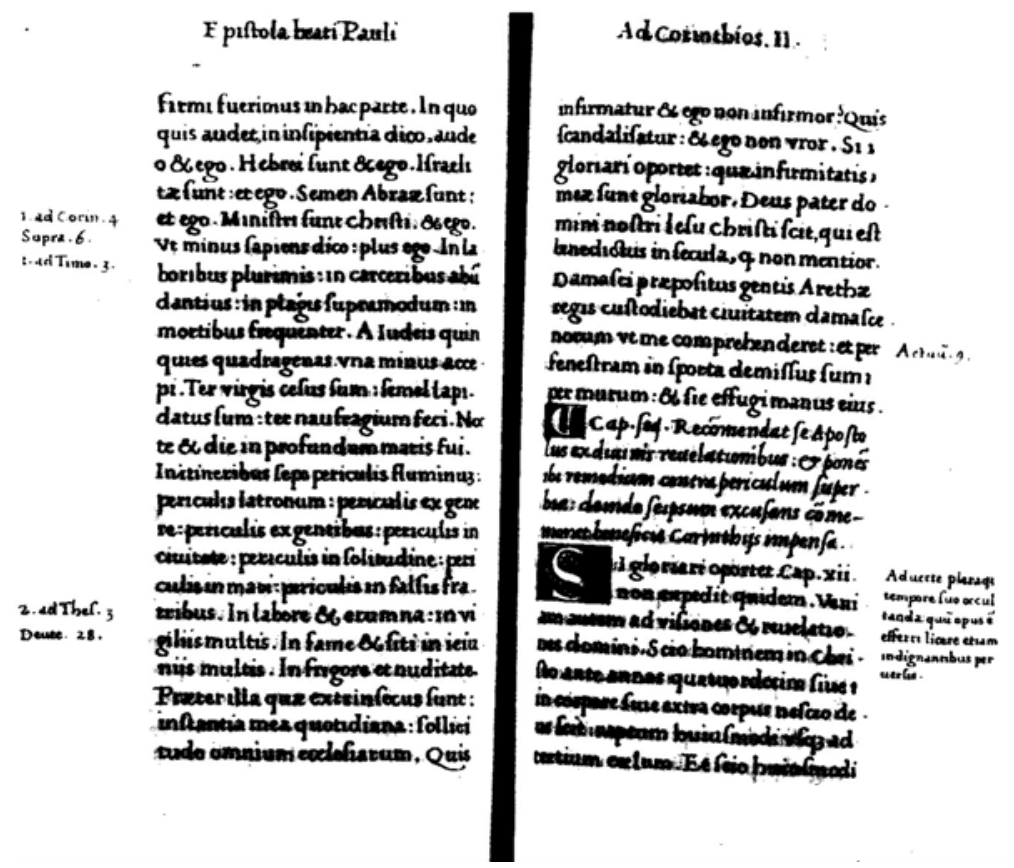

Abb. 17

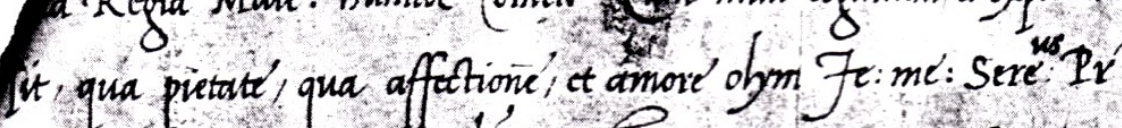

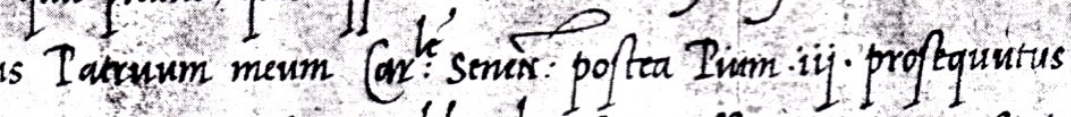
itict quantis eum immortatibus benefrijs offecerit: nisum of mitn

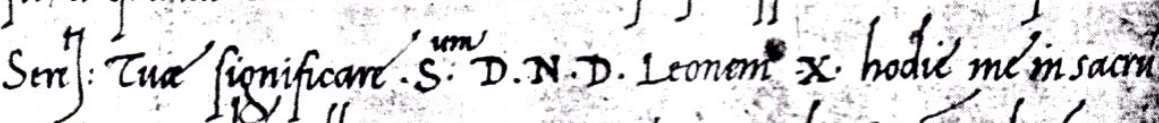

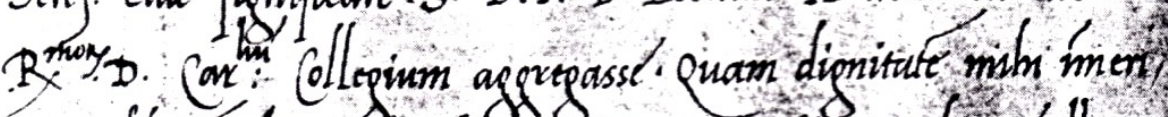

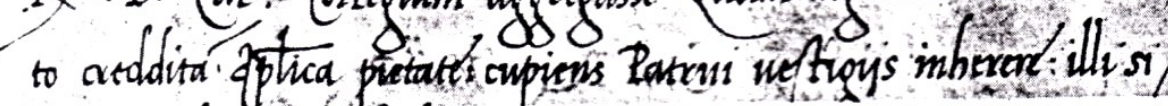

Abb. 18

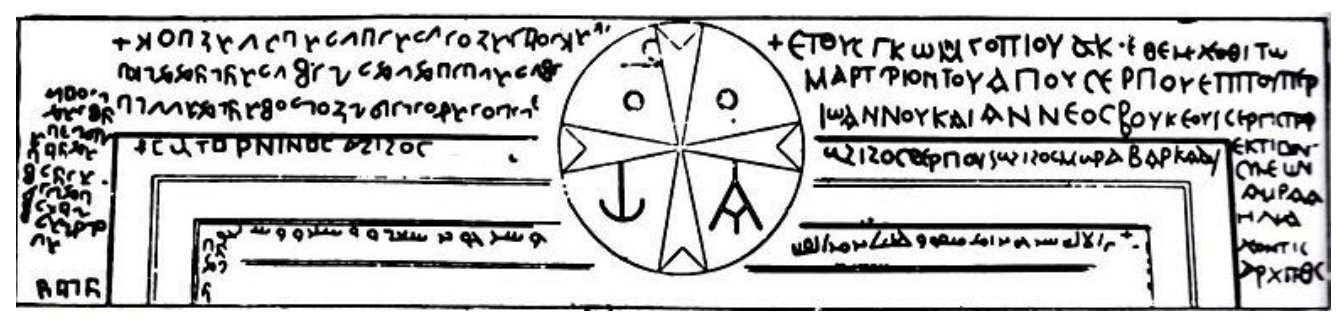

Abb. 19 


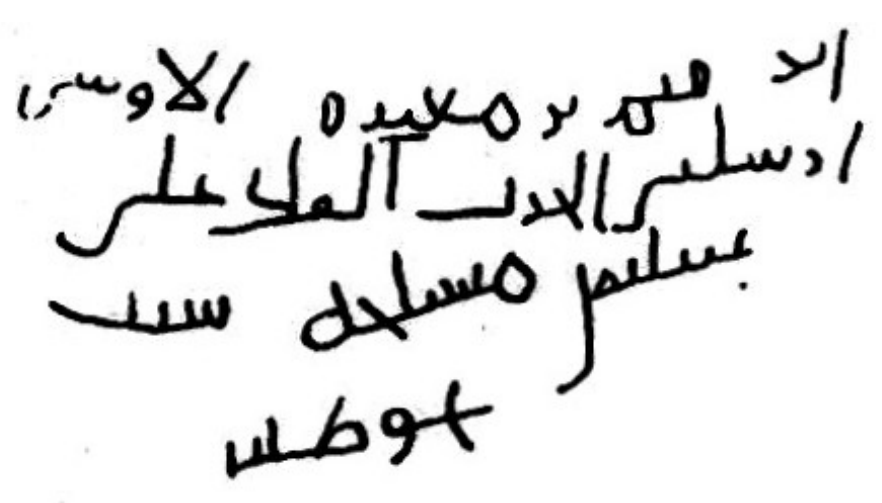

Abb. 19 a

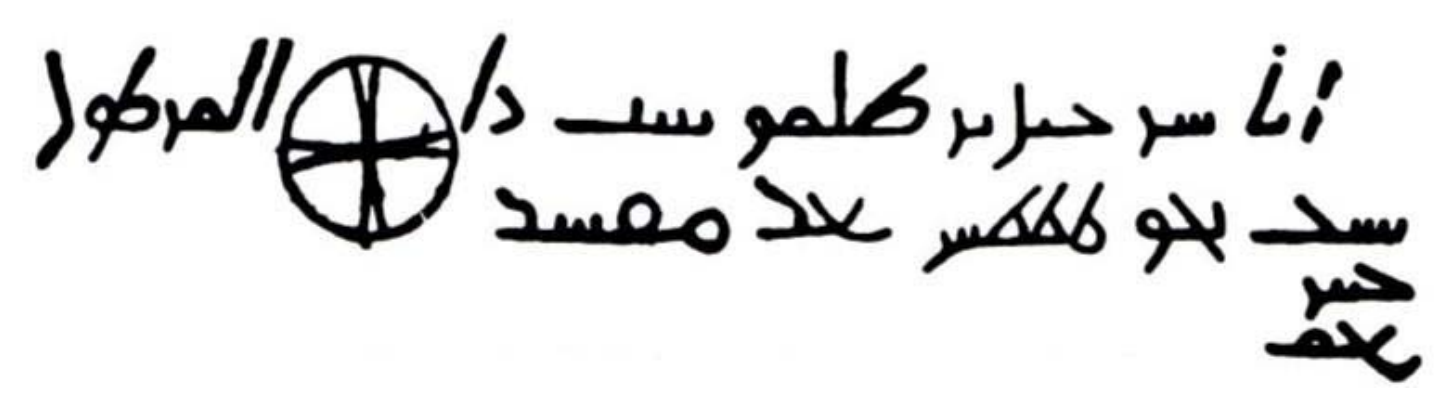

Abb. 19 b

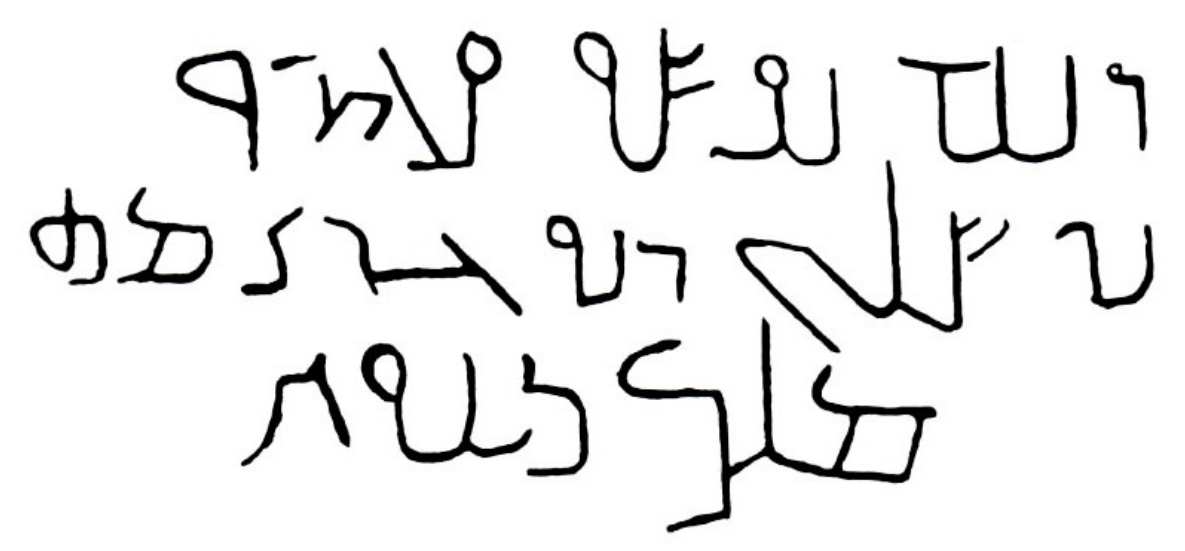

Abb. 19 c 


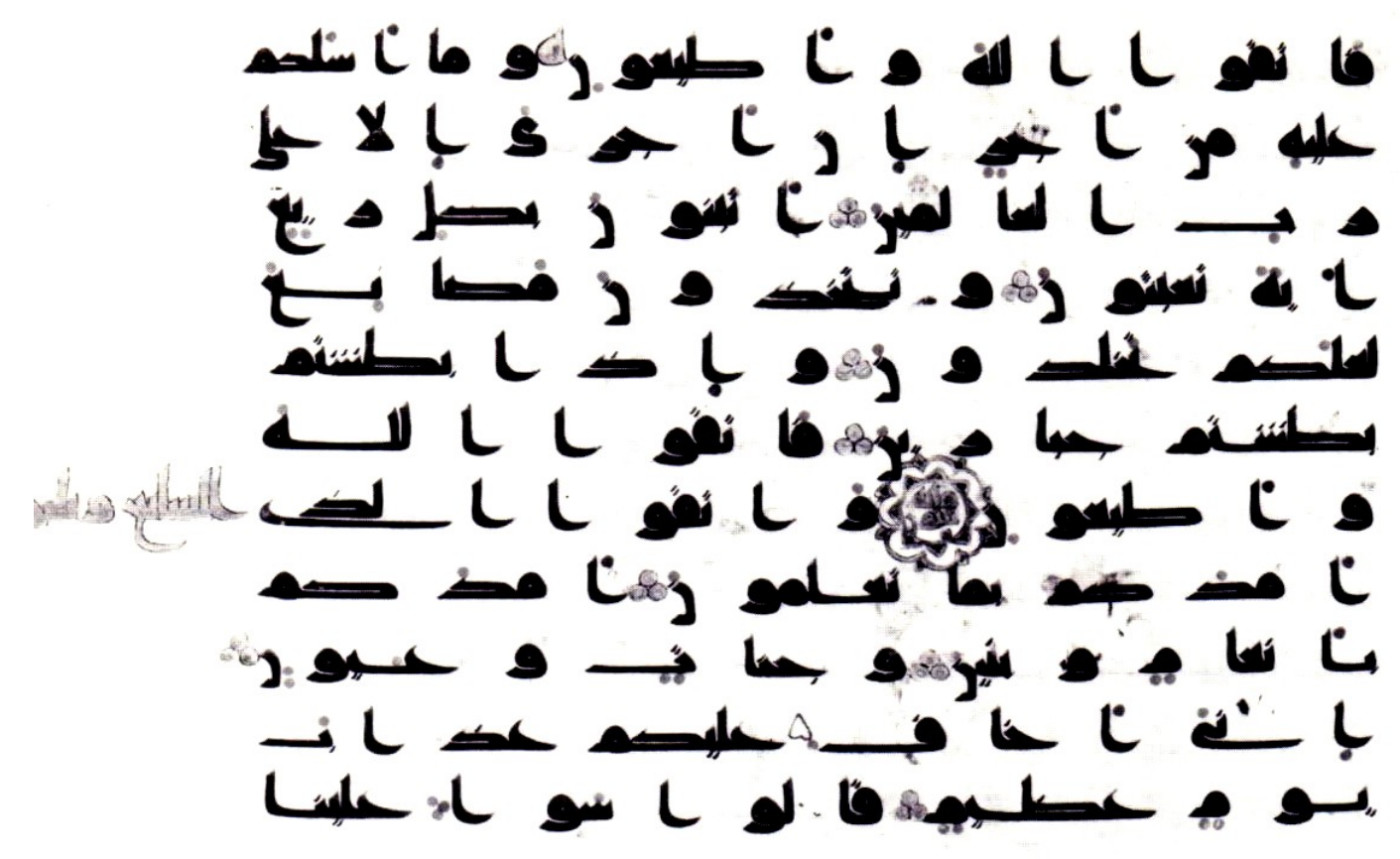

Abb. 20

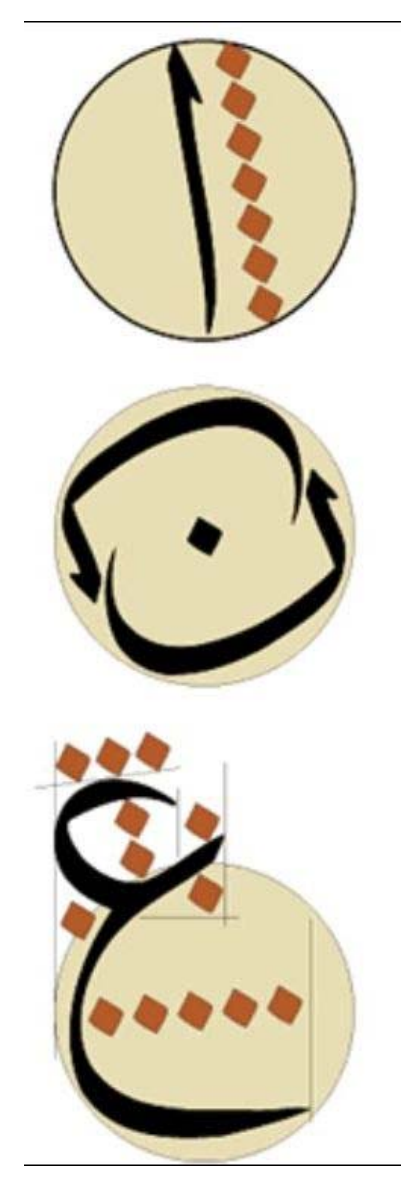

Abb. 21 

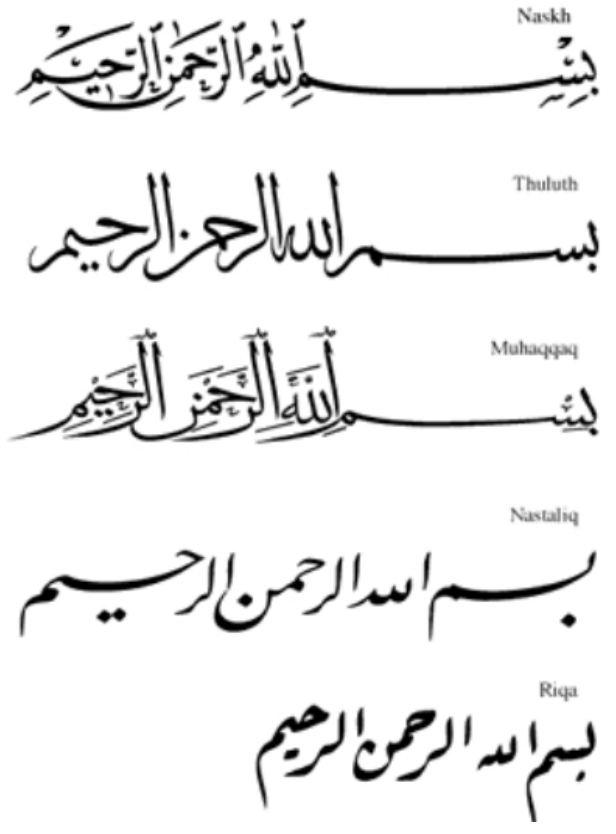

Abb. 22

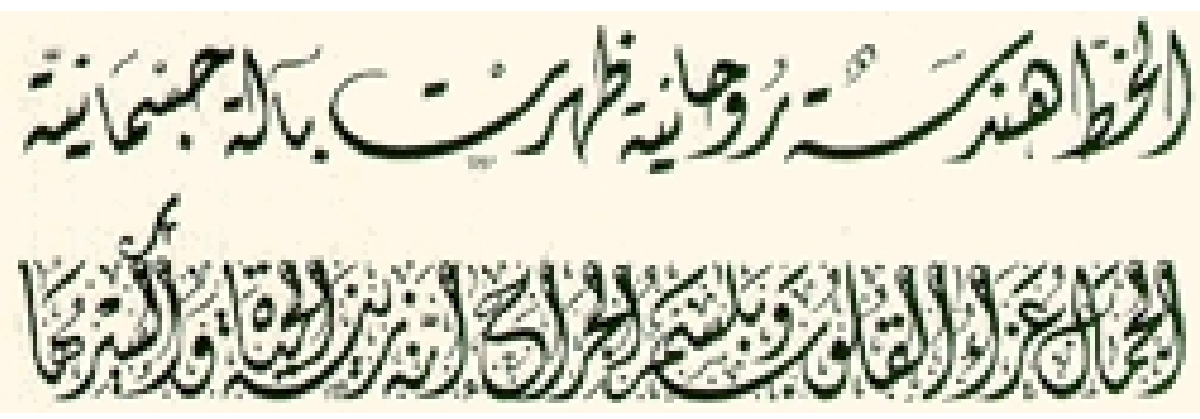

Abb. 23

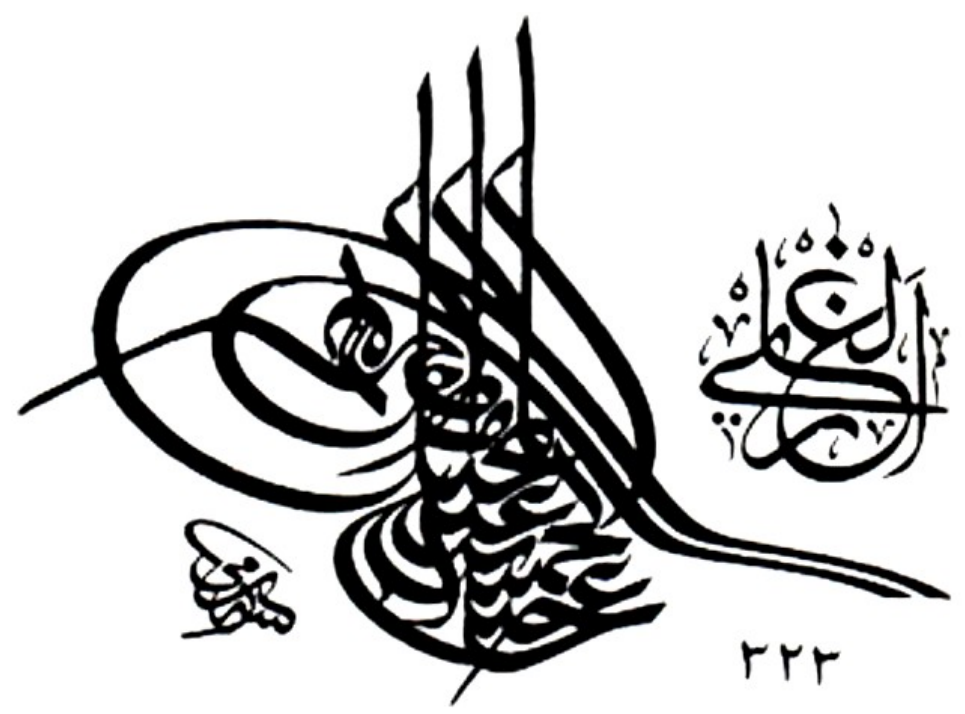


Abb. 24

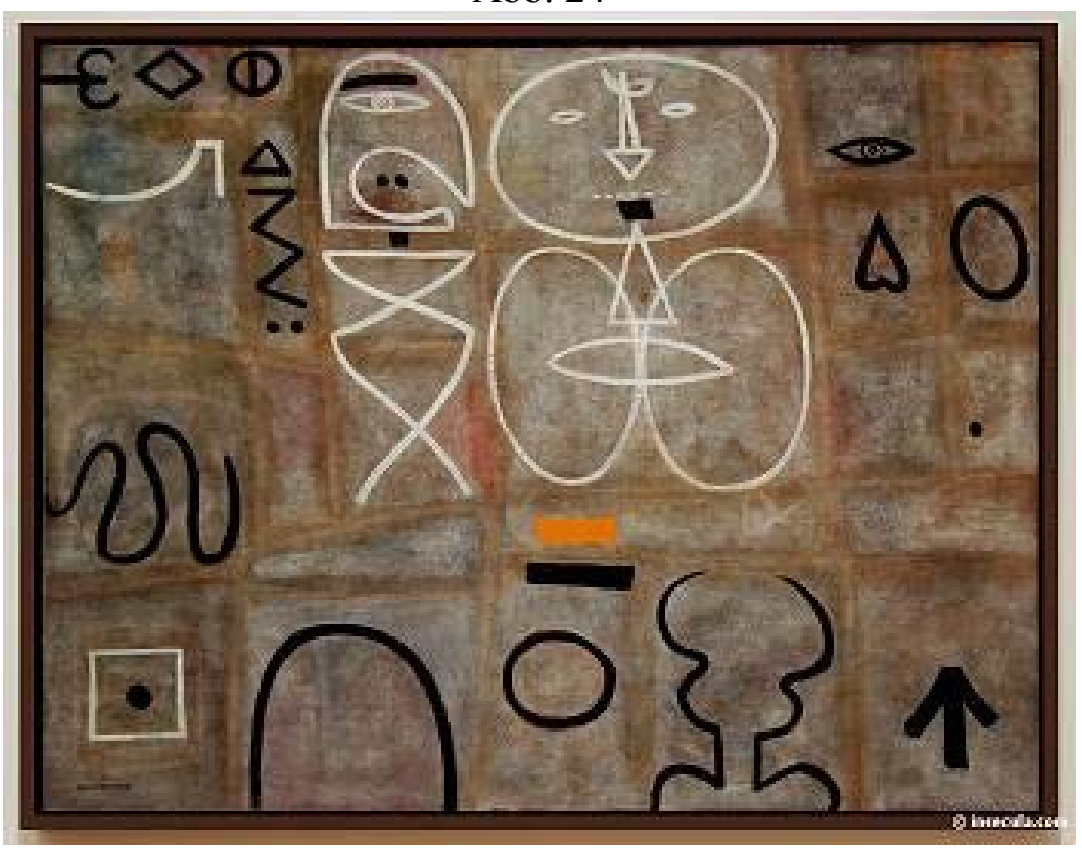

Abb. 25

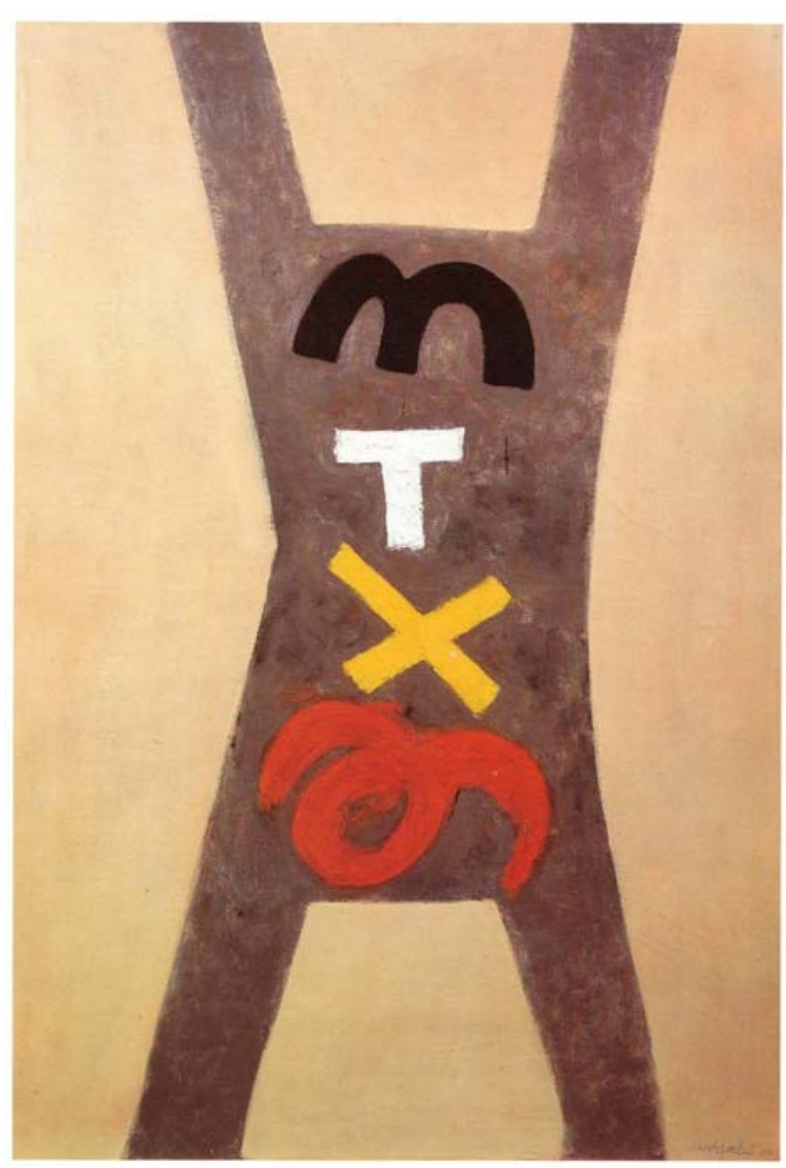

Abb. 26 


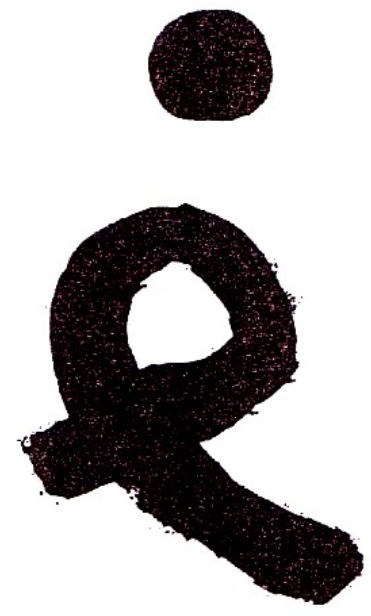

Abb. 27

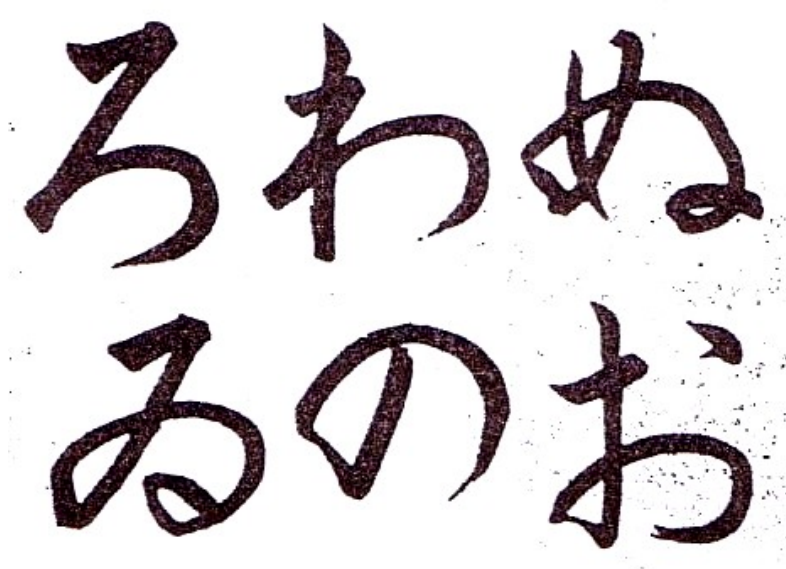

Abb. 28

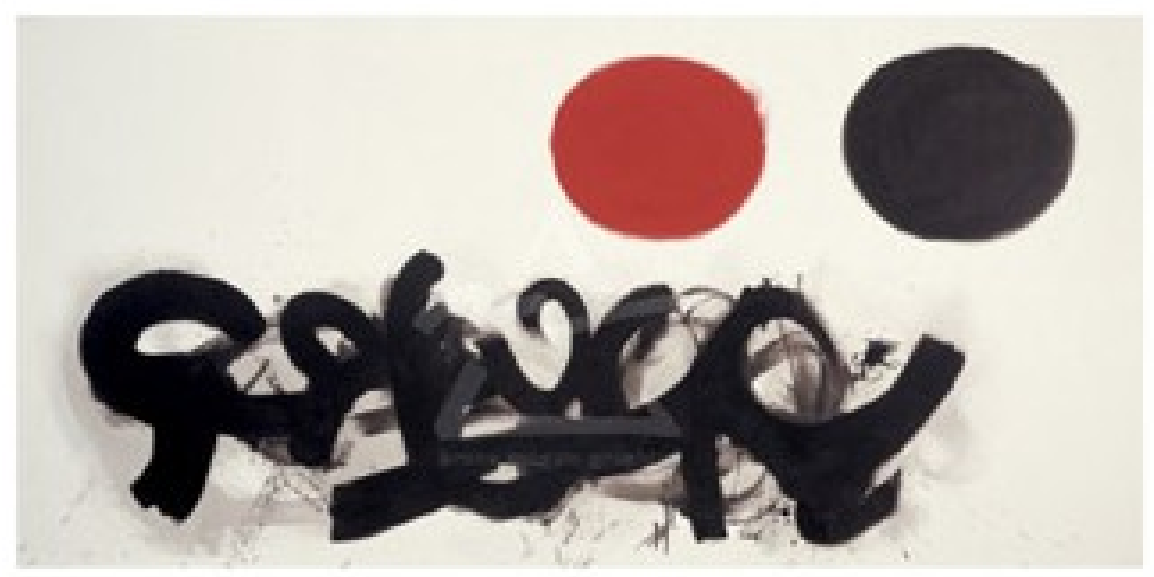

Abb. 29 


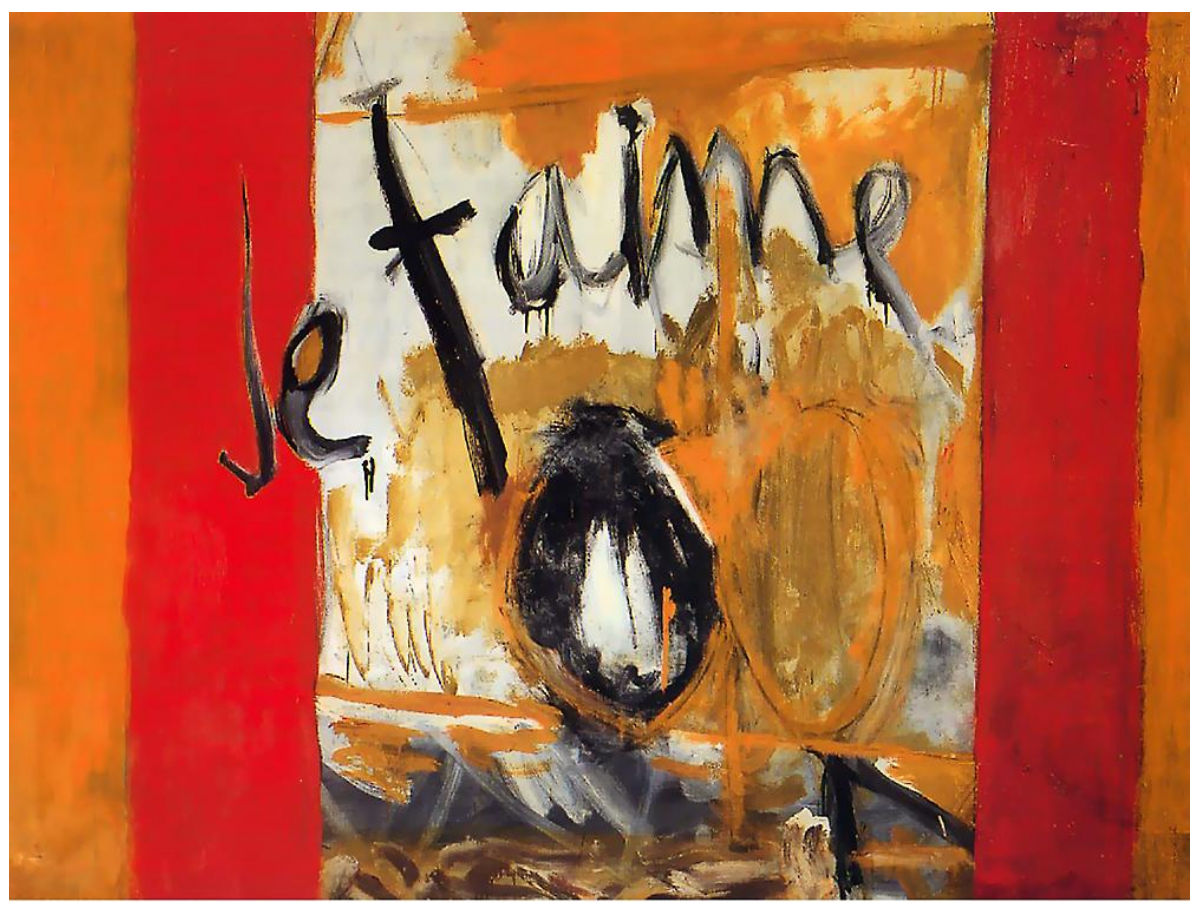

Abb. 30

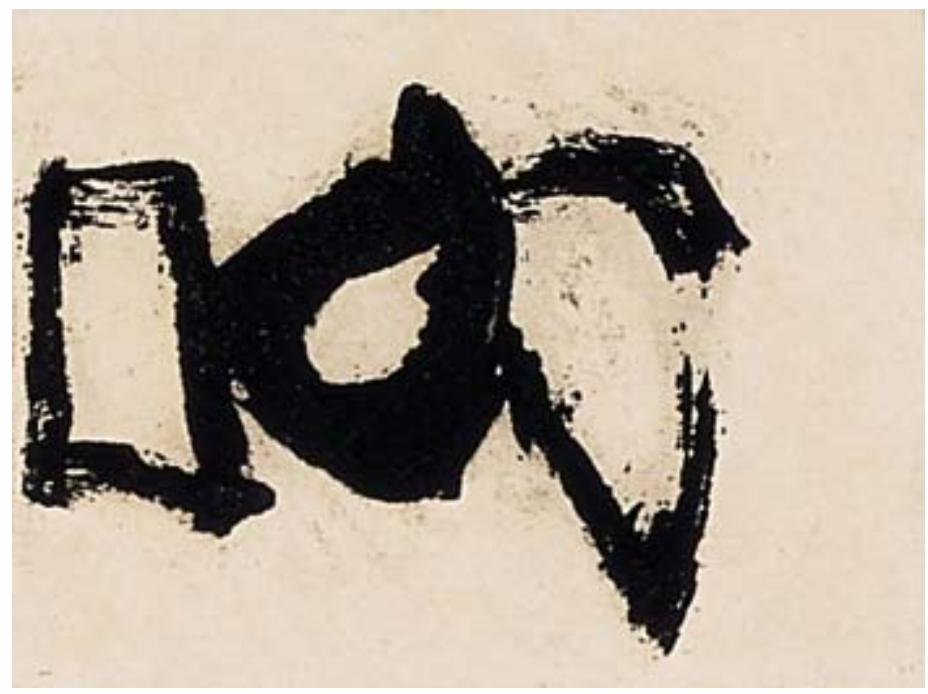

Abb.31 


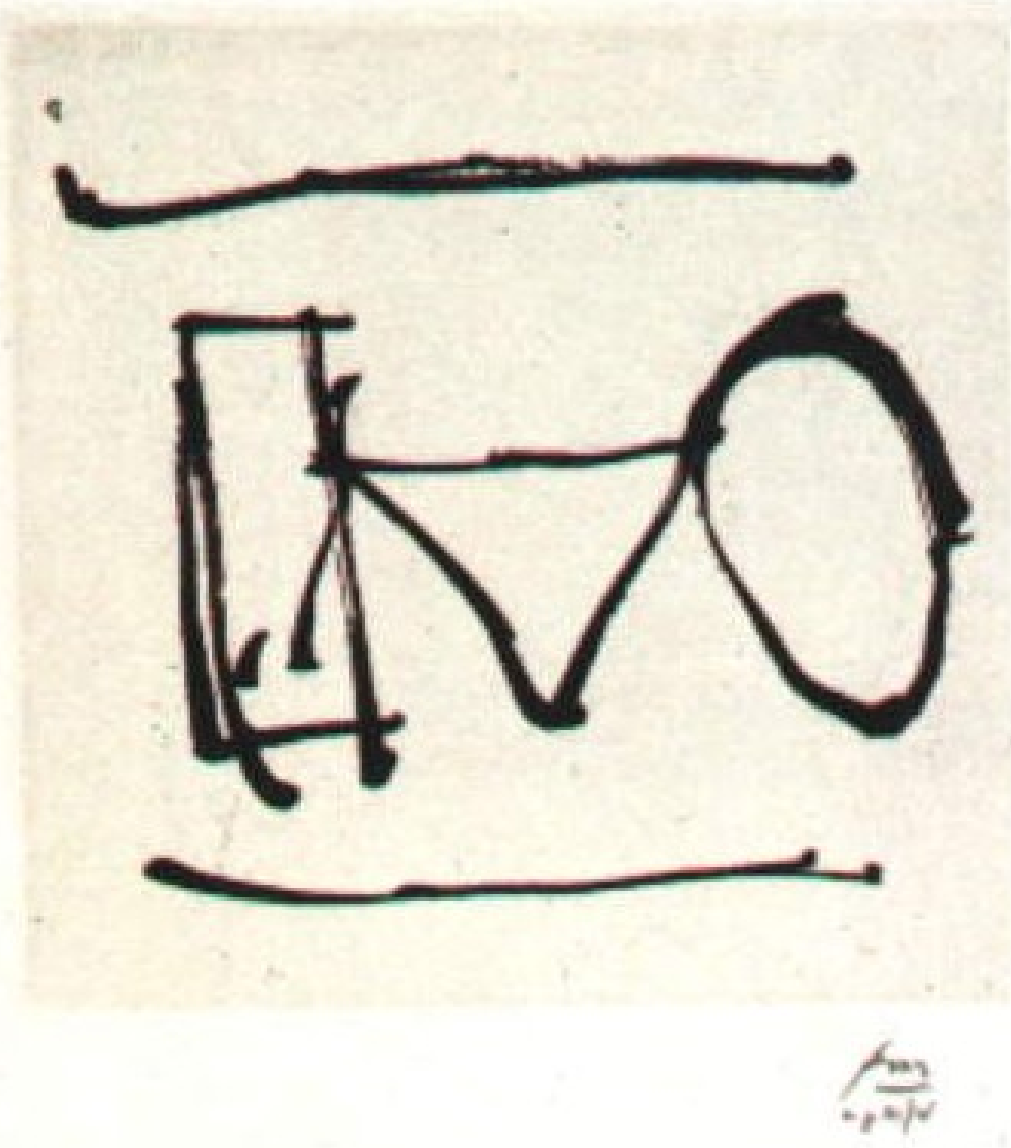

Abb. 32

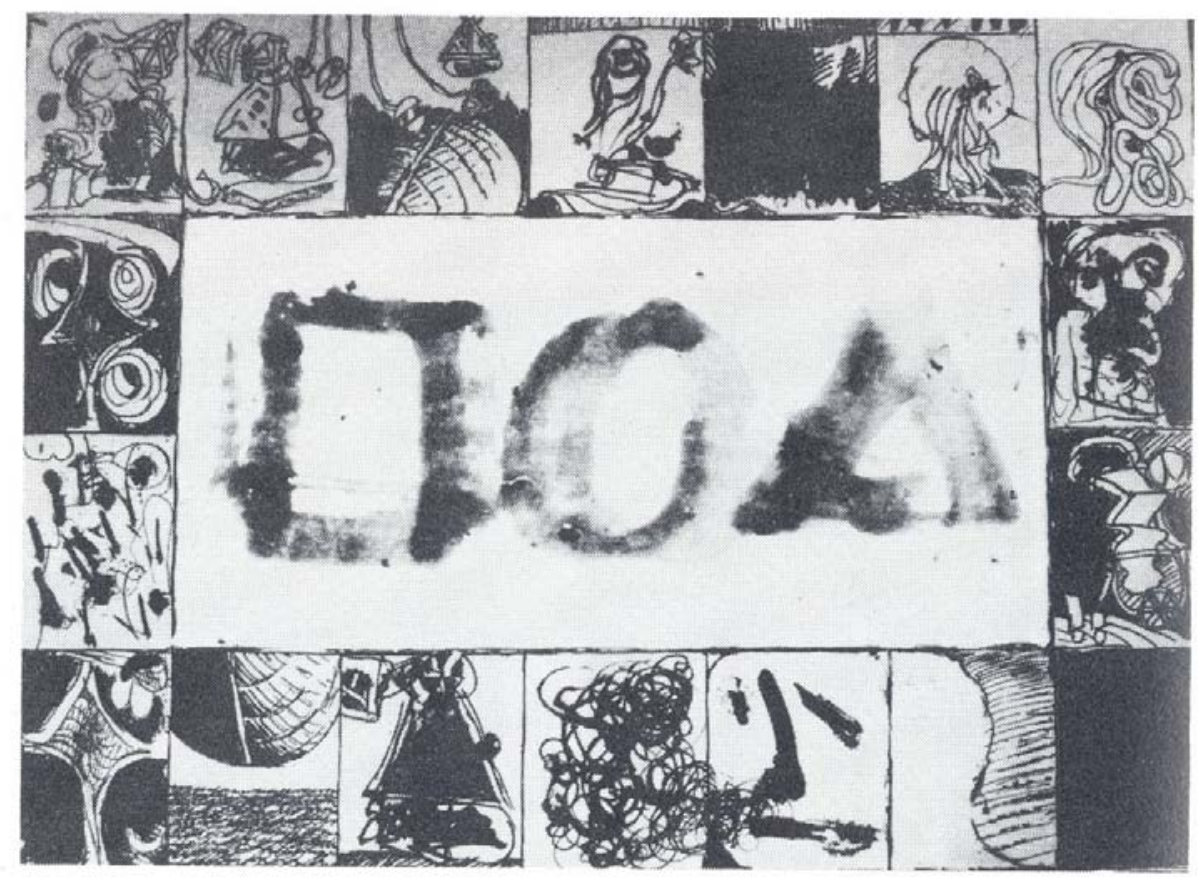

Abb. 33 


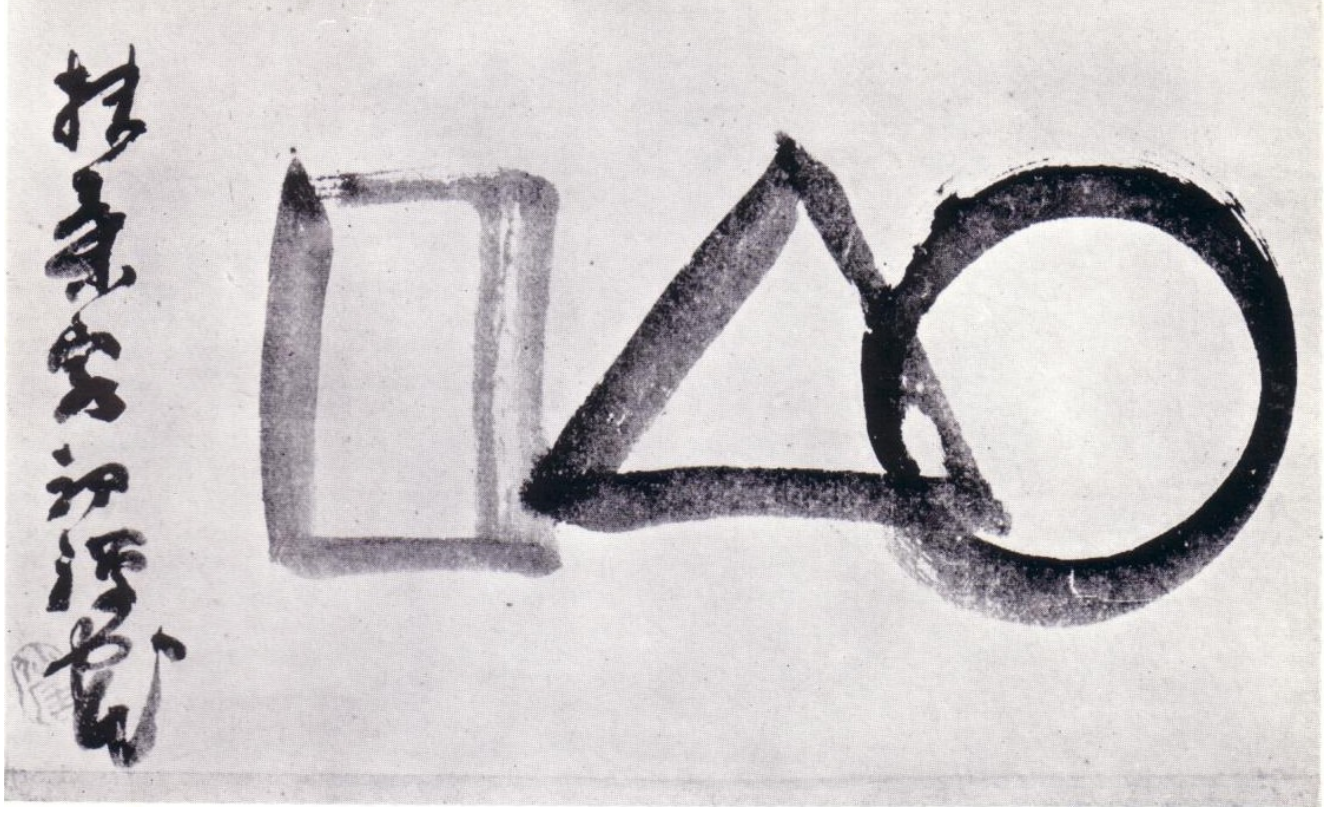

Abb. 34

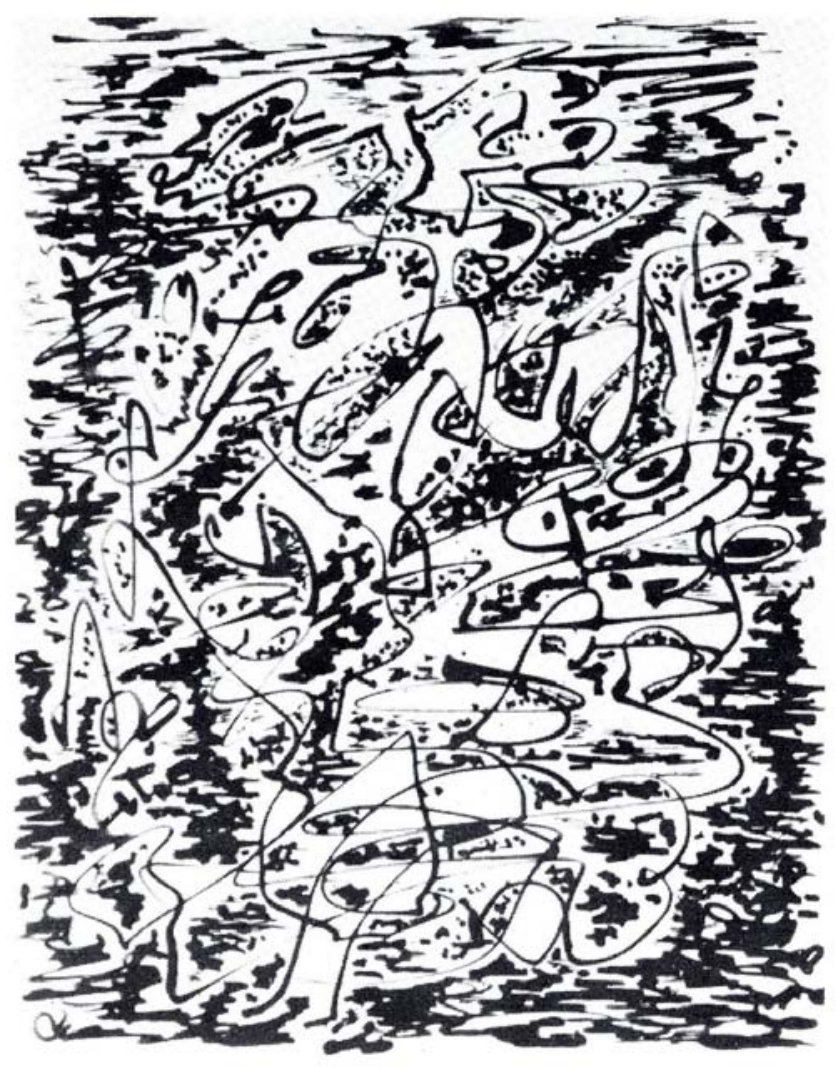

Abb. 35 


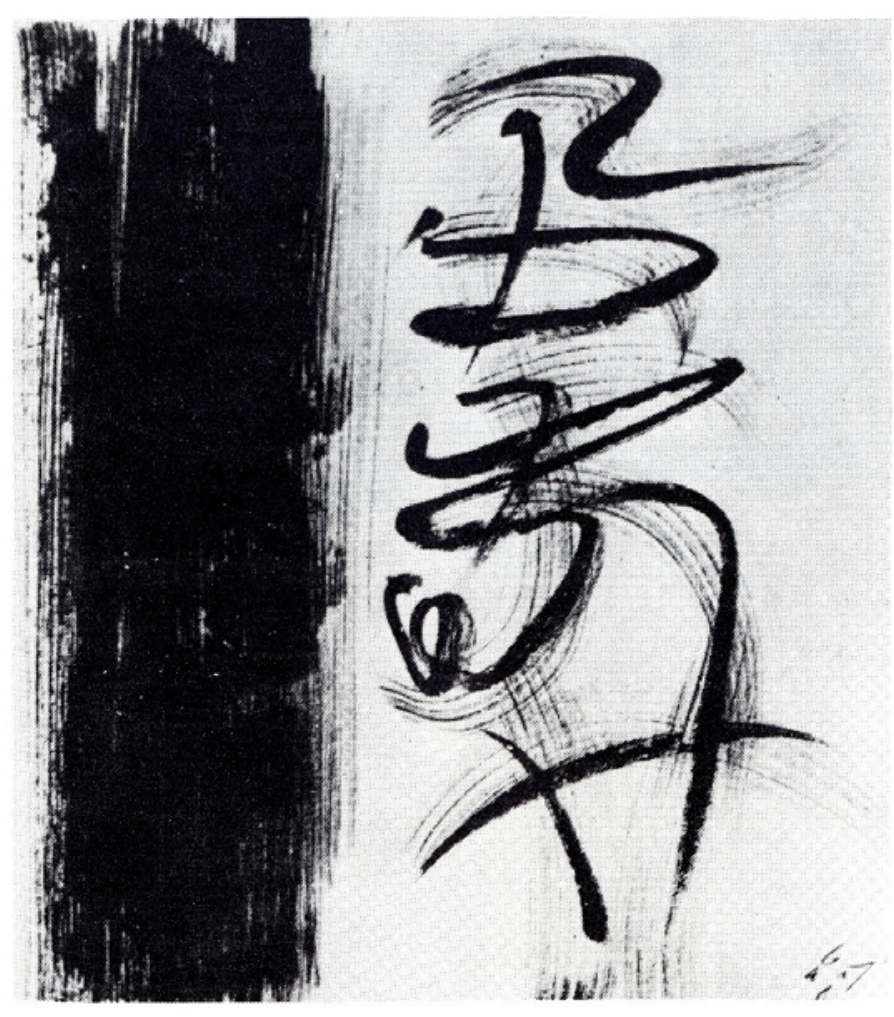

Abb. 36

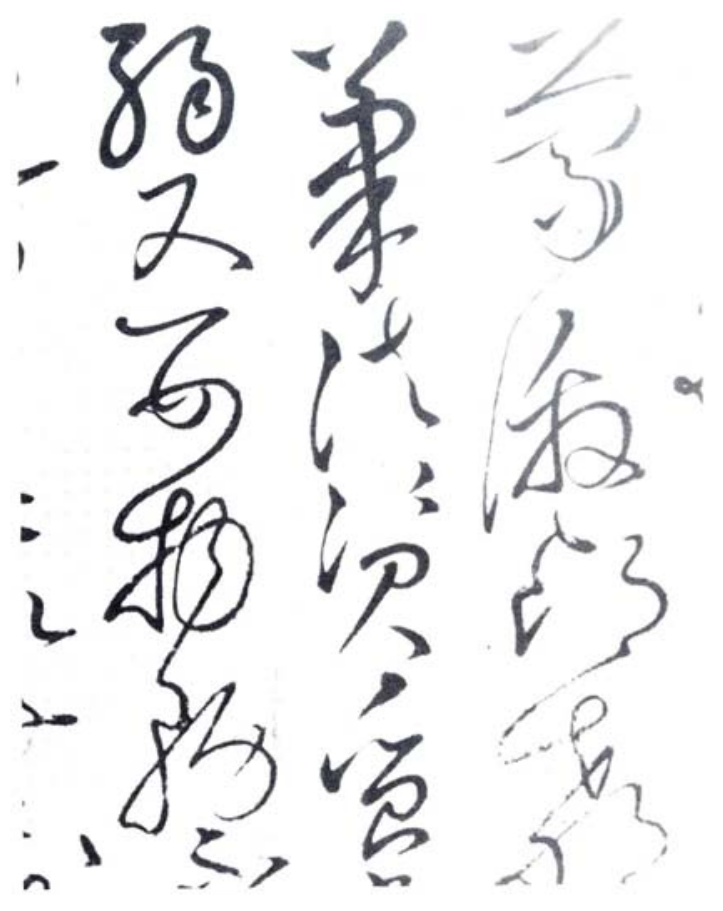

Abb. 37 


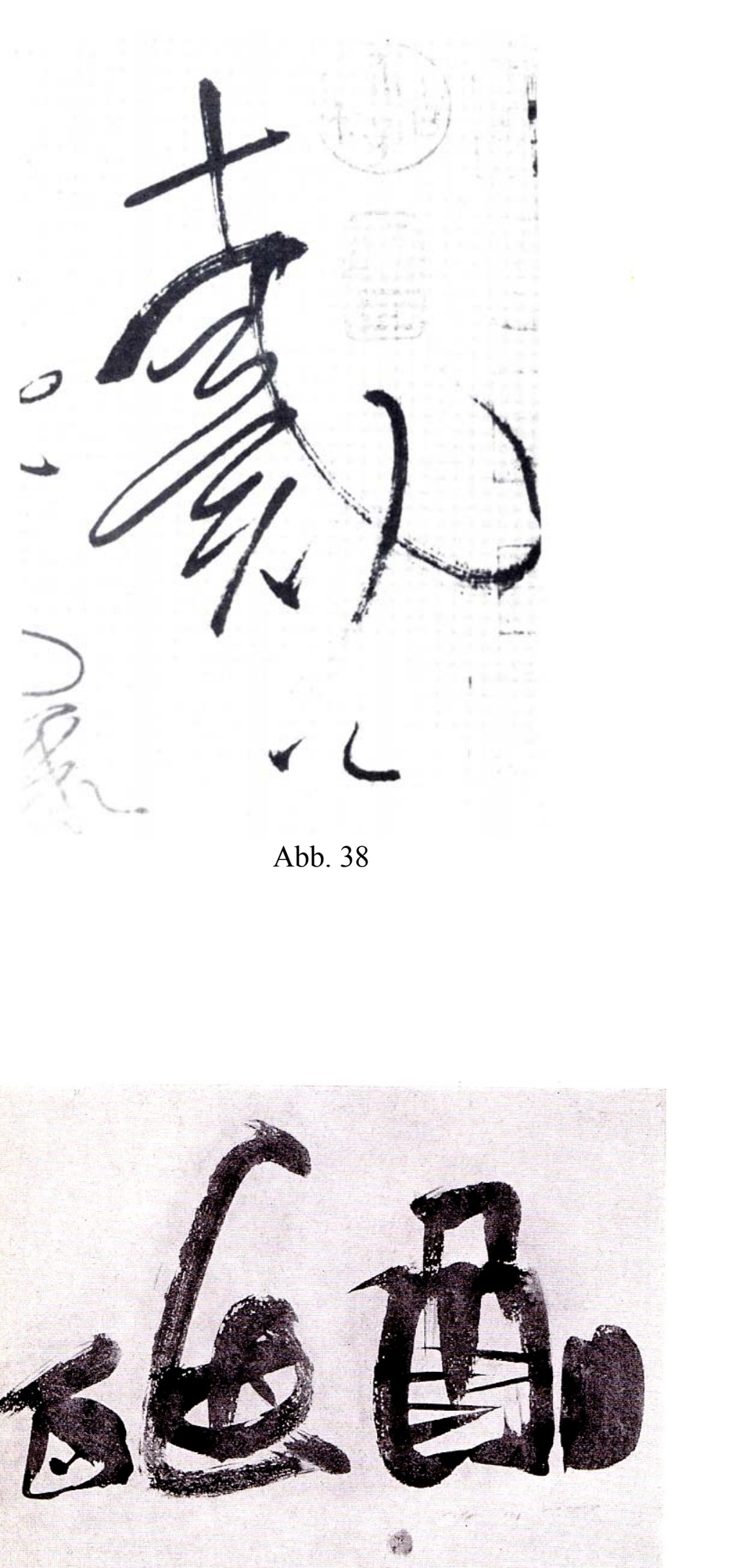




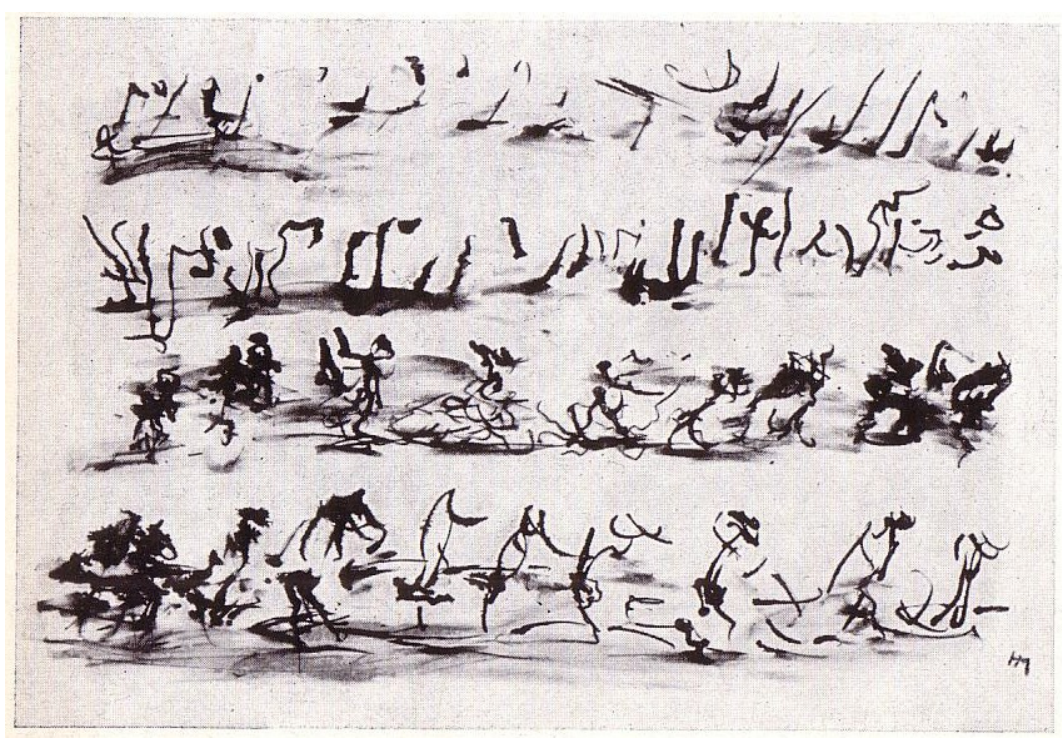

Abb. 40

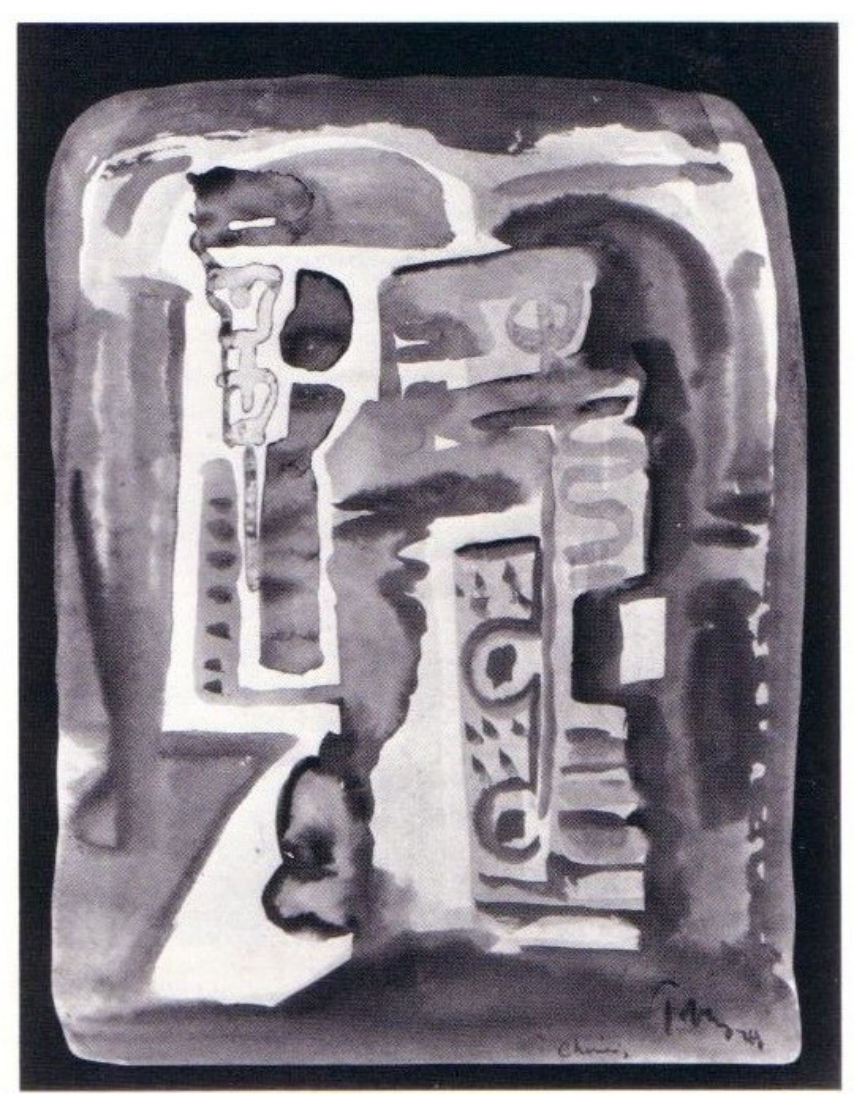

Abb.41 


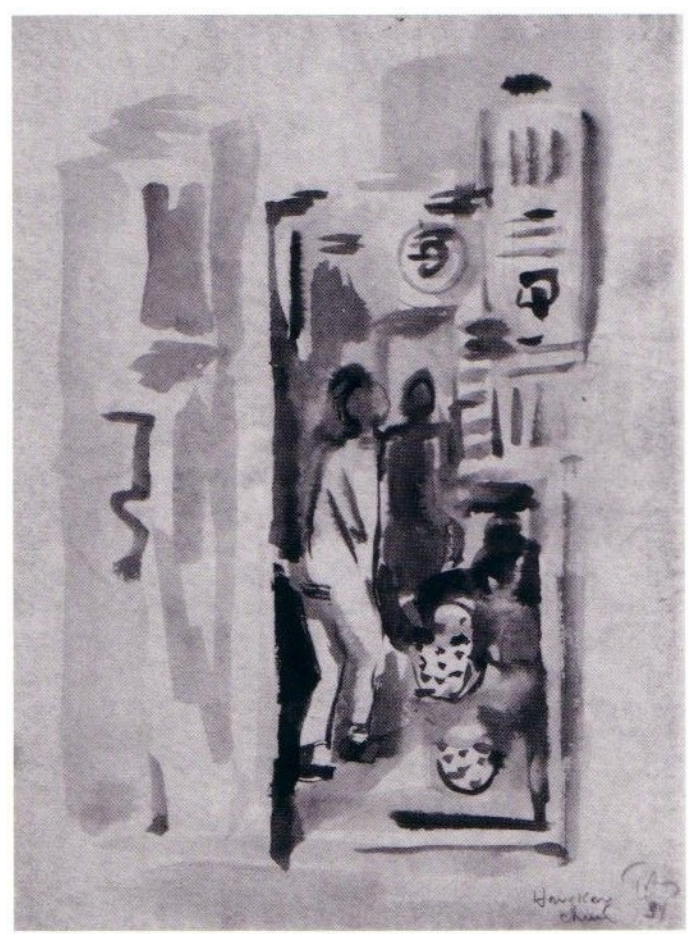

Abb. 42

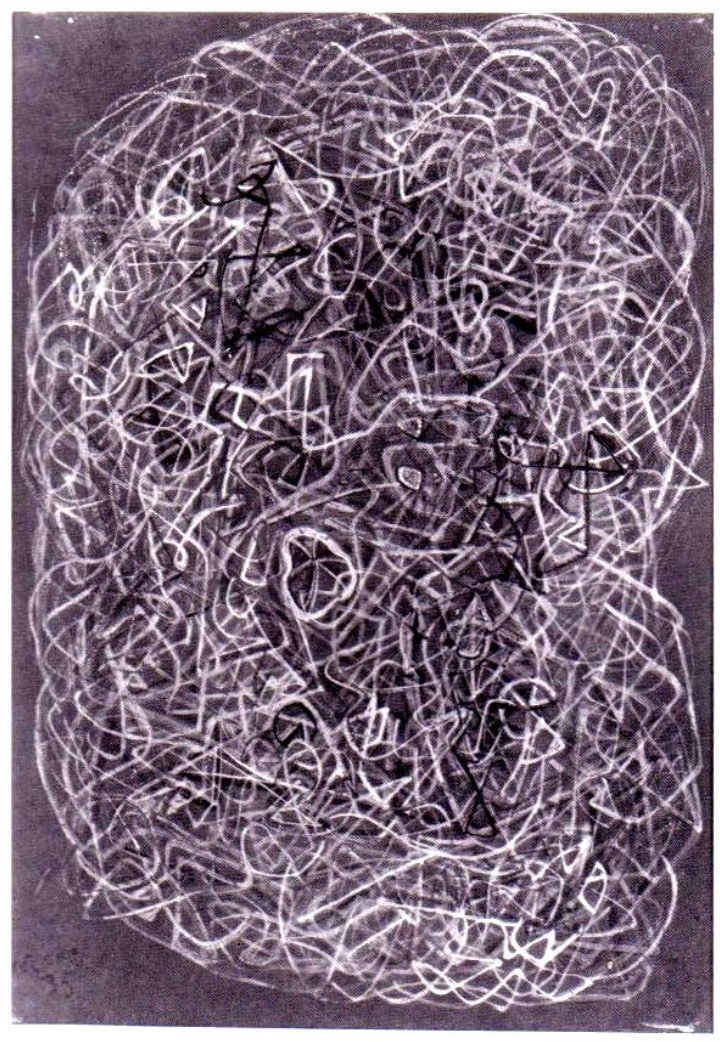

Abb. 43 


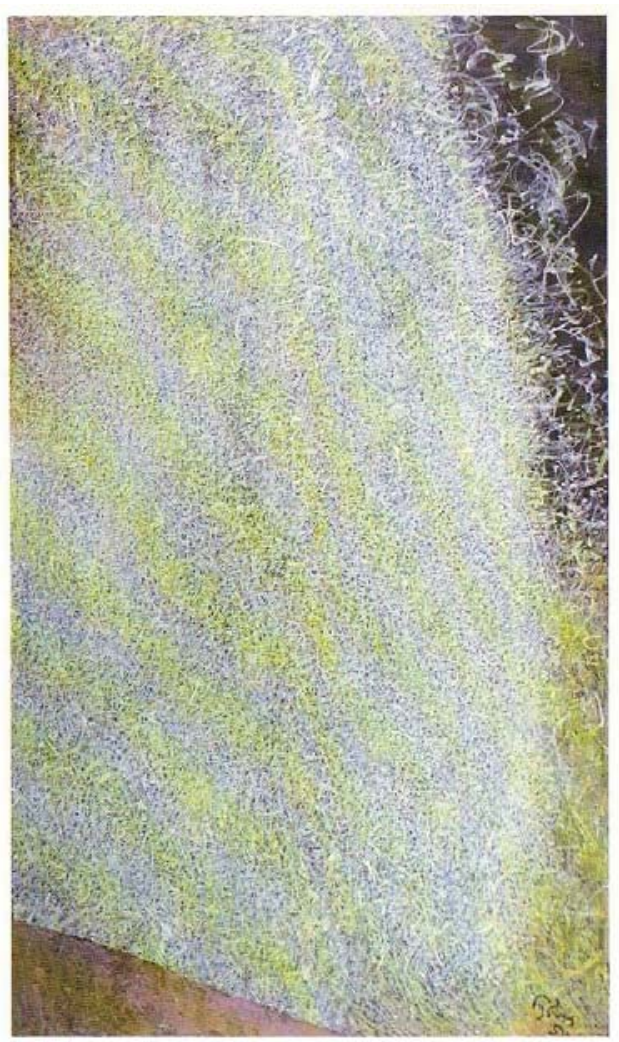

Abb. 44

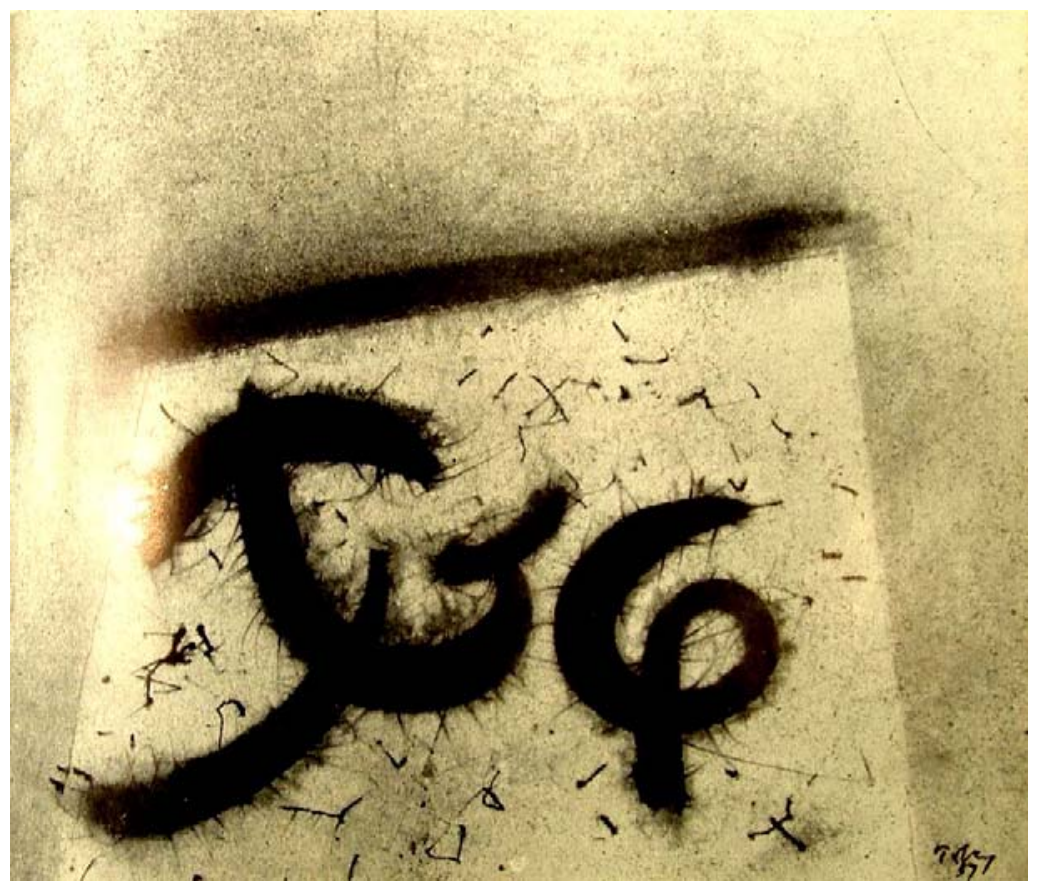

Abb. 45 


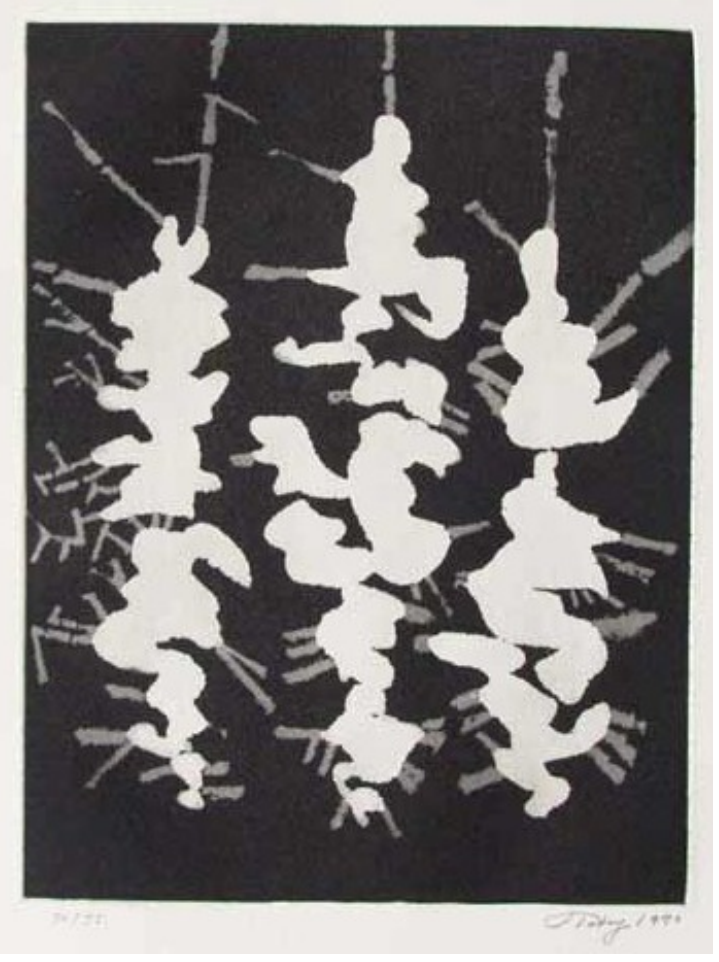

Abb. 46

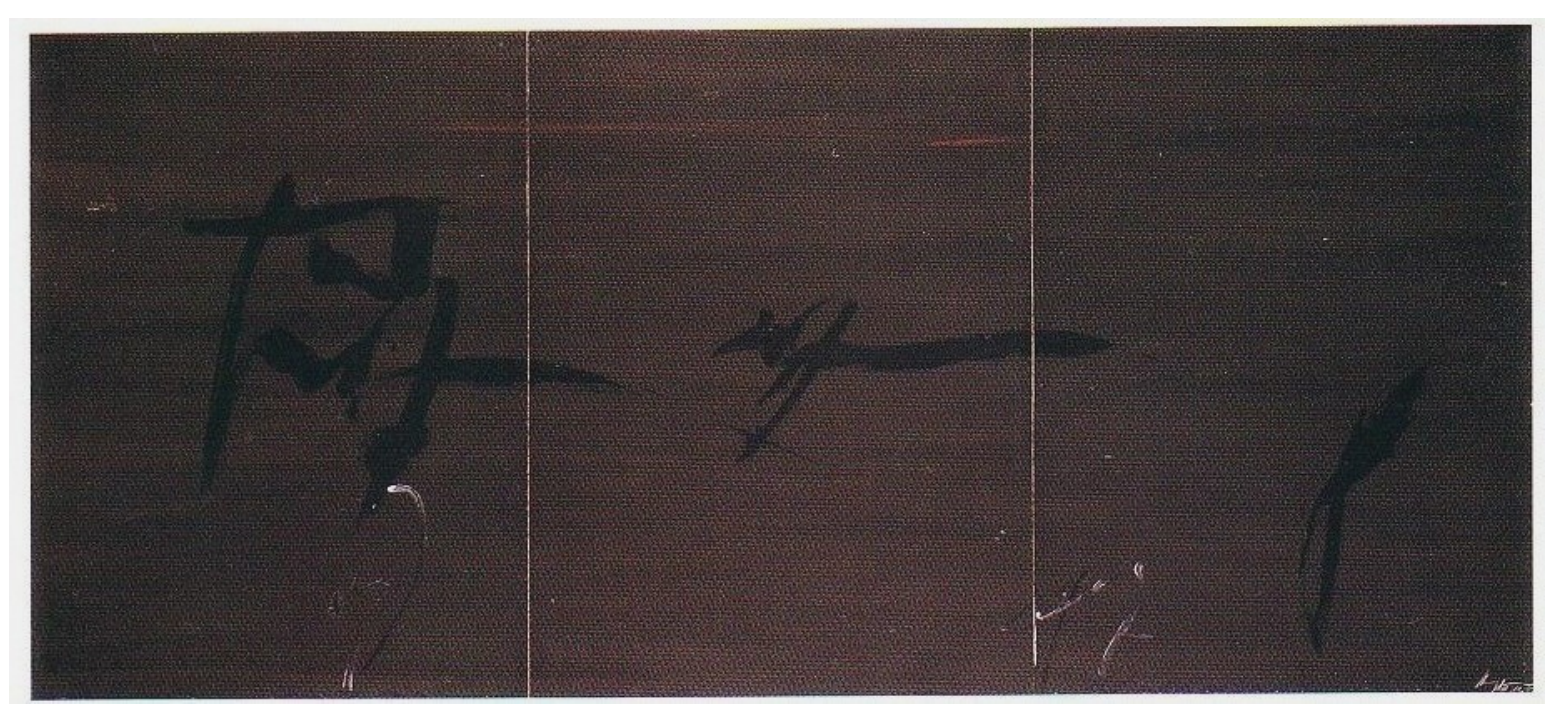

Abb. 47 


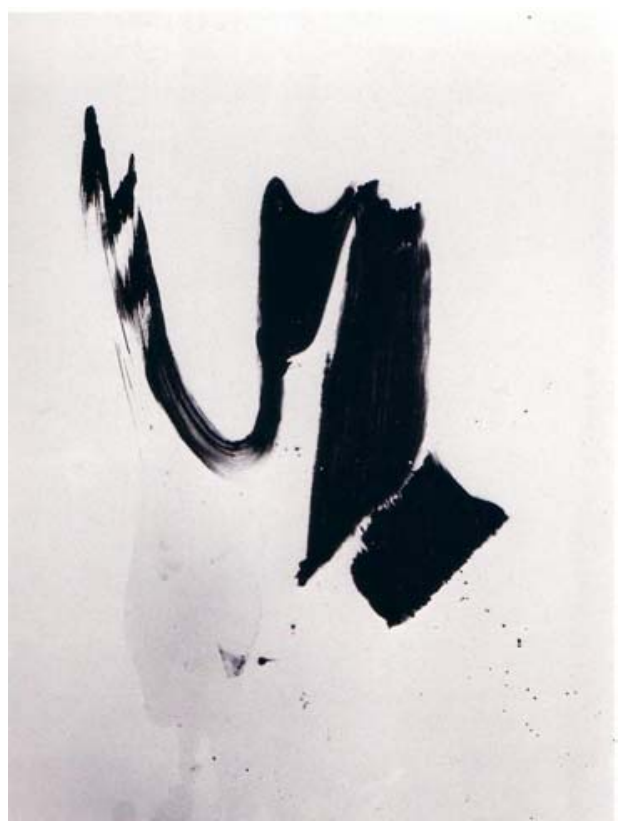

Abb. 48

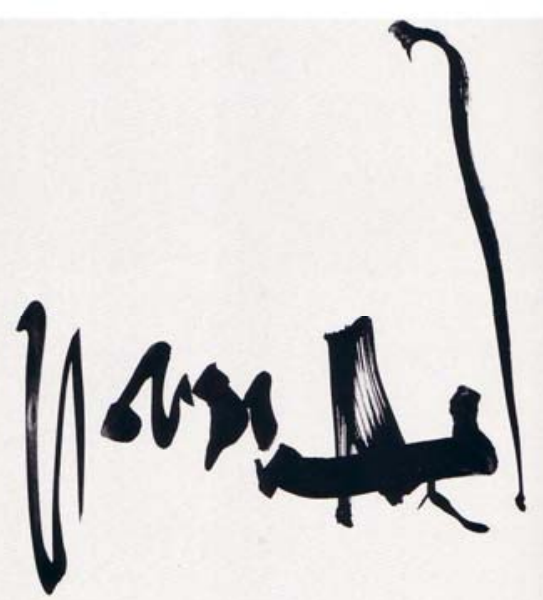

Abb. 49 


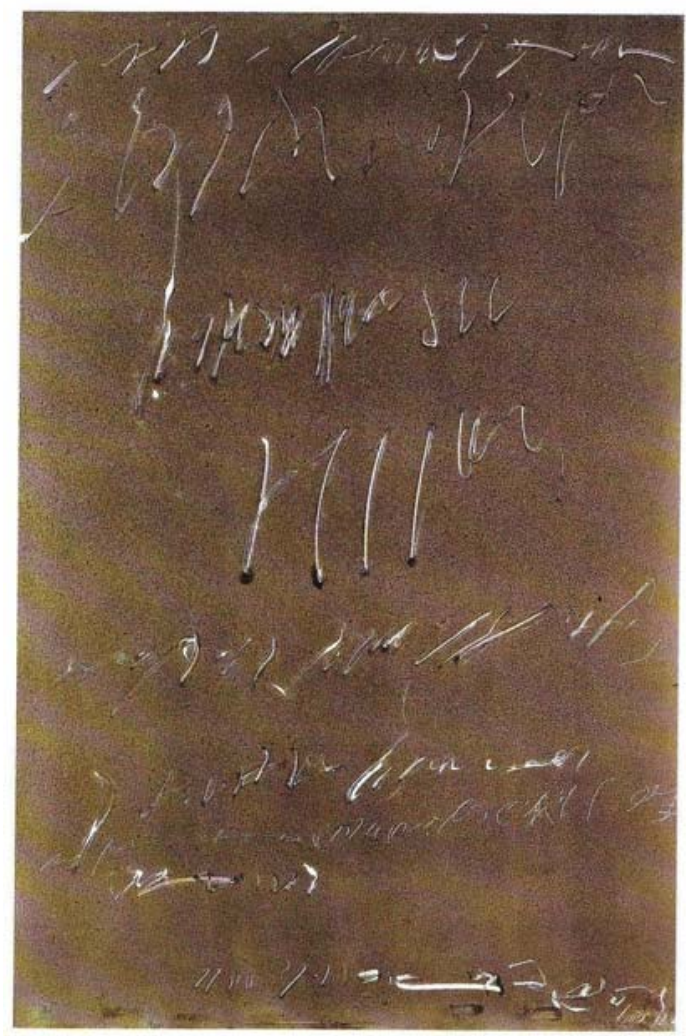

Abb. 50

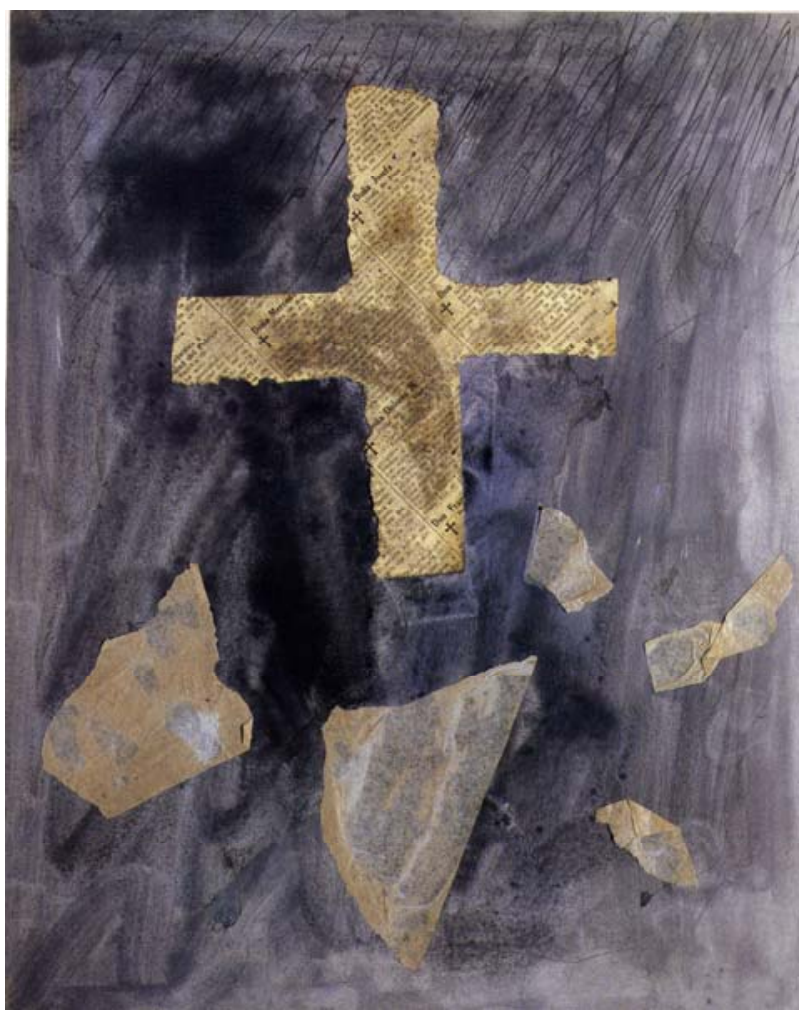

Abb. 51 


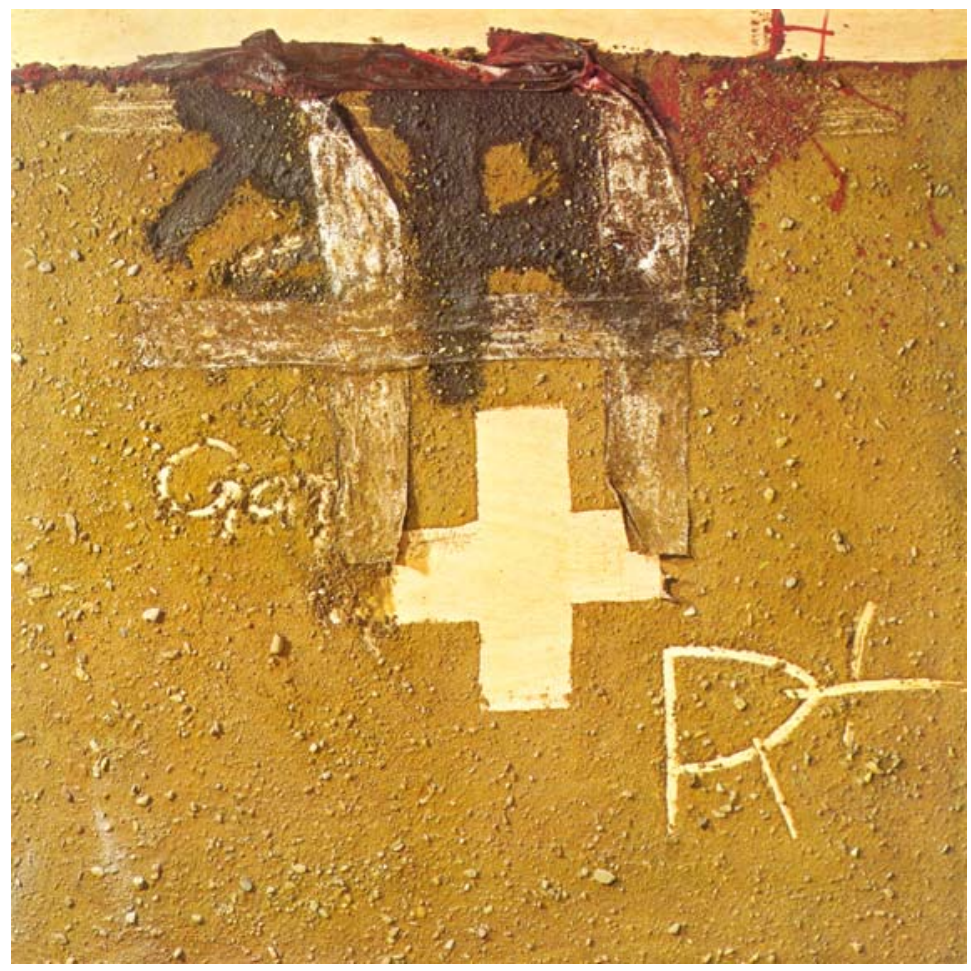

Abb. 52

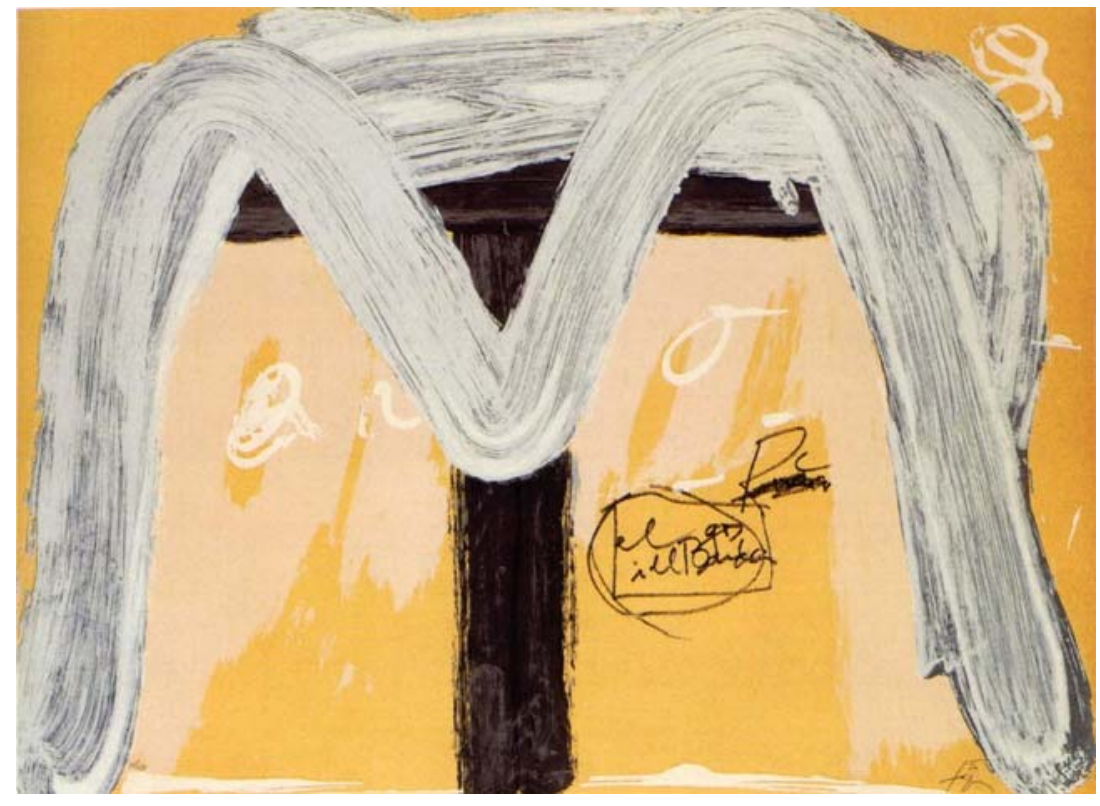

Abb. 53 


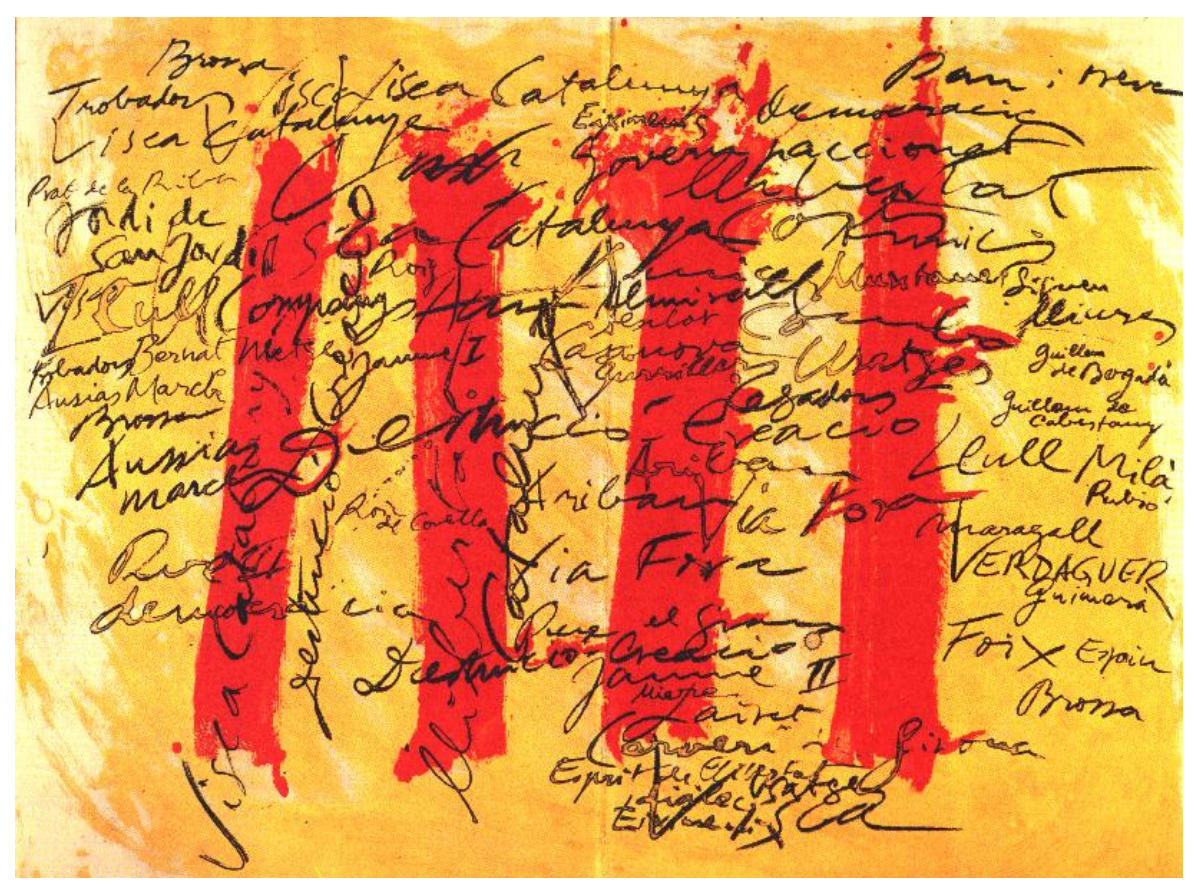

Abb. 54

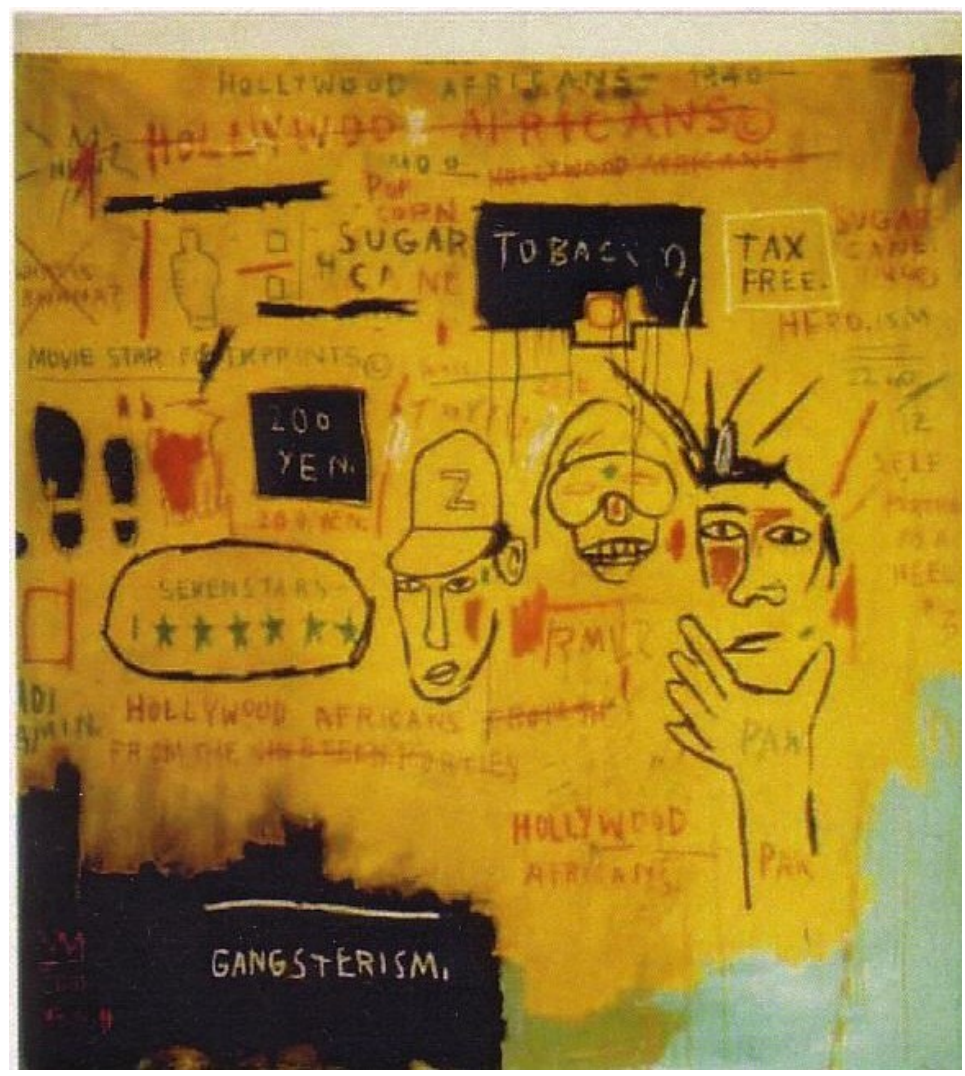

Abb. 55 
Pigment $4.6 \%$, titanium dioxide $87.1 \%$, iron oxide $5.6 \%$, benzidene yellow $7.3 \%$; non-volatile $11.3 \%$ soya styrene resin $84.0 \%$, hydrocarbon resin $16.0 \%$

volatile $84.1 \%$, aliphatic, aromatic, chiorinated and

Abb. 56

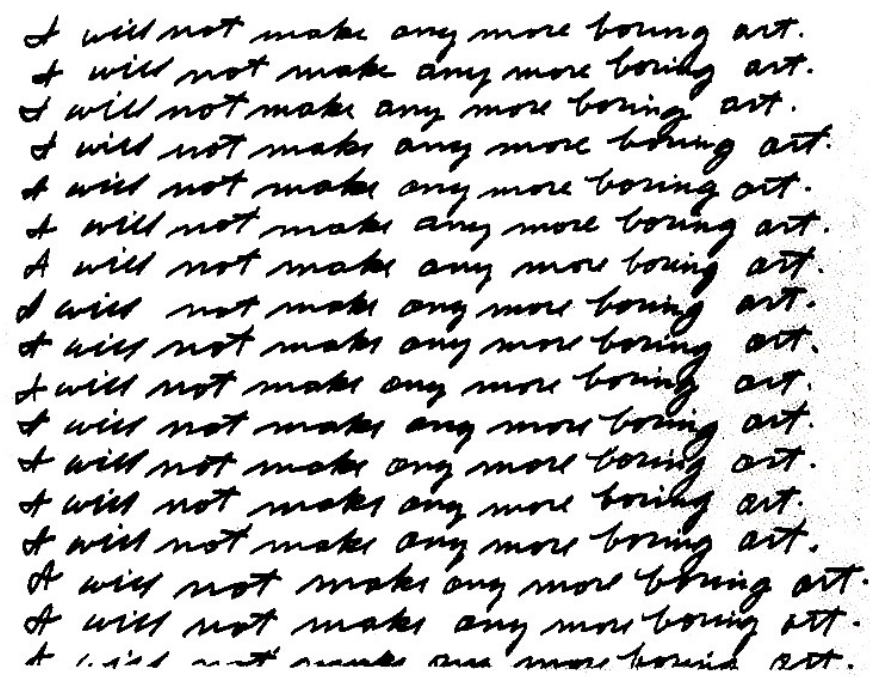

Abb. 57

subject, adj, n, v; subjection, subjective hence $\mathrm{n})$. In $\mathrm{E}$, as for $\mathrm{F}$ sujet, the adj precedes $\mathbf{n}$; both of the $E$ uses come from $\mathbf{F}$; the $\mathbf{F}$ ( suget, OF sugez) comes from ML subjectus, $\mathrm{p}$ subjicere, L subiicere (subicere), to throw, henc bring or place under: sub, under $+-i(i) c e r e$, of iacere, to throw, the active aspect of iacere lie down: f.a.e., JET.-'To subject' derives f MF subjecter, ML subjectāre, L subiectäre, fre subiicere; subjection and subjective derive $\mathrm{f}$ OF-MF subjection (ML subjectiōnem, acc subjectiō, L subiectiō, from the pp subiectus) late MF-F subjectif, f -ive (ML subjectivus).

Abb. 58 


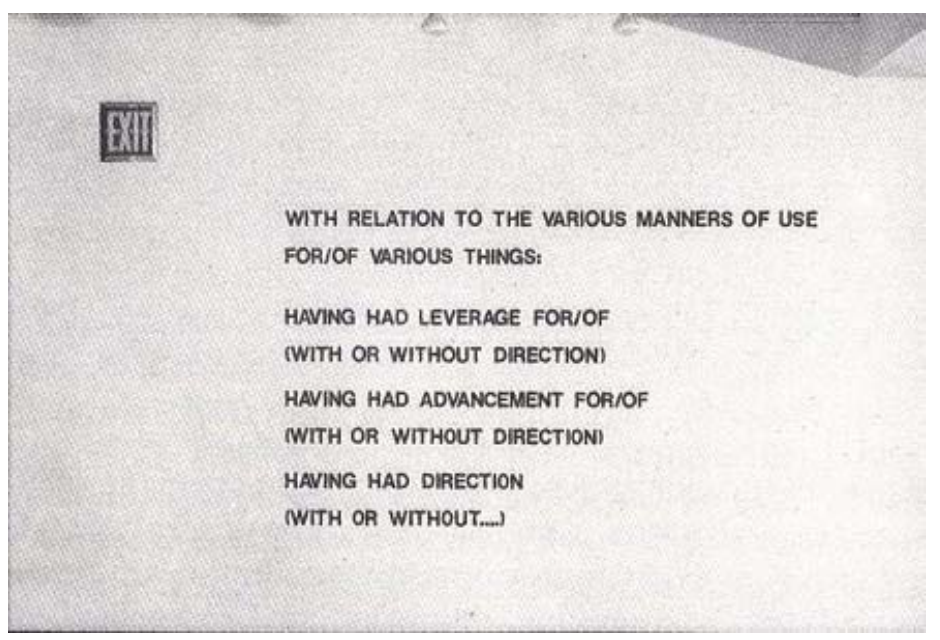

Abb.59

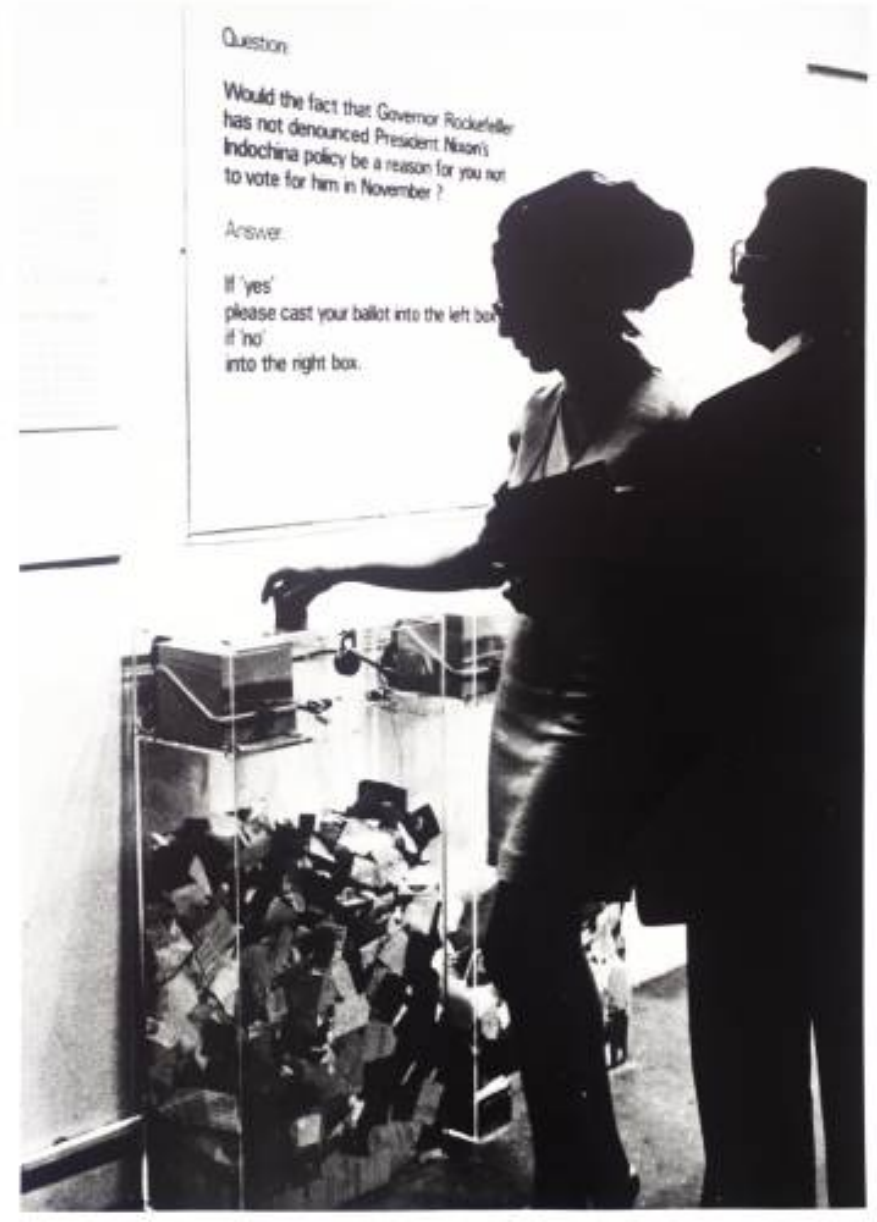

Abb. 60 

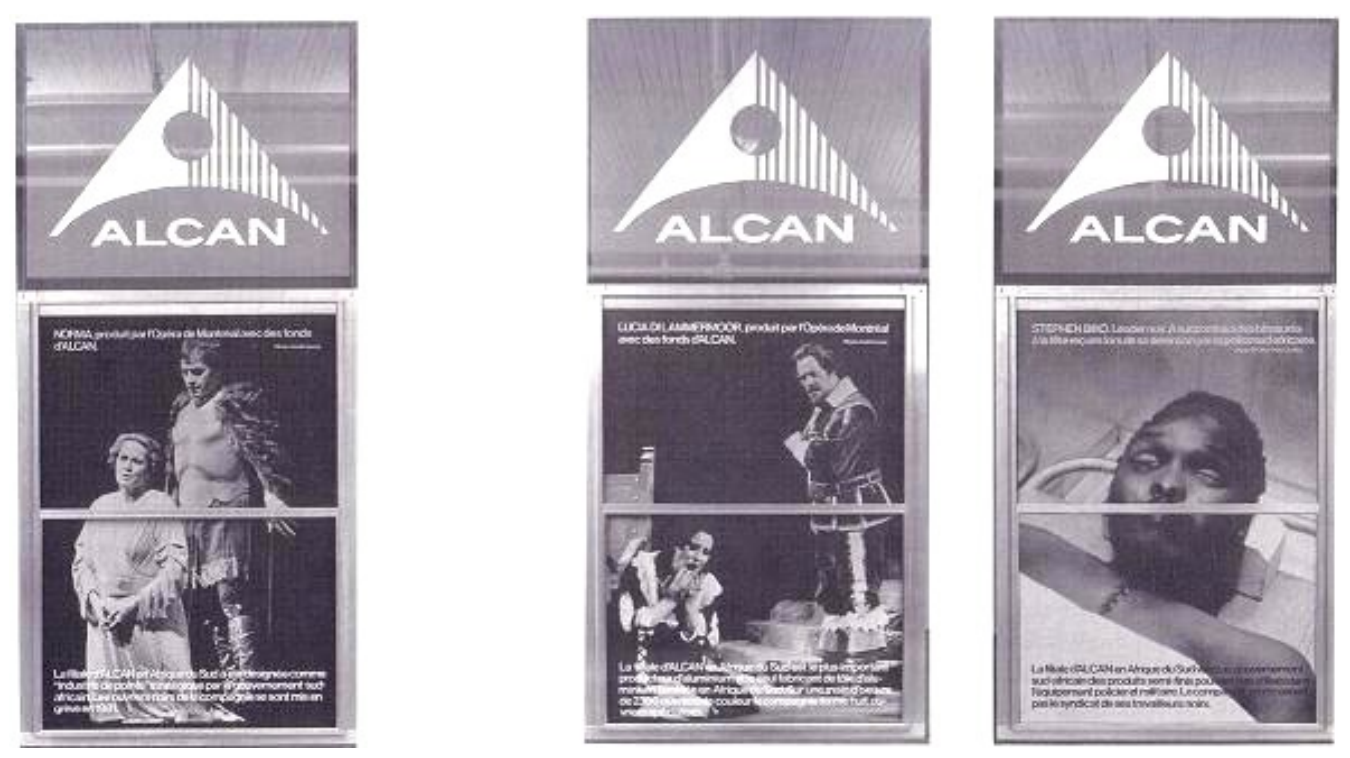

Abb. 61

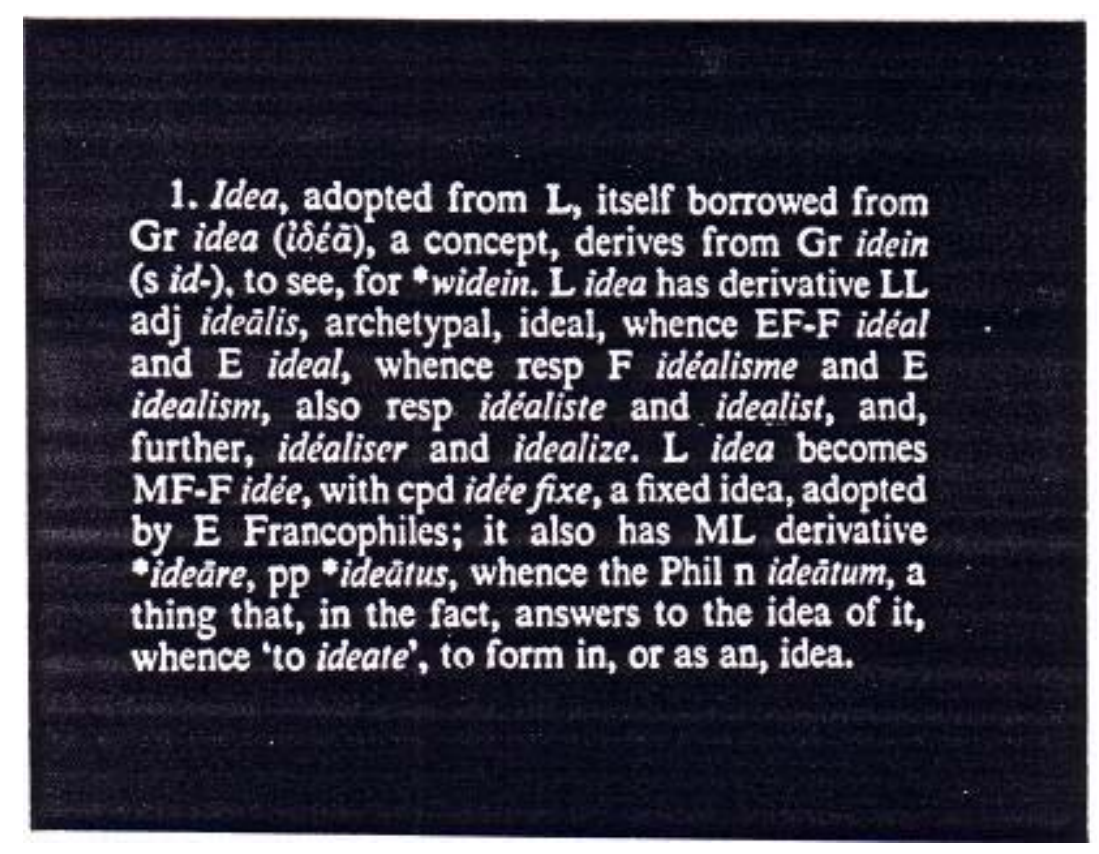

Abb. 62 


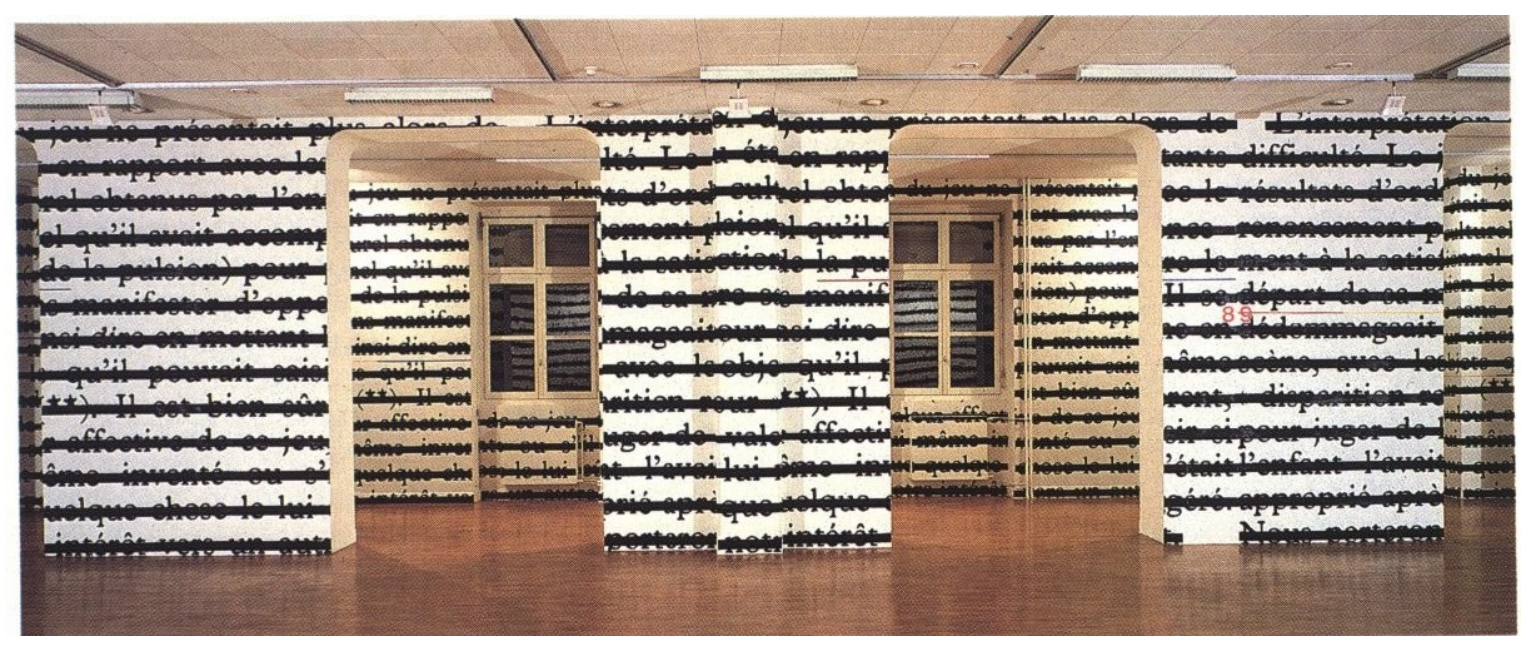

Abb. 63

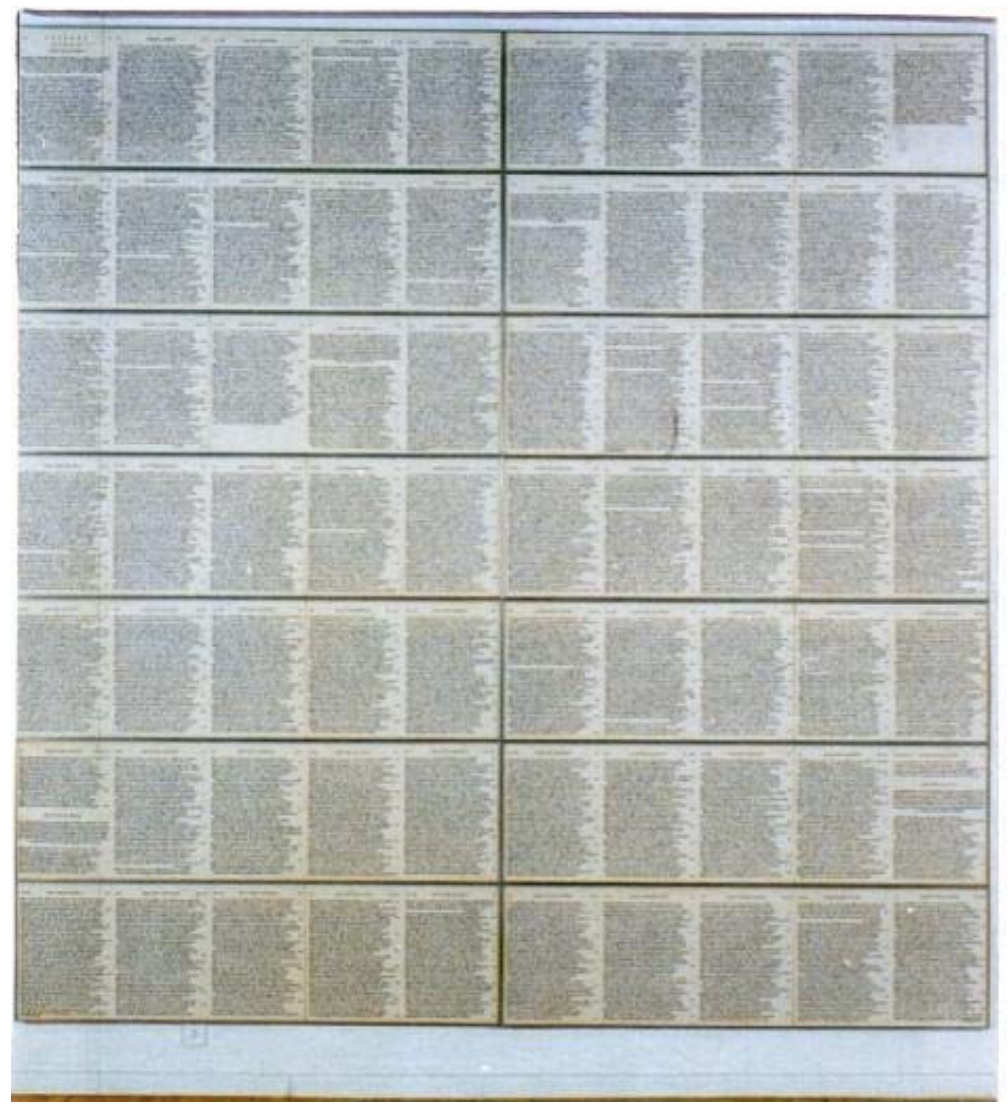

Abb. 64 


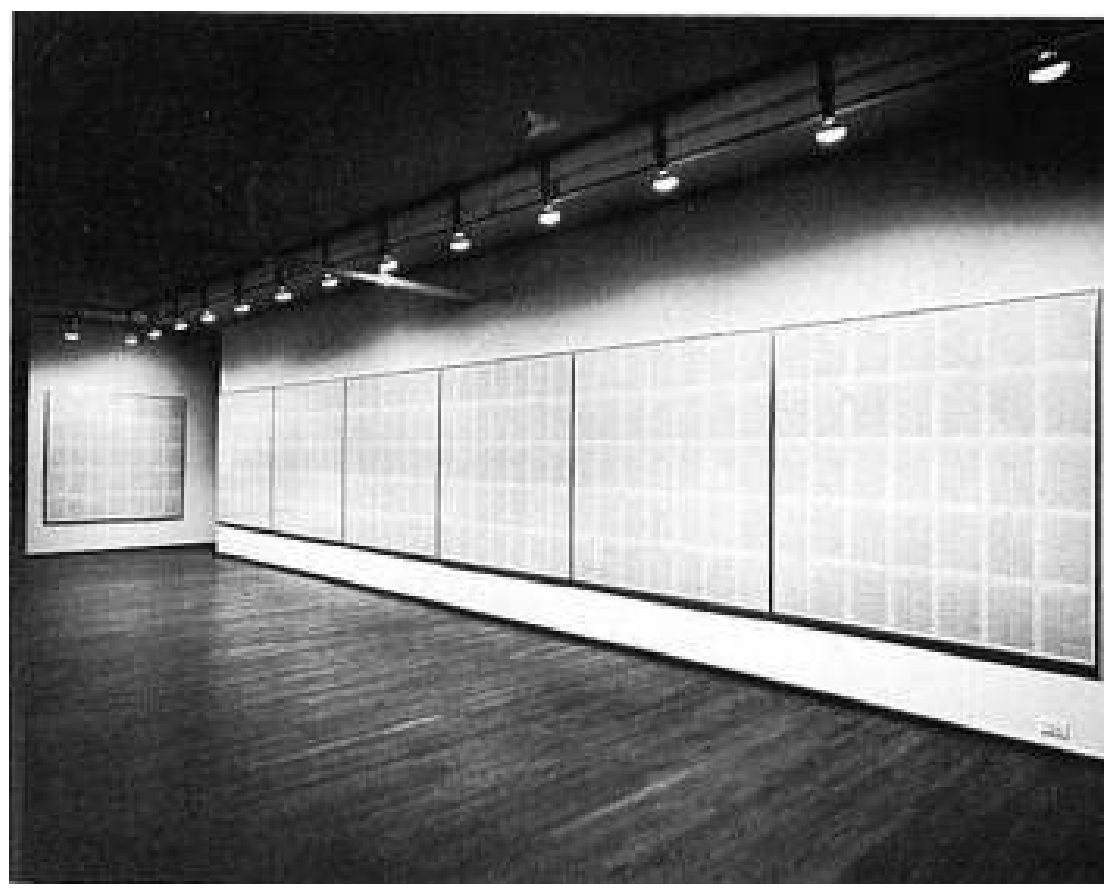

Abb. 65

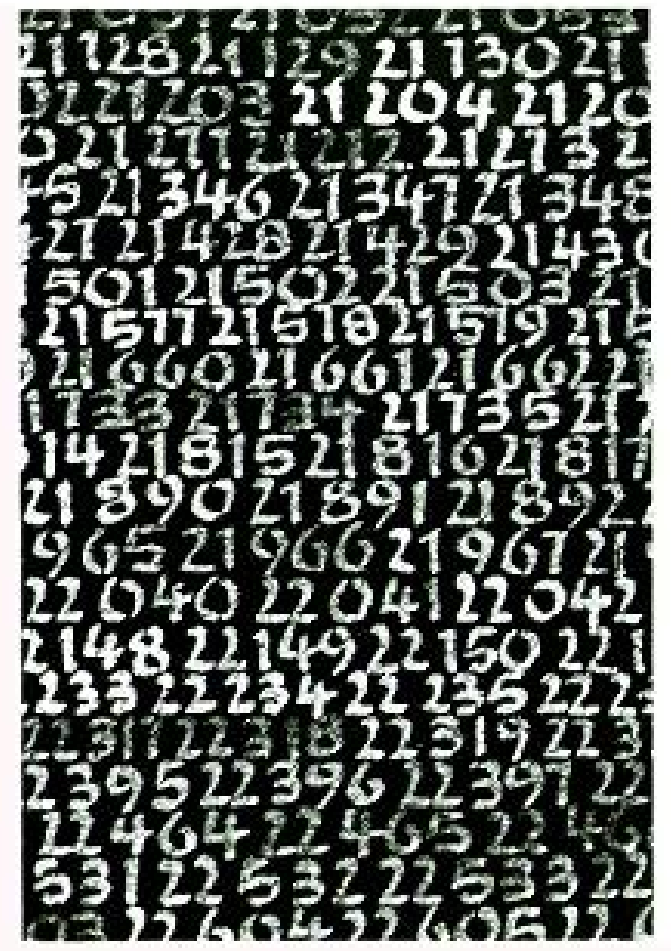

Abb. 66 


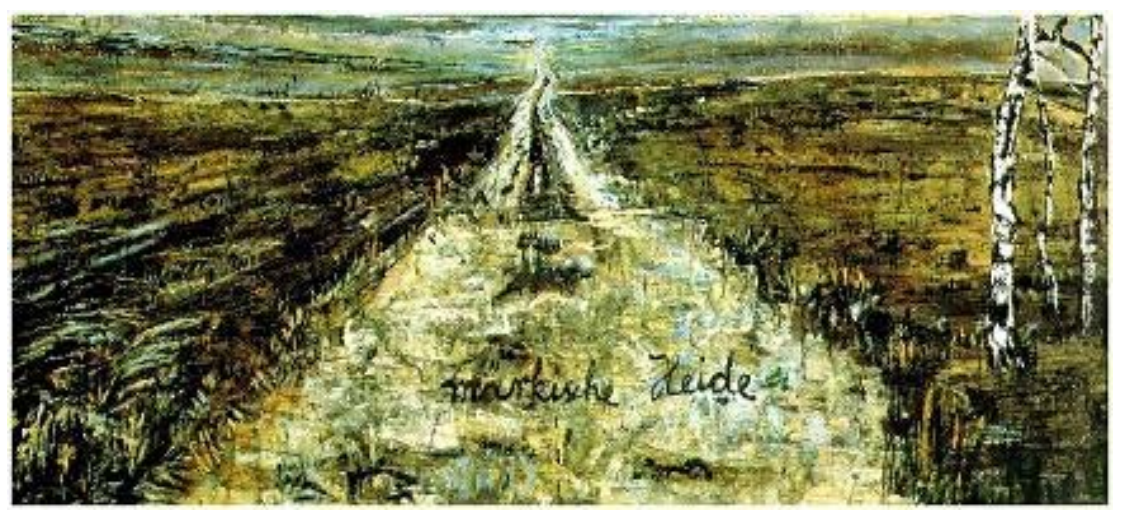

Abb. 67

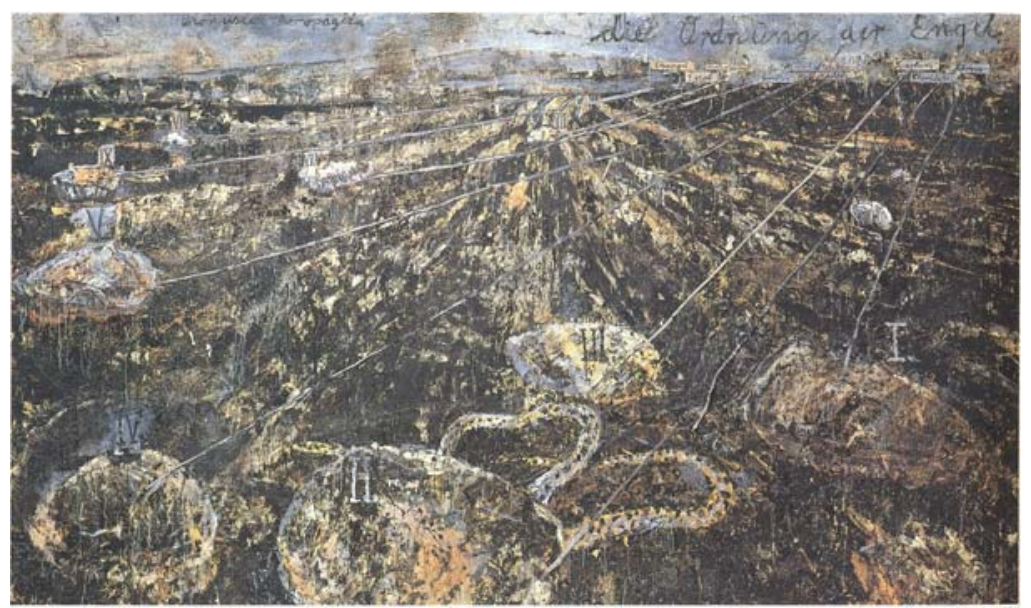

Abb. 68

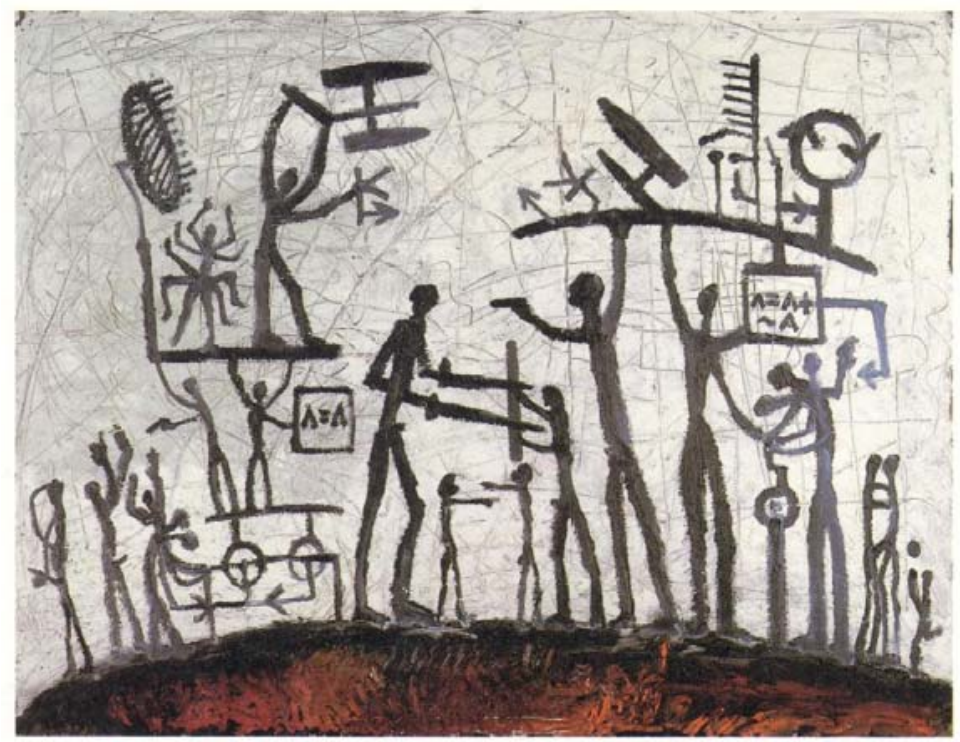

Abb. 69 


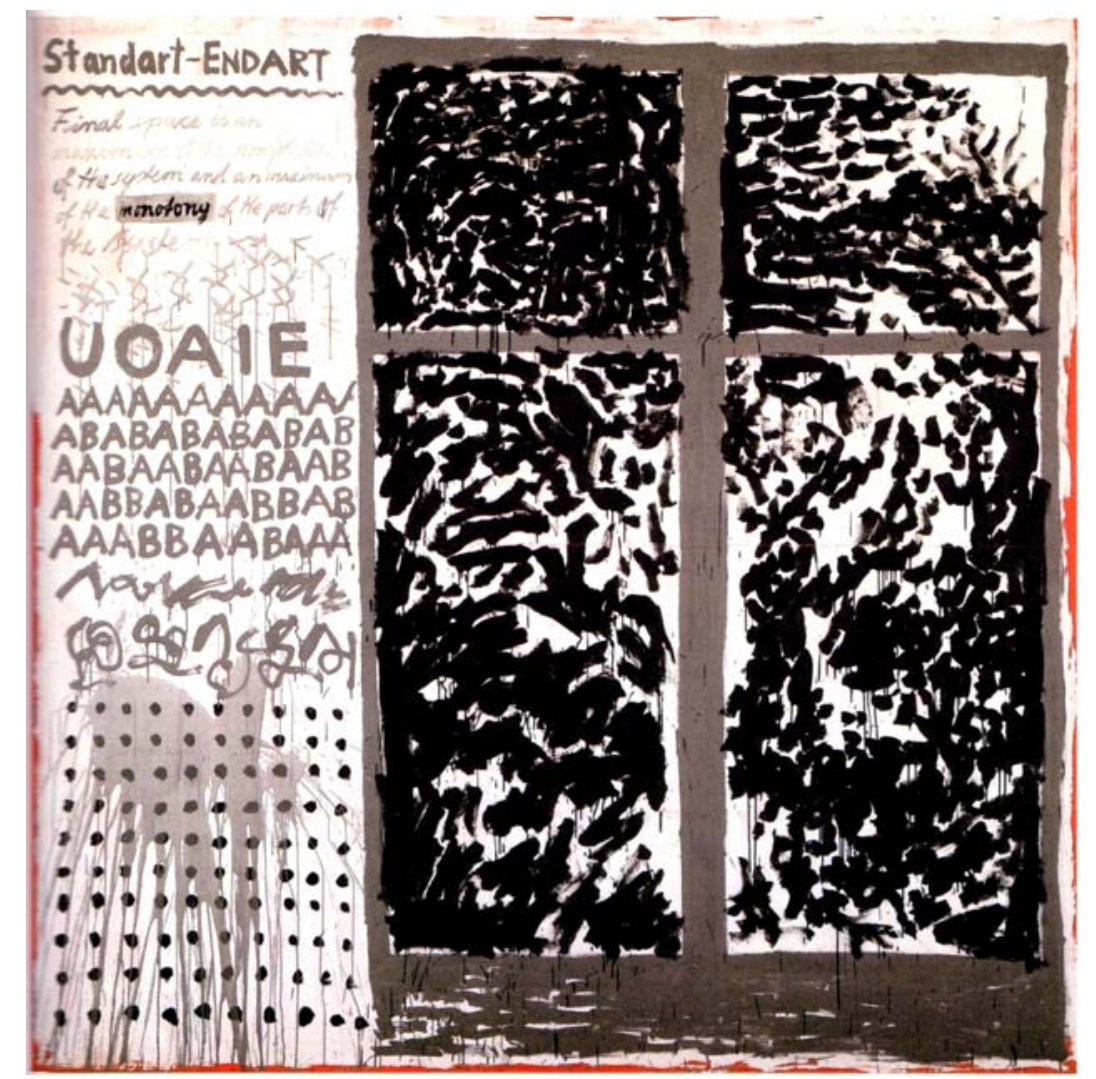

Abb. 70

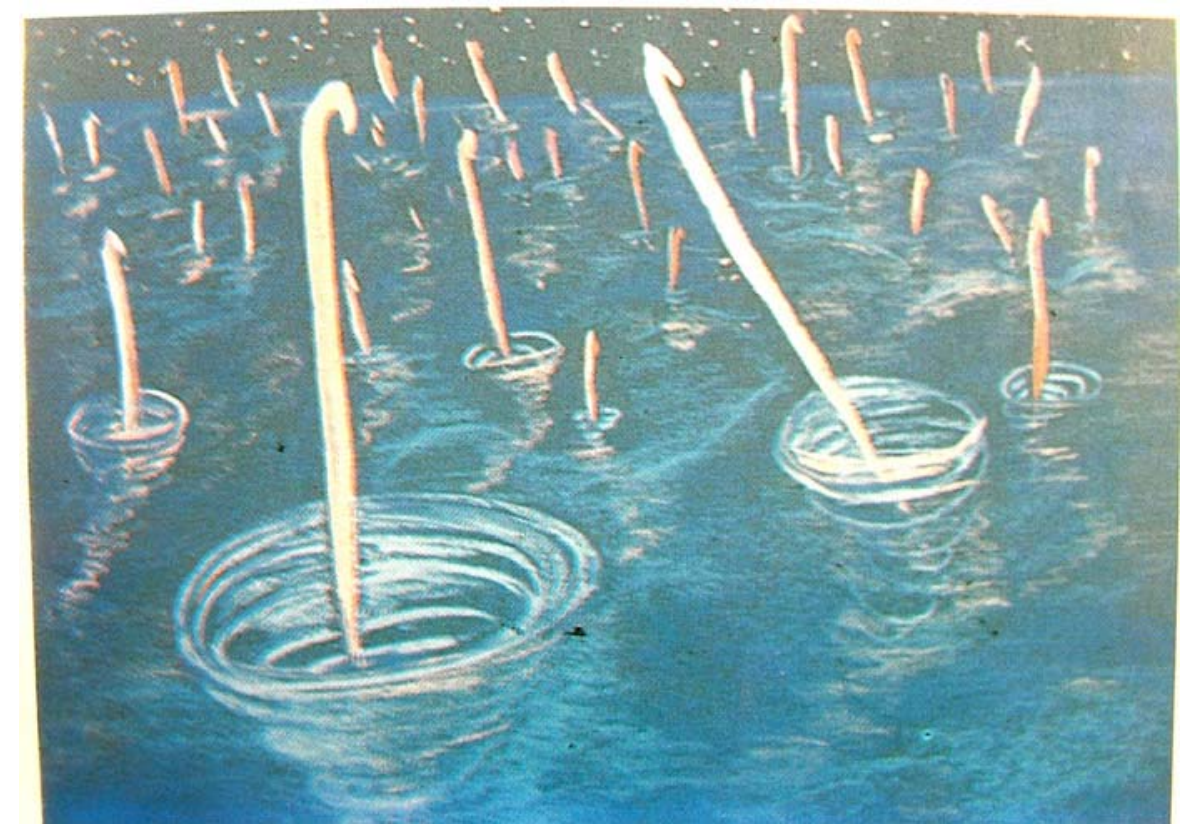

Abb. 71 


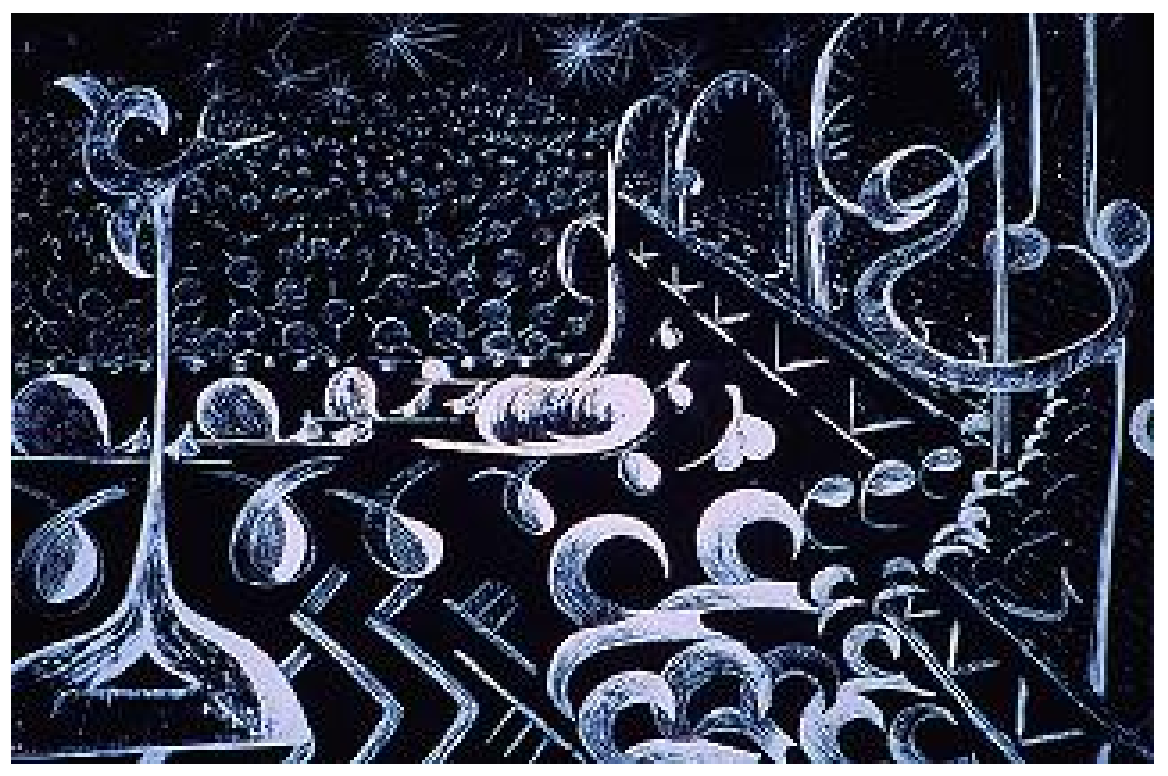

Abb. 72

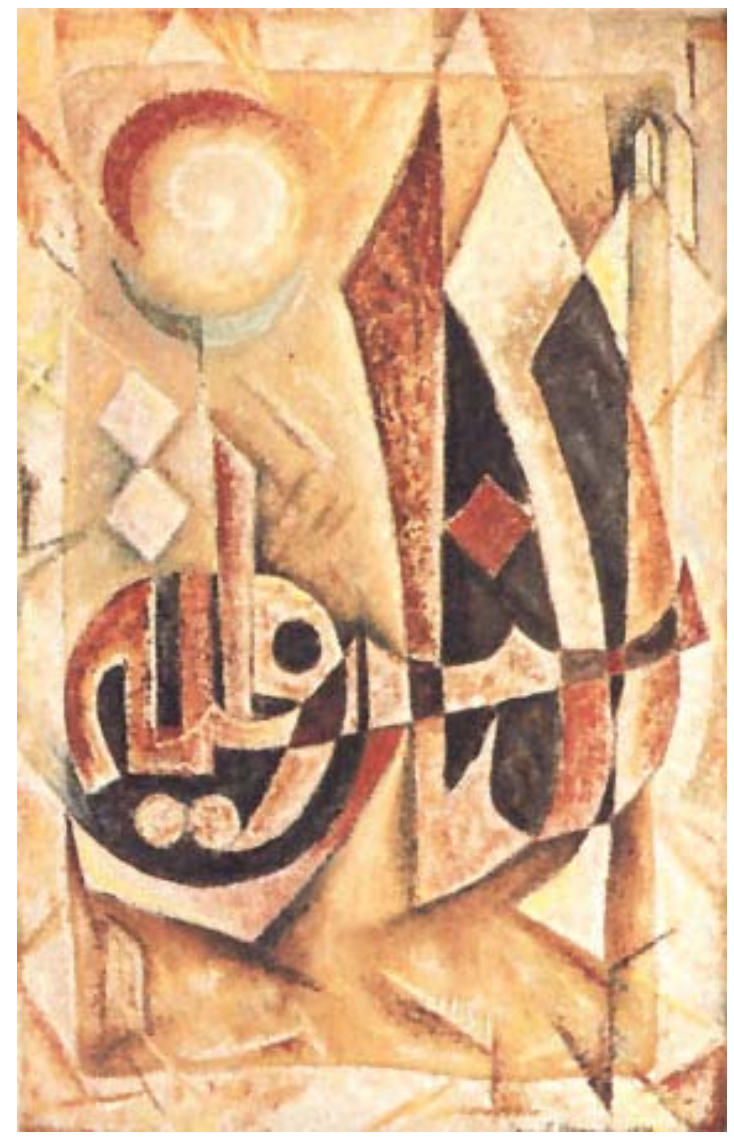

Abb. 73 


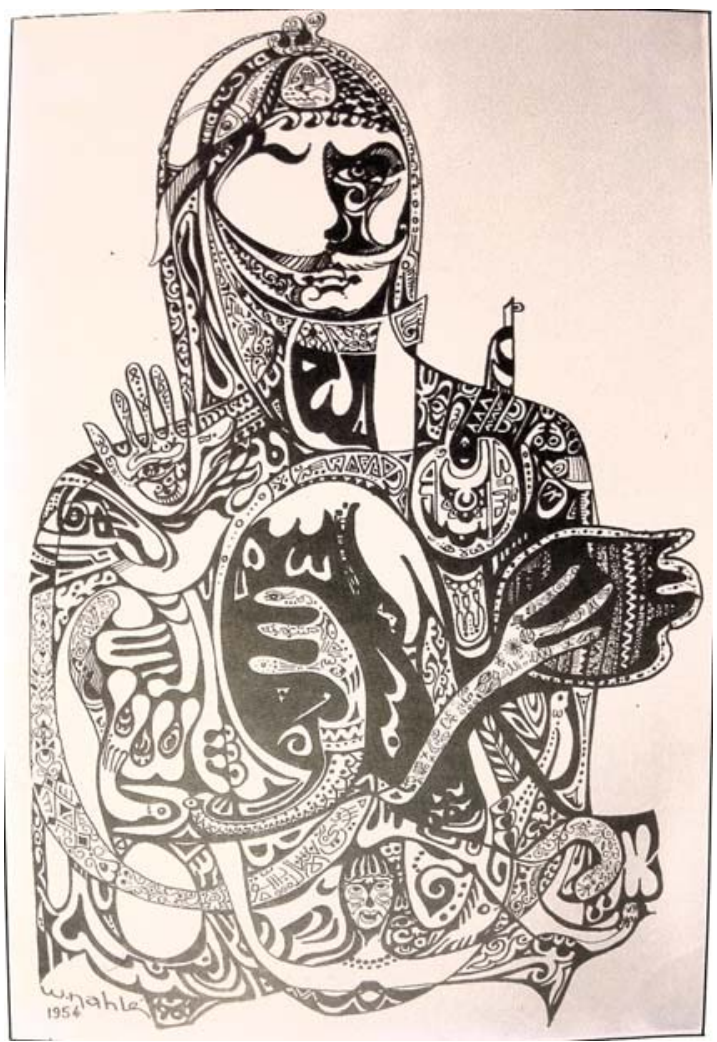

Abb. 74

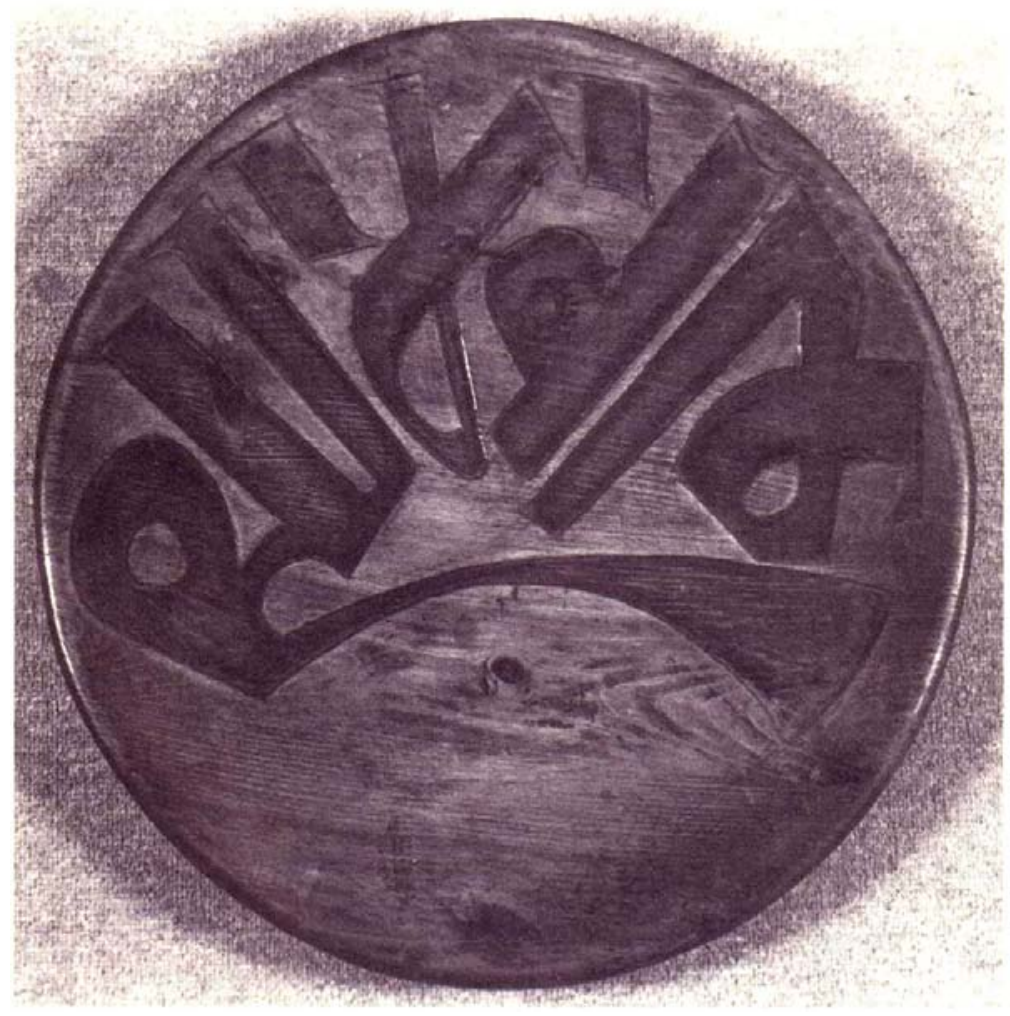

Abb. 75 


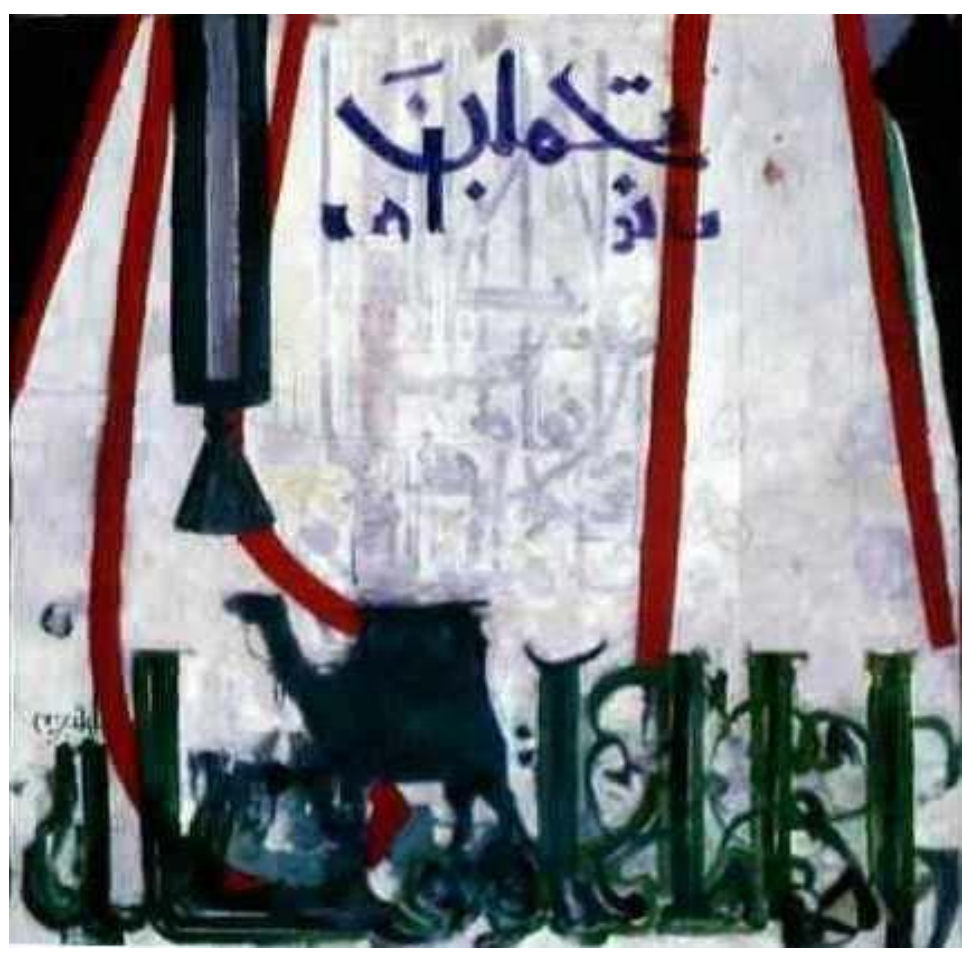

Abb. 76

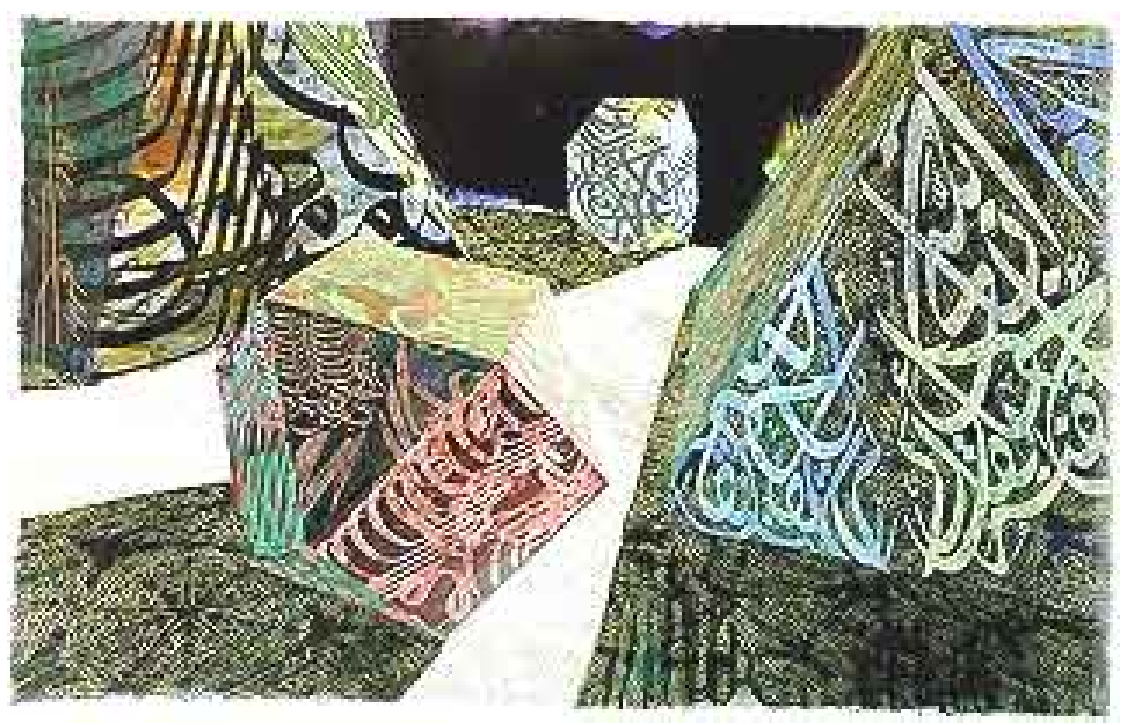

Abb. 77 


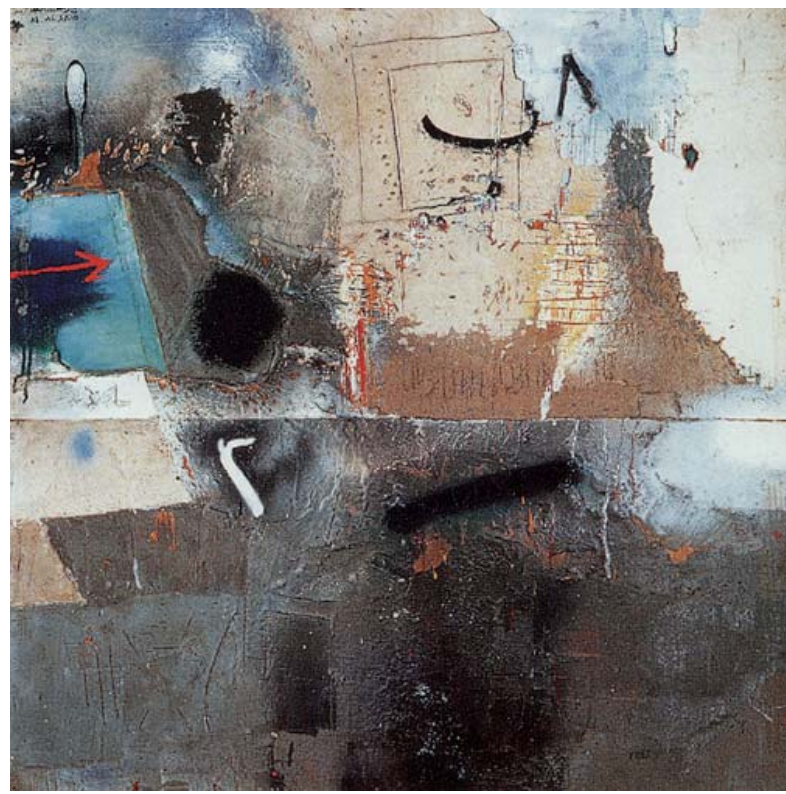

Abb. 78

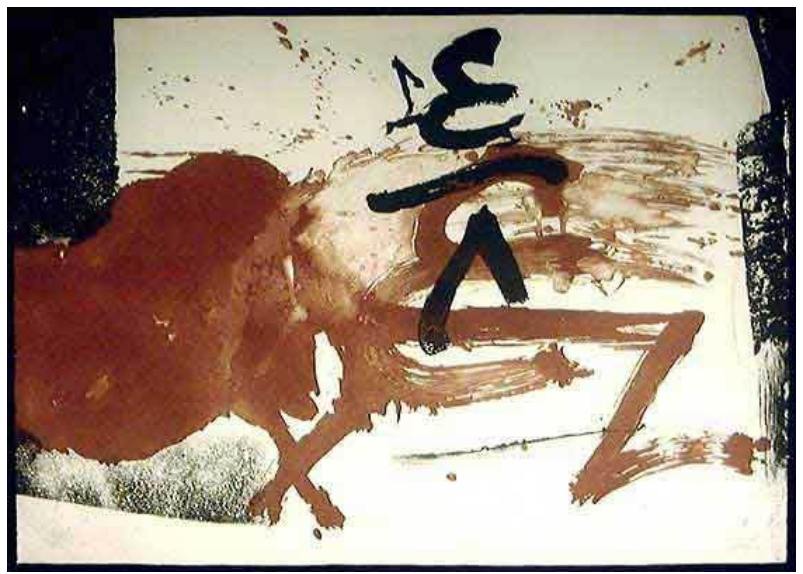

Abb. 79

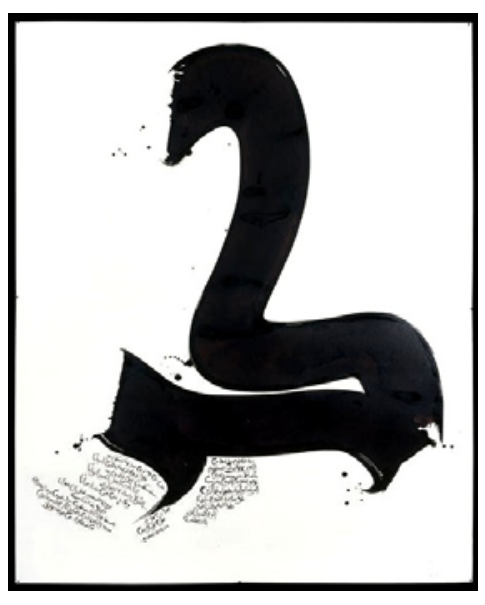

Abb. 80 


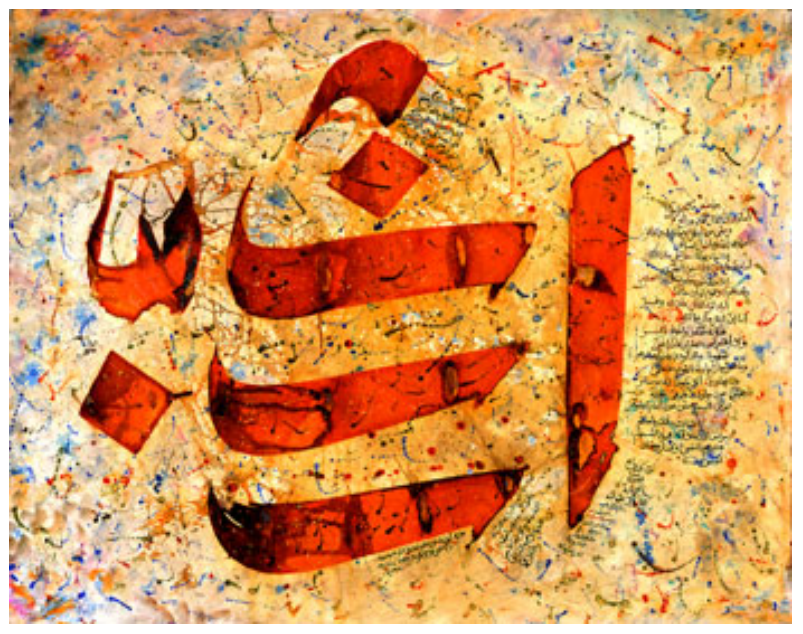

Abb. 81

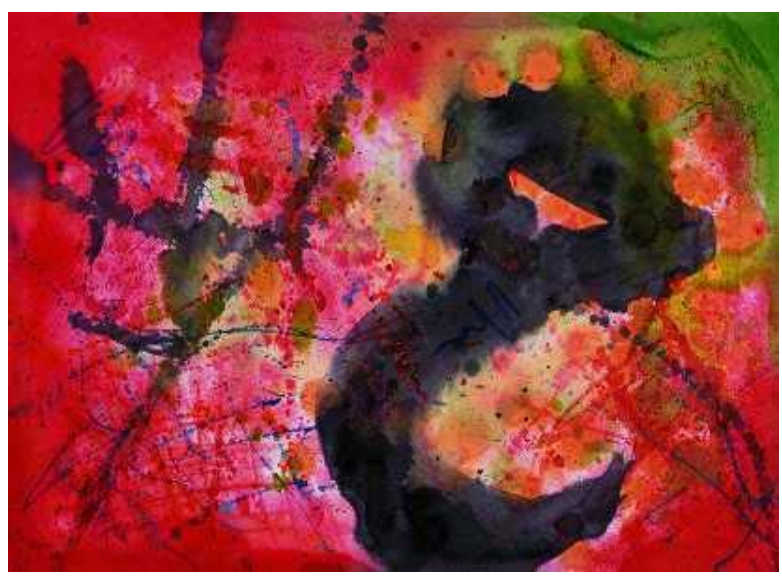

Abb. 82

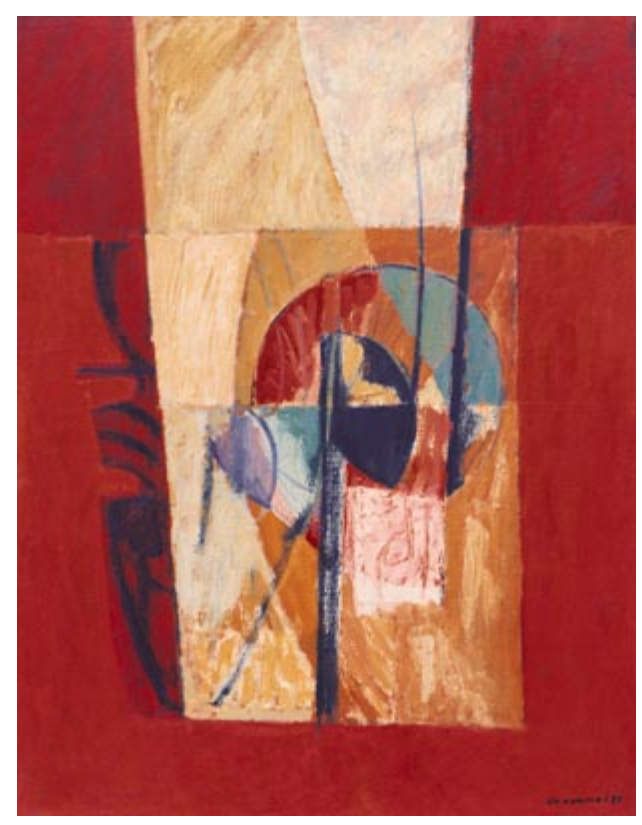

Abb. 83 


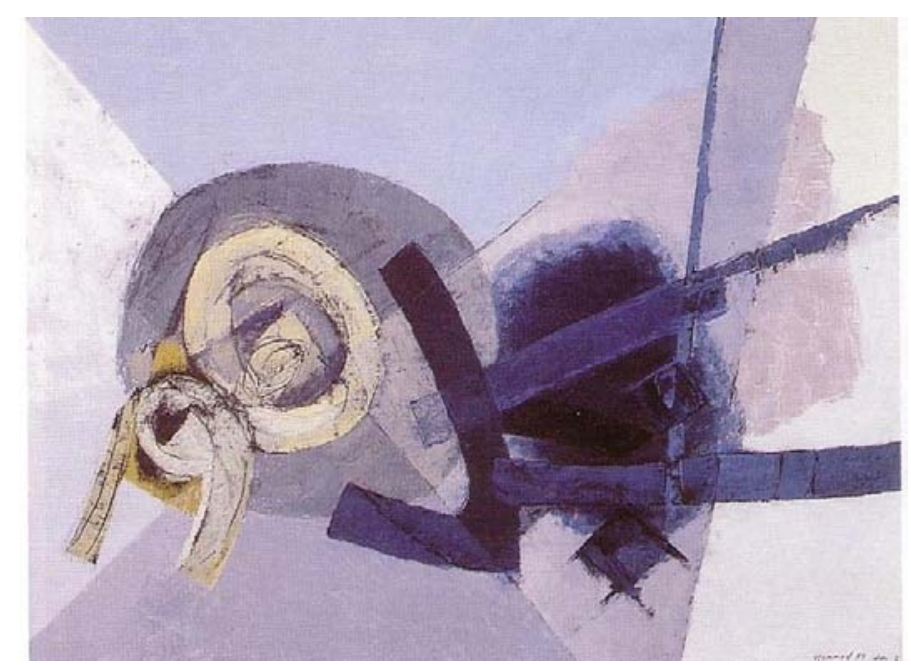

Abb. 84

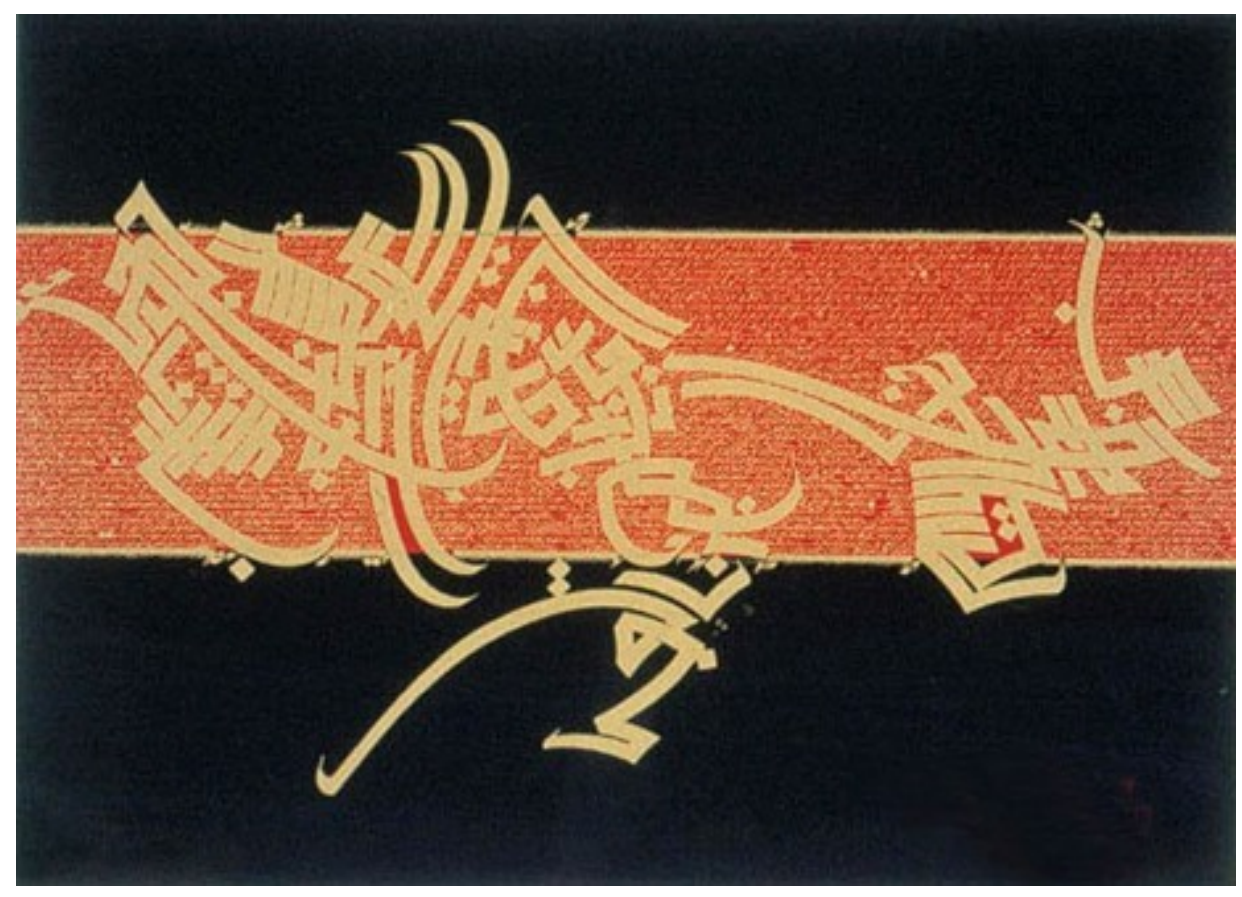

Abb. 85 


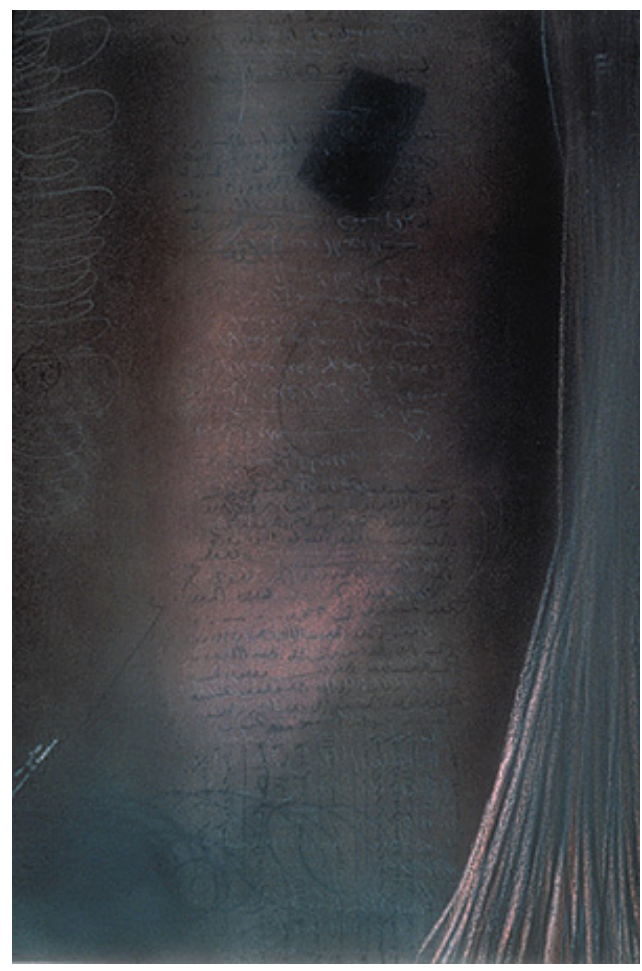

Abb. 86

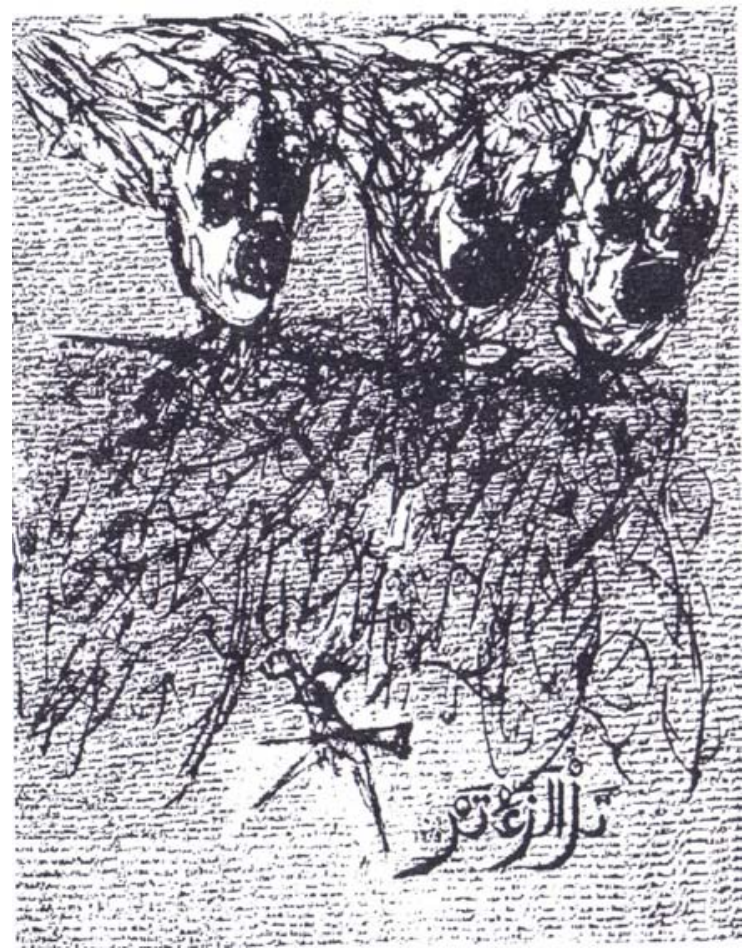

Abb. 87 


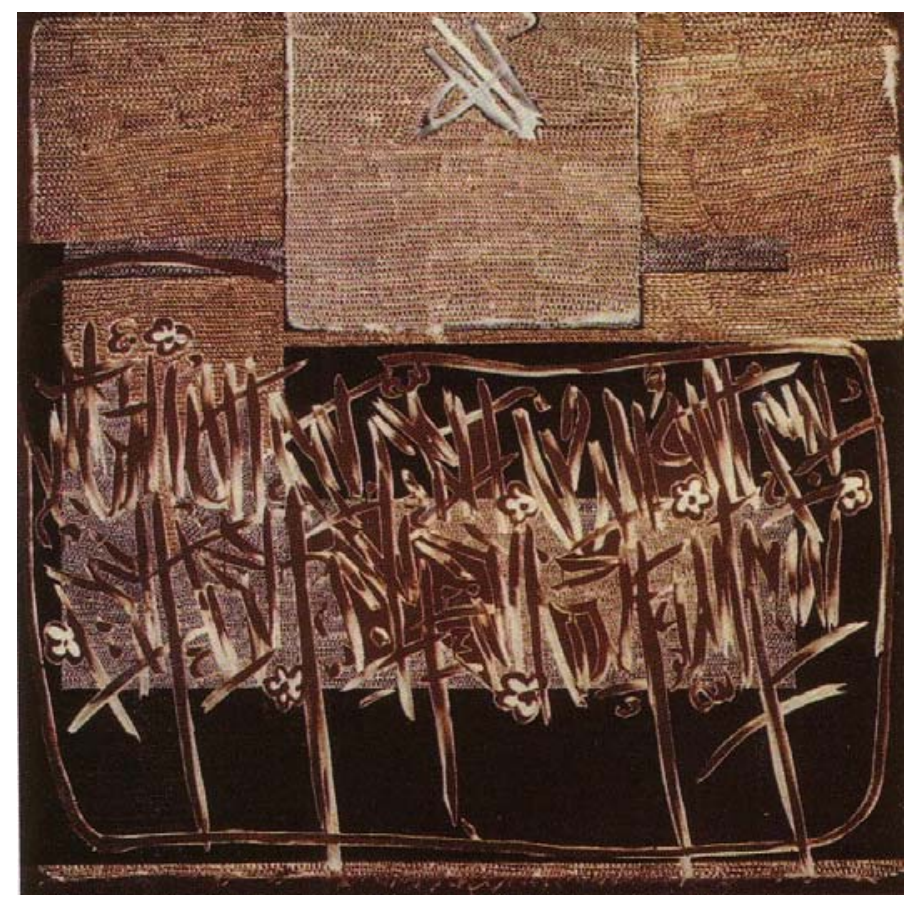

Abb. 88

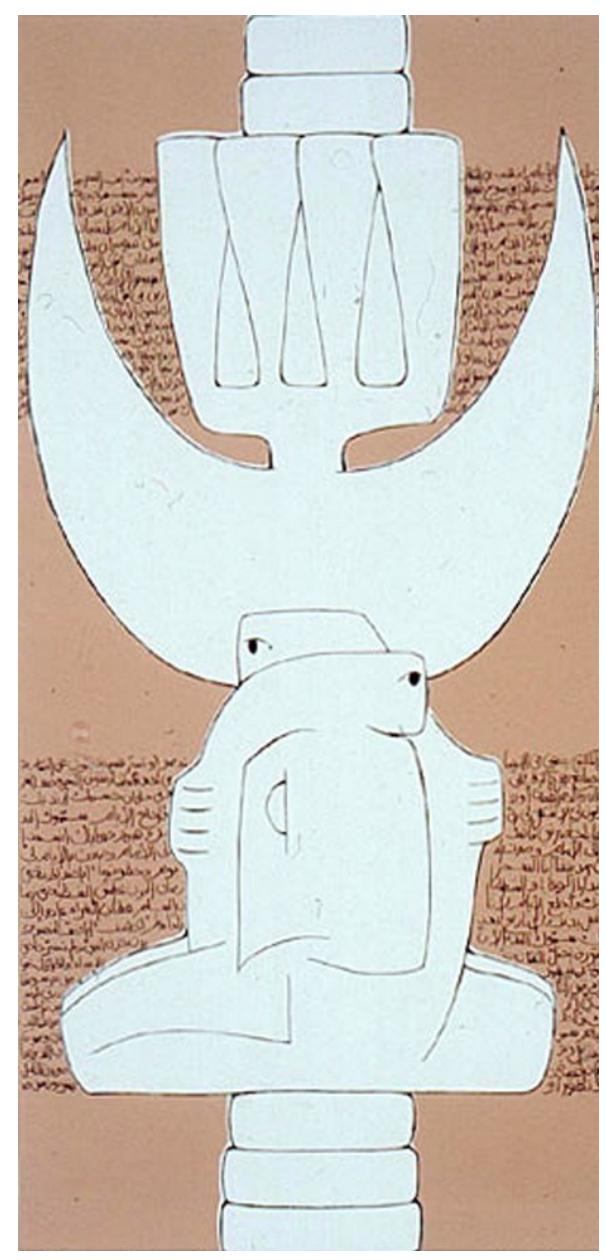

Abb. 89 


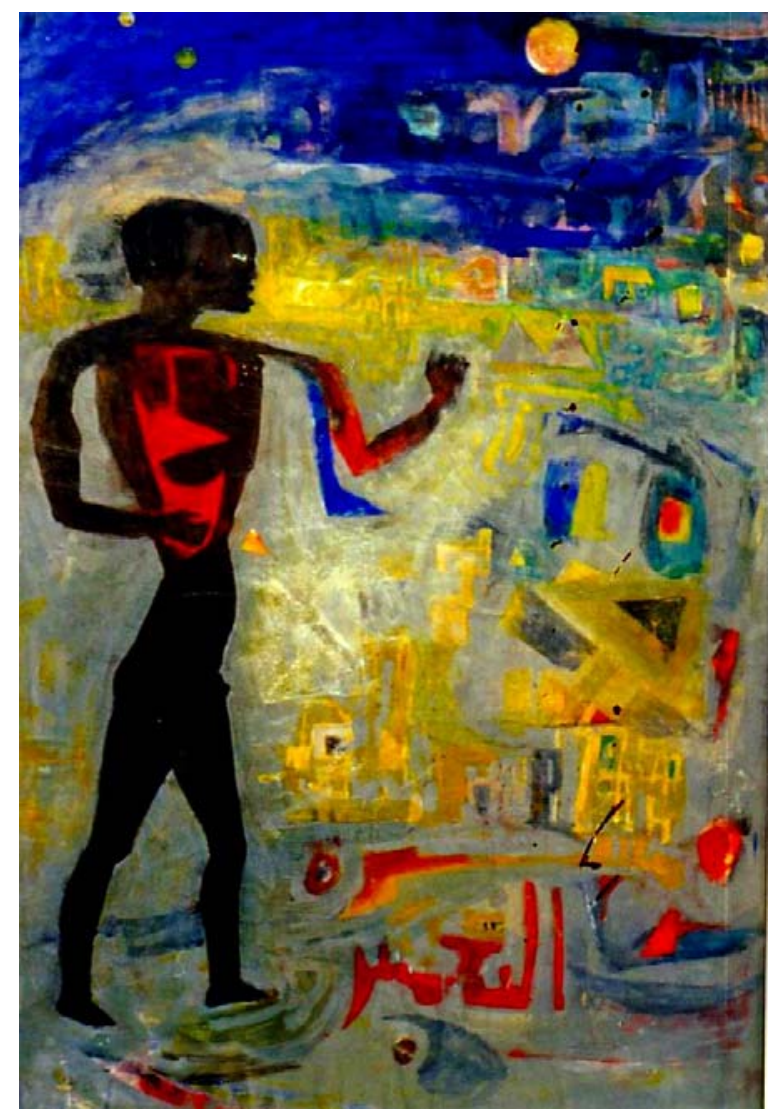

Abb. 90

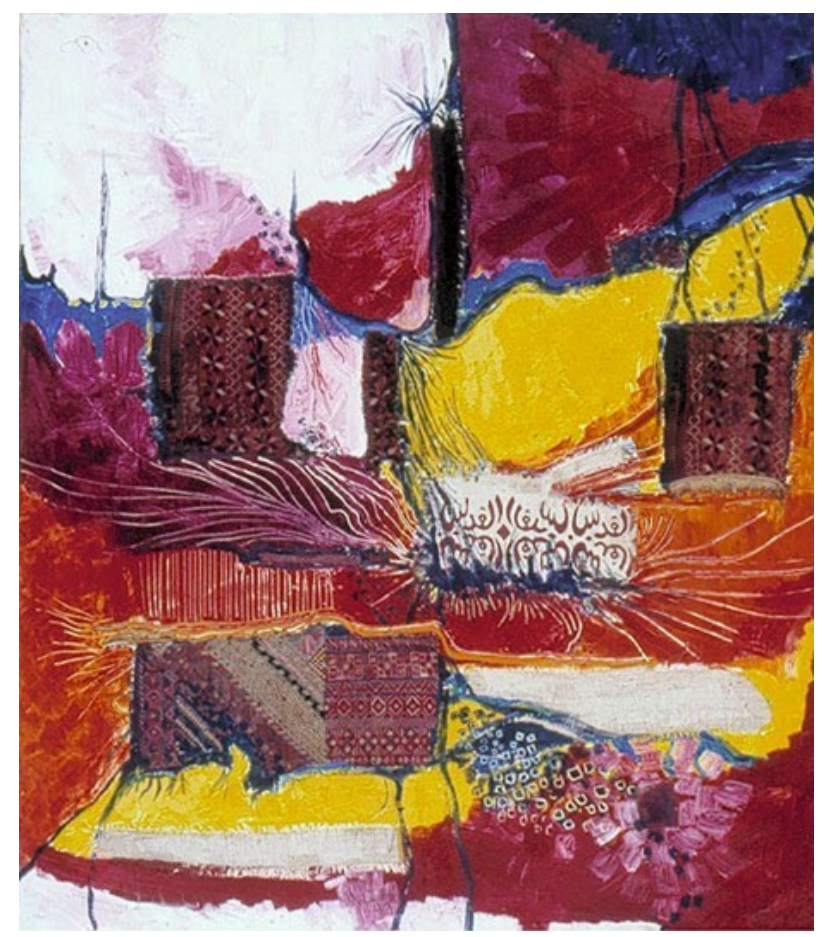

Abb. 91 


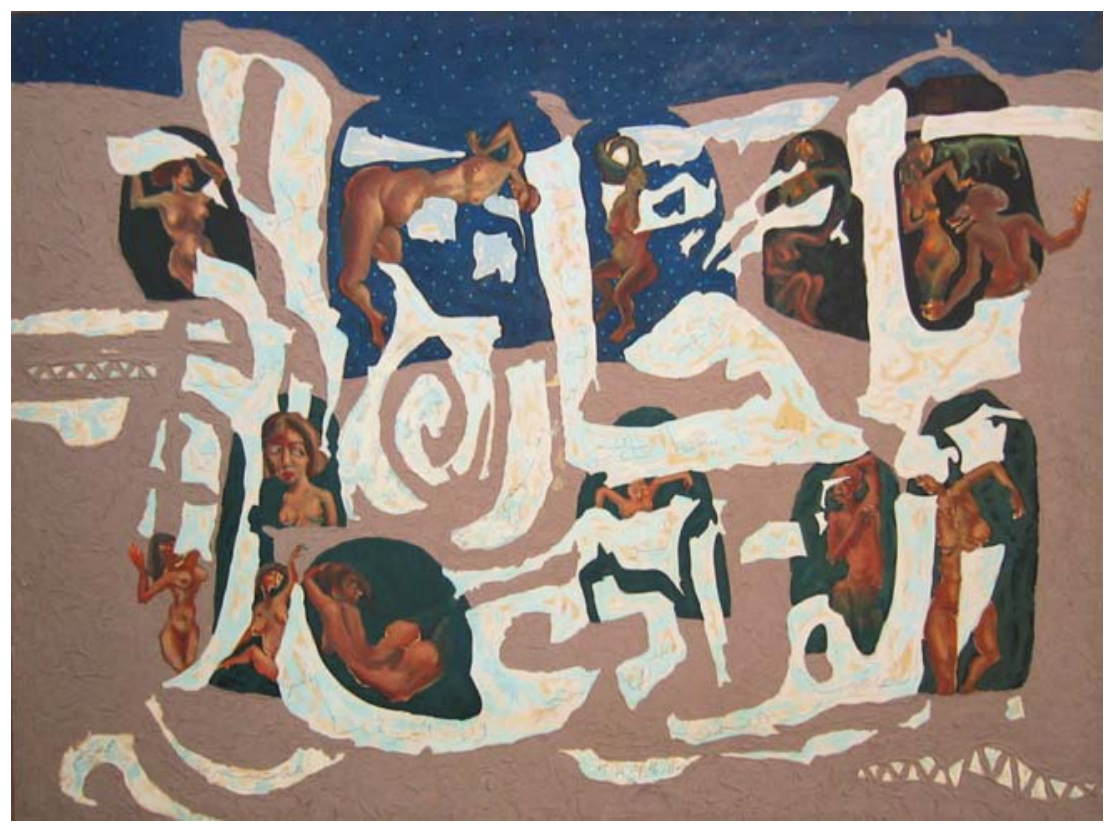

Abb. 92

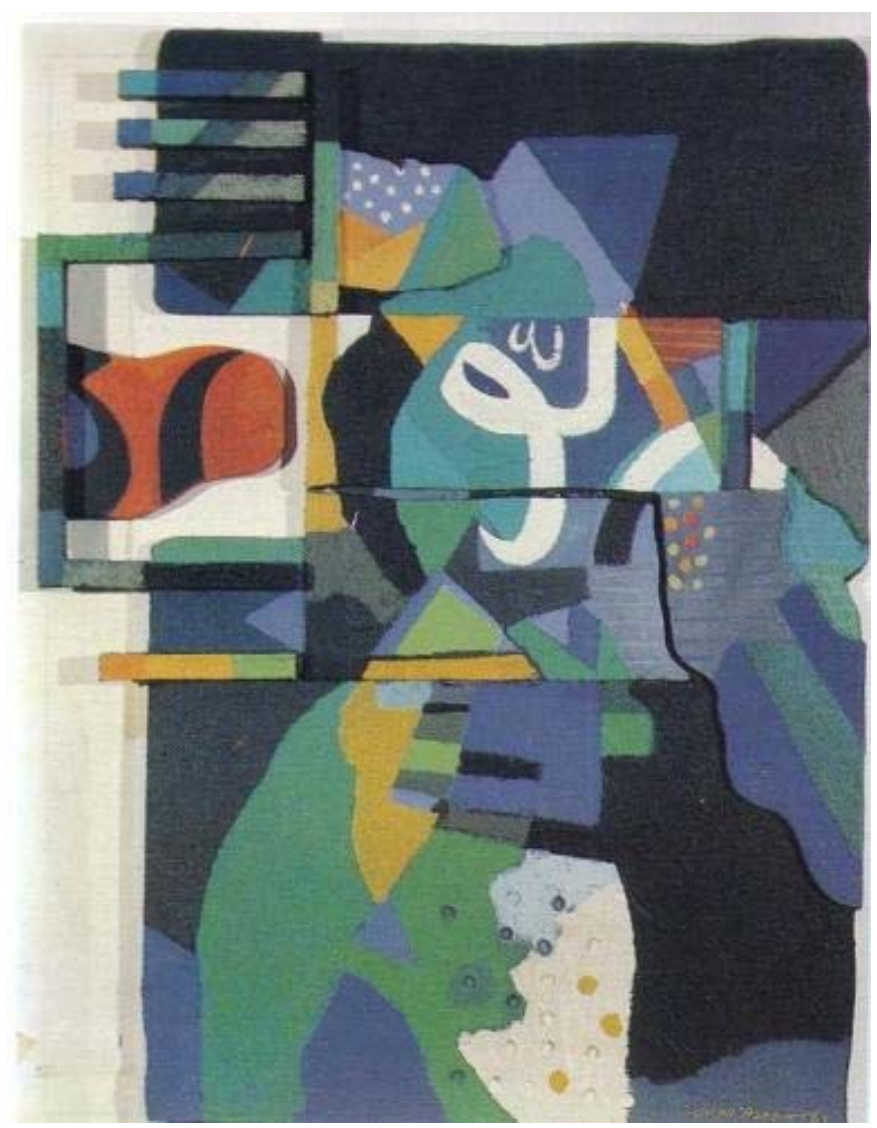

Abb. 93 


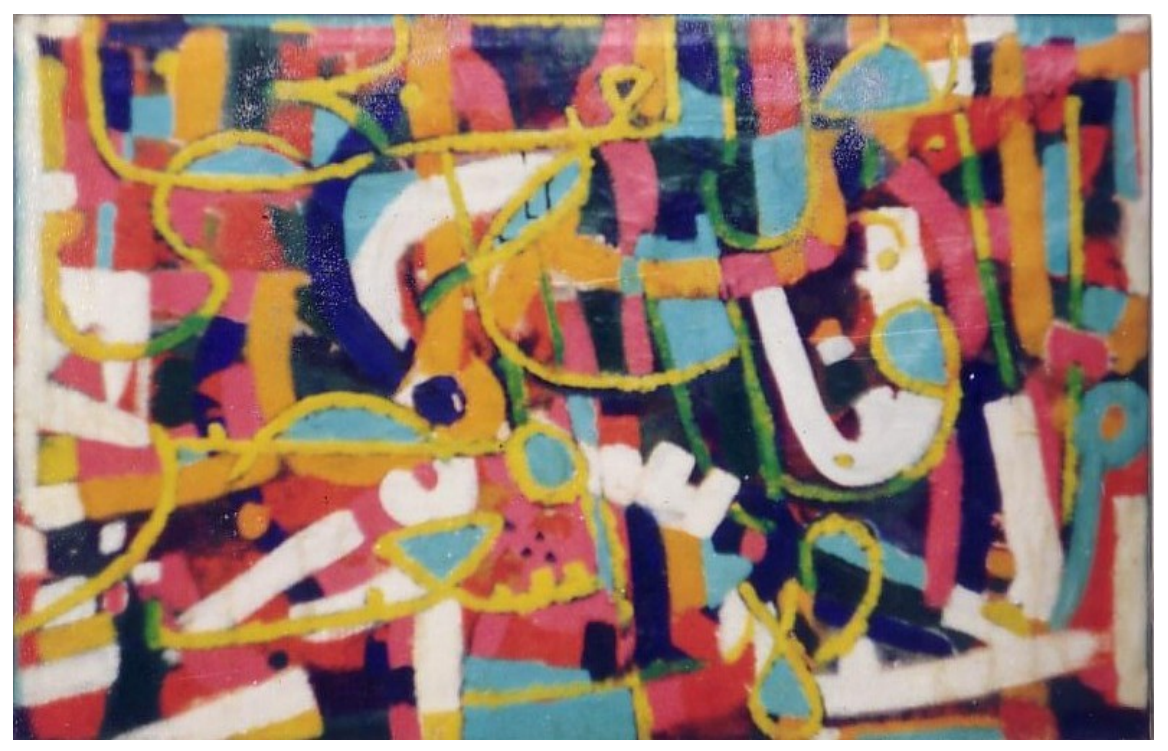

Abb. 94

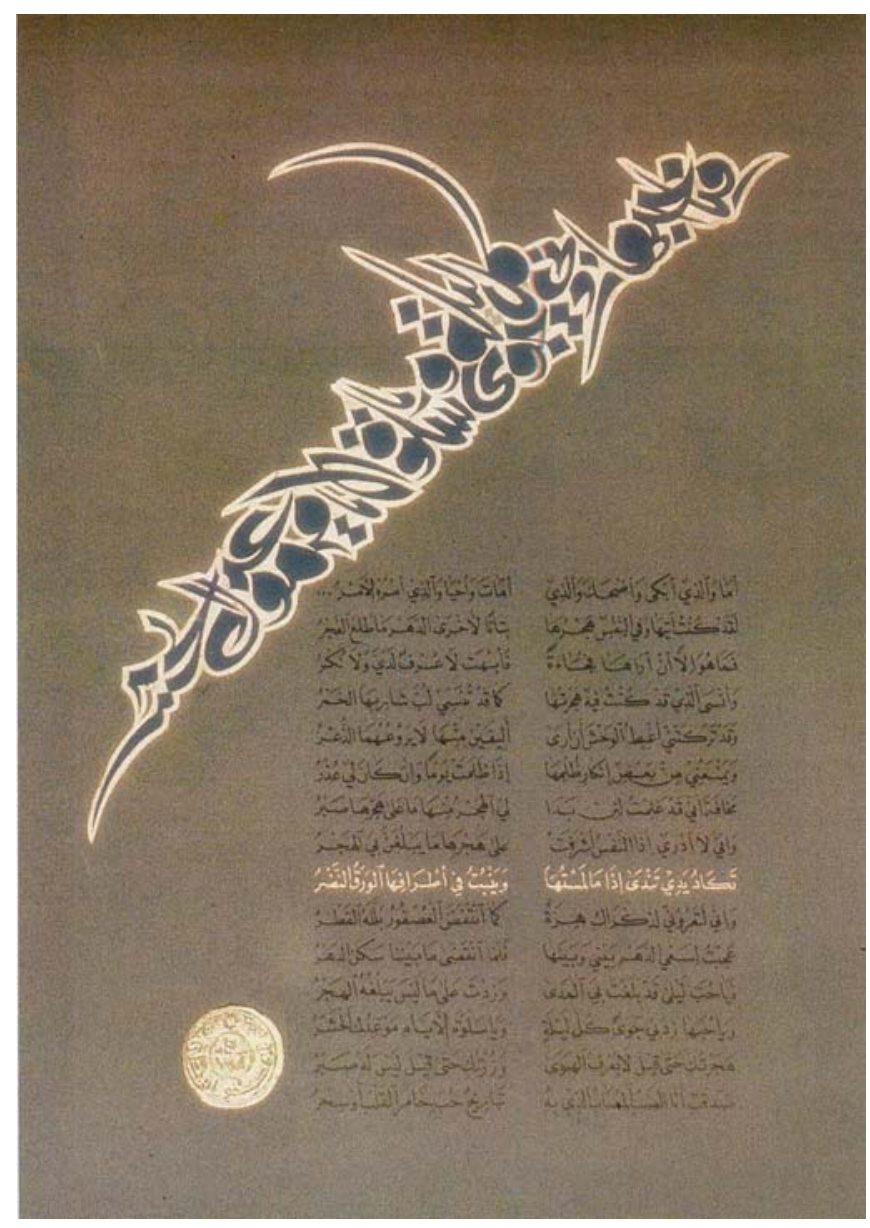

Abb. 95 


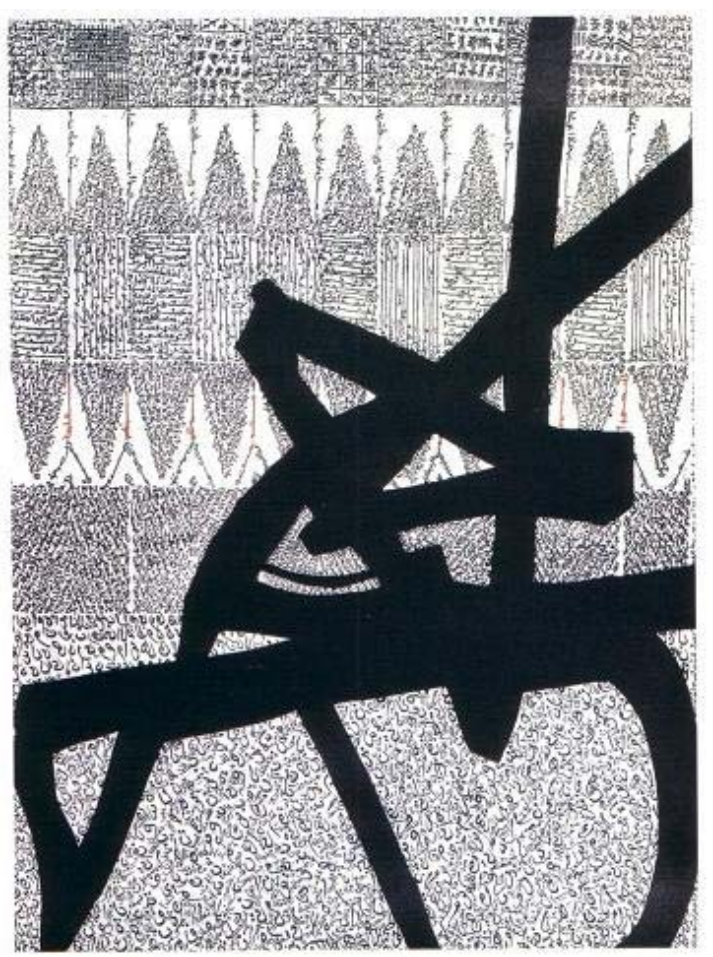

Abb. 96

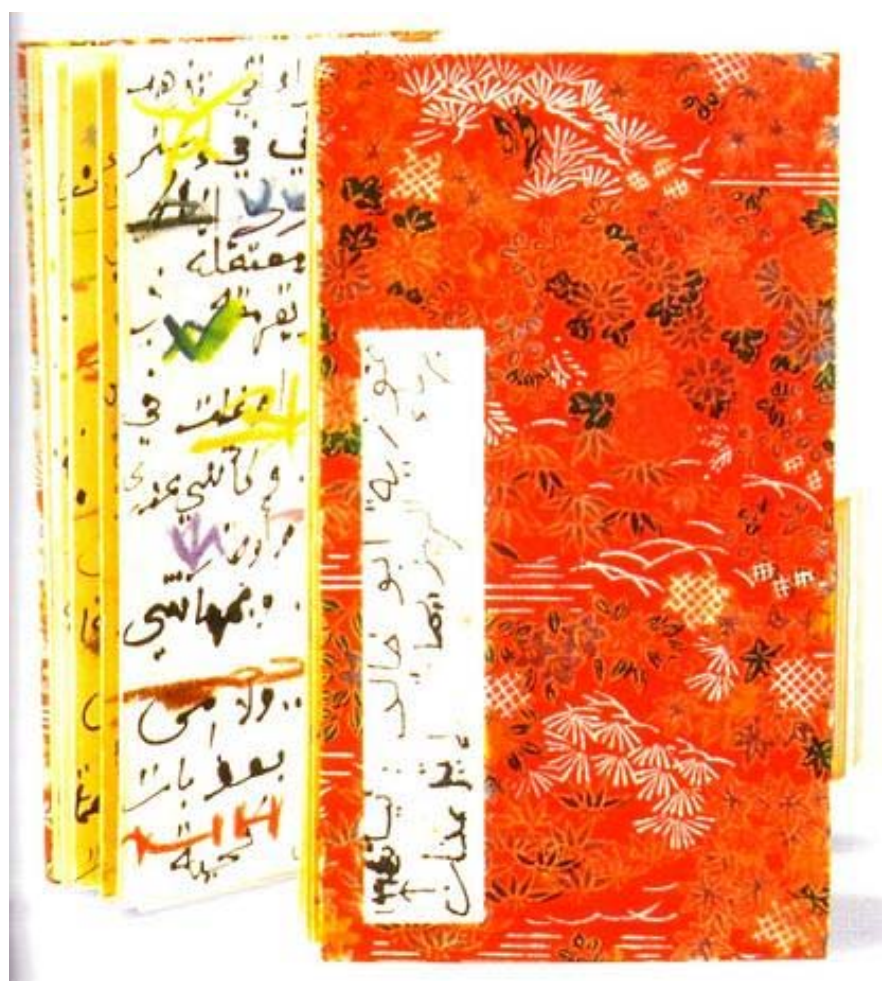

Abb. 97 


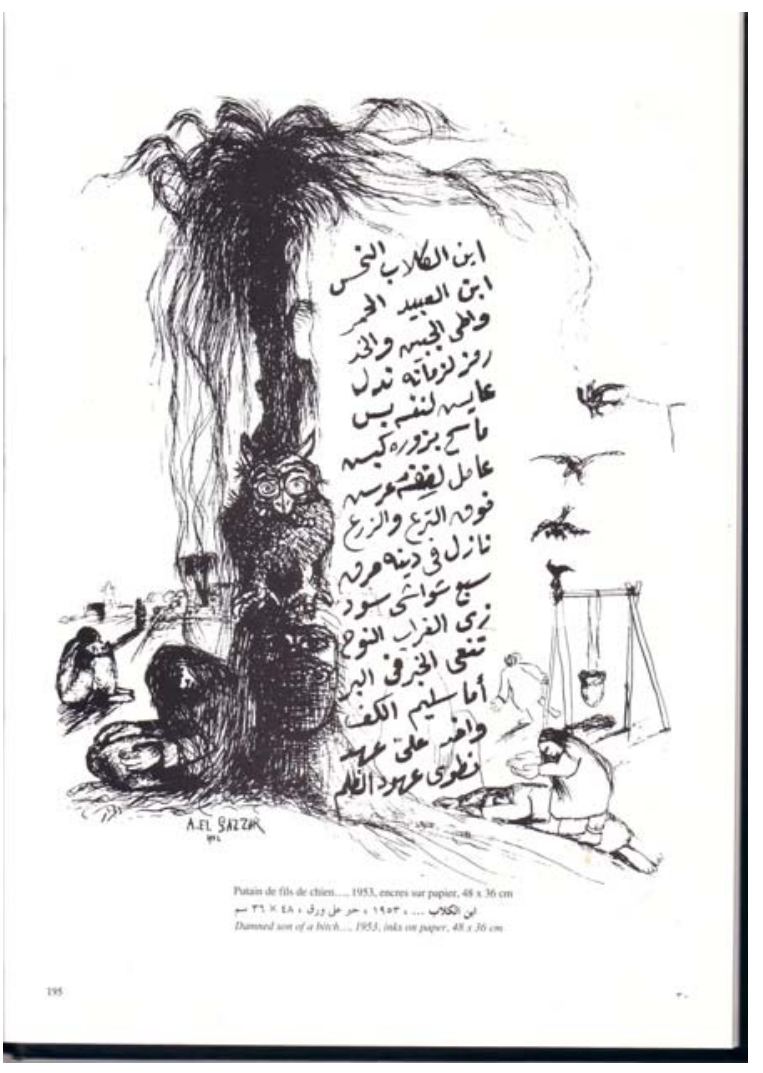

Abb. 98

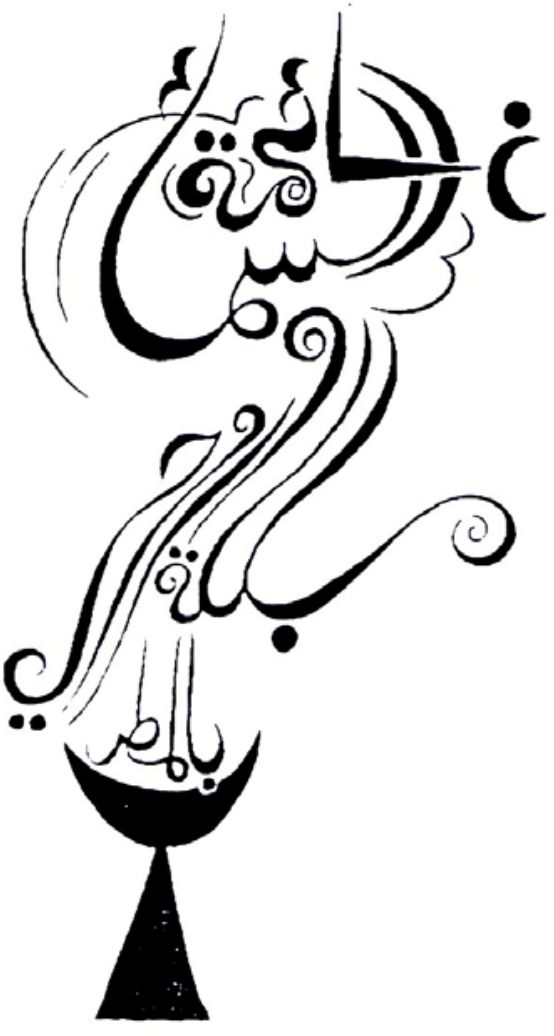

Abb. 99 


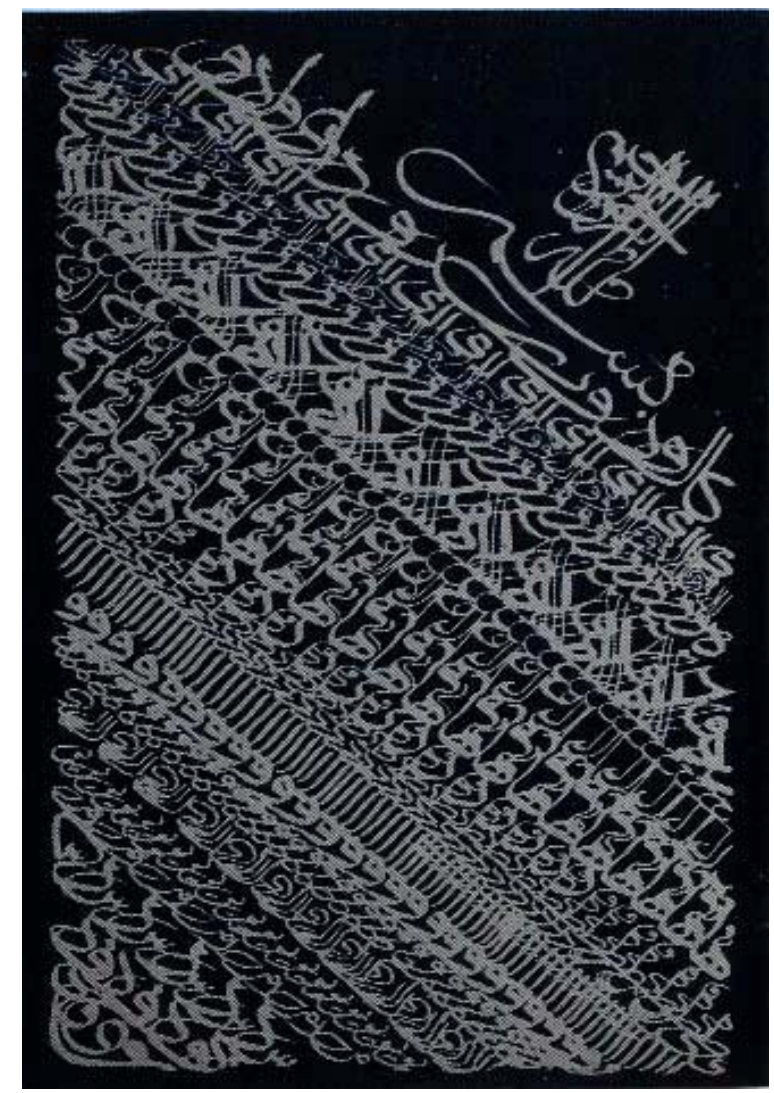

Abb. 100

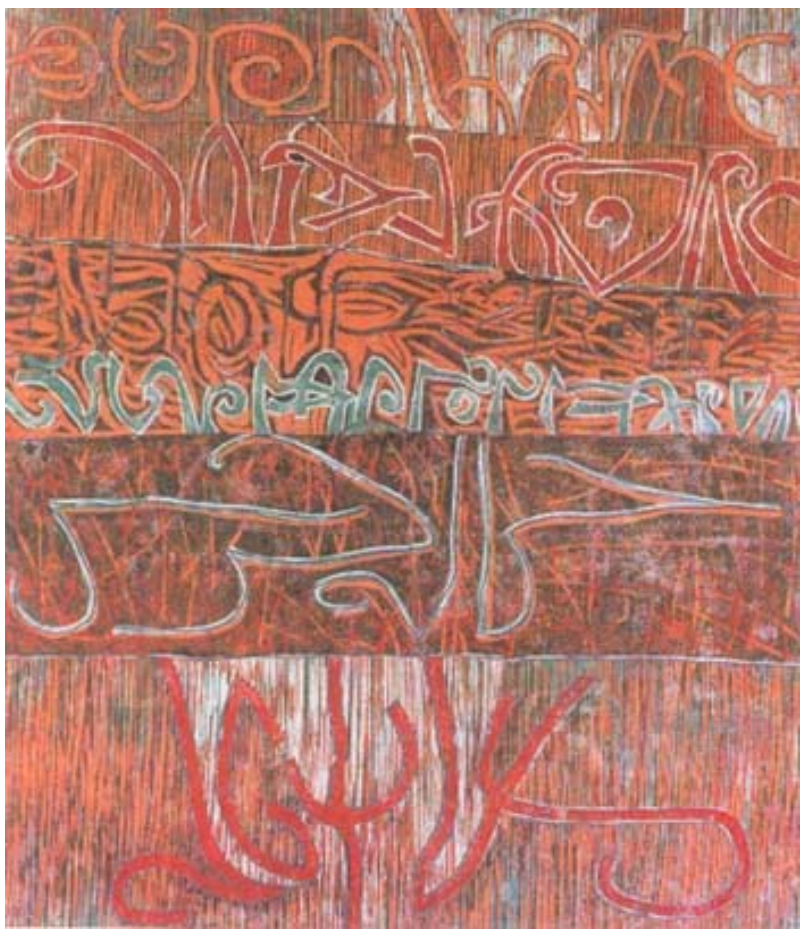

Abb. 101 


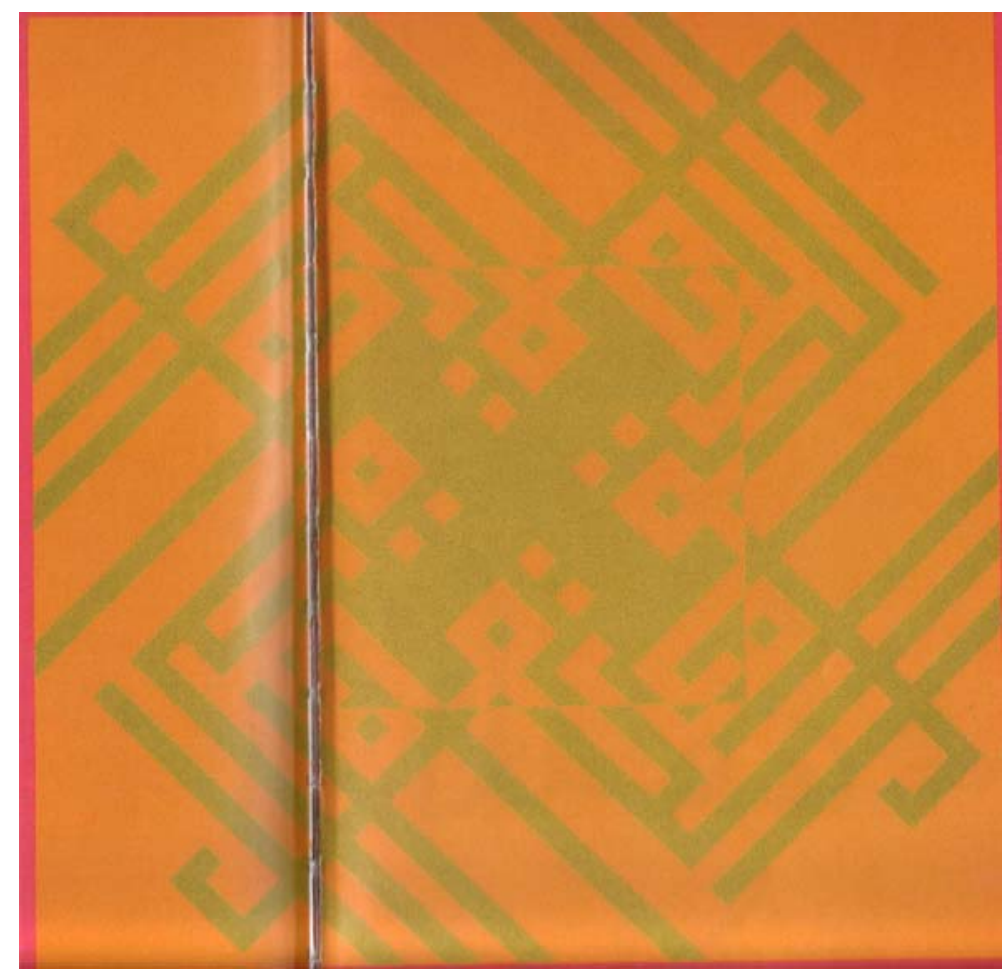

Abb. 102

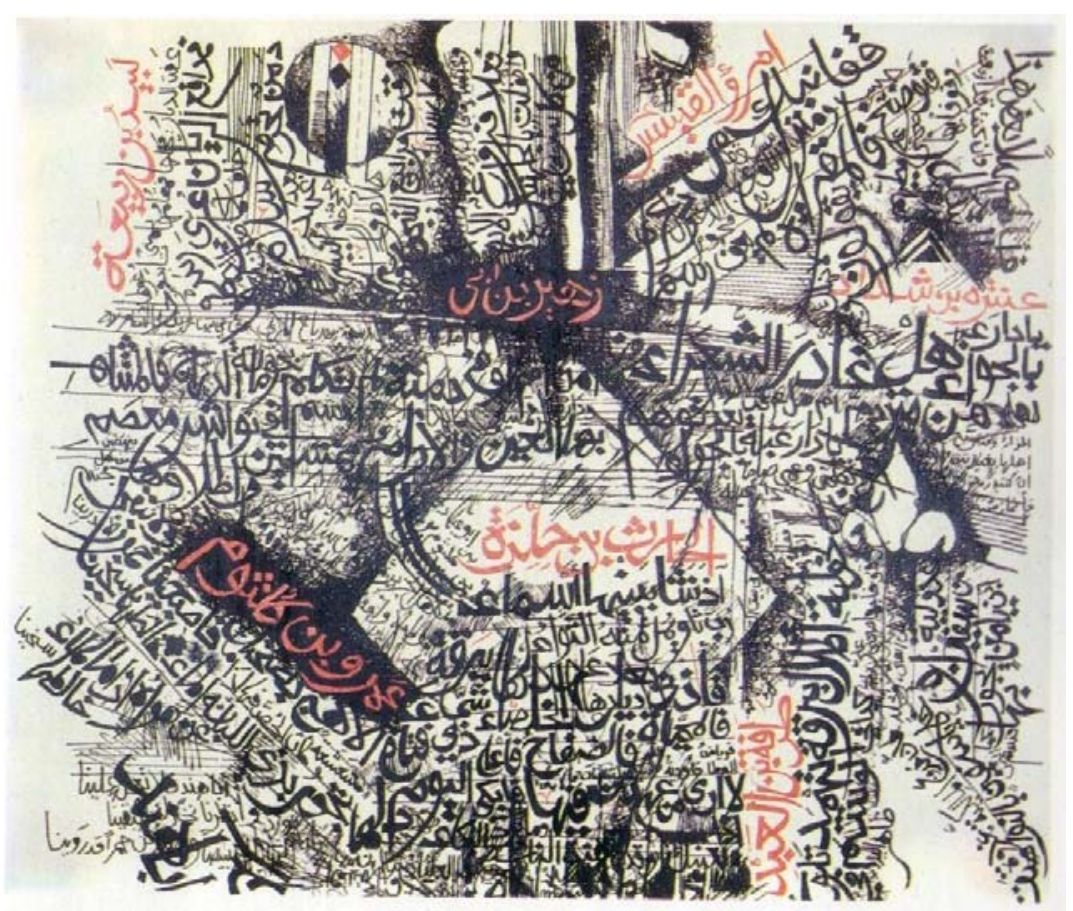

Abb. 103 


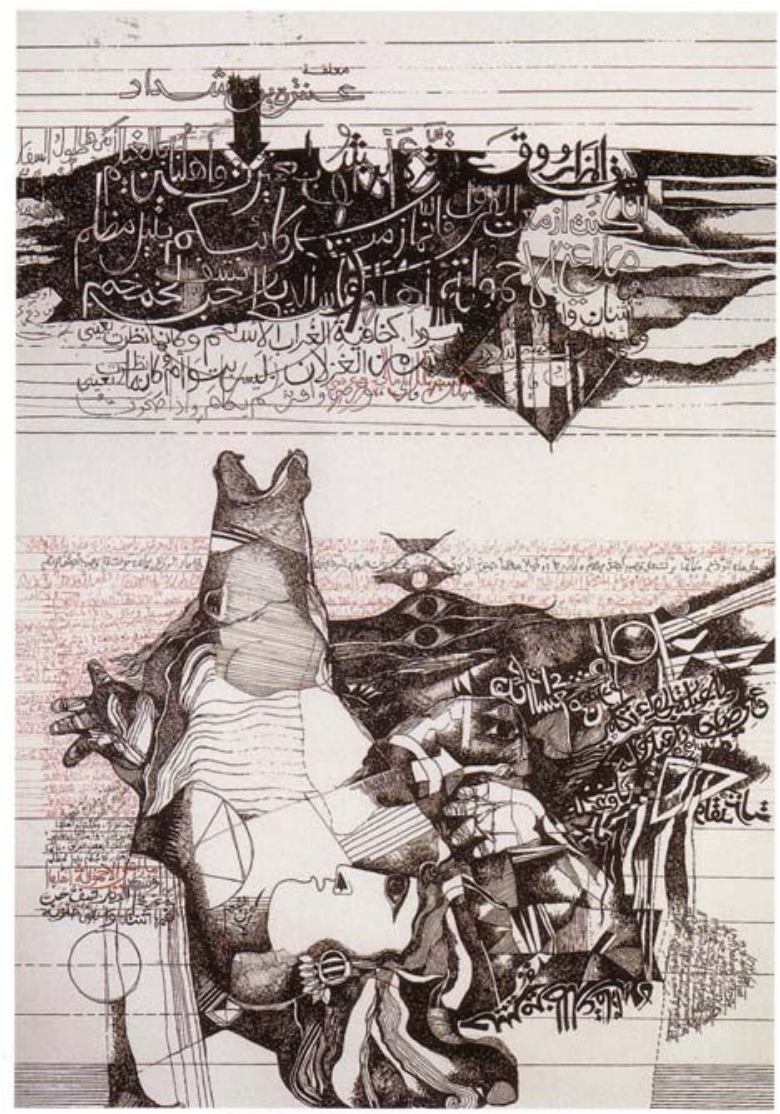

Abb. 104

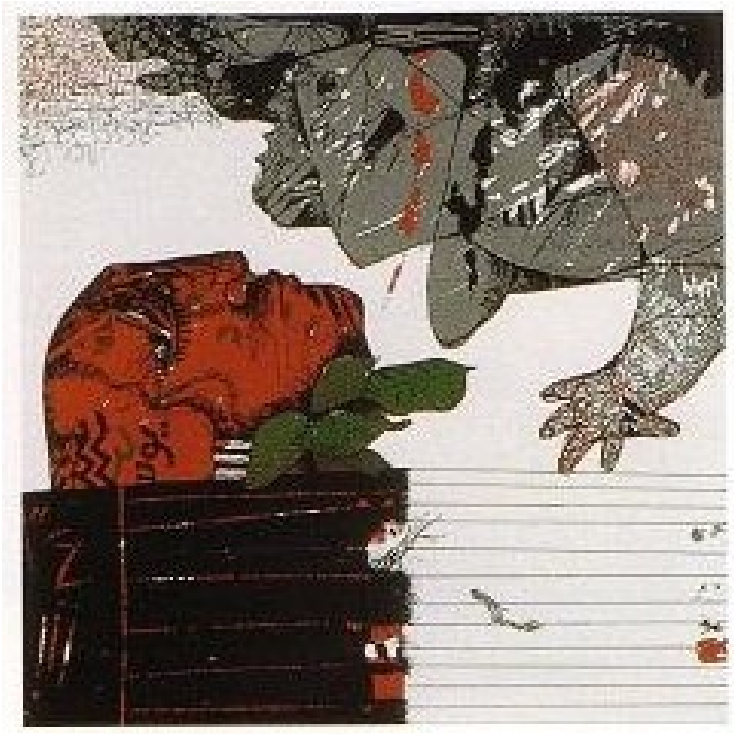

Abb. 105 


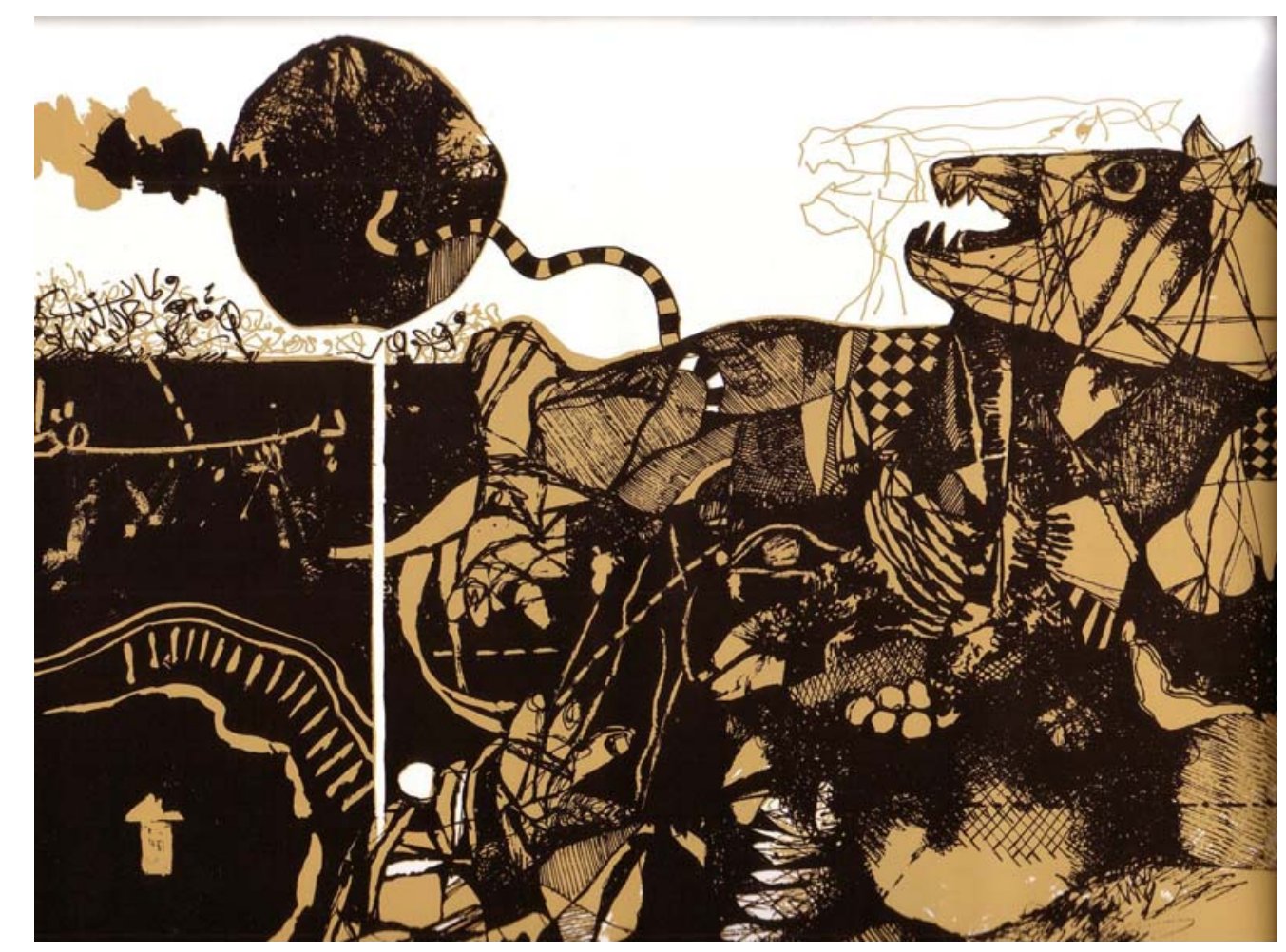

Abb. 106

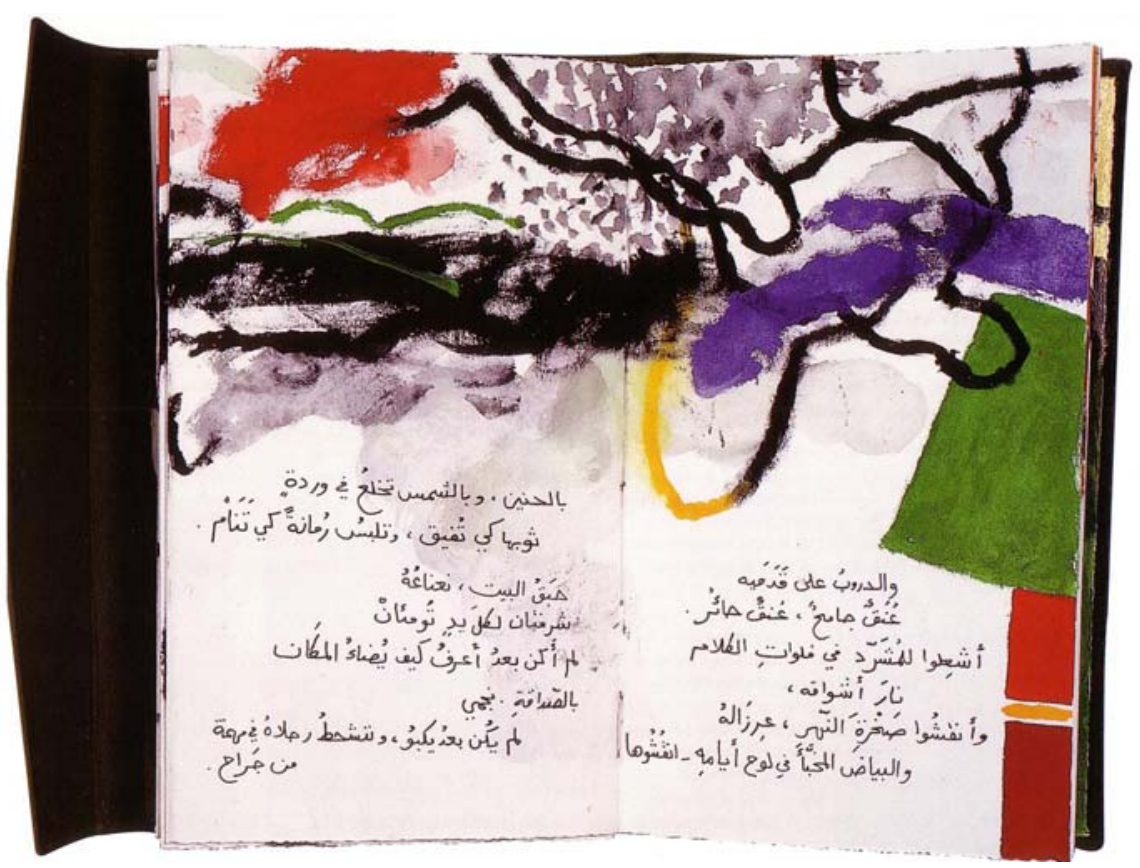

Abb. 107 


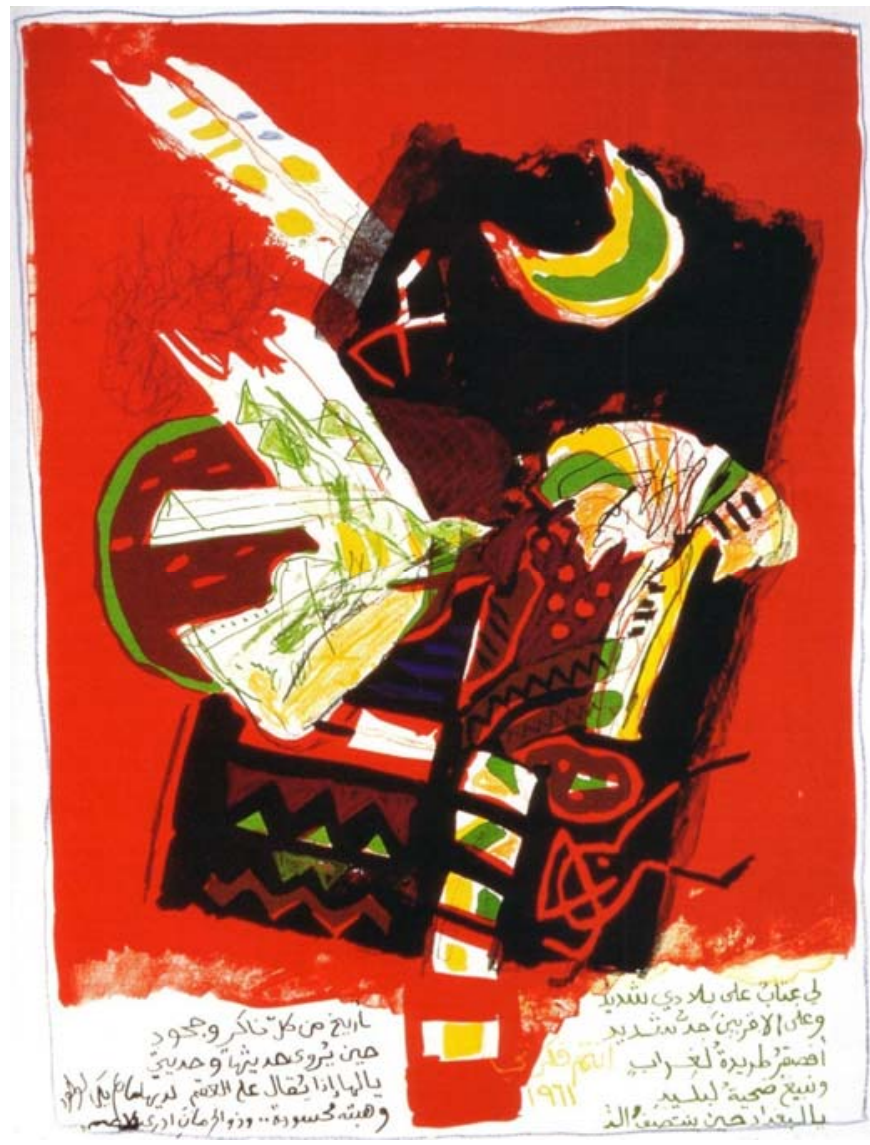

Abb. 108

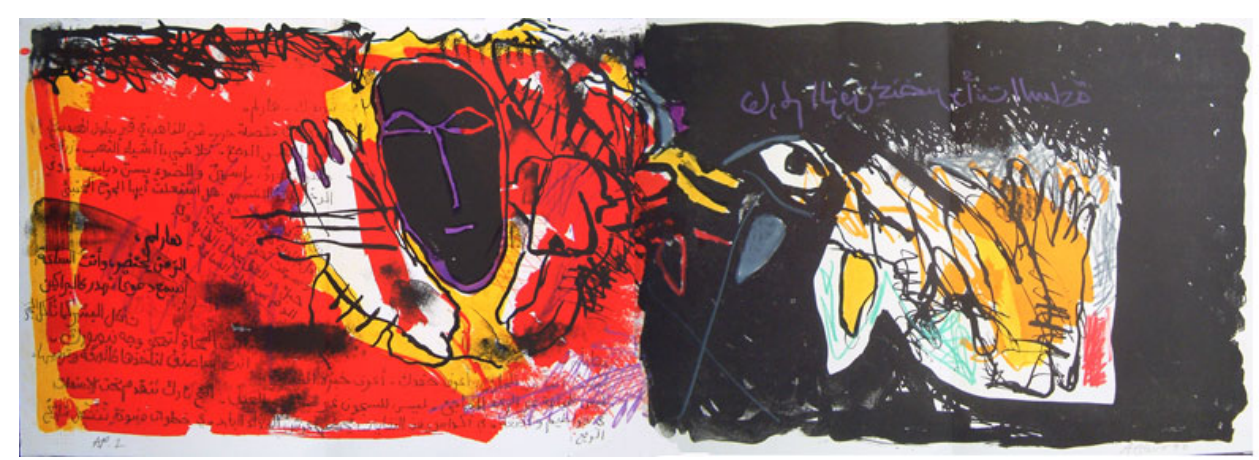

Abb. 109 


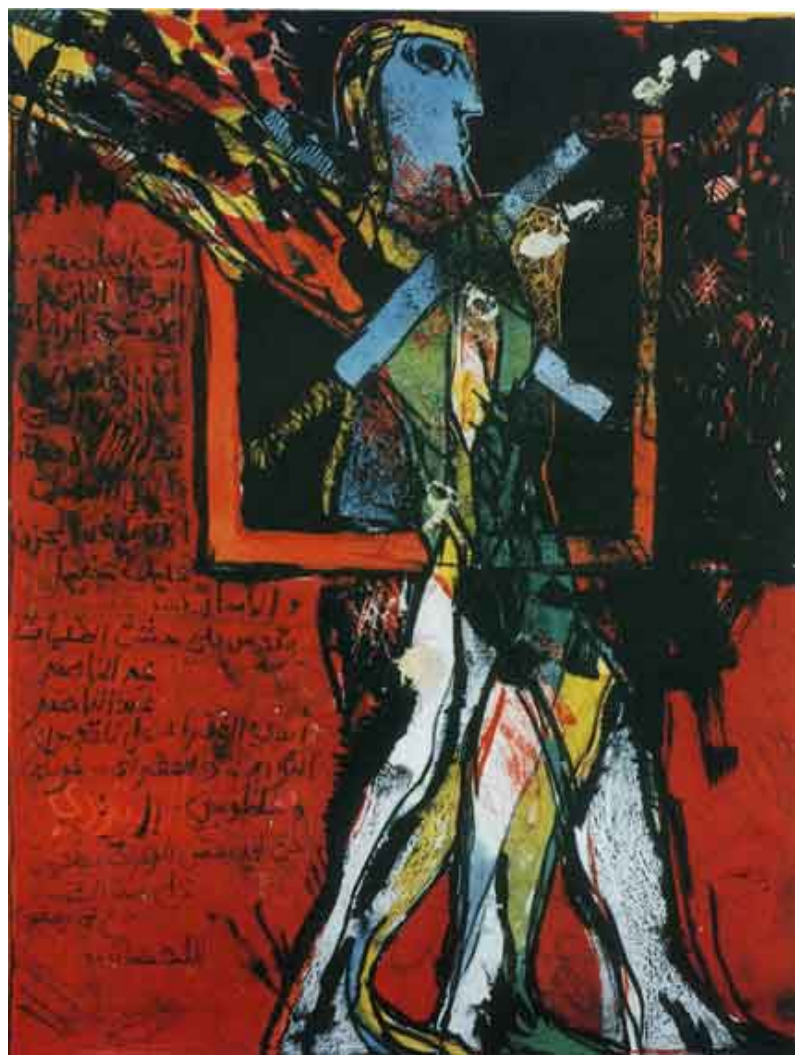

Abb. 110

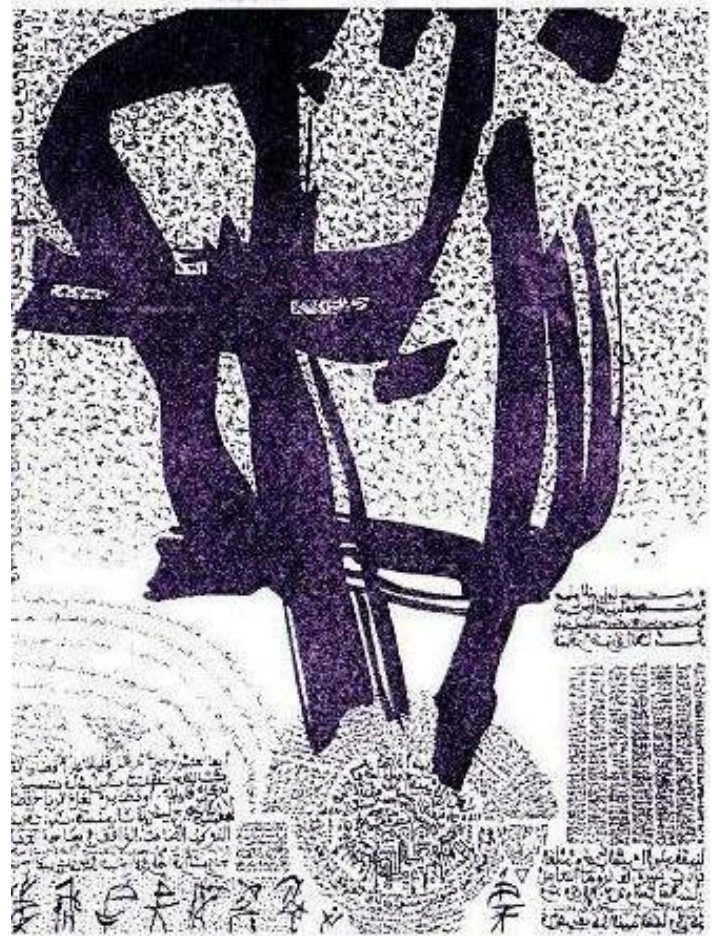

Abb. 111 


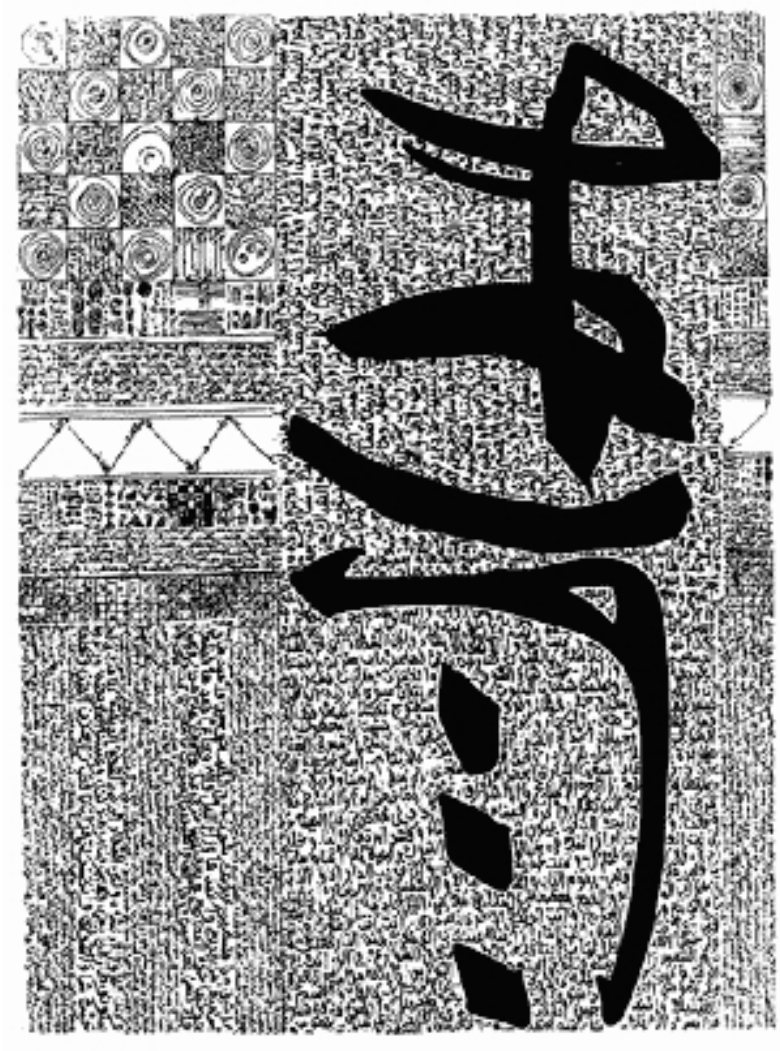

Abb. 112

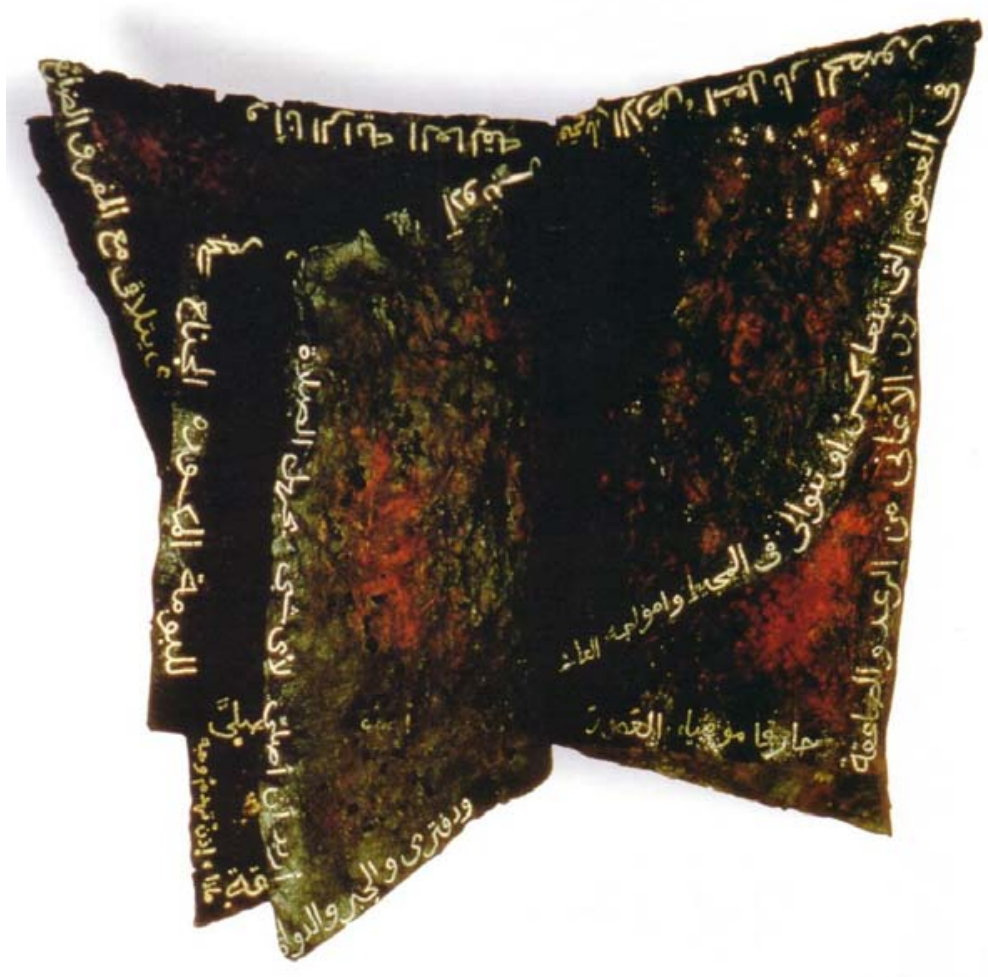

Abb. 113 


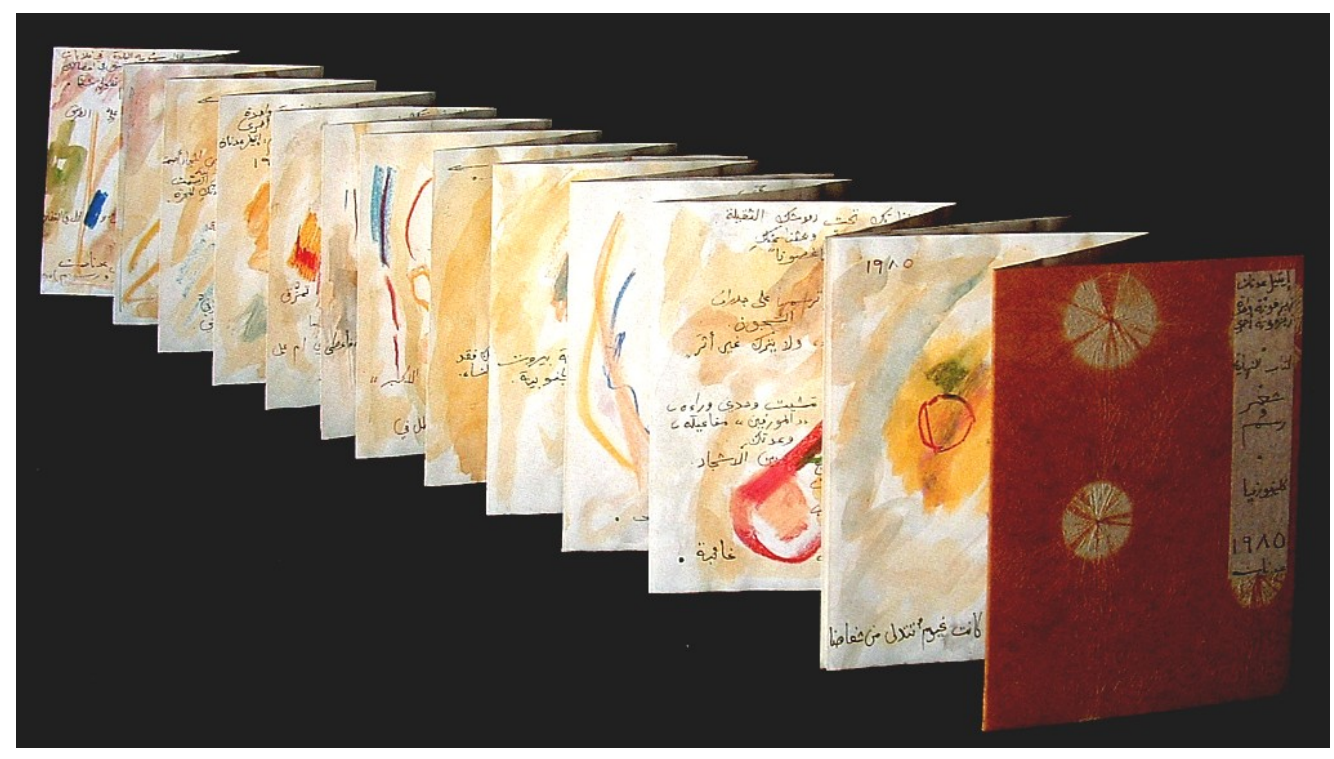

Abb. 114

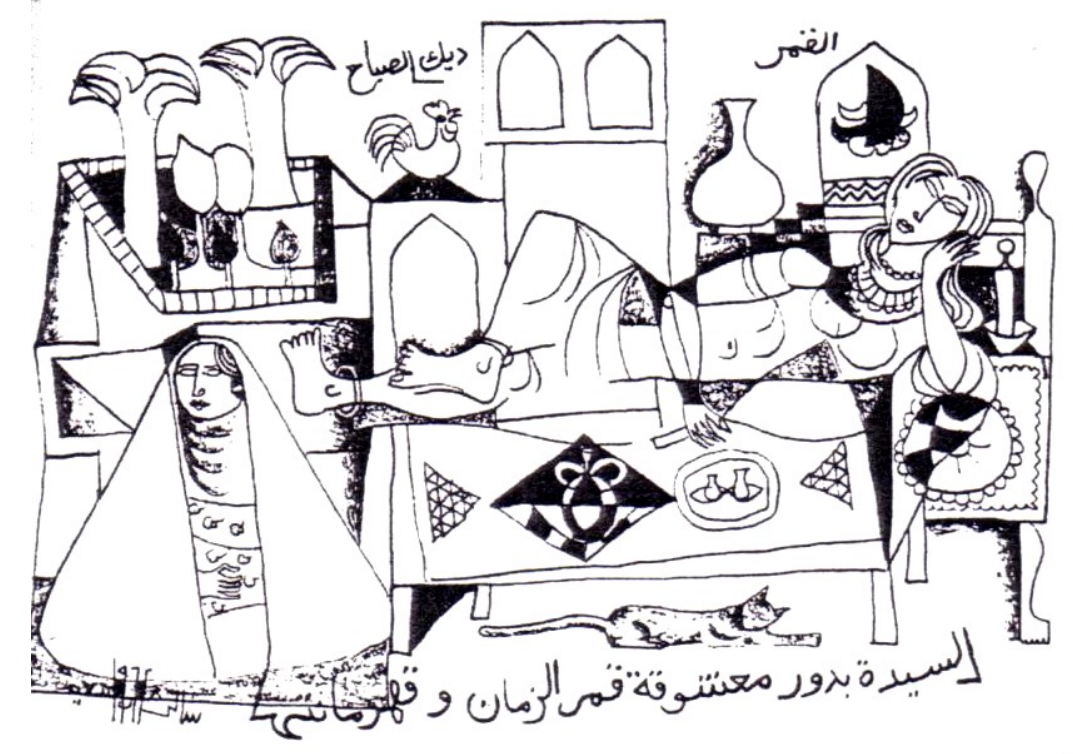

Abb. 115 


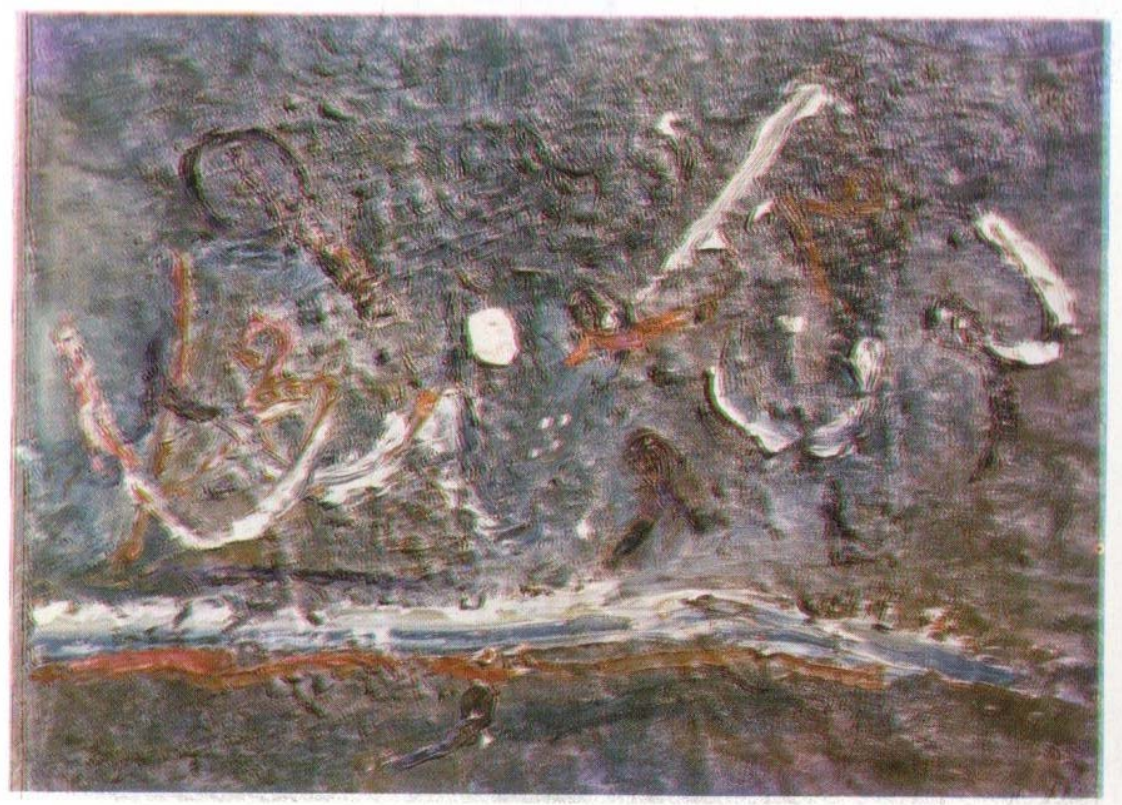

Abb. 116

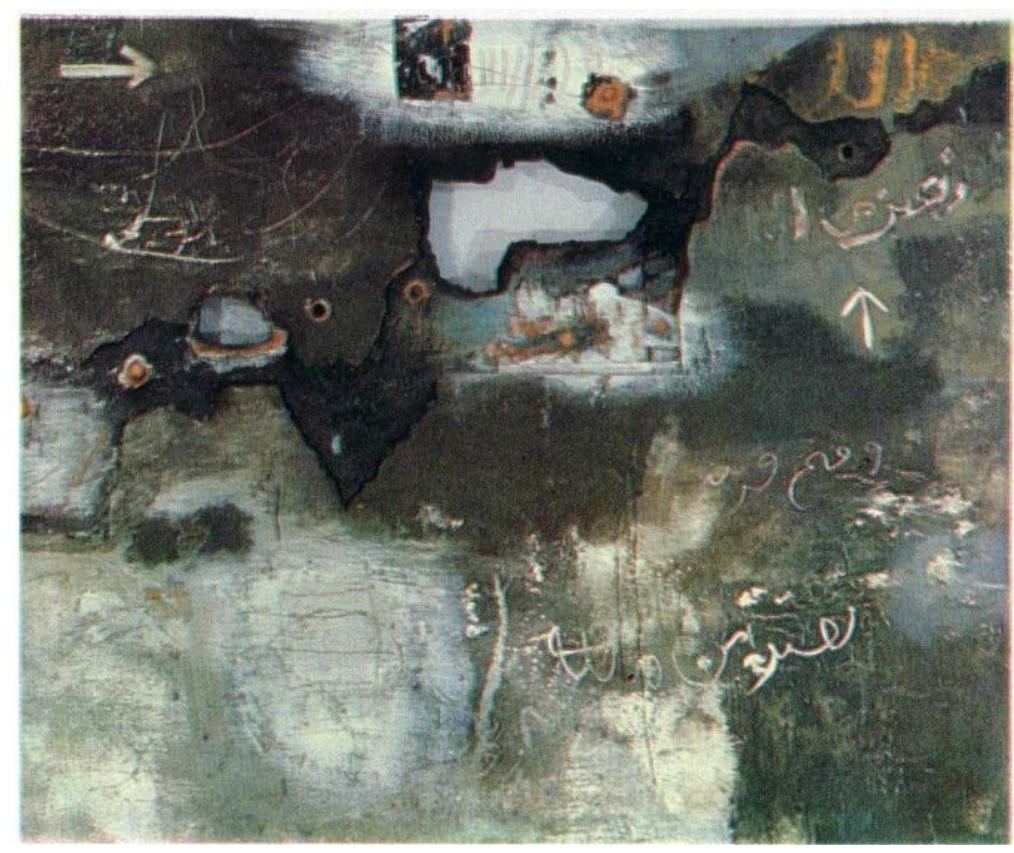

Abb. 117 


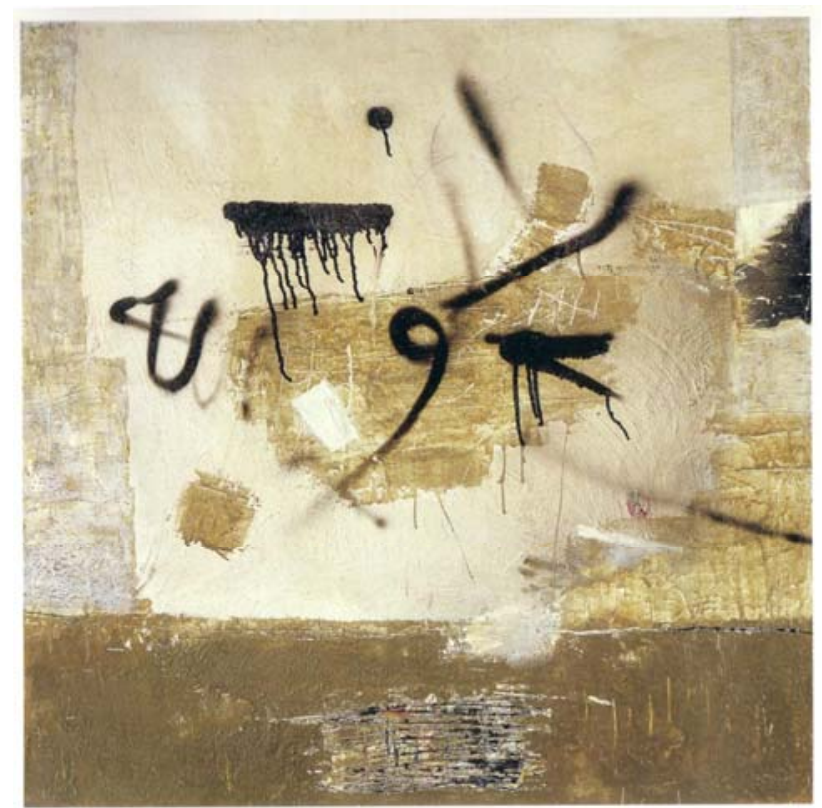

Abb. 118

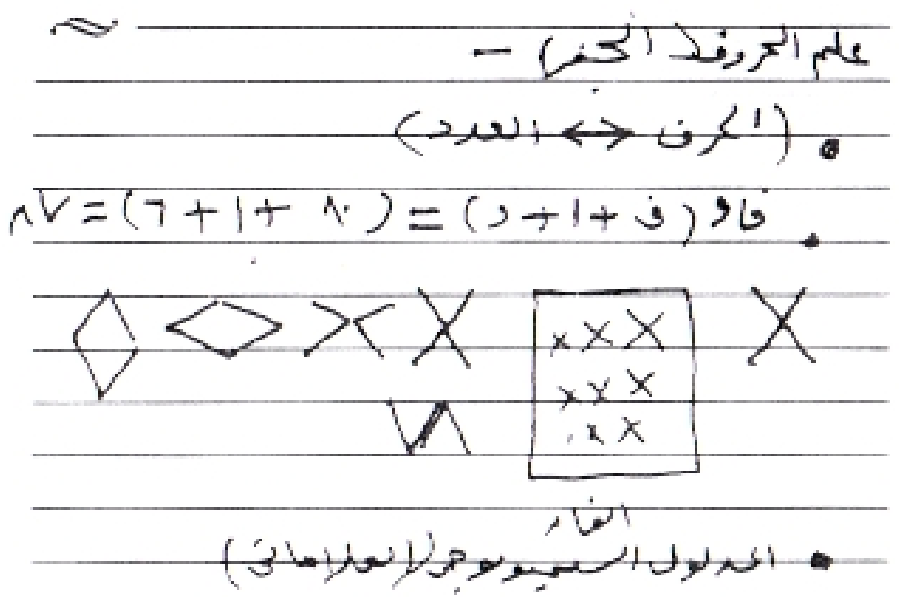

Abb. 119

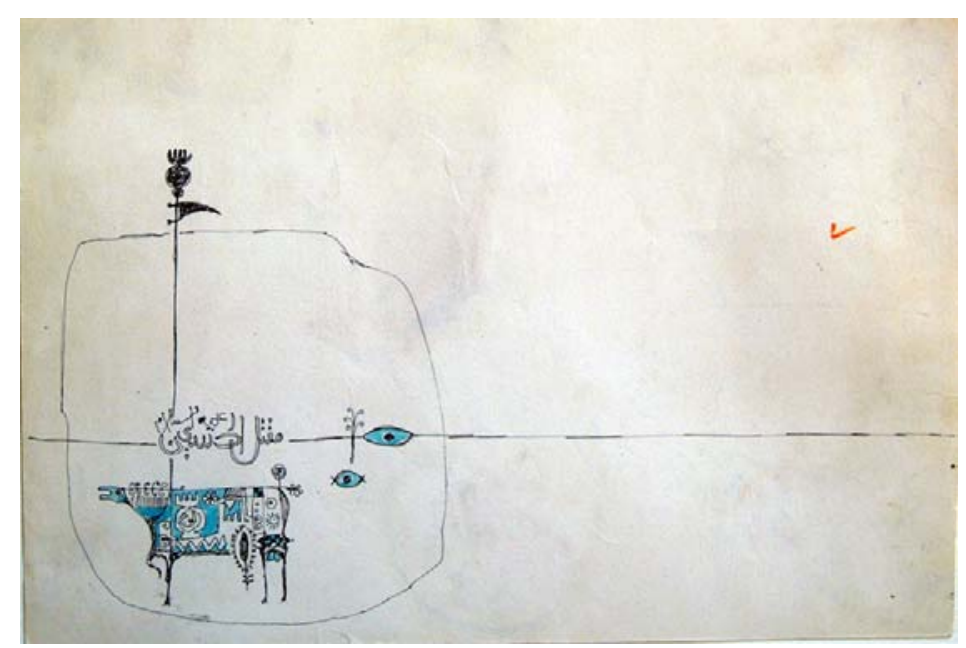

Abb. 120 


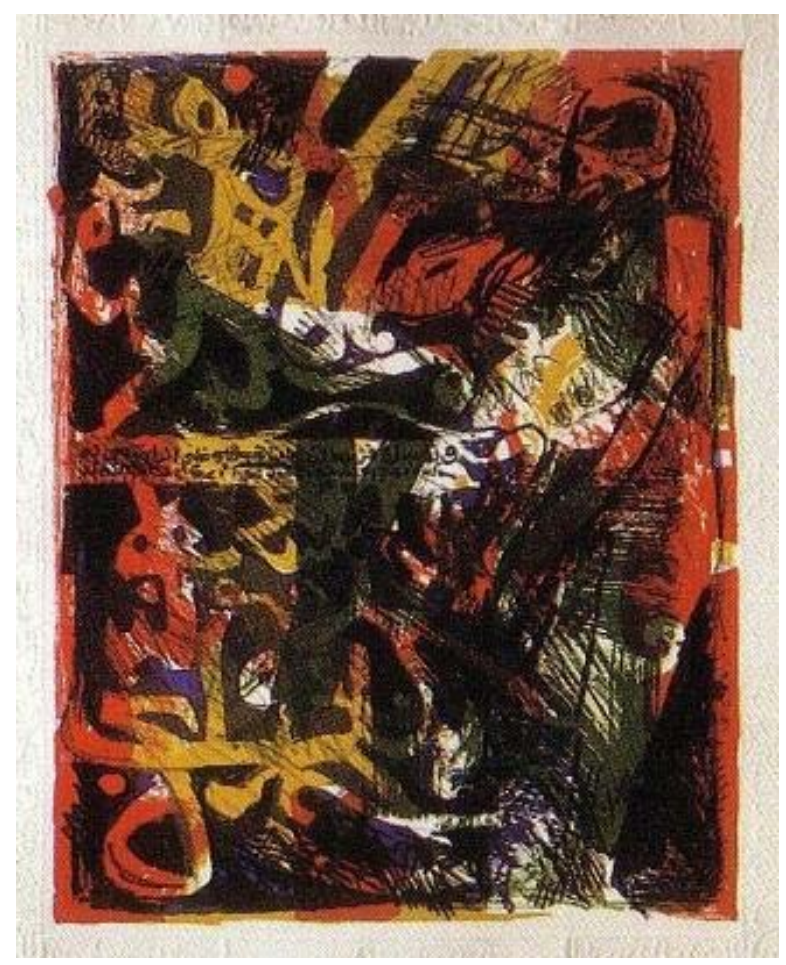

Abb. 121
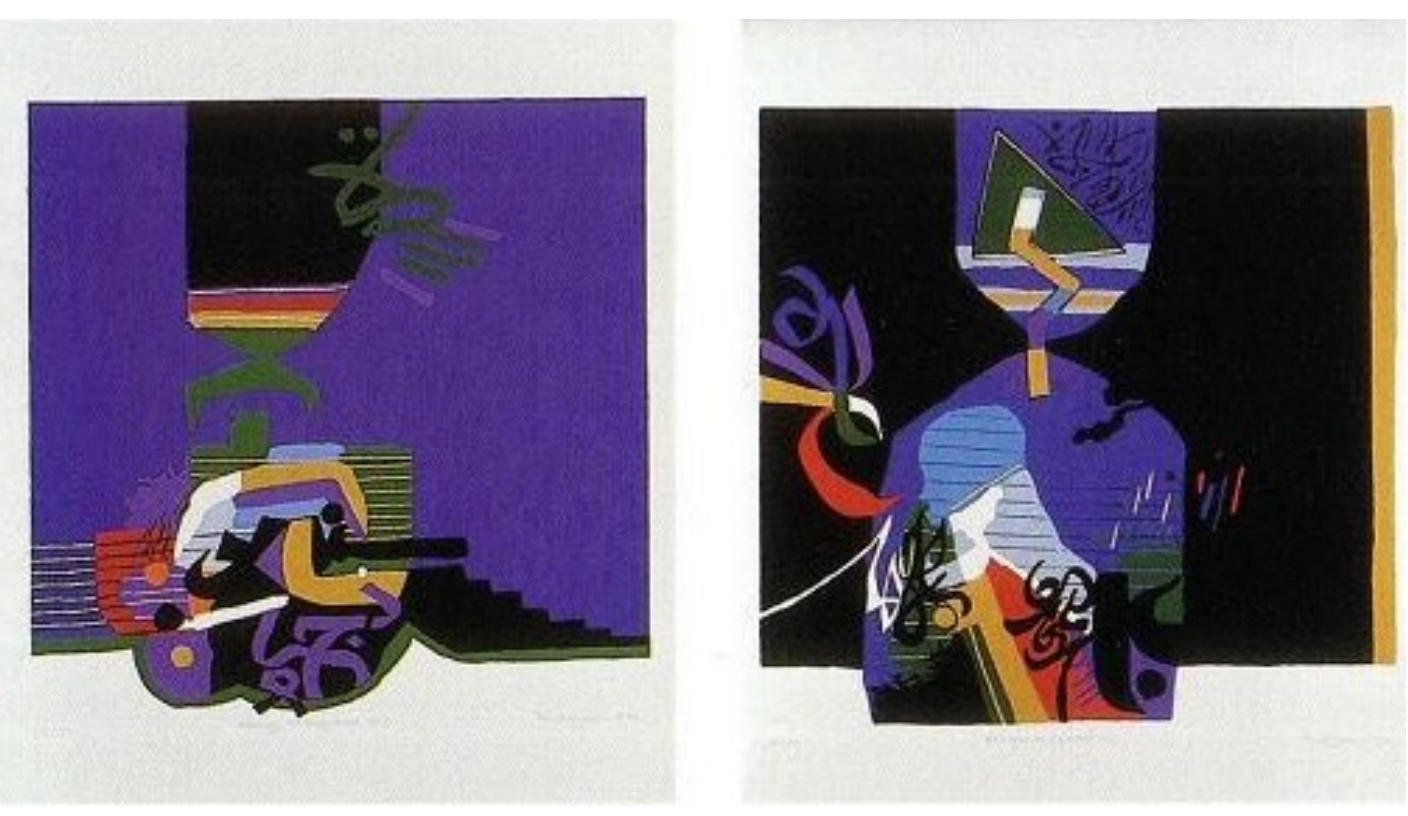

Abb. 122 


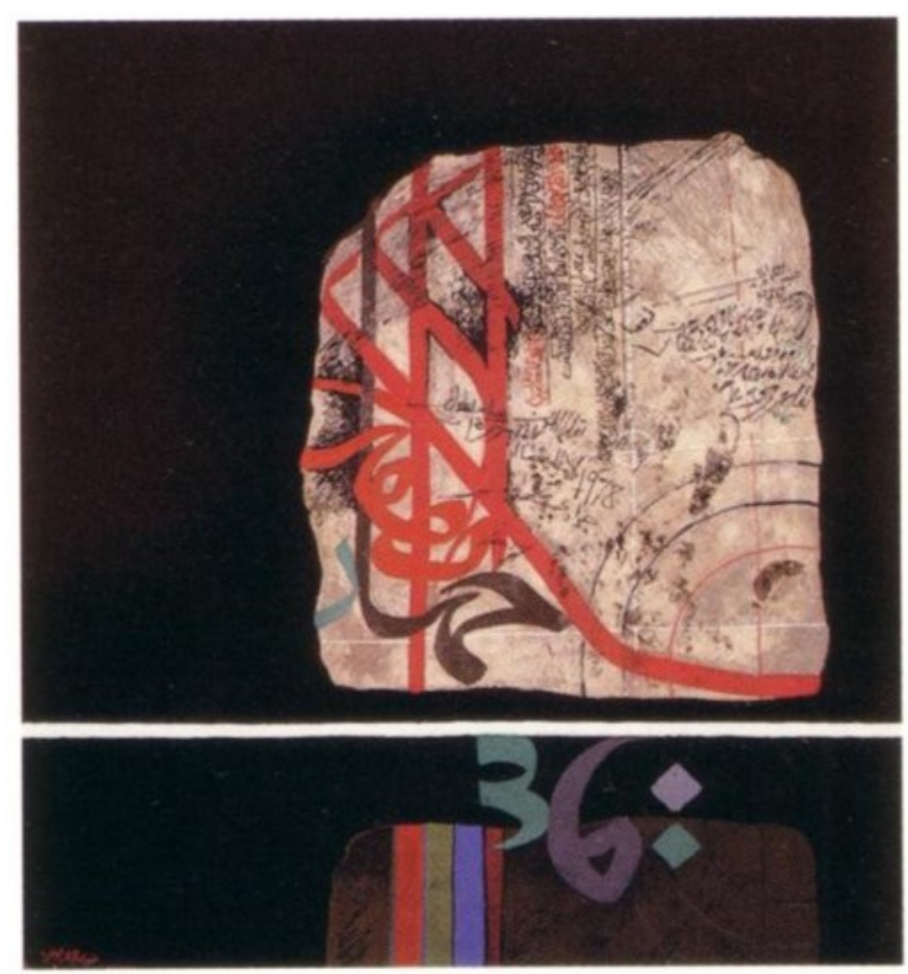

Abb. 123

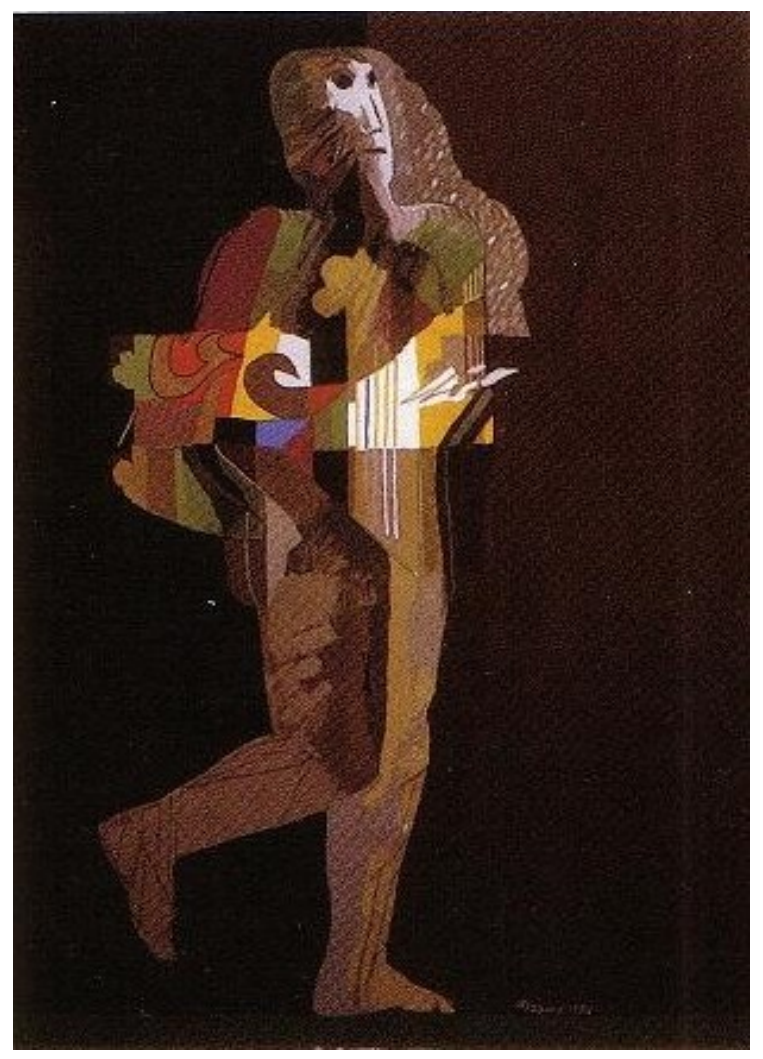

Abb. 124 